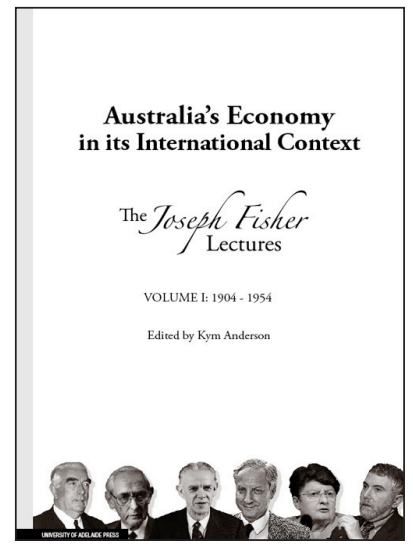

Welcome to the electronic edition of Australia's Economy in its International Context: The Joseph Fisher Lectures, Volume I: 1904 - 1954.

The book opens with the bookmark panel and you will see the contents page. Click on this anytime to return to the contents. You can also add your own bookmarks.

Each chapter heading in the contents table is clickable and will take you direct to the chapter. Return using the contents link in the bookmarks.

The whole document is fully searchable.

Enjoy. 


\section{Australia's Economy in its International Context}

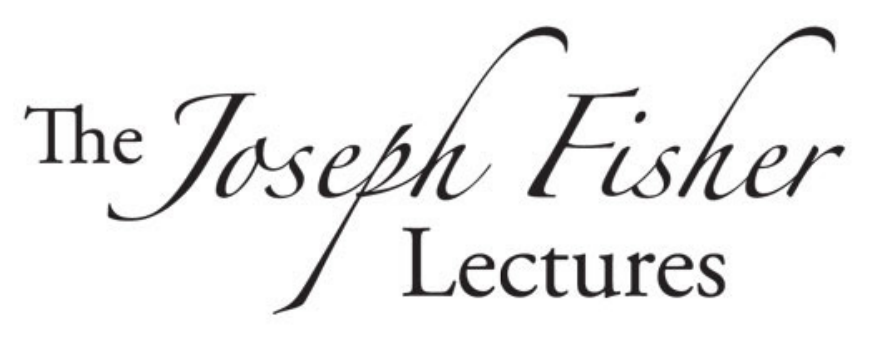

VOLUME I: 1904 - 1954

Edited by Kym Anderson 


\section{Australia's Economy in its International Context}

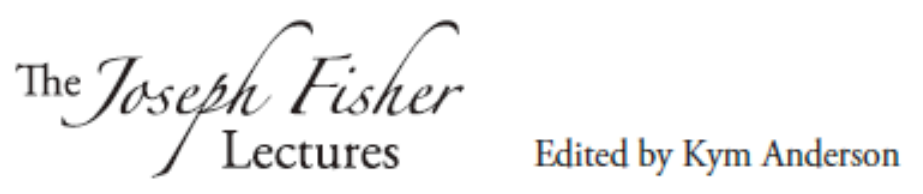

This two-volume collection brings together the first 53 Joseph Fisher Lectures in economics and commerce, presented at the Adelaide University every other year since 1904. Funds for the Lectures, together with a medal for the top accounting student each year, were kindly provided by a $£ 1,000$ endowment to the University by the prominent Adelaide businessman Joseph Fisher in 1903.

The Lectures address a wide range of Australian economic issues, in addition to some international economic issues of national significance. They have stood the test of time extremely well, while also providing a reminder of the events and concerns that were prominent at different times during the past century.

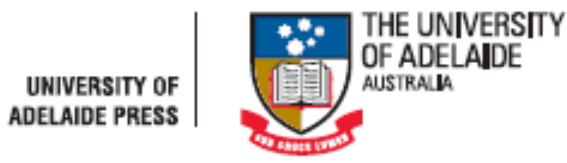




\section{Australia's Economy in its International Context}


Cover photos published with kind permission of Peter Morris/Courtesy of Fairfaxphotos.com, Nicholas Gruen, ANU ePress, Butlin Archives ANU, The University of Melbourne Archives, World Bank, wikicommons.

L-R: Robert Menzies, Heinz Arndt, John Crawford, Fred Gruen, Anne Krueger, Paul Krugman. 


\section{Australia's Economy in its International Context}

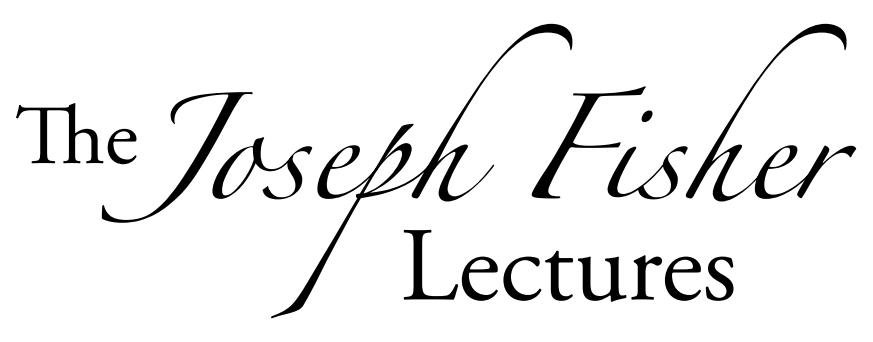

VOLUME I: 1904 - 1954

Edited by Kym Anderson

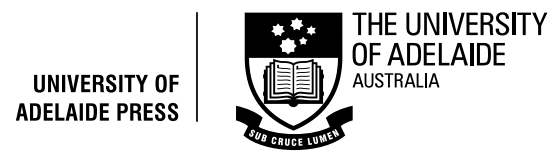




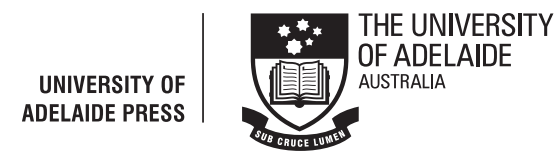

Published in Adelaide by

University of Adelaide Press

Level 1, 254 North Terrace

The University of Adelaide

South Australia

5005

press@adelaide.edu.au

www.adelaide.edu.au/press

The University of Adelaide Press publishes externally refereed scholarly books by staff of the University of Adelaide. It aims to maximise the accessibility to its best research by publishing works through the internet as free downloads and as high quality printed volumes on demand.

Electronic Index: this book is available from the website as a downloadable PDF with fully searchable text. Please use the electronic version to complement the index.

Originally published April 2001 by the Centre for International Economic Studies, University of Adelaide. This revised edition includes 5 new lectures.

(C) The University of Adelaide 2001, 2009

This work is licenced under the Creative Commons Attribution 3.0 Unported License. To view a copy of this licence, visit http://creativecommons.org/licenses/by/3.0/ or send a letter to Creative Commons, 444 Castro Street, Suite 900, Mountain View, California, 94041, USA. This licence allows for copying any part of the work for personal and commercial use, providing author attribution is clearly stated.

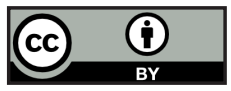

Subject Keywords International economic relations - Australia Economic conditions 20th century - Australia Economic conditions 21st century - Australia Economic policy 20th century - Australia Economic policy 21st century - Australia Foreign Economic relations - Australia Commercial policy

For the full Cataloguing-in-Publication data please contact National Library of Australia: cip@nla.gov.au

ISBN 978-0-9806723-4-3 (paperback)

ISBN 978-0-9806723-5-0 (electronic)

Cover design: Fiona Cameron

Text: Céline Lawrence

Paperback copy printed and bound by Griffin Press, South Australia

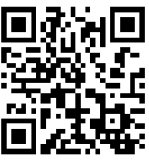




\section{Contents}

\section{Volume 11904 - 1954}

Preface vii

List of lectures in volume 2 (1956-2009) ix

Contributors to opening chapters xi

The benefactor Joseph Fisher

Extract from Joseph Fisher - A Pioneer Colonist by F. R. Fisher

xiii

The lectures by Kym Anderson

xxiii

The lecturers by Kym Anderson and Keith Hancock

xxix

11904 - Commercial education by Henry G. Turner

21906 - Commercial character by Lewis A. Jessop 27

$3 \quad 1908$ - The influence of commerce on civilization by J. Currie Elles $\quad \mathbf{4 7}$

$4 \quad 1910$ - Banking as a factor in the development of trade and commerce by J. Russell French

51912 - Australian company law, and some sidelights on modern commerce by Henry Y. Braddon

61914 - Problems of transportation, and their relation to Australian trade and commerce by David J. Gordon

$7 \quad 1917$ - War finance: Loans, paper money and taxation by Robert F. Irvine

$8 \quad 1919$ - The humanizing of commerce and industry by Gerald Mussen

91921 - Currency and prices in Australia by Douglas B. Copland

101923 - Money, credit and exchange by J. Russell Butchart 
121927 - The financial and economic position of Australia by Stanley M. Bruce

131929 - Public finance in relation to commerce by Richard C. Mills 323

141930 - Current problems in international finance

by Theodore E. G. Gregory

151932 - Australia's share in international recovery by Alfred C. Davidson

161934 - Gold standard or goods standard by Leslie G. Melville

171936 - Some economic effects of the Australian tariff by Lyndhurst F. Giblin

181938 - Australian economic progress against a world background by Colin Clark

191940 - Economic coordination by Roland Wilson

475

201942 - The Australian economy during War by Robert G. Menzies

501

$21 \quad 1942$ - Problems of a high employment economy

by H. C. Coombs

221946 - Necessary principles for satisfactory agricultural development in Australia by S. M. Wadham

231948 - The importance of the iron and steel industry by Essington Lewis

$24 \quad 1950$ - The economic consequences of scientific research by John B. Condliffe

251952 - Australian agricultural policy by John G. Crawford 


\section{Preface}

This two-volume collection brings together the first 53 Joseph Fisher Lectures in economics and commerce, presented at the Adelaide University every other year since 1904. Funds for the Lectures, together with a medal for the top accounting student each year, were kindly provided by a $£ 1,000$ endowment to the University by the prominent Adelaide businessman Joseph Fisher in 1903 - before his death, to avoid 10 per cent going to the government! (Since the average adult male wage is now well over 200 times greater than it was in 1903 in nominal dollar terms, that endowment represents more than $\$ 0.5$ million in terms of today's spending power.) An additional sum of $\$ 10,500$ was donated to the Adelaide University Centenary Appeal in 1974 by Trustees of Settlements made by Joseph Fisher. The Lectures, which are free and open to the public, have been published by the University as stand-alone booklets, and copies distributed at the fund's expense.

The Lectures are mostly on economic issues and reflect Fisher's interests in liberal markets and non-interventionist government. They have stood the test of time extremely well, while also providing a reminder of the events and concerns that were prominent at different times during the past century. That, plus the fact that many of the earlier Lectures are now out of print and only a small subset of them were reprinted in scholarly journals, justifies putting them together in this collection for posterity.

The timing of this collection's first publication, in 2001, celebrated the centenary of economics teaching at Adelaide, which began with the Federation of Australia in 1901. It also celebrated the fact that it was 50 years since the 2001 Joseph Fisher Lecturer, Peter Karmel, took the Chair of Economics at the University of Adelaide and built the department to an outstanding level (before Peter moved on in the mid-1960s to establish the Flinders University of South Australia). Since 2001, five more Lectures have been added to this second edition of the collection. (See List of lectures in volume 2, 1956-2009 following this Preface.)

The Centre for International Economic Studies (CIES) at the University of Adelaide is proud to be the publisher of the collection, particularly since so many of the Lectures deal with international economic issues or Australian issues that were influenced by major international events. 
The lectures have been reproduced fully, preserving the spelling, punctuation and citation forms of the day, with reproduction of figures wherever possible.

This collection would not have been published had it not been for the thorough bibliographical research and editorial assistance including copy-editing and typesetting provided by Jane Russell. Our thanks go to her, and to Bob Fisher and Keith Hancock in providing material for the opening chapters. Finally, to the descendents of Joseph Fisher, we thank them for their on-going support to the University of Adelaide.

Kym Anderson

October 2009 


\section{List of lectures in volume 2 (1956 - 2009)}

$27 \quad 1956$ - Japan and the General Agreement on Tariffs and Trade by James E. Meade

281958 - National superannuation: Means test or contributions? by Richard I. Downing

291960 - Mass entertainment: The origins of a modern industry by Asa Briggs

$30 \quad 1962$ - Industrial research and economic growth in Australia by Bruce R. Williams

$31 \quad 1964$ - Australian foreign aid policy by Heinz W. Arndt

321967 - Australian tariff policy by W. Max Corden

331969 - Balancing external payments by adjusting domestic income by E. H. Phelps Brown

341971 - Income inflation in Australia by Ronald F. Henderson

351974 - Political economy and the problems of our times: In defence of general economics by John Vaizey

361976 - Comparing the Industries Assistance Commission and Jackson Committee approaches to industrial development by G. Alf Rattigan

371978 - Australian economics, 1967 to 1977 by Fred H. Gruen

381981 - Work and welfare in the years ahead by Robert G. Gregory

391985 - Japan faces affluence by Martin Bronfenbrenner

$40 \quad 1986$ - What do we really know about monetary policy? by David Laidler

$41 \quad 1988$ - Pacific challenges to the United States by Paul R. Krugman 
421993 - How convincing is the evidence linking education and income? by Orley Ashenfelter

431994 - The role of the NAFTA debate in US trade policy by Anne O. Krueger

$44 \quad 1995$ - Protection and liberalization in Australia and abroad by W. Max Corden

451996 - Population, food and trade by D. Gale Johnson

461997 - Strengthening intellectual property rights in Asia: Implications for Australia by Keith E. Maskus

471999 - Human behaviour and the transmission of infectious disease: An economist's perspective by Mark Gersovitz

482001 - Public policy and higher education by Peter H. Karmel

492002 - The role of natural resources in economic development by Edward B Barbier

502003 - Globalization by Mike Moore

512006 - Paying for the past: Economics, cultural heritage, and public policy by C. David Throsby

522008 - Globalization and the Great Divergence in the long run by Jeffrey G. Williamson

532009 - Globalization and the environment by Brian R. Copeland 


\section{Contributors to opening chapters}

Kym Anderson (FASSA) is George Gollin Professor of Economics and was the foundation Executive Director of the Centre for International Economic Studies at the University of Adelaide, where he has been associated since 1984. Prior to that he spent 7 years at the Institute of Advanced Studies at the Australian National University in Canberra, following doctoral studies at the University of Chicago and Stanford University. During 1990-92 he was on leave at the GATT (now WTO) Secretariat in Geneva, as deputy to the director of economic research and he spent 2004-07 as Lead Economist (Trade Policy) at the World Bank's Development Research Group in Washington DC.

F. R. (Bob) Fisher (AO 1990) is a great grandson of Joseph Fisher. A graduate in law from Adelaide University, he became a QC in 1970 and was a Judge of the Federal Court, 1978-89, when he was also Deputy President of the Administrative Appeals Tribunal. He served on the Council of Flinders University of South Australia from 1969 to 1988, and in the latter part of that period he was Pro Chancellor and then Chancellor.

Keith J. Hancock (AO 1987, FASSA) is a graduate of the University of Melbourne and the London School of Economics. His first academic appointment was as a Lecturer at the University of Adelaide, before he transferred to the new Flinders University of South Australia in 1964 as first Professor of Economics and then Pro Vice-Chancellor (1974-79), Vice-Chancellor (1980-87), and thereafter Emeritus Professor. He spent 1987-89 in the Australian Conciliation and Arbitration Commission and was then appointed Deputy President of the Australian Industrial Relations Commission where he served until 1997. Since then he has been an Honorary Fellow in Economics at the University of Adelaide. 



\section{The benefactor Joseph Fisher}

\section{Extract from Joseph Fisher - A Pioneer Colonist by F. R. Fisher (Printed by Open Book Publishers, Adelaide, in 1998)}

Joseph Fisher was born in Yorkshire on 14 September 1834, to Joshua and Hannah Fisher. Joseph and his parents and sisters sailed for South Australia in the Pestonjee Bomanjee, leaving from London on 11 June and arriving in Glenelg on 12 October 1838, when Joseph was 3 years old.

A family friend, Anthony Forster, probably influenced their decision to choose South Australia. Forster himself travelled to South Australia in early 1841, to take possession for George Fife Angas of the latter's Barossa Estates. This was a fortunate event for Joseph, with whom Forster had a particularly close association both as a friend and mentor consequent upon Joshua's untimely death on 3 September 1841.

Joseph appears to have had the bulk of his schooling at the Oddfellows School and subsequently in Anthony's Forster's old home. He left school at age 12, five years after his father's death, to work in the merchantile business established by Anthony Forster. Two years later Forster took up an offer of a share in the Register and Observer newspapers, and Joseph joined the Register's commercial department. In an interview in 1903 Joseph described his duties as follows:

"I had to assist the bookkeeper, deliver papers, take a turn at the old hand press, occasionally read proofs and also numerous other odd jobs at the office. I frequently remained on duty for 12-14 hours a day and I soon gained a practical knowledge of the work in almost every department of the newspaper office."

In his article entitled 'A Man of Honor', which appeared on 17 February 1958 in the Adelaide News, Douglas Pike (a distinguished historian at Adelaide University) wrote the following about Joseph's early activities: 
"With its new copper wealth and heavy immigration, Adelaide in 1846 was full of opportunities. At 14 Joseph needed no prompting. For two years he quietly imported potatoes from Tasmania and had $£ 2,000$ in the bank before his little monopoly was invaded. He was still employed in the Register when it came up for sale in 1853. With his potato money he joined the syndicate that bought the newspaper."

Shortly after that time Joseph took over the management of the commercial department of the paper, in which position it was his function, in the words of Dr Pike, to know 'the ins and outs of every business deal in town'. It appears that he also acted as shipping reporter for the paper.

By 1857 Joseph had acquired a quarter share as a proprietor of the Register. During that year he both married and purchased the 8-acre property Woodfield, his home until his death, in what is now the State Heritage-listed building at 78 Fisher Street, Fullarton. His wife for the next 50 years was Anne Wood Farrar, the eldest daughter of Henry Wilkinson Farrar, a 'highly respected Melbourne Merchant' and also originally from Yorkshire. Joseph appears to have been intensely interested in and proud of his home and gardens. His obituary states that in the later years of his life he spent several hours daily in his garden and was never happier than when tending his roses and fruit trees. Tragedy hit the family at the end of 1865 , however, with the death of three of their children of diphtheria. Subsequently three further children were born.

Joseph sold his interest in the Register and left his employment there in October 1865, at age 31. In recording his retirement, the newspaper made reference to his 'recent domestic afflictions and the fact that his retirement would give him leisure for which he and his family would be grateful.'

At the time of his retirement he had already acquired what appears to have been his first outside interest, having accepted appointment as one of the trustees for shareholders of the Deed of Settlement of the Bank of Adelaide. This institution was established in August 1865 and Joseph's association extended over the next 23 years, he having been appointed a director in 1868 . He is quoted as having been a shrewd and industrious director, and acting for a time as Chairman. 
Another South Australian Bank in whose foundation Joseph was involved was the Commercial Bank of South Australia. Trevor Sykes, in his book Two Centuries of Panic: A History of Corporate Collapses in Australia, says that the Bank was 'the brainchild of Joseph Fisher, a shrewd, restless entrepreneur'. It was as a Member of the Legislative Council that Joseph in 1878 sponsored a Bill of Parliament and presented a petition to the House of Assembly. Hansard quoted Joseph as saying on the second reading that the Bill was almost a verbatim copy of the Acts under which the National Bank and the Bank of Adelaide had been incorporated. The shares had been subscribed three times over, he said, and five gentlemen who stood high in the colony for honour and probity had been named as directors. However, the accounts of the Commercial Bank were signed by a Manager appropriately bearing the surname 'Crooks'. The Bank collapsed in 1886 and Crooks was convicted of embezzlement and sentenced to eight years in gaol. It is unlikely that Joseph was ever a director of this bank because, throughout the years in question, he was a director of a competing bank, the Bank of Adelaide. Neither he, nor any members of his family, at any time owned shares in the Commercial Bank of South Australia.

Joseph's advice was, as Douglas Pike says in his newspaper article in 1958, greatly sought after and he became director of a number of companies in addition to the Bank of Adelaide. He served on the Boards of the South Australian Gas Company, the Port Adelaide Dock Company (as chairman), the Adelaide Steamship Company, the Adelaide Marine and Fire Insurance Company (as Chairman) and the Momba Pastoral Company. He was also on the local Board of Advice in South Australia of the South Australian Company, established in England in 1835.

The centenary history of the Stock Exchange of Adelaide, entitled Bulls, Bears and Wildcats, has this to say of Joseph and his assiduous interest in the performance of Adelaide companies:

"Several city capitalists, with holdings in a number of companies, customarily attended company meetings to hear of current progress. One of the best known was Joseph Fisher. A doughty supporter of private enterprise, by his own practice of it he had become an early proprietor of the Register and a director of several companies. Fisher also served in Parliament, though he was better known for 
his business investments and astuteness. His remarks at the Gas Company's annual meeting in 1895 were typical of his attention to company affairs. He claimed that on a visit to England and to Europe he had taken as much interest in the Gas Company as if he had been in South Australia. He had walked the foreign streets to see how gas was competing with electricity, and was delighted that Adelaide's citizens had turned down the Corporation's proposal to light the streets with electricity."

In addition to his interest in urban business, Joseph was involved in pastoral investments, frequently in association with a number of other South Australians such as Barr Smith, Elder and James Francis Cudmore. It would appear that his interests were financial in nature, however, rather than those of an active pastoralist. His first venture into this field was probably the property north of Adelaide known as Hummocks Run, comprising 97,000 acres of freehold land as well as some leasehold.

In 1870 Joseph and Anthony Forster each acquired a one-eighth interest in the partnership that owned the Mount Murchison Run in New South Wales. In 1872 the partnership acquired a one-third interest in the Momba Run and the ownerships were amalgamated. The other partners at this time were Robert Barr Smith, McCullock Sellar \& Co. of Melbourne (the then proprietors of Mt Gipps Pastoral Company of Broken Hill which was the employer of Charles Rasp, the discoverer of the Broken Hill lodes), Peter Waite, W.C. Swann, and Thomas Elder. In 1888 the interests of the partners were acquired by a limited company in which Joseph became a partner. In 1881 Thomas Elder and Joseph each acquired a one-eight interest in the Ned's Corner Run, which held 1300 square miles in Victoria just over the South Australian Border. On 1 August 1899 Joseph transferred half of his interest to the Fisher Trust.

Joseph made five visits in all to England. The first of these was in late 1866 or early 1867. Upon his return, at the age of 33, Joseph entered the Legislative Assembly representing the District of Sturt. He served there until February 1870, and then in the Legislative Council from July 1873 to March 1881. In the obituary published on his death, the Register commented that 'he was at all times plain spoken and was not the man to make compromises of principle for the 
sake of securing any private advantage'. His speeches in the House were usually shorter than those of many of his colleagues, but he made his points clearly and forcefully. In his opening speech he expressed two strong views, which he was often to repeat in later years: a distaste for waste and profligacy, and insistence on his own imperviousness to pressure from any quarter.

During his next seven years at the Legislative Council, Joseph gave his views on a wide variety of matters in a typically uninhibited manner. In his first speech in the Council on July 30 he touched on an issue that was eventually to lead to his political downfall: immigration.

In November 1873 Joseph opposed a Bill that would increase the Ministry from five to six members. He said he would be glad to see a Government that did not seek to be judged by the large number of Bills it introduced. In his view many of the Bills involved an expenditure of time and money for which there was not the slightest necessity.

Then in December that year, in an unusually lengthy speech, Joseph vigorously opposed a Bill providing for compulsory education and State schools. He said the voluntary system of education had not failed, whereas a Government system introduced in 1851 had been an utter failure. He was not opposed to education, but to the compulsory clauses in the Bill. He objected to the unwarrantable interference with the rights and duties of parents, and believed some parents who could afford private schools would no longer be able to if they had to contribute also to the cost of State education.

In the following year, 1874, he berated the Government for its lack of enterprise. He urged, not for the first or last time, that telegraphic communication be extended to Cape Borda to avoid uncertainty about shipping movements. $\mathrm{He}$ regretted that 'no action had been taken in the matter of inter-colonial free trade' and wanted 'this colony to step forward and invite the more important colonies to come in'.

He also stressed what he believed was an urgent need for a new railway to tap the Murray River trade. He said a Murray rail connection would enable the Riverina wool then being shipped through Melbourne to be diverted to Port 
Adelaide. This, he felt, would give employment to thousands: there would be 30 extra ships at the Port within twelve months of the line opening, and the squatters of Riverina would make their headquarters in Adelaide.

As well, he wanted better shipping arrangements than those provided by $\mathrm{P} \& \mathrm{O}$ steamers for landing mail to Glenelg; he opposed a Customs Bill imposing new tariffs to foster manufacturing; and he opposed a Bill to close hotels on Sundays to all but travellers (on the grounds that it simply would make people sneaks).

In 1877 Joseph strongly supported a no-confidence motion carried against the Chief Secretary, Sir Henry Ayers, the only Minister in the Legislative Council. The dissatisfaction with Ayers arose from a Government contract to build a new Parliament House, with an estimated cost of $£ 200,000$ and without the proposal being put before the Council. Joseph took exception not only to the Council being ignored but also to the proposed site of the new Parliament House, at the corner of North Terrace and King William Street. The site, he contended, should be reserved for the future railway station. He looked forward to the time when the colony would be regarded as the great centre of Australia. He thought mail steamers would possibly make Adelaide their terminus, with the mails being conveyed to the other colonies by railway. He believed the new Parliament House, with the University and the Institute, should be designed together on North Terrace and become 'three of the grandest buildings in any of the colonies'.

In December 1877 Joseph successfully moved for an award of up to $£ 4,000$ to John Ridley, the inventor of the reaping machine, for whom he had acted as an agent before entering Parliament. He said it was a standing disgrace to the colony that no substantial public recognition had been made of Mr Ridley's services: had he taken the precaution to patent his invention, he would have been one of the richest men in South Australia.

Joseph's parliamentary career, which he had never seen as the most important phase of his life, ended in 1881. His failure to win re-election was widely attributed to his opposition to legislation intended to restrict Chinese immigration, legislation that he regarded as unchristian, uneconomic and meddling in imperial matters. Joseph spoke about his election defeat in an interview published in the Register on 15 April 1903 as follows: 
"Some of my friends thought that I was unnecessarily outspoken at times, and I was frequently told that it would be better for me to give more diplomatic answers when questions were put to me on the hustings respecting popular measures which I could not support; but I refused to make compromises in connection with matters of principle merely for the purpose of gaining a seat in the House."

It was during the decade of the 1890s that Joseph established what thereafter became known to his descendants, somewhat incorrectly, as The Fisher Trust.

On 14 April 1903, Joseph wrote a letter to the Editor of the Register newspaper in which he made charitable donations totalling $£ 3,315$, which he requested the Register to distribute on his behalf. In his letter he sets out his reasons for making the donations during his lifetime rather than by will on his death. The letter reads as follows:

"Sir - I have much pleasure in sending you herewith a list of donations, which I have decided to give to the various institutions enumerated therein. Will you kindly communicate with the representatives of those institutions so that they may collect the amounts in which they are respectively concerned. Subject to your consent, the sums are payable at The Register Offices, in Grenfell Street, Adelaide.

"In explanation I may say that for many years past I have made provision in my will for charitable and other public purposes, but I am now led by several considerations to anticipate the date on which effect can be given to that document. The only one of these which I need mention here is the law now in force that all moneys given in his will by a testator for charitable purposes are subject to a deduction of 10 per cent payable to the Government. I regard this exaction as equally unjust and unwise, and as one tending to check the flow of public-spirited benevolence. In these circumstances I have resolved to make during my lifetime the distribution, which I have intended to reserve until after my decease." 
The first item reads:

"Adelaide University - To encourage commercial education - (1) a perpetual gold medal to the student of exceptional merit on completion of the course for the advanced commercial certificate; (2) a special lectureship on the commercial side - a lecture to be delivered in alternate years, and published; and (3) the remuneration of lecturers, examiners, and professors engaged in the general work of the commercial course - $£ 1,000$.”

For the last 20 years of his life, Joseph had been suffering from gout and diabetes. In mid-September 1907 he suffered an attack of influenza which, on 26 September, assumed a serious form and he died the same day at Woodfield.

He left a will in which he appointed his two sons his executors. It was signed on 21 May 1903 in the presence of G.J.R. Murray, subsequently Sir George Murray, Chief Justice, Lieutenant Governor and Chancellor of Adelaide University, and W.A. Magarey, Queen's Counsel and donor of the Magarey Medal.

On 5 October 1907 the Register published an obituary, which concluded as follows:

"The late Mr Fisher was a man highly respected in business and private life, and though in recent years he had taken little active part in public affairs, in his earlier political career he expressed himself as sternly opposed to many of the political ideals which have since found favour in certain quarters, and refused to shirk what he deemed to be his duties and responsibilities merely to retain his seat. He was at all times plain spoken, and was not the man to make compromises of principle for the sake of securing any private advantage. He always manifested a deep interest in the district in which he dwelt, and progressive municipal movements found in him a warm supporter."

Half a century later, Dr Douglas Pike wrote in his article 'A Man of Honor' (the News, 17 February 1958):

"What makes a pioneer and brings him honour? Publicity, land ownership, and pastoral wealth? Does a townsman qualify? Some early arrivals did not care. Sincerity meant more to them than fame. 
Joseph Fisher was content to boast that he had spent his life in sight of Adelaide. Parliament claimed him for 10 prosperous years when honest men were scarce. Reporters sharpened their pencils whenever Fisher rose to speak, but landjobbers and speculators quailed before his revelations. He knew the ins and outs of every business deal in town. His advice was sought by high and low. Proposals below his moral standards he denounced in plain unvarnished terms; what he approved was supported with equal vigour. He had too much candour to be accepted by the genteel, yet a dozen boards sought him as a director. Even the Cricket Association made him its president for 25 years. As agent for colonists retired to England he had further inside knowledge, but he rarely used it for personal gain. His own investments were varied, safe, and seldom changed. His family and home meant more to him than power. Solid and unpretentious Woodfield at Fullarton gave Fisher Street his name. Its roses and trees were his pride. The full extent of his charity was revealed only after influenza laid him low in 1907." 



\section{The lectures}

\section{Kym Anderson}

There is of course no sense in trying to summarize as eclectic a set of Lectures as this one. The purpose of this note is simply to whet the reader's appetite by describing the range of economic issues discussed over the almost one hundred years the Lectures cover.

Given the interest of Joseph Fisher in fostering higher education in matters commercial, it is not surprising that the first Lecture was on precisely that topic. The Lecturer, who headed a major bank at the time, was evidently very widely traveled and well informed of the embryonic attempts in other affluent countries to introduce economics and commerce courses into universities. The Inaugural Lecture provides fascinating reading for today's graduate economists and accountants unaware that their courses had hardly begun to be established a century ago. Adelaide University can take pride in being at the global forefront in developing a course as early as 1901. Its initial requirements were not as tough as the University of Birmingham's though, where commerce students had to master at least two modern foreign languages in addition to English!

The next few Lectures cover practical commerce/business issues before the topics turn to mainstream economics and finance issues that were important at the time and, in numerous cases, have remained so.

The issue of price stability concerned Copland in 1919 in the aftermath of the Great War, for which he saw a return to the gold standard as an inadequate solution. That issue also concerned Gregory, Davidson and Melville at the time of the Depression in the early 1930s, where it was addressed more in an international context.

Another big economic issue discussed just prior to the Depression was public finance, particularly in relation to Australia's rapidly growing public debt. Prime Minister Bruce provided a political perspective while Professor Mills gave an academic economist's view. It is also a crucial issue in times of war, as Irvine's 
Lecture in 1917 and Wilson's in 1940 make clear. Within the public finance field, Federal-State financial issues are never far from the top of the agenda in a federation. It is surprising, therefore, that only one Lecture has been devoted to the topic, namely by Prest and not until 1954.

Shortly after the Depression, Giblin provided a detailed analysis of the effects of import tariffs. This had been a hot political topic before federation in 1901, and it continued to be so well into the twentieth century. At a superficial level the issue seems to have not changed, with Giblin referring in 1936, just as we do today, to the highly protected sectors of textiles and motor vehicles. But analytically the economics profession has come a long way since then. A comparison with Corden's Lectures three and then again six decades later (1967 and 1995) reveals a progressive development of understanding, not only by economists but also by the public at large, of the economic cost and distributional consequences of tariffs. Also noteworthy is a warning by Menzies at the end of his Lecture in 1942: despite his predisposition to favour import tariffs, he acknowledged that Australia would have to do its part in reducing barriers to international trade once the war was over. As Corden's 1995 Lecture makes clear, Australia took a long time to get to that stage, but in the final quarter of the $20^{\text {th }}$ century it did eventually liberalize its markets.

Just before World War II broke out, Colin Clark treated his Adelaide audience to an application to Australia of ideas that appeared shortly thereafter in his classic treatise on The Conditions of Economic Progress ( $1^{\text {st }}$ edition 1940). His estimates suggest Australia in 1938 was the $4^{\text {th }}$ most affluent country in the world after New Zealand, the United States and Great Britain, and perhaps equal to Argentina down from first or second at the time of federation and a sharp contrast to today's ranking of around $20^{\text {th }}$ (using similar purchasing power parity measures). As if to link with the previous Lecture, by Giblin on tariffs, Clark points to the comparatively poor labour productivity performance in Australian manufacturing. He also stated that the future for Australian farm exports lies in the politics of trade agreements rather than in the economics of comparative costs of production - precisely what the post-war history of the GATT/WTO has revealed.

Following World War II, attention turned to ensuring full employment. Among the chosen approaches were efforts to boost agricultural and industrial 
development, including through infrastructural and research investments. These are the themes of the next five Lectures, by Coombs, Wadham, Lewis, Condliffe and Crawford. Coombs focused on the macroeconomic challenge of ensuring full employment once wartime activities ceased, suggesting the need for non-trivial government intervention. However Wadham, a Professor of Agriculture, warned that trying to boost employment by allocating land in small parcels for one-person farms could lead - as it did - to them being uneconomic, and at the same time adding to environmental and resource management problems associated with soil, water and forests. On the positive side, he stressed the crucial importance of education for rural people if they were to share in the fruits of economic growth.

Condliffe in 1950, like Williams in 1962, drew attention to the growthenhancing role of investments in research and development and the probable underinvestment in such activities by Australia. This topic has risen again in 2001 as an election issue, along with the perennial concern with brain drain problems. Less emphasis is being given by today's government to the other great contributor to economic growth, namely investments in formal education - despite the strong empirical evidence linking educational attainment and income, as demonstrated for example in Ashenfelter's 1993 Lecture.

Another lecture topic in the 1950s that has a contemporary resonance is superannuation. Downing in 1958 argued that the Australian system of age pensions subject to a means test was not necessarily inferior to the compulsory national superannuation systems operating in numerous other countries at that time.

The 1970s was a period when serious concerns with inflation and associated wages policy and unemployment arose. Some if their effects on economists' activities are surveyed in Gruen's 1978 Lecture, including the increased use of macroeconometric modeling designed to assist policy makers. Related lectures are the ones by Henderson in 1971 on inflation, by Laidler in 1986 on monetary policy, and in between by Gregory in 1981 on unemployment.

Not surprisingly, as globalization has proceeded, international issues of relevance to Australia are more prominent in the second volume of these lectures. Important among those in the 1950s was the issue on which Nobel Laureate James 
Meade focused in his 1956 Lecture, namely, why post-war Japan's membership of the GATT should be expedited. The arguments presented are remarkably similar to those currently being used in connection with China's application to re-join the GATT/WTO system. Japan is also the subject of Bronfenbrenner's Lecture three decades later, when that country had become far more affluent. At that time (1985), Bronfenbrenner argued that Japan was not yet suffering from the sclerosis problems of other advanced economies, a claim that would be less easy to make today.

Trade issues were the subject of several other Lectures since the 1950s. The two by Corden have already been mentioned. His analysis of Australian tariff policy in 1967 is still regarded as a classic reference. It provides great detail and insight into the tariff policy formation process and a critique of, and suggested alternatives to, the method of setting tariff rates at that time. His retrospective analysis in 1995 reviews the extent and causes of the massive trade liberalization in Australia since his first Lecture, and compares it with the forces at work in many developing countries. One of the key forces aiding reform in Australia was greater policy transparency, thanks to the transformation of the Tariff Board in 1973 to the Industries Assistance Commission (subsequently changed to the Industry Commission and most recently to the Productivity Commission). Its first Chairman, Alf Rattigan, contrasts in his 1976 Lecture the IAC's approach with that of the more interventionist Jackson Committee's proposal for boosting industrial development.

Regionalism and American trade policy were the focus of the Lecture in 1994 by Krueger (the only female Fisher Lecturer to date). She expresses concern that regional arrangements such as the North American Free Trade Agreement are being designed in ways that make them more stumbling blocks than stepping stones to freer global trade, for example through diverting the attention of trade negotiators away from the GATT (and now WTO). Since then regional agreements have sprung up like mushrooms, making this Lecture even more pertinent now than in 1994.

Food trade problems wax and wane, but the perceived long run problem of population outstripping supply growth, commonly associated with the name of Malthus, is erroneous according to Johnson in his 1996 Lecture. With population 
growth slowing and new farm technologies expanding supplies, food-exporting countries will be under continual pressure to adjust to a long-run decline in international food prices - notwithstanding potential food import growth by China in the 21st century. This view contrasts sharply with that of the Australian government in the early 1950s when, according to Crawford's Lecture of 1952, the prime aim of agricultural policy was to produce more.

External payments problems also received attention. In 1969, PhelpsBrown focused on it from a UK perspective, prior to the freeing of currency exchange rates. The issue was revisited by Krugman in 1988, in his case focusing on the persistent US deficit which he saw as the other side of the coin to persistent trade surpluses in Japan, South Korea and Taiwan. He claimed he would not be surprised if the high value of the US dollar was sustained for a long time, as indeed it has been.

Problems of developing countries had been barely touched on in this Lecture series until recently. The three exceptions in addition to Johnson's Lecture on population and food are Arndt's treatment of foreign aid policy (1964), an assessment of the impact of strengthening intellectual property rights in developing Asia (Maskus, 1997), and an economist's perspective on the transmission of infectious diseases (Gersovitz, 1999).

Only a few of the Lectures since at least the mid-1920s are not part of mainstream economic thinking of the time. One in particular is worthy of mention, namely that by the British social historian Asa Briggs, in 1960, on the mass entertainment industry. It provides a fascinating history of that industry's development since the 1800s. According to Lord Briggs, it has been quoted more than any other lecture he has given.

Joseph Fisher would have been pleased that this series not only started with a Lecture on higher education, but also includes the 2001 Lecture by Peter Karmel who has had a distinguished career in higher education administration since leaving the George Gollin Chair in Economics at Adelaide in the mid1960s. Unlike the first Fisher Lecture by Turner, Karmel's is focused not on the education of economists but on the need for better economic analysis to inform the higher education policy reform process. 
Several of the lectures since 2001 focus on issues associated with globalization, including its impact on trade, natural resources and the environment.

In a collection that covers a period longer than a century, the Lecturers' word usage reveals changing social norms. Readers should be warned that the use of gender-neutral language does not become common until well into the second half of these Lectures! 


\section{The lecturers}

\section{Kym Anderson and Keith Hancock}

The Joseph Fisher Lecturers to date have been a mixture of prominent economists in academia and government, senior politicians including three Prime Ministers, and influential Australian bankers and businessmen. Most shared Joseph Fisher's interests in liberal markets and small, non-interventionist government. Only one female has given a Fisher Lecture so far, a reflection of the male dominance until recently of the world of economics and business. More than a dozen of the past Lecturers appear in Who's Who in Economics (edited by Mark Blaug and published by Edward Elgar), thirteen were knighted, and two have been awarded the Nobel Prize in Economics. Brief biographies of each of them follow. They are listed in alphabetical order, with the Fisher Lecture number and date given after their name.

Arndt, Heinz W., 1915-2002 (FASSA) (No. 31, 1964): Economist. After moving from Germany to Oxford with his parents in 1933, Arndt studied politics and sociology there and took up economics only after taking an appointment at Chatham House and then the University of Manchester under John Hicks. The University of Sydney attracted him to Australia in 1946, and by 1950 he moved to the new Chair of Economics at Canberra University College (later ANU), where he is still affiliated as an Emeritus Professor and continues to write and edit journals profusely. Arndt has done more than anyone to link Australian and Southeast Asian (especially Indonesian) development economists.

Ashenfelter, Orley, 1942- (No. 42, 1993): Economist and wine enthusiast. Ashenfelter specializes in labour economics, law and economics, and econometrics, with some of the latter skill being dedicated to understanding the viticultural determinants of the ultimate quality of premium wines, including Penfold's Grange. A professor of economics at Princeton since 1971, he has directed the industrial relations group there most of that time. Since 1985 he has been Editor of the American Economic Review, but that has not stopped his own research program from flourishing. 
Barbier, Professor Edward Barbier 1957- (No. 49, 2002): Economist. Professor Barbier is currently with the University of Wyoming but he has previously served at the University of York, UK and as Director of the London Environmental Economics Centre at University College London. As an environmental and resource economist, he has worked mainly on the economics of environment and development issues, including land degradation, wildlife management, trade and natural resources, coastal and wetland use, tropical deforestation, biological invasions and biodiversity loss. His latest book, Natural Resources and Economic Development, was published by Cambridge University Press in 2005.

Braddon, Sir Henry Yule, 1863-1955 (No. 5, 1912 and No. 11, 1925): Businessman. Braddon worked for 44 years with Dalgety's, the livestock and station agency, and was director of numerous companies. He was President of the Employers' Federation of New South Wales in 1905-07, of the Sydney Chamber of Commerce in 1912-14, and of the Associated Chambers of Commerce of Australia in 1913-14. He also lectured on business principles and practice at the University of Sydney, and he served terms in the New South Wales Legislative Council as both an appointed and an elected member.

Briggs, Asa (later Lord Briggs), 1921- (No. 29, 1960): Social and cultural historian of the $19^{\text {th }}$ and $20^{\text {th }}$ century. Born in Yorkshire, Briggs became Professor of Modern History at Leeds University (1955-61) before moving to the (then) new University of Sussex where he rose to Vice-Chancellor by 1967 . He spent 1976-91 as Provost of Worcester College, Oxford and 1978-94 as Chancellor of the Open University. He is President of the British Social History Society and of the Victorian Society. His trilogy, Victorian Things, Victorian Cities, and Victorian People is published by Penguin.

Bronfenbrenner, Martin, 1914-1994 (No. 39, 1985): Macro-economist. Shortly after finishing his $\mathrm{PhD}$ at Chicago in 1939, Bronfenbrenner was engaged in the US Navy in Japan, which gave him an abiding interest in that country. In addition to economics professorships at such universities as Wisconsin, Michigan State, Minnesota and Carnegie-Mellon, he was Professor of Japanese History and Kenan Professor of Economics in Duke University (1971-84) and then of International Economics in Aoyama Gakuin University, Tokyo (1984-90). 
Bruce, Rt. Hon. Stanley Melbourne (later Viscount Bruce of Melbourne), 1883-1967 (No. 12, 1927): Prime Minister of Australia 1923-29. Bruce entered the conservative side of politics in 1918 with strong business connections. He was a strong believer in Empire economic development, a supporter of tariff protection for selected industries, and a successful protagonist of reform in Commonwealth-state financial relations. His government was defeated in 1929 after Bruce failed to persuade the Parliament to pass legislation for abolition of the federal conciliation and arbitration system. Offices he later held included that of Australian High Commissioner in London.

Butchart, James R. (No. 10, 1923): Banker and dealer. At the time of the Lecture he was a foreign exchange dealer with Edward Dyason and Company. Previously he had been an Inspector in Victoria with the London Bank of Australia. In 1918 he wrote a text on Money and its Purchasing Power.

Clark, Colin Grant, 1905-1989, (No. 18, 1938): Economist, public servant. Clark originated many of the concepts of national accounting and was a major contributor to the economics of economic development. He arrived from England in Australia in 1938 to take up an appointment at the University of Western Australia, but soon moved to Queensland as Director of the Bureau of Industry. He remained in Queensland until 1952. After a further period in England, at Oxford University, he returned to Australia, where he spent his later years.

Condliffe, John B., 1891-1981 (No. 24, 1950): Economist. At the time of his Lecture Condliffe was a Professor of Economics at the University of California, but his first appointment to a Chair was at Canterbury University College in New Zealand in 1920. In 1931 he joined to the Economic Intelligence Unit of the League of Nations in Geneva for a time.

Coombs, Dr. Herbert Cole ('Nugget') (AC 1975, resigned 1976; FASSA), 1906-1997 (No. 21, 1944): Central banker, public servant, university leader, advocate of aboriginal rights, supporter of the arts. Formerly an assistant economist in the Commonwealth Bank, Coombs transferred to the federal Treasury in 1939, was appointed to the Commonwealth Bank Board in 1942 and in the same year 
became Director of Rationing. In 1943, he was appointed Director-General of Post-war Reconstruction. He became Governor of the Commonwealth Bank in 1949 and of the Reserve Bank in 1960, retiring in 1968 to take up a Visiting Research Fellowship at the ANU in Canberra.

Copeland, Professor Brian, 1956- (No. 53, 2009): Economist. At the time of his Lecture, Professor Copeland was Head of the Department of Economics at the University of British Columbia, where he was an undergraduate before completing his $\mathrm{PhD}$ at Stanford. His research has focused on developing analytical techniques to study the interaction between international trade and the natural environment. He (with Scott Taylor) wrote the seminal book on Trade and the Environment: Theory and Evidence, published by Princeton University Press. $\mathrm{He}$ has been co-editor of the Journal of Environmental Economics and Management and an Associate Editor of the Journal of International Economics.

Copland, Professor (later Sir) Douglas Berry, 1894-1971 (No. 9, 1921): Economist, administrator and diplomat. Copland, a New Zealander, was appointed a Lecturer in the University of Tasmania in 1917 and Professor in 1920. He was a Professor in the University of Melbourne from 1924 until 1945. During World War II, he was Prices Commissioner. Copland was the first Vice-Chancellor of the Australian National University, the first Principal of the Australian Administrative Staff College and founder of the Committee for the Economic Development of Australia. He held diplomatic appointments in China and Canada.

Corden, Warner Max (AC 2001, FASSA), 1927- (No. 32, 1967 and No. 44, 1995): International economist. One of the world's best-known analysts of tariff policy, Corden in more recent years has focused on the international monetary system, following a period as senior advisor to the IMF (1986-88). He has had long periods on the faculty of such universities as Oxford, Melbourne, ANU and, since 1989, Johns Hopkins University. He was instrumental in having the first official estimates of effective rates of protection included in the Vernon Committee of Economic Enquiry report of 1965. His writings on Australian economic policy are published in The Road to Reform (1997), but his globally influential works are Trade Policy and Economic Welfare (1974) and Inflation, Exchange Rates and the World Economy (1977). 
Crawford, (later Sir) John Grenfell, 1910-1984 (FASSA) (No. 25, 1952): Economist and administrator. After humble beginnings, Crawford became Economic Advisor to the Rural Bank of NSW before moving to Canberra as the head of a new Bureau of Agricultural Economics (1945-50) and then the Department of Commerce and Agriculture which became the Department of Trade. In 1960 he returned to academia as Professor of Economics and head of the Research School of Pacific Studies, became Vice-Chancellor (1967-73) and then Chancellor (1976-84). His impacts on agricultural economics, trade policy (especially towards Japan) and international development assistance were profound. In 1982 he was declared 'Australian of the Year'.

Davidson, (later Sir) Alfred Charles, 1882-1952 (No. 15, 1932): Banker. Davidson, at the time of the lecture, was General Manager of the Bank of New South Wales. He had played a leading role in the financial adjustments of the early phase of the depression. His actions included initiation of the breach of parity of the Australian pound with sterling. He was an advocate of an independent central bank. Davidson, in 1936, was a major witness before the Royal Commission on Monetary and Banking Systems.

Downing, Professor Richard Ivan, 1915-1975 (FASSA) (No. 28, 1958): Economist. In 1954, after service as a lecturer at Melbourne, wartime public servant and economist at the International Labour Office, Downing was appointed to the Ritchie Chair of Economic Research at the University of Melbourne. $\mathrm{He}$ had wide interests and occupied various public positions. At the time of his death, he was Chairman of the Australian Broadcasting Commission. Throughout his career, Downing displayed a strong conviction of the obligation of economists to improve the lot of people. His interest in national superannuation reflected this conviction.

Elles, J. Currie (No. 3, 1908): A self-described commercial man, Elles also refers to himself as a Member of the University of Glasgow, Honorary Member of the Institute of Bankers of New South Wales and Correspondent in New South Wales of the Board of Trade of Great Britain (Intelligence Department). 
French, Sir John Russell, 1847-1921 (No. 4, 1910): Banker. French was for the last 27 years of his life the General Manager of the Bank of New South Wales. He was a founder of the Institute of Bankers of New South Wales, President of the Sydney Chamber of Commerce and President of the Associated Chambers of Commerce of Australia. As the leader of Australia's largest bank, he played an important role in relations between government and the banks, especially during World War I.

Gersovitz, Mark, 1949- (No. 47, 1999): Economist. Following his PhD at Yale in 1995, Gersovitz has had faculty appointments at Princeton University, the University of Michigan and currently Johns Hopkins University. He has also taken time out to be Editor of the World Bank Economic Review and World Bank Research Observer, 1992-94. As an applied microeconomist, he has focused his research on the problems of poor countries, traveling widely to many African and Asian countries.

Giblin, Professor Lyndhurst Falkiner, 1872-1951 (No. 17, 1936): Economist. Formerly government statistician in Tasmania and advisor to the Premier, Giblin was appointed in 1929 to the Ritchie Chair of Economic Research in the University of Melbourne. He was actively involved in the policy debates of the 1920s and 1930s and served on various advisory bodies, including the inaugural Commonwealh Grants Commission and the Bridgen Committee of enquiry into the Australian tariff. As Acting Commonwealth Statistician, he prepared the 1933 census. A friend of J. M. Keynes, Giblin did much to introduce Keynesian ideas into the Australian debate.

Gordon, (later Sir) David John, 1865-1946 (No. 6, 1914): South Australian journalist and politician. Gordon had been employed by the South Australian Register in various capacities. He became active in the non-Labor side of politics and in 1911 was elected as member for the federal seat of Boothby, which he lost in 1913. In the same year, he was elected to the Legislative Council, of which he was President from 1932 until 1934. He served a brief term, in 1917, as Minister of Education. Gordon was an enthusiast for rural economic development. 
Gregory, Robert George (AO 1996, FASSA), 1939-(No. 38, 1981): Economist. Following doctoral studies at LSE and a short teaching period at Northwestern University, Gregory has been based at ANU's Research School of Social Sciences where he has been Professor of Economics since 1987. He shot to fame in the mid1970 s with the 'Gregory thesis', on the structural changes that a mining boom inflicts on an economy, but since the 1980s has focused mainly on labour market and associated welfare issues where his research has been very influential through being widely disseminated. He has served on many government committees and was on the Board of the Reserve Bank from 1985 to 1995.

Gregory, (laterSir) Theodore Emanuel Gugenheim, 1893-1970 (No. 14, 1930): Economist. Gregory was, at the time of the Lecture, a Professor of Economics at the London School of Economics. He accompanied Sir Otto Niemeyer, who visited Australia in 1930 as a representative of the Bank of England to advise the federal government and the Commonwealth Bank on Australian economic problems.

Gruen, Fred H. (AO 1986, FASSA), 1921-1997 (No. 37, 1978): Economist. Gruen was born in Austria, lost his father when he was 15, was sent to boarding school in England in 1937 knowing no English, heard his mother died in the Auschwitz camp, was deported on the ship Dunera to Sydney in 1940, and then was interned in Hay, NSW until war's end. Few would have risen from that beginning to become one of the country's most widely appreciated economists. Starting as an agricultural economist for the NSW government and then as Professor at Monash University, he moved to general economics at ANU's Research School of Social Sciences in 1972. From there he made a formidable contribution to a wide range of economic policy debates, and mentored generations of economists including his two sons.

Henderson, Ronald Frank (CMG 1976, AO 1988, FASSA), 1917-1994 (No. 34, 1971): Applied social economist. Henderson took economics at Cambridge and, after World War II, was appointed a Lecturer in Economics there and a Fellow of Corpus Christi College. He visited relatives in Australia from time to time and took part in policy debates here. In 1962 he accepted an appointment to the University of Melbourne where he built up a team that became the Institute 
for Applied Economic and Social Research. When Henderson retired in 1979 the Institute had 50 staff and a reputation as the country's most influential unit analyzing economic and social policy issues, particularly poverty.

Irvine, Professor Robert Francis, 1861-1941 (No. 7, 1917): Economist. In 1912 Irvine was appointed as the first Professor of Economics in the University of Sydney. He resigned, in controversial circumstances, in 1922. His views about economics, both during his tenure as a Professor and thereafter, were unorthodox.

Jessop, Lewis Angelo (No.2, 1906): Little is known of this Lecturer beyond the facts that he was married in 1879 and at the time of the Lecture he was employed at the Alliance Assurance Office in Adelaide.

Johnson, David Gale, 1916-2003 (No. 45, 1996): Agricultural economist. Johnson has been a member of the Economics Department in the University of Chicago since 1944, a full Professor since 1954, and Eliakim Hastings Distinguished Service Professor since 1970. During that long tenure he has served in a wide number of University positions including Provost. Outside the University he has been equally influential in a vast array of offices, including as President of the American Economic Association in 1999. Notwithstanding, he is a prolific researcher and for decades has been the world's most influential agricultural trade economist. He is best known for his book World Agriculture in Disarray.

Karmel, Professor Peter Henry (CBE 1967, AC 1976, FASSA), 1922-2008 (No. 48, 2001): Economist, educationalist and administrator. Appointed Professor of Economics at Adelaide University at the age of 28 (in May 1950), Karmel built up a vigorous and highly regarded Department. In 1961 he became Principal-Designate of Adelaide University's Bedford Park campus. This became Flinders University in 1966, with Karmel as its first Vice-Chancellor. He was later Chairman of the Australian Universities Commission and the Commonwealth Tertiary Education Commission, and Vice-Chancellor of the Australian National University. He has served as chairman or member of many governmental, university-related and public-interest entities, and was the first Chancellor of the 
University of Papua New Guinea. Since 1965 he has been an Emeritus Professor with Adelaide University.

Krueger, Anne O., 1934- (No. 43, 1994): International economist. Krueger, the only female Joseph Fisher Lecturer to date, has been on the faculty of the universities of Wisconsin (1955-59) and Minnesota (1959-82) before spending a period as Vice President of the World Bank (1982-86). She then moved to Duke University until 1991 when she transferred to her present position at Stanford University. A prolific researcher in the areas of economic development and international trade, she is author or many influential books on the scope for policy reform, and an advisor to numerous developing countries. In 1996 she was President of the American Economic Association.

Krugman, Paul, 1953- (No. 41, 1988): International economist. A PhD from MIT in 1977 launched this brilliant analyst and advocate onto the world stage. He has since taught at Stanford and Yale universities as well as MIT, before moving in 2000 to Princeton. In addition to profound academic writings in international economics he is one of the most prolific and successful popularizers of complex economic ideas via the mass media. All of those popular writings get posted on his website which must be the most visited of any economist. In 1991 he was awarded the John Bates Clark Medal, given by the American Economic Association every two years to the top economist under 40, and in 2008 he received the Nobel Prize in Economics.

Laidler, David, 1938- (No. 40, 1986): Monetary economist. English born and raised, $\mathrm{PhD}$ from Chicago in 1964, a professor back in England (Manchester) until 1975, and then Laidler migrated to Canada to take up a Chair at the University of Western Ontario whre he still is employed. In addition to research for his books and articles on monetary theory, Laidler has been heavily involved in monetary policy debates, particularly in Canada. In 1987/88 he was President of the Canadian Economic Association.

Lewis, Essington, CH, 1881-1961 (No. 23, 1948): Industrialist. A diplomate of the South Australian School of Mines and Industries (now the University of 
South Australia) and with major involvements in the Port Pirie smelters, Lewis remained with the BHP Company after its disposal of the smelters. He became general manager of BHP in 1921 and Managing Director in 1926. During World War II, Lewis occupied the major office of Director of Munitions, returning to the iron and steel industry in 1945. He was Chairman of BHP during the Korean War years (1950-52).

Maskus, Keith E. 1954- (No. 46, 1997): International economist. Maskus has been on the faculty of the University of Colorado ever since he completed his $\mathrm{PhD}$ at the University of Michigan in 1981, and a full Professor since 1995. He has been a Research Fellow with the Institute for International Economics in Washington, D.C. since 1998, and was also appointed as an Adjunct Professor at the CIES in Adelaide University in 2001. As a specialist in international trade policy and in intellectual property rights, he has been widely sought as a consultant/visiting scholar by international agencies, government and business.

Meade, Professor James Edward, 1907-1995, (No. 27, 1956): Economist. From 1947 until 1957, Meade was Professor of Commerce at the London School of Economics. During this period he wrote several seminal books about international trade. He was Professor of Political Economy at Cambridge University from 1957 until 1968. Meade served a term as President of the Royal Economic Society. In 1977, he was awarded the Nobel Prize in Economics. During a visit to Australia in 1956, Meade collaborated with Adelaide's Professor Eric Russell in producing an important paper on wages, prices and the balance of payments.

Melville, (later Sir) Leslie Galfreid (FASSA), 1902-2002 (No. 16, 1934): Economist, public servant, Vice-Chancellor. Trained as an actuary and employed in the South Australian Treasury, Melville in 1929 was appointed at age 27 as the first Professor of Economics in the Adelaide University. He left his Chair in 1931 to become the first economist in the Commonwealth Bank. His later distinguished career included leadership of the Australian delegation at the Bretton Woods conference in 1944, Vice-Chancellor of the Australian National University (1953-60), Chairman of the Australian Tariff Board (1960-63), and Board member of the Reserve Bank of Australia (1965-74). 
Menzies, Right Hon. (later Sir) Robert Gordon, 1894-1978, (No. 20, 1942): Australia’s longest-serving Prime Minister, holding office between 1939 and 1941 and between 1949 and 1966. Prime Minister at the outbreak of World War II, he resigned in 1941 as Leader of the United Australia Party and Prime Minister. When the Labor Government led by John Curtin came to power later in 1941, Menzies moved to the Opposition benches. He became Leader of the Opposition in 1943 and in 1944 founded the Liberal Party.

Mills, Professor Richard Charles (OBE), 1886-1952, (No. 13, 1927): Economist. As Professor of Economics in the University of Sydney (1922-45), Mills was one of the founders of the Economic Society of Australia and New Zealand in 1924. He had previously undertaken a searching analysis of the Wakefieldian experiments in South Australia and elsewhere. He was later to serve on the Royal Commission on the monetary and banking systems, chaired by Mr Justice (later Sir Mellis) Napier. Near the end of his life, Mills served with distinction as a public servant and was much involved in the early federal funding of universities.

Moore, Right Hon. Mike, 1949-, (No. 50, 2003): After serving as New Zealand's Prime Minister in 1990 and as minister in charge of numerous other portfolios including Foreign Affairs, Trade, Tourism and Sports and Recreation, Mike Moore became the second Director General of the World Trade Organisation (1999-2002). He has been honoured and recognised for his contributions by various governments and universities and has been awarded New Zealand's highest honour, the Order of New Zealand. He is a member of the Privy Council. Of his nine books, his most recent is A World Without Walls, published in 2003.

Mussen, (later Sir) Gerald, 1872-1960 (No. 8, 1919): Industrial relations consultant, newspaper proprietor and promoter. In 1915-19, Mussen assisted Broken Hill Associated Smelters in its efforts to improve conditions of working and living at Port Pirie. He then undertook a similar task at Broken Hill. Mussen was an initial proprietor of the Adelaide tabloid The News. He played a major role in the establishment of the paper industry in northern Tasmania and also (from 1937) developed the fish-canning industry at Port Lincoln. 
Phelps Brown, Professor (later Sir) Ernest Henry, 1906-1994 (No. 33, 1969): Economist. Between 1947 and 1968, Phelps Brown was Professor of the Economics of Labour at the London School of Economics. In 1969, he held concurrent visiting appointments at Adelaide and Flinders universities and gave the Lecture during the term of this visit to Adelaide. He was later President of the Royal Economic Society.

Prest, Professor Wilfred (CBE 1966), 1907-1994 (No. 26, 1954): Economist. Prest was a staff member at the University of Melbourne from his arrival in Australia in 1938 until his retirement in 1972, and succeeded D. B. Copland as Truby Williams Professor. He was a member of the Commonwealth Grants Commission from 1953 until 1965. Originally a specialist in industry economics, Prest became an expert in federal-state financial relations.

Rattigan, Godfrey Alf, 1911-2000 (No. 36, 1976): Public servant. From his position as Comptroller-General of Customs, Rattigan was suddenly appointed as Chair of the Tariff Board in 1963 when Leslie Melville resigned in protest at John McEwan's attempts to circumvent due process in tariff policy formation. The move from law enforcement to policy advising suited him, and with his chief of staff, Bill Carmichael, he brought order, transparency and an economywide approach to the Board and its successor, the Industries Assistance (now Productivity) Commission. That facilitated greatly the opening up and deregulation of the Australian economy from the 1970s.

Throsby, Professor C. David, 1939- (FASSA) (No. 51, 2006): Economist. Internationally known for his work in the economics of the arts and culture, Professor Throsby has analysed the economic role of artists, the economics of public intervention in arts markets, cultural development, cultural policy, heritage issues, and sustainability of cultural processes. He has also written extensively on the theory of public goods and the economics of higher education. His most recent book is Economics and Culture, published in 2001 by Cambridge University Press. His PhD is from the London School of Economics, but he has been Professor of Economics at Macquarie University in Sydney since 1974. 
Turner, Henry Gyles, 1831-1920 (No. 1, 1904): Banker. Turner was the General Manager of the Commercial Bank of Australia and a Fellow of the Institute of Bankers, London. He had occupied that position in 1893, when the Bank suspended, reconstructed and reopened.

Vaizey, John (later Lord), 1929-1984 (No. 35, 1974): Economist. For more than a decade from his mid-teens Vaizey suffered with osteomyelitis, and even thereafter he was often in considerable pain. That did not stop him excelling at Cambridge and being appointed a Lecturer in Economics and Economic History at Oxford (1955-66), before accepting the Chair of Economics at Brunel University. His writing helped to pioneer the economics of education. He was offered the Vice-Chancellorship of Monash University in 1975 but decided to stay in the UK, where he received a life peerage.

Wadham, S. M., 1891-1972 (No. 22, 1946): Agricultural scientist. Wadham was the professor of Agriculture in the University of Melbourne at the time of his Lecture. His keen interest in the history of agricultural development led him to write in 1967, in his retirement, a book on Australian Farming: 1788-1965.

Williams, (later Sir) Bruce Rodda (FASSA), 1919- (No. 30, 1962): Economist and administrator. Williams began his teaching as an Economics Lecturer at Adelaide University (1940-45) before moving to the UK for appointments at Queens College Belfast, Keele University and then Manchester, prior to his return to Australia to become Vice-Chancellor of the University of Sydney (1967-81). He held many prominent board positions including on the Reserve Bank (1969-81). His music interests included chairing the Sydney International Piano Competition.

Williamson, Professor Jeffrey, 1935- (No. 52, 2008): Economic historian. Williamson has written extensively on globalization issues over the long term. His books (no less than 25) and myriad journal articles have focused on its effects not only on economic growth but also on income inequality, industrialization, urbanization and farmers. He was Chairman of the Harvard University's Economics Department from 1997 to 2000, and before that was President of the Economic History Association (1994-95). He has been highly awarded as a 
teacher too. A prolific traveller, he has had three spells at the Australian National University including as the F.H. Gruen Distinguished Professor in 2003. He is also currently also a research fellow with the London-based Centre for Economic Policy Research, and on the editorial board of a wide range of economic history and development economics journals.

Wilson, (later Sir) Roland, 1904-1996 (FASSA) (No. 19, 1940): Economist, public servant and director. After lecturing at the University of Tasmania, Wilson joined the Commonwealth public service in 1932. In 1936, he became Commonwealth Statistician. He was Director of the Department of Labour and National Service from its inception in 1940 until 1946 and was Secretary of the Commonwealth Treasury from 1951 until 1966. From 1966 until 1975 he was Chairman of the Commonwealth Banking Corporation. 


\section{Commercial education}

\section{Henry G. Turner ${ }^{1}$}

We live in a land where the somewhat nauseating, but one-time popular couplet:

"Let Law and Learning, Arts and Commerce die,

But give us still our old nobility,"

has no power to charm us. In the first place we have no old nobility, and in the next place, we have more common sense. In this community we have Laws which owe their binding attributes to the fact that they have been made by ourselves for our own guidance, and though we may not always find in them the expression of the highest wisdom, even their shortcomings are more tolerable than the fiat of an amiable despot, or of unsympathetic class rule.

If for our learning we are still to some extent dependent on the "Pierian spring" that gushes so plenteously from the seats of British culture, it is beyond controversy that the influence of our own Universities has already stirred in the rising generation a keen appreciation of the glamour of academic life and promises a plentiful crop of erudition in the near future.

Art knows no country, and cannot be cabinned, cribbed, confined by local conditions. While her Australian disciple toils resolutely through the constant labour that alone ensures success, seeking the inspiration that shall immortalie his brush, a fine selection of the world's masterpieces is brought to his aid in this far away corner of the earth, largely by the munificence of those who having done well by the country, have righteously determined that the country shall profit by them. And South Australia has been preeminently fortunate in producing that admirable type of colonist.

1 Inaugural Joseph Fisher Lecture, 14 April 1904. 
But Laws and Learning, Literature and Art, much as they are to be desired for their own exceeding great reward, are the appropriate embellishments of social progress and material success. It is when we come to Commerce as the final item in the quartette of qualities which this grovelling rhymester would willingly let die, and recognise how largely we owe to it the means and opportunity to cultivate the beauties, the refinements, and the aspirations of modern life, that we plainly realise his hopeless imbecility.

It is to Commerce then - the basis on which the supremacy of our motherland has been reared - and to the roads which lead to its successful command, that I am privileged to ask your attention this evening. Through the enterprise of the governing body of your own University this city enjoys the honourable distinction of being the first in Australia to make provision for giving to a high form of Commercial Education the dignity and prestige of a share in that University recognition, hitherto practically monopolised by students in classical, legal, artistic, or scientific lore. It has placed within the reach of most of you - however lightly equipped with fortune's favours - the opportunity of winning the "hall mark" of capacity in the life's work which you have selected as your sphere of distinction.

As all work in connection with higher Commercial Education is at present - as far as results are concerned - largely tentative, it is perhaps not of immediate importance to decide upon the exact terms of this award and recognition. Whether it takes the form of a certificate by the Examiners of your University; a State business Diploma, as in the New York University; the formal conferring of a degree of Bachelor of Commerce, as proposed by the University of Birmingham, and in force in some of the American Universities; or that of Bachelor of Science in Economics, as in the London University and the celebrated Wharton School of the Pennsylvania University, may not be of vital importance so long as it is distinctly the reward of the successful mastery of a three or four years' course of true University rank.

For my own part I am strongly of opinion that the one thing needful to make the higher walks of this important branch of study more attractive to young men with business careers before them is to give it that wide public acknowledgement which crowns other University studies, and, in the form of its reward at least, 
to place it practically on a par with a classical education. From an examination of the synopses of some of these commercial courses I am satisfied that their mastery implies an amount of study and a capacity of brain power that in other walks would certainty earn for the student his Bachelor's degree. Such genuine work appears scarcely sufficiently repaid by the possession of a certificate, the value of which necessitates possible enquiry and explanation I recognise fully the benefits it confers on students whose preliminary education has not been up to the matriculation standard, but I believe that in response to the earnestness with which this question is being now discussed, the day is not far distant when every University of standing will include a Faculty of Commerce and Economics, and will confer degrees therein, that shall be at least as honourable and advantageous to the recipients as those in relation to Literature, Art, Science, Law, and Medicine. Indeed, it seems to me to be one of those conditions of change, everywhere apparently which will demand the serious attention of all Universities, if they are to retain the honourable prestige they enjoy in public esteem, as the guardians of the wisest culture. The desire of most parents who are in a position to do so, is to give their sons the imprimatur of a University education. But to carry it through in its entirety means to enter them for one of the overcrowded professions to which alone the ordinary courses lead. The slow starvation of hundreds of young briefless barristers, and the forlorn outlook of scores of "general practitioners" relegated to back block townships, must eventually work a cure by giving pause to the enthusiasm which creates them in such profusion. Their places would be more than supplied, if it were possible to offer a truly educational course, having a direct bearing on business life equal to that lavished on the professions. This would offer a strong inducement to parents who shrank from submitting their sons to the risks of a professional career, and would strengthen the University both by a more widely spread interest in its work, and a substantial addition to its students.

Do not for one moment suppose that, in glorifying that utilitarian form of education which is the necessary groundwork for successful commerce, I am in any way depreciating the highest aspirations of learning for learning's sake. To have had the advantages of several years of classical training in one of our old Universities, with all its reflected lights on the most brilliant pages of literature, or the most stirring feats of history, is indeed a privilege that cannot be too highly prized. But in our present environment it is necessarily a privilege in which but 
a few can hope to share. Our Australian life has failed in its lessons if it has not taught us to labour and to wait, and not too hastily to despise out three-rail fences and weatherboard abodes, because we prefer the moss-grown walls and ivy-crowned turrets in which older communities can afford to indulge.

Your generous fellow-citizen, Mr. Joseph Fisher, has provided the University Council with the means of honouring the student who has most distinguished himself in the Advanced Commercial Course, and also for a course of lectures intended to stimulate public interest generally in commercial education.

Having been honoured with a request to deliver the Inaugural Lecture, I propose to treat of the subject on broad, general lines only, leaving all technical and administrative details to those educational experts coming after me, who will by that time have acquired a fuller experience of its workings and of the results it is expected to show. I glean that the work done in Adelaide so far, justifies high expectations of those results which the Examinations will disclose in December next. Certainly the tentative movement has attracted attention, and stimulated proposals in similar directions in other States of the Commonwealth, though in Victoria the clamour has been more for that form of technical education in manual work, by which it is expected to counterbalance the dislike the Australian youth manifests towards apprenticeship.

The Royal Commission on the Melbourne University, which has been sitting for the last two years has not yet submitted its report to Parliament, but it has been drafted and I believe the recommendations are practically agreed upon The scope of the Commission's enquiry was very wide, a large part of it dealing with questions of management and finance. But of the 108 witnesses examined, more than a score gave evidence on the question of Commercial Education. Though there were one or two dissentients the great majority strongly urged that the elementary work of the Business Schools and the Working Men's College, should be followed by a systematic course on true University lines. It is probable that the Commissioners will hesitate to recommend at present a full commercial degree course for day work, because some of the witnesses were strongly of opinion that it was premature. It is however tolerably certain that they will endeavour to meet the demand for the higher form of education in this department by providing a Board of Commercial Studies to control a course carrying a diploma of Commerce 
based upon evening or afternoon lectures of true University standard. In such case the Adelaide University will be the recipient of the sincerest form of flattery.

In considering the causes which have given rise to the pronounced movement in favour of a higher phase of Commercial Education, I think there is a consensus of opinion that the first great International Exhibition in London in 1851 gave the initial stimulus, though fully twenty years elapsed before the conditions it had revealed began to be seriously discussed. The business methods and business technique of the long list of foreign competitors in the world's industries, were, by that Exhibition, brought before the British manufacturer and distributor with a comprehensiveness hitherto unattained. It did not take long to discover that the Continental workman was, as a rule, better educated in his trade than the conservative Briton running in the grooves that his father had traversed before him. There was an adaptability in the work of the foreigner which ignored the superstition that "whatever is, is right." And such progressive ideas were not confined to, nor did they originate with the artisan. They were inspired by the employers of labour, the producer, the manufacturer, and the distributor alike. For it must be borne in mind that without adequate commercial equipment, the mere mechanical process of manufacture would soon create a block. It is too often overlooked how largely the success of great factory industries is dependent upon the ultimate dealing with its products at the hands of the merchant class.

It was the enterprise, the daring, and the resourcefulness of the British merchant adventurers of the $17^{\text {th }}$ and $18^{\text {th }}$ centuries that laid the foundations of the acknowledged industrial supremacy of the motherland.

The story of how that supremacy passed from Venice and Genoa to Spain and Portugal, to Antwerp to the Hanseatic towns, and to Amsterdam, and was finally wrested from the Dutch by our forefathers, is an intensely interesting stage of history, but does not bear on the educational aspect. The world was indeed very wide in those days. New fields of commercial enterprise; often it must be admitted of rather a filibustering character, were opening up month by month. It was essentially an era of exploration and exploitation, and the man, or the company possessing the capital, and the ships, found profitable use for both in almost any direction, without having to study the laws of supply and demand, or to wrestle with problems connected with theories of exchange. Ruthlessly oppressive 
measures of protection - often exacted from an impecunious government by open bribery - shortsighted and inequitable laws, like the Navigation Acts; giant monopolies like the East India Company and the Hudson's Bay Company, all helped to pour wealth into the coffers of the individual merchants and the powerful trading corporations which they formed, and to make them a real power in the land. It was only during the eighteenth century that the long unchallenged domination of the land-owning class, in social and political life, began to be undermined. It took quite a hundred years to wring a grudging acknowledgment that that was really no sufficient reason to be assigned for the prevalent belief that a man who inherited a large estate and lived on his rentals was necessarily superior to the enterprising man who had amassed a fortune by commerce. The literature of the age is full of contemptuous references to the aggression of men whose money had been made on the mart. You perhaps remember the reply which that epitome of stilted wisdom, Dr. Johnson, made to Boswell's enquiry, what was the reason we were angry at such men acquiring opulence. "Why, Sir, the reason is, we see no qualities in trade that should entitle a man to superiority. We are not angry at a soldier getting riches, because we see that he possesses qualities which we have not. If a man returns from a battle, having lost one hand, and with the other full of gold, we feel that he deserves the gold, but we cannot think that a fellow by sitting all day at a desk is entitled to get above us."

I venture to think we have to-day a truer appreciation of the value of commerce, and a more reasonable estimate of its just rewards than had the great lexicographer, though he undoubtedly echoed the current opinion of the time Indeed it was a notable fact that the successful merchants of those days were not free from sharing in the popular feeling themselves, for numbers of them sought to improve their social status by buying estates, intermarrying with the aristocracy, and in several cases, securing patents of nobility for themselves and their descendants.

During the first half of the last century it looked as if English commerce; would possess the earth, as English ships swept the seas. The thirty years peace which followed Waterloo saw vast developments. The Navigation Acts were repealed, and in response to petitions, originating with the merchants of the City of London, every restrictive regulation of trade, not imposed for revenue, and every duty of a protective character were swept away. So by the time of the 
memorable Exhibition of 1851, the British merchant stood on the apex of the world's commerce; his banking colleagues controlled the world's purse strings from Lombard Street; and his manufacturing colleagues continued to make things in the way they had decided that people ought to want them, and were too rich, or too independent to worry as to whether their customers were pleased or not.

The trade competitors they had to face from all other countries, fifty years ago, were comparatively unimportant. The mercantile, the financial and the manufacturing interests were largely in the hands of wealthy and responsible men, with the accumulated experience of three or four generations. The era of Joint Stock Companies, as applied to Commerce and Banking had scarcely dawned, and men did what they thought was best their own interest, without the delays of Board Room counsels.

This self-complacent belief that the world was submissive to dictation of the British merchant and manufacturer was destined to receive a shock. In the United States especially, great improvements in the direction of labour-saving appliances - the first consideration in a new country - were so startlingly rapid in their introduction or adoption, that whole cargoes of English exports were condemned as out of date, and valueless compared with the locally invented or adapted substitute. In England, in the fifties and sixties, there was a remarkable immigration of young and generally well educated Germans, Austrians, and Frenchmen, who, without attracting any special attention, secured a footing in the offices, factories, and warehouses throughout the land, learned all the resources of the country - its weaknesses equally with its strength - and repatriated themselves, with a fixed determination to improve on what they had seen, for the benefit of themselves and their own people.

Now commenced that era of competition which caused John Bull to bestir himself and ask questions. Cassandra-like wailings went up that England's commercial supremacy was being undermined. Comparative statistics were made to show very discouraging results, many of which were undoubtedly delusive. The volume of British trade was really not materially affected by this competition, for during the last forty years of the century the Exports of merchandise rose steadily from $£ 164,000,000$ in 1860 , to $£ 354,000,000$ in 1900 , while the Imports in the same period grew from $£ 210,000,000$ to $£ 523,000,000$, the figures under 
both headings for the latest year being the highest then ever attained. Vast as is the commerce which these figures indicate, it has been so much the fashion in certain quarters to prophesy the approaching supercession of British industries, that it cannot but be satisfactory to note, in passing, another important fact. For the year ended on the 31st December last, there was an increase of $£ 25,000,000$ in the volume of trade over the figures just quoted $-£ 6,000,000$ in the Exports and $£ 19,000,000$ in the Imports. But while the actual increase might have been deemed satisfactory, especially as it certainly kept all the manufacturing industries fully employed, the relative progress of other countries began to arouse disparaging comparisons, and, in a considerable section of the press, gloomy vaticinations of national decadence.

From about 1870 there arose, under the inspiration of the public journals, Chambers of Commerce and kindred organisations, an ever increasing demand for better technical training for our artificers, enforced by references to the inroads which German, French and American competitors were making in markets hitherto controlled by Great Britain. Imposing commissions of enquiry followed. In all cases the success of the foreigner was attributed not to any local advantage in production, but to the superior training of the artisans, and to the wider knowledge of international wants and economic conditions acquired by the manufacturers and distributors alike.

Thirty years ago a commercial education was a kind of training looked down upon in England as something below the level of a gentleman's requirements; something that it was hardly fair to call by so dignified a name. And in view of what was understood by the phrase, even in good secondary and public schools, it had little attraction for any but the average clerk - none at all for the ambitious. The established supremacy of British commerce tended to make the mercantile class contemptuous of foreign theories, and resolute to ignore their example in matters educational or otherwise. They declared that it was not possible by any theoretical training, however specialised, to equip a man competently for mercantile pursuits. Experience alone, often very dearly bought, was the only possible means of acquiring a mastery of the varied ramifications of commercial enterprise. But the rapidly advancing strides in the business operations of other countries, where it was an imperative article of faith and practice, was a sufficient answer. Conservative opposition dies hard, and it is only within the last decade 
that the full value of the higher commercial education has commanded attention in England and Australia.

I say the higher commercial education advisedly, and I am inclined to date the rise of this awakened interest from the establishment of the faculty of Economics in the London University, as recently as 1895 . For what was commonly understood as commercial training, there had indeed been an agitation twenty years earlier. It had been met to some extent by increased attention in many of the secondary schools to matters pertaining to mercantile work, and by the promotion of numerous private ventures in the shape of special or technical schools, or business colleges. Their establishment and initial success was largely due to a recognition of the fact that foreign clerks were invading the merchants and bankers offices in London, and were often securing preference by reason of a fitness due to superior training. Hence the direct aim of all these institutions was to make good clerks and to put a specialised finish on such groundwork as had already keen acquired; to construct a perfect machine for recording and controlling business operations, but not necessarily with any equipment for originating, or even thinking out the wider questions which frequently influence action in important mercantile transactions.

Up to a given point they undoubtedly supplied a want, and as a rule they have been, both in England and Australia, fairly successful from the stand point of their promoters. They cater for the wants of a large class of young men whose expectations do not extend beyond being efficient clerks. And it is surprising how large a proportion of them take up office routine as their life's work, preferring light duties and a moderate salary to the anxieties and responsibilities which beset their employer. It is not so in America. That shrewd millionaire, Mr. Carnegie, says that the youth who goes into an office or a bank, without a firm resolve to be a partner, or a general manager, is wasting his time. To the English or Australian youth who has this laudable ambition, the business colleges do not cover all the ground.

Of course, as pointed out by Professor James in the report which he prepared on this subject for the American Bankers' Association, no commercial high school, and no school of finance and economy can make a successful merchant or banker, any more than a law school or medical school can make a successful barrister or 
doctor. But if the commercial training is really educational in character, and not a mere top dressing of specialities, it will certainly prepare the youth to learn his business more thoroughly and more rapidly than he could have done without it. He proceeds to show how the six months' courses of the so called business colleges, which have a certain value in securing situations for young men, differ essentially from the objects aimed at in three years' courses of the commercial colleges in Vienna or Paris, or Leipzig or Antwerp. It is the practical and liberal work of this latter character, which educates for life while it trains for a livelihood. But unhappily there was not until the last half dozen years any institution in England or her dependencies that aimed so high, and the establishment of the Birmingham University but yesterday, so to speak, was the first serious answer to the demand.

In Victoria, outside the clerical division of the Civil Service, it is a reasonable estimate to put down the number of clerks employed in Banks, Financial, Insurance, and kindred companies, and in Merchants' offices, at little short of 20,000. It is depressing to think that 95 per cent of this large army has no prospect of doing anything more than routine clerical work until worn out. But it is a hard fact, due largely to the mistaken ambition of parents to put their boys into what is regarded as a light and genteel occupation, for which they have probably shown no special adaptability, and for which their schooling has given them the poorest training. During the last few years, there have been numerous agencies whereby these deficiencies might have been remedied to a large extent, though it must not be over looked that a specialised course of any kind not based on a fair substratum of wider culture, is often found to leave large gaps in the mental equipment when called upon to meet unlooked for developments. But even such facilities as were provided have not by any means been eagerly seized upon. I think it must be candidly admitted that the rising generation in Australia regards study with less favour than their prototypes in Great Britain, and are absolutely out-distanced in self-culture by the youth of most of the European centres of business. It has been the too common experience of all advocates of a voluntary extension of our educational methods that the enthusiasm they are able to evoke is too often of a transitory character and easily damped. Eighteen years ago, when I delivered the inaugural address on the establishment of the Bankers' Institute of Australasia, I was led by the apparent enthusiasm around me to prophesy great things for it that are yet unaccomplished. For a year or two the lectures 
were kept up to a high standard, were nearly always the work of capable experts, and were some times followed by well sustained discussion. But ere long the apathy of the senior officers, and the more seductive attractions which kept away the juniors reduced the attendances to such a point, that the periodical lectures became at first intermittent and finally extinct. In 1900, under the auspices of the Chamber of Commerce, the Bankers' Institute, and kindred organizations, a series of University Extension Lectures were commenced in Melbourne covering such subjects as the Formation and Management of Companies, Accountancy, Commercial Geography, and so forth, but the response was so unsatisfactory that the guarantors had in most cases to be called upon to make up a deficiency. The Bankers' Institute has done some good in formulating an examination for entrants into office life, which though falling short of the ordinary matriculation standard, has by many of the banks been recognised as satisfactory, and made a necessary preliminary. During the last year or two it has formed a Bankers' Students' Society, which has been of great benefit in helping to provide the few who are willing to learn, with a good foundation for their higher studies. Similar work is being done by the Institute of Accountants, the Insurance Institute, the Accountants' and Clerks' Association, and one or two other bodies. The Working Men's College only last year commenced a four years' Elementary Commercial Course covering a fairly wide synopsis. A few students have taken up one or two of the subjects, but there is not, so far, a single name down for the complete course, though the lectures are delivered at night, the fees are very small, and the instructors mainly men of University standing.

The other organisations in Victoria which have grown out of the demand for commercial training are the so-called business colleges - private schools with a specialised curriculum in which the mere machinery of business, book-keeping, office routine, stenography and type-writing stand well in front, with occasional excursions into elementary mercantile law and commercial geography. Now all these efforts indicate a recognition of a want and a desire to provide for it, while, to the extent, the opportunities offered are availed of, they undoubtedly raise the average of ability in the rank and file of clerical assistants. But they come a long way short of the training which is required to make notable "Captains of Industry" and merchant commanders. It has to be admitted that some prominent writers on education take the view ordinarily held by the successful English businessman of a few years back, that no school or college can possibly teach commerce in 
its entirety, that is to say, it cannot turn out a merchant as completely equipped for all contingencies as it can a barrister or a doctor. The weightiest argument in support of this contention is that the area of knowledge to be cultivated is so wide that it would be impossible to get teachers capable of doing justice to all the phases. German educationalists, who have had much to do with the matter, theoretically and practically, very generally maintain that the success of their people in commerce and manufactures is due far more to the thorough and diversified training received in their secondary schools, than even to the liberal provision made for technical and commercial education, which latter they declare succeeds in proportion to the soundness of the general education of the pupils who receive it.

I do not suppose the most strenuous advocates of commercial education expect it to turn out every pupil as a capable businessman. No educational scheme ever devised or dreamt of could do that; certainly not while mental and physical variability remain, whatever may be done under the uniformity of the coming Socialism. There are and always will be plenty of young men on whom a wealth of education has been lavished under most promising conditions, without stint of cost, who have turned out failures in the walk of life towards which their studies were directed. There are things which cannot be learned as a course of study, such as urbanity, tact, a wise reticence, and perhaps most important of all, a demeanour which commands the approving confidence of our kind. A sound judgment of character is rarely acquired in our college days, and yet it is probably one of the most essential factors of success in business. Yet when all has been said the fact remains that the further a youth can carry his general education the more thoroughly will he be benefitted by the specialised preparation for a particular career when he undertakes it.

It seems to me that the methods most generally in vogue in English speaking countries have been rendered somewhat confusing by the want of a more defined line between the commercial training which aims at raising the knowledge and the status of the ordinary clerk, and the real commercial education of the men whose position and prospects justify the assumption that they are likely to be leaders in, and controllers of wide mercantile operations wherein their own individuality and capacity will be the final measure of success or failure. Professor Harrison Moore in his evidence before the Melbourne University Commission 
last year was emphatic in maintaining that the toying with technical education as a means of improving the work of the artisan - such as is the first care of our Working Men's College - must be supplemented, if not superseded, by a far more efficient training for our future captains of industry and commerce. These he maintains demand an education standing in the same relation to the life's work of the manufacturer and merchant, as the medical school of the University does to that of the doctor. There is no questioning the statement that such attainments as proficiency in two or three modern languages, clear views on the higher finance, and knowledge of the world's products, markets, and complicated tariffs, can only be acquired by sustained and systematic study. A really scientific enquiry into the structure and organisation of modern trade movements, and the causes by which prosperity may be tested, as they are shown in the experience of Great Britain and foreign countries, cannot be pursued as a pleasing mental adjunct to the day's hard work, or be satisfactorily answered by listening to any number of evening lectures.

Here then, we come to the parting of the ways. In England and her dependencies there has been growing up for the last twenty years - mainly as the result of private effort - a materially improved method of both technical and commercial training. Under that impulse the scope of general teaching bas been greatly widened, the producing power of the country has been stimulated, and the rank and file of the officers connected with its output and distribution disciplined and rendered more efficient. This has distinctly raised the status of the ordinary clerk - raised him from a mere recording machine into an interested and intelligent worker, and, where industry and ability have been combined, has opened to him possibilities of responsible leadership.

But within the last decade, and more notably since the commencement of the present century, there has arisen a demand for a much further stride in the preparation for a business life. It is not aimed at an all-round increase in the teaching of thc privates in the army of commerce, but a special and exhaustive curriculum for its administrative officers, those fortunate few who, by the command of capital, the inheritance of an established business, or like social advantages, may expect as directors to take a prominent part in guiding the business activity of the country. Wealthy merchants have very generally, and very commendably, sent their sons to Universities for that thorough grounding in the higher education which cannot 
so satisfactorily be acquired elsewhere. The result has too often been to give those sons a distaste for business, and a keen desire for a professional life. It is because the professional courses are supposed to offer a higher intellectual stimulant, and to the receptive mind a more pleasing and satisfying exercise of the mental qualities, than what has been heretofore somewhat coldly regarded as a training in the art of making money. Such certainly was the view, when the matter was considered at all, from the University standpoint; but the old order is changing. The commerce of to-day is not a matter of that shop-keeping which evoked Napoleon's sneer at the English people. The ever-recurring fresh discoveries of science; the practical annihilation of time and space in our means of communication; the rapidity with which new markets spring into existence; the transference of great interests by unlooked for developments; the subtlety of keen rivals; and the drastic changes which an acute financial crisis, or a war, may work in a country's position, are interesting problems, which fifty years ago were calmly put aside. To-day they demand that alertness of mind which is born of a knowledge sufficiently wide to enable the merchant rightly to estimate accurately what is going on in the world beyond the horizon of his own daily duties. Professor Ashley, of Birmingham, deals in a few vigorous words with the charge that such studies cannot be made "intellectually interesting." He says:

"To be brought to realise the larger issues involved in business decisions; to understand the place a man's own undertaking occupies as a whole all over the world, and the relation of that industry to others; to be accustomed to weigh conflicting considerations for and against a particular policy; to get into the habit of following the larger movements of manufacturing progress and international trade; and to learn how to get at the best accessible information, in foreign sources as well as English - surely this will prevent business from being dull?”

The Oxford and Cambridge Schools Examination Board, which, stimulated by the united Chambers of Commerce, had formulated an examination for a commercial certificate; the Faculty of Economics in the London University, and efforts by Owen College at Manchester and kindred institutions, all tended in the direction of giving a higher tone to the movement. It culminated in the establishment of a Faculty of Commerce in the Birmingham University in 1902, and thus secured for the first time the formal recognition of the right of 
Commercial Education to occupy a distinct and recognised place in the wide scope of true University training.

Now the commercial curriculum at Birmingham is a very imposing one. The Faculty of Commerce consists of the Principal and Vice-Principal of the University, the Professor of Commerce and Public Finance, the Professor of Accounting, and the Professor of Commercial Law. To this faculty are attached the Professors of English, French, German, Mathematics, Philosophy, and History; and such other professors as may for the time being be taking part in the course of study prescribed for the degree of commerce. And this course comprises studies which come mostly under four main headings: (1) Languages and History; (2) Accounting; (3) Applied Science and Business Technique; and (4) Commerce. With regard to the first the History is almost entirely modern, dealing mainly with the political and economic movements and revolutionary changes of the world during the last century. No student can receive a degree in commerce unless he is thoroughly master of at least two modern foreign languages. Accounting is dealt with on highly scientific grounds in three ascending courses, one in each of the three years. Applied science and business technique cover courses on Commercial Law, Money and Banking, Statistics, Transport, Public Finance, Taxation, the technique of Trade, and general Economic Analysis. The courses on Commerce, however, give the tone to the whole scheme of instruction. The first year is devoted to a study of the modern development and present position of the industry and trade of Great Britain, her Colonies, and Dependencies. Not only in respect of geographical position or productiveness, but covering the supply, the organization and the efficiency of labour, and the state of the mechanical arts. The second year covers the same ground in respect to the United States, Germany, Russia, France, and other countries, leading up to a critical survey of international commercial relations. The third year is concerned with higher business problems and the results of applied economics. It embraces amongst other things Capitalisation, relativity of Production, Combinations of Merchants or Manufacturers, Trusts, Limited Companies, the financial and industrial consequences of Machinery, Relations of Employer and Employed, Hours of Labour, Markets, Credit, Goodwill, and such an apparently speculative subject and Cycles of Trade. Throughout the courses it is nevertheless to say that Commercial History and Commercial Geography enter largely into these lectures. 
This may be taken as the high water mark of advanced commercial education in the British Empire, and in continuity and completeness it seems to be arranged for a highly developed, though probably for some time to come, a very limited contingent of directing power in mercantile affairs. It can only be profitable to students who have attained a certain maturity of mind, and whose training has been at least up to matriculation standard before entry.

It is to be borne in mind also that it is devised for people who are in a position to give their full time to University work. There is no provision for evening lectures. Professor Ashley contends that if such were introduced, they would influence a number of people who now make a sacrifice, by giving their main time to full University work, to attempt such work, less efficiently, by reason of a large portion of their energies being diverted to something else. In the heart of Great Britain, with only one University so far fully equipped for complete commercial training, it may be easy enough to fill the classes, even under very conservative conditions. But at present in Australia the people who can command the time and the means for such an absorbing course, as well as the inclination towards it, are few and far between. The public feeling here trends towards demanding a display of utilitarianism in University work. To make that phase of its work apparent, the conditions under which it has been conducted for centuries must be brought into harmony with a greatly changed environment. Indeed it looks as if the Socialistic trend of Modern Democracy was going to forcibly invade the seats of learning. One of the accepted planks in the platform of the Victorian Labour Party is - "Free primary, secondary, and University teaching for all, the Government to bear the expense of all incidentals thereto," which is probably a euphemism for books and stationery, with possibly railway fares thrown in. It is needless to say the classes are to be the sequel to the statutory eight hours.

So far I have only dealt with the demand for this form of education in our own country. At the risk of wearying you I must with all brevity refer to what has been done in other countries, as it was unquestionably the doings of our commercial rivals that woke us up to the necessity for imitating them. I have had the opportunity of perusing the British Consular-Reports on Commercial Education in France, Germany, Austria, the Netherlands, Italy, Switzerland, and the United States, and the manner in which it has been made a State care in those 
countries has been a revelation. It may be confidently affirmed that the methods in force in either France, Germany, or the United States, would each form an ample text for a whole course.

To Germany, I think, must be accorded the palm, though the Commercial Courses there are even yet quite outside the recognised University life. The development of the educational system of Germany has proceeded along lines consistent with the most scientific provision for progressive continuity. It is a national pride and passion, and the interest taken in its advancement by all classes is in singular contrast to the apathy commonly displayed by the people of England not specially interested. The Government provides compulsory education for all children up to 14 years of age, but it does not, like our State School system, consider them finished at that point. No person is allowed to work in a factory or workshop under the age of 17 , so that there still remains three years for further tuition. With us the whole area between our Primary schools and the University is chaos and conflict. In Germany, the complete system of Secondary education is so admirably organised, the grades of schools so well defined and generally understood, that the pupil emerging from the Primary school at 12 or 13 , who can give another five or six years to study, finds his steps marked clearly before him. He passes through the "Realschule," where mathematics and modern languages are the prominent features, into the "Real Gymnasium," where he makes his first acquaintance with Latin, and, if he is intended for the University, he passes thither through the portals of the "Classical Gymnasium," whose certificate of maturity is necessary for his acceptance. If not intended for the University, his continuation is arranged in the High Commercial School, where, in progressive stages, he may continue his studies up to the age of five-and-twenty. There are several hundreds of Commercial Schools in operation throughout Germany; a preponderance of them have evening classes. In some of the States attendance is compulsory up to the age of fifteen. Of the Higher Schools of Commerce there are some five-and-twenty, and there more than a dozen where Commercial Courses of University grade are given to pupils from 16 to 25 years of age. The highest point is reached in the Leipzig Commercial School, which is practically of University standing, though it does not confer degrees. Admission to it is strictly limited to those in possession of certificates of a high grade of general education. The Professors of the Leipzig University take part in the lectures, and organise the course of studies. It is largely used for the training of teachers for the ordinary 
Commercial Schools; and though the fees are, for Germany, rather high, it is not self-supporting. It receives a subsidy from the Government, but its financial requirements are cared for by the wealthy Chamber of Commerce of that city.

In France, Government recognition of the Commercial side of education is of quite recent growth. In 1889 in an official report by the Inspector General of Technical Education it was stated that the pupils attending any Commercial Schools throughout France numbered only 2,000, as against 400,000 youths annually entering a business career. Here was then a marked indication that parents could afford to keep their sons at school beyond the higher primary courses, desired them to take up the classical side, as leading to the liberal professions. There has since been a considerable change in this feeling. The Government schools were formerly under the joint control of the Minister of Education, and the Minister of Commerce and Industry. There was much friction, and as recently as 1892 a division of authority took place, and the control of the higher primary schools, in which the teaching in mainly industrial or commercial, was handed over solely to the latter Minister. Since that date there has been a rapid increase in the number of these establishments throughout the Republic, but it is complained by the Conservative party that the tendency to unduly specialise is too much in evidence. There is some confusion and much overlapping because they have not the highly scientific organisation of progressive teaching which so eminently distinguishes the German system. The fullest fruition of all these efforts is found in the School of Higher Commercial Studies in Paris, which is mainly supported by the Chamber of Commerce. The French Government supervises and aids about a dozen High Schools of Commerce in leading business centres of the country, and though in all of them the three years course is of a very high order, the Paris school named approaches nearest to University rank. Quite recently the Minister of Commerce established in this School a special section for the training of Commercial teachers. It is housed in the centre of Paris in a magnificent building that cost over $£ 100,000$, and forms the goal of the ambition of the young Frenchman who is training for the work of the merchant or the banker. The age of students range from 18 to 22 and the demand for the training is in excess of the accommodation. It covers Economics in relation to the history and organisation of the world's commerce, foreign languages, commercial law of all trading nations, customs, tariff, factory laws, and other regulations affecting industry, commercial and historical geography, and the routes and methods of 
transport by sea and land. Indeed in looking over the curriculum, which occupies twenty pages in Professor James' report, it strikes one with amazement as to where it is possible to find all the teaching power.

Time will not allow me to give you more than the barest outline of what is being done in The United States. Secondary education there is a matter of wider public interest than it has ever been in England. In nearly all the States there are Grammar Schools, or High Schools, maintained at the public cost. There were 5,100 of them in 1897 , with over 400,000 pupils. But in these the classical side has never found the favour it has with us. As each State is sovereign in matters of education within its limits, there is of course great diversity in the system, and the uniform organisation which has done so much for Germany is impossible. Now, though the American people were not suffering from that foreign rivalry in business which caused this question to be taken up so warmly in Europe, they were early infected by the pressing demand for comprehensive business training. "Commercial Colleges" as they were called, began to spring up in all industrial centres giving very specialised preparation for clerkships. Commencing about 1875 they came with a rush, and twenty years later there were 500 of them, with over 120,000 pupils. This stirred the Education Authorities to action, and they met the invasion by introducing business courses into the public secondary schools. By 1900 a large number of the business colleges were closed, and a demand for something higher set in. In $1881 \mathrm{Mr}$. Joseph Wharton gave $£ 20,000$ to the University of Pennsylvania for the foundation of a higher Commercial Department. With this money a Chair of Finance and Economy was founded and endowed. In 1891 its scope was enlarged, and it now covers a four years' course of the most exhaustive kind, leading to the degree of Bachelor of Science in Economics.

Opinion grew that a careful scientific training, based on a sound general education, and covering a wide survey of human affairs, could he better under taken by the Universities than any other educational institution. In democratic America there lurked a feeling that the man of commerce should not be cut off from the high traditions which the Universities stood for. So, in rapid succession the University of Chicago, the University of California, the Columbia University in New York, and several of the smaller Western Universities established faculties, or, as they call them, Colleges of Commerce, within their borders. While it has to 
be admitted that there are American Universities which fall very short of what an Englishman understands by that word, the four institutions named which have fathered the claims of commerce, are held in high estimation. Certainly in this affiliation America led the way now being followed in England, and it is probable that in due time Harvard and Cornell Universities will find it to their interest to comply with the popular demand.

I confess that I approach the consideration of the Schedules of your Courses for the "Advanced Commercial Certificate" with some misgiving as to my being able to offer any criticism worth listening to. A thorough mastery of the six subjects dealt with should enable a man to take a leading part in responsible business affairs or financial administration. They would give him a firm grip of the why and wherefore of his operations, and enable him to lay his course with intelligent decision. Necessarily they come considerably short of that highest form of Commercial Education in the Superior Schools of Leipzig and Paris, and some of the Universities I have mentioned. If in Victoria it is held to be premature to initiate a Faculty of Commerce, it is probable that in South Australia the number of students seeking to go so far would be still smaller. It is, however, very gratifying to find the evolution of business training progressing on such sound lines. We may feel assured that the enterprise which founded the Board of Commercial Studies will be equal to providing for its highest development when the demand, which it has had a large part in creating, is sufficiently pronounced.

Business Practice, Accountancy, and Commercial Law alone, well learned, should create a class of clerical assistants that will, with the development of the country, be in ever-increasing demand. During thirty years of active Banking management, I do not think I have passed a single year in which I did not have reason to regret the want of capable men to take up positions of responsibility. The opportunities of doing business of a profitable kind were far more frequent than the finding of the competent man to take charge of it. I believe, therefore, that the movement inaugurated by the Adelaide University, and which bids fair to be followed in the other Australian States, will be, and indeed already is, highly valued by the Banking Institutions.

Probably I am infected with the common failing of "magnifying my office," but I confess to a feeling of doubt whether twenty lectures at weekly intervals 
can do more than touch the fringe of such complex subjects as Banking and Exchange. I am reassured, however, when I consider how important a part of Banking training is found under the heads of Commercial Law, Economics, and Commercial History and Geography. Indeed, these four subjects form the staple of the lectures delivered before the Bankers' Institute in London for the last twenty years. They are properly regarded as covering an area of knowledge with which every banker in an administrative position should be fairly familiar. It is impossible to have clearly defined views of Exchange operations without some study of Commercial Geography. The mercantile future of Australia must be largely in touch with India, China, Japan, the Malayan Archipelago, and the Islands of the South Seas. We are on the eve of great trade developments in little known lands. The sooner we can make ourselves acquainted with their resources, and their wants, the better chance shall we have of maintaining that commercial supremacy of which we are proud, and for which we shall have to contend with the keenest rivals. Think what it would mean to Australia if we could persuade the stalwart races of Northern China to wear woollen goods, instead of the cotton padded garments with which they encumber themselves in the winter. Our entire clip might go to Shanghai or Tientsin, with vastly enhanced profit to the growers. But as a rule Australians form their opinion of the Chinaman from a degraded type - the Cantonese (who almost alone come here) - and seek to know nothing of the trade potentialities of that vast hive of industry in the interior.

To-day there is probably no Merchant, or General Manager of a Bank, who could hold the knowledge which the Birmingham Faculty of Commerce propose to pour into him. The training of a generation ago was on quite different lines. But it would be an immense relief in times of stress, to have men about them who could intelligently discuss the problem of the hour, and bring to bear upon it the knowledge garnered from wise teachers and shrewd experts. Such are the men for whose laudable ambition in the direction of self-improvement your Board has offered a way of usefulness. The fact that they are striving for a distinctive mark of excellence predicates industry and self-reliance, qualities which, when capacity is shown, will make them welcome everywhere. It may be that only a small proportion of them will rise to be administrators, but I know some merchants in Melbourne, of high standing, who were office boys within my own recollection. In nearly every case the administrators of our large financial institutions are men who have risen from the ranks, and owe nothing to fortune or favouritism. One 
thing is certain, that every winner of the Board's certificate will be an apostle of the higher Commercial Education, and besides stimulating others to follow in his foot steps, he can hardly fail to recognise that he has acquired something of value, not only to himself but to the community with whom his lot is cast.

To sum up the whole matter, I would say that the result of all the Royal Commissions and formal enquiries, leads to the conclusion that all education is indissolubly linked together, and to the belief that a course of specialised instruction commenced too early, or at the cost of curtailing the time spent on subjects which every intelligent youth should master, is very undesirable for the pupil, and generally produces unsatisfactory results. That shrewd but sordid philosopher, who wrote the "Letters of a Successful Merchant to his Son," says:

"The first thing that any education ought to give a man is character, and the second thing is education."

Seriously, however, there are two well-defined stages in education. The first aims at developing the faculty; the second seeks to apply it along the lines that are most related to the student's future career, be it professional or commercial. The first stage - rudimentary, perhaps, but vastly important - the making of the man, is the work of our Primary and Secondary Schools, aided, or ought to be aided, by the too often neglected factor of a judicious home influence. It implies things not scheduled in any school curriculum. Inflexible honesty and truthfulness in thought and deed; moral courage in speech and act; magnanimity without censoriousness; self-reliance without dogmatism. These are the foundations to be built upon if we wish to render the finished product, apart altogether from the question of financial success, a worthy representative of the best traditions of our race. The second stage - the making of the man into a lawyer, a doctor, or a teacher - has hitherto been the work of our Universities, to whose scientifically organised methods we would fain also entrust his transformation into a merchant, a manufacturer, or a director of finance. For it is certain that though the rudimentary principles of commerce may be taught in an ordinary school, it is quite outside that province to deal with the wide-reaching problems of its higher walks; and it is only an institution of foremost teaching rank that can command the highest skill and the rare expert knowledge necessary to bring out the best energies of the willing student, and endow them with its honourable recognition. 
Finally, let me say that while the demand for this specialised training has been so marked a feature in educational circles during the last decade, there is the strongest reason why it should be taken up warmly in Australia; for, on extended production, and judicious distribution of her products, the future importance of the Commonwealth mainly rests. Even to-day the volume of her trade relatively to population stands in the front rank. Her exports of domestic produce exceed $£ 58,000,000$ per annum. Her imports for home consumption from countries beyond her borders exceed $£ 42,000,000$, while the total of her interstate trade touches another $£ 50,000,000$. If these impressive figures can be quoted for a population of less than four millions, what may we expect in another generation. The population of the Commonwealth States has more than doubled in the last thirty years. The volume of its external trade in the same period has increased threefold. If we may base estimates on these figures, and if we are not thwarted by suicidal legislation, another thirty years should give us eight millions of people. To minister to their local needs, in a material aspect, to find the most profitable outlets for the results of their labour and their skill, will demand the services of men well trained in the ramifications of commercial enterprise. Men sufficiently well grounded in sound Economic principles, who will not be led aside by the fads of hasty tentative legislation, which may indeed hamper, but can never override the laws upon which the world's commercial progress is founded.

Conditions which we may reasonably anticipate will, I feel assured, bring dignity of position and satisfactory emolument to many of the energetic young Australians who are to-day, and here, earnestly working to attain that wide knowledge which in every walk of life is power. Let me heartily wish that their laudable efforts may be crowned with deserved success. 


\section{Appendix}

The following Memorandum on the state of Commercial Education in the newly awakened Empire of Japan was intended to be incorporated in the Lecture, but consideration of time and space necessitated its exclusion. The Board of Commercial Studies considers it worth adding in the form of an Appendix.

When I visited the Tokyo University, some dozen years ago, there were four British and five foreign European Professors on the staff - three, if not four, of the latter, being Germans. To-day, I understand that the entire Professorial staff is native born. The eagerness of the Japanese youth to learn is quite phenomenal; and, from the first glimpses of Western knowledge, they displayed a special aptitude for History, Geography, Foreign Languages, Political Economy, and International Law.

The Tokyo University has no Commercial department, but the Tokyo Higher Commercial College, affiliated to it, approaches nearly to University standing. It is a Government Institution, belonging to the Department of Education, and has branches at Osaka and Kobe. There are, throughout Japan, some fifty Commercial Schools of high grade, where the curriculum prepares for this College. The period of study for the College diploma is five years, and under no circumstances can it be issued for a shorter course. When the diploma has been obtained there is open to the successful graduate a further two years' course, in which special instruction is received in Finance, Commercial, Civil, and International Law, Science of Commercial Economics, and Consular Duties and Obligations. The completion of this extra two years' course carries with it the dignity of a Degree - "Scholar of Commerce" (Shyogyo Gakushi) - which is eagerly coveted, and worn with pride.

There are some very interesting points in dealing with education in Japan. Before a student can enter the College to try for the diploma, he has to pass a physical examination as to whether he has bodily health that will serve him for a five years' course; and if he is successfully passed, he has to give three hours a week during the term to exercises in the military system of his country. 
The five years' Commercial Course, besides giving the soundest general education, covering everything but Classics, is strong in Mathematics, Physics, Chemistry, the Morals, History, Science, Practice and Laws of Commerce, Machinery, Statistics, Finance, English, and a choice of at least one other language out of French, German, Spanish, Italian, Russian, Chinese, or Korean! Two or three of these are desirable, but easy conversational English is indispensable.

The fees payable at the College are absurdly small, according to Australian notions: but every expenditure in connection with education is borne by the Government, and such fees as are received are paid into the General Revenue. 



\section{2}

\section{Commercial character}

\section{Lewis A. Jessop ${ }^{1}$}

When your Council did me the honour to ask me to deliver the second of the Fisher lectures, I naturally hesitated, being by no means by way of being a lecturer, and, furthermore, feeling a diffidence in following in the footsteps of one so well qualified by education and commercial experience as Mr. Henry Gyles Turner, who delivered the inaugural lecture. However, succumbing to that so natural feeling that it is so much easier in the majority of cases to say yes than no, so much more difficult to deliver oneself of a negative with more or less truthful reasons in support than of an affirmative prompted by inclination, I decided to stand before this important, but I trust not hypercritical, tribunal, and use my humble endeavours to further the views of my munificent friend, $\mathrm{Mr}$. Joseph Fisher, which are, I understand, to foster commerce education. This same question of education, in the broad and comprehensive sense, is one claiming, and which should claim, a large share of publication. In these days, when printed knowledge is so condensed and codified, so cheap, so accessible, I, who am little but an item in the commercial world, with a strong natural leaning towards utilitarianism, cannot help entertaining the conviction that the most important principle underlying all others in a national educational system is the teaching of the teachers, the instillation of the delicate art of adapting the seed to the soil; and I venture to prophecy that there will be no more vital science in the future than the science pedagogy. This is especially true of commercial education, for commerce and must be for many a day, the universal king.

1 Second Joseph Fisher Lecture, 11 May 1906. 
Now having consented to make my debut as a lecturer, I pondered the subject, and the result was "character," giving myself, however, the license, which an amateur may fairly claim, of wandering into such byways as seemed attractive. Did you ever a counterfeit presentment of a portrait of Carlyle by James McNeil Whistler. It is in the Luxembourg. A strange rugged figure, with a rough hewn head, a granitic shell covering a mighty brain, that studied the world through eyes that saw far deeper into things than those of most men. They made him Rector of Edinburgh University, and young and old may well study his address to the students. One extract as bearing on my subject I will venture to give for the benefit of those whose minds, yet impressionable, may mayhap find some help in it. He quotes from Goethe's Wilhelm Meister. Three of the wisest men that can be got are met to consider what is the function which transcends all others in importance to build up the young generation. The eldest of the three says,

"There is one thing that no child brings into the world with it and without which all other things are of no use. Wilhelm asks what is that? The answer is, reverence, Ehrfurcht, reverence! Honour done to those who are grander and better than you, without fear; distinct from fear, Ehrfurcht - the soul of all religion that ever has been among men or ever will be."

Yes, reverence is no spontaneous growth. Do we, the unthinking, remember that when we accuse our boys of being wanting in it? Do we recognise that reverence is a result of education, of environment, and, above all, do we recognise the immensity of the power as models for good and evil of those in high places? I am not one of those who contend that the world is going to the devil because I have experienced more of its kicks and gathered fewer of its halfpence than fall to the lot of some other men, and while admitting that the keen competition of to-day does not make for commercial morality; while recognising that there exists a somewhat cynical tolerance, not untinged with envy, of successful rogues, I confidently anticipate acquiescence when I ask those of the British race if much comfort is not to be derived from the fact - and I sincerely entertain the conviction that it is a fact - that the methods of the majority of English firms are founded on honesty and fair dealing, and that good faith plays a marvellous part in the conduct of the Empire's stupendous commerce. When I speak of English firms I of course include Australian firms, albeit our commercial reputation is somewhat besmirched by some latter day revelations. 
While posing as a commercial apologist, I do not pretend that Commerce is carried on on altruistic or philanthropic principles. It may be regarded as a reflection on some 2,000 years of Christianity, but the fact remains that to those engaged in trade life is a battlefield, and the prizes go to the fiercest fighters. It is strange to consider the gradations of trade from retail to wholesale, wholesale to limited liability, and thence to the zenith, to that weird triumph of destructive and constructive intelligence and organizing power, the combine or trust. If the chief aim of the man of to-day is to be to make money - money as a means to sustain life, money to provide comforts, money to furnish luxuries, money to gratify a longing for artistic ostentation, money to deck our women with coloured crystals and costly fabrics, money to enable us to oppress and move our fellows as pawns on the chess board of life - why, let us face the music, and honestly admit not on six days, but on seven, that there is no God but Mammon, and Rockefeller is his prophet. For John D. Rockefeller is the greatest exponent of the art of making money since the days when money meant not houses, land, stocks, bonds, shares of sorts, or any of the manifold pecuniary symbols of today, but just cattle. A strange psychological study this same master of millions, a curious illustration of the doctrine of heredity, for I have read that his father was partly gambler, partly quack, possessed with not entirely disinterested views with regard to the proprietary rights of others; and that his mother was a lady with a Puritan upbringing. Mr. Rockefeller himself is a commercial Machiavelli, in whose sight the end, meaning the accumulation of unwieldy hoards, justifies any means to attain it, and is also a pillar of the Baptist Church. My experience of life teaches me that the man who does not make his Sunday professions square with his weekday actions is not necessarily a humbug in his own sight. It was said of Mr. Gladstone that he could convince most people of many things and himself of anything. Nobody, of course, reads Tristram Shandy nowadays, but there's a sermon by Sterne well worth the studying, the text, for we trust we have a good conscience. America has been called the land of effort, and if strenuous industry and an insatiable habit of accumulating count for anything, then she should be the richest country in the world, and not only that, but an object lesson in many, in fact in most, vital respects. A land of some 80 millions of people, absorbing a million aliens in a year; a land possessing an independent geographical position, vast and diversified resources, and a race of financial giants, whose methods we may condemn, but whose ability is convincing; a land with a colour question 
always growing; a land, if common report is not a common liar, honeycombed with corruption - political, social, commercial, but the most interesting land in the world, especially to Australia. For notwithstanding a perennial deluge of legislation, as many as 15,000 Acts of Parliament having been passed in one pear, Cunning exults, Greed triumphs, Wealth accumulates; and thanks, possibly to the infusion of new blood, no talk of men decaying. Labour alternately fights and coalesces with Capital; and Boodle and Graft are the greatest Gods in the national Pantheon.

But look at the other side. Consider the incessant influx of selected brain and muscle from other countries. Think of the fight America has had to make to achieve her marvellous industrial success. To use the words of Mr. Fraser:

"She has milked the world for ideas, appropriated anything and everything in the way of invention to her own service, and has good reason, though at times she trumpets it a little too blatantly, to be proud of her achievements."

The virus of ennui and its sequent cynicism find no place in this sane organism. The great fact is recognised that the world must be a world of workers, and that the chief function of the state is to so equip men and women that they can worthily fill such places in the vast industrial army as suits their capacity. Some say that the pernicious abuse of their power by capitalists will convert America into the first purely socialistic state. I cannot believe it, for there, if anywhere, is a field where energy and ability can find due recognition and reward, and I cannot admit that energy and ability, even though exercised, for the benefit of their possessors, have ceased to be the most potent factors in life I need scarcely remind you that ability is a term susceptible of many applications, but of course the ability we are concerned with is business or commercial ability, an article representing a money value to its owner. Commercial ability is often characterised nowadays as smartness. Now I have heard that there is a saying in America that the smart businessman is the man who knows how to keep out of gaol, which, from an ethical standpoint, seems to indicate the existence of but a very fine line dividing smartness from dishonesty. The clear inference to be drawn is that for the man of ordinary ability it is true now as ever that honesty is the best policy. It is an important day in a man's life when he discovers that he hasn't brains enough to be a rogue; and he is indeed fortunate if he makes the discovery before the 
world's scorn shows the penalty attaching to faiiure. You have doubtless heard of Disraeli's diocesan conference speech. You know how England jeered at and ridiculed the man who declared himself on the side of the angels. There was a wonderful cartoon by Tenniel representing Disraeli in scant but graceful garb, wearing the wings which we are wont to ascribe to angelic beings posing before cheval glass; it was irresistibly comic, and every one laughed and applauded. Yet that same speech was full of wisdom. As Froude says in his biography:

"The note of scorn with which it rings has preserved it better than any affectation of pious horror. What, said Disraeli? It is not our iron ships, it is not our celebrated regiments, it is not these things which have created, or really maintain an Empire. It is the character of the people. I want to know where that famous character of the English people will be if they are to be influenced and guided by a church of immense talent, opulence, and power, without any distinctive creed. You have in this country accumulated wealth that has never been equalled, and probably it will still increase. You have a luxury that will some day, peradventure, rival even your wealth, and the union of such circumstances with a church without a distinctive creed will lead, I believe, to a dissolution of manners and morals which prepares the tomb of empires."

Yes, the character of the people. How is it to be formed? Is there a more momentous question for the leaders of this young nation to ponder? I venture to think, Disraeli to the contrary, notwithstanding that in this analytical age, neither creed, doctrine, nor dogma, or a combination of them, will, unsupported, serve to make a people truthful, honest, and moral. I have spoken of the responsibility attaching in this respect to those in high places, and as my theme is "Character," I will say that I recognise no such potent earthly force for good or evil as the force of example afforded by our leaders; social, political, commercial. The lives of good, not goody, men and women are now, as ever, the brightest beacons to guide inexperienced youth aright through this puzzling pilgrimage. Yes, life is a complicated business, a puzzle to the wisest, but to few more than to the aspirant for success in the commercial career. The youngster who goes into an office is somewhat at a disadvantage compared with the boy who proposes to make his living in a trade. For while the latter knows what it is that he has to learn, the ordinary clerical fledgling, unless he have good friends behind him, is like a rudderless boat 
in a rough sea, with heavy odds against his making a safe port. There is, I believe, an institution in London called The Future Career Association which undertakes to supply full and accurate information relative to spheres of occupation, and one can readily see the valuable potentialities of an organization which would show one desirous of entering commercial life the various specialties into which it is divisible, and indicate the studies necessary to qualify for the one selected. When I was young the ordinary parent with an ordinary boy to provide for, and a soul above retail trade, put him into an office. Young hopeful was supposed to rub along somehow in Commercial life. Many did rub along comfortably enough, and some came remarkably well through the process. But times, alas! have changed. The world is dead against the men who propose to rub along. The class of rubbers along are going to have a bad time in the near future, especially in the commercial sphere. In commerce, as in other walks of life, the all round man must give way to the specialist, and commercial education, whatever be the branch of commerce one desires to engage in, is a pretty serious matter. There is an excellent treatise entitled "Commercial Education in Theory and Practice", by Mr. E. E. Whitfield, M.A., late Lecturer at the City of Liverpool School of Commerce. The following are the subjects treated of: Organization of Commercial Instruction, Study and Teaching of Languages and Literature, Mathematics, Natural Science, and Drawing, Principles of Business and its Modern Features, Organization and Commercial Management of Industrial Concerns, the Theory of Trade, its Organization and Promotion, Economics and Mechanism of Transport, Economics and Framework of Taxation, Economics of Money-Banking-Stock Exchanges-Insurance, Bookkeeping and Accounts, its Theory and Practice, Mercantile Office Work, and lastly, the formation of character and the conditions of success. This you will admit is pretty formidable list of subjects but to be considered, of course, in relation to the finite capacity of human intelligence, and to the particular branch of commerce the student proposes to engage in.

The word Commerce has a most comprehensive meaning. Let us consider what it includes. Primarily the cultivation and production of everything needful to sustain life, to gratify taste, and pamper luxury, with the necessary transport and manufacture. Commerce caters for the necessities, the tastes, the weaknesses, and the vices of the world's population, and we must not overlook the elements of increase and variation. Invention is always at work seeking to evolve what in its delicacy, intricacy, and absolute certainty of performance, may almost be 
regarded as sentient machinery. The fertile brain is ever striving to comprehend and utilize the forces of nature. Every invention and every discovery tends to the increase and the modification of commerce, and everything points to universal commercialization. The reign of the cult will, in all probability, be superseded in the teeming east by the enthronement of the almighty dollar, and the true yellow peril may be found to be the patience, the thoroughness, and the cheapness of oriental labour. The situation in the clerical world is becoming more interesting from the fact that Woman, "once our superior, now our equal," to appropriate the toast of the old beau, is entering into serious competition in this as in other walks of life. I need scarcely remind you that Australia's commercial reticulation must spread when labour suitable to the physical conditions is profitably employed in our tropical country under the auspices of that true empire builder, the enterprising speculator, or under intelligent state supervision, and a general settlement of something over one or two people to the square mile is effected. When a trained and educated national government renouncing commercial empiricism leave to old and congested countries the task of settling the modus vivendi between rich and poor, and of reconciling the views of contented and discontented, in short, substitute for a policy of somewhat obstructive, even if well intentioned meddlesomeness, one of enlightened statesmanship, patriotism, and honest endeavour for the good of all. I have long held the opinion that next to the social detective, ever on the look out for evils and defects in the universal scheme of life, the most mischievous person is the political quack who tries to remedy them, breeding uncertainty instead of tranquility, and fostering the unrest that develops delusions, not yet, if ever to be realized. You may ask, why introduce politics? My excuse, if excuse be necessary, is to be found in the fact that there are few more important subjects before us than the principles of state interference. The difficulty of defining the proper limits of individual volition in business matters is accentuated by the desire of so many staunch individualists to invoke state interference for their own benefit, while bitterly condemning its exercise for the advantage of others.

The great power of public opinion which is behind the state naturally enough revolts against the arbitrariness and the offensiveness of that phenomenal result of industrial development, the latter-day plutocrat, and welcomes any measure, however chimerical, framed by the adroit and complaisant politician for his discomfiture. The position of the state in relation to the mercantile world 
has to be established here as elsewhere. While on the subject of employers, let us consider the question of joint stock companies. I remember many years ago a prospectus appeared, I think it was in connection with the well-known Langham Hotel in London, and the name of, I believe, the Earl of Buckinghamshire was in the list of directors. The document caused considerable comment, for in the days of unlimited liability, when the possession of one share in say the City of Glasgow Bank meant ruin, and when in the language of flunkeydom, noblemen were noblemen, prospectuses, especially with titled names, were comparatively rare documents.

What is the position to-day? There are over fifty thousand companies in the United Kingdom, with a paid up capital of nearly two thousand millions and a borrowed capital of four hundred millions. It was a saying of one of the older Rothschilds that a fool may make money, but that it takes a wise man to keep it, and in this fact may be found some reason for the popularity enjoyed by joint stock companies. The raison d'etre of a large proportion of these concerns is to be found, too, in the low rate of interest yielded by what are known as giltedged securities. Forty or fifty years ago the most unexceptionable investments in England returned about six per cent; to-day they pay about half that rate. The small capitalist is therefore in a measure forced to take the risk incidental to trading enterprise, and so as a shareholder become a factor in commercial life, or he gambles. To the ordinary shareholder a balance-sheet is about as comprehensible as a cuneiform inscription, and everything goes as smoothly as possible so long as the management can so finance that the periodical dividend is forthcoming. Seldom is enquiry made if it has been earned, and never how, whether legitimately and fairly, whether by excessive charges or inconsiderate or unfair treatment of others, or produced by that faking process which goes to prove the truth of the aphorism that there's nothing so fallacious as facts except figures. The duties of directors and auditors, the controlling influence, are by no means well defined. I recall the instance of an auditor of an insolvent bank who said he did as much as he was paid for; moral, don't underpay auditors. Directors of companies are too often chosen, not for their commercial ability, high character, and experience, but because of successes achieved in a walk of life which gave them no title to aspire to the position, or occasionally, as in mining companies, for their willingness to work the share market in the interests of a clique of wire-pullers. 
While on the subject of joint stock companies, I will give expression to a fad of mine. That is, the abolition of liability on shares. I quite anticipate an outcry and a free use of such words as visionary and unpractical. History repeats itself, and I have no doubt but that the introduction of the Limited Liability Act was greeted with a similar outcry. Nevertheless, experience proves that the generation of to-morrow is largely plastic in the hands of the generation of today, and were the provisions of the No-Liability Act gradually extended to trading companies, I believe that business would soon adapt itself to the change. I do not advocate such an innovation without cogent reasons, reasons which will appeal not to the arrogant, not to the selfish, but to the man of business who yet retains some human sympathy, and to such as recognize that foresight is not only not unlimited, but that its possession is limited to the comparatively few. After all, what is a joint stock company? A number of co-adventurers agree to risk so much each. They pay a certain proportion, and they render themselves liable for the balance. In old days, as I have pointed out, there was a joint and several liability; every partner took on his shoulders all the obligations of the partnership. Legislation provided a means for limiting the individual liability. Why not go a step further and abolish it? If one thousand men are prepared to risk say $£ 20$ each for a purpose, and after a time the success of their operations seems to warrant it, why not issue more shares, and so do away with the liability, which all have assumed, but which only the few may be able to discharge. And then, again, when a crisis comes, the original shareholder may be dead, and the successors in interest may be unbusinesslike persons, who would be sufficiently penalized by losing their principal without being compelled to pay liquidators' calls on their own shares as well as on those of such as make default. A true man's first care is to make provision for his widow and children, always assuming that he is not sufficiently advanced to deride the titles sanctified by nature and hallowed by time of wifehood and motherhood. What better shape can the provision take for the small capitalist than shares in a reputable trading concern, and yet experience has shown us that this very provision too often means ruin for the unfortunate legatees. We know what we are, but we know not what we may be, and most of us, no longer in our first youth, can recall changes most unexpected and most disastrous in the characters and methods of the wisest and most respected.

I have spoken of the possibilities of the expansion of Australia's commerce, and in this connection we must not overlook the fact that in addition to some 
three million square miles of country in Australia proper, we have the destinies of an immense tropical territory in New Guinea in our hands. A great deal of time and trouble would seem to have been devoted to the task of determining who shall be excluded from this vast domain, but the tide is, I hope, on the turn, and legislators are beginning to think that the question of populating our estate is one worthy of consideration. With every sympathy with the ideal of a white race - physically perfect, mentally excellent, morally superlative - I can but think that we shall have to reconcile actuality with idealism, and determine to solve the problem what human stock the country will carry, always having regard to the changes which will be wrought on the white race by physical conditions, and the class of labour necessary to the development of tropical regions. In our very legitimate aspiration to figure as a factor in the world's manufacturing, we must not lose sight of the vast and increasing value of water power, especially in electrochemical industries. In our anxiety to compete with such lands as America and Canada, it would be folly to ignore the fact that in the fall of Niagara River those countries possess the greatest hydraulic energy on earth, together with immense possibilities of this character in other directions. That they have the capital and energy to develop and the brains to avail themselves of these advantages to the utmost is undoubted, and it seems to me that our protectionist friends, when proposing to counteract their effect by a high tariff, supply the consumers with a very strong argument in favour of free trade, although character, enterprise, technical knowledge, industry, and other factors do much to efface disabilities in international industrial competition.

The part that Science plays in commercial life is a most interesting one. There was a time when the scientific student was a man apart. One pondering the phenomena of nature, floundering among first principles, groping slowly and laboriously from darkness towards light, wondering, guessing, but ever helping to solidify the slough for future generations to find firm foothold. There was a time when men wrought for the glory of God and the love of their craft, and under that sanctified inspiration did work so lasting, so beautiful; achieved triumphs artistic, architectural, of such supreme excellence as to make moderns wonder but despair of emulating. The genius of man to-day revels in the utilization of natural forces and systematized records, which it should be the care of all governments to preserve, make of each age a stepping stone to higher things. Michael Faraday said he had no time to make money, and 
was content with a pension as a pecuniary recognition of his life's work in the cause of science. The more modern philosopher floats on the sea of high finance. The discovery that crowns research, the invention that rewards ingenuity, is the legitimate prey of the promoter, the sport of the speculator, unless the discoverer or inventor is safeguarded by the possession of business acumen. Faraday had no time to make money. The "Marconi" Company insure the great electrician's life for $£ 100,000$. Hereditary partiality for exclusive information it was mayhap that caused the priesthood to force Galileo to recall his rash statement about the movement of the earth. What would they have done to Edison and Tesla? It may be as the Fabians say, that selfishness and greed as motive powers are waning, and shade of Disraeli, who would not be on the side of the angels? My experience teaches me, however, that much disregard of the rights and feelings of others is condoned by the oft-expressed axiom, "Business is business." But we must be optimists in our estimate of human character as in other aspects - we dare not be pessimists. Every thinking human being must be on the side of the angels. None can calmly face the terrible alternative so vividly depicted by Pope in the concluding lines of "The Duncead":

Religion blushing veils her sacred fires,

And unawares morality expires.

For public flame, nor private, dares to shine,

Nor human spark is left, nor glimpse divine!

Lo! thy dread Empire, chaos! is restored;

Light dies before thy uncreating word;

Thy hand, great Anarch! lets the Curtain fall

And universial darkness buries all.

Can it be possible that the development we see around us, the improvement in the conditions of life, the accumulated and recorded knowledge, the universal growth can be without their beneficent influence upon man? Can he alone remain stagnant, when to remain stagnant means in this busy world to go backwards? Stagnation is to my mind impossible for the individual, the state, or the race. I know that there are those who in their blindness would put back the clock, but if I read aright, the results of their efforts can be but as rocks in a rushing stream, which may divide but can never obstruct the mighty force hurling itself in tumultuous majesty towards a boundless sea. The crystal face of conscience is 
too often made dim and obscure by the fetid breath of feverish competition, or the foul exhalation of insensate greed, and we can only hope to foil the demon pessimism by cherishing the conviction expressed by Carlyle that the world is not founded on falsehood and jargon, but on truth and reason. May I be pardoned here for pleading the tyro's want of experience as a cause for lack of continuity. I notice that a discussion has been published in the Argus between employers and employees on the work and remuneration of clerks. On the one side there is a complaint of long hours and poor pay, on the other a declaration of the difficulty in finding young men of energy and ability. The conclusions the newspaper leader writer arrives at are that the market for clerks in Australia is over supplied, and the possibility of competition from women is greatly on the increase, while admitting inferentially the existence of room at the top. An article in the October fortnightly on Technical Education in Germany gives one an idea of the characteristic thoroughness of its scholastic system as compared with the somewhat haphazard British methods. In this, as in other respects, the Teuton seems to have adopted Strafford's motto, and by due recognition of its value, forges ahead in industrial competition. There is an excellent series of books published by George Newnes, Limited, describing life in town and country of the different European nations. Mr. William Harbutt Dawson, who treats of Germany, says of its public education:

"The very mention of Germany calls to the mind the vision of endless processions of pedagogues with spectacle on nose and ferules on side."

The early introduction and (very largely) of free education is not sufficient of itself to account for the exemplary schools which Germany possesses. The true secret of their excellence lies in the fact that the state insists on controlling the entire system of education from the bottom to the top. Elementary schools higher schools, technical schools, boys' schools, girls' schools, municipal schools, private schools, universities - all are subject to state approval and state regulation, and in everything the Minister of Education and Public Worship reserves the right of last word; nor is he slow to say it if necessary. It is commonly believed that German schools drive their children; and the discipline which they undergo is certainly exacting. Those who enter the elementary school do so on the completion of their sixth year, and they cannot leave it until the are of fourteen. Let the child be never so bright, he is not on that account deprived of his full course of education. But 
there is this difference between the German and the English system: the former does not tolerate the pitiable "half time" system. The school years are undividedly devoted to school work, and the factory and the farm are bidden to wait their time. In the North American Review for October the Professor of Political Economy and Politics - mark the title - in Cornell University writes on the question of the extension of American Commerce in the Far East. I can confidently recommend a perusal of the article. A few extracts are worthy consideration by politicians of the "rushing in" order. The Professor says:

"There is no true economic science that is not based upon actual business," and again, "Business is a complicated subject requiring intelligence and training to understand it thoroughly, and ability often of a very high order to conduct it successfully on any large scale. The needed training must be gained in good part in actual touch with business itself, but the training in a business house may doubtless be shortened, and likewise made broader and better suited to modern operations on a world wide scale by preliminary study in special schools and colleges adapted to that end."

Under the heading "General training for commerce" the following views are expressed:

"In current discussions in the press and elsewhere, many of the more fundamental principles of commerce, and the training which is requisite to enable our young men to cope with the problems which may arise in their business, have been adequately considered. It is generally conceded that besides the principles of accounting and cost keeping referred to, one should possess a fair knowledge of foreign exchange, a comprehensive outlook over the most important markets for the purchase and sale of leading staple products, a reasonable understanding of shipping by water and rail routes and the relative costs of different routes and classes of freights, an insight into the fundamental principles of commercial law, a sufficient knowledge of the languages of the countries in which one is to work; besides, of course, a detailed knowledge of the goods to be handled and the special requirements of the individual business which can be learned only in the business itself." 
We know that in Australia there is a very strong party which sees in protection, almost to the verge of exclusion, a panacea for all or nearly all the evils from which we suffer. The feelings of the man who buys are studiously ignored by the extremists of this party. A desire for cheapness, natural in a commercial age, and too often created, or at all events fostered, by the peremptory claims of necessity, is greeted with contumely, and a craving for excellence of material and superiority of workmanship stamps its possessor as hypercritical and unpatriotic. One result of protection will certainly be the production of more than we need, and possibly, under a faulty economic system, more than we can afford to retain for necessary home consumption. We are only beginning to realize the fact that while things are as they are the debtor, be he an individual or be it a state, must work for the creditor, and Australia, having for many years discounted her prospects in a somewhat light-hearted manner, can rehabilitate herself only by increased production, economy, or taxation, or a mixture of them. Our great want is education and educational facilities - moral, physical, rudimentary, economic, technical, artistic, political - but, above all, progressive, for we must never forget that nothing will avail us but material and equipment of the best, nor ignore the fallacy of the dreamer and the fool that all men are equal. Nothing is truer than Pope's dictum: "Some are and must he greater than the rest."

It may interest some of our anti-Asiatic fanatics to know that a leading English Commercial Magazine writes thus:

"Japan is said to be the hot-bed of perils innumerable to the white races of the world. The latest alarm seems to be the birth of a new mechanical science in Japan which will relegate all our old world machinery to the scrap heap, if we European engineers do not give ourselves a mental shake and educate ourselves up to the scientific standard of Japan in machinery."

Imagine Tokyo and Kyoto instructing Europe in engineering science, and yet those of us who have studied the art of Japan - not of course the globe trotters' art - can well understand that a country which produces work so perfect will reach mechanical excellence in any direction to which the genius of the people may be influenced. It may astonish some of our political wiseacres to be told that nations are very human and that our attitude towards the outside world is 
not calculated to engender the friendly feelings on which commercial relations are founded. It may come as a shock to our national vanity to be informed that we are still embryonic in some of our methods and crude in a proportion of our results, and yet it is pretty evident that the ratio of those who hold this opinion, of those who hold any opinion about us at all, is, it is to be regretted, not a small one. Truth to tell, our attitude towards the outer world is not conciliatory; in fact, to my mind it is almost frankly and childishly churlish. We are for the moment realizing the truth of Burke's celebrated definition of party government:

"Party is a body of men united for promoting by their joint endeavours the national interest upon some particular principle in which they are all agreed."

This definition is so far charitable, as it implies the existence in the party of sincerity and the absence of self-interest. I feel apologetic once again for the introduction of King Charles's head, but I really cannot help thinking that our political pundits are on the wrong track when they seek not merely to guide, but to force, commerce in divers directions at the behest of an interested compact faction. And when it is considered that those in authority over us, those who "ride on the whirlwind and direct the storm," base their assumptions on inexperience, and too often draw their conclusions from a bottomless well of egotism, where the sceptic naturally asks the necessity for commercial education. It seems an inevitable corollary that if a preliminary training is deemed indispensable to the successful conduct of a private mercantile business, then those who aspire to manage the commerce of the nation should in a greater degree be equipped by education and experience, unless indeed they trust, like the Irish pilot, to learn all about the rocks by running on them. Fight as we will, wriggle as we may, we shall have to come into line commercially, as in other respects, with the rest of the world. We shall have to recognize that the true policy of a nation lies not in isolation, but in friendly communion with the world's peoples. We shall have to realize that although population means responsibility, it means safety, if of the proper quality. Let us consider wherein lies the strength of the Germany born some 35 years ago. Call to mind the impressive pageant at Versailles, when the stately first William was hailed as the chief of the new empire. An empire then of under 41 millions of people - to-day, with nearly 60 millions, adding yearly more than 800,000 to its numbers, and a constantly increasing factor in the world's policy, history, and commerce. A country poorly endowed by Nature, but 
developed in a business-like manner; a gigantic co-operative industrial concern; a nation that recognizes the value of virility and its dependence on rural industries for the maintenance of the standard of manhood. For strength and endurance count and strength and endurance are developed in the wholesome natural surroundings of a country existence and not in the artificial life of crowded cities. While we hear so much of physical degeneration in England, where four-fifths of the population live in towns, there are no similar complaints in Germany, and the fact that the rapid increase of that country's population is not accompanied by a falling off of the national physique is attributed by German statesmen to her prosperous agriculture. Nowhere in the world does the value of science and co-operation as means to the creation of agricultural prosperity receive more recognition than in Germany. They have credit societies; societies for cooperative buying and selling; societies for developing irrigation, and many others to assist and encourage small cultivators. The yearly outlay on agricultural education in Germany is about $£ 500,000$. The part that chemists play is shown by the growth of the beet sugar industry the production of which increased from 358,000 tons in 1876 to $1,970,000$ tons in 1901, while the history of the chemical industries of Germany reads like a fairy tale. - their imports of manufactured chemical products in 1889 were valued at $£ 5,330,000$, and in 1902 at $£ 5,560,000$, an increase of only $£ 230,000$; while the value of the exports for the same period rose from $£ 11,335,000$ to $£ 19,300,000$. In other words, there was a growth in the excess of exports over imports in the period of no less a value than $£ 7,735,000$. The production of soda rose from 42,000 tons in 1878 to about 400,000 tons at the present day; while the production of sulphuric acid increased from 112,000 tons in 1878 to 857,000 tons in 1901 . The principal chemical manufactures exported were Antipyrin, Antifebrin, Alizarine, Aniline, and other dyes made from coal tar, Oil of Aniline, Quinine, Cyanide of Potassium, and Indigo. My statements in reference to Germany are drawn from a volume entitled Modern Germany, by Mr. O. Elzbacher. He tells us that the commanding position of Germany's chemical industry is in no way due to Nature's bounty, for she is largely dependent on foreign nations for the supply of chemical raw products, which she works up into chemical manufactures. The great success of Germany's chemical industry is attributed by Mr. Elzbacher to the simultaneous action of the following causes: (1) the natural disposition and aptitude of the individual German for close, patient, persevering, and painstaking work and study; (2) the 
munificent and enlightened assistance and encouragement given by the German Governments to the study of chemistry in all its branches, regardless of expense and regardless of immediate profitable returns; and (3) the spirit of combination and the absence of jealousy among chemical scientists and manufacturers, whereby scientific co-operation on the largest scale is made possible.

It seems clear that the commercial prosperity of the German Empire owes much to a policy of high protection, regarded not only as a defensive but also as an offensive weapon, for Mr. Elzbacher writes as follows: "The German Government observes the development of huge trusts in Germany not only with a benevolent interest, but lends them its active assistance and encourages their formation." And further: "The German Government adopts this attitude chiefly because the activity of the German trusts outside Germany largely consists in undermining and ruining foreign industries by swamping them with surplus products, which are sold below cost price, and in thus ridding German industries of dangerous competitors."

Assuming this to be true, and I know no reason to doubt it, what a lurid light is thrown on the spirit in which our latter-day Commerce is con ducted. Let it be written on the walls of the Temples, "There's no sentiment in business."

What Germany has done Australia may do, and do it on a more colossal scale if her people so desire. We have our fate in our hands in this young country. We can, if we will, profit by the triumphs and take warning from the failures of nations who have bought their experience and paid for it with an expenditure of blood and treasure through the ages. But there seems a tendency to deride tradition and the teachings of the past and to apotheosize false prophets, who pretend to interpret the views of the multitude, and while oftentimes seeking their own ends, aspire to furnish an object lesson to an unappreciative world. The conditions of old and densely-populated countries, while possessing an undoubted interest for the Australian sociological student, should, it seems to me, be to him of merely academic importance. If the cry of want of employment be heard from a population such as ours, in a country such as this, one cannot help feeling that the cause is to be found in ineptitude, ignorance, deficient training, prejudice, want of enterprise, or some other source other than that in which the distressing wail finds its origin in the crowded centres of the old world. The deductions to be drawn from this rambling and imperfect address of mine concern chiefly one 
class of boys - not those who have shown their discernment by selecting wealthy or influential progenitors, not the abnormally astute, not the morally obtuse, but ordinary, honest, healthy boys, who are forced to engage in the struggle at what seems a somewhat immature age, and propose to start life in an office. It is clear that the elaborate curriculum, which some theorists regard as providing an indispensable equipment for commercial aspirants, does not concern this latter class. Those who have to work all day for a living, if they possess the necessary physique and are pricked by the spur of ambition, must rely to a great extent on evening classes for such technical education as will conduce to an improvement in their position. But this means self-denial and an irrepressible determination to succeed; no golden gate welcomes the loiterer on the primrose path of dalliance nowadays. In every walk of life courage, endurance, and ready wit count.

Such a lecture as this is naturally merely suggestive, and I leave it at that, and will conclude, harking back to my original theme, "Character," with a few words such as boys may well take in good part from one who has been "on his own," as the modern phrase goes, for not far short of half a century. I have known men to whom the feelings, the fortunes, even the lives, of their fellows, were as nothing in their struggle to gain the golden citadel. Some have succeeded, some have failed, but take my word for it, when settling day came none ever thanked God he'd been a rogue. I am too conscious of my own shortcomings to pose as a preacher, but I trust that you will credit me with sincerity when I express my conviction that no better, safer principle can be instilled into the youthful mind than that embodied in an old German motto, Thue recht und scheue niemand, "Do right and fear nobody". I do not pretend that of such are the kingdom of the plutocrat's heaven. I do not aver that the Pagoda tree will drop its golden fruit into their laps at their shaking. It is more than likely that they will experience aspirations unrealized, anticipations unfulfilled, and the futility of fight for a foremost place; but if no satisfaction is to be found save in a successful progress over the bodies of our compeers, heedless of their cries, regardless of their struggles; if no complacency is to be derived from a sense of difficulties surmounted without lying, cheating, loss of self-respect, and a prostitution of our manhood generally; if Machiavelli is to be our model, and the national motto, "The end justifies the means," then I ask in my bewilderment, what may be our conception of that Deity who made man after his own image? 
We have the making of a nation in our hands, a task concerning the lives and the fortunes of this generation and of generations to come, the achievement whereof, as we do well or ill, will bring blessings or curses on our heads. The tendency of those who are satisfied with things as they are, including such as have reached the grand climacteric and, favoured by fortune, ask for but an easy descent; and of those who pursue the golden ignis fatuus untiringly, remorselessly, to the end, is to delegate to others the management of things they have neither the time, the inclination, or the energy to manage for themselves. What wonder, then, that the discontented accept the burden of Government; what wonder if the would-be representatives of those who want, suggest some new system, having for its crown that so-difficult-to-be imagined condition, universal content. Kingsley's song says, "Men must work while women must weep," and certes one-half of the dictum may be deemed axiomatic, for to labour must be the universal lot. Be it labour to support life, labour for individual gain, labour for the advantage of others - labour it must be. And our aim must be production, production allied to excellence, but, above all, production, under such conditions as will improve the lot of the lower stratum of society.

Never get away from the fact that production involves serious training, mental and mechanical. Those who, like our friend Mr. Fisher, recognise the necessity for training or education, and do something during their lifetime to help it along, are among mankind's greatest benefactors. Post-mortem beneficence is too often a mere compromise not free from selfishness. The world is full of intelligence and natural aptitude, which need but direction in the proper channels to vindicate the attributes that separate man from beast. There is no graver question than this. What is to be the nature of the directing force? Much is to be hoped for from the formation of character as a fundamental principle of national education. 



\section{The influence of \\ commerce on civilization}

\section{J. Currie Elles ${ }^{1}$}

As an unknown man to you, I have been paid a most graceful compliment when I received an invitation from your honourable University to deliver a lecture under its auspices on a subject relating to commerce. I have since ascertained that to one or two kind friends I am indebted for the pleasure I feel in being here to-night at your invitation. That pleasure is not unassociated however from apprehension, for no matter how much I may believe in what I say, others may have different views. I trust, however, that I may at least interest you in a subject which engrosses my entire attention; which has such romantic surroundings, and which so well repays the student, as the Influence of Commerce on Civilization. I have found it difficult to condense what I have to say in a mere paper. Volumes would not exhaust the subject. I feel proud in being privileged to address an assemblage of University men. Though now a commercial man, may my remarks, as I am a University man also, not now be out of place, as Horace says, "Nota quae sedes fuerat columbis".

I have in my paper endeavoured to give a short history of the Influence of Commerce on Civilization, and, during the course of the paper as I have endeavoured to put it to you, I have quietly tried to portray the varying influence, one over the other, between the conflicting good and bad in commerce and civilization, since history began. There has ever been a conflict between practice and theory; between commonsense and visionary ideas; between sound fact and, shall I call it, irresponsible mania, in all our mundane existence. There has ever

1 Third Joseph Fisher Lecture, 23 April 1908. 
been the individual effort, the hope of the family and of the individual in the great object of self-support, self-sacrifice, and self-competence, often to be blasted in the hour of prosperity by the predominant weight of irresponsible, unreasoning barbarism and ignorance. In the language of the great German poet, Schiller,

"Es reden und träumen die Menscchen viel

Von bessern künstigen Tagen,

Nach einem glücklichen goldenen Ziel

Sieht man sie rennen und jagen,

Die Welt wird alt und wird wieder jung,

Doch der Mench hofft immer Verbesserung."

Where I have failed in continuity of theme, I hope I may be judged mercifully, because also, "quandoque bonus dormitat Homerus."

Commerce, Civilization. These two words in the English language mean much and their analyses and corresponding equivalents in many other, now unknown tongues, mean more. Since ever the world began, from the earliest records now extant of ancient peoples and buried civilization, these two words are stamped on the records of time. Commerce presupposes and marches hand in hand with civilization, and commerce through all times has developed civilization, while civilization has often failed and retrograded to the detriment and set-back of commerce. During all the turbulent mundane history of this our earth, through all the effacements of empires and the downfall of civilization, commerce has ever emerged supreme from the ashes of her predecessors to initiate and establish a new era even more extensive and far reaching; and civilization, real or supposed, has always followed, brought into birth by the energy of commerce, to again die away by the effeteness of its own luxury and ineptitude. The "Sturm und Drang" of commerce "non habet leges", and in this science, for science it is, "necessity has no law", and necessity is the mother of invention. Many are the theories expounded by civilization, and many the fads begotten of luxury derived from commerce, which have for a time held sway, but the Nemesis of cold fact and practice when brought into contact with the visionary theories of so-called civilization, has shattered them as on an iron-bound coast on the sea of philosophy. Is there any civilization? Is what we have now worthy of the name? This will be my effort to elucidate. 
Very much of what is good and honest in this world has been called into being by commerce. The pre-supposition of and the establishment of honourable dealing rendered imperative on the first traders, as their raison d'être, their existence and their livelihood, has survived in the high moral tone and character in trade initiated by the pioneers of commerce. In the old policies of insurance in the East, still surviving some forty years ago, the phrase, "In the name of God, Amen", was the first line in a policy of marine insurance. This phrase or declaration was an oath by the signatories to such policy, binding even unto the third and fourth generations through their descendants. This form of insurance, the oldest in the world, was derived from the Arabians, but I am sorry to see the phrase no longer exists. The commercial morality of the Eastern nations, the Arabians, Parsees and Chinese, survives in all its strength, and is a pattern to all Western nations from its integrity. In China a debt is a debt: it descends from father to son, and Chinese law can compel the son to make good his father's debts. Civilization being a growth on commerce has of times raised its baneful arguments against the hereditary law of honesty, established by commerce, and brought about side issues and legal technicalities to evade true indebtedness: in this way so-called civilization has hindered commerce. Commerce always is the honest, practical fact in history: civilization often the theoretical fad. The older the period examined, the more unique the honesty of commerce disclosed.

The great economic study of the wants and requirements of the present day, and the means to satisfy them, is evolved in many ways; and the varied aspects of the question present an ever-changing front, an ever-varying quantity, sometimes giving rise to much speculation, and always the subject of much controversial argument. The growth of human knowledge and often the preponderating influence of human ignorance, the increased and exacting requirements of civilization; the discoveries of science, and their consequent developments in turning these factors to practical account, have, during the last century especially, all contributed towards a cosmos, complete in its composition, and changeable as the kaleidoscope in its disposition. Old-established laws and customs, in every known branch of trade and profession, give way to new: old sources of supply become dried up, and in turn have become sources of demand. Staple articles of trade and commerce lose ground and become supplanted by others whose existence hitherto had barely maintained a place in economy, from their very uselessness for any known purpose. Science having investigated the various capabilities of 
the products of the earth, one class is kept in check by the resources of the other. Should the price of one article rise by attempted monopoly to a prohibitive basis, another product is called in to supply its place, which, by intrinsic merits, or by combination with others based on scientific authority, supplants the previous competitor.

This is an iconoclastic age: an age realistic rather than idealistic; an age of inventions, of perfecting of scientific discoveries; an age no longer of steam, but of electricity, which not only puts a girdle round the earth in forty minutes, but which grasps the lightning from the clouds to do its bidding. Prometheus stole fire from the sun to illumine the world, and was thrown into Tartarus by Zeus: the present age subdues the cloud compeller, Zeus, and yokes him in bondage to toil for the good of man. The question arouses many and various speculations and theories in the mind of anyone who studies the aims and ends of those whose lot it is, by circumstance or by adoption, to cater for the requirements of the world. The keen competition which enters into the case is the cause of the still keener efforts to supplant the successful ones, in turn giving way to some power or combination which is able to supply the demand on some newer and cheaper principle; and thus the world goes on, and the "survival of the fittest" doctrine in every case holds good: the newest acquisition of science and the latest discoveries in art and manufacture, all combining and being turned to account in the struggle for existence.

From the earliest known records of ancient times, as far back as even the records disclosed by the most recent excavations of the sites of ancient cities have proceeded (and, let me say, these researches into the ancient and buried world are only in their infancy) we have still ever-recurring recorded evidences of even more remote systems of commerce and civilization. The most ancient of these discoveries has proved the existence of immense commercial organizations and subsequent highly-graded systems of civilization, which have disappeared for ages, now to be exhumed, as to their remains, by the energy and "sinews of war" provided by commerce. The period when the first man began to barter or to trade, we shall never know. A learned professor, a member of the same school, and of the same University as myself, traces by means of their monuments the migrations of the Megalithic peoples from Mauritania, through Britain, Southern Europe and Asia, and through Northern Asia across Behring Straits to British Columbia, and down to Yucatan, and again separately, through Siberia, Korea, 
and Japan, down to Tonga and Samoa, and thence to New Zealand, as having been about 150,000 years ago. Whether this theory be right or wrong, I cannot say. Anyhow, the monuments remain, and it is a singular fact that to the present day, the trade and commerce routes, from the East in Asia to the West in Europe, follow very closely the routes of these Megalithic peoples. What their commerce and civilizations were we have no means of knowing, but the remains are still existent that such interchange of peoples took place.

The earliest known records of commerce and civilization are evidenced in late discoveries of the remains of the ancient Accadian race, which race was closely allied in its language with the Chinese, who preserve their ancient language to the present day, and who are among the most ancient commercial peoples known. In days long gone by they traded to Africa and the Arabian Gulf; even in ancient Egypt traces have been found of their commerce. The history of the vast commercial organizations of the Chaldeans and afterwards of the Babylonians, the Hittites, and the Egyptians, all of whom had intercourse with India and China, is vague and uncertain, but we do know that there was vast commerce conducted between these countries, as is shewn in the case of the Hittites, who were great miners and who paid tribute to Egypt, which Empire gradually declined over most of Africa. The Hittites attained an advanced state of civilization, and the commercial importance of their capital, Carchemish, extending from all Western Asia to the Mediterranean, was practically supreme. The Phoenicians controlled the commerce of the Mediterranean and Persian Gulf their trade was enormous and their civilization of a very high order. The alphabets of Greece, Rome, and all modern nations are derived from Phoenicia. Arabia also contributed largely in ancient times, and also, as we shall see in more modern times, to the commerce and the civilization of the world; and, though derived from India in the first instance, we have the word "cypher" and the Arabic numerals now used. The Phoenician traders penetrated to Great Britain and Spain, and the remains of their enterprise now exist in the tin mines in Cornwall and in the copper mines in Spain, the Rio Tinto, and the Tharsis: the latter called after one of their cities.

We thus see that commerce by exploring the earth and accumulating wealth and also great knowledge was founding a vast civilization over 6,000 to 7,000 years ago; and even then these records allude to far earlier huge commercial organizations and advanced systems of civilization. We learn of complete systems 
of banking, of highly codified laws, of religions, and high scientific knowledge, which not only foretold eclipses, which mapped out astronomical calculations, but also had in some of these ancient long forgotten cities a scientifically and perfectly arranged sanitary system of sewerage and drainage. That the ancients understood water is evinced in the present day by the embankments on the Yellow River, in China. These embankments were built 2,500 B.C. They are standing yet, and have ever since controlled the waters of this mighty river in flood. It may well be asked how many centuries did it require to instruct the Chinese engineers to possess the knowledge sufficient to measure the volume of flood waters and to build these embankments? Probably another 2,500 years. The question now comes what caused all this disruption of commerce and effacement of civilization among these ancient peoples? We shall never truly know, but the probable cause may be learned by the consideration of the downfall of more modern nations.

The Phoenicians whose commerce, as I have said, spread from India to the British Isles, embraced all the products of the then known world at Tyre, their capital. They formed colonies on the Mediterranean at Carthage, the modern French naval station Bizerta; and though their commerce was immense, extending to all parts of the then known world, they paid tribute to the Lybians, from whom they acquired a site for a trading centre. Enriched by commerce, they acquired the unrest which comes from prosperity, which has been the overthrow of other nations, and many individuals. They threw off the yoke of the Lybians, sent their fleets abroad to annex territory; and this brought them into conflict with Rome, the power then rising over the horizon, and eventually succumbed after many years of struggle to the Roman General, Publius Cornelius Scipio Africanus, at the Battle of Zama, $9^{\text {th }}$ October, 202 B.C., which general then and there gained for the Romans a decisive victory over Hannibal, the Punic commander. The tribute of the Phoenicians to civilization has been great. They invented the purple dye made from shellfish, which has only been superseded in later days by the dye from the central American insect the cochineal. The remains in literature of the Phoenicans are handed down through the Hebrews, in Psalm CVI, 23 to 30:

"They that go down to the sea in ships, that do business in great waters:

These see the works of the Lord, and His wonders in the deep.

For he commandeth, and raiseth the stormy wind, which lifteth up the waves thereof. 
They mount up to the Heaven, they go down again to the depths: their soul is melted because of trouble.

They reel to and fro, and stagger like a drunken man, and are at their wits end.

Then they cry unto the Lord in their trouble, and he bringeth them out of their distresses.

He maketh the storm a calm, so that the waves thereof all still.

Then are they glad because they be quiet: so he bringeth them into their desired haven."

Only a sailor could have written this beautiful description of a storm at sea, and no shepherd could ever have conceived it. Again, we have, through Rome, in the works of Terence, a Phoenician slave, that immortal passage which, on being first spoken in the theatre at Rome, brought the entire audience to their feet in thunders of applause: "Homo sum: humani nibil a me alienum puto". As Max Müller says: "As far as we can tell, the barbarians seemed to have possessed a greater facility for acquiring languages than either Greeks or Romans. Soon after the Macedonian conquest we find Berosus in Babylon, Menander in Tyre, and Manetho in Egypt compiling, from original sources, the annals of their countries. Their works were written in Greek, and for the Greeks. The native language of Berosus was Babylonian; of Menander, Phoenician; of Manetho, Egyptian. Berosus was able to read the cuneiform documents of Babylonia with the same ease with which Manetho read the papyri of Egypt. The almost contemporaneous appearance of three such men - barbarians by birth and language - who were anxious to save the histories of their countries from total oblivion by entrusting them to the keeping of their conquerors, the Greeks, is highly significant. But what is likewise significant and by no means creditable to the Greek or Macedonian conquerors is the small value which they seem to have set on these works. They have all been lost, and are known to us by fragments only, though there can be little doubt that the work of Berosus would have been an invaluable guide to the student of the cuneiform inscriptions of Babylonian history; and that Manetho, if preserved complete, would have saved us volumes of controversy on Egyptian chronology.

Through Greece we have the great poet Menander. The sayings of this poet have unfortunately come down to us only in the shape of a very few fragments, 
but some that have come down to us in the New Testament, quoted by St. Paul, are household words to-day, and are sublime. For instance: "Evil communications corrupt good manners" (1 Cor. XV, 33). And also, though not quoted by St. Paul:

"If thou wouldst know thyself, and what thou art,

Look on the sepulchres as thou dost pass:

There lie within the bones and little dust

Of mighty kings and wisest men of old:

They who once prided them on birth or wealth

Or glory of great deeds, or beauteous form,

Yet nought of these might stay the hand of Time.

Look, and bethink thee thou art even as they."

Such is one result of the building up of commerce from humble beginnings, the amassing of wealth commercially and intellectually by the long intercourse and interchange of commodities and languages with other nations. Aggressive action on others was the downfall of the Phoenicians. Next in the procession of commercial nations we see the Romans. The history of Rome is the most interesting and entrancing in Europe. Having cleared the Carthaginians on their way, in succession every other opponent was subjected. The Empire of Rome extended from the Indus to the British Isles, and from the Sahara to the North Sea. Every product of every country was to be found in Rome; every subject of every nation resided there either free or as a slave. The wealth from commerce and power in the Roman Empire was enormous, and stimulated and encouraged the highest pursuits of literature and learning. The legacy given by Rome to civilization and literature is incalculable in its value. In all parts of Europe, the British Isles, in Asia and in Africa, even now immense remains of Roman commerce and civilization are only just being unearthed. The code of Roman law, the Institutes of Justinian, have remained the basis of all present law, and are especially prominent in Scottish law. In proportion as Roman prosperity in commerce became greater by having enterprisingly pushed itself forward among other countries in Europe, Asia, and Africa, so did the zenith of her power gradually approach, her commerce became menaced, and her existence threatened by those whom she had conquered. The barbarian hosts under Alaric, Genseric, and Attila, driven by necessity, arose, invaded Rome, and finally made terms with the Eastern Empire at Byzantium, thus accomplishing the fall of the Western Empire and the degradation of Rome. 
One of the most potent causes of the fall of Rome and the decrease of her civilization was the rise of Christianity. Having gained ascendency in Rome, the complete dissolution of Roman society, commerce, and civilization followed. This is what Leeky says on the subject: "Not quite a century after the conversion of Constantine, the Imperial city was captured by Alaric, and a long series of barbarian invasions at last dissolved the whole framework of Roman society, while the barbarians themselves, having adopted the Christian faith and submitted absolutely to the Christian priests, the Church, which remained the guardian of all the treasures of antiquity, was left with a virgin soil to realize her ideal of human excellence. nor did she fall short of what might be expected. She exercised for many centuries an almost absolute empire over the thoughts and actions of mankind, and created a civilization which was permeated in every part with ecclesiastical influence. And the dark ages, as the period of Catholic ascendency is justly called, do undoubtedly display many features of great and genuine excellence. In active benevolence, in the spirit of reverence, in loyalty, in co-operative habits, they far transcend the noblest ages of pagan antiquity, while in that humanity which shrinks from the infliction of suffering, they were superior to Roman, and in their respect for chastity, to Greek civilization. On the other hand, they rank immeasurably below the best pagan civilizations in civic and patriotic virtues, in the love of liberty, in the number and splendour of the great characters they formed. They had their full share of tumult, anarchy, injustice, and war; and they should probably be placed, in all intellectual virtues, lower than any other period in the history of mankind. A boundless intolerance of all divergence of opinion was united with an equally boundless toleration of all falsehood and deliberate fraud that could favour received opinions. Credulity being taught as a virtue, and all conclusions dictated by authority, a deadly torpor sank upon the human mind, which for many centuries almost suspended its action, and was only effectually broken by the scrutinizing, innovating, and free thinking habits that accompanied the rise of the industrial republics in Italy. Few men, who are not either priests or monks, would not have preferred to live in the best days of the Athenian or of the Roman republics in the age of Augustus or in the age of the Antonines, rather than in any period that elapsed between the triumph of Christianity and the fourteenth century. The time came when the Christian priests shed blood enough. Indeed, the more carefully the Christian legislation of the empire is examined and the more fully it is compared with 
what had been done under the influence of Stoicism by the pagan legislators, the more evident, I think, it will appear that the golden age of Roman law was not Christian, but pagan. Great works of codification were accomplished under the younger Theodosius and under Justinian, but it was in the reign of the pagan emperors, and especially of Hadrian and Alexander Severus, that nearly all the most important measures were taken: redressing injustice, elevating oppressed classes, and making the doctrine of the natural equality and fraternity of mankind the basis of legal enactments. Receiving the heritage of these laws, the Christians no doubt added something; but a careful examination will show that it was surprisingly little. In no respect is the greatness of the Stoic philosophers more conspicuous than in contrast between the gigantic steps of legal reform made in a few years under their influence, and the almost insignificant step taken when Christianity had obtained an ascendency in the Empire, not to speak of the long period of decrepitude that followed.

About this time the Western Empire was finally overthrown by the Mohammedans hailing from Baghdad, who conquered Egypt and Mauritania and settled in Spain. The history of the Saracen occupation of Spain is one brilliant record of commerce and civilization. Spreading their commerce to every part of the known world, the Saracens encouraged literature, learning and art by every means in their power. The world was ransacked for manuscripts and books of all kinds. The Saracenic cities of Cordova, Granada, and Seville were the depositories of every branch of learning known, which rivalled, as the results of civilization, even the commerce itself which had given them birth. In the bazaars in the cities of Seville, Granada, and Cordova all known commodities, from the silks of China to the tin of Britain, from the products of Sokoto and Timbuctoo to those of the Baltic were gathered together. Indeed, it was once said that, even "if you wanted bird's milk, by Allah, you will procure it at Seville.” All branches of learning, in astronomy, in medicine, in surgery, were practised and studied here during the Saracenic occupation. Brazen and leaden pipes conveyed, by gravitation, the water stored in the reservoirs to the inhabitants of these cities. Gunpowder was known and made in Spain; glass was made; and printing was known, having been acquired from the Chinese, through Arabia. The connection between the plague rat and the dissemination of plague was believed by the Saracens. Indeed, the period of the Saracenic occupation of Spain was one of the most brilliant epochs - if not the most brilliant of all - in civilization and commerce, Europe has 
ever seen. I say Europe because the Saracens exemplified the highest efficiency in commerce and the highest luxury in civilization that was to be found in the world, they themselves being Asiatics, and knowing all that was best to know and learn in the civilizations of China and India. We have only to read the "Arabian Nights" to understand the intimate relationships between Arabia, India, and China. The contrast between Arab civilization and the civilization of Northern Europe of that date is sharply accentuated by the fact that, while the literature of the Arabs was such as to remain for our instruction to this day, Charlemagne, the greatest Monarch of the West, could not write. One of the principal things in which Cordova was said to surpass all other cities was the "sciences therein cultivated." It was reported to have more books than any city on earth. Andalusia was converted into a great literary market, and the most skilful men in learning of every clime were invited to Cordova and welcomed there for their attainments. The catalogue of the library at Cordova consisted of forty-four volumes. The Saracens left much, and would have left more had their records not been destroyed by fanaticism; but if they left one word, and if only that word were all, it lives in the annals of our British Empire - the word "Admiral". The Arab word for Admiral (Amiral-Bahr) means "Emir of the sea". I take it that a British Admiral is Emir of the Sea; that the office, British Admiral, is the highest given to any subject of any nation on earth. Long may he remain so, and long may a British Admiral's flag be feared, respected, and admired! The collapse of the Mohammedan power in Spain, destroying as it did, the high state of commercial organizations and system of civilization is a calamity from which the civilized world has not recovered to this day. Religious fanaticism, to which the world seemed to have been given over, made it a matter of conscience to destroy the literature which centuries of enlightenment had amassed in the libraries of the Mohammedans. The condition of barbarous ignorance and sloth into which Europe was plunged after the downfall of the Roman Empire and the expulsion of the Saracens from Spain were a great set-back to both commerce and civilization; but commerce again rose supreme, and at the hands of the Florentines and the Venetians a new era for trade began. After the fall of the Saracens in Spain the growth of sacerdotalism and fanaticism in all their bald narrow-mindedness culminated in a set-back to commerce and a stagnation of civilization. The darkness of the Middle Ages has often been referred to; and the marvellous and malignant growth of sacerdotalism, paralysing, as it did, the civilization of Northern Europe, gave birth 
to the Crusades. Here, again, commerce rose to the occasion. The Florentines and especially the Venetians (who threw their whole energy into the trade of the East) financed the Crusaders during the long era of the eight Crusades, on account of their knowledge and practice of the science of exchanges. In fact the genesis of the science of foreign exchanges - one of the most important constituents in modern commercial operations - began in Italy. At a time when the Northern nations show signs of infancy of commerce merely, Italy was advanced in the art and practice to a most highly developed commercial and financial state. It is to her that we owe our system of book-keeping and the use of bills of exchange; and it is certain that Italy, by keeping her finger on the monetary pulsations of Europe, reaped her harvest from the bi-metallic fluctuations of the fourteenth and fifteenth centuries. Trading to and having constant intercourse with the East, Venice had sent her great traveller, Marco Polo, to the distant realms of India and China. In China he was received by the Great Khan most hospitably, and the Khan was impressed by his skill in acquiring the language of the people of his dominions. Marco Polo visited many cities in China, amongst others, the great city of Chin-Chew, which city had an immense commerce extending to Arabia and the Persian Gulf He was even, through his friendship with the Khan, made Governor of a province. On the great science of the foreign exchanges I shall have much, I hope, to say later on. We all know the graphic account in "Ivanhoe" of the payment by Gurth to Isaac the Jew of York, in golden Venetian byzants, for the hire of Ivanhoe's horse and suit of armour; and how, if the last piece had "rung a little less truly he would have given it to Gurth.” The Jews were also a factor in the Middle Ages as to foreign exchanges - an art, let me say, they have never since forgotten. We also know the plot in Shakespeare's comedy, "The Merchant of Venice," beginning "Three thousand ducats and three months; well." This was on the Rialto, at Venice.

The next step in the variations in commerce and the centre of finance is the shifting of the venue to Antwerp. The drawback to Venice inasmuch as her commerce was restricted by the limited volume of exchanges due to its being undertaken on an overland route from Asia, was the opportunity of the Netherlands and Portugal. These two countries opened up trade and commerce with the coast of Africa and extended it to India, thereby initiating the era of sea-borne commerce to the East round the Cape of Good Hope, which has since assumed such vast and preponderating dimensions under the Union Jack, the flag 
of our great British Empire. The Dutch ships and the great Portuguese navigators, Vasco da Gama, and others, sailed to the East and founded colonies, which remain to this day. Traces of the navigators of these countries are found in Australia today, by the names affixed to parts of our coastland. Though sadly shorn of her former glory, the Portuguese colony of Macao, founded in the sixteenth century, still remains; and here, as a result of commerce, the literature of Portugal survives in the beautiful poem, the "Os Lusiados", of Camoens, who was born at Macao. The Portuguese here exemplified their Phoenician descent. This trading with India and the East by the Dutch and Portuguese retained the centre of the foreign exchanges in Antwerp, regulated the flow of silver to the East, and retained gold as London does now to-day. This is what Venice could not do from the raison d'etre of her commerce. But Spain was not idle in the meantime, and with the discovery of America by Columbus, albeit a Genoese, a new era arose over the commerce of Europe. The fabulous wealth of Mexico and Peru in precious metals paralysed Europe, and in Spain especially, promoted all effete luxury, which, aided by a malignant sacerdotalism, gradually overthrew the civilization and finally the commerce of Spain. The stories recorded by Prescott, of Pizarro, in Peru, shoeing his horses with silver and releasing the tortured Incas on promises to fill their cells with gold, reached the ears of other nations. In Spain at this time the horrors of the Inquisition raged supreme. No horrors of ancient Rome ever surpassed the tortures of the Spanish Inquisition. In the words of Lucretius: "Tantum Religio potuit suadere malorum", rendered into English verse: "Learn thou then to what damned deeds religion urges men". The enterprise of Spain attracted the notice of the Britons Drake, Hawkins, and Frobisher, who, though they be called buccaneers, were probably no worse than the Spaniards, whom they bespoiled. This led to the attempted invasion of Britain by the Spanish Armada, the result of which, under Drake's able seamanship, left England mistress of the sea, as far as Spain was concerned. The star of Britain, rising over the horizon as a sea power, now definitely took a place in European maritime commerce.

From this on, the defeat of the Dutch, the Napoleonic wars when the British fleet under Admiral Nelson shattered the combined fleets of France and Spain at Trafalgar in 1805 are matters of every-day history; but this event and the subsequent triumph of the British arms at Waterloo left the commerce of the world, won by war, at the feet of Great Britain. To hark back to our story. On $31^{\text {st }}$ December, 1599, Queen Elizabeth signed the charter of the great East 
India Company. To wrest this prize from the British Empire was the endeavour of Napoleon, but Nelson, sailing into the Bay of Aboukir in 1798, destroyed the French fleet; while shortly after the French army in Egypt was annihilated by Sir Ralph Abercrombie at the Battle of the Pyramids. Then the way to the East was clear. From hence on a new era in commerce rises, and a new epoch in civilization begins. While reflecting on the failure of Napoleon in his attempt to boycott Great Britain's trade with Europe, we must not forget that much of the trade and commerce of Great Britain was derived from France as far back as the massacre of St. Bartholomew. The operatives, mostly Huguenots, who were driven from their homes and country, found a place in Britain; and when Napoleon attempted to boycott British commerce from Europe, and even blotted Great Britain from the map of Europe, declaring British property lawful prize, the British Islands to be held in a state of blockade, the continent of Europe to hold no correspondence with nor to transact any business with Great Britain; when British manufactures and produce were declared contraband; when letters to and from the shores of Great Britain were to be kept and opened at the post offices, the traditions of France, if not the traditions of human nature, asserted themselves; and notwithstanding these decrees, White, in his history of France, says: "Artillery, horse, and infantry were always defeated when opposed to Napoleon's battalions, but printed ginghams were irresistible. There were conspiracies beyond the reach of his spies, in every parlour, where the daughters were dressed in coloured muslins; and cloths, cutlery, and earthenware were smuggled wherever a British vessel could float".

The traditions of France responded to the pre-eminent place in commerce that their exiles, the Huguenots, had given Great Britain, their adopted country, and the decrees of Napoleon, being without the pale of economic science, were frustrated by one, whom Max O’Rell calls “Her Royal Highness, Woman”. But the success of such commerce with France and Europe was due to the neversleeping vigilance of the British fleet. Lord Cornwallis, in the blockade of the English Channel, between Brest and Ports mouth, for two years never saw a green leaf or a tree. The sailors of the British Fleet were said to be web-footed, inasmuch as they had never been ashore for years. The great Nelson himself, though he was seasick nearly every day of his life, at one time never landed, and that for only an hour at a time, more than thrice in eighteen months. This indeed was a struggle for supremacy in commerce, if not for very existence, during the Napoleonic 
wars. Never was a struggle maintained with such determination and with such courage as was the fight for supremacy during the wars of 1789 to 1815 .

Often as a boy in Scotland I have asked, when looking at a house with several blind windows, "Why are those windows walled up?" The reply was: "There was in those days even a tax on windows to prosecute the war; and the people in Scotland being too poor to pay a tax on the four windows in that house, two were bricked up, and the tax paid on the two remaining. If the tax on these two had proved too much we should have remained in darkness". But still the struggle went on. During the Napoleonic wars, when Great Britain was fighting the greater part of Europe, and also at one time America as well, with a population of something under 14,000,000, it may be interesting to know that during that period the enlistments in the 42nd Highlanders (the Black Watch) totalled 70,000 men. I have no records of other regiments, but they must have been similar. This, it may be remarked, is not commerce; but it records the struggles and the determination of the rising and predominating power in commerce, Great Britain, to keep what she had attained. After the Battle of Waterloo all the world was at the feet of Great Britain. The road to the romantic, glorious, and historic East was hers by the prowess of her armies. and the vigilance of her naval administration. Before this a few years conflict had, it is true, been in evidence in India with France, under her able general, Dupleix. Here be it recorded the world has much to owe to France in civilization and in commerce, though this power had to give way in the routine of fate to Britain's power, not only in India, but also in America. We have much to thank France for in literature, in science, and also in war; and war has always been a most potent factor in establishing commerce in her true place over a dying and ofttimes a defunct civilization.

Having now arrived at the results of the events culminating in 1815 which placed Great Britain in the proud position of mistress of the seas, it might not be out of place to consider her heritage from past ages in the commerce and civilization of the world. As I have said, a new era arose after 1815 and a new arbiter in commerce wielded the sceptre. The mantle of past empires was cast on Great Britain. As heir to all the ages she inherited all that was to be known from Chaldea, Babylon, Greece, Rome, Egypt, and Arabia. Supreme in war, invincible in conquest by the power of individual effort, in the language of Homer, who described the ancient Egyptian Thebes, "She spread her conquests o'er a thousand 
States, and poured her heroes through a hundred gates". The great Empire of India became her vassal; a British subject is the Governor-General of India, and $300,000,000$ of people are now governed by their Emperor, the Kaisar-I-Hindh, our beloved and able King, Edward VII. The great Empire of China, the pearl of all price of the East India Company, who reckoned their trade with India far inferior to their trade with China, became, is now, and may it ever remain so, dominated by majority of influence and commerce by the Union Jack. From the Genoese, the Portuguese, the Venetians, and the Spaniards, all of whose efforts in commerce were turned on the fabulous and glorious East, Great Britain inherited all that these nations had acquired, thrown in her lap by the prowess in war of her fleets and battalions, and by the indomitable energy of her mercantile pioneers. The control of markets, which had rested with the Portuguese, Dutch, and Venetians, reverted to Great Britain. The consequent and subsequent control of the ebb and flow to and from the cast of the precious metals was vested in Lombard and Threadneedle Streets. Pliny has called the East "The sink of the precious metals". The same opinion is true to-day. We have now the same state of things as in Pliny's day, and what went on as regards interchange of gold and silver between East and West from the time of the Hittites, the ancient Egyptians and Arabians, and lastly of the Venetians, the Portuguese, and the Dutch, whose mantle has been cast on Great Britain, prevails now; but instead of Carchemish, Alexandria, Venice, Lisbon, or Antwerp being the centre where the intricacies of exchanges and arbitrages are settled, London is now the "drawing post" for the whole world.

But we must not overlook another factor in the foreign exchange history. A new element has arisen as a gold-producer in late years, and the importance of this new factor in the science of foreign exchanges is neither generally recognised nor acknowledged. Juvenal, the great Roman poet, said, "Rara avis in terris nigroque simillima cygno", and also "Felix ille tamen corvo quoque rarior albo". Now I do not know whether Juvenal ever saw a black swan or a white raven, but this we know, that our black swan exists, and records are existent that a white, or albino, raven has been known. Anyway, I am inclined to think that black swans were known of in Europe, probably by having been seen in Australia, and I prefer to believe that Australia and her inhabitants were known to Asia and Europe in remote times through commerce. I have seen accounts, for whose authenticity I do not vouch, of kangaroos and cassowaries having been seen in Spain in the 
middle ages, also of boomerangs in ancient Egypt. However, the "rara avis" I refer to is Australia. The black swan is the crest of at least one of her States, and Australia has entered the commerce of the world in no uncertain manner by her gold resources. To go into the intricacies of the foreign exchanges would be here too long. But I would say this: Australia now holds a very leading position in the science of the foreign exchanges throughout the world. Coupled with the Cape colonies she is also an immense producer of gold; and as the Cape has no mint at present, while Australia has three, and as India is an immense consumer of silver and Australia largely produces this metal, it will readily be understood by an expert what a powerful position Australia holds, properly directed, let me say, by capable men and not by irresponsible politicians, in the immense trade of the $900,000,000$ who constitute the population of the East, and who hoard gold in return for their inexhaustible products.

The science of the foreign exchanges is one of the most important factors in commercial economy. The proper understanding of this science, or ignorance of it, means the success or the failure of any commercial people. The science of the foreign exchanges is as firmly fixed and governed by laws as are the rise and fall of the tides or the laws of storms. Anyhow, Australia is so far a portion of the British Empire that she cannot afford to remain apart, if not from very dependence in every way on the Old Land, at least from her being part of the machinery upon which the old world's commerce and finance revolve and have their raison d'etre. But, with this notice of the large and overwhelming commerce of Great Britain, what must not be overlooked is the great impetus to research and learning given to the world, and consequently to its civilization, by the security ensured to all countries in research, in the East and Far East, under the Union Jack. The great and hitherto unknown (since the middle ages) classics of India and China were unlocked and again opened to the world by the scholarship of Sir William Jones, Colebrook, Burnouf, Pauthier, Langlois, Max Müller, and others. Also, in China especially, commerce provided the sinews of war necessary to translate the sacred books of Confucius and other Chinese sages, works which even now proclaim the sublime thought and almost divine philosophy of a hoary antiquity. Morrison wrote his "Dictionary of the Chinese Language", and printed it in 1824 at the East India Company's press at Macao. The funds to publish it were provided by that great commercial institution, the East India Company. Legge translated Confucius and was enabled to publish his works and give them to the world 
through the munificent generosity of the princely house of the Jardines, one of the greatest commercial stars that has arisen over the Eastern horizon. Commerce also produced, in China especially, a race of men who bear the proud position of second to none in the attainments of civilization, and who, by keeping their fingers on the pulse of every event passing in this wondrous land, by being past-masters in knowledge of the people, have kept British commerce in the far forefront above all other nations. How many delicate questions have been settled in consultation by the Home Government with these able scholars and silent workers for Great Britain, in her intricate dealings with China, no one will ever probably know. State secrets are secrets, but the names of Sir Henry Parkes, Sir Robert Hart, Sir Ernest Satow, Sir John Macleavy Brown, and Sir Pelham Warren will ever live in the annals of the Far East as pillars of strength created by commerce and handed down to posterity as monuments of civilization. All these great men I am proud to say I have known.

Even later, and quite lately, we have only to look at what has happened in Egypt under the gigantic intellect of one man, Lord Cromer. The chaos when he took the reins was the antipodes of the glory of ancient Egypt. Her population decimated by insurrection and tyranny, her trade stagnant, her laws conspicuous by their absence, the present state of Egypt is a matter to make one gasp in admiration, a name to conjure with, and a word carved on the Rock of Doom as the result of the united efforts of commerce and civilization. The greatest compliments I have ever seen paid to the British Civil Service were spoken by Americans and Russians. The American compliment was, that when brought into contact with the British Asiatic Civil servants all things paled before their ability. The Russian was, that when Sir Peter Lumsden's expedition to the Pamirs was undertaken to delimit the frontier, the Russians acknowledged themselves outclassed in talent-knowledge of detail and knowledge of language by the British officers. The popular theory is that the Russians are the best linguists in the world. I can only say they self-declared themselves beaten, and that by Sir Peter Lumsden and his staff. But the advance of civilization in Egypt under the able administration of the one man I have mentioned does not stop here. In ancient days the sway of Egypt extended from the Equator to the Mediterranean, and from the Red Sea to the Atlantic. The interior of this great country of Africa, the regions of Darfur and Kordofan, and the districts known as Lybia to the Romans, at one time civilized by them, and developed to such an extent as to warrant 
their long being called the Granary of Rome, are now being, after the strenuous ordeal of war, peacefully opened up by the sway of Britain under the Union Jack, throwing her influence and protection over Egypt. The lost civilizations of the ancient tribes and kingdoms in the Sudan and Nigeria are being revived under the energy of British commerce. In these lost and defunct kingdoms in the region of Nigeria and around Lake Chad evidences of a forward commercial organization and a high state of civilization are now being laid bare to the world. In Nigeria have been found advanced scientific methods of treating ores, of salt-works and the recovery of salt from the earth and from the waters, and also of languages made intelligent by an alphabet. All these were no doubt derived through Egypt from Arabia, but they survive, are being fostered and exploited by the British Empire under her newly-acquired protectorate, Nigeria. On the British has fallen, even here, the mantle of all previous nations, and what has lain dormant and unproductive for centuries is now being developed by our Empire. Population is being increased owing to the suppression of the slave trade, and what was once called the Granary of Rome may in time to come be called the Granary of Britain. From our Eastern African port, Mombasa, by the Uganda railway, to the sources of the Nile, the country is being opened up to the cultivation of cotton and other tropical products; and as raw cotton is one of Great Britain's greatest importations for manufacturing purposes, for which she is largely dependent upon America, it would be the irony of fate if in the future America should buy her cotton from Africa, where she formerly seized her slaves for the cultivation of the cottonfields of her Southern States. Such is one result of the domination by war, the subsequent extension of commerce, and the consequent rise of civilization in Africa, hitherto known as the Dark Continent, under the British flag.

In this the first decade of the twentieth century we have before us, as it were, the concentration of all the previous knowledge of bygone ages, and the vast and searching investigations of science all combine to make the struggle for existence most keen and exhausting. In the daily avocations of the world, whether in commerce, in science, in literature, or in surgery, the demand is exacting, and the new discoveries in all of these branches call forth on all sides fresh incentives and caterers for the supply. The problem in all classes or professions is now how to adjust the supply, already over abundant, to the demand. The professions are over-crowded, and, though the prizes may be great and few, the blanks are many and the list of failures is long. In these days anyone engaged in profession or 
trade has to keep pace with the times in everything bearing on his calling. The successful or rising man has to know everything to keep his place. The struggling unsuccessful majority - it may be superior to the successful minority - is wasted by the contest in endeavouring to fill the demand from an over-abundant supply. Fashions change, new ideas prevail, and the race for existence goes on with unchanged severity. Every nerve is taxed to meet the strain, and, should the human machinery give way, the ingenuity of medicine and the developments of surgery are present to supply the deficiency and repair the broken-down system. The demand for scientific treatment of complaints and disorders has, during the past fifty years, brought out competition for supply which is simply astounding. The advance of surgery and appliances during the Victorian era is marvellous. Strange as it may seem, the very changed habits of every-day life and the daily avocations in this new scientific world evolve complaints previously unknown, whose demand for treatment calls forth in the supply the greatest wonders of human ingenuity and sagacity. The effects of over-education, or high education, promote a species of nervous disorders, which call forth the efforts of science to adjust, on the inhabitants of our day.

The present state of Europe is that of a slumbering volcano, which may at any moment break forth into an eruption which will convulse humanity. The entire position is the outcome of long intervals of peace, the cultivation of progress in all its branches of science, colonization, and national development. Distrust and want of confidence have engendered a deplorable issue, and with the growth of education and development an unfortunate element of social unrest has arisen which bids fair to blast the prospects and arrest the progress of civilization. Viewing the events in Europe during the last fifty years, with the growth of anarchy, socialism, and nihilism, we may well wonder whether we have not taken a cast back to the horrors and darkness of the middle ages, and whether all our progress and civilization, as contrasted with that of the middle ages, can have anything to boast of. There has been no demand for it, but unfortunately there has arisen a supply of promoters of discontent and annihilation which is a satire on the philanthropy and liberal ideas of the twentieth century. With these elements and these ideas prevailing amongst all classes, is it any wonder that there should be a want of confidence and an apprehension throughout the world as to the outcome? There is no demand for fresh enterprise, there is no speculation or energy for new undertakings where the capital of the thrifty is 
brought into jeopardy by the crude, wrong-minded, impudent, and mischievous doctrines of the levellers who have nothing to lose and who would spoil the possessions of those by whose enterprise and intellect they exist. This is the state of things at the present moment as regards the supply of capital and the demands of labour. The whole world is convulsed and paralysed by the mania from which no country is exempt, and which threatens to end in a revolution, the outcome of which will, if our position in the twentieth century be one of progress, initiate a base and degraded course in the progress of this cycle. It would seem as if in the so-called growth and progress of education and liberal ideas all that is to be revered and traditional in our minds is to be swamped by the irreverent and irresponsible The worst feature is that the demand for intellect exceeds the supply in the conduct of the world's affairs. The inertia begotten of luxury and life made easy is throwing the control into other and less scrupulous hands. Maine, in his "Ancient Law," says: "In spite of overwhelming evidence it is most difficult for a citizen of Western Europe to bring thoroughly home to himself the truth that the civilization which surrounds him is a rare exception in the history of the world. It is indisputable that much of the greatest part of mankind has never shown a particle of desire that its civil institutions should be improved since the moment when external completeness was first given to them by the embodiment of some permanent record. One set of usages has occasionally been violently over thrown and superseded by another; here and there a primitive code, "pretending to be of supernatural origin," has been greatly extended and distorted into the most surprising forms by the perversity of sacerdotal commentators; but, except in a small section of the world, there has been nothing like the gradual amelioration of a legal system. There has been a material civilization, but, instead of the civilization expanding the law, the law has limited the civilization. It may also be remarked that the stationary condition of the human race is the rule, the progressive the exception." This may or may not be a true estimate, but it is none the less true and sad that the greatest commercial organizations the world has seen have led up to highly cultured systems of civilization, again to fall away through what I must call the era of theories and fads which have been the wreck of so many nations. It was the wealth accumulated through commerce which promoted highly graded civilizations which in their turn promoted socialistic and dangerous theories which brought about the fall of Babylon, Egypt, Rome. Greece, Carthage, Arabia, and in modern times Spain and Portugal, and from 
within these Empires their own people were those who hastened their downfall. Gibbon says that one of the causes of the downfall of Greece was the hostility of the people of Athens to outside nations. Their social state, or in other words their civilization, had become inert, aggressive, provocative of retaliation. The same must be recorded of all other ancient and some modern nations. Now, in our great British Empire, the greatest the world has ever acknowledged, with her dependencies extending to every part of the globe, her hand directing through her commerce every movement of finance, the writing is on the wall indicating trouble created from within. In time the pre-eminent position of this great Empire will be challenged. It will not be the fleets and armies of other nations that will strike the first blow. It will be by what Maine calls the law stopping civilization. We see daily the accounts published of the treatment of our own and the subjects of other Asiatic nations by sections of our colonial empire. As this was the cause of the downfall of Greece, it may be the beginning of the downfall of our empire. Should the pernicious doctrines and theoretical fads of a large and increasing body of members of the British Empire succeed, legislation may be carried by them in the parliament of Great Britain, and the overthrow of our vast empire may follow. As the barbarians from without overthrew Rome, the barbarians from within may do the same for Great Britain. We have only to look at what is going on in India, where our commerce, our science, our able government have controlled for good a mighty Empire. We see the apostles of unrest busy, and I cannot overlook the fact, as I believe it, that these agitators are upheld in their beliefs by the pernicious utterings and the unbridled licence of a section of the press. This is what Count Okuma, a Japanese, says on the subject: "from ancient times onwards, the realm of India was attacked or subjugated (many a time) by a foreign foe, and then, being invaded by Spain, Portugal, France, and Great Britain, the destruction of its immense riches and the degradation of its industry, arts, and literature were completed. And who is answerable for all this? I say it was not any of these aggressors, but India herself, that annihilated the realm".

Count Okuma also goes on to say: "In Japan Buddhism has assumed a very different shape from its prototype ill India, having undergone a careful process of purification. When it was first introduced from India through China it was intermingled with great evils, of which we contrived ingeniously to purge it so as to extract its healthiest essence, and as a consequence it is still exercising a great influence on our social life. On the contrary, India, Turkey, Persia, Siam, 
and most other countries have more or less suffered from religious poisoning. Thanks to our peculiarity of subjecting every exotic thing to a refining process, we Japanese turned to account the Indian and the Chinese Buddhism by applying it to our customs and spiritual culture. Again, fifty years ago we came into contact with the influence of the West, and, when once we became aware of our own inferior points and errors, we promptly appropriated the excellences of others and assimilated them. Far from being satisfied with the present state of things, the Japanese, every time they turn their eyes to the world, itch to avail themselves of any superior points of other nations, and that is the reason why they have sprung up so suddenly".

In these references to religion and comparison with Western ideas of their own customs and civilization Count Okuma indicates the spirit of inquiry, or it may be called the apostle of unrest, begotten in the Japanese breast by the contact created by commerce with Western nations and their ideas. It is a singular and interesting thing to witness the return of the cycle of thought from East to West, where the East enquires of the West for whatever is good in her philosophy, whence in earlier times the West derived all that she holds most sacred in learning and knowledge. But we cannot put Japan on a level with China in ancient civilization. Japan acknowledges her tribute to India and China for her Buddhist religion, and some centuries ago Japan adopted the Chinese written language as her own. No such classics survive in Japan, at least to my knowledge, which will compare with those of China. Indeed, many of the arts and sciences of Japan in ancient times were derived from and adopted from China. Japan has during the last fifty years since her latest contact with Western civilization always been of an acquisitive and enquiring mind. Count Okuma has, as I have stated above, referred to the examination by Japanese theologians of Western religious systems. I would just like to record a most interesting incident that occurred to myself in Japan on this very point. In 1878 I was in Kyoto, the ancient capital of Japan, in company with a friend who was an apt Japanese scholar and spoke the language fluently. We were in one of the greatest Buddhist temples in Kyoto; hundreds of Buddhist monks thronged the great area of the temple, dressed in surplices and hoods of various colours, purple, yellow, blue, and lilac, denoting their various ranks. My companion and I paused beside one of the great wooden pillars which supported the large roof of the great Temple of Honganchi. My companion said, "I must go and enquire of one of these priests if any can show us or tell us 
something about this temple." Judge our surprise when a priest stepped from behind the pillar, and said in the most polished and courteous English, "I think, sir, I heard you remark that you would desire to see someone who could show you over this temple. Allow me to conduct you." He showed us all, even to the Holiest of Holies. My friend then asked him, "You speak English well; may I ask how you acquired it?" The priest replied, "Yes, I am one of those sent by the Emperor to Europe to enquire into western religions and civilization, and to discover a new religion. I speak equally well, as you have heard me speak English, French, German, Italian, and Spanish. I have returned from Europe undecided”. From this I deduce exactly what Count Okuma has said above: the Japanese priests have adhered to the Buddhist religion, probably, as he has said, in its original form, sifted out.

I come now to consider the effect of commerce on our own land, Australia. Australia has acquired her territory under the aegis of the Union Jack, and that cheaply and without contest. The great motherland flag, fluttering over this great island - or continent, shall I call it - ensures peace and prosperity to her inhabitants. No other country in the world enjoys such freedom, without preliminary expense in blood and treasure, as does this land of Australia. The great mother country is lenient with her fair daughter in her woman-like perverse moods. She lends her money, she shields her with her sheltering arm, and she allows her such freedom and protection as no other community in history on record has ever enjoyed. Her far-seeing, broad-minded statesmanship has ever been on the side of toleration and aid. The people of Australia in their traditions, at present anyhow, look back to the Old Country as the land that gave them birth. 'The commerce of the Old Country has initiated the commerce of Australia. The call to arms in Australia has been responded to for the support of the commerce of the Empire; and may I hope that when again the Empire calls, Australia will not be the last to respond? But there are rifts in the lute. The present legislation of Australia is baneful in its effects on the commerce of the Old Country, which protects Australian commerce. Even by the present Liberal-Radical Parliament of Great Britain statements have been made that, if the British navy protects Australia and Australian commerce, the least British shipping should expect is to be exempt from the harassing effects of the Navigation Act lately passed in Australia. It is too serious to contemplate, but suppose, for instance, the protection of the British fleet were withdrawn from Australia. What would then happen, if left to our own resources, might stagger 
humanity. Australia at present, as regards a certain class of the community, is suffering from a surfeit of pseudo-prosperity. The condition of the labour classes is, not through oppression, but from its antithesis, in almost a state of revolt against law and order. There seems to be a want of reverence in the Australian character. To quote Lecky: "Reverence is one of those feelings which, in utilitarian systems, would occupy at best a very ambiguous position. Yet there are few persons who are not conscious that no character can attain a supreme degree of excellence in which a reverential spirit is wanting. Of all the forms of moral goodness it is that to which the epithet "beautiful" may be most emphatically applied. Yet the habits of advancing civilization are, if I mistake not, on the whole inimical to its growth. For the reverence grows out of a sense of constant dependence. Every great change, either of belief or of circumstances, brings with it a change of emotions. The self-assertion of liberty, the levelling of democracy, the dissecting knife of criticism, the economical revolutions that reduce the relations of classes to simple contracts, the agglomeration of population, and the facilities of locomotion that sever so many ancient ties are all incompatible with the type of virtue which existed before the power of tradition was broken, and when the chastity of faith was yet unstained. Benevolence, uprightness, enterprise, intellectual honesty, a love of freedom, and a hatred of superstition are multiplying around us; but we look in vain for that most beautiful character of the past, so distrustful of self and so trustful of others, so rich in self-denial and modesty, so simple, so earnest, and so devout, which, even when, Ixion-like, it bestowed its affections upon a cloud, made its very illusions the source of some of the purest virtues of our nature. Its most beautiful displays are not in nations like the Americans or the modern French, who have thrown themselves most fully into the tendencies of this age, but rather in secluded regions, like Styria or the Tyrol. Its artistic expression is found in no work of modern genius, but in the mediaeval cathedral, which, mellowed but not impaired by time, still gazes on us in its deathless beauty through the centuries of the past."

Now, in the days of our old land, when constant struggles for existence promoted a spirit of individual effort - not dependence, but a character for independence - these qualities seem to be decading, not only in Australia, but also in the old land. The great prosperity in Great Britain in the last two generations has engendered in the present era an effeteness and dependence on others. The wealth of the erudite and ably commercial father, acquired by brain- 
power and daily toil, has, in Great Britain, come down to the sons, who, without the strenuous ordeal of individual effort, have in many cases relapsed into the ease begotten of bequeathed affluence and luxury. The same, to a certain extent, is true in Australia, though I must say that State aid to education is, I believe, having a most baneful effect on this country, through its indiscriminate favours, and especially so on the individual. The great principle of individual effort is being suppressed. There is an old saying, "There shall be hewers of wood and drawers of water". Such is the present constitution of this world that the hewers of wood and the drawers of water are constantly in conflict with the more suitable and better adapted classes, through a malign system of nepotism. The decay of independence, self-reliance, and individual effort is one of the things which are tending to sap our national greatness. I may say here that when I was a student at Glasgow University, some forty years ago, I saw and knew men who were my fellow-students who studied during the winter months at Glasgow. To acquire the means to prosecute their studies these men during the summer months in Scotland, or may be in Ireland or England, drove the plough, herded sheep, and worked in coal mines. I have kept some in view, and to their lasting credit and to the glory of the traditional grit of their country some now occupy the highest positions of trust and confidence, not only in their own land but also in other countries.

This condition of independence in these matters I would like to see adopted in Australia. There is, to my mind, too much "spoon-fed" education in Australia, where the youth of both sexes are educated - save the word - at the free schools at the expense of the taxpayer. I am sorry to say, but I am afraid it is true - at least it seems to me so from my humble observation - that hundreds of youths are annually let loose on the great towns, such as Sydney, and it may be in other cities, with a certain amount of rudimentary conglomerated knowledge absolutely useless to themselves or to any employer of their services. Such is the condition of their surroundings that they are absolutely without reverence for anything, and are quite unamenable to any kind of discipline. The result is, having no home restraint nor paternal guidance, they are quite unfitted for any employment whatever when they have to abide by prescribed rules and regulations. To meet this state of things in Sydney - and I speak of Sydney as the city I know most about in Australia - the Chamber of Commerce has instituted a course of instruction for youths and invited them to attend lectures and other 
media of acquiring commercial information. Also, going further than this, the Institute of Bankers of New South Wales, which has silently, steadily, and successfully progressed during the last eighteen years in everything pertaining to the better intelligence of the youth in the banking community, for some years past has organized a system of examinations for youths who wish to enter banks as clerks. I know of one great bank in Sydney, and I believe there are others also, which declines to receive amongst its ranks any tyro who has not passed the prescribed matriculation examination at the Institute of Bankers of New South Wales. The incidence of this must be manifest to all who know what it means to have even a subordinate who has at least some idea of what he has to do. The promiscuous state aid to education may be all very well, but at the best it only exemplifies what the French call un embarras des richesses. Personally, though I may be put down as prejudiced and harsh, I would like to see less dependence on the State in matters of education: I would like to see more love for knowledge for its own sake, more reverence for what has gone before us, more real desire to be acquainted and conversant with our great antecedents, among the youth of the Commonwealth. I should like to see more responsibility laid on the heads of families to educate their youth at their own expense in all the reverence and appreciation of the past, present, and future, following in the footsteps of their great forefathers, from whom they inherit this vast free-given Commonwealth of Australia. These are my own opinions, good or bad. I am in favour of all encouragement being extended and prosecuted, and opportunity given, at a small expense to the individual, towards making the youth of this country capable of grappling with their great future. In time to come, and it may not be in my time, probably not in the time of our children, this great continent of Australia, with its predominant position on the shores of the Pacific, will enter the arena of the Pacific Ocean, along with the countries on its shores, in the battle for existence and self-preservation. On the shores of this great ocean countries numbering in population probably half the inhabitants of the globe exist, have their being and their raison d'etre. To meet the wants of the case, and to enable the youth, and the ever-recurring youth, who will in future call Australia their mother country, to cope with a situation which will present itself in no uncertain attitude in coming years, I would earnestly advocate the establishment and the endowment in all our universities of chairs of commerce. The "Joseph Fisher" lectures in your honourable University have already struck the key-note of what I would desire. I would go further and advocate the establishment of chairs and professorships 
of Oriental languages in the universities of Australia. The study of ancient and modern Oriental languages and literature will fit the youth in this country to be in the running with what will, and must, come from the future expansion of Australia. As Roosevelt has said, "Every country is now our neighbour." This will be true as regards Australia in the remote if not in the near future. Not that I am an advocate of the meaningless phrase "The Yellow Peril": I know Asia better than that. But when our Australian commercial community is educated thoroughly to understand, appreciate, and respect the great civilized nations of Asia, from whom most, if not all, of our civilization has been derived, then may commerce and civilization go hand in hand, and may it be said about Australia that she has derived "Ex Oriente lux". May her desire be to merit a motto engraved on her national history, similar to that on the memorial tablet to Sir Christopher Wren in St. Paul's, "Si monumentum quaeris circumspice".

In conclusion, Mr. Chancellor, ladies and gentlemen, seeing that I have advocated in my paper the establishment of chairs for Oriental languages in Australian universities, may I, as a tribute to the patient hearing you have given me to-night, in the Oriental language I know best, the Chinese, say: "Sun hong sun tsui-tiong siong". The characters for these words are inscribed on the sterns of all Chinese sea-going vessels. Literally translated they mean: "A fair wind and a fair tide, very high and overflowing always". In other words: "May your course be onward and your path smooth for ever". This wish I respectfully tender to the University of Adelaide.

In the course of my paper I have to acknowledge tribute to the following authors:

Max Müller's Chips from a German workshop, and Essays on language, religion, and thought.

Lecky's History of European morals.

S. Laing's Human origins: patterns of the future.

Lady Lugard's On Nigeria.

Shaw's History of currency.

Delmar's History of monetary systems. 
Maine's Ancient law.

Langlois's Sacred books of the east (in French).

Griffiths's The Mikado's Empire, and Korea, the Hermit Nation.

The Latin, Greek, French, and German authors whom I have quoted, also the Chinese classics, to all of the foregoing, in the original or in translation, I respectfully tender my obligations. 



\section{4}

\section{Banking as a factor in the development of trade and commerce}

\section{J. Russell French ${ }^{1}$}

Before I commence this lecture which I have undertaken to deliver tonight, I would like to thank you for the kind reception you have given me. It is quite true, as the Chairman said, that I came straight through from Sydney to deliver this lecture, but I feel that perhaps my knowledge and acquaintance of the subject may be of some value and use to the students of this University. When the authorities of the Adelaide University ask me to give the Joseph Fisher lecture on a commercial subject for this year, however, I felt some diffidence in undertaking such a task, because I recognise that it is one thing to be classed among the ranks of those who are viewed as experts in commerce and financial matters, and quite another thing to consolidate and crystallise that knowledge as it were, and place it before an audience of students so that they may derive some benefit from it in their studies.

The subject I have chosen for to-night's lecture is the relation which exists between Commerce and Banking, and the extent to which the latter has acted as a developing factor in connection with the former. They are by no means the same thing. Banking is one thing and trade and commerce and their operations are quite another, and I hope to show you, or I expect to show you as I go along that although banking and commerce are indissolubly connected, nevertheless there is an essential difference between trader, or the commercial man. I suppose you will expect me in a lecture of this kind to define what I mean by banking, and the ground that I propose to cover in connection with trade and commerce.

1 Fourth Joseph Fisher Lecture, 29 April 1910. 
In its modern conception - and I propose really now to define the term "bank" as we view it in these modern days - a bank is an organisation or an institution having usually a definite status by authorisation of a Parliament or other ruling authority of domicile. It is owned by a greater or less number of shareholders. They are the owners of the bank the proprietors who contribute the joint stock or capital, and it is a generally conceded principle underlying the whole concern that this capital should represent a due proportion of the liability engagements the bank undertakes. That, I think, is an essential principle of all modern balancing - that there shall be a due proportion of shareholders' capital to the business which the bank undertakes. If it merely traded on its own capital it would not be a bank as we now recognise a bank, but a loan company. It is created for the purpose of supplementing that capital by taking deposits; that is to say, gathering in the floating capital of the country, which would otherwise for the most part remain dormant - useless from a financial point of view. It has also been further recognised in many countries that the function of issuing notes on the credit of the bank is a natural feature of its business. Thus you will find the institution as a rule referred to in legal terms as carrying on the business of a bank of issue and deposit in the first place, and then follows as a necessary consequence the lending of money on bills of exchange and other securities. I have not been able to verify the fact as applied to all countries where banks are established, but in the English speaking countries at any rate, banks, as now constituted, are forbidden to trade. That is an important factor in connection with banks. They are not traders. You will see that this was so in the case of the Bank of England, established as long ago as 1694, when I refer to that institution a little later on. The reason in brief is that the banker's resources, being largely derived from the public on the strength of his capital, it is not desirable as a matter of principle that he should embark those resources in trade. He reserves those deposits and issues those notes in a quasifiduciary position. It is quite true that the legal position is not fiduciary. The legal position is that of an ordinary debtor and creditor. He makes his advances and there, is where his connection with trade comes in, and he performs other operations in that way in connection with trade and commerce. He is always supposed to have as a buffer, the trader's capital between himself and loss, so, that while the trader risks his own capital the banker on the other hand has the trader's capital to stand between himself and a loss. I think you will realise the distinction. It is a very clear and well known principle in connection with banking business. 
In its scientific aspect banking is, as you are aware, a branch of science and economics. Economics, of course, covers a very wide field, and banking must be reckoned as a branch of that science. As now developed it has taken its place among the highly organised parts which go to make up the vast and intricate machinery by means of which the enormous volume of modern trade is carried on. With regard to trade and commerce, with which I am going to associate banking, the ground which I propose to cover is perhaps a wider one than would be admitted by some at any rate, of the political economists. I consider that I am entitled to take the widest view of trade and commerce, and particularly when I come to apply it to a country such as Australia. In its narrow sense, of course, commerce is an exchange of articles between one country and another, or between one individual and another, but I am going to apply it to all business which issues from the production and manufacture as well as the distribution of the articles relating to the country with which they are concerned. So that you see I propose to take a wider view of trade and commerce altogether. It is worth while to devote a little time to a study of banking history, so that we may arrive at some idea of the steps by which modern banking development has been reached, and thereby gain some insight into how far banking has operated as a factor in connection with trade and commerce. If you study the commercial history of England and her dependencies you will find that among English people, banking, even in its elementary stage, did not make its appearance on the stage of national history till quite a comparatively recent period. It is true that the trade and commerce of our empire was a very small thing indeed until comparatively recent times. No one except a student of commercial history realises how very small the trade and commerce of Great Britain was, within, perhaps, the last 100 or 150 years. But nevertheless it had reached very considerable dimensions before the idea took root that its operations might be very largely assisted by the gathering together of the stores of money held by the people of the country, and put away in such places of safety as their ingenuity could devise, or of diverting those resources and putting them into trustworthy hands by way of deposits whereby they could be utilised in the shape of loans and advances in furtherance of trade - in other words by supplying traders with resources in addition to their own capital. That is the science of banking - the gathering up of the dormant resources of a country and making them valuable for purposes of trade or business. As one French writer puts it:" Banks exist to make capital circulate, and not to lock it up." That is the 
Frenchman's way of putting it in a very terse form. Long before England took up the idea there had been a considerable development of banking in the Italian States. The Latin races no doubt are quicker to grasp ideas than the slower moving Teutonic people, and as we know there was a very active trade done by the various Italian States within the Mediterranean and beyond it.

One writer on banking says that Italy is the native country of banks and adduces as evidence the acceptance of Italian terms among bankers. However this may be, we must, on general evidence, concede priority of origin so far as Europe is concerned to Italy. Very naturally, knowing what we do of the history of Venice, we would expect to find some of the earliest bankers in that enterprising State, and it is believed among banking historians that the bank of Venice (or the Bank of St. Mark's as it is more generally referred to) is the very oldest of such institutions, that is to say of anything which by any possibility we could term a bank. The Italian banking of those days, as you will find when I refer to English banking to have been the case in England itself, was identified to a large extent with the Government operations of the various States in which the banks were domiciled. The Bank of Venice itself had its origin in a sort of forced loan made by the governing power upon Venetians of the opulent classes, who were granted certain privileges and favours which enabled them to establish the nucleus of the banking business. For favours granted by them to the States they received favour in the way of rights and privileges which were of great use to them in their business. We may accept it as a fact that they were important factors in the commercial activity which characterised the Italian States in the $15^{\text {th }}$ and $16^{\text {th }}$ centuries. You will see that there was a very considerable trading activity in those Italian States of which Venice was the most important, perhaps, in regard to the trade in the Mediterranean and beyond, and there is no doubt that these banks were very important factors in making and furthering that trade and commerce. To some extent I am afraid they did not carry out the modern idea that banks are not to be traders. When all is said however, the bank of the Italians was a very elementary affair when we come to compare it with its modern development. I would not be quite fair if did not mention that among the early banks preceding of the England by some years there was a bank in Amsterdam, and it was a peculiar instance to us in these days of how a bank might take its rise. The coinage of Holland was becoming valueless by reason of wear and tear, and it was thought a good plan to institute 
a bank to take over this coinage at its face value, and in consideration thereof received certain rights and privileges. In those days people were not anxious to look into principles and some enormous profits were made by corporations and institutions. It was peculiar that the bank should be started by taking over the worn coinage of the State. They were, however, as I have said, an elementary affair when we come to compare them, and other early banks, with the modern development of banking.

Turning to England, our mother country, you can date back the history of banks to the Stuart times, say in the $17^{\text {th }}$ century, and the period immediately succeeding that. Suppose we say 250 years ago. We may concede to the London Goldsmiths the honour of being the forerunners of our English banking system, and it would seem as if the circumstances of the time - that stormy period of English history which is covered by the Stuart reigns, almost forced them into the position against their will. There is some evidence of this at any rate. Their own occupation, involving the possession of valuable articles in a small compass, compelled them to provide themselves with the safest possible places for their safekeeping. It was quite a natural course for those who had similar valuables, and particularly money, and whose occupation led them into very precarious situations, to ask the Goldsmiths to take charge of those valuables. At first the deposits were clearly by way of safe custody. At least that is so far as I can gather. Not a banking operation at all, but this was only a short step to accepting the money on deposit in the way we mean, and which could be utilised by the person with whom deposited. Generally speaking, it became a loan, and that position was very early recognised. Most frequently no interest was paid to the depositor, but sometimes the deposits carried interest. The Goldsmiths, or private bankers, used the funds so supplied in discounting mercantile paper, but as yet such paper did not exist in any great quantity, and their operations for the most part were confined to ordinary loan transactions to individuals, and more particularly to the needy monarchs who ruled England at that time. Macleod, in his " History of Banking in England," says that banking in the modern sense of the term arose in the rapacity of Kings, and there is good evidence that the evolution of the banker, as distinct from the mere moneylender, was due in a large degree to the stimulus given by political demands.

But I think the banker was coming all the time, and that his evolution was, I may say, a necessary accompaniment to the development of trade and commerce 
in itself. By and by I will show you how this is a necessary factor in the position that the banker follows the trader. Trade follows the flag, and the banker follows the trader. The Goldsmiths under took what was at the time a dangerous and enormous responsibility in accepting the money of the people, and we can look back on them with the utmost respect and admiration. The first distinct attempt made to reduce banking to a definite system was the establishment of the Bank of England - the mother of us all. I mean of all banks, of course, (Laughter). "The Old Lady in Threadneedle Street" as she is whimsically but affectionately termed. Here again we have the political factor coming in. The creation of the bank of England was due wholly and solely, as you know, to political exigencies. The Statute which incorporated the Bank of England in 1694, provided for certain duties on ships and spirituous liquors being hypothecated by Parliament to secure an advance of $£ 1,500,000$ towards carrying on the war with France. Just think of that for one moment. What would the Chancellor of the Exchequer say now? Truly a remarkable beginning for an institution which has since become a vital factor in connection with the trade and commerce of the British Empire. The persons subscribing the sum mentioned were thereupon incorporated as a bank. This corporation was not - and here is where we get the beginning of that idea - to engage in any direct trade operations whatsoever. They were not to buy or sell goods, but they were allowed to buy bills of exchange, which of course is a banking operation in connection with mercantile affairs. Those bills of exchange were ordinary mercantile paper of the day. They were also permitted to buy bullion - gold or silver. Likewise they were permitted to advance money on documents of title to merchandise of various kinds. The Goldsmiths were as much traders as bankers. The Bank of England was not to trade, and this characteristic has been preserved in all modern banking developments, the reason being, as I have outlined, that the banker is in a more or less fiduciary position in respect to his creditor. It is held to be a sound principle of banking that it shall not be exposed to trade risks, which must be greater than the risks involved in lending to those who are engaged in trade. In the latter case it is the bank's duty preserve a margin of security so that he may protect against a loss. The liberty to purchase gold or silver perhaps to some extent an inheritance from the Goldsmiths' bankers. It was a reasonable thing for an institution whose province was to deal in the money market to be able to acquire that, which was then, and still is, the basis of our currency and the basis of our financial system. That, no doubt, is the true 
economical or philosophical reason, as the case may be, because it must not be supposed that banking is merely rule of thumb, or has grown up anyhow.

As this is not a lecture on the bank of England I do not purpose to set down its various vicissitudes. For a long time its business was comparatively small. It supplemented its resources by taking deposits and issuing notes. There was for a time no great call for its energy. Trade was as yet of very small dimensions. It met all the requirements of the London business community. The beginning of the $18^{\text {th }}$ century was remarkable for an era of speculation, notably the wild scheme known as the South Sea Bubble. This no doubt originated in a trade idea. We all know what came of the South Sea Bubble, and it is not very remarkable, so great was the public excitement at the time, that the Bank of England at first, to some extent assisted in the promotion of that bubble. But they ultimately withdrew before they burnt their fingers too much. It caused them some trouble, however, to do so, and even the intervention of the Government of the day to get them clear of complications.

To come to the present time. The Bank of England now occupies a unique position in connection with the trade and commerce of the country, and its influence is very wide spread. It even extends to Australia. I am anticipating to some extent my remarks which I shall have to make with reference to other banks, both private and joint stock, which have played their part in the development of the trade and commerce of England. I mention them now because one of the most important features in connection with the modern Bank of England is that it is a banker's bank. It holds the reserves of the principal banks in the country. Without going too lengthily into the matter tonight it would be impossible to adequately describe the position to you, but you are all probably more or less aware that the Bank of England has to all intents and purposes a monopoly of the note circulation of England, not of the British Isles, however, for Scotland and Ireland are on a different footing. By an Act of Parliament known as Sir Robert Peel's Act this as separated from the ordinary banking departments of the institution. In virtue of this arrangement the bank is allowed to issue notes, in the first place, against a fixed amount of British Government Stock, which is practically an extension of the first loan of $£ 1,500,000$. The remainder of the issue must have sovereigns or bullion of an equal value of all the notes issued. Of 
that sum $£ 15,000,000$ is invested in Government stock. The Bank of England has come to be the custodian of the banking reserves, and it is because of this position that it occupies and fills such an important position in the trading interests of England herself. The whole banking system of England rests with the Bank of England. It is the banker's bank, where most of the banks in England keep their reserves, and it is because of their responsibility in connection with the note issue - which is really at the bottom of all the reserves - and because of the responsibility of the banker's balances which they keep, they have to take great care to keep a very large reserve of coin. In a nutshell that is the position.

So far as their influence on trade is concerned they, of course, take their part in providing the accommodation required to carry on the commercial business of the country. They discount bills just as other banks do, although to a limited extent, indeed, compared with their importance as the banker's bank. But in respect to their banking department they do not carry on a very much larger business than some others of the great banking establishments in the City. You will be surprised, I think, later on to hear what proportion of business the Bank of England, as a Bank does. Where its influence is really felt is in the fact that it practically controls the banking reserves of the country. It will not be difficult to realise that a contraction or expansion of the resources of such an institution, occupying such a position, must be an enormous factor in determining from time to time the relation of trade, and you may be sure that the figures of the bank reserve, that is to say, what it has got in hand as the basis of the business operations of the country they are published every week - are scanned very closely by all who have any connection whatever with trade - the merchant and large trader, even the retailer. In consequence of this position the reserves of the bank are liable to fluctuate from various causes which are not otherwise easy to follow. In justice to trade I must say that these fluctuations do not always arise from any incident in connection therewith. The operations in connection with foreign loans and other international matters connected with what are known as the "higher finance" may affect the reserve and often do, but whatever the - cause and I certainly cannot be expected to go into those causes - the fact remains that the expedient which has been devised to adjust a falling off in the resources of the Bank of England, naturally has an effect on the trading of the public. The method adopted is to raise the bank rate. This automatically has the effect of raising the rate for accommodation all round and experience so far has shown 
that by this device, gold, which is the basis of the reserve, flows in from other countries. The margin of profit in gold operations - that is, the buying and selling of the metal - is not large, and usually a moderate rise in the bank rate effects the purpose of steadying the reserve, at any rate. But sometimes the conditions will not be satisfied with anything but a very material rise in the rate and you will well understand, therefore, that the Bank of England in the capacity of the custodian of the reserves of the country is a very great factor in connection with trade and commerce.

As I have said before this is not a lecture on the Bank of England and therefore I will conclude my remarks in that respect by giving it as my opinion, which I share with a good many other bankers, that it will be to the advantage of English trade, using the term in its limited sense, if some scheme can be devised whereby the metallic reserves of the country are placed on a more scientific and reliable basis. The expedient of a rise in the bank rate may not always work to restore the equilibrium of reserves, on which, virtually, the trade of the country depends, and the volume of that trade now is so enormous that it is not reasonable to allow it to depend upon anything but a very solid foundation. The nature of the business transacted by the Bank of England, and its connection with various Government operations, to some extent limited its scope as compared with what it might have been if it had been a bank working on purely mercantile lines. Hence the banking necessities of the country had to be met from some other source and those were provided in the first instance by various private bankers, some of them in London and some in the country. Thus we have a connecting link, as it were, between the original Goldsmiths and the more modern joint stock bank, to which I will refer immediately. They served all the purposes of bankers so hr as the trade of the country required, and though lacking in some of the essentials which we look for in a modern bank, they were, on the whole, trustworthy gatherers of the floating capital of the country into a more concentrated form in the $18^{\text {th }}$ and $19^{\text {th }}$ centuries. Those institutions have played their part and the fate of almost all of them has been to be absorbed in the joint stock banks whose growth has been so phenomenal during the last few decades. Statistics and historical records of those private banks are hard to obtain. Being private banks they were not required to publish a balance sheet, though under some regulation as to their note issue, and we can now leave them as an unimportant factor in connection with the commercial development of England. We now come to the joint stock bank. For 
a long time the influence of the Bank of England militated against joint stock banking in England, but the expansion in trade which followed on the settlement which brought about the termination of the long European war in 1815, and the industrial development which soon began to make itself felt by the introduction of machinery into manufactures and so forth, all combined to influence those who were connected with trade to cast about for other methods which would increase the facilities for carrying on operations. The Bank of England was very well. But it was semi-political, and confined its operations to a limited and probably very choice sphere. The private banks were also very well, but for one thing their capital was not large and, for another, when trade gets beyond a certain stage those who conduct it are prone to feel that they prefer the official manager, who has no interest in the matter beyond his banking safety and profit, to deal with, rather than the principal of a private firm, who may have interests inimical to his clients' ventures. That is one of the reasons why private banks are going out.

Whatever the cause, however, a movement was set on-foot in the first half of the $19^{\text {th }}$ century for the establishment of a joint stock bank, and The London and Westminster Bank was the result, established in 1836. From then onward numerous similar banks have been established until now the aggregate Capital paid up of the purely English banks excluding the Bank of England, but including two or three private banks which publish returns, amounts to something like $£ 50,000,000$ of money, that is, capital. The reserves amount to over $£ 30,000,000$, the deposits and current accounts to very nearly $£ 700,000,000$, and the discounts, loans and advances to $£ 425,000,000$. Those figures will, to some extent, indicate the influence of banking, and it is not too much to say that without some such machinery as the banker provides for the depositor, and the gathering together into a concentrated form of all that 700 millions of money, the trade of the country which has produced it could not have reached any such stage. The figures would have been very much smaller but for the bankers' agency. I do not pretend to say that the whole $£ 700,000,000$ has been derived from trade; neither do I say that the $£ 425,000,000$ of advances and discounts has been directed to assist purely mercantile enterprises. No doubt some of the business of the banks drifts into other channels, but speaking generally, those English banks, by their enterprise and skill in gathering together all this money, caring for it, responsible for it and dealing with it, have provided an enormous reservoir which has been so conveniently adjusted as to gather in practically all the floating capital on the 
one hand, which would other wise have remained in the people's pockets, or have been hidden away, and from this reservoir have provided the supplies whereby a considerable proportion of the trading community has been enabled to carry on and to extend its business operations.

Turning for a few moments to Scotland, we find that when that country began to settle down after the Stuart troubles, there was a rapid development of trade and commerce, including manufactures, and it was only a few years after the establishment of the Bank of England that successful efforts were made to establish a bank in Scotland. It is rather a singular circumstance when one considers the self-reliance and independence of the average Scotchman that for a short time the direction of the new institution was not wholly entrusted to the local men of business and affairs. The controlling voice was at first directed from London. It may possibly have been for political reasons, but whatever the cause it was only a passing phase, and it was soon found that the men north of the Tweed were quite capable of managing their own financial affairs, and they were left to do so, and to develop their banking system on their own lines. In passing I may add that at the present time it may be asserted with confidence that no section of the English speaking people has produced more capable men than the scotch trained bankers. They stand in the very front rank, and they soon extended their first bank into others. Banks followed each other in rapid succession, and all were established on much the same lines. Their system is aimed at gathering together in the most exhaustive fashion the floating resources of the country. To do so they adopted at an early stage in their existence a chain, or network, of agencies and branches to further that object, and they worked the deposit system very thoroughly. The resources thus supplied have been utilised to provide capital for the growing business of the country. Their cash credit system whereby enterprising young traders or manufacturers could acquire capital by advance on current accounts, from a bank on a cash credit bond given by one or more respectable persons of means, who were not themselves engaged in business, was admirably adapted to cheapen the capital then supplied, for the borrower in such cases pays interest only on what he uses from day to day. This was an advance on the English system.

In this, country, as I will mention later on, we have much the same system. But the Scotch bankers were the first to grasp the idea, and it contrasted to the advantage of the borrower with the English plan, which involved a borrower 
taking a loan for a fixed amount, usually for a fixed term. Of course this lending business was not confined to that particular kind of advance. They discontinued bills and performed all the other usual offices which are open to bankers. Their great merit consisted in the machinery which they employed to augment their resources, by the acquisition of deposits from the members of the community, and the skilful manner in which they have utilised the resources thus acquired in the furtherance of the trade and industries of the country. It is not too much to say that the splendid shipbuilding establishments which stud the banks of the Clyde, and which are the pride of Glasgow and its neighbourhood, and the woollen and other manufacturing industries which represent so large a feature in the, commercial activity of that wonderful country, the south of Scotland, owe their present proportions in no small degree to the supply of capital supplied by the banks through the medium of their deposit resources. The united shareholders' capital of the Scotch banks at the present time is $£ 9,200,000$, and they have reserve funds amounting to another $£ 8,000,000$. On that basis they have built up a deposit business of $£ 100,000,000$, and in addition they have a note circulation of upwards of $£ 7,000,000$, which is an equivalent amount to their resources. The Scotch banks have in the past made a feature of the note circulation in their banking institutions. Later on I will refer to note issues by banks in view of what I conceive to be the tendency of modern banking with regard to them. The figures I have quoted give you a very good idea of the influence which Scottish banks have exercised in the development of their trade and commerce. The benefit to all classes of the community - but in their case principally to the mercantile and manufacturing interests - is measured by the discounts made, which amount to nearly $£ 70,000,000$, a large sum, when it is remembered how small the country is geographically. It is worthy of note that the joint stock banks of Scotland have upwards of 1,200 branches and agencies between them, illustrating the extent to which the operations of the banks have been made to permeate the country.

The trade and production of Ireland have not lent them selves so thoroughly to the banking business as has been the case in Scotland. Ireland has produced some first-class bankers and banks, but the occupations of a large section of the community have not been so conducive to the conservation and distribution of banking resources. Nevertheless the figures are respectable. The shareholders' capital at the latest returns was over $£ 7,000,000$, the reserves $£ 4,000,000$, deposits 
$£ 60,000,000$ and note issues $£ 6,000,000$. The resultant advances and discounts were $£ 43,000,000$. These figures allow that the Irish banks have made the most of their opportunities, and we may be sure that the great shipbuilding industries at Belfast, the linen manufactures for which the country is famous, and the various agricultural industries of the prolific island have been all helped along by the use of banking facilities and accommodation.

Time will not permit me to make more than a passing reference to what has been done in other parts of the empire. Australia's banking system I have reserved for the last. The bankers of Canada have been no laggards in carrying out banking enterprises. Their system is somewhat different from any of the foregoing and from our own, inasmuch as their deposits are taken on the Savings Bank principle. They have also a comparatively large note issue, and consequently a small current accounts business. They have, however, a very adequate shareholders' capital and reserves to back up their other resources. Anyone who has visited the country and has had the opportunity of studying their operations can fully recognise their great activity in stimulating, with useful and judicious supplies of accommodation, the developmental energies of the people. The great Canadian Pacific Railway itself, the lumber industries, the moving of the wheat crops, and all the many ramifications of trade in that country, are indebted more or less indirectly or directly to the supply of banking capital forthcoming. The Banks have been prolific of branches throughout the length and breadth of the country, but with all, they have kept in view the precept which I am mentioning in connection with Australian banks, that the banker is a follower of trade, not a forerunner. They have a circulation more than three times ours, their capital is $£ 20,000,000$, reserve fund $£ 15,000,000$, deposits $£ 160,000,000$, and advances $£ 115,000,000$.

The banks doing business with India are divided into two classes - the Presidency banks as they are called doing purely local business, but within their limits - which are somewhat narrow - following the trade of the country; and the exchange banks which are for the most part engaged in undertaking the business connected with the import and export trade of India. The volume of this business is very large indeed, and calls for much skill in dealing with the financial side of it. These banks all follow the rule of substantial capital, and large reserves to protect their deposits. 
The same remarks apply to banks further east, and so far as the institutions of English origin are concerned, they preserve the same characteristics I have mentioned in the foregoing remarks. The banks of South Africa work on much the same lines as Australian banks, and those of Germany, France, and all the continental centres of Europe, have undoubtedly done as much to help in the trade of their respective countries as any of those I have referred to in detail. Likewise the banks of the United States have adopted similar banking systems. In detail they differ very materially in some important respects from any of the English pattern, but the principles underlying their methods of business are essentially the same. As I have said all these banks have identified themselves very thoroughly with the financial side of their respective country's development.

Now let us turn our eyes homeward, and see what banking has done for Australia. I think you will find that a study of Australian history exemplifies as forcibly as that of any country in the world the important part banking plays as a factor in the development of the trade and commerce of a country. Australian banking has been for the most part free from any political obligations such as I have called your attention to in respect to other countries of the old world. At a very early stage in the settlement of Australia, in the Mother Colony of New South Wales, it was recognised by those in authority at the time, that banking facilities were desirable to further the operations of trade. That far seeing man Governor Macquarie, who was essentially a pioneer, and whose vision was not limited to the small surroundings which he had immediately to deal with, before his term of office closed, realised that the infant community over which he presided, was in need of some more definite and systematic machinery for conducting its financial operations - small and simple though they were - than those afforded by the casual, and for the most part irresponsible efforts of the merchants of those days. He therefore set in motion the movement for the establishment of a bank. In 1816, a meeting was held by direction of the Governor, under the auspices of the Judge Advocate of the colony. At this meeting it was proposed "that a public bank be established, with a capital of $£ 20,000$, with the object of advancing on due interest, and the credit of the bank pecuniary assistance to the colonial traders, agriculturists and settlers as well as to afford a safe depository of money committed to its security and charge." The phraseology is somewhat quaint, but it was sufficient to cover the ground required, and you have in this the foundation of Australian banking. First you have the capital as the corner 
stone, then the acquisition of deposits on the security of that capital, and lastly, the utilization of the resources, thus acquired in promoting the commercial and industrial enterprises of the infant community. Collaterally with those objects the promoters had in view an improvement of the currency. Of metallic currency there was very little and much of that was defaced, for I have no doubt you all know of the expedient of dumping a hole in the Spanish dollar, which was largely in use in those days, and utilising the piece dumped out to enlarge the currency - the "holey" dollar, remaining of the same nominal value as it possessed before its mutilation. It is a matter of history, likewise that the currency such as it was, was eked out by the use of rum. The people bought and sold in terms of rum. The issue of paper money by banks had long been considered to be one of their particular functions, and it need occasion no surprise that every effort was made to purge the existing system through this new institution. At that time the trading operations of the people were very limited indeed, and the new bank had not much scope for usefulness at first. It fulfilled its mission, however, and ministered effectively to the sparse population of the country. This institution was the Bank of New South Wales - and I need not say that I have not brought its name forward because I happen to be connected with it, but because I think you will be interested to know that here was the beginning of Australian banking history. It must be acknowledged that it was a very small affair to start with. It may amuse you to know that one of its regulations solemnly passed at one of its meetings, was to the effect that its manager should not be absent from the banking premises after dark! How small it was, and how insignificant the trade of those days, may be gathered from the utterances of the President at a meeting held in July, 1819 , when he congratulated the shareholders on the fact that in the previous half year the bank had discounted 527 bills of an aggregate amount of $£ 56,000$, all of which had been promptly met at maturity. Many of the ordinary branch establishments of the existing banks at this date would do as much. But small as the business was, there is good evidence to show that the bank by supplying the much-needed banking facilities of those days, gave valuable assistance to the trade and commerce of Australia. So much for the earliest period. During the period which elapsed from then up to the discovery of gold in Australia, the progress of settlement was slow, sheep farming was the principal industry, and it was not surprising that the combined total of commerce was still a small quantity. However, it had advanced sufficiently to justify the establishment of several new 
banks, but when I tell you that the united deposits and circulation of the four banking businesses in 1836 was only $£ 474,000$, and that their advances were but $£ 646,000$ including everything, you will see that they were but small forerunners of the great banking institutions you are familiar with today in your midst. But still, they were keeping well abreast of the requirements of the people. We must now pass on to a very important epoch in the development of Australia - the period of the gold discovery. You will find that the existing banks and many others which quickly followed in their wake have been very fully identified with the enormous activity in trade which those discoveries brought forth.

The stimulus which was the direct result of the gold production, produced in the first place, by the introduction into the country of a large amount of floating capital to work the mines, and then by the addition to that capital by the produce of those mines, had a material effect upon the position of the banks. Their deposits increased by leaps and bounds, and their note circulation did likewise. This addition to their resources enabled them to cope with success with the increasing demands for accommodation from merchants and traders. It is obvious that the sudden influx of a large number of adults to a community which had been sparsely populated was calculated to tax the resources of all engaged in the business of supply. It was fortunate that the banks already existing had their machinery in good working order to meet the situation. Branches and agencies - following the Scotch System - were established wherever there was a large settlement of people, and the conveniences provided were all that were needed to make the transactions of the day work smoothly. All the banks were buyers of gold and bullion, and it must be confessed that at first they made enormous profits. The risk however, was great, not alone in the possibilities of buying spurious bullion, but in respect to the custody of the genuine article. Old officers of the banks who still survive, can tell of stirring adventures and hair breadth escapes, which do not fall to the lot of the banker of these days, for police protection was scanty and the premises in which business was conducted for the most part consisted of either tents or the most flimsy weatherboard.

The modern period of Australian banking, may be dated from the time when the first great goldfields activity had passed, and the diversion of a great number of those who had been engaged in mining, and who had amassed capital, to the more permanent occupation of the country, in the industries of sheep and 
cattle raising and agricultural pursuits generally. The necessity of supplying the large population of the fields had already given a stimulus to those callings. In all human probability, these lands of ours would not have reached anything like their present development, if they had not received the stimulus of the goldfield's operations. The banks had fairly kept pace with the growth thus far - in the two earliest periods by transactions based on purely mercantile lines, for the most part and in the third part by grafting on to this the peculiar business incidental to the goldfield's operations which came within their scope. It is quite evident if you study banking statistics from that time onward, that they have expanded in about an exact proportion to the growth of the business of our country. Of course they have had to enlarge the scope of their operations. By their extensions from time to time of their branch establishments, they have been almost as diligent as their Scotch prototypes in gathering in the scattered and idle resources of the community. And as those branches have been for the most part established in centres around which the production of our most important industries - wool raising and wheat growing - have gathered, they have been able, through their position to assist those industries by the supply of capital which would otherwise have remained idle and useless.

It has been argued, that it is not part of a banker's province to supply capital for such enterprises as the working of the land. It is certainly not his business to lend on land as such, but in all countries it has been considered part of a banker's duty, to assist financially the productive industries of the country of his domicile. They are part and parcel of the trade and commerce of the country. What he has to be careful to do is to preserve the characteristic of productiveness in dealing with his securities; that is to say, that he has some market able article in sight as we call it. He must, when he undertakes any financial responsibility in connection with the, land which produces it, be sure that the land is being put to productive uses. The land answers to the personal bond of the Scotch cash credit. It is what you get out of the land that is the banker's test of the quality of the business. The assistance which bankers in Australia at the present day afford in connection with financing the annual out turn of wheat, wool, and other productions is very great. I made some reference to that in an address I gave in Sydney, before the Bankers' Institute a few days ago. In many countries of the world, the task of financing their staple products, which generally come to hand within very limited periods of the year, is productive occasionally of big disturbances in the local money 
markets. In Australia, thanks to the very large reserves of coin held by all the banks, no such disturbances have hither to taken place in connection with those operations.

In no other direction is the co-operation of the banker more strongly exemplified than in the financial operations involved in the disposal of our great staple pro ducts. I have no means of telling you the amount which is the result of a single wool and wheat season, because there are no statistics published on the subject, and no information is forthcoming, but I shall not be very far wrong, I think, in estimating that the banks must have dealt with upwards of $£ 30,000,000$ of transactions in the six months comprising the wool and wheat season. Think of what this means to the producer and trader. You know that the larger proportion of our wool is sold locally, and most of it is bought under credits established through the banks here. The same applies to wheat, although not to the same extent, and indeed to all articles of export. With regard to both exports and imports, the perfection of banking methods in Australia, as experience has dictated, has undoubtedly been of the greatest benefit in making all the transactions entered into work smoothly and economically. The growth of the banking business of Australia is best illustrated by the figures of the deposits and advancers. You will readily appreciate from those the extent to which our banks have been factors in connection with the commerce of the country - using the word in its widest sense as inclusive of the producing activities. Without some such machinery as the banks have afforded, it would have been impossible to have reached such a stage of development, and I think they have provided the most suitable machinery.

Knowing something of the banking history of Australia, I can say that the aims of those who have been responsible for the management; have for the most part been to follow the legitimate evolution of trade in all its bearings. I say, "follow" advisably. It is not the banker's part to precede trade or production, and certainly contrary to sound principles to boom trade or to over-stimulate production, and in the main bankers have adhered to those principles. I would not be candid if I did not admit that in a very short period prior to 1893 , there was a more or less departure from sound principles in this way - that there was too free accommodation given to stimulate enterprises in respect of which there was no reproductive return in sight, as I have put it before, but only a speculative 
possibility. I confess this was not assisting trade. But the lessons of that time have been taken deeply to heart, and it speaks volumes for the soundness of Australian trade and production, that we came through the ordeal as well as we did. The figures of Australian banking speak for themselves. Capital $£ 18,000,000$; reserves $£ 9,000,000$; circulation $£ 5,000,000$; deposits $£ 158,000,000$; and advances $£ 123,000,000$.

You may have noticed that save for a few casual remarks here and there, I have not said much about note issues as factor in banking business, nor of the part which they have played in the operation of its machinery for assisting trade and commerce. I have, however, pointed out that in the evolution of the bank, the right to issue notes on the credit of the bank has been generally recognised. In the early stages of the modern banking development of the British Empire, the note has played a rather important part. The Scotch banks made extensive use of their note issues in furtherance of their operations. They were in good credit and their notes were accepted as a convenient form of currency. It is quite certain that under the practice then existing they could not have maintained the greater number of their smaller branches and agencies if they had been compelled to stock them with gold. The English country bankers of the eighteenth and nineteenth centuries also carried on their operations in the same manner. The Bank of England soon virtually obtained a monopoly of the note issues in England itself. That note has indeed played an important part in mercantile matters. By virtue of the position it attained in the middle of the nineteenth century, symbolised the strength of the bank itself and its moral effect was correspondingly very great. Its practical use, too, in connection with all bank and mercantile settlements very great, until the clearing house system became more fully developed. The Scotch bankers established a clearing house at a comparatively early stage in their history, and the London bankers have also had their clearing houses for long time. You know what a clearing house is. Briefly is a device by which the various banking transactions of the day as between bank and bank are brought together in a room set apart for the purpose, and set off against each other. The result and balance, generally small, is settled by cash or by some other simple way. The clearing house system has undoubtedly lessened the importance of the note connection with the more important banking transactions. But there are signs in England and Scotland at any rate, and most unmistakably in Australia, that the branch bank and the facilities which are now given for opening current accounts, with 
the liberty to draw small cheques is still further working in the same direction. The circulation of the Bank of England, the Scotch banks and of the banks in Australia is year-by-year becoming less important in comparison with the growth of current accounts. I have given some of the figures representing the present position of the circulation and deposits of British and Colonial Banks. Two or three decades back, the relative positions of the two classes would have been quite different. Those who have become used to the current account would not willingly go back to the time when they were only allowed to keep a trading account under certain restrictions as to use.

I remember a Canadian friend of mine who visited my own bank in Sydney, on a busy Saturday morning, sitting down and watching the people at the paying counter half a dozen deep, a sight I am sure you would see in your own busy banks here. He asked me afterwards what it all meant. I told him it was payday at the warehouses and so forth, and that the employees were paid by cheque, that every transaction small as well as large, was paid by cheque if possible. He said, "In Canada we would get the large people to draw one cheque, and take the money out in notes and distribute the proceeds themselves". I told him that such used to be our own practice, but that the banks in Australia had by degrees given more and more drawing facilities to the people of the country, with the result that the circulation has dwindled away to a very small proportion of its former volume, and from being a very useful factor in connection with mercantile affairs, is now used as pocket money only (so to speak) and has very little real significance in the operations connected therewith. Under certain conditions it might possibly be restored to some of its usefulness, but it would be impossible now to wean our people of the use of the current account, and so far as I have been able to judge, the same tendency is going on in England and Scotland also. I have mentioned my Canadian banking friend's statements with regard to Canada. The banks there on the one hand have not encouraged the current account to the extent we have, and the people will more readily accept notes and gold, or keep them in circulation, than our people will, but when all is said and done, the Canadian note is only pocket money on a more extended scale. The larger transactions are settled by cheque as with us, and the clearing systems of modern banking which are in vogue there as well as here, are so perfect that there is very little scope for the note in a progressive well educated community. The current account I think must be acknowledged to be a more advanced form of banking, and its free use 
and expansion is calculated to further the convenience of traders and others, to a much greater extent than the note can ever do.

In concluding my remarks, I would like to say, that I am very glad to observe from the syllabus of lectures in your University on banking and exchange for 1910, that a large amount of attention is being given to the subject. I desire to thank the class lecturer for his courtesy in supplying me with information. What I have been able to say to you has been necessarily restricted to general outlines, but if I have given you any real idea of what banking is, and how intimately it is connected with the daily financial life of the community, and what a useful, and, in my judgment, essential factor it is in connection therewith, then these words will not have been altogether spoken in vain. 



\section{Australian company law, and some sidelights on modern commerce}

\section{Henry Y. Braddon ${ }^{1}$}

The first time two or more people clubbed their capital in order to start some common venture with a view to profit, they began a movement which culminated in the modern "Limited Liability Company." Their venture took the form of a partnership, and partnership has ever since played a conspicuous part in the industrial and commercial development of the world. It has enabled thousands of successful ventures to be initiated, upon which no one of the contributing parties would have cared to embark alone. It has, of course, yielded its quota of failures, but that applies to any form of commercial enterprise - since it is impracticable to eliminate the gambler, the fool, and the inexperienced operator.

But the real canker at the heart of partnership, as a method of co-operative enterprise, was the unlimited liability of the partners for the firm debts. Within the ambit of the recognised partnership business each partner could pledge the credit of the firm to any extent, and each partner became liable for the common debts to the last pound of his private assets. This pre-supposed the greatest confidence between partners at the outset of their mutual career, yet almost necessarily planted in the minds of each an uneasy feeling about the possible actions of his co-partners. Furthermore, private partnership became a clumsy affair with several partners, and impossible with many. The system excluded the practicability of a great number of people, with little capital each, contributing towards a common enterprise with individual safety as regarded liability for the joint debts.

1 Fifth Joseph Fisher Lecture, 25 April 1912. 
It was to meet this case that business men set their wits to work in the direction of limitation of individual liability. All sorts of expedients were legislatively tried mostly unsuccessfully. "Charters of incorporation" from the Crown (under the Act of 1825) did something in the desired way; also special Acts of Parliament granting incorporation. Charters were, however, very reluctantly granted; and both methods were expensive, involving undue delays. Modern business required something more rapid, more elastic, and less costly. Then at last came the English "Limited Liability Act" of 1862 - rightly called the Magna Carta of co-operative enterprise.

Under it any seven persons could register a Company with limited liability, which thereupon became a distinct legal entity - a corporation with perpetual succession and a common seal. Whereas a partnership required to sue in the names of all the partners, the limited Company could do so as a separate entity. Whereas partners could pledge the firm's credit without consulting their co-partners, the limited Company carried on through its Directors and Managers, who alone could pledge its credit. Whereas partners were liable for the mutual debts to the uttermost farthing of their private estates, the shareholder of a Limited Company was only liable to the extent of the uncalled portion of his own shares.

There are, of course, other features in the company; but these are the most important. With their risk limited to the sum they originally agreed to find, people no longer hesitated to go in for joint stock enterprise, and any business man knows to-day the vast range of commercial activities conducted under this system. The '62 Act - adopted sooner or later by the Australian States - gave a tremendous impetus to trade, and many enterprises sprang into existence which would have remained untouched under the partnership aspect. As might have been expected, there have been abuses, with consequent losses in a percentage of instances but, on the whole, the world's business operations have immensely benefited by the stimulus afforded by the "Limited Liability" idea. In England, during 1910, over 7,000 Companies were registered, with an aggregate nominal capital of $£ 212,975,700$. Over 54,000 Companies are said to be in existence there to-day, with an aggregate capital exceeding $£ 2,200,000,000$.

Now, while the various States have necessarily followed in the wake of the mother-country in the adoption of the "Limited Liability Company," they have done so unevenly both as regards time and detail. Some were quicker to adopt 
the English scheme than others, while all have differed from the model in some particulars. The English Act of ' 62 has been amended more than once, and some fresh ideas have been grafted. Each Australian State has followed these changes in its own way - some fairly closely, others not so closely; and in one or two cases (as the "Proprietary" Company, in Victoria) fresh ideas have been developed. Now that we are supposed to be a Commonwealth - "One nation, one destiny" - this sets up a ridiculous situation. It is absurd, on the face of it, that a "Limited Company" should imply one set of statutory conditions in New South Wales and another in Victoria or South Australia. Throughout the Commonwealth "limited liability" should mean one thing, under one comprehensive statute, framed by business experts from each State after full consideration of Australia's special needs.

First, let me analyse public requirements in this matter of "Limited Liability." Broadly, there are three classes of Limited Liability Company: Class No. 1 - "No Liability" Mining Companies - To induce the public to subscribe towards mining companies, there has been created - for instance, in New South Wales - this type of limited company. The shareholder can stop calls any time he chooses, forfeiting his shares; and nothing can compel him to pay up the full nominal value, as in the case of the ordinary company. He may sell, of course; and the right passes to his buyer to go on subscribing if he chooses, or to drop out of the concern as soon as he is personally convinced that it is desirable to cut his loss. This is a class of company peculiarly suitable for mining operations, and the one essential feature is that the "no liability" aspect should be freely advertised, to protect traders giving credit to the concern. If they give credit, knowing the conditions, the rest is their own affair. The special feature referred to has made it possible to develop many a mine to a successful issue which otherwise might have remained neglected. It goes without saying that the community has benefited greatly by these successful ventures, both in the aspect of capital profitably invested and labour satisfactorily employed.

Class No. 2-Private Companies - as in the statutory "Private Company" in England, or the "Proprietary" Company in Victoria. In both cases the membership limited to 50; and there is no need to file prospectus or statement, balance sheet or report - at any rate for public inspection. In Victoria the balance sheet is lodged with the Registrar in a sealed envelope. These private companies do not appeal to the 
public to take up shares or debentures; and the Victorian Proprietary Company can only take deposits from its own members.

Such Companies form practically an extension of ordinary partnership, with some of the advantages of limited liability super-added. They render it easy to effect divisions of interest, in the form of shares; and they facilitate realisations of interest, or part interest, in a way not practicable under ordinary partnership. As they do not appeal to the public for funds, it is reasonable that they should be freed from some of the conditions applying to the ordinary limited company, eg., the lodgment of a balance sheet every year with the Registrar for public inspection.

While working mainly on capital subscribed by their own members, such Companies may of course secure credit in the way of trade debts. The trading public in such cases rely (as with partnerships) on the reputation and the management of the Private Company rather than on knowledge of the actual position. So far as I am aware there has been no great abuse of the facilities offered by this type of Company. Any Australian Company Statute should contain provisions of this description.

The absence of compulsory annual exposure of its business is nowadays an advantage. Such may still be necessary and advisable in the cases of concerns appealing to the public for funds; but, while existing conditions hold, there seems no need to compel these private companies to publish annual balance sheets. If criticism upon balance sheets were always fair - if due allowance were always made for difficulties surmounted, and for unremunerative periods before Companies began to pay - then all Companies alike might publish figures without misgivings. But while balance sheets are so easily misrepresented in interested quarters, it is advisable to save from compulsory publication at any rate those concerns which make no claims upon the public for funds.

Class No. 3. -Ordinary Limited Liability Companies - For the sake of convenience these Companies are analysed in our daily Stock Exchange lists into the following divisions: Banks; Steam; Insurance; Gas; Coal; Brewery; Miscellaneous; Finance, etc.; Land and Building; Mining.

These are the Companies whose operations may reasonably be said to be "public" and (with the exception of "no liability" mining companies already treated) the following comments refer to this class. 
Such companies represent a vast amount of capital, subscribed by many thousands of shareholders; to a far greater extent in small individual holdings than is generally supposed. Some of them are now in command of very large capitals - many of them have Head Offices in England, and draw a large part of their resources from the British Isles for investment in Australia; and collectively they cover a huge area in our commercial and industrial affairs, the value of which it would be impossible to calculate fully. But for the "limited liability" structure it is a certainty that a very large proportion of these enterprises would never have seen daylight.

To emphasise the need for a Federal Company Act, I propose first briefly to draw your attention to some differences of treatment arising out of the varying Acts of New South Wales, Victoria, South Australia, and Queensland; and then to suggest some desirable points in any Australian Company Statute.

Appended are some of the differences (table 5.1).

It will be understood that the foregoing is not intended to be an exhaustive list of the differences. Some of these have been taken as illustrations, and there are no doubt many others.

The various State Stock Exchanges differ in practice on material points: thus accentuating the differences in statutory conditions. New South Wales for instance has a rule barring Companies with Life Directors, or other permanent appointments of an irrevocable character. The Sydney Stock exchange holds that unsatisfactory results are apt to accrue, as some of these Directors are likely to continue in office after their fitness and vigor are gone. Two other State Exchanges treat the matter as one of discretion for their Committees; while a fourth Exchange has no rules on this point.

Again, New South Wales insists upon a certain scale of voting powers in any Companies it "lists" on change; objecting to "one share one vote," on the ground that undue power may thus be held in one or two hands to the jeopardy of the just interests of minorities. Victoria does not attach any special importance to the point, South Australia takes each case on its merits, and Queensland has no rule. These too are merely illustrations rather than a complete catalogue of Stock Exchange differences of method in the States of the Commonwealth. 


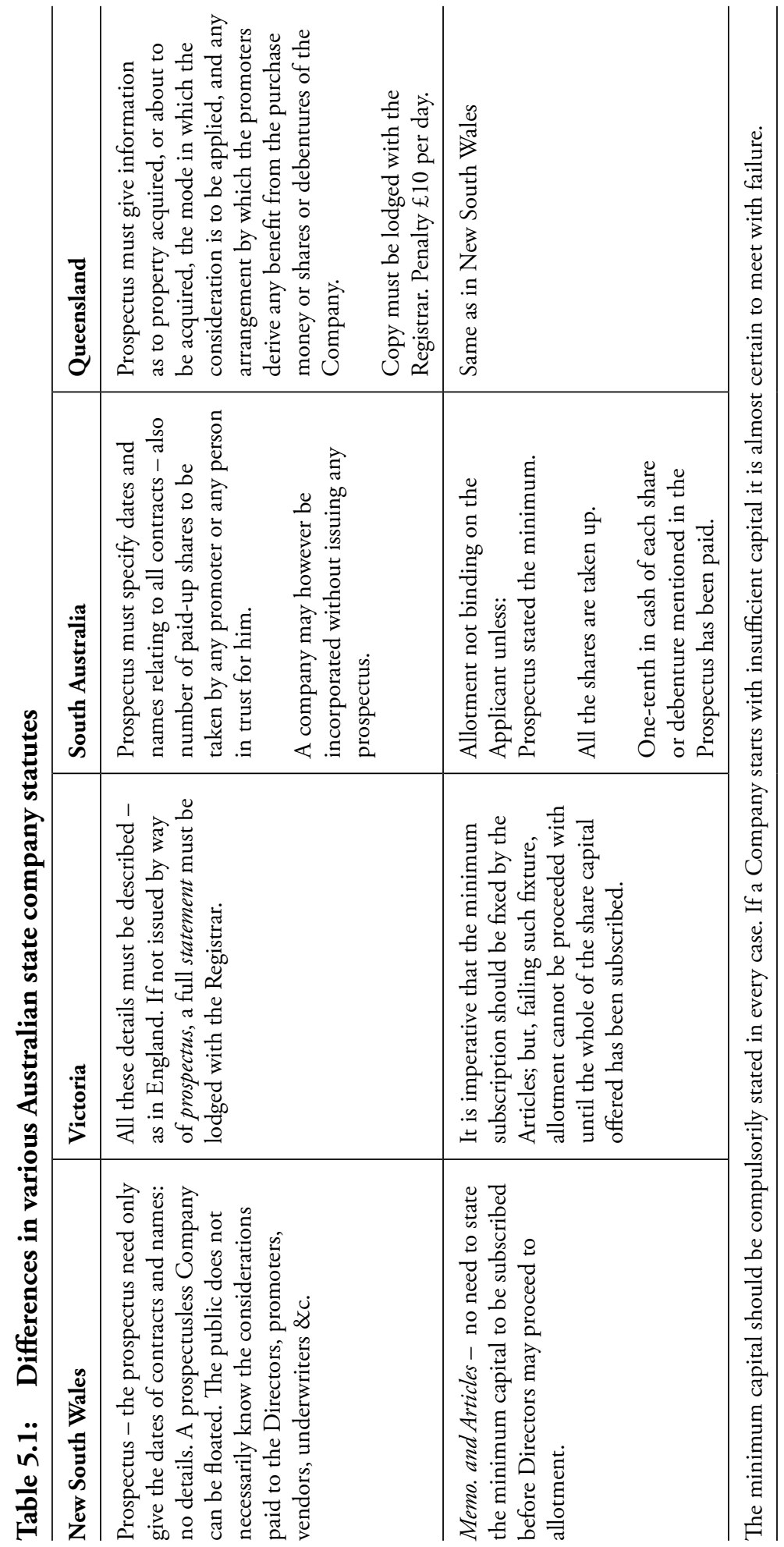




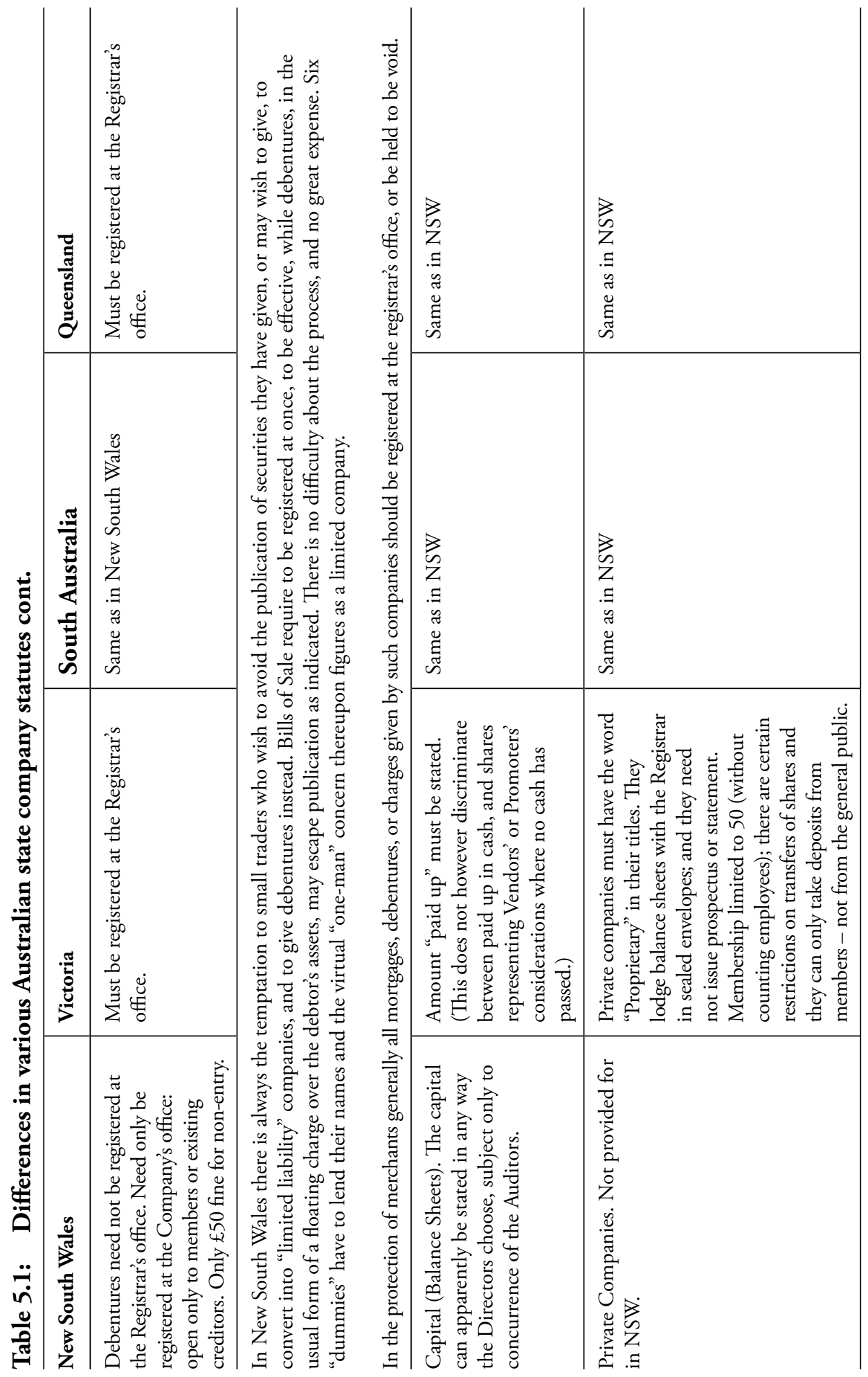


If Australia had one Company law throughout, it is probable the Stock Exchanges would soon follow with a uniform code of rules for "quoted" Companies.

Now in considering the question of a Company law for Australia three main points arise: (1) the Prospectus; (2) the responsibility of Directors; and (3) the duties of Auditors.

Some minor considerations will be treated later, but it will be well to address ourselves to these more important points first.

\section{The prospectus}

This document embodies the invitation of the promoters to the investing public to come in and buy the share of the described venture. In England the law is strict that not only must it contain no misrepresentations, but it must also be exempt from the charge of suppressing any material particulars. No honourable promoter need fear these conditions; yet In New South Wales it will have been seen we are far too easy-going in our statutory conditions. In New South Wales and South Australia a company can be floated without any prospectus at all. There should always be a prospectus, or its equivalent, lodged with the Registrar, and this document should contain all material particulars, under severe penalty for conscious misrepresentation. In it all considerations, whether in cash or shares, to vendors, promoters, provisional or other Directors, or to underwriters should be fully detailed. One might go further - any like "considerations," paid or issued subsequent to flotation should be recorded with the Registrar; (under penalty for failure so to record) within say a month of such payment or issue. Considerations of this type might be given (after flotation) on the acquirement of additional assets; and these should be recorded where the interested world may glean the information. In the absence of precise details-of all contracts and considerations, including the amount paid for goodwill, it is impossible to trace what the vendors received, so as to compare this with the sum asked of the public. The difference may be fictitious capital to an unjustifiable extent. Such cases should not have the protecting cloak of the law. Honourable and reasonable promoters will raise no objection to strict rules about the prospectus. In practice such men usually state the material details as a matter of course. Broadly it should be axiomatic that the 
prospectus must give without reservation all requisite particulars to enable the public to gauge the position accurately.

Also deliberate misstatements in the prospectus should vest in any holder of shares the right (within a reasonable time) to sue the responsible parties for damages; whereas (in New South Wales, for instance, this right vests only in the original allottee.

Here is a useful definition of "fraud" in company promoting: "A false representation of fact, either with knowledge of its falsehood, or recklessly, not knowing whether the matter is true or false, with the intention that the party to whom it is made should act upon it, or be induced to act upon it, to his detriment."

Exaggerated views of the advantages, expressed as matters of opinion, would hardly constitute a fraud - unless very gross, while concealment of material facts might amount to fraud.

\section{Directors}

The Directors' remuneration and qualification should be stated in the prospectus. It is an interesting question whether the qualification should be pitched high or low, and the point would not be easy to legislate upon by reason of the difficulty in fixing the happy mean for all companies, large and small.

A small qualification may be argued to be likely to banish the sense of a personal stake: to limit the Director's interest to little beyond the collection of fees. On the other hand a large qualification limits the choice to wealthy men, and wealthy men are not necessarily the wisest in the community.

A more important question, perhaps, is that of the legal responsibility of Directors. This arises first in respect of the prospectus, and later in the actual working of the company.

As regards the prospectus, it is unfortunately a fact that men of influence will at times accept "free" shares, or other inducement, by way of consideration 
for adding their names to figure as Provisional Directors. If such considerations are frankly stated in the prospectus no great objection need be raised: but the investing public should be protected against secret inducements. Unless so protected they will naturally imagine the Provisional Directors are investors like themselves: that these folk have accepted their positions solely from a belief in the venture. Where such is not actually the case the public should be made aware of the special inducement, no matter what its form, under penalty for suppression of the information. This is a point for the expert framers of an Australian Company Act to weigh carefully.

In the subsequent working of the Company the fixing of responsibility on Directors - for the Company's failure in any really grave way - is a matter of greater difficulty. Such men must not be taxed beyond their abilities, beyond their reasonable opportunities to detect mismanagement. Usually they only attend Board meetings periodically - say a couple of hours once a week. They rarely examine books - that being the duty of the Auditors. Finally, they not unnaturally rely, as a rule, upon the judgment and recommendations of the Manager - the trusted servant of the Company who is far more conversant with the details than they can possibly be.

At the same time it has happened that failures have occurred of a kind that inevitably suggests distinct dereliction of duty on the part of Directors - failures to detect fairly obvious irregularities. What then? Ought not such directors to be made responsible, however innocent of personal participation in such irregularities, on the same principle that a railway signalman, innocent of murder, may he convicted of manslaughter (and punished) if his dereliction of duty arises through gross carelessness, and leads to a grave accident involving loss of life?

If men accept fees for work which theoretically suggests some sort of supervision, ought they not logically to accept the collateral responsibility? The reply will probably be, "Certainly." We might say, "Certainly let them be responsible - to such personal extent as the Court may think appropriate, in cases where their failure to detect irregularities on the part of the Company's officials amounts to gross carelessness, and leads to losses for shareholders."

In such case should all the Directors on a Board be treated alike, or distinctions be made between the experienced men and the amateurs? Boards of 
Directors are sometimes burdened, especially in England, with titled folk, who understand little or nothing of business, and who cannot be expected to detect fraud or mismanagement as a trained business man might reasonably be expected to do. At the same time they should not in such case accept the fees, or the responsibility; and in practice it would no doubt be unwise to attempt subtle distinctions in responsibility between one Director and another.

There is no law in the land to compel any man to accept a Directorship. But, if he does so, he should be competent to do the work, and he should in any case accept responsibility for its neglect. Otherwise he is an unjust steward, accepting a fee without honourably yielding consideration in services rendered.

\section{Auditors}

An auditor is no doubt a guardian rather than a detective; or, as has perhaps been better said, a watchdog rather than a bloodhound. While it may be admitted that he is not called upon to regard every official with distrust, and every entry with a jaundiced eye, he should as certain everything the books have to tell him, and he should entertain all reasonable suspicions the books may suggest. Any such suspicions must be ruthlessly traced, and if wrong has been done, that wrong must be exposed, for it is the auditor's duty to inform the shareholders of everything it is advisable in their interests they should know. He is not the friend of the management, though under sound circumstances he may work in perfect amity with them: his duty is to the shareholders.

From this point of view an auditor's task is clearly something far wider than testifying to the correctness of additions in the books and to the correspondence of the book records with the formal extract styled the balance sheet. That is the merely mechanical part of the work, and the merely mechanical auditor is not a profitable servant. No doubt all audit fees are sometimes paid on the assumption that the duties amount to no more than this unilluminating review; but, with a wider recognition of the true sphere of audit, several desirable results will, it is to be hoped, follow: (1) the auditor will always be expected to be a technically trained expert; (2) he will be asked to devote to the work a greater amount of time than is often now-a-days deemed sufficient; and (3) he will be paid a fair and adequate fee, commensurate with this recognized responsibility. 
His work must subject him, in all cases where the fee is inadequate, to a temptation to "slum" his duties on the theory of fitting the service to the fee. That would be only human nature, but gravely undesirable. Also, he is under temptation not to see too clearly, or to say too much in the report, lest he offend the Directors or the management. On them may depend his chance of re-election at the next annual meeting. The law should protect him in some way, but the point is a difficult one, for a more or less unfettered choice must obviously be with the general meeting as regards the election of auditors. This, at any rate, might be done - a provision that auditors are not to be removed from their positions without, say, two months' notice. Such a provision would present no great obstacle to the removal of a really undesirable auditor, while it would yield some protection to the honest auditor whose fearless report had incurred the resentment of one or more of the Directors. Without the notice, he might be quietly engineered out of his position at the general meeting, but with the notice, he would have two months' respite to enable him to explain his position to shareholders.

In fairness to auditors, they should, where trouble of any kind has arisen, be judged as auditors, and in the light of the comparatively limited scope they often have for enquiring (as compared with Directors) outside the books and entries. For purposes of assessing their responsibility, they should not be confounded with Directors - unless, of course, they have deliberately concurred with Directors in action demonstrably contrary to shareholders' interests, such as the suppression of vital information.

Finally, only certificated men should be employed, members of such Institutions of Accountants, and the like, as may be authorised by the GovernorGeneral. To meet the cases of distant centres - where a small company might find it unduly costly to obtain a certificated man from the city special provision might be made for audit by two responsible persons, whose vocations should be stated in the certificate. The English Act contains a provision of this kind.

Now highly important as the Auditor's work, the New South Wales Companies Act, for instance, make no reference to audit, through the articles of "Table A" contains some provision in connection. This is not as it should be. Any satisfactory Australian Act should have a great deal to say about auditors and their certificates. 
The Audit certificate should be expert testimony to the technical correctness of the general methods of the Company. But Balance Sheets can be made to tell very little; and in the hands of a mechanical auditor this testimony may only serve to lull shareholders into a false sense of security. The following hints as to some of the desirable contents of an ideal certificate are not offered as final solutions; but rather as matter for consideration by expert framing an Australian Act.

\section{Balance sheet items}

The term "Reserve Fund" only to be used in Balance Sheets where such fund consists of cash or ear-marked securities. These to be fully detailed. Reserves "invested in the business" to be explicitly so described in the Balance Sheet.

"Good will" item. The Good will item (if any) always to be shown separately in the Balance Sheet.

"Preliminary Expenses" item. Same.

Liabilities, secured and unsecured to be shown separately. It is only fair that creditors generally should know what proportion of this item is covered by security.

Assets. Advances to be separated in the Balance Sheet into secured; unsecured; bills under discount.

Depreciations. The certificate to state such have been either: (a) not written off; or (b) auditor satisfied these have been reasonably written off. It may not be necessary to mention the rates, or that the Auditor should specify his explicit satisfaction with the rates. The Auditor can hardly be expected to be an expert on all types of depreciation: and it should suffice if he is satisfied on general principles.

Bad and doubtful debts. The Certificate should state that due provision appears to have been made for any probable losses. Terms of credit vary in different trades, but, making allowance for these, the Auditor should enquire into overdue accounts, and comment accordingly. Such work takes time, but it is well within the compass of a scientific audit. 
Insurances. No actual duty to certify to insurances is recognised in England; but it is matter for consideration whether the certificate should not mention that these have been examined, that premiums have been paid to date, and that the policies appear to cover adequately all assets calling for insurance. If such assets are not insured, surely the shareholders should be made aware of the circumstance in the Auditor's certificate.

Valuations of Securities, Premises, Plant, Stock, etc. The question of certifying to the reasonableness of valuations may be argued to be outside the scope of audit, partly because the Auditor is not an expert all-round Valuator, and partly because such work would in some cases (eg., Stocks), involve far too great a task. At the same time the fairness, or otherwise, of the valuations in any given Balance Sheet, may easily mean the difference between a sound and an unsound position. To call in qualified outsiders to assist the audit in this particular work might involve an unduly heavy expense which might handicap the Company in competition with private firms not so saddled. No doubt the Auditor is in most cases justified in accepting the signed statements of the Company's Managers, or departmental heads: and, possibly, it would suffice if his certificate stated the name of the documents relied upon, and by whom signed. If the circumstances suggested the need for fuller investigation, it should be the recognised duty of the Auditor to recommend the calling in of outside expert aid.

In any case the certificate might state that valuations of premises, plant, and stock are not taken at more than cost: or, to go further, that such are taken at cost or market value - whichever is lower.

Appreciations in market values should never be taken into profits unless: (a) realised in cash, or (b) shown specifically in the Balance Sheet, i.e., original cost, plus the amount added by way of appreciation.

Now for one or two general considerations in Company law.

Some Stock Exchanges object to Companies which retain a lien on shares for debt other than uncalled liability. Such liens may complicate sales "on change", where the broker is unaware of the debt, and the Company subsequently blocks transfer. The objection is probably justified. If the lien (other than for uncalled 
liability) were removed, such would tend to discourage advances by a Company on the security of its own shares. If the shares are sound and marketable, the shareholder can borrow on them elsewhere than from the Company concerned: if unsound - then it is only the more undesirable that the Company should lend to its own shareholder on such security.

Also some Stock Exchanges object to Companies which forfeit unclaimed dividends; and here they do not seem to be on such secure ground. If the forfeiture only takes effect after a legitimate period - say six years - there does not seem much ground for objecting to the proviso.

\section{Advances to officers of a company}

No advance should be made to Auditors (or to firms in which they are interested) under penalty. Advances to Directors, Managers, or officers need not be barred - subject, however, to one strict condition. Such advances should be shown in a special list, with full particulars, signed by the Auditor. The certificate might read: (a) no such advances; or (b) list examined and approved by the Auditor as being apparently in order.

\section{Liquidation}

A Liquidator may act unwisely, or in the interests of Directors, and in practice it may prove difficult to bring him to book in the Courts, unless, of course, he acts outrageously. It is matter for consideration whether it would not be wise to provide some unimpeachable authority to enquire into cases of voluntary or compulsory liquidation of companies, when a substantial number of shareholders desire an independent enquiry, and where the circumstances suggest its desirability. The question is not an easy one: for on the other hand it is undesirable to facilitate action on the part of a few ignorant or malicious shareholders.

In any case a full liquidation statement should always be filed at the Registrar's office.

So far we have been concerned with defects and suggested remedies, and I want now to turn to a brighter page. I am a firm believer in a selected point of 
view, and in the collateral circumstance that we call to a large extent make the outlook either rosy or dingy, as we may elect. If you regard your work as sordid drudgery, then such it becomes, and you a drudge. But no law of the land compels you to such an attitude. Every man creates his own working atmosphere, and no earthly power can make it murky if the worker steadfastly intends otherwise. At any time we are perhaps too prone to keep our eyes upon the dusty track, and an admirable corrective is to gaze round occasionally upon the changing beauties of the land and sea and sky. It is healthy to do that, because it lifts the individual away from his littleness, if only for a brief space.

So, in business, we may easily concentrate too continuously upon the ledger folio and the monotony of the task, completely losing sight of the wonders inherent in modern operations and the quaint history of their development. By regarding our duties as such should be regarded - and incidentally as participation in work calling for high qualities of judgment, skill, and tact - we alter the entire outlook for the better. The drudge becomes the artist, and the daily round claims a fresh interest.

This is no mere theorising. I have made my own life brighter by some study of the history of commerce and some effort at appreciation of its inwardness. The same avenues are open to others in commercial circles, and I strongly commend such studies to all young men engaged in business pursuits.

Let me illustrate by brief surveys of three commercial developments - in currency, foreign exchanges, and in c.i.f. transactions. The instances could be easily multiplied, but I do not want to strain your patience, so these must suffice.

\section{Currency}

Take the $£ 1$ bank note, and the shilling. The former is in effect merely a piece of specially prepared and printed paper - inherently of no value; yet it is freely accepted as value for one pound sterling. The shilling is mainly alloy, and only contains some $5 \mathrm{~d}$. worth of sterling silver; yet it passes current for $12 \mathrm{~d}$. value. Why?

You might say the bank note passes because there are certain statutory gold reserves, and because the public have confidence that the value is there - since 
the credit of the country is behind the note. Also that the shilling passes for $12 \mathrm{~d}$. because the law so ordains, and because coined silver has to be accepted as a legal tender up to 40s. As far as they go those explanations would be quite correct, but if they exhausted the knowledge of the speaker he would necessarily be taking a somewhat drab, uninteresting view of the question. The man with wider knowledge would see behind these forms of currency a long vista of effort and experiment stretching back through the centuries, and gradually leading up to the forms of money current to-day. In the bank note he would recognise a dozen lurking dangers; any one of them likely to materialise under foolish administration, and all amply illustrated in the histories of other nations. $\mathrm{He}$ would know that whenever the Government press has been employed to create fictitious wealth, under circumstances of national stress - many years of untold troubles and miseries have followed. In metallic currency he would see the final triumph, after hundreds of years of striving to discover a suitable medium of exchange and store of value. All sorts of commodities tried in this country or that, but as a rule failing in one dimension or other, under the strain of prolonged experience.

Let me briefly trace the history of that development.

The world's trading interests could not advance very far on the basis of direct barter. A tailor, for instance, has a suit of clothes to sell: how is he to exchange it, on the basis of barter of article for article, for the house space, the food and clothing, that he needs? Clearly he cannot do so, with out a needless waste of time and trouble, unless he can sell his suit for some medium which others will accept, when he in turn wishes to buy from them the necessaries he desires. Very early in its history the business folk of the world set themselves to solve this riddle: to find the something which anyone would accept as recompense for services or goods, and which would incidentally serve as a store of value, to be kept in hand if desired, and spent later on in whole or part. Putting it briefly, what was wanted was a common denominator, a measure, and also a store, of value.

In the centuries' long search for the best possible, all sorts of quaint articles hare been tried: leather, skins, sheep and cattle, slaves, ivory, ornaments, cowrie shells, cereals, tobacco, eggs, fish, pieces of cloth, salt, rum certificates, cubes of tea, and implements. Some of them were, of course, peculiar to various countries, 
some of wider application. Meantime metals had been tried here and there, and gradually, by a natural gravitation in the direction of fitness, the coinage metals were reduced to gold, silver and copper. The commercial world of the 7 th to the 13th centuries worked largely on silver; while the modem history of currency commences with the introduction of gold into Europe in the 13th century when the Venetian and Florentine Republics were at their zenith. To-day silver and copper represent till or pocket money, while gold is the almost universal basis for international settlements.

Why then is gold so peculiarly suitable as a medium of exchange? It is worth while to glance briefly at the reasons. It has no utility value beyond a slight ornamental one. You cannot eat, drink, or wear it as a garment: but it procures all these things for you - and it is the fittest medium so far discovered to subserve the exchange needs of individuals and countries. This because it has:

- Portability - high value ill relatively small compass. At one time Swedish merchants settled debts in large copper "dahlers" and it required a handbarrow to do a day's collecting.

- Indestructibility - gold does not rust, like iron for instance.

- Homogeneity - equal weights, equal values. Two half-sovereigns are worth exactly one sovereign but a diamond would be worth greatly more than two smaller ones of the same aggregate weight.

- Divisibilty - two half skins taken together would not have the same value as one whole skin. This objection does not apply to gold.

- Stability - no commodity one can conceive would maintain an undeviating value through the centuries. Gold is the nearest available approximator. Steadiness of value, as between debtors and creditors, is of course a great desideratum.

That which unfailingly maintains the identity between the nominal (coinage) and intrinsic value of gold is the fact that the Mint is always open to its free coinage, at a fixed price of $£ 317 \mathrm{~s}$. $10 \frac{1}{2} \mathrm{~d}$. per ounce. This keeps the coin and the bullion values always on approximately the same level.

Now, it will be seen that in the British sovereign there is a pound's worth of gold, if I may so express it. Why, then, is there only $5 \mathrm{~d}$. worth of silver in a shilling? Silver is only "token" money, rather than standard money like gold. Any 
country will take British sovereigns at full gold values, but they would not accept British silver at nominal values in settlement of debts because standard silver value is not there. Only a Parliamentary decree enables the shilling to masquerade as value for $12 \mathrm{~d}$., and it is by decree maintained in a subordinate relationship to gold, at a fixed ratio. Great care is taken not to over-issue silver, the Treasuries very carefully and closely watching this point. No Parliamentary decree could prevent the shilling becoming depreciated in exchange value if serious over-issues were forced upon the public.

\section{Foreign exchanges}

The effects its business transactions in a multitude of ways, and in its darker corners the methods we regard as archaic still persist. Let us glance backwards for a moment. The slow caravan moved across the desert with manufactures, and returned with ivory and spices - something in the nature of direct barter. The wind-borne vessel urged its perilous way over the face of the waters with merchandise for sale abroad, where the master - often both navigator and merchant - purchased goods for sale at home. There were not only perils of the deep for these tiny craft, but very material danger of piracy on the high seas; and in those days there were no protective insurance policies. If settlements had to be effected, the master had to carry metallic money, or this had to be sent - with loss of interest in transit and the attendant dangers of wave and buccaneer.

The business men of that day - the Jew and the Italian - were far too keen-witted to keep on running these risks indefinitely, and in the fourteenth century they invented the Bill of Exchange. They literally turned money into paper, re-convertible only under certain stipulated conditions, so that settlements effected abroad might be placed beyond the reach of the roving pirate. "The Lombards (bankers) of those days invented the letter of change (credit), which immaterialised their wealth, made it portable, imperceptible, defying the confiscation of persecutors."

To-day the Bill of Exchange enters into every transaction between countries, and facilitates trade to an extraordinary degree, as we shall see presently.

What then, precisely, is a Bill of Exchange? 
Prosaically it is this: An unconditional order in writing, signed by the Drawer, addressed to some person (the Drawee) demanding the payment of a certain sum at some definite future date to the order of a third party (the Payee). A Bill of Exchange pre-supposes a debt, and the document is not complete until it is "accepted" by the Drawee - the man who is receiving the goods, and who owes the money. When duly completed it is transferable by endorsement, and then represents a "negotiable claim to receive money at a date in a distant country."

In form it would read somewhat as follows:

$$
\text { (place) } \quad \text { (date) }
$$

$£$

(amount in figures)

Sixty days after sight of this first of Exchange (second and third of same tenor and date being unpaid) Pay to the order of the

(Payee)

sum of .......................... for value received.

(amount in writing)

To

(Drawee)

Signed

(Drawer)

Address

Now that would be a fairly complete description of a Bill of Exchange, but it would be a pity, for his own sake, if the describer saw no more in the document than just that.

To the eye of imagination it is a veritable (and beneficent) Dragon, traversing the world's marts in its ceaseless sea for debts to devour. It is a dexterous shuttle, 
darting to fro through the intricate web of international transactions, and settling a debt at each move.

The reason is because a Bill of Exchange, when accepted, rarely remains dormant. The Payee is usually a banker, at any rate a Bill negotiator, who takes his percentage toll of the original Drawer in an exchange charge when negotiating the Bill at the Export point. Once accepted the Bill is an order for a certain sum, at a certain date ahead, usually in London; and people all over the world want those London orders to settle debts of their own. So the Banker, after acceptance, usually sells the order to some other party, who happens to wish to settle his own debt by a London Bill; and the recipient often passes it on again in quittance of some further obligation - and so on. It is always the same order; but at each transaction it has cancelled a debt - and saved a transmission of coin in settlement. At each stage a fresh endorsement is added to the Bill, and sometimes an extra piece of paper ("allongement") has to be pinned on, to carry the additional names.

In its utilitarian journeying the Bill may visit a dozen countries for a London Bill is in demand universally. If for the sake of illustration we isolate two countries, and imagine the sum of their mutual transactions to be exactly balanced - then Bills of Exchange, passing to and fro, would do the whole business without the need of transmitting one piece of coined metal. As coin transmissions are troublesome and expensive, the facilitation to trade implied by the Bill of Exchange is enormous. Let me give a simple two sided instance of how the thing works:

An Englishman "A" buys cotton from an American, "B", and the latter, when he ships the goods, draws on A in England. B sells the Bill in New York to another American, "C", who has imported, and has to pay for, English manufactures. C transmits it by post to the English exporter, "D", who presents it to A for acceptance: and one payment of cash at maturity closes the circle of transactions. In practice the American exporter B does not actually hunt round New York to find his importing compatriot C: the former sells to a Bank and the latter buys from a Bank - but in their essence the transactions cancel one another as described. The Banks and Bill brokers intervene, and secure a marginal profit by working on the continual demand for accommodation both ways. Even if the transactions were isolated there would still be a total saving of two transactions of coin across the Atlantic and back. 
The world could not compass anything like the present volume of trade if each trader had to separately settle his transaction, with his creditor, in gold. The whole system would shatter in a few days, if only for lack of anything like sufficient gold to go round. The alchemist who performs the marvels is Creditthe instrument is the Bill of Exchange - and the crucible is London.

Why then is London the centre where so many nations are settled? The question is interesting, because settlements are frequently made through London, in respect of goods (from say Sydney to Shanghai - or New York to Yokohama) which never touch England's shores: the goods may go from anywhere to anywhere: the settlement is usually made through London. The obvious circumstance that it pays to do so really gets us no further: for one might reasonably assume that no one would settle via London if they could do so more economically through some other centre.

It is because:

- London pays at once - and in gold.

- England trades with all countries, and many are in debt to her.

- London is the one free gold market in the world.

- London carries the largest supply of loanable capital at reasonable rates.

- Her immense mercantile marine: policy of unhampered trade: and sea command all materially assist.

- As a big world's creditor she attracts a large amount of commerce: and so it has come about that in any recognised trading centre there is a larger supply of, and demand for, London Bills than for bills on other money centres

- London at any given moment is said to carry something like $£ 350,000,000$ of bills against produce: and as her gold supplies are paltry in comparison, it is obvious that credit enters largely into the calculation.

- Possibly the most important factor of all is the worldwide and unquestioned belief in British mercantile integrity.

In any large population centre the Banks effect their mutual cheque and note settlements through a Clearing House Totals are set against totals: and only the differences are paid in coin. In much the same way London has become 
the world's Clearing House for international settlements in Bills of Exchange: and her extraordinary structure of credit, upon a comparatively small supply of actual gold, is one of the greatest wonders of this or any other era. It is only rendered possible because the transactions are backed by England's reputation for scrupulously honourable dealing.

\section{C.I.F. transactions}

A "cost freight and insurance" transaction, as usually understood in business circles, may be described as a cable offer to lay down certain commodities at some foreign port at a definite landed cost. The exporter makes up his calculation of local cost, adds freight, insurance, handling, exchange, and his profit; and so arrives at a figure at which he is prepared to land the goods at a quay in the named port of the buyer's country. He cables accordingly, and the buyer either accepts or cables a counter offer. In either case a couple of days may suffice to complete a transaction involving some thousands of pounds' value - say from Adelaide to Hamburg - between total strangers.

Now, one of the necessary features in such a rapid transaction between two centres 12,000 miles apart is that that the seller should be assured that he will be paid. He may know little or nothing about the financial standing of the buyer, but under the extraordinarily efficient business methods now in vogue this creates no difficulty whatsoever. In making his offer, the seller merely asks the buyer to set up a cabled Bank credit. If the transaction is fixed, the buyer arranges this and directly the seller gets the confirmation from the local agents of the foreign Bank, he goes straight ahead.

The local banker negotiates his Bill of exchange on the buyer's London agents, and if he has adhered to the stipulated conditions as to quality of goods, time of shipment, \&c., he has nothing else to fear. Such a transaction - easily effected - indicates not merely the tremendous quickness of modern transactions, but also their safety. While business men have thus bent science to their purposes, they have by no means abandoned reasonable precautions.

Truly, then, it may be said that commerce to-day is invested with a mantle of wonders. Four magic words - and on the other side of the world, $£ 50,000$ 
obediently turns itself over, within the day, into the pockets of the appointed recipient. Nor is the modern Prospero a very awe-inspiring person. On the street he resembles other men, and is usually quite a mild individual. His wonderworking Ariel is the telegraph operator, and the magic incantation reduces itself to the inspired "ticking" of the Morse code.

A man sits at his desk in a Sydney counting house, and is presented with a piece of paper giving him the similitude of a message issued an hour or two earlier in Manila, and which has traversed the ocean beds with lightning speed to find him. It asks him to quote the lowest price at which he can land a cargo of wheat at Manila - by sailer - shipment within a certain period, reimbursement by 60 $\mathrm{d} / \mathrm{s}$ draft on the London representative of the Manila merchant. Three or four cypher words convey all this in a cabled message; in itself a unique testimony to man's ingenuity.

Without moving from his desk the Sydney merchant speaks - along a slender wire - across the housetops, or under the pavements - to his wheat broker, and his ship broker: and presently the one tells him of the suitable vessel, and the other of a line of wheat guaranteed "fair average quality." He makes his calculations: and, within an hour or two, a return message traverses the ocean beds, telling the Manila man the exact price of a cargo, by a certain vessel within a certain time. A reply comes back to accept possibly next day: and the transaction is sealed. To-day, for business purposes, Adelaide is closer to Vladivostock or Hamburg than a century ago two places on the mainland one hundred miles apart. Yet there are some of us who would argue that, while marvels may exist in the universe, such are not to be found in the dull grooves of commerce. 


\section{6}

\section{Problems of transportation, and their relation to Australian trade and commerce}

\section{David J. Gordon ${ }^{1}$}

The problem of transportation is the problem of civilisation. National progress rests upon production - the full use of natural resources - and production and distribution determine trade and commerce, and profitable business ultimately regulates wages and governs the standard of living. At one time economists held that Commerce made transportation and controlled it. The accepted axiom today is that transportation determines commerce by encouraging or checking industrial growth. Not mileage, but the cost of carriage is the true commercial measure of distance. The traders who can reach the markets of the world most cheaply control the commerce of the world. Railways, roads, and rivers, are factors of the first magnitude in the industrial and social life of a nation, for unless transportation is available production in excess of the most elementary personal needs is useless and commerce impossible. The theory of efficient means of transit is reducing the unit in the cost of production. Increased production stimulates consumption, multiplies avenues of employment, and adds to private and national wealth from which the community draws daily sustenance.

\section{Australia as a wealth producer}

Australia is essentially a producing country. Public credit has been pledged for money to build railways and roads and make harbours in order to facilitate the development of resources and shipment of products on such an economic basis

1 Sixth Joseph Fisher Lecture, 28 April 1914. 
as will meet all costs, and leave the grower, carrier, and trader a margin of profit. The State, having a monopoly of railway carriage in Australia, is the chief arbiter in breaking down distance from the point of production to the seaboard, and thus the question of multiplying trade routes and keeping them open is one for the public to study and appreciate.

The producer cannot live in remote parts unless modern channels of communication are provided and without the winning of wealth from the soil and the mine, the country would speedily revert to the desolate conditions recorded by early explorers. In order to appreciate the national importance of problems of transportation it is essential that there should be a clear understanding of what has been accomplished by a mere handful of people in occupation of a Continent larger than the United States, more than three-fourths the size of Europe, and twenty-five times as large as either the United Kingdom, Norway, Austria, or the Transvaal.

The annual wealth produced in Australia was $£ 114,585,000$ in 1901 , $£ 174,503,000$ in 1909 , and $£ 188,000,000$ in 1911 . The value of Agricultural products increased from $£ 23,000,000$ in 1901 to $£ 25,000,000$ in 1906 , and $£ 39,000,000$ in 1911. Pastoral and dairy products in the same years were worth

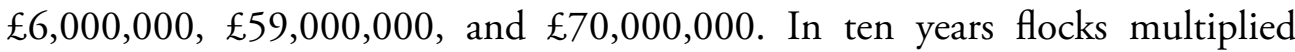
from $53,000,000$ to $93,000,000$ and herds $7,000,000$ to nearly $12,000,000$. The approximate value of plant and machinery employed in our factories was $£ 24,686,000$ in 1907 . By 1911 it had risen to $£ 31,600,000$. The output of the factories in 1907 was $£ 86,000,000$ and in $1911 £ 133,000,000$. Salaries and wages paid by manufacturers rose in the same period from $£ 18,000,000$ to $£ 27,531,000$. In 1911 the mines of Australia yielded nearly $£ 24,000,000$ bringing the value of mineral production recorded to the end of 1912 to the colossal total of $£ 784,000,000$. In 1908 Australia’s total interchange was $£ 114,000,000$. It rose to $£ 116,000,000$ in 1909 , and reached, $£ 134,000,000$ in 1910 . In 1912 our total trade was $£ 146,000,000$ a truly marvellous record for less than five millions of people in occupation of a great continent.

Rural expansion and a corresponding increase in production and growth of trade largely depends upon improved land and sea transport. Professor Gregory, the well-known Geologist, was a keen observer and an outspoken critic, and as the result of his investigations during his sojourn in Australia he wrote: "The difference 
between the pastoral and agricultural lands of Australia is relative. It depends upon their accessibility by railway as well as on the rainfall. At first the western plains of Victoria were of value only for pastoral purposes, but as the railways extended across them, as towns grew up on their borders, providing better markets for perishable produce, and as a denser population afforded a better labour supply, pastoral districts have become agricultural. The four railway lines that traverse the north-western plains of Victoria have converted land once barely of any value, even for pastoral purposes, into the great granary of the State. And as the arid plains of the interior of the continent rest mainly upon rocks of primary composition, their soils are rich in food materials, and could be used for agricultural purposes whenever there is an adequate water supply, and transport for crops."

Australian experience has proved: (l) That the natural volution from pastoral occupation to agricultural settlement, and mixed farming can be accelerated by cheap transport methods, and (2) that the limit of industrial expansion in Australia is not necessarily a question of rainfall.

The promise of future expansion due to increasing activity in the development of latent resources, cannot be fulfilled unless there is a simultaneous growth in railways, and improvements of roads and rivers. In other words, the commercial prosperity of Australia cannot continue on its present level without increased attention being devoted to the economic influence of improved land and water carriage. That is the problem which the present generation must face not in the spirit of spoilers, concerned only in immediate exploitation, but rather with due regard for the sacred obligation of stewardship of a continent - an important outpost of a virile Empire.

A short time before the close of a life devoted to the writing of history, and an active participation in politics, Lord Macaulay, writing to a friend in the United States said: "As long as you have a boundless extent of fertile, unoccupied land, your people will be far more at ease than the people of the Old World. But the time will come when population will become congested, and thousands of persons will be idle. Then your institutions will be brought to the test!"

An American writer of note admits that this remarkable prophecy has been realised, partly because Americans have taken no thought of the morrow. They 
have exhausted fertile lands without stopping to rest and replenish them. They have devastated the forest; worked out mineral fields: neglected waterways; and generally conducted national affairs with a prodigality bordering upon criminal extravagance. Such waste is a warning to younger countries not to overlook the importance of conserving natural resources.

\section{Object lessons from other countries}

What are the object lessons to be derived from other lands where some of the problems under consideration have been faced and solved? The development of transportation systems and lines of communication preceded and made possible the marvellous industrial expansion of the United States. "When the Union Pacific Railroad was completed in 1869," writes Van Hise (Centralization and Control), "it was thought to be a mighty achievement. It was accomplished only through liberal, indeed extravagant, federal grants and guarantees." As in Australia at the present time there were those who scoffed at these so called "desert" railways and predicted the loss of public and private capital invested in them. Now there are six Continental railways stretching from the Mississippi to the Pacific Coast! "The increase in the railway mileage east of the Mississippi has gone on with accelerating speed. Thus the United States is linked together by agencies of transportation and communication. A large proportion of the population lives within half a dozen miles of a railway. It is only in the sparsely settled places of the United States that a railway is ten or twenty miles distant. Railway speeds and weights have been increased. A few trains move passengers and valuable freight a thousand miles in twenty-four hours! The freight and passenger rates have steadily fallen. Since 1864 the charge on a bushel of wheat, in car load lots, from Chicago to New York - 1,000 miles by the shortest route - has been reduced from one penny to one-tenth of a penny.

Heavier, cheaper products, such as coal and iron ore are transported in great quantities at a cost of about one-fifth of a cent a ton-mile (one-tenth of a penny). It may cost a farmer who lives twenty miles from a railway more to get his wheat to the station than it does from there to the ultimate market."

An American economist writes: "The most virile and effective physical agency for making this country great and prosperous is our magnificent railway 
system of 243,000 operative miles, a system when necessary is worked twenty four hours a day and 365 days in the year. These railways have opened up new and vast territories; converted useless mines into producers of fabulous wealth; transported cereals of the western farmers to the distant cities and seaports; found profitable markets for the fruits of Florida and California and returned to them the manufactured products of the East. No tribute to the services rendered by the railways of the United States can be made too strong, and it is safe to say that the direct effect of railroad transportation has been not only to keep down the cost of living, but even to make living in large cities a possibility."

In the United States during the last ten years while the population has increased by 21 per cent; the railways have added to their operative mileage by 24 per cent; the number of locomotives by 54 per cent; the number of freight cars 50 per cent; capacity of freight cars 107 per cent; while during the same period the national conscience has been aroused to an increased use of inland waterways in solving of problems of transportation to meet the growing requirements of trade and commerce.

In "Canada as an Imperial Factor" our recent visitor - Mr. Hamar Greenwood, M.P. - writes: "Modern life depends upon the railway, which triumphs over all obstacles and connects the most distant parts. In Europe the railway man follows the roadmaker, and the riverman, to supply an existing need. In Canada he is a pioneer going into regions where no man has trod, creating the need and bringing the roadmaker in his train. When federation was discussed in the early days, the leaders saw clearly that without a railway there could be no United Dominion. Soon three railways will cross Canada from East to West and one from North to South, all bringing prosperity in their train.”

In their bold policy of transcontinental railways the United States and Canada have provided a fine object lesson for Australian statesmen to emulate. Australia can never be regarded as a self-contained Commonwealth until South is lined up with North, and East is bound by ribbons of steel to West. Lord Cromer reminds us that the modern Imperialist "will not accept the decrees of Nature" and progressive Australians should not be deterred in their bold schemes of nation building by the fears of provincialists to whom unknown parts of the Continent are always "desserts". Several of the Provinces made the stipulation 
when joining the Canadian federation that they should be linked up by railways and had it not been for a similar undertaking Western Australia would not have become part of the Commonwealth, neither would South Australia have transferred the Northern Territory. The building of the Trans-Australian EastWest Railway is therefore merely observing a portion of the national obligation accepted by the people of Australia. The other part will not be honoured until Adelaide shall have been connected with Darwin by railway. Alaska, a country of great wealth, already proved, is a land of desolation because of the vast distances and the prohibitive rates of land carriage. The problem of transportation is to be solved for Alaska by a bold railway policy estimated to involve an expenditure of, $£ 7,000,000$, but Alaska to-day is no worse off than is Central Australia where the only means of transportation in the twentieth century is the system (camel train) which was available when the first Pharoah was developing Egypt! If a miner in the McDonnell Ranges wants machinery from Adelaide, it is sent 700 miles by railway to Oodnadatta, and placed in the station yard to wait the pleasure of an Afghan, the arbiter of transportation in Central Australia!

The Northern Territory (Federal) Royal Commission has pointed out that the isolation of the Territory is reflected in the exceedingly high rates of inland carriage. "Rates on the railway from Darwin to Pine Creek, 150 miles, range from $£ 3$ upwards per ton. As the roads are closed for several months in each year during the wet season, the teamsters are compelled to fix rates at a figure which will compensate them for the long period of enforced idleness. In the mining districts of the North cartage averages 2 s. to 3 s. per ton per mile! The same disability exists in regard to the development of the pastoral country. Carriage from Burketown in the Gulf of Carpentaria to stations on the Eastern border of the Territory costs $£ 10$ to, $£ 12$ per ton. To Brunette Downs, 430 miles from Burketown, up to $£ 20$ has to be paid. From Boorooloola to the same centre on the tablelands the rate is $£ 12$ per ton. The southern and central portions of the country, served mainly from South Australia, are subject to similarly high charges. Carriage by rail from Adelaide to Oodnadatta is, $£ 7$ per ton. From Oodnadatta to Alice Springs the rate is $£ 10$, and to Newcastle Waters $£ 23$. The average cost of carriage from Oodnadatta to Arltunga Goldfield is $£ 14$ to $£ 17$ per ton. It is clear that, with such a high rate of transport charges, development suffers extreme handicap. "Without transportation the hinterland of Australia must continue to be unproductive and unprofitable an economic waste. "The Trans-Siberian railway" says Viscount Bryce "is the one 
big factor that worked the evolution of Japan and is civilising Russia as well," and railways will do much to solve the problem of Central and Northern Australia.

In a recent address on "Geography and Statecraft" Lord Milner clearly indicated that railways had helped to consolidate South Africa and made Union possible. He said: "Then came the railway, by far the most potent of modern inventions in transforming the life of mankind, potent and revolutionising everywhere, but most of all in thinly populated and newly settled countries, and, among those, of incomparable potency in South Africa, owing to the vast distances which separate the chief centres of European settlement, and to its almost total lack of navigable waterways."

The author of "The Argentine in the Twentieth Century" attaches great importance to the influence of railways in the economic development of the Republic. The constant expansion of its network of railways is regarded as a necessity to the Argentine. The Trans-Andean Railway across the Cordillera, connects the Argentine and Chile and represents the completion of a bold railway scheme. The Argentine Republic provides many examples for Australian railway managers in the carriage of livestock. In that country stock trains take precedence over other traffic, with the exception of a few express trains. Cattle are not allowed to remain in a truck continuously for more than twenty-four hours. A recent report on the possibility of obtaining supplies of meat from Australia stated that owing to the methods of moving stock by rail considerable depreciation in quality took place between the locality of production and the seaboard. This, it was said, would mean a heavy daily loss to producers should the meat export trade from the Commonwealth grow to large proportions. The transportation of livestock by railway in most States of Australia leaves much to be desired and stock owners are continuously pressing for reforms.

The accepted policy of Germany towards transportation problems has been officially stated in the following terms: "Any means whereby the distances which separate the economic centres of the country from one another can be diminished must be welcomed, and considered as progress, for it increases our strength in our industrial competition with foreign countries. Everyone who desires to send or receive goods wishes for cheap freights. Hence the aim of a healthy transport policy should be to diminish as far as possible the economically unproductive cost of transport." 
"One of the most important factors in the development of industry" (says the author of Industrial Germany) "the opening up of the Home Market, and even to some extent the promotion of foreign trade, has been the wise use of the German railways." Before the German railways were nationalised there were 600 different sets of rates. Since 1910 rates for passengers have been uniform throughout Germany, and those for goods virtually so. Although each German State manages its own lines, and so far as possible regulates its policy according to what it conceives to be the best interests of its own population and territory, there is a 'Central' Railway Office, similar to the Railway Clearing House, London, which exercises a kind of federal supervision the objective being to make for uniformity of charges, management and exchange of rolling stock.

\section{Australian railways}

Of the total public debt of Australia more than one half is represented in its 17,000 miles of railway by means of which products are transported to home and oversea markets and national and private wealth is multiplied and distributed. The railways alone - not to mention other public utilities - represent more than adequate security to Australia's creditors. The length of Australian lines has steadily increased until the figures for 1913 reached a total of over 17,000 miles. This gives 34 miles of railway for every 10,000 people in the Commonwealth as against the Untied States 27 miles for every 10,000 people where the density of population removes any significance in the comparison excepting that the figures prove that there has been a progressive policy of railway extension in Australia where, it should be remembered, the public credit has to be pledged whenever a new line is authorised. In that respect the comparative figures are not without their lesion. The train miles run in Australia were 58,168,409 in 1913, or nearly double what they were ten years ago. (table 6.1)

Table 6.1: Train miles run

\begin{tabular}{l|l}
\hline 1904 & $33,500,000$ \\
\hline 1907 & $38.600,000$ \\
\hline 1910 & $46,200,000$ \\
\hline 1913 & $58,168,409$ \\
\hline
\end{tabular}


The total cost of construction rose form $£ 131,303,098$ for the 13,474 miles open for traffic in 1904 to $£ 171,226,323$ for the 17,775 miles available in 1912 . The total revenue received from these public services was $£ 11,193,7454$ in 1904 and $£ 19.954,073$ in 1913 . Total working expenses have been nearly doubled in the same period having increased from $£ 7,205,812$ in 1904 to $13,594,569$ in 1913 the percentage of working expenses to gross revenue for these years having been respectively 64.37 per cent and 68.13 per cent. The lowest point reached during the last ten years was 57.18 per cent in 1907. The net earnings of Australian railways per train mile run (table 6.2) have varied from $28.54 \mathrm{~d}$. in 1904 to $37.07 \mathrm{~d}$. in 1907 and 26.24d. in 1913. The percentage on cost of construction and equipment has fluctuated from 3.04 per cent in 1904 to the highest point 4.43 per cent in 1911 and 3.71 per cent in 1913.

Table 6.2: Net earnings of Australian railways

\begin{tabular}{l|l|l}
\hline Year & Per train mile run (pence) & Per cent on cost of construction and equipment \\
\hline 1904 & 28.54 & 3.04 \\
\hline 1905 & 31.51 & 3.28 \\
\hline 1906 & 35.37 & 3.91 \\
\hline 1907 & 37.07 & 4.37 \\
\hline 1908 & 34.38 & 4.24 \\
\hline 1910 & 32.43 & 4.14 \\
\hline 1911 & 31.89 & 4.19 \\
\hline 1912 & 31.77 & 4.43 \\
\hline
\end{tabular}

Allowing for all charges there has been a profit each year on the working of Australian railways since 1905 , in which year the loss amounted to $£ 465,000$. The largest credit margin was $£ 1,401,789$ in 1911 - a year of high tide in production and prosperity - but the profit fell to $£ 404,164$ in 1913 on account of unfavourable seasonal influences. In 1913, 3,098 locomotives and 67,199 vehicles were employed on all lines as compared with 2,266 engines in 1904 and 44,653 vehicles. The "passenger journeys" increased from 116,391,004 in 1904 to 
249,856,206 in 1913 and the tonnage of goods and live stock from 15,728,776 tons to 26,964230 in the same period. On the mainland railways the tonnage handled rose from 9,869,231 tons in 1897 to 26,229,000 tons in 1913 statistics which are most significant in connection with problems of transportation when it is remembered that there are three different gauges. (table 6.3)

Table 6.3: Tonnage handled in five states during the years ending 1897 and 1913

\begin{tabular}{l|l|l}
\hline \multirow{2}{*}{ States } & \multicolumn{2}{l}{ Tonnage handled } \\
\cline { 2 - 3 } & $\mathbf{1 8 9 7}$ & $\mathbf{1 9 1 3}$ \\
\hline New South Wales (4 ft. 81/2 in. gauge) & $4,173,880$ & $11,400,000$ \\
\hline Victoria (5 ft. 3 in. gauge) & $2,383,000$ & $5,150,000$ \\
\hline South Australia (5 ft. 3 in. \& $3 \mathrm{ft.} 6$ in. gauge). & $1,210,000$ & $3,016,000$ \\
\hline Queensland (3 ft. 6 in. gauge) & $1,243,603$ & $3,797,000$ \\
\hline Western Australia (3 ft 6 in. gauge) & 858,748 & $2,866,000$ \\
\hline Total & $\mathbf{9 , 8 6 9 , 2 3 1}$ & $\mathbf{2 6 , 2 2 9 , 0 0 0}$ \\
\hline
\end{tabular}

(South Australia and Western Australia will be connected by a 4 ft. $81 / 2$ in. gauge, Port Augusta -Kalgoorlie.)

A successful effort has been made to increase the average freight-paying load carried per train. In New South Wales it has risen from 66.32 tons in 1902 to 90.57 tons in 1913: South Australia from 69.09 tons to 100.42 tons (the highest point reached in Australia); in Tasmania from 25.26 tons to 31.17 tons; but in Western Australia there has been a decrease from 74.67 tons in 1902 to 67.25 tons in 1913. The freight charge per ton of agricultural produce in truck-loads (table 6.4) varies considerably in all the mainland States the lowest rates being charged in New South Wales and the highest in South Australia and Western Australia where the rates for hauls of 50, 100, 200, 300, 400, and 500 miles are in every instance above the average for the Commonwealth. The same comparison prevails in respect to mileage rates for ordinary goods (highest and lowest class freights) (table 6.5) the charges in New South Wales and Victoria being below the average for the Commonwealth, and the rates in Queensland, South Australia and Western Australia being above, with a few exceptions in the shorter hauls. 
These comparative statistics of freight rates represent an important factor in transportation in the high charging States and call for the closest examination and thought from responsible authorities. The average rate received by the railways in the United States for hauling one ton of freight one mile is 0.375 pence (table 6.6). The rate in England for the same service is 1.125 pence, or more than three times as much, while in South Australia it is $0.97 \mathrm{~d}$. and in New South Wales $0.88 \mathrm{~d}$., or more than double the rate in the United States and slightly less than the English charge.

Table 6.4: Rates for agricultural produce in truck loads on Australian railways, 1913

\begin{tabular}{l|l|l|l|l|l|l}
\hline & \multicolumn{6}{l}{ Miles } \\
\cline { 2 - 7 } & $\mathbf{5 0}$ & $\mathbf{1 0 0}$ & $\mathbf{2 0 0}$ & $\mathbf{3 0 0}$ & $\mathbf{4 0 0}$ & $\mathbf{5 0 0}$ \\
\hline Average & $5 / 8$ & $8 / 8$ & $11 / 6$ & $13 / 9$ & $16 / 3$ & $18 / 3$ \\
\hline Average per ton mile (pence) & 1.36 & 1.04 & 0.69 & 0.35 & 0.48 & 0.43 \\
\hline
\end{tabular}

Table 6.5: Ordinary goods mileage rates on Australian railways, 1913

\begin{tabular}{l|l|l|l|l|l|l}
\hline \multirow{2}{*}{} & \multicolumn{6}{l}{ Charge per ton for a haul of miles } \\
\cline { 2 - 8 } & $\mathbf{5 0}$ & $\mathbf{1 0 0}$ & $\mathbf{2 0 0}$ & $\mathbf{3 0 0}$ & $\mathbf{4 0 0}$ & $\mathbf{5 0 0}$ \\
\hline Average & $29 / 9$ & $53 / 8$ & $97 / 9$ & $133 / 1$ & $159 / 4$ & $179 / 9$ \\
\hline Average per ton mile (pence) & 7.14 & 6.44 & 5.86 & 5.35 & 4.88 & 4.31 \\
\hline & \multicolumn{7}{l}{ Lowest class freight } \\
\hline Average & $4 / 2$ & $7 / 6$ & $11 / 1$ & $15 / 1$ & $18 / 5$ & $21 / 7$ \\
\hline Average per ton mile (pence) & 1.00 & 0.84 & 0.66 & 0.60 & 0.55 & 0.51 \\
\hline
\end{tabular}

Mr. Herbert Gibson, an old resident in South America, in the course of a paper read at the Royal Colonial Institute, London, this year, said: "I had occasion some years ago at the request of the Editor of a well-known Australian Journal (The Pastoral Review) to make a comparison between the rate of railway freights in Australia and the Argentine: and, taking various units of staple products and their cost of transportation for various distances, and comparing the quotations furnished me from Australia with those I had access to in the Argentine, I found 
that in every case the cost of transport was lower in the South American Republic than in Australia."

Table 6.6: Average ton-mile and passenger rate

\begin{tabular}{l|l|l|l}
\hline & $\begin{array}{l}\text { “P” Private } \\
\text { "S” State }\end{array}$ & $\begin{array}{l}\text { Average ton-mile } \\
\text { (pence) }\end{array}$ & $\begin{array}{l}\text { Average passenger } \\
\text { rate (pence) }\end{array}$ \\
\hline United States & $(\mathrm{P})$ & 0.375 & 1.001 \\
\hline Germany & $(\mathrm{S})$ & 0.7 & 0.6 \\
\hline Austria-Hungary & $(\mathrm{S})$ & 0.75 & 0.5 \\
\hline Belgium & $(\mathrm{S})$ & 0.625 & 0.375 \\
\hline Switzerland & $(\mathrm{S})$ & 1.28 & 0.65 \\
\hline France & $(\mathrm{P})$ & 0.775 & 0.67 \\
\hline Great Britain & $(\mathrm{P})$ & 1.125 & 1.125 \\
\hline Norway & $(\mathrm{S})$ & 1.0 & 0.58 \\
\hline Norway & $(\mathrm{P})$ & 1.3 & 0.58 \\
\hline Denmark & $(\mathrm{S})$ & 0.72 & 0.38 \\
\hline South Australia & $(\mathrm{S})$ & 0.97 & 9.25 \\
\hline New South Wales & $(\mathrm{S})$ & 0.88 & 8.87 \\
\hline West Australia & $(\mathrm{S})$ & 1.94 & - \\
\hline Tasmania & $(\mathrm{S})$ & 1.94 & - \\
\hline Commonwealth & $(\mathrm{S})$ & - & 8.08 \\
\hline
\end{tabular}

(The absence of uniformity in compilation of statistics prevents a complete comparison.)

The density of population is an important factor in rates of transportation and especially averages. By far the greater population in Australia is confined to a fringe of country near the coast and the proportion of light traffic over long distances through country sparsely populated, is greater in Australia than in America or Europe.

\section{Neglect of geographical outlets}

In general terms it can be affirmed that in Australia production has kept ahead of the means of transportation and that Trade and Commerce have suffered because of the absence of modern facilities of carriage on the one hand, and the congestion of traffic on the other, due to the crime of centralisation. In some 
countries - notably the United States, Canada, and the Argentine - the policy has been for the railway to precede settlement - the theory being that "trade follows the train." In Australia the practice generally has been to wait for country to be pioneered and proved before spending money on public utilities. Indeed it not infrequently happens that districts which come suddenly into prominence during periods of prosperity are granted railway facilities while older and even more productive localities are overlooked or ignored. The neglect of geographical outlets in Australia represents a daily enormous waste. Produce is dragged hundreds of miles through mountain passes and across wide plains away from natural channels. It is not necessary to give specific examples, because this policy is familiar to Australians, who unanimously concur in condemning centralisation, but do nothing to stop this waste of effort and wealth. Greece and Rome went to their doom because they neglected the fields and allowed population to gravitate to the cities. In Australia 38 per cent of the total population live in metropolitan areas, and this unhealthy condition is mainly due to the policy of centralization - the pull of city interests - faithfully observed by successive Governments and managers of State-owned railways.

In this connection Professor Hugo Meyer (Professor of Political Economy in the University of Chicago) who is at present in Australia studying the Railway system of the country, offers some pointed criticisms. He has already made a prolonged study of the railways of the United States, Germany, France, AustriaHungary, and in his book on "Government Regulation of Railway Rates" he says:"In the Australian Colonies, the Railways, which are owned and operated by the several States, have refused to introduce the basing-point system, with the result that there are, generally speaking, no interior distributing trade centres so that all trade is concentrated in the seaboard cities, such as Melbourne, Sydney, and Adelaide. As the railways have been pushed inland, the enterprising merchants of the local towns have sold out and moved to the seaboard, for the purpose of availing themselves of the advantage accruing to the seaboard merchants from the absence of the basing-point system. In the United States the existing rates have been made as a matter of judgment and arbitration, controversy, and war. They have been heated, and forged, and moulded, and pounded, and hammered into their present shape. The American railways have drafted into their service men of consummate tact and diplomacy - men who in the service of European Governments would have acquired International reputation. Contrast the 
situation in the United States with that in Australia, where the making of railway rates by public authority has concentrated in three seaboard cities the trade that, under the making of railway rates by the railways themselves, would have been distributed among half a-dozen seaboard cities and numerous interior jobbing centres.

"Melbourne contains 45 per cent of the population of Victoria, and handles about 78 per cent of the railway trade of that State; Sydney houses 38.97 per cent of the population of New South Wales, and all thoroughfares concentrate on Sydney until the trade and commerce of that State has become almost hopelessly congested. It was stated a few weeks ago at a public meeting at Wagga (New South Wales) that there were 600,000 bags of wheat awaiting transportation by rail and "at the present rate of removal it will take three years before the last bag reaches Sydney." Because of the policy consistently observed of not taking advantage of geographical outlets the railway system of New South Wales is unable to cope with the present rate of production. Rural expansion is checked by the failure to solve problems of transportation by making use of the nearest ports and owing to repeated refusals on the part of Governments and railway managers of that State to utilise available waterways to relieve the congestion.

Queensland, in which State the railway terminals are at the nearest coastal port to the system, offers a better comparison, Brisbane only accounting for 23 per cent of the population. South Australia provides the worst example in the Commonwealth, the Metropolitan population being over 46 per cent of the whole, or 8 per cent above the Australian average which is much in excess of any other country. "To get 45 per cent of the population of the United States," says Professor Meyer, "one must begin with New York and go down and include every place with upwards of 3,000 inhabitants." How is it that so large a proportion of the people in the United States are to be found on the land or residing in inland cities and towns? "Largely because the traffic managers, unhindered by political considerations, have knit the different producing, distributing, and manufacturing sections of the country into a more compact trading unit and a more homogeneous whole than is to be found any where else except in Great Britain. "Mr. Meyer claims they have done it by means of scientific rate devices "outer port differentials, long and short haul practice, group rates, commodity rates." "By such methods the railway managers have built up a heterogeneous 
conglomeration of railway rates, the very essence of which is discrimination. That discrimination is not the result of caprice or favouritism; it is the result of meeting with intelligence the needs of industry and trade - industry carried on at numberless points, and trade flowing in every conceivable direction."

It is the practice in some Australian States to impose a higher freight charge on a finished product than on the raw material, thus penalising country manufacturers and rural labour. At the present time a controversy is proceeding in Victoria which serves to illustrate this vital aspect of the transportation problem and the strong pull of vested interests through even Government-owned railways. The following is taken from a Melbourne paper of recent date: "The disabilities under which country manufacturers suffer as the result of high railway freights are manifold, and it is claimed that as a result of them many factories outside the metropolis are on the verge of closing up or of removal to the city. It is urged that as railway freights are collected on fully half the goods that inland manufacturers use for production, a continual revenue being thus assured to the department from the very fact of industries being established in the country districts, freight rates on the finished article, which is sent to Melbourne for a market; should be placed on as low a basis as possible. Produce for oversea export is carried at a cheaper rate than produce for home consumption. In the course of a complaint about the disadvantages country manufacturers suffer through high freights being charged on the railways, one of the Bendigo foundry proprietaries says: 'In tendering for a boiler weighing 16 tons, we would pay freight from Melbourne on the plates, angles, rivets $34 / 3$ per ton, and on the boiler when completed, 27/6 per ton from Bendigo to Melbourne. This would amount to $£ 9 / 10 /-$, so that a Melbourne firm could tender this amount less than us and then make the same profit that we do.'

It is cheaper for merchants in Ballarat to send their goods to Melbourne and then consign them back to Adelaide than to send them direct to Adelaide from Ballarat. The freight from Ballarat to Adelaide direct is 144s. per ton, but from Ballarat to Melbourne and back to Adelaide it is only 99s. A Melbourne paper which condemns the "petty provincialism" of New South Wales for seeking to drag Riverina trade 461 miles to Sydney instead of allowing it to flow naturally 214 miles to Melbourne has strenuously fought against trade finding its geographical outlet at any Victorian port other than Melbourne! The same journal opposes the locking of the rivers because of the fear that water carriage might compete 
against Victorian Railways! It is "common sense" to that paper to pull trade to Melbourne, but it is the "narrowest provincialism" when other States play the same beggar-my-neighbour game! The policy of centralisation should be abandoned in favour of utilising natural outlets, thus saving the cost of unnecessary haulage, but before this can be accomplished "federal sentiment" will have to be developed from an illusive theory into a practical, commonsense, tangible thing!

A question that calls for reply is: "Are we as a community employing defective methods of transportation and paying so much for services that the profits on our staples depends too little on the actual cost of production and too largely on cost of carriage?" If so the producer carries a heavy burden, trade and commerce suffer, and the loss to the community represents a waste of national wealth.

\section{Curves, grades and gauge}

A constant source of anxiety to Australian railway managers and of loss to producers and traders and consumers are the curves, grades and variety of gauges - ruinous legacies of previous generations of legislators and engineers. Curves and trades are most wasteful. During recent years $£ 200,000,000$ has been spent in the United States in straightening and levelling railway tracks. Toboggan-like roads have been laughed out of existence excepting in some Australian States where a great deal is still sacrificed to cheapness in the initial stages of construction with the result that the working expenses are out of proportion to earning capacity. Engineers in other parts of the world, when given a free hand, do not hesitate to spend millions in order to save minutes and increase the haulage power of the locomotive. At a cost of $£ 250,000$ grades and curves on one South Australian line were reduced to such an extent that the hauling capacity of each locomotive was increased by one third. The work of levelling and straightening lines must be continued in order to conform to the demands of modern railway management. On a recently constructed railway in South Australia the first grade reduces the haulage capacity of the engine to 120 tons. After a certain point is passed the haulage power is doubled. This involves the departure of two sets of trains with working staffs in order to make up one load at the nearest station to the point where the heavy grade is reduced. This represents a considerable increase in working expenses which if not paid by the settlers in the district served must be 
borne by the general community as owners of the railways. On another system the grades fluctuate so rapidly that the train is raced on the down grade in order to give sufficient impetus to climb the incline across the narrow valley! Such a system of construction is false economy representing as it does a constant drain on the resources of the department and a heavy tax on the traffic. Such economic factors as these have induced the railway companies of the United States to spend the millions referred to in straightening existing lines and reducing grades. "A given type of locomotive," says one authority, "can haul over a grade of one per cent ( 52.8 feet per mile) a train weight of 810 tons. On the level the same engine can pull 3,869 tons. A one per cent grade means a heavy reduction in engine hauling power and a corresponding tax on the users of the line. If the grades were reduced from 52.8 feet to 21.12 per mile the power of the engine would be increased from 810 tons to 1,596 tons." Imperative instructions were issued to the constructing engineers of the Grand Trunk Pacific line (Canada) that low grades must rule no matter what the initial outlay might be in making a "straight level line" even through mountains.

The Chairman of the Railway Commissioners in Victoria in an official statement points out that although certain types of locomotives in use are equal to those on certain English lines they cannot do the same work owing to the relatively high ruling grades on most of the main lines of that state.

During the last ten years in order to respond to the growing demands of trade and commerce freight cars in the United States have been steadily increased to fifty tons and the haulage power of locomotives has been doubled. Simultaneously grades and curves have been reduced, the whole policy having been dictated by the pressing need to lower transportation charges and correspondingly decrease the cost of production. It was the business acumen of the railway managers that saved the farmers of America during the nineties. By reducing grades and curves and strengthening the roads to allow of an increase in the haulage capacity of locomotives, transport charges, particularly for long distances, were reduced, and this economy neutralized the downward movement in the price of grain and carried the agriculturalist over a period which severely tested the resources of farmers in Australia as well as in other countries. One of the leading railway authorities of America has laid it down as an axiom that "the straight level road wins, every time, and all the time." 
No consideration of the problems of transportation and their relation to Australian trade and commerce would be complete without reference to the colossal national waste represented by the variety of gauges. The Railway Commissioner of South Australia in evidence before a Royal Commission stated that the break of gauge "hung like a nightmare over railway construction work in Australia" and the General Traffic Manager described it as "a curse and a calamity." Railway officials, legislators, traders and the people generally condemn the system but the unanimity of public opinion makes for nothing but delay and a steadily accumulating loss and liability. At the recent Premiers' Conference in Melbourne this important question, directly affecting State Railway interests, was referred to the Federal Interstate Commission. The only result of this diplomatic shelving of a problem of the first magnitude will be delay, and every year the cost of conversion goes up one million sterling! By adopting a gauge of $4 \mathrm{ft} .8^{1 / 2} \mathrm{in}$. for the Trans-Australian Railway (Port Augusta to Kalgoorlie) the Federal Government of the day forced the position and by subsequently obtaining the acquiescence of the Parliaments of South Australia and Western Australia, in the granting of the necessary lands and rights, committed those States to the connection of their respective capitals at each end of the line by the Commonwealth gauge in $4 \mathrm{ft} .8 \frac{1}{2} \mathrm{in}$. That was the time for protest if the gauge was not acceptable, for at least main trunk lines, but the States chiefly concerned submitted to Federal domination and the Commonwealth is finally committed by the work already accomplished on the Trans-Australian Line. In a memorandum dated 11th April, 1913, and addressed to the Minister for Home Affairs the Chief Engineer of the Commonwealth Government and the States of New South, Victoria, South Australia, Queensland, and Western Australia, reported: "The estimated cost of the conversion of all the $4 \mathrm{ft} .8^{1 / 2}$ in. and $3 \mathrm{ft} .6$ in. gauge lines in New South Wales, Queensland, South Australia and Western Australia to a uniform gauge of 5 ft. 3 in. amounts to $£ 51,659,000$ while that of the conversion of all the $5 \mathrm{ft} .3 \mathrm{in}$. lines to a uniform gauge of $4 \mathrm{ft}$. $81 / 2$ in. is $£ 37,164,000$ showing a difference in favour of conversion to $4 \mathrm{ft} .8^{1 / 2} \mathrm{in}$. of $£ 14,495,000$. Dealing only with the $4 \mathrm{ft} .8^{1 / 2} \mathrm{in}$. and $5 \mathrm{ft} .3$ in. gauges in New South Wales, Victoria and South Australia, the estimated cost to convert the $4 \mathrm{ft} .8 \frac{1}{2}$ in. in New South Wales to $5 \mathrm{ft}$. 3 in. is $£ 19,319,000$ : while the conversion of the $5 \mathrm{ft}$. 3 in. gauge in Victoria and South Australia to $4 \mathrm{ft}$. $81 / 2$ in. is estimated at $£ 7,295,000$ - a difference in those States only in favour of the $4 \mathrm{ft} .8 \frac{1}{2} \mathrm{in}$. of $£ 12,024,000$. We think it is desirable to give this particular estimate, as there is a possibility that it might be determined for some time at least to maintain partially the $3 \mathrm{ft} .6$ in. gauge railways in those States in which they are now worked." 
The following resolutions were adopted:

(1) After carefully considering the necessity for uniform gauge from all sides, we conclude that the adoption of a uniform gauge for Australia is desirable at the earliest possible date, for the following reasons among others:

(a) There would be a saving of expense at every break of gauge.

(b) The comfort and convenience of passengers would be enhanced.

(c) It would be imperative in connection with military movements should they at any time become necessary.

(d) It would lend encouragement to traffic as it would facilitate the transfer of goods and passengers, and

(e) It would tend to reduce the total quantity of rolling stock required for railway purposes in Australia.

We wish to emphasise the fact that the longer unification is postponed the more serious will the cost become.

(2) With regard to what is "the most favourable gauge from the point of view of efficiency and economy of working, having in mind the conditions likely to be experienced in Australia" this question was fully discussed from the following standpoints:

- Are existing gauges adequate to meet the needs of Australia, or is it desirable - in view of what is stated to have been the opinion of eminent men - to adopt a wider gauge, such as $6 \mathrm{ft}$. or $7 \mathrm{ft}$.?

- Is a gauge of $3 \mathrm{ft}$. 6 in. equal to requirements? If choice is confined to the $4 \mathrm{ft} .81 / 2$ in. gauges, what is the relative efficiency of each?

- Is there any difference in working cost (a) with the same traffic, and (b) with the maximum traffic that each can carry?

- Are there any advantages with one or the other outside the question of efficiency - such as the possibility of purchasing rolling-stock from other countries in an emergency?

- What advantage is there from the point of view of less cost of conversion in one case over the other?

- We decided to eliminate from selection all gauges wider than $5 \mathrm{ft} .3$ in. thus disposing of the contention that the existing wider gauges are 
inadequate for the needs of the future. We also concluded that the future gauge of Australia should not be less than $4 \mathrm{ft} .8 \frac{1}{2}$ in., leaving the choice between he $4 \mathrm{ft} .8^{1 / 2} \mathrm{in}$. and the $5 \mathrm{ft} .3$ in. gauges.

The advantage of each gauge were the subject of very exhaustive discussion, and it was finally resolved (Mr. J. H. Frazer, Victoria, dissenting) that "The relative advantages of the gauges of $5 \mathrm{ft} .3$ in. and $4 \mathrm{ft} .8 \frac{1}{2}$ in. from the point of view of efficiency and economy of working, and disregarding the question of interest on cost of conversion, approximately balance one another."

As our estimates indicate that the cost of conversion would be very greatly in favour of a $4 \mathrm{ft} .8 \frac{1}{2} \mathrm{in}$. gauge we recommend the adoption of that gauge as the standard for Australia.

(3) The estimated cost of conversion of all lines in the several States to the gauge recommended is as under:

\begin{tabular}{l|l}
\hline New South Wales & $£ 120,000$ \\
\hline Victoria & $£ 6,117,000$ \\
\hline Queensland & $£ 12,578,000$ \\
\hline South Australia & $£ 6,228,000$ \\
\hline Western Australia & $£ 10,840,000$ \\
\hline Commonwealth & $£ 1,281,000$ \\
\hline Total & $\mathfrak{1 3 7 , 1 6 4 , 0 0 0}$ \\
\hline \multicolumn{1}{c}{ Comparison of estimates } \\
\hline $\begin{array}{l}\text { Cost of conversion of all lines in } \\
\text { Australia to the } 5 \mathrm{ft} .3 \text { in. gauge }\end{array}$ & $51,659,000$ \\
\hline Cost of conversion of all lines in & $37,164,000$ \\
Australia to the $4 \mathrm{ft} .81 / 2$ in. gauge & \\
\hline Difference in favour of $4 \mathrm{ft} .81 / 2$ in. & $£ 14,495,000$ \\
\hline
\end{tabular}

The engineers also suggested an alternative "limited" scheme involving an expenditure of $£ 12,142,000$. This they considered "would possibly meet the immediate requirements of Australia, and would from a Federal point of view, be perhaps a more attractive proposition than any other which could be suggested at 
the present time." The issues involved are tremendous in their consequences. The official estimate of converting the $4 \mathrm{ft}$. $81 / 2$ in. lines of New South Wales to a gauge of $5 \mathrm{ft} .3$ in. (including alteration to rolling stock) was $£ 4,260,000$ in 1897 . In 1913 the same work would have cost $£ 19,319,000$, or nearly five times as much! All the $5 \mathrm{ft} .3$ in. gauge lines in Victoria and South Australia could have been changed to a gauge of $4 \mathrm{ft} .81 / 2$ in. in 1897 for an expenditure of $£ 2,360,500$. Today the cost would be $£ 7,295,000$. It is not surprising that these responsible officials urged the desirableness of "adopting a standard gauge at once and carrying out the work of conversion as soon as possible.” The longer this national work is delayed the greater will be the ultimate cost. The advantages of a uniform railway gauge - at least between the capitals -are too obvious to call for argument. The Engineerin-Chief for the Commonwealth said: "The following are some of the advantages which would result from unification. In the case of a shortage of rolling-stock in one State, waggons belonging to another State may be borrowed and brought into use. It has frequently happened in the history of New South Wales that, during droughts, sheep have died of starvation, as owing to the insufficiency of rollingstock they could not all be removed to more favourable localities. If the resources of Victoria could have been taken advantage of, life of stock would have been saved and loss of money would have been avoided. In the same way Victoria or South Australia might at some time suffer from want of waggons, in which case the deficiency could be supplied from surplus stock in New South Wales. It rarely happens that all the States or even all districts have similar reasons at the same time. There would be opportunity offered for the interchange of products. Coal and coke could be conveyed to Victoria, or Victorian and South Australian produce taken into New South Wales when shortage in the latter State occurs. The express traffic between Sydney and Melbourne, and vice versa, is sometimes exceedingly heavy, so that the New South Wales train has to run in three divisions."

The wisdom of the Federal Government of the day in adopting the $4 \mathrm{ft}$. $81 / 2$ in. as the gauge for Australia's Trans Continental and main trunk railways has been the subject of much discussion in view of experiences in other countries and the strong opinions expressed by experts in favour of a broader track.

A leading German engineer writing recently in one of the foremost Continental technical magazines affirms that the railroads have "outgrown their clothes" - that the freight cars used are too small to meet the demands of trade 
and commerce. He therefore proposes to increase the freight cars to 100 tons and broaden the gauge in order to permit of the haulage capacity. In America some freight cars have been increased to 50 tons as against 10 ton cars in Germany. The German engineer contends that a change in railway transportation is inevitable, and he advocates broader gauges.

Eminent American engineers have regretted that the vast American system of railways is built on the $4 \mathrm{ft} .8^{1 / 2} \mathrm{in}$. gauge. The expense of conversion of the enormous mileage is prohibitive, and yet they say the narrow lines are a bar to such an increase of weight in haulage as would be most economical. The widths on the South American lines are as shown in table 6.7.

The Russian railways are $5 \mathrm{ft} .6$ in. Mr. Pym, the Chairman of the Irish railways, says the narrower gauge in England is unfortunate, and Mr. Asworth, a noted English expert, agrees. Railway authorities, like the late Mr. Harriman, are said to have deeply regretted the adoption of the narrow gauge, and to have said that only con version to a broader gauge can overtake the congestion of the traffic. The Indian railways are generally $5 \mathrm{ft}$. Gin. Mr. Hales, M.I.C.E., in a paper to the Federal Government, said: "The largest practicable locomotive on a $5 \mathrm{ft} .3 \mathrm{in}$. gauge would probably be 20 per cent more powerful than the largest locomotive on a $4 \mathrm{ft} 81 / 2$ in. gauge. Carriages and trucks could be made about 10 per cent wider, with a similar increase in carrying capacity. It may safely be affirmed that a railway of $5 \mathrm{ft}$. 3 in. gauge can handle fully 10 per cent more traffic than a railway 4 , $\mathrm{ft} .8^{1 / 2} \mathrm{in}$. gauge at a less cost per passenger mile and per ton mile, and the cost of construction per mile in an easy country like Australia will be little greater." 
Table 6.7: South American railways

\begin{tabular}{l|l|l|l}
\hline & Miles & \multicolumn{2}{l}{ Gauge } \\
\hline Argentine Great Western & & ft. & in. \\
\hline Argentine North-Eastern & 867 & 5 & 6.0 \\
\hline Bahia Blanca \& North Western & 500 & 4 & $81 / 2$ \\
\hline Brazil Great Western & 722 & 5 & 6.0 \\
\hline Buenos Ayres \& Pacific & 917 & 3 & $33 / 8$ \\
\hline Buenos Ayres Great Southern & 3,184 & 5 & 6.0 \\
\hline Buenos Ayres Western & 3,003 & 5 & 6.0 \\
\hline Central Argentine & 1,460 & 5 & 6.0 \\
\hline Cardoba Central & 2,529 & 5 & 6.0 \\
\hline Entre Rios & 796 & 3 & $33 / 8$ \\
\hline Leopoldina & 688 & 4 & $81 / 2$ \\
\hline Nitrate Railways & 1,622 & 3 & $33 / 8$ \\
\hline
\end{tabular}

Table 6.8: Track mileage in each of the states upon which estimates for conversion have been based

\begin{tabular}{l|l|l}
\hline \multicolumn{1}{l}{ Conversion to $\mathbf{4}$ foot $\mathbf{8} \mathbf{1} \mathbf{2}$ inches } & Estimate 1913 (Track miles) & Estimate 1897(Track miles) \\
\hline New South Wales & 100 & 51 \\
\hline Victoria & 5,145 & 3,858 \\
\hline Queensland & 5,350 & - \\
\hline South Australia & 2,021 & 590 \\
\hline Western Australia & 4,225 & - \\
\hline Commonwealth & $\mathbf{6 4 5}$ & - \\
\hline Total mileage & $\mathbf{1 7 , 4 8 6}$ & $\mathbf{4 , 4 9 9}$ \\
\hline
\end{tabular}


Table 6.8: Track mileage in each of the states upon which estimates for conversion have been based cont.

Conversion to 5 foot 3 inches

\begin{tabular}{l|l|l}
\hline & Estimate 1913 (Track miles) & Estimate 1897(Track miles) \\
\hline New South Wales & 6,099 & 3,340 \\
\hline Victoria & - & - \\
\hline Queensland & 5,350 & 2,445 \\
\hline South Australia & 1,111 & - \\
\hline Western Australia & 4,225 & 1,057 \\
\hline Commonwealth & 645 & - \\
\hline Total mileage & $\mathbf{1 7 , 4 3 0}$ & $\mathbf{6 , 8 4 2}$ \\
\hline
\end{tabular}

\section{Rivers as highways of commerce}

In the Murray Australians possess one of the largest rivers in the world, and, with its tributaries, the longest inland waterway system in King George's Dominions! It is not creditable to Australia that navigable streams of such magnitude should have been neglected for so many years. Navigation on rivers cannot be destroyed without abrogating the Federal Constitution, and the Commonwealth Government has given proof of a desire to co-operate in a reasonable settlement of the riparian rights as affecting three States of the Union. The basin of the River Murray and its tributaries comprise 414,253 square miles, an area double that of France and a little more than twice the area of the Ohio River basin in the United States, and a little less than the combined areas of the basins of the Ohio River and the Mississippi River above the mouth of the Ohio, omitting the Missouri River basin. The length of the Murray between Albury and the mouth is 1,366 miles, while the navigable lengths of its principal tributaries - the Murrumbidgee and the Darling - are 1,180 miles and 666 miles respectively, a total navigable distance of 3,212 miles. This length is a little less than that of the Amazon River, South America, about the same as that of the Yangtze Kiang, China, and slightly greater than that of the Hoang Ho, China, and of the Niger River, Africa. The navigable length of the Murray River proper below Albury (1,366 miles) is slightly greater than that of the Mississippi below the mouth of the Missouri. It is essential as part of a solution of the pressing problems of transportation that 
there shall be created a broad, liberal, progressive policy in favour of improving the natural waterways of this country.

At the Fourth International Congress on Inland Navigation in the United States, a resolution was adopted as follows: "The existence and development together of railways and waterways is desirable, first because these two means of transport are the complement of each other, and ought to contribute each according to its special merits to the public good; second, because, viewed broadly, the industrial and commercial development which will result from the improvement of the means of communication must in the end profit both railways and waterways."

Captain Johnston, the Engineer brought from the United States by the Government of South Australia, makes the following observations in the course of his Report: "The transportation of freight from Murray Bridge to Port Adelaide is handicapped by the fact that a range of hills has to be crossed. The length of the line between Murray Bridge and Port Adelaide is 68 miles, and between Morgan and Port Adelaide 105 miles. The size of load is diminished and the cost of transportation increased by the skep grades of these railways. It is understood that the grades of the railways leading from the Murray Valley to Sydney and Melbourne are such as to handicap them seriously in competing with the carriage of freight by water to a port in the vicinity of the mouth of the river. With a view to providing an outlet for the products of the Murray Valley which would permit of their more economical placement on ship board than practicable under present conditions of transportation, the improvement or formation of a harbour in the vicinity of the mouth of the river has been contemplated for many years."

The locking of the Murray and the bringing together of the river boats and oversea steamers would mean a big saving in the carriage of wheat, wool, and other riverine produce. An equally important consideration is that Darling River wool would not be left in the sheds for sometimes two years, owing to low rivers preventing transit to market. Capt. Johnson estimated that the wool forwarded by railway from Bourke in 1890 was 55,000 bales; in 1908, 18,000 bales. On even the smallest quantity there would have been a saving by shipment to Victor Harbour instead of to Sydney of $£ 6,800$. Assuming that all of this wool was taken to Bourke by river boat there would have been an additional saving of 
the cost of transfer from boat to rail. Based on one year's traffic of only 45,000 tons river transport would mean a saving to producers, capitalized at 4 per cent, of $£ 778,000$ ! This authority further points out that "even if goods were carried free of cost between Echuca and Melbourne it would still be cheaper to ship from the Darling to Goolwa or Victor Harbour, because the river distance is less than to Echuca, the haul is downstream instead of upstream. Even if the railway rates were lowered as an offset the settlers of the Murray Valley would benefit from the resulting cheaper rates to such an extent as would probably lead to increased settlement of the valley and increased value of real estate, which would in turn lead to increased revenues to the States through increased value of taxable property, etc., etc. The economic disadvantage of restrictions of trade finding its proper geographical outlet is generally understood through out the world, and in my opinion, there is no doubt that the proper geographical outlet for the trade of the Murray Valley is in the vicinity of Goolwa." Captain Johnston continues: "In my opinion no fear need be had that the establishment of a port at the natural outlet for the great Murray Valley will be detrimental to the interests of the railways. Experience throughout the world indicates that the cheap transportation upon improved waterways of a large tonnage of low grade articles stimulates industrial development and creates an increase of population to such an extent that the revenue of the railways from the carriage of manufactures and other high-grade goods is increased to such an extent as to lead to a net increase in the profits of the railways."

As having a direct bearing upon the advisableness of locking these rivers and constructing such harbour works as would permit of the direct transhipment of goods from barges to ocean vessels, the following is quoted from a report by Lieutenant-Colonel George A. Zinn, Corps of Engineers, U.S. Army: "The cost of producing a commodity is a function of the value of labour, the use of machinery, and various other elements. The cost of the commodity to the consumer is a function of cost of production plus cost of transportation, and since all commodities as above outlined are moved a greater or less distance to reach the consumer, cost of transportation forms a large element in the value of every commodity at any particular place. If the movement of a single shipment of goods is followed from origin to destination it will be found generally that the following operations are involved: 
(a) Loading on a slow and expensive conveyer (animal or wagon).

(b) Conveyance to a storage depot, located at the terminus of (or point on) another system of transportation, for cheaper or more rapid movement (rail or waterway).

(c) Loading on the new conveyer.

(d) Transportation by the new system.

(e) Unloading at terminal or new system (reverse of c).

(f) Loading on and conveyance by a third system, probably slower and more expensive than the second (animal or wagon).

(g) Unloading at destination.

Lessening the cost of any one of the seven operations lessens the total cost of transportation, but the greatest reduction is accomplished by eliminating one or more of these operations. The operation of transfer from one vehicle to another is not only more or less expensive in time and labor, but is, as a rule, detrimental to the value of the commodities - perishable fruits furnish probably the most notable example. The conclusion is obvious, that trans-shipment must be avoided wherever possible, and that a single line of transportation should be used if possible from consignor to consignee, provided also that the method of transportation is the cheapest available."

For many years the Victorian railways carried river borne goods at less than half rates charged for Victorian products transported the same distance. At one time river goods were carried over New South Wales railways from Bourke at less than the charge for similar produce raised one third the distance from Sydney. Mr. Roosevelt as President of the United States when submitting the report of the Inland Waterways Commission to Congress, said: "The development of our Inland Waterways will have results far beyond the immediate gain to Commerce. If the policy of waterway improvement here recommended is carried out, it will affect for good every citizen of the Republic. The first condition of successful development of our waterways is a definite and progressive policy. The improvement of our inland waterways can and should be made to pay for itself so far as practicable. Navigation should of course be free but the greatest returns will come from the increased commerce, growth, and prosperity of our people. For this we have already waited." Mr. Roosevelt's message to Congress in 1908 might 
well be repeated in 1914 to the people of Australia who are not yet persuaded that Nature did not make a mistake in providing a semi-arid portion of the Continent with a splendid system of waterways. There has been appropriated by the United States Congress for the improvement of rivers and harbours in the United States up to January 1 st, $1913, £ 158,910,000$. There are now in course of construction, or maintenance 640 projects for river and harbour improvements. In his speech accepting the nomination for President of the United States, President Woodrow Wilson stated: "It is plain too that vast sums of money must be spent to develop new waterways where trade will be most served and transportation most readily cheapened by them. Such expenditures are national investments." A Conference of the Governors of the States and Territories of the United States declared:- "We especially urge on the Federal Congress the immediate adoption of a wise, active, and thorough waterway policy, providing for the prompt improvement of our streams, and the conservation of our watersheds required for the use of commerce and the protection of our people." At this same conference Mr. Bryan, Secretary of State, said: "I shall not advocate the improvement of these waterways on the ground that such improvement would help to regulate railway rates ... but water traffic is less expensive than traffic by rail, and there are many commodities that can be transported much more cheaply by water than they possibly could be carried on land. If this saving were equally divided between producers and consumers it would be an enormous profit to both."

France has developed her inland waterways more systematically and completely than any other large European country, 3,062 miles of canals and 4,500 miles of rivers being used for navigation. Although the inland waterways systems of England are not generally considered as being very efficient owing to railway control, the traffic upon her 4,000 miles of canals and improved waterways amounted in one year to more than 37,000,000 tons. The United States National Waterways Commission reported that "in France, Germany, Holland, Belgium, Austria and Hungary waterways have attained a high standard of development. This is due both to the fostering care of the States and to private enterprise. In Germany especially, and in fact all countries except England, the increase of inland water-borne traffic has been marked." Every effort has been made by the chief industrial nations of the Continent to provide economical, regular, and speedy transportation of their products to market and of raw material to the factory. In France rivers and canals carry over thirty per cent. Of the country's 
trade and commerce, in Germany, where $£ 30,000,000$ was spent in 20 years in improving inland waterways the proportion is about the same and in the United States, where there has been a return to inland navigation, about twenty-seven per cent. Mr. Andrew Carnegie in his book The Empire of Business refers to the neglect of rivers and canals, and predicts that one of the features of the twentieth century will be a return to water transport. That prediction has come true in every progressive country, with the possible exception of Australia where the dependence upon railways and unmade roads - bush tracks - shows a singular neglect of economical methods of carriage. A German economist has said: "It is economically wasteful not to extend and develop the natural and artificial waterways which a country possesses, and it is absolutely suicidal and criminal to let them fall into neglect and decay." These examples of the national attitude of other countries towards inland waterways are quoted in order to support the national policy of locking the Murray.

Mr. Roosevelt appointed the Inland Waterways Commission because, said one authority, "there is a strong feeling that the nation has worked an injustice by retaining domain over navigable waterways, yet in such manner as to discourage waterways, if not absolutely to prevent navigation. It is even alleged that railways have been so designed as to destroy river carriage." It is a noteworthy fact that while in most countries private interests have opposed the development of inland waterways, the chief antagonists in Australia of river carriage have been the managers of State-owned railways! An officer of the Railway Department of New South Wales publicly boasted that the railway policy was to "fight hard to divert trade, and the department had seen successful in crippling the river shipping industry of the State"! Truly a remarkable achievement for Governmentowned railways! Other State owned railways by tapping the rivers and providing alluring preferential rates have sought, to destroy these natural highways, the chief objective being to make for centralisation by preventing trade flowing through geographical channels and outlets. A prominent Victorian legislator has pointed out that river navigation ought not to be encouraged to the detriment of Victorian railways, even if producers and traders were materially benefited and national wealth increased! Private railway companies in England bought out the competition of canals; while in the United States railway interests checked for some years the development of inland waterways. The author of Industrial Germany says: "The development of the waterways went hand in hand with 
the nationalisation and extension of the railway system. So long as the railways were in private hands the waterways were neglected. The nationalisation of the railways, however, was at once a result and a sign of the State's recognition of the immense importance for national development of efficient transport facilities. Hence the era of State railways was simultaneously an era of canal construction on a large scale, the one means of transport being regarded as complementary to the other. For nowhere out of England is the idea prevalent that the days of the canal as a means of transport for heavy goods, for which quick transit is unessential, are over. Even to-day, after so much has been done, Germany is increasing the number of its canals and improving its old waterways, both canal and river, at enormous cost. The length of Germany's navigable waterways at the date of the last official estimates was over 8,600 miles, and of this length no fewer than 2,200 miles consisted of canals or canalised streams. No estimate of the capital represented by canal construction in Germany is available, but including the projects now in hand, Prussia alone has expended $£ 50,000,000$ on canals during the last twenty-five years. While the waterways have thus been extended and improved, and while the traffic carried by them has increased by leaps and bounds, the sea and river ports have undergone a transformation not less striking." Such object lessons cannot be ignored when Australians approach the problems of transportation.

Experience in America and Europe has shown that the most economic transportation is only secured by maintaining railways and rivers to the highest point of efficiency in order that full advantage can be taken of geographical outlets. In several continental countries State-owned railways are forbidden to quote rates as low as river and canal charges. In Australia, Government railways have been employed to destroy the economic value of natural waterways! The policy of other countries where the railways are owned by the State is that these public utilities exist for the purpose of facilitating trade, not monopolising and then penalising it. The biggest monopoly in Australia is the Government owned railways, and with few exceptions these State agencies have acted in restraint of trade, and therefore have proved harmful monopolies wherever they have touched the river system. It has been found necessary in the United States to employ Federal law to control private railway companies. The exercise of Federal powers may yet have to be invoked in Australia to prevent the destruction of natural waterways which are and should continue to be national highways of trade. It has been 
officially estimated that the Murray and its two main tributaries could be made permanently navigable at a cost of $£ 3,000,000$. This would give 3,000 miles of water highways to the interior - a distance equal to that from Adelaide, through the heart of the continent to Darwin, and half way back again! Australians have not hesitated to pledge the national credit to the extent of $£ 171,000,000$ in order to provide 17,000 miles of railway, the annual upkeep of which means an enormous outlay. They are proud of this accomplishment, but the same people collectively hesitate to spend $£ 3,000,000$ to provide 3,000 miles of navigable rivers and simultaneously provide water for productive purposes! No sane person would think of destroying a railway system. Why they then should it be regarded as something incompatible with sanity to advocate the conservation of the inland waterways of a country for purposes of production and transportation? We want both rivers and railways in Australia, and shall want them more and more as settlement extends and population increases. The patriotic policy of Australia is not to destroy but to "save the rivers," - for use, not waste.

\section{Economic importance of roads}

There are few things so wasteful as a bad road. It is a constant drain upon the resources of a country and a continuous tax upon the users of it. Although railways in the United States have been multiplied and charges reduced to a minimum, 70 per cent of traffic, in that country, passes over roads. The Chairman of the Country Roads Board of Victoria contends that the value of good roads cannot be stated in pounds sterling, and, he adds, "a great deal of dissatisfaction with country life and the drift of people to the towns is due to the terrible conditions they have to put up with in many country places. In some districts, visited by the Board, the people were practically confined to their homes as prisoners for six months of the year. With reasonably good roads and gradients the cost of haulage would be reduced and the value of farm lands increased 30 to 50 per cent." An effort is being made in South Australia to concentrate control in order to make for better thoroughfares, and in this patriotic movement, the Good Roads' Association is proving helpful. Increased power has been conferred upon the Government Roads and Bridges Department and it is hoped that the lost art of roadmaking in this State will be regained and that good roads will be made and then main trained. It often costs more to move produce from the farm to a 
railway than the combined railway and ocean transit charges and it is because this fact is recognised as economic ally wasteful that there is a world-wide movement in favour of improved highways. This is not surprising in view of the rapid improvement in motor traction. In a recently published American magazine the writer of an article on "Motorized Highway Commerce" says: "We have out grown our present commerce on highways, born centuries before the Caesars, and but little more efficient now than 3,000 years ago. We have outgrown our present roads even as 'horse highways' for several decades. Science and invention have placed at our disposal a new transportation tool that demands a new highway to move our commerce with economies that will add millions of dollars per year in time to our wealth.”

In Europe every country is offering the greatest possible incentive to the utilization of freight carrying motors by the construction of magnificent permanent highways which have reduced the cost of European highway haulage to a fractional part of what it costs to move freight over undeveloped roads. Large subsidies ranging from $£ 16$ to $£ 120$ at time of purchase to a $£ 10$ to $£ 50$ additional annual bonuses per vehicle for two or three years thereafter, encourage merchants to "motorize" their transportation. In this way Germany, France, England and Austria have built up land transportation squadrons of many thousands of privately owned subsidized motor-trucks whose manufacturers have qualified them through annual tests of the war departments to be entitled to subsidy. These vehicles are subject to governmental requisition in times of war at a stipulated rental per day to their owners. The future of the freight carrying automobile is rich in economic and social promises. Distribution, which means transportation, is the greatest single item entering into the selling price of food and many other commodities.

There is a growing demand in America and Europe for Trans-continental roads, national highways connecting States in order to facilitate passenger and goods traffic by motor power. This movement should be encouraged in Australia as its influence will be in the direction of increasing the importance of roads as feeders to the Government-owned railways and generally lessening the cost of transit. At least the capitals of the States should be linked up by good roads.

Some guarantee of uniformity in policy, in respect to railways, rivers, and roads, may yet have to be found by Australia in the appointment of a National 
Highways Council or Commission to control these national interests, should the pressure of other work prevent the Interstate Commission giving the necessary supervision. There is scope for Federal and State co-operation in providing better roads; devising means of increasing train loads; eliminating curves and grades; making for an acceptable common gauge; standardizing equipment; and, generally, making for economy and efficiency in order that the unit of transportation shall be reduced to a minimum in this land of great distances.

\section{Harbours and ocean freights}

The problem of transportation is by no means finally solved, as far as trade and commerce are concerned, when produce has been moved at a minimum of cost from the most distant inland point to the seaboard. Oversea carriage is a prime factor to the producer, trader, and country of origin, since all surplus produce over home requirements has to meet world-wide competition. Although at a disadvantage, in the matter of distance from European consuming centres, Australia has been well served on the whole by shipowners. Rates of freight compare favourably with shipping charges against other exporting countries and no exception can be taken to the ready and continuous response for larger and faster steamers. It is just at this point that State enterprise has failed to anticipate the sudden demands of an expanding trade and the narrowing margin of profit on oversea shipments due - to increasing charges and keener competition in the markets of the world. Some steamers trading to Australia have reached the maximum depth of the majority of shipping ports, and freights are more and more are being regulated by the carrying capacity in a single bottom which in turn is governed by draught. Professor Sir John Harvard Biles, L.L.D., D.Sc., in an address before the Institute of Naval Architects on "The Economic Size and Speed of Steam Vessels" said: "If unrestricted draught is attainable the large vessel will carry cargo more economically than the small vessel, but the extent to which this conclusion holds good is dependent upon the relative amount of cargo and passenger traffic." The same authority points out that "the working draught of harbours governs the economic dimensions of vessels," and concludes "it is not unreasonable to predict that within twenty or thirty years; a depth of harbour of sixty feet would be profitably employed." There are only two Australian Harbours where there is the minimum depth of forty feet as recommended by the Dominions Royal 
Commission. The deepest points in the main harbours at low water spring tides are: Sydney, thirty to fifty feet; Hobart, thirty-four to forty-two feet; Adelaide (Outer Harbour) thirty-three feet; Fremantle, thirty two feet; Melbourne, thirtytwo feet; Brisbane, twenty-seven feet. When it is appreciated that an additional draught of three feet to a given steamer (the P. \& O. Moldavia, for example) would increase that vessel's freight-earning capacity by sixty-six per cent it will be easy to realise how vitally is the problem of oversea transportation affected by the policy of the various Australian Harbour authorities. The minimum depth of Australian ports will-in the near future be a growing factor in the development of Australian Commerce. The Dominions Royal Commission in its second interim Report stated, "We found that the facilities of Australasian Harbours, with the exception of Sydney, Hobart, Wellington, and in the near future Auckland, fall considerably below this standard. It cannot be denied that the natural facilities of certain existing ports are unfavourable to the cheap and speedy development of trade. The depths of Australasian harbours vary greatly. We question whether, at some of them, the authorities are properly alive to the quick increase in the draught of vessels in prospect. We found on our visits that the tendency was towards more modest schemes than deepening to 40 feet sufficient for all requirements. "The Commissioners further stated, "We are of opinion that the great increase in the draught of shipping in recent years, and the further development to be anticipated in the future, render argent an increase in the depths of some of the larger harbours of the Empire. To meet the future requirements of InterImperial trade a first class harbour should provide a working depth of not less than 40 feet. At present the larger ships now sailing to Australasia are not built in accordance with their most efficient proportions, because of the shallowness of some of the ports at which they touch. Given harbour facilities adequate to the modern development of shipping, the enterprise of British and Australasian shipowners may be relied upon to build up to the fullest capacity of the ports."

When it is remembered that the oversea freight charges against Australian produce exceeds every year the interest on the public debt, the importance of these two factors - harbours and ocean transit - in the problems of transportation will be better appreciated. During recent years there has been an appreciable increase in freights between Australian States, and trade is handicapped by a movement which seems to be continuous and persistent. 


\section{Conclusion}

On a per capita basis Australians have been able to invite comparison with any other producers or traders in the world. Productions from all industries in 1911 reached the fine total of $£ 188,745,000$, equal to $£ 42 / 0 / 8$ per inhabitant. Australia's combined trade export and imports - equalled $£ 33 / 17 / 2$ per head of population. There must be a ready response to the growing demand for cheaper methods of transportation if this high standard is to be maintained. Earl Grey, after his recent tour through Australia, said: "I confess I stand, hat in hand, before the energy and enterprise of a people, who with little more than half the population of London, has been able to accomplish what it has done in Australia. The undeveloped wealth of Australia has been to me a profound revelation. I had no idea you had such a splendid and such a delightful country. I do not believe that people outside Australia - I do not believe that a great portion of your people - sufficiently realises the amount and variety of wealth waiting to be garnered in your rural districts. I agree with Sir George Reid that the future of Australia rests, not as much on the starch collar, as on the open shirt! How to increase your rural population is the one great, overwhelming problem with which Australia is faced. On the satisfactory solution of that problem everything else depends. Unless you make good use of your land a stronger people, who can make better use of it, will take it from you. If you wish to keep your Continent while you must increase your population.”

The problems referred to by our distinguished visitor are so interwoven with the questions of transportation that they cannot be separated. Rural expansion, which means the development of natural resources - production will be regulated from time to time by the facilities provided for reaching the final market. There is no reason why Australia should not supply the needs of her own people and supply them well too, and then help to keep full the cupboards of other countries. There are vast areas in the Commonwealth of no productive value to-day simply because of the absence of modern means of carriage to the seaboard. A majority report of the Northern Territory Railway and Harbours Commission states: "On the general evidence however it would seem reasonable to expect that on the Barkly tableland and on the Victoria River district together there is room for $15,000,000$ sheep, and it is possible that the districts to the south will in time be capable of supporting another 10,000,000, not to speak of 
the large number of cattle, horses and goats, which will continue to be bred even when the sheep industry has been established. No sheep development, however, is possible without railways, as the cost of carriage is too high to allow of the improvement of the country for sheep. It is contended that the construction of the north-south line would facilitate the occupation of $281,000,000$ acres that is taking a strip 200 miles on each side for the entire length.”

Australians should unite in a patriotic effort to inaugurate an era of improved transportation, embracing increased efficiency in railway management; full use of inland water ways; and a "good roads" movement in order to encourage the occupation of waste places of the continent and so multi ply production and add to the volume of trade and commerce. Problems of transportation not only have a close relationship to trade and commerce and the general material concerns of the country but they affect national life in all its numerous interests. We owe much to the pioneers who so well and truly laid the foundations of our already great Commonwealth but upon this, and succeeding generations, devolves the sacred duty of courageously facing the daily obligations of making this continent the home of a prosperous and progressive people. By such means, and such means only, will Australia occupy its rightful place as the economic centre of the Pacific - the dominating commercial power of Southern Seas. 


\section{War finance: Loans, paper money and taxation}

\section{Robert F. Irvine ${ }^{1}$}

In a paper read before the Actuarial Society of New South Wales ${ }^{2}$ last year I tried to clear up my own ideas about the nature or modern money, of loanable capital, and especially of the huge War Loans and Debts, swelling now to figures which three years ago would have been considered incredible and impossible. I reached certain conclusions which were obviously not in accord with those commonly held by economists and practical financiers. This was, no doubt, very presumptuous on my part. At any rate, a good many people have thought it their duty to tell me it was, and at the same time to hint at retribution to come for me and any misguided people who might agree with my heresies.

Naturally, therefore, I approach my task to-night with some fear and trembling, for it may be that I shall have once more to say things which will call down the wrath of the stern deities of Finance. On this account, and also because the subject is naturally difficult and technical, I shall need all your patience and forbearance.

As this lecture is a continuation of the paper referred to, it seemed desirable to recapitulate the principal arguments and conclusions of the latter. It is impossible to deal intelligibly with Loans, Paper Money, and Taxation without some clear conception of what modern money and loanable capital really are. I found, however, after various trials, that the recapitulation I had first in mind would of itself make a whole lecture. I am obliged, therefore, to content myself with a brief re-statement of my views as to the nature of money and loanable capital.

1 Seventh Joseph Fisher Lecture, 5 June 1917.

2 The Veil of Money, paper read before the Actuarial Society of New South Wales, 26 October, 1916. 
Some time ago I heard a well-known politician speak of the grand total of British War Loans as "four thousand million golden sovereigns." He even amused and interested his audience by calculating how long it would take a single person to count this golden pile! When it was suggested to him that all the gold in the British Empire probably did not amount to more than 5 per cent, or at the outside 10 per cent, of this vast total, he explained that he did not mean what he said; but he did not explain what he really did mean.

It was the delusion to which such language gives rise that I attacked in my paper - the idea that for every note, for every cheque and bill of exchange, and for all the loans, public and private, there is somewhere an equal amount of golden sovereigns; or the little less crude, but equally superstitious idea, that although it is not possible to match every pound of money with a golden sovereign, the whole of the immense superstructure of "money", "credit", and "loanable capital" is nevertheless based on the stock of sovereigns or bullion which the Banks hold in their strong-rooms. It seemed to me that money was something quite different both from what the "man in the street" and the practical banker often conceived it to be. The problem is this: the Banks hold, let us say, $£ 100,000,000$ of gold in reserve, but nevertheless are able to provide ten times that amount of the thing we call "money". What does the $£ 900,000,000$ consist of? At the same time the country is able to raise a War Loan of $£ 1,000,000,000$ ! What does this huge sum stand for? Is it, too, based on the hundred million sovereigns?

\section{I}

In the Veil of Money I defined Money as simply a collective name for all the devices used to enable us to exchange goods. With this definition, it is meaningless to talk of money being a standard of value. By this, of course, I do not mean to say that the monetary system does not need a standard or unit of value, in which the value of goods may be stated. For modern systems the unit is a given quantity of the commodity, gold. But because gold is the recognised unit of value, it would be illogical to assume either:

a) that the standard, in the shape of coined money, must necessarily form any but a fractional part of money defined as means of exchange; or 
b) that the quantity of money, so defined, functioning at any particular moment, is based solely or even to a large extent on the amount of gold held in reserves.

Against these assumptions I put two facts:

a) by far the greater part of the exchanging done in civilised communities and in international trade, is performed without any use of the unit-of-value material.

b) the greater part of what is variously known as "bank money" or "bank credit" is certainly - one may even say obviously - not based on actual holdings of gold.

\section{II}

The first statement cannot be denied: the circulating medium of to-day is not gold but credit. The second, however, is strenuously opposed by those who desire to keep the Golden Calf on its old pedestal.

In my previous paper I had argued that credit, which forms the greater part of modern money, is based not on gold, but on "claims to vendible property" or wealth either existing or in course of production; and I explained the process by which Banks, through their loan and discount operations, converted such claims into money or currency.

Let me put the basic facts in as simple a setting as possible.

Suppose you put 200 sovereigns in the Bank on fixed deposit, with interest at the rate of, say, 2.5 per cent. The Bank may lend this, or rather its equivalent in "bank money", at 5 per cent. But if the Bank treated all its deposits in this simple fashion, it could hardly cover its expenses, and would be failing to render its most valuable services to the community. Without any waving of a magic wand, or any departure from sound principles of banking, it can seemingly convert your 200 sovereigns into perhaps $£ 2,000$ worth of money, purchasing power, or liquid capital. It can lend not $£ 200$, but $£ 2,000$. To the uninitiated this appears to be a creation of something out of nothing, and the popular use of the words "credit" and "bank credit" gives colour to this supposition. Hence the fiction that the whole $£ 2,000$ is, in some mysterious way, based on your deposit of 200 sovereigns, 
the additional $£ 1,800$ being an intangible and rather doubtful something called "credit." But the explanation and its implications are almost wholly false. Those who borrowed from the Bank, where there was any doubt of their solvency, left securities, usually gilt-edged, in pledge for the loan, and the Bank took good care to insist on a margin of safety sufficient for any probable fluctuations in the value of the securities. The latter are collateral. They are, however, the real and the only basis for the additional bank money, the $£ 1,800$ for which the Bank holds no gold at all. Clearly, what the Bank has done is to liquefy or convert into general purchasing power $£ 1,800$ worth of the borrowers' "vendible property". And the $£ 1,800$ has just as permanently substantial a basis as, say, 200 one pound notes issued on the security of your 200 sovereigns, because it rests usually on forms of wealth indispensable to the satisfaction of human wants.

But, it may be replied, it was the reserve of 200 sovereigns that enabled the Bank to venture on this process of converting or liquefying claims to specific wealth into general purchasing power. Experience, it is alleged, has taught the Bank that it must keep a certain proportion of gold to its liabilities, and therefore the amount of the reserve of gold (or legal tender) certainly limits the amount of loans that may safely be made. If this be so, is it not reasonable to say that the $£ 1,800$ is based on the 200 sovereigns? I agree that under existing conditions and presuppositions the Bank's capacity to loan, or what amounts to the same thing, its power to liquefy specific forms of wealth, is to some extent artificially restricted by its legal-tender reserve. The minimum amount of the reserve may be determined by law, but more often it is merely a matter of custom. But even granting the limiting effect of the reserve, it is none the less a very misleading use of words to talk of this relatively small reserve as the basis of the additional money created by the Bank on the security of, and in proportion to, the claims to wealth left in pledge with it by borrowers. Until this is admitted, I see no hope of ever establishing a scientific theory of banking or money.

Into what absurdities this misuse of words had got us, will be apparent from a consideration of the proportion of gold or legal-tender reserve it is considered necessary to keep. What is the right proportion? What is the practical or theoretic line of safety? On these questions there is no agreement either in the practice or in the theory of the practical man. All that we find is a vague statement that, as the Banks are supposed by law to repay deposits in gold - and this is, after all, an 
elaborate make-believe, for nobody expects them to do what is patently impossible, or, if possible, would be extremely stupid, viz., to hold gold sufficient to liquidate all liabilities - they will come to smash if they do not keep an "adequate" reserve. But this does not help us at all to define "adequate". Is it 15 per cent, or 20 per cent, or 30 per cent, or what? The Bank of England returns may show a reserve of 30 per cent or 40 per cent against its own liabilities; but if we include, as we ought, the liabilities of all the other Banks whose final reserve is that of the central institution, these percentages may shrink to 3 per cent or 4 per cent or 5 per cent. And yet, in spite of the pessimists, this relatively small amount of gold, with its accompanying legal-tender paper, has proved sufficient for the monetary needs of a world Empire. The reason surely is that our practical banking is far ahead of the theories which the practical banker himself often thinks he is following, but which he dodges, where possible, by extremely ingenious and useful devices.

The anxiety to keep an "adequate" gold reserve is explained on the ground that this reserve is necessary in order to avert panic and save us when once the panic has arrived. But, as has been pointed out by a recent writer ${ }^{3}$, panics are psychological phenomena which have but the smallest relation to nice questions of mathematical proportions. If once John Bull (who, however, is neither the fool nor the nervous person we sometimes suppose him to be) has thoroughly lost confidence in the soundness of his banking institutions, will he be satisfied if you tell him that the Bank can give him in gold only $£ 15$ of his $£ 100$ deposit? If it can give him $£ 40$ or $£ 60$, or even $£ 80$, will he be satisfied? Will he not want to know what has become of the balance? There is no use burking the truth: it is impossible to say what reserve will be of any use if people are determined to go mad. But people are not nowadays so ready to run amuck as they were a century or half a century ago. It had long been predicted that the outbreak of a war such as this would lead to universal panic and financial breakdown. Yet when it came, when all the world plunged into the greatest war of history, nothing in the nature of real financial panic occurred, and the War has lasted three years without the financial breakdown which was to have come at the end of a few months.

3 Walter William Wall: The War and Our Financial Fabric. 
With their accepted theory of reserves and proportions, bankers, in a time of crisis, find themselves involved in hopeless mental confusions. They are warned by one set of advisers to keep high reserves, and by another to loan freely when the panic comes, so as to avert general disaster to the business community. But how, on these principles, can they do so? It is impossible for them at the same time both to lend freely and yet to maintain high reserves. In England they get over this difficulty by acting as if the opposite of their theory were the correct one: ${ }^{4}$ that is, with the sanction of their Government they replenish their reserves with legal-tender paper based on public securities. It may indeed be laid down as an incontrovertible truth that no financial crisis was ever met simply by heaping up gold, but rather by an extension, usually through State guarantee, of credit, i.e., of the ordinary machinery for the liquefying of the wealth of the nation into means of payment.

Well, then, to sum up this part of the argument, we may say, I think: (1) that the greater part of modern money is not gold, nor based on gold, but simply claims to the community's wealth which have been converted into general purchasing power; in other words, it is the value, in terms of the gold unit, of a part of the community's wealth; and (2) that, in spite of current doctrines, we have long been advancing in the direction of almost eliminating gold from domestic currencies and economizing its use even in reserves.

The experience of the War shows what indeed has long been evident that we do not need an expensive gold currency when cheques, notes, and other means of settling indebtedness will serve the purpose at least equally well. So the drift of experience for many years, especially in times of crisis, is compelling us to admit that we have over-rated the importance of gold reserves, and that, so far as they are economically unnecessary, they form a heavy tax on, and sometimes a danger to, the community.

The attempt to keep modern currencies in a definite relation to supplies of gold accumulated in reserves of Banks or Treasuries has constantly broken down in practice just as in right theory we should expect it to do. For, with the wealth of the world doubling, trebling, and quadrupling itself in a single generation

4 Hartley Wither: The War and Lombard Street, p. 103. 
and requiring a corresponding increase of currency and liquid capital, it is surely absurd to expect the currency and the capital to be limited by the supply of a single item of wealth, a supply which may in time be exhausted and is subject to changes which do not always synchronise with changes in the general growth of wealth. Fortunately, our practice is better than the theory which is supposed to guide us; and, as I have said elsewhere, business, with the aid of the Banks, has to a large extent created its own currency. This being so, I believe it to be of the utmost importance to give up the old theory and frankly to "teach the people that the currency of the country is in reality based upon the wealth of the country, and not upon an extraneous thing like the capricious production of gold"; 5 in other words, that money is a function, not of gold, but of the general wealth of the community. Had we realised this truth, prophecies made before the War as to the rapid collapse of the national finances would never have been made. So in the future we may hope that the criterion of sound banking will no longer be the obstinacy with which bankers sit on their hoard of gold, but the judgment they show in the conversion of real wealth into liquid form or currency, always, of course, in terms of the accepted unit of value (gold).

It is, no doubt, important to keep the actual currency of the modern world - cheques, notes, bills, drafts, etc. - at parity with the standard or unit of value, that is, with gold. This can only be done by frequently testing the one against the other in open market. It is in this testing that we find the real function of gold in the monetary system; for in English-speaking countries, at any rate, its use as a medium of exchange has practically ceased. The circulating medium of to-day is credit, and this, as I have shown elsewhere, is so far as it is legitimate, primarily based on the mass of goods being continually produced, exchanged, and consumed. The adoption of this system has meant an enormous economizing of gold. The necessity of testing it so as to preserve a single standard of value does not require a great hoard of gold, but only an open market for the commodity gold.

We must thus conceive of modern money, not as a pile of golden coins and bullion or even as notes representing the coin and bullion, but as Bank deposits, representing general wealth and operated by cheques or other orders. These

5 Wall, op cit., p. 177. 
deposits are of two kinds: (a) claims to wealth left or deposited in the Banks by customers; and (b) advances made by the Banks to customers who can furnish adequate security. In each case a "deposit" is created on which the customer can operate. But in neither case is the deposit necessarily a gold deposit. When "A" gets an advance of $£ 100$ from the Bank and gives a cheque for this amount to " $\mathrm{B}$ " and " $\mathrm{B}$ " lodges the cheque to his account, a deposit of the first kind has been created out of what originally was a loan deposit.

If a banking system works on a gold reserve of $£ 100,000,000$ and has deposits amounting to ten times that sum, the difference between the two has no metallic support. What then does it represent? If my theory is correct, the greater part of it represents marketable securities or titles to wealth in process of production, and, on the whole, it can have no better basis, if the banker has shown judgment in estimating the values of the property and the kind of property he converts into money.

Loanable capital is nothing more than unexpended purchasing power credited to customers in the Bank's books and not required by them for immediate use. In war time the fund of loan capital may be increased by extended conversion of securities or valid claims to marketable wealth into Bank deposits. So far as this process keeps well within the limits of actual values, no harm is likely to result. But as we shall see, the necessity of War has tempted most of the belligerents to exceed these limits.

The point I wish to make is that both the "money" and "loanable capital" of a community are not dependent on the available reserves of gold; but that they are in mathematical language, a function of its wealth in general. A country which has abundant resources, technical knowledge and skill, and plenty of fighting men need not worry much about its capacity to finance a war: nor need it worry about its power to get gold if it wants to get more than it has. Gold can always be bought if one has the commodities to exchange for it.

\section{III}

With this introduction, we may now proceed to consider the real subject of the present lecture: "War Finance: Loans, Paper Money, and Taxation," as illustrated 
by the methods followed by the three greatest belligerents, Germany, France, and the United Kingdom. I omit reference to the United States because her entry into the Great War is so recent. An analysis and comparison of these methods will cast a good deal of light on the questions already discussed and reveal other problems of a very important character.

A modern government, when faced with war, does not venture to commandeer the materials and services it requires. It may compel men of military age to join the colours; but it adopts another method to bring about the reorganization of the civil population that war renders necessary. It acts in the customary commercial way. It persuades people to do what is required by offering them general purchasing power in return for goods and services. In order to do this, it must itself have command of general purchasing power or money. But clearly the money is only a convenient intermediary to the "real stuff" - the men, munitions, food, clothes, ships, and so on.

The sources from which a government may draw are the following:

a) War chest, established for such an emergency

b) Borrowing or issuing loans

c) Taxation

d) Debasing the coinage

e) Issuing paper money

f) Other forced loans

g) Tributes and indemnities

h) Government business undertakings

An economist of some distinction has recently reduced these to four: issuing loans, taxation, paper money and more paper money.

It is perhaps necessary to add that he was not trying to be facetious, but was merely admitting and recording the facts of actual war finance.

Of these four ways, we may say at once: that no great war is likely to be financed by the proceeds of increased taxation alone, for this would involve too 
sudden a dislocation of existing economic life; and that the issue of inconvertible paper money is almost universally condemned by economists and financial authorities. Of the first point I shall speak later. As to the last, it is desirable to point out that nearly all the belligerents in the present War have had recourse to the device of inconvertible legal-tender paper. Either, therefore, necessity has compelled them to adopt a desperate kind of financiering or their advisers have come to the conclusion that the method is not so bad as it is painted, or that it can be used in a new and less dangerous way. Further consideration, moreover, may suggest that the loan policies of most of the nations are likely to have, after all, many of the evil results attributed to the issue of paper money.

In the analysis which follows of the War Finance of the countries chosen for consideration, I shall give most attention to Germany, because her methods are not so well known and also because they best illustrate good and bad principles of finance.

\section{Germany}

It is evident that the German Government and the officials of the Reichsbank had for years been maturing plans for financing a war which was to give Germany the first place among nations. Details of measures to be taken "had long been decided upon. It would be an insult to the Imperial officials to believe otherwise."

So far as can be ascertained, these plans "hinged on a credit system of such elasticity that it could cope with the suddenly increased call for credit which would mark the beginning of a war. The Reichsbank, through its power to issue notes, was to provide the means of payment to cover the expenses of mobilization and also to quiet the panic and tide industrial life over the disturbances incidental to a war. There was much discussion as to whether or no the regulation requiring the redemption of bank notes in gold should be suspended. The general opinion of financial writers was that a war should be carried on with irredeemable paper money. Provision was to be made for institutions which should grant loans on security and relieve the Reichsbank

6 Dr. Ströll, Bank Archiv, III, No. 2, p. 18, Oct. 15, 1913. 
of such business. [Public] loans were to be relied upon to meet the actual war expenses after mobilization" 7

In preparation for the plan to issue large quantities of notes, a process of gold concentration was begun, ostensibly as a final reserve for the paper money. With the object of accustoming the people to a paper currency, the note issues were gradually increased and in smaller denominations than formerly. The other Banks were encouraged to keep larger balances at the Reichsbank. Thus when War actually came, the latter institution found itself practically the sole holder of the metallic reserve of the country. The War Treasure in the Julius Tower at Spandau which had been increased to 205 million marks, was shortly after the outbreak of hostilities transferred to the Reichsbank.

Now let us see how these schemes worked out in practice. During the month of July, 1914, when the likelihood of war gradually increased, there was much disturbance in the business world and heavy falls took place in stock exchange quotations. Many were anxious to sell goods and securities, but few were willing to buy. Depositors began to withdraw "hard" money from the Banks. On the 28th July the private Banks ceased to pay out gold and there followed a rush to the Reichsbank to get its notes redeemed in gold. On August 1st the Reichsbank ceased to redeem its notes in gold - a step afterwards legalised.

The hoarding of gold, together with the greatly increased demand for currency usual on the outbreak of war, led to a currency stringency and there was considerable difficulty in supplying the small change needed in business. The Government put into circulation some millions of marks in silver, a large amount of token money, and 35 million marks of Treasury Notes, in denomination of 10 marks. But for a time the stringency was so great that some municipalities issued 50 pfennig and one-mark notes and factories issued their own promises to pay.

When the Reichstag met on August $4^{\text {th }}, 1914$, it formally legalised the measures long since decided upon.

a) It annulled the Reichsbank's obligation to redeem its notes in gold or anything else, its notes still retaining legal-tender power.

7 M. Chase Going, “German War Finance,” Journal of Political Economy, June, 1916. 
b) It made the notes of other Banks of issue redeemable in Reichsbank notes.

c) It made Imperial Treasury Notes irredeemable and legal tender.

d) It authorised a vastly extended use of the loan bureaux or Darlehnlskassen. These institutions were multiplied and permitted to issue notes by way of loans on the security of various types of property. The notes were irredeemable, and though not endowed with legal-tender power, were nevertheless taken at their face value by all Imperial and State offices.

Technically, the Bank Act requirement of a one-third cash reserve still remained in force; but the constitution of this "cash" reserve was entirely changed, since it now included large quantities of Darlehnskassen notes. The "commercial paper" by which the other two-thirds of the notes were required to be covered, was now made to include Imperial Treasury Notes and Imperial bonds falling due within three months.

The Darlehnskassen were intended to help those who wished to raise money on stocks of merchandise or securities; but they did not help the small tradesmen or the landowner or the man who had only his own personal security to offer. Other institutions were provided for these purposes. Land mortgage Banks were institutions of long standing in Germany. In addition, there were now created a number of Kriegs-kredit Banks, which have no power to issue notes, but discount bills and grant book credits. They will also lend on promissory notes, if the borrower can get two well known sureties.

With this close-knit and elaborate system of credit or, rather, machinery for liquefying general wealth, the Government was easily able to finance itself during the first months of the War. During the first six days, the Reichsbank advanced 750 million marks largely by the discounting of Imperial Treasury bills. These loans were made mainly in notes, large quantities of which were soon in circulation. By February 29 $9^{\text {th }}$, 1916, 6,554 million marks had been issued.

But in the meantime the gold reserve of the Reichsbank was steadily increasing, as a result of the transfer of the War Treasure and a vigorous campaign to get possession of hoarded gold. It is probable, however, that the figures ${ }^{8}$ given

8 See Table in Appendix, "Gold Held by Belligerent Nations." 
are to some extent delusive. There is reason to suppose that much of the gold hoard has been drained away secretly to assist Germany's Allies and to pay those countries with which Germany still remained in trade relations. ${ }^{9}$ But so long as the people believe it is there, their minds, it is thought, will be at ease and internal exchange will in no way be hampered.

It must be evident from these facts that a totally new currency situation had been produced. Gold had disappeared from circulation, and, so far as it was not hoarded, was now piled up in the vaults of the Reichsbank, from which much of it, however, may have flowed away secretly to other countries. Whatever amount may be held, it is not a reserve in the usual sense, since the whole system of currency is inconvertible. Its sole uses are: (l) to give a psychological impression of financial strength and safety; (2) to make payments abroad for imports which cannot be balanced by exports; and (3) to provide a fund for helping to reestablish credit and trade at the end of the War.

Summing up, we may say: (l) "that a more whole hearted resort to irredeemable legal tender paper than Germany's can hardly be imagined;" 10 and (2) that in mobilising her wealth Germany has used to the full and probably beyond its extreme limit, the principle of converting actual wealth into means of payment.

When I have described the measures of the other countries selected for consideration, I shall have something to say as to the effects of the general issue of legal-tender paper. The second point mentioned above may be illustrated by some of the measures taken to facilitate the raising of War Loans; from which it will be seen that what practically amounts to a wholesale pledging of the people's possessions has taken place. Almost every form of property has been mortgaged up to 40 per cent, 50 per cent, and 60 per cent of its estimated value. In this way the Reichsbank and the various credit institutions have given every aid to persons subscribing to War Loans. But financial ingenuity has not stopped here. It is clear now that the principle of "pyramiding" has been used to a large extent. That

9 J. M. Keynes, "The Economics of War in Germany," The Economic Journal, Sept., 1915.

10 A. C. Whitaker, "Currency Depreciation in Time of War," Quarterly Journal of Economics, February, 1916. 
is, the scrip of one Loan is made the basis of a private loan and then of further purchase of War scrip. This is the method of the "inflation loan" described in my previous paper.

No doubt the same method has been used by individuals in France and the United Kingdom, ${ }^{11}$ but it has not received the same stamp of public approval as a legitimate financial device. It is evident that so far as this principle is put into practice, it creates a mass of credit money which has no basis in actual specific wealth. It does not differ much, therefore, from an issue of inconvertible paper money, the only basis of which is the confidence the people have in their own government and in their own capacity to produce wealth in the future.

\section{France}

In France the notes of the Bank of France were made irredeemable and given full legal-tender power, The limit upon the issue was raised through several steps from 6,800 million francs to 15,000 million francs. At the same time gold export was prohibited, by private persons at any rate. As a result of the first measure, gold disappeared from circulation, its place being taken by paper, five-franc silver coins and subsidiary tokens of nickel. As in Germany, considerable quantities of gold were hoarded at the beginning of the War; but appeals to the patriotism of the people have succeeded in getting a large part of these private hoards transferred to the central reservoir. As M. Ribot says: "Week by week the bullion account of the bank was swollen, in spite of the fact that the bank bad to export large quantities, on account of purchases made for military purposes, both to the United Kingdom and the United States.

"In the initial stages the Bank of France financed the Government by making advances, "creating notes for that purpose. As the notes are pledged by a debt which is not repayable before the end of the War, the Bank would not be able to collect gold enough to have these fresh notes redeemed at once, should these be presented at its counters. As no distinction is made between them and those

11 According to Mr. Withers the Bank of England undertook to advance money to customers on the security of scrip of a former War Loan. See The War and Lombard Street, p. 131. 
which are created for commercial purposes, the unavoidable outcome is that legal tender quality must be given by law to all the notes." ${ }^{12}$

For a considerable period France, unlike the other belligerents, did not resort to Loans. It financed the War mainly by short-time Treasury Bills, redeemed presumably by issue of paper money and new Treasury scrip. Towards the end of 1915, however, the first Loan was floated. It brought in over a thousand million sterling, but on terms more costly than the Loans of the other great belligerent States. It was issued at 88 , giving a return to the investor of almost 6 per cent. This Loan enabled the Government to pay off most of its floating indebtedness and to resume the issue of Treasury bills.

\section{United Kingdom}

The only direct currency changes made by the British Government on the outbreak of War were the issue of Currency Notes of the denominations of $£ l$ and 10s., and the endowment of postal notes with full legal tender. The Bank of England was also permitted, so far as temporarily authorised by the Treasury, to issue its own notes "in excess of any limit fixed by law": a permission, however, of which it does not appear to have availed itself.

The Currency Notes were intended to supplement the note issues of the Bank of England and the cheque currency which, in England, does the greater part of the money work. These measures were more than sufficient to provide for the additional currency that war always requires. The notes were redeemable in gold at the Bank of England; but it is doubtful whether as a matter of fact this privilege is being exercised. Certainly, any attempt at wholesale redemption would probably lead to actual suspension of the Bank Act.

The Currency Notes, it is evident, were also intended to discharge reserve functions. To quote Sir Edward Holden, they "are a most important part of our finance, because they play the same part as gold and Bank of England notes,

12 Ralphael Georges Levy, "French Money, Banking, and Finance During the Great War," Quarterly Journal of Economics, November, 1915. 
inasmuch as they form a portion of our reserves upon which loans are granted and credits created, and, in our reserves, they assist in the protection of our credits." 13

There is no restriction upon their issue except the provision for redemption in gold, for which a sum of $£ 28,500,000$ has been set aside. Critics, it may be said, regard the redemption clause as little more than nominal. According to Sir Edward Holden, the notes outstanding in England at the end of 1916 were as follows:

\begin{tabular}{l|l}
\hline Bank of England notes & $£ 39,000,000$ \\
\hline Currency notes & $£ 150,000,000$ \\
\hline Notes of private and joint stock banks & $£ 34,000,000$ \\
\hline & $\mathfrak{£ 2 2 3 , 0 0 0 , 0 0 0}$ \\
\hline
\end{tabular}

The corresponding figures for Germany were:

\begin{tabular}{l|l}
\hline Reichsbank notes & $£ 403,000,000$ \\
\hline Darlehnskassen notes & $£ 170,000,000$ \\
\hline Reichskassenscheine & $£ 18,000,000$ \\
\hline & $\mathfrak{£ 5 9 1 , 0 0 0 , 0 0 0}$ \\
\hline
\end{tabular}

Apart from direct currency measures, Great Britain is financing the War by: The issue of short-time paper, i.e., Treasury Bills and Exchequer Bonds.

The issue of Loans, mainly for the purpose of consolidating the floating debts.

Increased taxation, to which I shall refer later.

It is not my intention to go into details with regard to the Loans issued by the British Government. Later I shall go into the question whether its loan policy has resulted in inflation.

13 “Great Britain's Financial Strength”, an address delivered on January 26, 1917. 


\section{IV}

It is thus clear that the three belligerents whose finances I have discussed have each resorted to the issue of legal tender paper money. In Germany and France it is frankly inconvertible; in Great Britain it is nominally convertible on presentation at the Bank of England, but the under standing evidently is that gold is released only at the pleasure and discretion of the Bank of England. Compared with the vast issues of Germany and France, and of other belligerents like Russia ( $£ 340,000,000$ in 1916 alone), the United Kingdom has made but a sparing use of this device. The explanation lies mainly in this fact that the United Kingdom has relatively little need of an enlarged special currency, the cheque and deposit currency, universal in English-speaking countries, being sufficiently elastic to provide for all but small payments.

But in each country more notes have been issued than are actually required for currency. What are not needed by the public will not continue to circulate, but will find their way to the Banks, whose assets are thus diluted by the large holdings of inconvertible, non-interest-bearing paper. The Banks would, no doubt, prefer to hold interest-bearing securities, which make profits in two ways, whereas notes can only increase dividends by enabling the Bank to loan

There are two modes of issue of such paper: (a) the government may print its own notes and pay with them for goods and services; or (b) it may throw the onus of issuing the notes upon the Banks.

In the latter case the Banks undertake to discount short time government paper, like treasury bills, and to issue notes or give credit equal to the discounted value of the securities. The government bills are put in the same category as bills of exchange and promissory notes It is held, however, they are not the same as commercial paper, which is based upon, and limited by, specific wealth already existing or reasonably certain to be produced in the near future. There is no restriction upon the issue of government short-time paper or of the notes arising therefrom, or upon direct issue of notes; and there is, therefore, no clearly definable relation between them and the actual productivity of the nation. 
Whilst this distinction is valid in the main, it is possible to give too much weight to it. As suggested elsewhere, a country at war may and frequently does increase enormously its total production (including in this, as I think we must, its war production). Much of the new wealth is the direct product of governmental activities and monopolies. It has been estimated that nearly half the working classes of Germany are now working for the Government. In England probably 3,000,000 men and women are engaged in the many War establishments. Whole industries, like transportation, have been taken over. It is thus evident that a modern government at war takes on the semblance of a vast industrial company for the production and continuous supply of all the requirements of war and even of many of the requirements of the civil population. Does not all this productivity form as valid a basis for the issue of credits as the productivity of private enterprise?

Though the second method is probably preferable to the first, there is little, if any, practical difference in the results. In either case the currency is temporarily increased, and this additional currency is based on the general credit of the nation. In the past, knowledge of this fact has not sufficed to prevent depreciation of the whole system, in so far as it was inconvertible. Now, I am one of those who believe that the last word has not been said on this question. There are several considerations which lead me to discount the importance of the precedents: (1) During the last century public credit has progressively increased in strength and reliability, partly as a result of the growth of stable and responsible government, and partly as a result of the enormous power of production, and hence of taxable capacity possessed by a great modern nation. (2) The public credit, so far from being negligible and unsubstantial, has become the final support of the Banks and the monetary system in times of stress. When the English accept a Currency Note for one pound as in no way inferior to a sovereign, they do so not because they believe that every such note can be converted into gold, but because they have faith in the wealth and power of their country - in themselves as a nation. Could there be any sounder basis? If that fails them, is there any other to which they may have recourse?

At the same time it must be granted that a reckless use of this device may lead to the depreciation of the paper in comparison with gold and a corresponding rise in paper prices. These results are the more likely to follow when the issue has 
been very large, when to guarantee of early redemption has been given, and when the political situation is insecure. I shall inquire in another section whether the paper money of Germany, France, and Great Britain shows signs of depreciation.

It is also true that an increase in the quantity of money in circulation, the money work remaining the same, involves an increase of prices. This is true both of gold and paper money (convertible or inconvertible). If gold be the only medium of exchange in use, doubling the quantity of it in circulation will merely halve its value; unless, of course, a proportionate increase has taken place in the exchanging to be done. Multiplying money without multiplying the production and exchanging of goods can have no effect beyond altering the level of prices.

On the other hand, it must be remembered that the condition of war greatly increases the money work and therefore the demand for currency. This may be so even if the production of wealth remains the same as before or even if it is diminished. The experience of the past three years, however, has proved that production may increase enormously during war and justify a corresponding increase of money or means of exchange.

It may be added that a really redundant currency - more than is required for the money work - is not so easy to bring about as is commonly supposed. People are not now likely to keep in circulation or to hoard any large supply of notes not required for business purposes. The surplus finds its way into the Banks, and must be held by the Banks as part of their reserves, along with any supply they hold of gold or of interest-bearing securities. The money in circulation is usually increased in an indirect way. The Banks having large reserves, are anxious to lend freely. Their customers use the loans as a demand for labour and materials, the prices of which will rise in consequence. The same result will follow whether the reserves are full of gold or of paper. As already stated, the Banks do not like them, not because under modern conditions, they are afraid that the government will fail to redeem them, but because they are less profitable than interest-bearing securities. They also know that for some purposes - e.g., for payments abroad notes, whether convertible or inconvertible, are useless. Hence, if they have to hold a non-interest-bearing asset, they prefer gold, and this preference in itself constitutes at least a mental depreciation of the value of the notes. There is no reason, however, why actual depreciation arising from this cause should exceed 
the small percentage required to put the notes on a par with interest-bearing public securities.

\section{V}

Postponing for the moment the question whether the inconvertible notes of belligerent countries are actually showing signs of depreciation, let us attack the cognate problem of the possible inflation of credit arising out of certain of the Loan policies adopted.

First of all, it is clear that when Bank depositors use their real, as opposed to loan deposits, to subscribe for War Loans, new credit is not created. All that happens is "a transfer from the subscriber to the Government, from the Government to the contractors, and from the contractors to the Banks. The same deposit is capable of being driven around the wheel continuously, so long as its different owners are willing to take up Government loans." ${ }^{14}$

But new credit is created when the Banks make advances to their customers to enable them to subscribe to War Loans. New credit is also created when the Banks take up Loans on their own account. Every purchase by the Banks of Treasury Bills or other short-time paper, means the creation of deposit credits to that amount. Many authorities regard the credits arising in these two ways as tantamount to an inflation of the currency.

It seems to me, however, that there is a clear distinction between them. When, on the security of some marketable property, the Bank advances $£ 100$ to "A", it has not really increased his potential purchasing power. It has merely, for a consideration, given him general purchasing power in exchange for the title to specific wealth. Such transactions are among the most characteristic of the normal functions of Banks. Credits so created for the most part cancel each other. They are no more likely to affect prices than bartering cows for horses would.

14 Sir Edward Holden, op cit. 
When a Bank purchases Treasury Bills it merely gives the government the right to draw up to the discounted value of the Bills. In return for this privilege the Bank receives a government security, which during the war can only be liquidated by renewing it, or exchanging it for some other government security. Government bonds are thus, in effect, being made to serve as currency. The net result is very much the same as an issue of paper money, except that interest has to be paid on the bonds and not on the paper money. Still more remote from actual productivity is the German device of advancing money for subscription to a War Loan.

A considerable part of the German Loans appears to be based on fictitious credit, or rather upon obligations which individual lenders cannot possibly meet at present or in the near future. A man who has subscribed 1,000 marks to the first Loan was able to do so because he had valid claims to existing wealth to that amount. But if, when the second Loan is issued, he finds that his claims to real wealth are exhausted, what more can he do? The Germans have found a way out of this difficulty! All that he need do is to take the certificate of his stock to a Bank, which will then advance him 750 marks for investment in the second Loan. According to the Kölnische Zeitung (2nd September, 1915), he can even subscribe four times this amount, if he leaves with the Bank the new scrip. An obvious effect of this process of "pyramiding" will be the financial enslavement of many Germans to the Banks. Further, it is evident that whether such Loans result in the creation of inconvertible notes or not, they must inevitably increase the amount of money or purchasing power put into circulation having no basis in actual wealth. This "fictitious" purchasing power has the same influence in the market as "real" purchasing power. It artificially increases the amount of money offered for goods, and unless there is a proportionate increase in production, the result will be an increase in the prices of commodities.

\section{VI}

It is now necessary to inquire whether the issue of inconvertible notes and the "pyramiding" process in the raising of Loans have actually led to currency depreciation in Germany, France, and the United Kingdom. 
Various meanings may be assigned to the word "depreciation". It may, for example, denote: ${ }^{15}$

a) A decline in the exchange value of a given currency unit in terms of some other currency unit of the same country: as when a pound note is found to have less purchasing power than a sovereign.

b) A decline in the value of a money unit of one country in terms of the money unit of another: like the recent fall in the value of pounds sterling, marks, and francs in terms of American dollars.

c) A decline in the general exchange value of a given money unit, like the decline in the purchasing power of the sovereign or dollar since 1897.

Corresponding to these different meanings are three tests which economists have been in the habit of applying to currency: the existence of a premium on gold; a dislocation in foreign exchange rates; and a rise in the index number for the general price level.

The first, the existence of a premium on gold, is the most satisfactory test for ascertaining whether a country's paper money is depreciated in relation to the universal unit of value (gold).

If we are to rely on precedents, we might expect that the large issues of notes in Germany and France, to say nothing of "inflation loans," would be followed by depreciation; but if it exists the direct evidence is insufficient to prove the fact. An attempt by speculators in Germany to get gold by offering a small premium was nipped in the bud, and the practice sternly forbidden American travellers desiring to leave Germany and France have offered fantastic premiums; but this fact, explainable on the ground that gold exports from these countries has been prohibited, does not prove depreciation, nor justify the statement so often made - that gold is at a premium throughout Western Europe. It is even more difficult to find direct evidence of depreciation in England, which still maintains an open market for gold.

15 A. C. Whitaker, "Currency Depreciation in Time of War," Quarterly Journal of Economics, February, 1916. 
The second test, derangement of the foreign exchanges, is hardly more conclusive, Pounds sterling, francs, and marks have undoubtedly depreciated, in varying degrees, as compared with the American dollar. During the first months of the War, pounds were at a considerable premium, and for the simple reason that during these months America owed a great deal of money to the United Kingdom, and the competition of bidders for bills or drafts sent exchange soaring to a 44 per cent premium in favour of the United Kingdom. This means that it took about seven dollars in New York to liquidate a debt of one pound in London. The rates, however, gradually fell as confidence returned in the general situation, and particularly in the ability of the British Fleet to hold the sea safe for traffic, and in December the rate was at par. Since then it has been in favour of the United States, though rarely exceeding 5 per cent. A similar story may be told of the fluctuations of franc and dollar exchange, except that during 1915 the discount on the franc rose rapidly to 14 per cent., standing at the end of the year at 11.6 per cent. The German mark, during the same period, showed a rapidly increasing depreciation, in terms of dollars, in December, 1915 being at a discount of 20.7 per cent.

Now facts like these are commonly interpreted to mean that the paper currencies of Germany, France, and the United Kingdom have depreciated in terms of their own gold unit of value. But such an interpretation cannot be accepted. The fact that American business men had, at the beginning of the War, to pay seven dollars in New York for one pound in London, certainly did not mean that there was a monetary inflation in the United States. Nor does the swing in the opposite direction prove that the money systems of the United Kingdom, France, and Germany were suffering internal depreciation as compared with gold. If we take Germany as an illustration, what meaning are we to ascribe to the 20 per cent depreciation of the mark as compared with the American dollar? In the first place, it must be remembered that German exports to America were soon reduced to small proportions, and that American exports to Germany continued to be carried on through neutrals. Germany, therefore, could not pay for imports by exports; she could pay only by gold or by selling securities. The selling of securities for a time arrested the decline of the exchange rates against her; but the relief was only temporary. When securities were used up, there remained only the export of gold; and this, besides being illegal, could only be effected with great difficulty and at great risk. The adverse rates measure: (1) the difficulty experienced by Americans 
in getting payments from their German customers; and (2) possibly a growing lack of confidence in the issue of Germany's scheme of aggrandisement.

They cannot be taken as an accurate measure of inflation in Germany itself.

Nor is the third test any more conclusive. Prices of commodities in these countries have undoubtedly risen by leaps and bounds. From July, 1914, to the end of October, 1915, English prices rose 30 per cent to 35 per cent. If we trust to somewhat scanty data, prices in France rose, during the same period, about 50 per cent. In Germany there was a rise of from 75 per cent to 80 per cent. From the end of 1915 onward prices have been rising in all three countries. The increase in England is now computed at 97.75 per cent.

Now these rising price levels are undoubtedly equivalent to a fall in the purchasing power of the currency unit.

But does this prove that the actual currencies (mostly paper of one kind or another) have suffered depreciation in terms of gold? Might not the same phenomena have appeared had these currencies been freely convertible, or had the various governments refrained from issuing large quantities of inconvertible notes, or from doubtful methods of Loan finance? Some part - probably a large part - of the general rise in price levels is obviously due to general scarcity in the supply of commodities: a conclusion con firmed by the fact that Germany, which is most cut off from foreign supplies, has suffered the greatest rise in prices.

On the whole, it may be said that the available evidence is insufficient to prove that depreciation as compared with gold has taken place, or that the rising prices are due solely to currency inflation. All that we can say is that it is probably true that some depreciation has taken place, and that it is due not merely to the issue of inconvertible notes, but also to the illegitimate expansion of credit in the raising of War Loans. When the War is over, the problem of preventing a still greater depreciation will tax to the uttermost the financial ability of most of the countries concerned. But the problem is not insoluble. So far as inconvertible notes are concerned, they can be converted into Loan stock, and this will remove any anxiety alarmists may have felt. In the meantime, they have served a very useful - and probably necessary - purpose. 


\section{VII}

But with Europe organized financially on the basis of paper money, what has been happening to the world supply of gold? Europe, it has been said, has now all the paper and America all the gold. An exaggeration, of course, for Europe has still considerable reserves; but nevertheless the War has "caused an international shift of gold of immense proportions"16 The United States of America has received $£ 200,000,000$, an increase of nearly 50 per cent over previous holdings. Sweden, Denmark, Holland, Switzerland, and Spain have gained $£ 80,000,000$, or 107 per cent more than they had before the War began. The Argentine has netted $£ 20,000,000$. According to a recent cable Japan has $£ 70,000,000$ of new gold.

The fact is that Europe just now cannot afford the luxury of decorative gold supplies. Wheat, wool, meat, iron, guns, shells, are of far more importance to her than gold. She has ransacked private hoards and melted down plate and jewellery to the extent of $£ 200,000,000$ and has gladly parted with this and more for munitions and food. Life is too serious in the great European nations for indulgence in monetary "swank". It is, no doubt, fortunate that they were able to lay their hands on large supplies of gold; but they would have been in just as good a position if an equal amount of gold (or its equivalent) had been previously invested in neutral securities.

Neutral countries have been inundated with a golden flood. Strange to say, they have not regarded it as an unmixed blessing. Most of them would have preferred food, clothes, coal, and other commodities needed for daily consumption. Indeed, the gold has created something of a panic, and we have the spectacle of the Scandinavian countries passing legislation to exclude the "yellow peril". Holland, also, is taking its trade balance against England in British Treasury Bills. She wants no more gold. What all these countries fear is that too much gold will have the same effect as too much paper, viz., a rise in the general level of commodity prices. Their remedy is to invest balances abroad.

In the United States the same misgivings have frequently found expression. Even the most confirmed worshippers of the Golden Calf have begun to realise that vast accretions of gold cannot remain dead in reserves. They must be used.

16 G. E. Roberts, "The Situation of the United States at the Close of the European War; with special reference to the Gold Supply," American Economic Review Supplement, March, 1917. 
It is not in the human nature of bankers to see an idle stock of gold without attempting to make a profit on it. It can be used only by means of loaning, and loaning in the freest possible manner. In such a situation, "every borrower is a benefactor". But, as Mr. Roberts and others have shown, there are limits to the healthy expansion of loans. Industries in the United States are already working to their maximum capacity. Labour is fully occupied. New industries, started on the strength of cheap money, can get labour only by paying more for it. The effects are to raise wages and prices all round, and incidentally to give encouragement to all sorts of "wild cat" schemes which aim at "profiteering" rather than production.

America, too, has more gold than she wants, and most of the financial experts advise the Scandinavian and Dutch remedy, investment abroad, as a means of stopping the flow and getting rid of some of the present surplus. Probably, indeed, it would have been wiser to have adopted this policy at an earlier date.

It may be mentioned here that fears are entertained by some in America that Europe, after the war, will demonetize gold. There does not appear to be any real ground for this apprehension; but it is tolerably safe to assume that Europe has now fewer illusions than she had about the monetary importance of gold.

\section{VIII}

There remains still to be considered the second source from which a government at war may obtain money. I mean the increase of taxation. In this paper it will be impossible to deal adequately with the question. I shall have to content myself with: (1) an explanation of how taxation differs from other financial devices; and (2) a very brief discussion of the question how far a government should finance war by taxes or by loans.

A loan is a voluntary contribution to the expenses of government in return for the payment of a stipulated rate of interest. It is, therefore, simply an investment. Investors may, of course, be actuated by patriotism in deciding to put money into war loans rather than into other securities. They may lose a small percentage of gain by so doing; but, on the whole, investment in war loans is a business transaction, and sometimes extremely profitable. 
A tax, on the other hand, is a compulsory withdrawal, for public purposes, of some portion of an individual's wealth, on the clear understanding that it will not be returned, and that no direct compensation will be made for its use. So far as individuals are concerned, it is confiscation; and the fact that the whole society, including the taxpayers, may benefit by the public use of confiscated property, is not usually regarded as completely consoling for the loss of part of their wealth. The average "economic" man has no love for taxation. It is not merely that it may compel him to cut down his accepted standard of expenditure; this result may be necessary and beneficial in times such as these; but it also limits the amount of income he may devote to gainful pursuits, such as investing in war loans or in shares in the stock of companies providing the necessaries of war, or in businesses that cater only for the wants of a nation at peace.

For a long time Germany boasted that in her case increased taxation was unnecessary. Dr. Helfferich, in fact claimed that he had been able to meet the ordinary expenses of Government from current revenue without levying additional taxation. This is all the more remarkable seeing that the revenue has necessarily fallen off. The tariff, which usually accounted for 40 per cent of the German revenue, now brings in comparatively little. Income from other sources, like railways, has also decreased. It is difficult, therefore, to understand how the normal expenses of the Government could be met out of a greatly diminished income. Possibly, however, Germany had decided that it was unnecessary to bleed the people in two ways at the same time. They could not raise Loans up to the limit of their actual means and credit, and at the same time find the wherewithal to pay increased taxes. But more recently the Government has instituted heavy taxation on war profits.

France has naturally suffered a loss of normal revenue owing to the occupation of part of her territory by the enemy, and partly on that account she delayed levying increased taxation; but as the situation improved she found it practicable to raise considerable sums through taxation.

In the United Kingdom there has been a tremendous increase in taxation, particularly on war profits. Recent returns show that about 25 per cent of the British War costs has been paid out of taxation. 
The second question - How far a Government should finance a war by taxes, rather than by loans? - is one on which opinions greatly differ. There are some who prefer taxation to borrowing. They believe in the policy of "pay as you go", and they give the following reasons for their belief: (1) financing by taxation does not, they allege, throw a burden on the future; (2) it avoids the rise of prices commonly ascribed to financing by loans and paper money; (3) it compels an immediate reduction of unnecessary and wasteful consumption; and (4) if conscription of persons be decided on, then conscription of wealth should also be adopted, and this can only be brought about by taxation.

On the other side, the following considerations are put forward:

a) The whole drift of modern finance has been in the opposite direction for more than a hundred years. Wars have, as a matter of fact, been financed mainly by loans and paper money. This does not, of course, prove the case against the taxation method. It merely draws attention to an actual evolution in finance.

b) Loans, the first school asserts, throw a burden on the future. I shall give reasons presently for believing that this idea is grossly exaggerated. The argument is that loans limit the amount of capital which may be invested outside of war industries. Established peace industries suffer through depreciation of concrete capital, and during the war there is neither labour nor capital for the laying down of new plants. When peace comes the community is less well equipped than it might have been had no war taken place. So far as this reasoning is sound, it applies with equal force to taxation, which not only restricts consumption, but limits the extent of private investments.

c) The second argument referred to above for a confiscatory policy, depends on the correctness of the assumption that rising prices are solely or mostly due to expansion of credit. This, as I have suggested, is putting excessive emphasis on the monetary factors in the determination of price. The truth is, that price advance will take place under war conditions even if no expansion of credit exists. "Whether public borrowing will lead to an inflation of prices depends largely on the conditions on which loans are contracted. If the subscriptions to the loan are defrayed by borrowing 
from the banks, such a result would undoubtedly ensue, at least to the extent that analogous subscriptions might not have been made to ordinary industrial enterprises. But if, on the contrary, there is a large loan fund in existence - if in other words, the accumulated profits of recent years have not yet been invested, or if the subscriptions to the loan involve simply a change of investment from private enterprise to government service, there will be no such resort to credit and there will be no such inflation of prices." ${ }^{17}$

d) "Conscription of Wealth" or income advocated as the logical accompaniment of "conscription of persons" is probably neither just nor feasible. "Is it proposed to draft for personal service only the poor of purse? Will not the wealthy be called upon to make sacrifices of service? The proposal to permit able-bodied men of wealth to purchase exemption from military duty by surrender of their property would certainly not appeal to anyone. When war begins to reap its harvest, there will doubtless be a full measure of distress among the wealthy. Moreover, does not this argument appear to rest to some extent upon a desire to punish and to cause suffering? Paraphrased, it would read as follows: The poor will have to suffer by rendering personal service; let us make the rich suffer also he compelling them to surrender their incomes. There will be personal service rendered by both rich and poor, and if the war continues for a long time great suffering will ensue. The sacrifices of the poorer classes certainly must not be increased by the addition of heavy economic burdens. Wherever the expenditure of money will further the purposes of the war, will prevent suffering and save life, the money must be spent.

The financial burden of this must indeed be borne by those who have a surplus, and there is every indication that they will accept the burden willingly." 18

17 Edwin R. A. Seligman and Robert Murray Haig: "How to Finance the War," Colombia War Papers, Series I, Number 7 (Colombia University, 1917), p. 10.

18 Ibid., pp. 11-12. 
e) Finally, there is the "practical expediency" argument. Drastic confiscation of income as it accrues is a policy that no ministry would be likely to face. Even if its ultimate economic effect could be proved to be less harmful than borrowing, it ignores the "psychological factor". In all probability it would result in discontent and disunion at a time when harmonious co-operation is essential.

But although the arguments for raising war funds mainly or wholly through taxation are inconclusive, there are several reasons for the adoption of a policy of increased taxation.

In the first place, combined loans and taxation tap income and property which a loan policy by itself fails to tap. In the second place, as already stated, it limits unnecessary or wasteful consumption, and thereby saves labour for more urgent purposes. Finally, there is a reason connected with the question of wealth distribution. It may be true, as Pigou holds, that if everybody in a community had the same amount of wealth, there would be little to choose between borrowing and taxation. But wealth is far from being equally divided. Under the prevailing conditions of inequality and "as regards aggregate effects, there is a very great difference. Under the tax method, the rich and moderately rich shoulder the whole burden of the charge that is laid upon them", though this is true only so far as they are unable to shift the taxes. "Under the loan method they do not do this; because they are compensated afterwards through taxes laid for that purpose partly on themselves, but partly also on other and poorer sections of the community". ${ }^{19}$ Indeed, if indirect taxation is used to any great extent, the poor will bear a large part of the burden.

The exemption of loans from taxation, though it may at times be unavoidable, is a violation of the principle of equity of taxation, since it gives a permanent advantage to one class of investor in comparison with other investors whose services to the community may be equally important. It also gives added importance to the element of unearned income.

19 Pigou, "The Economics and Finance and War." Proceedings of Section 10 of British Association for the Advancement of Science, 1916. 
So also it may be that the poor suffer most heavily from such inflation of currency as possibly results from inconvertible issues and some of the loan methods I have described. Their wages do not rise as rapidly as prices, and their money incomes do not purchase as much as before. "This means that, in effect, a part of what the rich hand over to the State in their War Loan subscriptions is really exacted without interest from the poor." ${ }^{20}$

On the whole, it is probably true that the taxation method, so far as it is practicable, has a less harmful effect upon the distribution of wealth than borrowing is likely to have.

\section{IX}

This leads to consideration of two related problems to the first of which I offered a tentative solution in the Veil of Money. They are:

a) In accumulating these vast War debts, are the people of to-day transmitting a burden to the future?

b) Will the distribution of wealth in the immediate future be affected by War Finance to the disadvantage of the poor?

The answer to the first seemed to be that the war could be carried on only by the present use of men and resources. War Finance, whatever else it meant, was merely a method of organizing men to use existing resources in a special way. So far, then, as the nation is indebted only to its own citizens, the burden is not transferred to the future.

Since writing the first paper, I have read an interesting address by Mr. G. E. Roberts, one of the ablest of American bankers. I cannot do better than quote what he says on this point:

"But what about the debt? Is it true that these countries are drawing on the future, that they are expending capital before it is created, and heaping up burdens upon generations yet unborn? There is very great exaggeration about that. If you say that they are wasting capital which should be passed down to the future, and that the progress of the world is retarded, I will agree, but this is a different thing. 
"In the first place, there is no such thing as expending capital before it is created. Capital must exist in tangible form. There are no economic losses except in tangible things. The war, as we have seen, is carried on with tangible thing - with equipment and supplies - and these must he furnished now, not after the war is over. The armies are not being fed this year from next year's crops, nor are they using supplies of next year's make. Whatever else may be obscure about the incidence and effects of this body of indebtedness, one thing is clear, viz.: that all the production of the future will belong to the future, and none of it will belong to the past. A popular speaker is quoted as saying that 500 years after the war is over the people will be toiling to pay the interest on these loans. That may be so, but if it is, it is certain that the payments will be made to people then living, and that their use of the capital will react upon the entire community." ${ }^{21}$

But though this reply is conclusive as far as it goes, it may not appear to dispose of the whole difficulty. Is not the obligation to pay interest, and ultimately to redeem War Loans, a burden which we are transferring to the future? My tentative reply took this form:

a) The transfer by individuals of rights of action or titles to property to the State, does not alter the material economic situation, though it leads to a diversion of economic energy. If those rights had not been transferred, they would be functioning as ordinary commercial capital, and would exact a return for their services. Is there any essential difference between the two forms of burden?

b) If it be said that there is a radical difference, because in one case the loaned capital creates assets which have no value for peace, and in the other brings into existence more or less permanent instruments of production, the reply is that the war expenditure on equipment and supplies is as economically necessary as any of the economic activities of a nation at peace.

21 Business After the War, an address given in June, 1916. 
I did not, of course, argue that war did not involve an economic loss, but only that the principal loss "occurred when the proceeds of the loans were expended." That loss takes the form of the destruction or maiming of human life, the destruction or letting down of concrete capital employed for peace purposes, the comparative neglect of some industries important in times of peace, and the difficulty of reconverting plant and re-establishing industries at the close of the war.

I insisted, and still insist, that economic laws are not suspended during war. The wealth produced for war is just as much wealth as that which is produced for peaceful consumption. The enormous consumption of war must have an equally enormous production. The waste of war has, unfortunately, its counterpart in the wastes of peace; and the state of war has often this advantage - that it compels a degree of organization seldom realized in the careless and slovenly, even if "piping", times of peace. And as production may be actually increased in war time, it follows that the supply of loanable capital may also be increased. This capital is just as real and legitimate as the capital that arises out of the normal production and consumption of goods in peace time. Failure to appreciate this, and the fact that much of this war wealth is the direct product of the State's action, have led to some doubtful conclusions. For example, take the following statement by a thoughtful Australian banker, ${ }^{22}$ one who has nevertheless grasped the true meaning of modern money. He is criticizing severely - with what justice I need not here consider - the issue of Australian notes for the purpose of financing the War. He considers that this issue has resulted in the creation of fictitious credit or purchasing power, and goes on to remark:

"The Government, with the further purchasing power placed at its disposal, purchases with it further goods and services for destructive purposes. Thus, with each increase of credit there is no corresponding increase of material wealth; rather the reverse, an actual decrease."

But surely, if the goods and services are forthcoming at the requisition of the Government, there must be so far an actual increase of wealth. To say that it is produced for "destructive purposes" does not rule it out as an economic quantity on which credit may be legitimately based. ${ }^{23}$

22 J. H. Butchart, Money, Credit, and Banking.

23 I am not here, of course, questioning his criticism of the issue of Australian notes 
With respect to the second problem, I believe with Mr. Pethick Lawrence, ${ }^{24}$ that the rich, who are the principal lenders to War Loans, will be on that account in a stronger economic position after than before the War. A great deal of property held by people of moderate means will, before the end of the War, have passed into the hands of the rich. As already suggested, also, a good deal of the interest on War Loans will come out of the incomes of the poorer classes; and if it should turn out that paper currencies cannot be saved from depreciation, the poor will suffer disproportionately on this account. I do not, however, believe that considerable depreciation is inevitable or even likely. Nevertheless, there is a grave danger that distribution of wealth after the War will be more lopsided than ever. So far as that danger cannot be avoided, the economic condition of the poorer classes will be worse in the immediate future.

The danger will be greatly increased by the failure of the capitalist and labour interests to co-operate more harmoniously than in the past. The adoption of a reactionary policy by the former may bring us face to face with the "longest, fiercest, and most widespread industrial strife" 25 society has ever experienced. But such a crisis may be equally well precipitated by unreasonable demands or methods on the part of working men. One cannot but hope, however, that the War has taught the people of the United Kingdom, and perhaps the people of Australia, the enormous advantage of rational organization and co-operation. If we are to fail to accomplish in peace-time what we have so nearly accomplished with the enemy at the gate, then I do not see what hope there is for the world. But I do not believe that we are going to throw away the lessons of the War so readily.

On the whole, as will have become apparent, my views about the effects of the War Finance of to-day are less pessimistic than those commonly put forward. And I think that anyone who refuses to be hypnotized by figures and symbols, and honestly tries to get at the reality behind the figures and symbols, will be disposed to share my optimism. In particular, it has seemed to me desirable to get away from the purely monetary expression of the problem of War Finance.

24 The Economist, September 20, 1916.

25 The New Statesman. 
"A Roman, it has been said, was asked which be would prefer, a lump of iron or a lump of gold. He said, 'I will take the iron, as I can then get the gold also.' The iron of war is men and munitions, money is but the medium through which, for convenience, we can get them. Given men and munitions, money can be had for the asking. This is the whole philosophy of War Finance." ${ }^{26}$

26 Carl L. Plehn, University of California Chronicle, July, 1916. 


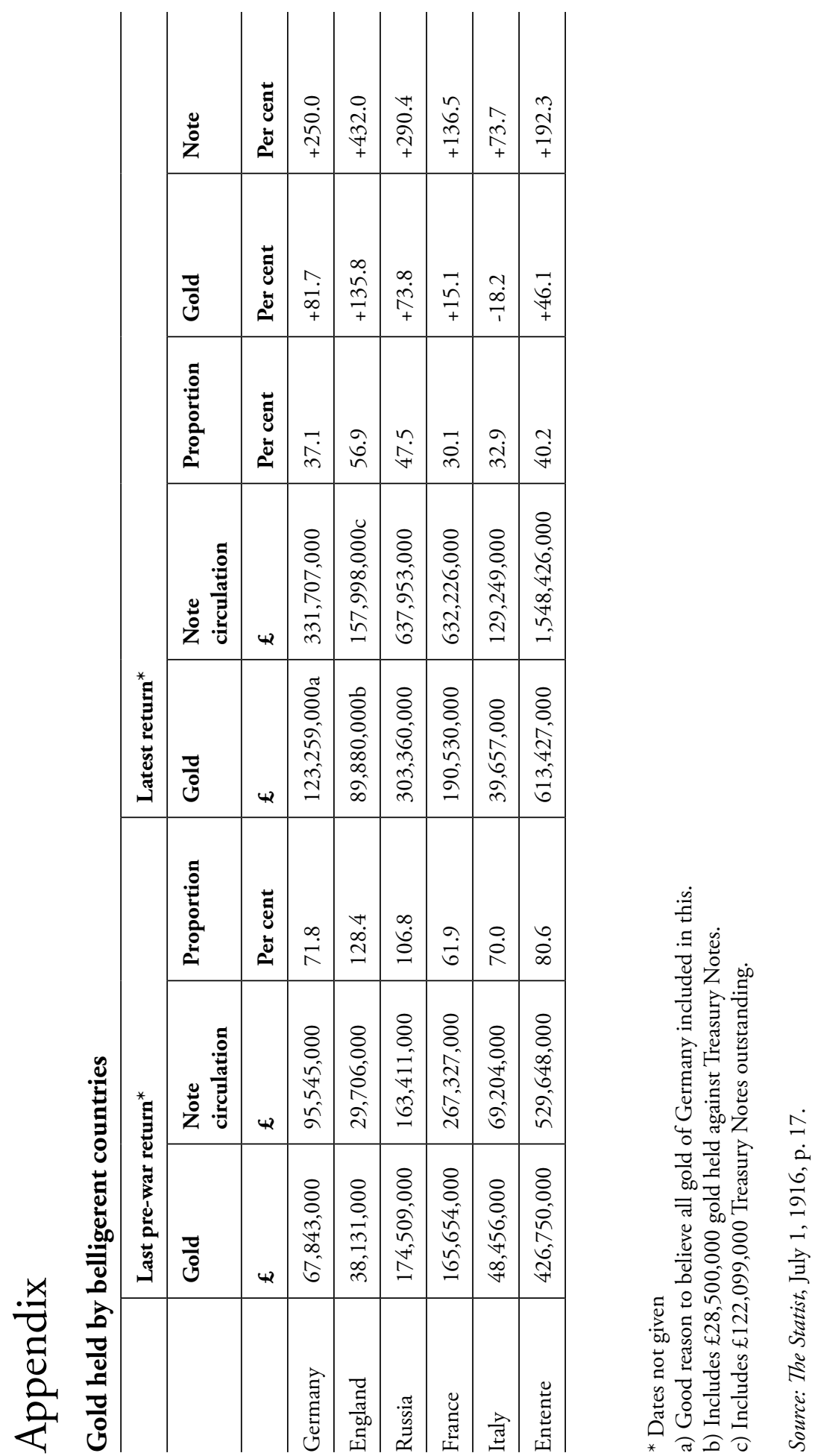




\section{The humanizing of commerce and industry}

\section{Gerald Mussen $^{1}$}

I would like it to be clearly understood that the views which I express to-night are my personal opinions, and that I do not speak on behalf of any of the companies to which I act as industrial adviser.

Do commerce and industry require humanizing?

Let us make a short examination of existing conditions and practices, to see whether Australia has been proceeding on the best lines. I do not propose to give a historical review of the growth of our present system of trade and commerce, its economic laws, and its industrial conditions. Our concern to-night is with the existing conditions of the lives of our people, not what brought those conditions about. We have gone through the greatest war in history, involving appalling loss of human life and uncountable destruction of the world's possessions. We have emerged victorious, with the cause of civilization saved and the road of progress standing out clearly in front of us. While we are still dazed with the noise and tumult. of Armageddon, our jarred senses and tired nerves have :been shocked horribly by a great outburst of social and political revolution. We have now become indifferent to the fact that almost each day, in some disturbed part of the world, a new social system is created by a band of rebels, who throw down the rulers of the previous day, and are in turn displaced before there is any clear understanding of what they stand for. All through the world a mighty ferment is working. Our old sense of peace, tranquillity, and security is gone. The old order changeth. Where will it end? We wearily admit, "We know not."

1 Eighth Joseph Fisher Lecture, 9 May 1919. 
Now this attitude of folding our hands helplessly in our laps, of waiting with humility to see what is going to happen is traitorous to our great homeland, Australia. We are living here to-day under the freest constitutional conditions that any social system can give. We have one adult one vote, and majority rule. No revolution here, no smashing of our social system, will give us greater freedom. To-day any citizen has only to convince a majority of his or her fellow-citizens that what he or she advocates is right and good, and it can be made the law of the land. If conditions exist to-day that are wrong or unfair, we have no one to blame but ourselves. We are free to alter our conditions at any time, so long as the majority wishes to do so. Our charter of liberty is the widest in the world. It is based on adult suffrage and majority rule, the only possible basis Upon which democracy can rest. Whoever preaches a class rebellion in Australia, whoever urges physical force to secure reform, is a traitor to our constitution, a plotter against our liberty, and an advocate of tyranny. Here in Australia our forefathers have laid for us the very corner stone of liberty. It is for all Australians, regardless of social position, to safeguard that liberty and to use it so that on the principles of right and justice we may build a national life that will place Australia's name in peace as high in the temple of fame as our soldier sons have placed it in time of war. Most of us here to-night have been permitted to live our lives under conditions of peace and order. Unless we bestir ourselves, our children may be deprived of that privilege, simply through our own supine ness. Those who are too tired to fight for liberty do not deserve to possess it.

In making this appeal for the preservation of our existing constitutional rights I do not mean that our Federal or State Constitutions should not be altered. As a free people we must retain our existing right to alter our constitutions in any way the majority wishes, and we may be sure that if we do our duty no alteration will receive majority approval that is not based on right, justice, and liberty for all equally, with privileges for none.

Let us turn now to the existing conditions of our Australian life and see whether they accord with these principles, remembering that if they do not we all share the blame. Let us remember, too, that the great war will have been fought in vain if it has not made us kindlier one to another, and if it has not left us determined to make the world in general and Australia in particular a better place 
to live in. Australia has been proud of her trade and commerce. There are plenty of people in the community who mistakenly use the volume of Australia's oversea trade as the gauge of our prosperity. Thus when, in spite of the war, in 1916-17 we soared up to the record oversea trade figures of imports $£ 76,299,000$, and exports $£ 97,955,000$, making a total of $£ 174,184,000$, or $£ 3514$ s. $5 \mathrm{~d}$. a head, there were glowing comments on our wonderful prosperity. Even if this gauge of prosperity were accepted as economically sound, which it is not, an investigator would be puzzled to explain why this seeming prosperity was accompanied by the most widespread industrial unrest, and the greatest number of strikes Australia has ever known. Clearly there were enormous monetary transactions in 1917, and no doubt somebody enjoyed great prosperity, but 173,970 employees became involved in 444 strikes, losing 4,599,658 days' work, representing $£ 2,594,808$ in wages. We all know that our seeming prosperity was accompanied by a great increase in cost of living. While some people were enjoying greater profits or remuneration than they had ever had in their lives, others found the margin between what they received and what they had to pay out to live rapidly disappearing. There has been no official investigation into the cause of the widespread industrial unrest in Australia, but in Great Britain the Royal Commission which investigated the cause of industrial unrest there, reported that in the great majority of cases discontent was due to the increase in the cost of living. No doubt the same cause was mainly responsible in Australia. No one can deny, however, that a country which in time of war permits some of its citizens to suffer want, while others do not know how to spend their great gains, is, to say the least, badly governed, and that a social system which produces such results requires amendment.

What then is wrong with this system under which we are working? Some of its faults are quite obvious, and the outlining of them will indicate the direction in which we may hope to make improvements. We produce annually about $£ 200,000,000$ worth of products. In 1917, owing to high prices, production went up to $£ 270,427,000$. According to the last census figures rather less than half of our population is engaged in production, trade, and commerce, the others being children, women, or dependents. We can probably reckon on 2,200,000 producers, workers, and traders, including 200,000 domestic helpers. How is this industrial army of 2,200,000 organized? How are the recruits for each occupation obtained? We are told that it is done by the law of supply and demand. Take any average Australian boy. How is his future avocation determined? Not by the 
general law of supply and demand, but largely by the law of supply and demand in his own home. In other words, the financial circumstances of his own home determine largely at what he is to work. If his parents are poor, he must get work at the best paying job available. Many parents have for long years stinted themselves in order that their children may get a skilled training of some kind, thus securing a better chance in life than their parents had. If the parents are better off they endeavour to find out their boy's natural bent, and to place him in some occupation he specially fancies. But they have nothing to guide them in making a decision. If they decide to make their boy an electrical engineer they do not know whether there is likely to be a shortage or a surplus of electrical engineers. Similarly there is no guide as to whether the community will want carpenters, or fitters, or bricklayers, or other skilled tradesmen. It is all just a blind choice, dictated by fancy, necessity, or accident. This is one of the contributing causes of the community finding itself every now and then with a number of unemployed in its midst. Nobody bothers to get out statistics indicating the industrial position and prospects, to guide parents in choosing occupations for their boys and girls. It is all just haphazard.

When we turn to the actual production of goods, we find just the same lack of organization and direction. Each man who goes on the land pleases himself what he grows. He comes into town, asks agents or other farmers how they reckon the markets are going, and on their inexact opinion decides what to sow. If when his crop is harvested there is no market for his products, we remark what a fool he was to grow that stuff. We forget that in forcing that farmer to decide for himself on insufficient knowledge, we are unfair. His loss entails hardship on his wife and family and loss to the community, which has thus grown a product for which it can find no use. Yet the community has a very direct interest in seeing that no productive effort like this is wasted. Other men drop wheat growing and go in for sheep, or vice versa, simply because they think the new occupation will be more profitable. If a man loses, who cares? It is the law of supply and demand. If he can catch the community short of some essential, he will in return extort from the community the biggest price he can get for his product. When he does that he forces up the cost of living of all the people who use This product, and they in turn require more wages. The increase is passed on and on until the whole economic structure shakes. We call this our organized system of production. It is not an organized system. It is only the beginning of a system. In manufacturing the same 
extraordinary haphazard conditions prevail. Nobody knows what quantity of any article the community needs. Each manufacturer makes his own guess, throws in one or two varieties as new season's patterns, and hustles his salesman out on the road to find buyers. If the market happens to be flooded with cheap Asiatic or foreign stuff, the salesman fails, the factory shuts down, the employees have to look for work elsewhere, while in the store room lie thousands of pounds' worth of goods not required. We laugh at the manufacturer for being short-sighted, but we should weep for him and his employees, as in the end the community has to pay for this mistaken effort of production.

It is interesting to note the action taken in other countries to cope with this problem during the war. In Great Britain and France there was an investigation into boot manufacturing. It was found that there were hundreds and hundreds of patterns being turned out, each year bringing forth a new crop. This in turn had led to thousands of shopkeepers buying quantities of each of these hundreds of varieties, and in each case they had to stock a range of sizes. The public bought a little, and then its vagrant fancy turned to other shapes and patterns. The result was that thousands of pounds' worth of boots were lying on the shelves of the boot shops, out of fashion and not required. Under war conditions this had to stop. An effort was made under expert guidance to reduce the patterns of boots manufactured to a reasonable number. This resulted in a saving of leather; also a number of those previously engaged in boot making were released for other war work. The community had conserved its stock of leather and the public got cheap boots. There is bound to be an effort made to continue this arrangement under peace conditions. The discussion in Great Britain regarding a national uniform of one pattern for all citizens to wear during working hours has shown ways of eliminating waste and cheapening production. In America the manufacturers, when brought together under the war-time hoard, made some extraordinary discoveries. They found in the furniture trade, for instance, that they could afford to cut out half of their two million patterns, and so cheapen the production and sale of standard lines. A committee investigated transport on the railways and found that by altering the sizes of packages of certain goods every inch of space in the railway trucks could be utilized. The equivalent of an additional 125,000 trucks' space was thus secured. This meant in practice a reduction of freight, and enabled a lower selling price to be charged. 
Against this organized campaign for eliminating waste effort and getting efficiency in production, Australia will have to compete. It is time we awoke on the business side. Then, too, our system of distribution could not be more ludicrous than it is. We are all familiar with the silly surplus of milk and butchers' carts in our home streets. Do we realize that there is no restriction whatever on shopkeeping other than in regard to the rate of pay and conditions of employees? A man goes out to a growing suburb and starts a retail shop. A year later his prosperous look leads another man to push in and open a second similar shop. The first man was able to run his business on, say, a basis of 15 per cent on cost, but the advent of a competitor, who gets some of his trade, forces his cost up to 25 per cent. There are now two retailers, each with a separate staff, to divide the trade of the locality. A year later a third man comes in, eventually gets a footing. and the three shopkeepers proceed to fill the public's requirements at a cost of 30 or 35 per cent. Two of them should not be there. One could do all the business. Yet the community permits this wastage of human effort and pays for it. The second and third shopkeepers and their staffs and carts should be prevented from becoming a charge on the community, and should be directed towards some productive employment. The same thing occurs in regard to unnecessary agents. It is no advantage to the community to have scores of agents engaged in selling and re-selling lines of goods, even if they do make a good living. Many of them are doing unnecessary work at the cost of the community, and their energies could, with advantage, be transferred to a productive occupation.

Is it not wonderful that under this disorganization our industrial army of $2,200,000$, despite the absence of our soldiers, produced in $1917 £ 270,427,000$. What would have been our production if all waste effort had been cut out and the number of middlemen, shop keepers and agents, reduced to those actually required for the public convenience and the remainder employed as wealth producers? If we are to carry our immense war burdens we must get increased production. We shall probably be forced by necessity to transfer many people now engaged in distribution to the productive industries. Our bad organization is due mainly to the fact that our business is a go-as-you-please method based on profit. If we systematized more, each individual would not be as free as at present to buy and sell as he pleased, regardless of whether he served the community well or ill. As the chief end of trade and commerce is to make money, we need not be surprised that in the struggle to snatch money out of our transactions 
we have often been blind to the human injury and injustice we have done. We have become the slaves of money. I suggest that in future, humanity will have to receive first consideration. If we are slow to act we may be compelled, like some other parts of the world to-day, to face the issue whether we are to be ruled by hatred and tyranny or by love and liberty.

Five short years ago the majority of us were simply money grubbing. We wanted all the money we could get each for himself. The object of life was profit. All sections of the community followed the same principle. We knew that suffering and misery stalked among us, but so long as we individually escaped we did not really care. The churches wrung their hands and deplored the general selfishness, but were content to float down life's stream mildly protesting. The politicians, being no better than the rest of us, made a game of life and played one party against the other for office and pay. Economists and financiers with very few exceptions cheered our country on to borrow vast sums abroad, and were content to see a national orgy of wasteful expenditure providing great opportunities for private accumulation. The universities and educationists generally were powerless, almost voiceless, for few of us heard their warnings. The mass of us accepted conditions as we found them, and did not worry. The higher side and purpose of life were forgotten. We were content to feed on husks.

The great war awakened us. Our Empire was endangered. Our own homes and liberties were threatened. The call of the blood of our forefathers thrilled us all. Volunteers poured into the training camps from bush and city, farm and office - rich and poor, all creeds, all conditions offering, not their money, but their lives to save us. Our patriotism became articulate and real. Australian manhood was united in a splendid mateship of self-sacrifice. On the battlefields of Gallipoli, Palestine, and France that mateship was made eternal. More than fifty thousand precious lives have been given for this Australian homeland of ours. Two hundred thousand have been maimed or injured, and thousands of others have toiled unceasingly so that our vast sunlit continent may be preserved to us and our children.

By the blood of our heroes the oneness of the Australian people has been cemented. That oneness, with the return of peace, now requires concrete expression. The old callous indifference to suffering and misery must go. A new 
understanding of life is breaking in upon us. The grandeur of humanity has been revealed to us by the sacrifice of our own flesh and blood. The old pre-war conditions have become intolerable. Upon us who have stayed at home in ease and comfort devolves the duty to probe deeply into the causes of unhappiness and discontent in our midst, and fearlessly to advocate remedies, so that the way may be prepared for a greater and fuller national life. Change is in the air. A new era is dawning. We have accepted the sacrifice of thousands of lives for our preservation. We cannot make payment for this across the money-changers' tables.

Great Britain has been setting us a worthy example by making great preparations for a new order. Time has been snatched from war duties to prepare a revolutionised system of education for the people. The housing problem has been faced and orders given to build at once 100,000 homes, to be followed by 300,000 more. It is reported that the British Government intends in future to provide, through the municipalities, all the houses required by the citizens. As a health provision the milk supply throughout Great Britain is to be nationalized. This is only the beginning. Investigation by the best brains available is proceeding into every possible post-war problem, and the way is being paved for fundamental changes. What is the key to all these changes?

It is the Gospel of Happiness. It means the recognition of the right of every citizen to live a life of happiness. It means the true realization of the equality of men. The rights of Magna Charta; the spirit of the French Revolution - Liberty, Equality, Fraternity; the freedom of the American Declaration of Independence, and our own Australian Constitution will, under the new conception, be enriched and widened. The human element in commerce and industry must have first consideration, and profit must be placed second The object of life is happiness not money.

Let us look back over our pre-war legislation and conditions, and see if they complied with the Gospel of Happiness. In a dim, unseeing way we have tried in the past to legislate to bring about ideal conditions. But we were working on a fundamentally wrong principle. We gave legislative recognition to the belief that the object of life is profit or money. But money is only a means to an end. We have always treated it as the end - not the means. We grasped at the shadow 
- money - and missed the substance - happiness. In missing the great truth that the object of life is happiness, not money, we unconsciously struck a staggering blow at all our money-making projects. The irony of it is that there is considerable experience to show that any business - private or public - carried out with due regard to the happiness of all concerned, will in the end return more profit than if run as a mere money-making concern.

To-day the great Australian mateship born in the heroism and suffering of war requires us all to recognize that every Australian man, woman, and child has a right to practical participation in the Gospel of Happiness. Why should anyone born in this world be sentenced to unhappiness by reason of the conditions surrounding his or her life? All are born with an equal right to happy conditions, and the true meaning of all the industrial unrest, so marked of recent years, is that the great mass of people have been trying to give voice to their craving and right to a share of the happiness of the world. But because their demands have been made usually in terms of money, resistance has been offered and strikes have occurred, with loss to the community and hideous suffering to many. It is pitiful to think that even the granting of increased money to wage-earners has left them just as unable as previously to obtain the happiness they sought. The reason for this is that the individual cannot buy with money the conditions essential to his happiness. What are these conditions?

The first is health. This is the essential basis of all material happiness. All men and their wives and children are entitled to be kept healthy. The greatest asset any nation has is the health of its people, and if the money-grubbers still fear costs, investigation will prove to them that no matter how high the expenditure on the preservation of the nation's health, it will still be profitable.

To appreciate this it is only necessary to examine the results obtained in our vast armies during the war. The most highly skilled and gifted doctors and specialists were called to the nation's service to devise means of preventing disease among the soldiers. The results were amazing. The same skill, supplemented by the efforts of thousands of warm-hearted nurses, has been devoted to making well the sick and the injured. In pre-war times could the humblest citizen in the community rely on receiving such gladly given and sympathetic attention? Certainly not. But in post-war times each of us will have to admit his direct 
interest in the health of every other member of the community, and gladly give support to some form of communal service under which the highest and the lowest of our citizens - tiny babes or aged men or women - will all receive the best medical, surgical, or nursing skill to heal them - not as a charity or for money, but as a right gladly acknowledged and a service anxiously rendered in the common name of humanity.

We have got to realize quickly that our personal obligation as. members of a community each to the other is to see that all have the basic conditions essential to human happiness. Delay will bring disaster in the aftermath of the war, but with the acceptance of this view comes the duty of putting it into practice and making the Gospel of Happiness real. Health - the base of material happiness, will have to be handled in new, far-reaching ways. Until then we shall never cease to shudder at our past neglect, with its untold suffering and misery.

I can hear some one say: "That is an amiable ideal, but is it practicable?" The answer is that it is not only practicable, but it is actually going to be profitable. I see from the published figures of the experience of members of friendly societies that each member averages ten days' sickness a year. If this experience is applied to the industrial army of Australia, excluding dependents, it enables us to calculate that in a year the loss to the community, at ten shillings a day, from sickness of workers, amounts to twelve and a half million pounds. This does not take into account the necessary attendance on the workers during their sickness, nor the provision of drugs and special comforts. If then we could remove sickness from our midst, the good health resulting would automatically increase our production by over twelve and a half million pounds a year. Even if it cost that sum, the expenditure would be justified to alleviate the human suffering involved.

In devising a practical policy to secure better health we shall have to rely largely upon the advice of our health authorities throughout Australia. It has been already recognized in other countries, particularly Great Britain, that a true health policy calls for a much greater effort on the preventive side than upon the healing side, and it is interesting to note that in Great Britain the members of the British Medical Society have vied with each other in making valuable suggestions as to the means by which the health of the people can be preserved. It is suggested that the future education of medical men should provide for about fifty per cent. 
of the training being devoted to means of preventing disease, the other fifty per cent. to the healing of disease.

With health guaranteed by the community, I suggest that the next essential to happiness is a system of proper education. Without it the citizen cannot enjoy the beauties of our world and of creation and mankind; his usefulness to the community is limited, and one more is added to the discontented, unhappy, inefficient section.

I am not competent to express any view on the practical alterations that should be made in our system; I can only speak from experience of the failure of our present methods to fit young men and women properly to start the business of life. Most of them find on commencing a business career that they have to begin to re-educate themselves. I have been particularly struck, too, with the fact that our educational system does not teach national ideals. I believe that if we are to succeed in the reconstruction of our part of the world, it is essential we should have clear national ideals as the goal towards which we as a people are seeking to travel. Ask any man or woman in Australia to-day what are our national ideals, and you cannot get an answer. As far as I know we have only one, "A White Australia." What are the other things that we as a people are striving to achieve? They do not exist in any concrete form that can be taught to children, and that can thereafter through life be used as a guide by them.

Are we prepared to accept this Gospel of Happiness as a national ideal? If we are we shall have to evolve practical means for safeguarding the health of every unit in the community and securing to all conditions that will permit them to live a life of happiness, while at the same time giving them absolute freedom as individuals to go on and develop to the highest of their capacity, and to secure as much more happiness and achievement as their self-expression requires.

I appreciate that if we attempted to instil some ideal like this into our children to-day we would be disconcerted by the comment immediately made that we were not living up to it; that we permitted sickness and misery, and that we were callous as to whether some sections of the community lived or died. I venture, however, to suggest to the educationists that in the reconstruction of education in the future national ideals should find a foremost place. 
To attain happiness, even if a man have good health and a good education, it is necessary for him to have the right to live in a good home. In the past we have left the matter of housing to the individual - with disastrous results. We have slums, tenements, overcrowded and insanitary homes, and exorbitant rents, resulting in the loss of health and happiness. Such conditions destroy individual efficiency. The present laws governing housing are absolutely inadequate, and the sooner we follow Great Britain's example and provide suitable homes for all, the better.

But if we are to have a huge housing campaign we must organize to carry out the job in the same way as a company would commence a campaign for the construction of big works. It is conceivable that we in Australia, having decided to build, say, fifty thousand houses, would take stock of the materials available in our own country; we would make enquiry as to the labour available; as it would be one big job we would proceed, after the preparation of plans, to prepare our timbers and other building materials in a large organized way. There would be no need for us to follow the methods of to-day. In some cities in Australia you can see bricks being carted from a brickyard in the north to a building site in the south, while at the same time bricks from a brickyard in the south are being carted to a site in the north; you can see labour residing in one suburb hurrying away to a distant suburb to work on a building, and meeting on the journey a stream of similar men travelling in an opposite direction. Naturally there is waste of time, money, and effort. A great housing campaign for Australia would have to be put in the hands of practical men, who should be given authority to lay out the job and to carry on the actual building regardless of the precedents of previous practice, and with the sole desire to fill the community's want at the earliest possible moment.

Strangely enough we Australians have not shown that we are a practical people, but we are willing to learn. Our young men during the war have shown what they can do. It is time that we gave them a chance here in our own country to show whether they are competent as organisers and carriers-out of such a scheme as has been suggested. Where energy and new methods are required the younger men have got to be given control. Experience in other countries has shown this to be necessary. 
I have suggested that it is essential to happiness that each individual should have secured to him health, education, and a good home. To this must be added the provision of decent town conditions with adequate facilities, such as parks and baths, for the enjoyment of his family and himself. I am rather hopeful of the birth of a new sense of civic pride. It seems possible to me that each town community can be so stimulated that it may be induced to organize its forces, its money, and its resources to make for itself any facilities which it needs. That this is practicable has been shown at Port Pirie.

To complete the basis of his happiness a man must also be placed in the position of receiving wages at a rate which will leave him an adequate margin after paying his cost of living. It is essential that each should have free money to spend on his or her hobby or pleasure or personal improvement. In earning these wages each must work under decent conditions, in a healthy atmosphere where there is no suspicion of tyranny. Increased money alone would not give these benefits.

A glance at these requirements, which appear essential to the happiness of Australians, shows that no increase of wages or reduction of hours would enable units of the industrial army to secure them. You cannot, as an individual, buy health by receiving an additional shilling a day in wages. Ill health will mar the happiness of any one, no matter what income he has. Hundreds of thousands of men have struck and suffered to get increased wages, and have succeeded, only to find that in a few weeks the increased cost of living has taken from them their increased wages. A man living with his family in a hovel, or a crowded tenement, cannot get a decent house for them even if his wages are increased, unless somebody else has. built a house and is willing to rent it to him. No individual by getting a rise in wages can improve the conditions of his town, nor remedy his defective education, and if I have correctly stated the basic conditions for material happiness, it is not difficult to understand that every advantage gained by trades unionism is doomed to failure, and the results of every successful strike turn to Dead Sea fruit. No wonder then that the world is filled with great unrest. A large number of people are disgusted with their failure to achieve happiness. See the true perspective of our present conditions in the light of this Gospel of Happiness, and is it any wonder that Australia to-day resounds with alarming discontent and unhappiness? We were only playing with industrial conditions when we legislated to provide a minimum wage, hours, and conditions. For instance, to fix wages 
without controlling the cost of living is love's labour lost. Cost of living can travel faster than increase of wages. Good conditions for a man during the eight hours he works, in the absence of the basic conditions just outlined for the other sixteen hours of each day, only barb his discontent.

If we attempt to re-organize our community so as to secure to each the basic conditions of happiness, we have to face the problem of unemployment. I do not think the community can evade its obligation to grant the right to work to all willing to do so, nor can it evade the obligation to find that work. I go further, and believe if the community fails to find work for one of its units it should pay him or her some form of sustenance. This latter principle has been introduced into Australia in connection with our returned soldiers, and in Great Britain in connection with displaced munition workers. A statement was recently made that one million munition workers were receiving sustenance at the rate of twenty five shillings a week owing to munition work having ceased. We in Australia have felt it a duty to returned soldiers to adopt a similar practice. When our soldiers come home, the duty rests on us of being able to re-establish them in civil life. The Federal Government has already put into operation the practice of paying liberal sustenance if it is unable to find work for the soldier. Great Britain admits a similar obligation in regard to munition workers. It is but a short step further to admit that a community which cannot find work for its units must pay them. A man has still to find a home, food, and clothing for his wife and children, even if he is out of work. They cannot be allowed to starve. It is wicked to suggest that any such dire necessity should be allowed to overtake them. It would be a vicious community which permitted such a thing to happen. In the past we have allowed them to be cared for through some charitable organization. I suggest that there should not be any element of charity in regard to such cases, but that the community should face its obligations and grant the right of sustenance to any person willing to work but for whom a suitable occupation cannot be found. If this is to be done a wise community, recognizing the liability which would fall on it under this system, and which to-day falls on it without it clearly recognizing its loss, would so organize its business as to have reserve occupations for people who have lost their employment. In this connection, in addition to all public works, the provision of new houses appears to be suitable. We need, say, fifty thousand houses in Australia to-day, and if the building of these were organized under one control, the actual work of construction could be carried out in respect to 
many of them at times when employment was scarce in other directions. If some hundreds of men lost their employment they might be transferred to the Home Building Department. They would not, in many cases, be efficient workmen, and their advent might infringe upon the claims of certain craftsmen that they have the sole right of doing such work as carpentering and bricklaying; but just as there was dilution of labour in England to secure an adequate output of munitions, so we may find it necessary to provide for a dilution of labour here in order to have an adequate output of homes in Australia.

Remembering now the picture which I have drawn of the disorganization of our present system, of its faults and its callousness, you will agree that reconstruction is going to be difficult, but I am sure that there are big-hearted Australians in our community who, if the call is made, will willingly give their time, their experience, and their knowledge in an effort to devise practical means for achieving greater happiness in Australia for all.

In such reconstruction we must necessarily keep clearly before us the necessity for increased production. This can only be achieved by greater efficiency. If we are to carry our enormous war burdens, and if we are to meet the competition of such countries as America, which is rapidly re-organizing its industries, as previously indicated, we shall have to make an early start. Personally I believe that under our Australian conditions we can only get true efficiency and high production by re-organizing our system under central direction, and by providing conditions of life which will ensure that everybody commences his daily work physically and mentally well. If it were possible to bring to their work in the morning all men and women at present engaged in commerce and industry, in a condition of perfect fitness - physical and mental - the output might easily be twice, if not three to five times what it is to-day. I do not believe that any special monetary inducement will, by itself, be successful in getting increased production from employees in Australia. The secret lies in the fact that the Australian, bred under free conditions, is a curious animal. There are plenty of things which you cannot induce him to do for money. Yet there is no effort that he will not put forth, even if it costs him his life, if he is doing it for a cause in which he believes, if, in short, he wills to do it. As I see the position, the secret of increased production as far as employees are concerned, lies in our bringing about a change in their point of view. If they feel that they are not fairly treated, no monetary reward will 
induce them to give their fullest production. Until we can get them to come to work physically and mentally well, we shall not succeed in obtaining increased output; but given these conditions, I believe they will no more be able not to give self-expression to themselves in increased effort than a flower can help opening to the sun. I further believe that when we have given absolute demonstration as a community that we intend to secure these basic conditions of happiness for all, the "go slow" policy will die; until then we have no remedy against it, nor much hope of increased production.

If we succeed in changing the point of view of our people and securing to them the basic conditions of happiness, it does not mean that every individual will be content with these minimum conditions, but I think it will be feasible to keep the way open for all men and women equally to get as much more happiness as their temperament and capacity require; in other words, we would say, "We give everybody the basic conditions of happiness which insure to them at least a minimum, and we leave everybody free, so long as they do not infringe on the rights of others, to go on and develop to the fullest, the capacity within them."

If we reach such a time, what will the duty of the individual be? If the community is warm-hearted, generous, and thoughtful of the individual, will the individual give a return in kind? I feel sure of it. In our Australian community at least eighty-five per cent of our people are decent, clean, white Australians, and with our majority rule they must always prevail. At the same time we have to do a little clear thinking on the question of equality. No matter what social system we are living under, we must realize that our industries will necessarily be organized in much the same way as they are at present. If you are to get high production you must have organization; if you are to have organization you must have discipline. The idea that an industry could be run by a committee of workmen is absurd. I have frequently pointed out in discussions with representatives of employees that every man in a community has two capacities. In the business in which he is engaged he has a position according to his capacity, and most of us find that owing to superior intelligence, or training, or knowledge, there are many people who occupy higher positions than we do. If we sought to alter these conditions and reduce all to an equality, we should in any organized industry where high technical knowledge is required, reduce our production to about one-tenth, and possibly to zero. For instance, in such a business as the Smelters of Port Pirie, 
there is a highly-trained staff of metallurgists, superintendents, and experts. These men have had a training from their early years in this particular business; if they had to commence to learn at their time of life to-day they would find it impossible to acquire the required knowledge. If a committee of workmen owned the Smelters and ran them, and, say, twenty experts were withdrawn, the production of lead would probably total not more than ten thousand tons a year. If the twenty experts then returned and took charge with exactly the same plant and exactly the same labour force, their production would be what it is at present - about a hundred and fifty thousand tons a year. We see, therefore, that the direct product of the labour force, uncontrolled and undirected, would possibly be ten thousand tons a year; but controlled and directed properly it ; a hundred and fifty thousand tons a year. Does this not mean that taking the total product, a hundred and forty thousand tons of it is produced by the directive capacity controlling the industry, and ten thousand tons by the labour controlling itself? It is, of course, only fair to point out that the increased production could not be obtained without the labour force, nor could the labour force obtain the increased production without the directive capacity. Consideration of an instance like this, I think, entirely explodes the idea current in some labour circles that the worker is robbed of the full product of his labour. It is inevitable that in such an industry men will be classified according to their capacity and receive remuneration accordingly. Hence certain men must have, control over certain others. Alter that condition and you destroy the organization and annihilate the greater portion of the production. The Soviet Government in Russia has found this difficulty insuperable. The workmen there took control of industries. The result was disastrous. Everywhere, in the absence of expert guidance and business management, production approached the disappearing point, until there came the compromise with the capitalists, under which interest was paid to the owner of a factory and high salaries to the management and experts. But even now the outlook is black. Discipline has been destroyed in the industrial army of Russia, and the impassioned appeals by Lenin to the workers to impose self-discipline on themselves appear to be unheeded. The revolution in this respect has caused production to dry up, and the smash has been so great that it may be impossible to return to the old basis before starvation takes toll of millions. The position there is ghastly. So then all men cannot be equal when working in the army of production any more than in an army for military purposes; but once a man 
passes out through the gates of the works where he is employed in Australia he becomes a citizen, and as such is the equal of, and has equal rights, with all other citizens.

There can be only one test of citizenship, namely, decency, and all decent Australian citizens, no matter what occupation they follow, are as good as the best people in the world; under our Constitution all have equal voting power and all have equality of opportunity to rise to the highest position in our country. It does not follow that because we are all equal in citizenship, we of differing tastes must make close companions of each other; ours would be only freedom in name unless we were free to seek as our special friends those who have similar tastes and similar likings. Many of the best men that it has been my privilege to meet in Australia go to work in dungarees. Among them the love for Australia, the desire to achieve greatness for their own country and to mould it and fashion it until it stands as the finest and greatest in the world are very strongly marked. Any man would be proud to take these true Australians by the hand. I suggest, therefore, that we should keep clearly in mind this distinction, that in our daily employment we work according to our capacity, and in our citizen-life we are .all equal. A more general recognition and expression of this principle will, I am sure, go a long way towards removing some of the prevailing bitterness in our community. As citizens we control Parliament, which in turn can control any industry. Hence there is no sound reason for seeking to set up some form of industrial control by employees.

We must at the same time make every effort to secure equality of opportunity for all. One of the greatest problems which the world faces to-day is to discover those in the community who have directive capacity. Speaking generally, I suppose there is only about one man in ten thousand with directive capacity, that is, capable of directing others in the carrying out of any big organized work. Again, I suppose there is not one man in half a million with directive capacity and constructive capacity combined. It is a most unusual combination, but any man who possesses it is a great asset to his country. He may be born in any home. The natural brain endowment of such a man is not hereditary in any class or section, although there are some people who, because of the accident of birth, claim superiority over others. 
A wise community must be constantly watching for the advent of specially endowed young women and men and ever ready to afford them opportunities for training and for the development of their talents. This must be done in the interest of the community itself, for these are the women and men who, when discovered and placed in suitable positions, will best serve it. The possession of this natural brain power enables men to become leaders or captains of industry. They are born, and development comes with education and experience.

You cannot make a directive and constructive brain out of an ordinary one. In the past we have in a vague sort of way endeavoured to provide educational facilities for the development of the individual with a super-brain. Our attempts in this direction, however, have been extremely defective owing to the fact that we have not fully recognized the urgent necessity that exists for finding and fostering these peculiarly gifted people and utilizing their great brain force for the community. Few of us clearly understand the difference which men of this stamp make to a country or an industry, and it is hard for some people to realize that it does not matter in a big industry, for instance, whether you pay them two thousand or five thousand pounds a year. If given the opportunity, such a man will be worth double or treble the money paid to him. During the war some countries were extremely fortunate in their possession of a large number of men of exceptional brain capacity. Other countries were less favoured in this respect, while others again neglected to take advantage of all the great mental forces at their disposal Great Britain and America buttressed their political administration by calling in the best business brains to assist during the war. Australia did not follow suit. The following extract from an article written by Sydney Brooks in the Fortnightly Review is applicable to Australia:

"The prevailing low standard of commercial statesman ship in Parliament has again and again prejudiced and retarded American development, and its adverse consequences are likely to be peculiarly felt in an era such as we are about to enter, when the relationship between the Government and businesses will be intimate beyond all precedent, and when national commerce and national prosperity will be largely dependent upon the directing wisdom and organizing vision and capacities of each separate State." 
If commerce and industry are humanized in the way in which I have indicated I should expect a surprising revelation regarding the increase in production. There will, of course, be many who will say that such conditions can only be brought about by the power of Parliament. Well, this is largely true, but special obligations fall on all employers to see that their employees are helped towards securing the basic conditions of happiness. It is comparatively easy to advance a theory. The difficulty is to create practical means of carrying it out. Hence any change from old conditions will be slow, and the methods adopted will be altered from time to time as experience is gained. A little detailed information regarding the policy which the Broken Hill Associated Smelters Proprietary Limited at Port Pirie has carried out shows some progress made in applying this new spirit. I have had the privilege of being associated with that policy, and from my purely personal point of view I believe everything done there has been in accordance with the basic principles of the Gospel of Happiness enunciated to-night.

So far, I have not referred directly to industrial unrest and its causes, but I may say here that in my opinion the provision of the conditions which I have set out will end industrial unrest. That it has not succeeded in doing so at Port Pirie already is not due to the failure of the policy, but to the fact that it is impossible for a single industry to cover the whole field. Much must be left to the government, but the Associated Smelters has gone a consider able distance along the road. A disgruntled handful of men can always cause a small strike, and in any case it will take many years to get the new policy fully established and recognized. The Smelter employees at Port Pirie can, however, claim the distinction of never having lost one hour in production of lead during the war. The major portion of the supply of lead for Great Britain and her allies went from Port Pirie, and night and day throughout the war, lead was poured out from the Smelters. No strike stopped the continuous stream. The staff and employees did their bit in the war, working continuously seven days a week until victory was secured.

At Port Pirie the health of the employees is considered of paramount importance, and everything possible is being done to protect and safeguard it. The progress in this direction has not been as rapid as was desired by the Company, owing to the stress laid upon it in producing the utmost quantity of lead during the period of the war. Reconstruction of buildings and rearrangement of plants were difficult under such circumstances, but the working conditions 
have been improved and every provision made at the works for succouring the injured and the sick. The directors of the Company recognized that the payment to injured workmen of one pound a week for incapacity due to accident was totally -inadequate; no married man could, with the present high cost of living, possibly maintain his family on such a sum. Arrangements were therefore made for establishing an accident fund, out of which the statutory payment of one pound a week could be supplemented. To this fund the employees contribute sixpence a week each, and the Company contributes sixpence a week, and out of the fund so created an injured man is paid thirty shillings a week. Under the South Australian Workers' Compensation Act as amended in December last, the rates were increased, so that Smelter employees who are members of the fund now receive altogether from the fund and under the Workers' Compensation Act, three pounds ten shillings a week if married, and three pounds a week if single. This fund has grown in the eighteen months of its existence until there is a credit balance of about two thousand four hundred pounds, and arrangements have now been made to extend the fund to cover sickness, without increasing the contributions. The sickness payment will be one pound a week, and the scheme will be operated for twelve months in order to see what the demands on it for sickness claims will amount to. If necessary the position will then be reviewed. The administration of this fund is carried out by eleven trustees, eight of whom are elected by the different unions represented in the works, and three nominated by the Company. Membership is confined to unionists. The Company voluntarily gave the unions a majority of the representation, although it finds half the money. It was one of those matters in which the Company and its employees could cooperate together, and the same spirit has been applied in other activities. In each cooperative scheme for improving conditions the Company has insisted that the management must be carried out by the men, assisted by such representatives as the Company may nominate as most suit able to aid in securing success.

Regarding the Accident Fund; after eighteen months' experience it can be safely said that the administration has been excellent. To-day the Company follows the decisions of the trustees in paying compensation to injured men under the Act. If the trustees decide that the sufferer from an accident is entitled to accident pay from the fund, the Company follows that decision in paying the amounts required under the South Australian Act; in other words, a committee of representatives of the men decides who shall receive accident pay. 
With a view to safeguarding the health and providing facilities for enjoyment and recreation, the Company not only grants a fortnight's holiday on full pay to all employees who attend regularly, but has provided a holiday resort eighteen miles from Port Pirie, to which employees and their families have the right to go at week-ends, on holidays, or on annual leave. Port Pirie is unfortunately situated inasmuch as, though it is close to the Gulf, it has no seabeach; it is low-lying and the climate is hot. The Company made a search for a suitable place at which to establish a holiday camp. An ideal spot was discovered eighteen miles away, On the opposite side of Spencer's Gulf, and it was named Weeroona. The only drawback is that fresh water has to be carried in barges from Port Pirie. There is a beautiful beach, good fishing and shooting. A main dining room has been erected, at which meals are provided by a permanent staff; each family has its own table, and one of its members does the waiting on the others. Sleeping accommodation is provided in well-furnished military tents equipped with wooden floors. The only work visitors have to do is to make the beds and keep the tents clean. For the rest of the time they may enjoy themselves in the way that pleases them best. Each night there is a concert or dance, or an openair picture show. The camp is equipped with electric light, and water is laid on adjacent to every tent. It is a prohibition area. Hundreds of employees and their families have this year enjoyed a holiday at low cost. The Company provides free transportation for the men and their families to and from Weeroona, and they only pay the bare cost of living. In this way a healthy, recuperative holiday is brought within the. reach of all.

Probably no innovation at Port Pirie has created more interest than the establishment of a co-operative store. This was the outcome of an investigation into the cost of living. The matter of cost of living is becoming a bugbear to every country in the world. Every where you can find large sections of employees who declare that they are no better off to-day when receiving, say, eleven and nine pence a day, than they were some years ago when they received seven and sixpence a day. In industries where the increased cost represented by an increase in wages can be added to the selling price and passed on to the consumer, it is comparatively easy to put up with the rise in wages, but in an industry such as the production of lead, this easy expedient of passing it on is not possible. Of every hundred tons of lead produced at Port Pirie, ninety-five tons have to be sold across the sea in competition with producers of lead in other countries. 
Australian lead has no special merit above any other pig lead; the buyer does not bother regarding the country of origin; he buys at the lowest price. Consequently the smelters in Australia have no say in deciding the selling price. It is therefore impossible to pass on an increase in the cost of production caused by increased wages. The problem facing the Company was that every increase in wages was followed by an increase in the cost of living, necessitating a further increase in wages, and this process gave every sign of being interminable. It can easily be seen that a succession of increases would lead to the cost of production going up so high that Australia would be unable to compete with other countries, and as its product would be unsaleable, the whole industry in Broken Hill and Port Pirie would die. It became of the utmost urgency, therefore, to see if something could be done to stop the irresistible march of the increase of cost of living.

It was decided, after close consultation with the employees, to establish a co-operative store; the money required was found by the Company by way of a loan, 'on which it receives interest at the rate of five per cent. The Company laid it down that any goods handled must be sold at the estimated cost price, including wages in the store and general charges. In practice it has been found that fifteen per cent on the landed cost at Port Pirie on any goods so far handled covers the cost of distribution; there is no profit, no advertising, and the business is concentrated under one roof and run in the least expensive way. Trading at the store is confined strictly to employees and their dependents. The co-operative store simply acts as agent for the employees. It buys for spot cash at the point of manufacture or production, brings the goods to Port Pirie in the most economical way, and distributes them from the store at the least possible cost. It may be remembered that evidence was given to the Interstate Commission in Melbourne by boot retailers that they could not carry on their businesses under an estimated cost of thirty-five to fifty per cent. on cost in the shop. These percentages, compared with fifteen per cent, indicate the savings which are being made in cost of living to employees at the smelters. So far only men's, women's, and children's boots, tobacco and men's clothing are dealt with, but the employees are now urging the Company to extend operations to cover most other necessaries of life. The management of the store is in the hands of the B.H.A.S. Co-operative Council, a body formed of representatives of each department in the works on the basis of one representative for every hundred employees. This gives twentyseven representatives to the employees. In addition the Company has the right 
to nominate six representatives on the Council. There is an Executive of seven, charged with the active management of the store, comprising four representatives of the employees and three of the Company. This Executive meets weekly, and the Co-operative Council monthly. The general manager has the right of veto over any decision of the Council or Executive which he considers inimical to the business. All transactions are for cash; there are no bad debts. Since the establishment of this store at Port Pirie a similar institution has been created at the works of the Electrolytic Zinc Company of Australasia Proprietary at Risdon, near Hobart, and several other large industries also contemplate attempting to hold down the cost of living by similar means.

Port Pirie has been unfortunate inasmuch as the increase in the labour force at the smelters to meet the war demand has led to congested housing. The Company has now made a start with a housing scheme - the first six houses having been erected. Others are to be proceeded with as early as possible. The directors recognize that special consideration should be given to married men who have the responsibility of a family. It has not yet been decided whether or not the houses will be sold at cost price to the employees, as the first six had to be handed over to urgent cases on a rental basis, special committee of the Co-operative Council was recently asked to frame a report on the best system of allotting the houses, and they produced a scheme under which due consideration should be given on a percentage basis to size of family, length of service, importance of a man to the industry, and other factors.

With a view to improving the town the Company supported a citizens' movement to improve the parklands by giving a donation of one thousand pounds. This area is rapidly being beautified, and is to be known as "The Soldiers' Memorial Park." The Company is also supplying the Municipal Council with electricity for town lighting at a low price.

Probably no event of recent times has brought the name of Port Pirie so prominently before the public as the building of the children's playground of ten acres in one day by two thousand employees, assisted by their wives and daughters. Originally the Company announced that it would provide a children's playground, and the town council made available an area of ten acres centrally .situate, from which to choose a site. This idea gradually expanded until, with the 
assistance of the Government Town Planner, a lay-out plan was prepared to cover the ten acres. This, it was estimated, could be carried out in five years by doing some portion every year, but one afternoon, while discussing the project with the Co-operative Council, I asked if any of the men would care to go and work on the ground voluntarily. I was asked: "How many men do you want?" I replied: "One thousand," and promptly one representative declared that they could get two thousand men. I undertook that if the Board consented, and two thousand men volunteered, we would make an effort to build the playground in one day. The directors of the Company generously agreed to find, free, all the material required if the men did the work. From then on, for six weeks, preparations were made. Hundreds of men came on the ground each day to put in foundations and make drains, while others gave up to one hundred hours of work in their spare time in the works, making wrought-iron gates, seats, and other requirements. Construction Day was favoured with fine weather, and the whole work went through smoothly to its completion. On that day the General Manager and the whole of the staff and men worked on a basis of equality; the General Manager planted trees under the direction of a smelterman; everyone was in shirt sleeves; only workers were allowed on the ground. Throughout the day no orders could be heard, there was no confusion, and the extent of the work carried out was almost unbelievable. It was a great Australian Day, evidencing the true Australian spirit of unselfish work for the benefit of all, providing in one day a much needed facility for the town and one which has been greatly appreciated, and in which the whole town has a pride.

Quite recently the employees, under their own leaders, organized another voluntary campaign which has resulted in a new fence being put round the Soldiers' Memorial Park by voluntary labour. Some of us hope that this new sense of citizenship may go on and develop in other parts of Australia, with advantage to all sections of the community.

One further institution in the works at Port Pirie is perhaps worthy of mention - this is a provident fund, administered-by a joint committee of the men and staff. The Company gave a sum of money to this fund and charged the trustees with the duty of lending sums of money to any employee in distress. The condition was made that no interest should be charged, as it was felt that any person in distress should be helped, and not burdened with interest. All 
transactions of these trustees are confidential, and are not disclosed outside their meetings. Instead of an employee in distress applying to the Company he applies to these trustees. They are the sole judges whether a loan shall be made. They decide the terms of repayment, and whether security shall be taken or not. In all these activities it must be noted that nothing is done without the close co-operation of the employees, but every assistance is given them to make such activities a success. An effort has been made to make them feel that they are members of the Big Lead Industry Family, and that they have the right to claim the assistance of the other members of the family in removing any condition which injures them.

With regard to unions, the Company recognizes them; it gives them wide freedom to bring up grievances and affords them opportunities for discussing them. Each employee in any case has the right to take his grievance to his foreman, or to the superintendent of his department, to the superintendent of the works, and, finally, to the General Manager. An effort has been made to give absolutely fair treatment to all, and the Company insists on getting similar fair treatment from its employees.

To me it seems that all these activities are based on the principles of the Gospel of Happiness. After all, life should not be all work; we find ourselves in the world under the necessity of working; if none of us works, then nature will not feed and clothe us. The community's obligation is to see that the essential things in life which we require are produced and obtainable. The biggest production that we can achieve with the least effort is only possible under skilful organization. As we all have to work it is better for us to co-operate; combined effort under efficient organization gives the greatest results for all. According to the census of 1911 there are only twenty-three thousand people of independent means in Australia; the balance of us are all workers. It may be that our present organization throughout the community is faulty; it may be that some people receive more money or remuneration than they should; it certainly is true that there is much waste effort. Obviously, if we can eliminate this waste effort and direct it to productive channels there will be a greater pool of resources from which we can all draw our share. It is for Parliament, in accordance with the will of the majority, to adjust the basis of sharing, by taxation or by other means. It seems probable in most English-speaking countries that in the years to come there will be some limitation of profits; we have already seen the principle introduced in the coal 
trade in Great Britain. What other changes will follow time alone will show, but I suggest that by making the human factor the most important and the one to receive first consideration in commerce and industry, we will be taking the first great step towards the solution of our difficulties in this, the greatest transition period which the world has ever faced.

We are all members of the one big union - the great Australian Union. It covers every man, woman, and child in our country. We want to help each other, but it is so difficult to find practical ways and means. Their evolution will be slow, and can only come from sustained thought, effort and planning. Therefore we must be patient. But we should seek to make our one big Australian union so real that all can achieve happiness, and only then can we demonstrate that we are truly one people with one destiny. 



\section{9}

\section{Currency and prices in Australia}

\section{Douglas B. Copland ${ }^{1}$}

My predecessor in the Joseph Fisher Lectureship has drawn attention to the great problems of industrial reconstruction awaiting solution before any reasonable measure of industrial stability can be attained. ${ }^{2}$ As a part of this question of general industrial reorganization, the variability of the-standard of value is, itself, of fundamental importance. In normal times, changes in the price level promote serious disturbances in industry, but during the past six years no set of factors have been so disintegrating in their influence. "The rise and fall of general prices is one of the greatest evils that can afflict a commercial nation"'; yet this rise or fall is the normal condition of the price-level in all modern communities.

Thus investigations into the price-level in the United Kingdom during the nineteenth century show that prices fluctuated as follows:

Table 9.1: Price fluctuations in the United Kingdom the $19^{\text {th }}$ century ${ }^{4}$

\begin{tabular}{l|l|l}
\hline Period & Movement & Percentage change \\
\hline $1789-1809$ & Rising & 85 \\
\hline $1809-1849$ & Falling & 59 \\
\hline $1849-1873$ & Rising & 50 \\
\hline $1873-1896$ & Falling & 40 \\
\hline $1896-1914$ & Rising & 35 \\
\hline
\end{tabular}

In Australia price fluctuations have been equally disconcerting.

1 Ninth Joseph Fisher Lecture, 15 June 1921.

2 Mussen: The Humanizing of Industry and Commerce.

3 Parsons: Rational Money, iii.

4 Jevons: Investigations in Currency and Finance, 134, Fisher: Purchasing Power of Money, 240-6. See also Layton: An Introduction to the Study of Prices. 
Many will remember the crisis of the early nineties, as well as the boom of recent years, with scant respect for our standard of value. ${ }^{5}$ The literature on currency and prices abounds with similar illustrations of changes in the general level of prices in all countries, and discusses freely the evils flowing therefrom. ${ }^{6}$ But the rapid increases in the general level of prices during the war gave greater emphasis to the problem, as may be seen from the following tables.

Table 9.2: Price movements abroad during the $\mathrm{War}^{7}$

\begin{tabular}{l|l|l}
\hline & $\begin{array}{l}\text { Wholesale prices } \\
\mathbf{1 9 1 3 = 1 0 0}\end{array}$ & $\begin{array}{l}\text { Retail prices of food } \\
\mathbf{1 9 1 4 = 1 0 0}\end{array}$ \\
\hline United States (March, 1920) & 253.0 & 196 \\
\hline United Kingdom (March, 1920) & 321.8 & 235 \\
\hline Japan (October, 1919) & 266.3 & - \\
\hline Sweden (March, 1920) & 345.0 & 291 \\
\hline France (February, 1920) & 522.4 & (Paris) 297 \\
\hline Italy (December, 1919) & 452.6 & 252 \\
\hline
\end{tabular}

Table 9.3: Price movements in Australia before and during the War

\begin{tabular}{l|l|l|l}
\hline Percentage increase in: & $\begin{array}{l}\text { Wholesale } \\
\text { prices }\end{array}$ & Retail prices & Cost of living \\
\hline (a) Last pre-war decade & 11.8 & 10.5 & 23.2 \\
\hline (b) Five years of war & 68.0 & 47.5 & 30.1 \\
\hline (c) From July, 1914, to June, 1920 & 166.0 & 87.1 & 53.0 \\
\hline
\end{tabular}

5 See the index number of Melbourne wholesale prices published in the Reports of the Labour and Industrial Branch of the Commonwealth Bureau of Census and Statistics. The data on which this wholesale index number is based are obtained mainly from reports of Melbourne market prices published in the ordinary press and in special trade reviews. No attempt is made to record the price movements of clothing footwear, furniture or furnishings; no index number is ascertained for wholesale prices in any capital except Melbourne. For full details of the method of ascertaining these index numbers see Report No1.

6 See particularly the investigations of Jevons in England and Irving Fisher in the United States. Fisher: Stabilizing the Dollar contains a short but searching analysis of the evils of a variable standard.

7 From a Report of the British Board of Trade (Cmd. 434). 
These tables suggest that some abnormal forces were operating during the war period, though the price-level increased in Australia considerably less than in other countries. The purpose of this lecture is to state briefly the causes of these changes in the price-level during the war, to explain the variability of the standard of value in normal times, to examine the social and economic effects of this variability, and to consider suggestions that have been advanced for promoting a more stable price-level. These problems will be developed as follows: causes of rising prices during the war; causes of price changes in normal times; social and economic effects of price changes; the functions and attributes of money and; suggestions for stabilizing prices.

\section{Causes of rising prices during the War ${ }^{8}$}

Changes in the general level of prices may be traced to one of two sets of factors, currency and trade. During the war the conditions affecting both these factors underwent some fundamental changes in all countries. It is generally assumed that trade decreased greatly, but this is not supported by a serious study of trade conditions for America and Australia, though it is doubtless true of many European countries, where the degree of trade paralysis varied with the duration of the war, and has been greatly accentuated by post-war conditions. In Australia a reliable measure of internal commerce ${ }^{9}$ (wheat, wool, hay, butter, bacon and hams, gold, zinc, tin, coal, sheep, cattle), overseas trade, railway freights, shipping, and postal business shows that from 1914 to 1918 there was a decrease in general trade of only 9 per cent. Professor Irving Fisher found that in America the volume of trade increased by 53 per cent from June, 1914, to December, $1918 .{ }^{10}$ No doubt European conditions affected the price-level in both these countries, but the war increase was much greater than this influence of external trade would suggest. It is apparent, therefore, that currency factors have had an important influence.

8 This section is derived mainly from results I obtained in an investigation into the war-time situation in Australia and published in the December number of The Economic Journal, Vol. XXX, 485-510,1920.

9 For the method of measuring these factors, see Economic Journal, Vol. XXX, 502-4. Complete statistics are not available for measuring trade after 1918, but the evidence available points to an increase from 1918 to 1919; yet prices rose in this period.

10 American Economic Review, Vol. IX, 407. 
There is much controversy over the causes of changes in currency, but economists are agreed that the relative abundance or scarcity of currency considerably affects the price-level. If currency is scarce prices will be low. Thus Hartley Withers quotes ${ }^{11}$ Dr. Johnson's remark when he was told that in Skye twenty eggs might be bought for a penny: "Sir, I do not gather from this that eggs are plenty in your miserable island, but that pence are few." Now it may easily be shown that wartime conditions promoted a great increase in currency in all countries. Banking progress in the nineteenth century placed two valuable weapons in the hands of Governments seeking to finance the war: (i) the note issue, and (ii) machinery for developing credit. In financing the war these weapons were used in the following ways: (a) gold payments were suspended by law or custom; (b) the note issue, now virtually inconvertible, became the legal tender reserve for banks; (c) great increases in the issue of notes were carried out by all belligerents; (d) these notes formed the basis of the clearing-house operations of banks; (e) governments borrowed heavily from their citizens through the banks; (f) the banks advanced considerable sums to their customers for investment in war loans; (g) bank deposits were thus increased, but the ratio of reserve to liability was maintained at a safe (and sometimes at the normal) figure by virtue of the increases in the note issue forming the legal tender reserve; and ( $h$ ) the fresh notes found their way to the public and the banks through the clearing operations of the "Government" bank. ${ }^{12}$

These operations were carried out in Australia, where a Government Bank and note issue made the situation entirely favourable to their development. The note issue was rapidly increased from $£ 9,573,738$ in June, 1914 , to $£ 32,128,302$ in June, 1915, and subsequently to $£ 52,535,959$ in June, 1918 ; the export of gold from Australia was prohibited; the associated banks of Victoria agreed to settle their daily differences through a reserve of notes, where before they had used gold, and the bank deposits increased steadily from $£ 159,000,000$ in the second quarter of 1914 to over $£ 265,000,000$ in the same quarter of 1920 . Meanwhile

11 Our Money and the State, 55.

12 This method of war finances has received much attention in recent economic publications. A popular account of it is given in Withers (Our Money and the State, chap. iii), and a more technical discussion will be found in Pigou (Economics of Welfare, 665-77); the Report of a Committee of the American Economic Association in 1918, American Economic Review, Vol. IX, Supplement No. 2, pp.90-118; Kirkaldy (editor): Industry, Finance, and the War, 228-9. The last publication, representing the considered opinion of British economists, concludes: "The amount of internal war loans that may be raised by an advanced community under modern banking conditions can be very great." 
the reserve of gold and notes to total liabilities rose, at first to 34 per cent, but afterwards fell, being 27 per cent on the average, while the pre-war average was about 23 per cent.

These facts may be seen more clearly from the following table (9.4).

Table 9.4: Bank deposits 1914-1920 (in thousands)

\begin{tabular}{|c|c|c|c|c|c|c|}
\hline \multirow[t]{2}{*}{$\begin{array}{l}\text { Quarter ended } \\
\text { June } 30^{\text {th }} \\
\end{array}$} & \multirow[t]{2}{*}{$\begin{array}{l}\text { Not bearing } \\
\text { interest } £\end{array}$} & \multirow[t]{2}{*}{$\begin{array}{l}\text { Bearing } \\
\text { interest } \mathfrak{E}^{\mathrm{a}}\end{array}$} & \multirow[t]{2}{*}{ Total $£$} & \multirow[t]{2}{*}{$\begin{array}{l}\text { Coin bullion and } \\
\text { Australian notes } £\end{array}$} & \multicolumn{2}{|c|}{$\begin{array}{l}\text { Percentage of } \\
\text { reserve }\end{array}$} \\
\hline & & & & & $\begin{array}{l}\text { IV } \\
\text { to I }\end{array}$ & $\begin{array}{l}\text { IV to } \\
\text { III }\end{array}$ \\
\hline 1914 & 70,195 & 89,014 & 159,209 & 41,447 & 58 & 26 \\
\hline 1915 & 75,381 & 92,177 & 167,558 & 55,378 & 73 & 33 \\
\hline 1916 & 92,822 & 90,641 & 133,463 & 58,312 & 63 & 34 \\
\hline 1917 & 105,466 & 91,384 & 196,850 & 53,777 & 52 & 27 \\
\hline 1918 & 112,262 & 97,276 & 209,548 & 56,360 & 50 & 27 \\
\hline 1919 & 118,989 & 112,281 & 231,270 & 57,894 & 49 & 25 \\
\hline 1920 & 133,913 & 113,734 & 247,647 & 55,940 & 42 & 23 \\
\hline $\begin{array}{l}\text { Percentage } \\
\text { increase of } 1920 \\
\text { over } 1914\end{array}$ & 91 & 29 & 55 & 37 & - & - \\
\hline
\end{tabular}

a. After 1912 the deposits given in the Commonwealth statistics include the deposits at the

Commonwealth Savings Bank. These latter are given separately as at the end of each quarter, and not the average for the quarter. Figures for the amount at the Commonwealth Savings Bank thus given have been deducted from "Deposits Bearing Interest" and thus also from "Total Deposits."

The increase in total deposits is thus 55 per cent for the six years, 19141920. In the previous six years, 1908-1914, the increase was only 40 per cent. The very large increase in deposits not bearing interest (i.e., deposits subject to cheque) portrays the operations of the banks in advancing to customers for war loan purposes. ${ }^{13}$ Now such advances created purchasing power in the hands of

13 For an explanation of these returns, see The Australian Insurance and Banking Record, Vol. XLXXX,

No. 8, p. 614. Three causes are advanced to explain the increase: (i) bank assistance in financing Government purchase of wheat and wool; (ii) bank policy in war finance; and (iii) heavy importations after the armistice. The financial measures adopted by Australia are discussed by J. R. Butchart in a lecture on "Money and Its Purchasing Power," given before the Incorporated Accountants' Students'Society, Victoria, on March 27, 1918. See also The Economic Journal, Vol. XXX, 492-99. From 1901-14 deposits not bearing interest increased by 50 per cent., and deposit-bearing interest by 25 per cent. Table 9.4 presents a striking contrast. 
the Government or of private individuals, and obviously increased the currency. Thus war finance resulted ill an increase in currency through both the note issue and bank deposits.

But other factors affect the real currency supply available for exchange purposes. Money circulates with varying velocities, according to political and economic conditions, and the actual quantity of money in a community makes purchases of much greater value each year than its face value. Thus in America, where the facts have been investigated thoroughly by Fisher, it is thought that money proper (gold and notes) had a velocity of circulation of 21 in 1913 and credit a velocity of circulation of 54; that is, each unit of money on the average performed exchanges of a value 21 times as great as its face value, and similarly each unit of credit a value 54 times as great as its face value. ${ }^{14}$ Now these velocities of circulation are of great importance in estimating the total amount of purchases made in a community in any year. Moreover, they are changing velocities, for the conditions affecting them change from year to year. Thus Fisher estimates the velocity of circulation of money at 30 in 1918 and of credit at 95.6, increases over 1913 of 43 and 77 per cent respectively. The influences operating on these velocities of circulation have been stated as follows: ${ }^{15}$ (a) the tendency to increased thrift or extravagance; (b) the method of wage payment; (c) the system of shop credit; (d) closer settlement and urbanization; (e) facilities of transport and communication; and (f) familiarity with monetary transactions.

Already before the war these factors were operating to promote an increase in the velocities of circulation. Thus there was less thrift, wages were paid frequently, shop credit was allowed to a greater extent, country lands were being more closely settled, and cities and towns more densely populated, facilities for transport and communication were developing, and the masses, as a whole, were becoming more familiar with paper money. It would, therefore, appear that the velocities of circulation of money increased, hut there are no means at hand of measuring it. Changes in the velocity of circulation of credit can, however, be ascertained with some certainty from the clearing-house statistics, though it is impossible to state definitely the actual velocity at any one time. Obviously, the

14 Fisher: The American Economic Review, Vol. IX, 407. See also his exhaustive analysis in The Purchasing Power of Money.

15 Barker: Theory of Money, 53-6. 
clearings depend largely upon the amount of credit available and the rapidity with which it circulates. Now reliable statistics of clearings are available and the bank deposits are known. Hence it is possible to measure changes in the velocity of circulation in the following manner:

Table 9.5: Changes in the velocity of circulation of credit, 1914-20

\begin{tabular}{l|l|l|l}
\hline & $\begin{array}{l}\text { Clearings for Melbourne } \\
\text { and Sydney }\end{array}$ & $\begin{array}{l}\text { Deposits not bearing } \\
\text { interest }\end{array}$ & $\begin{array}{l}\text { Velocity of circulation of } \\
\text { credit } \\
\text { I divided by II }\end{array}$ \\
\hline 1914 & 652,736 & 70,195 & 9.3 \\
\hline 1915 & 657,097 & 73,381 & 8.8 \\
\hline 1916 & 780,159 & 92,822 & 8.4 \\
\hline 1917 & 821,832 & 105,466 & 7.8 \\
\hline 1918 & $1,045,984$ & 112,262 & 9.3 \\
\hline 1919 & $1,134,308$ & 118,989 & 9.6 \\
\hline 1920 & $1,489,555$ & 133,913 & 11.1 \\
\hline
\end{tabular}

From 1914 to 1917 the velocity of circulation of credit decreased. This was no doubt due in part to the Government handling of primary produce and to its advances to farmers on their products; and in part to the contraction following the fear of a crisis on the first shock of war. Both factors would tend to decrease velocity of circulation. Thus the commercial transactions would be diminished, and credit advances to primary production would circulate less rapidly than credit advances for industrial purposes. After 1917 there was a steady increase in velocity in spite of these factors. This increase was pronounced in 1920, when it amounted to 15.6 per cent, and would thus have a considerable influence upon the price-level.

The general result of this analysis may now be given in tabular form (table 9.6).

Notes in circulation represent the notes in the hands of the public for the years 1915-20. For 1914 the figures include gold and notes in circulation and are based upon an estimate by the Commonwealth Statistician. ${ }^{16}$ This gives a reliable measure of money in circulation. The figures in column II do not require further

16 Commonwealth Year Book, No. 9, p. 772. 
comment, and those in column III are derived from the statistical information available on the trade factors mentioned above. The methods adopted in estimating trade have been fully described in The Economic Journal for December, 1920, and space does not permit of their repetition here. ${ }^{17}$ It is now clear that trade decreased but little in the period 1914-18, and had probably recovered in 1919), ${ }^{18}$ though there was doubtless a set back towards the end of 1920. But information is not yet available for a reliable estimate for these years. On the other hand, the money in circulation and total credit increased very greatly during the six years. Clearly this expansion of the currency largely explains the great increase in prices in Australia during the war. ${ }^{19}$ In a word, the methods of war finance produced a serious inflation of the currency, leading to increases in prices. ${ }^{20}$

Table 9.6: Movements in currency and trade, 1914-20

\begin{tabular}{l|l|l|l}
\hline Year & $\begin{array}{l}\text { I } \\
\text { Notes in circulation }\end{array}$ & $\begin{array}{l}\text { II } \\
\text { Bank clearings }\end{array}$ & $\begin{array}{l}\text { III } \\
\text { Trade }\end{array}$ \\
\hline 1914 & 11.6 & 653 & 113 \\
\hline 1915 & 9.6 & 657 & 93 \\
\hline 1916 & 13.9 & 822 & 110 \\
\hline 1917 & 16.5 & 1,046 & 104 \\
\hline 1918 & 18.5 & 1,134 & 103 \\
\hline 1919 & 20.3 & 1,489 & - \\
\hline 1920 & 22.0 & & - \\
\hline
\end{tabular}

17 See also Fisher: Purchasing Power of Money, 478-86.

18 Evidence of this is to be found particularly in overseas trade, shipping, and railway-ton mileage. The production statistics, so far as they are available, show but a slight increase over 1918.

19 Similar results have been obtained for the United Kingdom by Professor 3. Nicholson in The Journal of the Royal Statistical Society, Vol. LXXX, Part iv, p. 487; for America, by Professor E. W. Kemmerer in The American Economic Review, Vol. VII, p. 247, and Professor Irving Fisher in the same journal, Vol. IX, p. 407, and Stabilizing the Dollar, 29. Professor Gustav Cassel has obtained equally important results for Russia (Economic Journal, Vol. XXVI, 319-23). A remarkable return, published by the British Board of Trade in 1919 (Cmd. 434), compares with striking results increases in currency with increases in prices in many leading countries.

20 It must not be supposed that such paper inflation is the only form that inflation may take. There is also "gold" inflation, such as the United States experienced during the war, when gold supplies were increased rapidly through large imports. "Credit" inflation is another form, and may result from methods of war finance adopted by belligerents, or from banking policy in times of boom, such as land speculation in Australia in the late seventies. 
This general analysis may be supplemented by reference to tests I adopted in my earlier investigation. The accompanying graphs [Editor's note: Graphs handed out are not available for publication.] show the general effects of these tests, and only the results obtained will be stated here.

a) A comparison of movements in the note issue with movements in the wholesale and retail price index number suggested general agreement.

b) A much more reliable test was then adopted. The ratios between the successive numbers in each series were taken and a lag of three months allowed for movements in prices. The agreement was then more pronounced, and when tested by the method of correlation a very close connection between movements in the note issue and movements in retail prices was established. Movements in wholesale prices were not so closely connected with the movements in the note issue, but correlation was established there also.

c) The equation of exchange for Australia was established that is, the relation between movements in currency and movements in trade was estimated, and the changes in the price-level thus ascertained. This price-level showed a high degree of correlation with both the retail and the wholesale price-level as calculated by the Commonwealth Statistician.

These results are highly satisfactory from the point of view of monetary science, as well as being helpful in interpreting the Australian situation. They must, however, be related to the influence of external trade upon the Australian price-level. Clearly the rising prices of Australian products in the world markets influences the home price-level, but the influence is less pronounced than has been popularly supposed. In the first place, foreign trade is not as important as home trade, and the operation of increasing prices for exports and imports alone would raise the Australian price-level as a whole less than these increases themselves. Secondly, wholesale prices in Australia during the war increased more than the prices of imports and exports. ${ }^{21}$ Thirdly, the export and import of gold before the war regulated the Australian price-level in rough approximation to inter national gold prices, but during the war the operation of this factor

21 The actual increases from 1913 to 1918-19 were 78 per cent for wholesale prices and 68 per cent for import and export prices. 
was eliminated by Government action. The influence of foreign trade was then restricted, and though a rise in Australian prices was perhaps inevitable even had the gold standard been maintained, it is nevertheless true that "local action was free to push prices up without the normal corrective of an outflow of gold being set in motion." 22 We are forced to the conclusion that the price-level in Australia is higher than it would have been had Government policy not produced the inflation of the currency.

It has been repeatedly asserted that rising wages caused rising prices in Australia during the war, and this doctrine requires notice in relation to the analysis given above. It will be readily admitted that high wages cannot be paid without increased output or a high price level. Further, in times of prosperity producers may be able to "pass on" the increases in costs on a rising market. During the war the conditions were favourable to such "passing on," but this does not prove that the rising scale of wages caused prices to rise. When viewed in relation to the following points the theory breaks down as a complete explanation of the problem: (a) from July, 1914, to September, 1920, wholesale prices increased 162 per cent and wages of adult males 54 per cent; (b) labour is only one factor in production, and in Australian factories it absorbs about half the net output; (c) consequently if increasing wages offered a complete explanation of rising prices the rise in prices would have been less than the rise in wages. The position, however, is the reverse; (d) the wages per employee in Australian factories increased from $£ 100$ in 1913 to $£ 125$ in 1919 , that is, by 25 per cent. Meanwhile the net output per employee increased from $£ 193$ to $£ 255$, that is, by 32 per cent; (e) it may fairly be assumed that labour enters into the cost of production to a greater extent in retail business than in wholesale production. Yet the prices of wholesale goods have risen much higher than retail prices; and (f) producers have not complete power to vary their selling prices according to changes in labour costs.

In view of these facts the proposition that rising general prices may he wholly explained by wage increases is untenable. What then is the relationship between wages and prices?

22 Pigou: Economic Journal, VOL. XXVII, p. 293. 
Since labour is a factor of production, wages enter into the cost price of all commodities, and no employer can afford to pay higher wages than the industry will bear. The general practice of varying wages with the cost of living ignores this point, for doubtless some industries may readily pay the higher costs, while others are unable to do so without increasing their selling prices, a practice which producers can adopt only for a limited period, and that on a rising market. It is through individual prices that the wages factor operates, but it is only one factor among a number of others affecting conditions of demand and supply. To suppose that wage increases can be success fully passed on is to ignore the conditions of demand altogether. In actual fact, during the war, the conditions of demand were such that in most industries the selling prices were much higher than the increased labour costs warranted. And now, with demand conditions changing rapidly, selling prices are falling and, of course, in advance of wages. Thus from June to December, 1920, wholesale prices in Australia fell by nearly 16 per cent, while, according to the September returns, wages were still rising. How was this possible if producers could effectively control their selling prices?

\section{Causes of price changes in normal times}

The special problems created by rising prices during the war are likely to obscure the lesser though vital problems connected with price changes in normal times. These changes occur both in individual prices and in the general level of prices. Changes in individual prices may be caused by any factors affecting the supply of or demand for special commodities. Changes in the general level do not admit of any such simple explanation as the experience provided by the rising pricelevel in times of abundance proves. Thus for the twenty years before the war the general level of prices was rising, and this was a period in which the production of goods was increasing rapidly. In Australia trade increased by 80 per cent between 1901 and $1913^{23}$, while in the United States, according to Fisher, the increase from 1896 to 1913 was 138 per cent. Therefore the law of supply and demand, as applied to individual commodities, does not offer an adequate explanation of the general movements over the whole field of prices. Failure to observe this fact has given rise to much misunderstanding upon the problem of rising prices, and

23 According to the measures noted above and outlined in The Economic Journal, Vol. XXX. 503. 
has led many to suppose that the price-level could be controlled by regulating the prices of individual commodities. ${ }^{24}$ Even during the war investigations into the causes of the increase in prices were almost wholly confined, in Australia, to a consideration of individual commodities. ${ }^{25}$ Obviously, all factors affecting individual prices will also affect the general level of prices, but there are factors influencing the latter which do not exert a direct influence upon the former. "We cannot explain the level of the sea by the height of its individual waves; rather must we explain in part the position of these waves by the general level of the sea." ${ }^{26}$ Similarly, each individual price is partly a product of the general level, and the first step in explanation of individual prices is to measure and account for changes in this general price-level. Such explanations of price changes as monopoly, trade unionism, tariffs, labour unrest, speculation, profiteering, higher standards of living, public expenditure, etc., as are put forward from time to time do not adequately account for price movements, for these factors have operated in periods of falling prices as well as in periods of rising prices. They ignore the fundamental facts of the problem, as can easily be shown by a brief consideration of the meaning of "the general level of prices."

The general level of prices may be regarded as the relationship between trade movements on the one hand and currency movements on the other. ${ }^{27}$ Though it is true that all the factors affecting individual prices influence this relationship considerably, it is also true that this relationship may change, apart from the operation of these factors. Currency conditions are not necessarily affected by such influences. It is, therefore, important to investigate the causes of fluctuations in the currency, if the movements of the general level of prices are to be adequately explained. The factors affecting the currency may be stated as follows: (a) the money material forming the standard of value; (b) the growth of bank deposits or credit; and (c) the "efficiency" or "rapidity" of circulation of money and credit. Changes in any one of these factors will affect the total currency available for exchange purposes, and therefore alter the relationship between currency and

24 Jethro Brown: Prevention and Control of Monopolies, p. 126.

25 See in particular the investigations made by the Interstate Commission into the prices of several commodities during the war.

26 Fisher: Purchasing Power of Money, 177.

27 Many who oppose the analysis of price movements given here recognize this fact. Thus so whole-hearted an opponent is Professor J. L. Laughlin considers that "the general level of prices is the resultant of two sets of forces acting both on the standard of value and on goods in general." Money and Prices, 7. 
trade - i.e., will cause fluctuations in the general level of prices. Before the war gold was the standard of value and the basis of credit.

Though credit might change through the development of banking and the growth of cheques as media of exchange, as well as through increases in wealth, ${ }^{28}$ it was in the long run dependent upon the standard of value itself. The growth of credit is closely connected with banking policy, but there is a limit to which banks may increase their deposits by granting loans to customers. This limit is set by the requirements of the community for ready cash for making petty payments, and by other demands for gold noted below. If for any reason bank credits be expanded, greater purchasing power through cheques is available and the pricelevel will rise. With a higher price-level all petty payments increase and more cash is required. This cash, in the long run, is available only from the bank reserves, and bankers thus find their reserves depleted. They are forced, therefore, to restrict their credit advances to customers in order to maintain an adequate percentage of reserve to liability. ${ }^{29}$ In the same circumstances bankers might also have to face a drain upon their reserves for gold for export purposes or for use in the arts. With a rising price-level an adverse balance of trade is encouraged, and a settlement by exporting gold may be necessary. Further, the value of gold as money will have fallen and its value as a commodity increased. There will thus be a flow of gold from its money use to its use in the arts. An examination of the percentage of reserve (coin, bullion and Australian notes) to deposits in Australian banks shows that from 1901 to 1913 the percentage fluctuated slightly about 23 per cent. This demonstrates that bank credits are in practice regulated by the legal tender reserves of the banks, though the progress of banking tends to increase the use of credit relative to gold as a means of exchange. But while gold remains the standard of value, and the basis of the legal tender note issue, it effectively regulates the amount of credit available. Changes in the velocity of circulation of credit are similarly controlled, and gold, therefore, remains the vital factor affecting the currency supplies of the community. The supply of gold, therefore, greatly affects the general level of prices. But no attempt has been made hitherto to regulate the

28 For the factors affecting credit see Barker: Theory of Money, 53-59.

29 "The ordinary banks could create credit, but they endangered their stability if they exceeded a limit ultimately set by the amount of their Gash reserves." Rt. Hon. R. McKenna, in his annual address to the shareholders of the London Joint City and Midland Bank, Ltd., January 28, 1921. 
supply of gold according to changing trade conditions, and therefore to promote a stable price-level. It will generally be found that the great periodic changes in prices in the 19th century are very closely associated with important fluctuations in the gold production of the world. This was particularly true of the periods following the great gold discoveries of the middle of the century and of the early nineties. In 1890 the gold production of the world was 24.7 millions, and the total gold supplies were estimated at 1,674 millions. In 1916 the annual production was 93.9 millions, and the total world's stock was 3,431.9 millions. ${ }^{30}$ It is quite clear that gold production during this period had an enormous influence upon the price-level. The total increase in the world's supply of gold in the period was thus 105 per cent, whereas in the period 1871-90 the increase was only 38 per cent, and this at a time when many countries were adopting the gold standard and trade was rapidly expanding. It is clear that in the period 1871-90 the gold supplies were not adequate for the increasing monetary demand for them, while in the period 1890-1916 they were more than adequate, despite the enormous increase in trade. The supplies of gold are therefore of fundamental importance in explaining the movements in the general level of prices. This analysis, it is hoped, gives due weight to the influence of credit and to the increased velocity of circulation of both credit and money as factors affecting the supplies of currency, and therefore the level of prices; but it has been shown that all these factors are dependent upon the standard of value itself - i.e., upon gold. ${ }^{31}$ Of course, if gold supplies remain stable the general level of prices will alter through changes in trade conditions. But as gold supplies are not in any way regulated to changing trade conditions, it would appear that the standard of value has very grave defects.

30 Todd: The Mechanism of Exchange, 213.

31 This is very largely the real point at issue between quantity theorists and their opponents. The latter rightly insist upon the relation between goods and credit, showing that credit is a function largely of trade conditions, and that the bulk of exchanges in modern times are performed without the use of money. Now if credit were wholly dependent upon trade conditions, and free from all control, price changes would be largely eliminated, for a fairly stable relationship between trade and currency could be maintained. This appears to me to be the fundamental mistake of the so-called "credit" theorists, but Professor Irvine, of Sydney, in making a careful analysis of the basis of credit in goods, remarks: "I agree that under existing conditions and pre-suppositions the bank's capacity to loan, or what amounts to the same thing, its power to liquefy specific forms of wealth, is to some extent artificially restricted by its legal tender reserve." ("Loans, Paper Money, and Taxation," the Fisher Lecture for 1917, p. 9.) The case against the quantity theory has been most forcibly put by Johnson (Gold Prices and Wages), and by Laughlin (Principles of Money; and Money and Prices) On the other hand, some quantity theorists, recognizing the relationship between gold and credit, rather "worship the golden calf " as a means of regulating the currency. But Professor Fisher, perhaps the ablest of them, has for many years led the agitation against gold as the measure of value. 
These defects are associated with its variability in purchasing power; in a word, it does not possess the attribute of stability which modern communities insist upon in other measures, such as the yard or the pound weight. The evils associated with this instability are examined in the following section. It now remains to consider the movements in the factors affecting the general level of prices in Australia before the war. Money in circulation increased between 1901 and 1913 by 66 per cent, credit and its velocity of circulation as represented by the clearinghouse statistics by 91 per cent, and the total supplies of currency by 88 per cent. Meanwhile trade increased by 80 per cent, and thus the ratio between currency and trade was changed in the period.

Before concluding this section on the causes affecting the general level of prices, it may be pointed out in support of the above analysis that: (a) countries possessing the same standard of value experience similar price movements; (b) countries with differing standards of value experience different fluctuations in prices; and (c) not only do the price-levels of various countries having different monetary standards differ from one another, but the degrees of difference correspond to the degrees of difference in their standards. ${ }^{32}$

Thus movements in prices in the United States, Canada, Great Britain, Germany, and other countries with the gold standard, were remarkably similar in the period 1874 to 1893 , while prices in India, with a different standard, moved ill the opposite direction.

\section{Social and economic effects of price changes}

The evils of a fluctuating standard cannot be exaggerated. It is generally held that one of the most important attributes of money is stability of value, but no student of monetary theory can claim this virtue for our present standard of value. We are familiar with the evils of rising prices, particularly in their effect upon wage-

32 Fisher: Stabilizing the Dollar, 23-9. Professor Fisher concludes a searching analysis of the causes of price changes with the assertion that "to monetary causes (money, deposits, and their velocities) we should ascribe the great bulk of almost all changes in the price-level." Whilst perhaps not going so far as this, it can certainly be said that the variability of prices is caused through the failure of currency to adjust itself to trade conditions. But since currency may be controlled much easier than trade, it would appear that Fisher's assertion is true in the sense that no modern State attempts so to regulate currency as to stabilize prices. 
earners, the salaried classes, and the relations between capital and labour. But are falling prices to be desired, even though they may relieve these classes for a time? The critical days of the early nineties would suggest that falling prices may have serious effects upon commercial development and upon the whole community. Economists are, in fact, divided upon the question whether falling prices bring greater evils than rising prices. Apart from the great disturbances in contracts caused by our unstable standard, there are many forces set in motion by fluctuations ill prices, either up or down, which create the gravest disturbances in the economic order. ${ }^{33}$ Thus rising prices bring commercial prosperity and increase business enterprise. But they are unjust to wage-earners and creditors generally, and when the rise becomes severe serious industrial trouble may develop. On the other hand, falling prices tend to increase real wages, but they injure the debtor class and may check business enterprise, leading to a general slump, unemployment, and final]y even to a crisis. Again, rising prices may bring such a crisis on the confidence they impart to the business community. It is unnecessary, however, to pursue the argument, though authorities may be quoted on either side. Thus price considers that "the balance of general advantage lies on the side of rising rather than of falling prices." ${ }^{34}$ On this side, too, is Jevons. ${ }^{35}$ But Marshall considers that falling prices are beneficial because they promote a better distribution of wealth, while not diminishing production perceptibly. ${ }^{36}$ There is thus sufficient evidence beyond our individual experience to warrant the most careful consideration of proposals calculated to give stability to the standard of value. It cannot be argued that the sequence of periods of rising and falling prices bring their own compensations, for though the classes of the community suffer and benefit in their turn, the individuals differ, some amassing fortunes and others incurring debts. ${ }^{37}$ The problem is be coming more insistent in Australia, for the custom has developed of regulating wages according to changes in the cost of living. This has been endorsed by the Basic Wage Commission, ${ }^{38}$ and no one can regard with equanimity the disturbances that will be associated with these

33 See the searching analysis of the evils in Fisher: Stabilizing the Dollar, chap. iii. Also Layton: Introduction to the Study of Prices, 10-16; Jevons: Investigations, 13-111; Kinley: Money, 176-98.

34 Price: Money and its Relation to Prices, 68.

35 Investigations, 91, and the authorities quoted in Walker: Money, chap iv.

36 Evidence before the Gold and Silver Commission, quoted by Layton, 12. Layton is inclined to agree with Marshall. So also does Fisher, American Economic Review, December, 1914

37 Kinley: American Economic Review, Vol. III, 1-4.

38 Report, 55-7. 
regular adjustments. There is much to be gained by a stable standard of value, for it would: (a) lead to a more equitable distribution of wealth; (b) discourage speculation; (c) reduce uncertainty in industry; (d) render public finance more stable; and (e) promote more settled industrial relations. ${ }^{39}$

It must not be supposed, however, that such a stable price-level would bring stability in all individual prices. Individual prices would still fluctuate, for they are influenced by factors other than those which operate on the general level of prices. ${ }^{40}$ It would probably be undesirable that individual prices should remain totally unchanged, and certainly under competition it is impossible. What is required is that the general level, the final expression of all individual prices, should remain as nearly stable as possible.

\section{The standard of value and commercial crises}

Among the grosser evils of the fluctuating standard are commercial crises and inconvenient movements in the foreign exchanges. These evils are in a different class from those mentioned above, for they do not involve injustice to particular classes so much as disturbances to the whole community. This is not the place to enter into a detailed statement of the causes of commercial crises, but all economists are agreed that they are due partly to psychological factors and partly also to variations in the general productivity of the world. ${ }^{41}$ But the psychological factors may be regarded as the immediate causes of crises in most cases, though the ultimate causes are closely connected with trade conditions. Now it is through the defective standard of value that these psychological factors operate. A rising price-level benefits business profits and imparts confidence to businessmen, who make financial arrangements to enlarge their businesses and thus increase production. This necessitates an expansion of credit, which in its turn promotes a further increase in prices, and so the boom develops. Ultimately it is necessary for the banks to restrict their advances owing to the drain upon their gold or legal tender reserves. But before this has happened businessmen have committed themselves to

39 Chapman: Outlines of Political Economy, 116-7, 242-3.

40 Report of Commission on Cost of Living in New Zealand, 41-42.

41 See summary given in Chapman, Outlines of Political Economy, 254-62 
contracts, the fulfillment of which may necessitate further financial assistance, such has been their confidence in the markets. But with the banks tightening up their overdrafts, and with a turn in the market in prospect, the confidence of the business community soon gives place to doubts, depression, and even to the despair of a panic. According to The Economic Bulletin, published by the Chase National Bank, this was the situation in the United States in 1919 and 1920. "Business psychology in 1919 and early 1920 manifested au irrational exaltation of an extreme sort. From this we swung to a state of shell shock in December, 1920." Hence the rule that "the function of credit in a critical period is to mobilize the slow assets of solvent businesses, and not to validate the bad assets of insolvent businesses. ${ }^{42}$ It is true that by adopting such a policy modern banks are better able to withstand a crisis, but it is also true that the credit expansion pre ceding such developments is largely responsible for the crisis. This is just what has happened in Australia, for during the war bank deposits increased very greatly and the clearing-house statistics portray the extent of such credit expansion. It was found necessary towards the close of 1920 to check this development, and banks commenced to restrict their advances. Such action was necessary, and had beneficial results, checking speculation and warning business men of the impending trend of the market. How much better would it be if credit expansion were automatically adjusted to trade needs! This is precisely where the present variable standard of value fails. As a means of adjusting currency to changing trade conditions it is totally inadequate. In prosperous times there is little demand for the material forming the standard of value, but in a crisis a strong demand rapidly develops and may easily outrun the resources of the banks to meet it. Thus "metallic money is a cause of industrial disturbance and panic, and by retiring instead of expanding in times of stringency it adds to and intensifies the disturbances produced by other causes." ${ }^{43} \mathrm{~A}$ standard of value that operates in this way is certainly not conducive to industrial stability. Yet there are many who think that a simple return to the gold standard would solve the present currency problem, Apart from the impracticability of such a step in the immediate future, and even though the gold standard is greatly to be preferred to the present paper standard, its adoption would still leave us with a commodity money of quite uncertain value.

42 Anderson: Factors of Safety when Prices Drop, 7.

43 Parsons: Rational Money, 77. 
The present financial crisis, however, is due to a variety of factors, of which credit expansion has perhaps the most important immediate influence. In a suggestive analysis of the crisis in America in last December, Dr. B. M. Anderson, economist to the Chase National Bank, gives stress to the following matters: (a) the European situation; (b) export of gold through unfavourable trade balance with the non-European world; (c) rapidly rising prices with growing tension in the money market; (d) large Government expenditure; (e) defective transport services through the strain of war; (f) rising costs of production, particularly labour, coal, raw materials, and managerial ability; (g) speculation in commodities, securities, foreign exchanges, and real estate; (h) rapid expansion of bank credits, amounting to 25 per cent from April, 1919, to April, 1920; (i) excess of raw materials and food stuffs through failure of manufacturers in Europe and collapse of markets for foods; (j) Fluctuations in exchange rates; and (k) business psychology. ${ }^{44}$

Are not these the symptoms of the present crisis in Australia? With the exception of the second, all the above factors are operating at the present moment, and the severity of our crisis will be conditioned very largely by psychological factors. We cannot escape the consequences of the present European situation, but owing to the false prosperity engendered by financial and banking policy, and by our defective standard, we have scarcely appreciated the gravity of this situation. The prosperity of a rising price-level and the well-grounded suspicion of undue "profiteering" have produced a state of affairs in which it will be difficult to meet an impending crisis. For not only has the business community assumed obligations which it will find difficult to meet, but there is also a legacy of hostility between capital and labour which will render almost impossible the rapid readjustment necessary in such a crisis. The weakness of adopting the cost of living as a guide for the rate of wages is now becoming apparent. The rate of wages is de pendent Upon no such artificial standard, but upon the productivity of industry. It should have been noted more carefully that wholesale prices were rising much higher than retail prices, and that the cost of living as a means of regulating wages in a time of rising prices was to the advantage of the producer. ${ }^{45}$ Not so when

44 Chase Economic Bulletin, No. 3, February, 1921.

45 The facts are interesting. From July, 1914, to June, 1920, wholesale prices increased by 133 per cent. and retail prices by 77 per cent. From second quarter 1914, to second quarter, 1920, the cost of living, including rent, rose 53 per cent and wages of adult males 46 per cent. 
prices commence to fall, for wholesale prices will first feel the shock and fall more rapidly than the cost of living. Labour costs will then be reduced at a much slower rate than prices. Consequently producers will be inconvenienced both by a stringent money market and by a relatively inelastic labour cost. Is not this exactly the situation in the mining industry at the present time? According to press reports, it was stated by the employers in a conference between the Mount Lyell Company and the Unions concerned that wages could not be varied according to the cost of living, as the shareholders could not "entertain any greater loss which

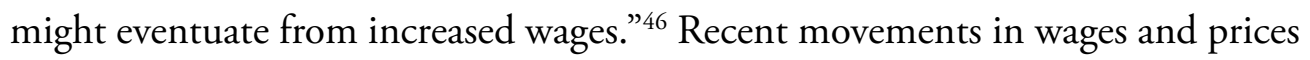
confirm these observations upon the defects of the cost of living as an adequate guide for wages. Thus from July to December, 1920, wholesale prices fell 16 per cent, while according to the last information available wages rose nearly 6 per cent from June to September. Thus the methods of wage adjustment necessary for a fluctuating standard are likely to intensify the difficulties of the transition period from rising to falling prices.

Now Australia has a further and vital interest in such a crisis as we are passing through. Two distinctive features of her economic system are (a) her indebtedness to the old world, and (b) her great dependence upon primary production. According to the Wealth Census of 1915, about 80 per cent of the wealth of Australia is associated with land and minerals, while statistics of production show that nearly 75 per cent of the total wholesale production consists of primary production, including minerals. Now such primary products as Australia exports are generally sensitive to price changes, fluctuating more than the general level. Reference to the graphs published by the Commonwealth Statistician confirms this. ${ }^{47}$ Hence the exports of Australia are likely to benefit greatly by a rise in prices, but to suffer severely by a fall. But the indebtedness of the Commonwealth intensifies these tendencies. Her obligations involve less real value on a rising market and greater real value on a falling market. Thus while we have profited greatly in recent years through our primary exports and our indebtedness, we shall find a falling price-level doubly embarrassing through the same factors. We are, on this ground, vitally interested in preventing any serious decline in the price-level.

46 The Mercury, Hobart, April 28, 1920.

47 Labour and Industrial Branch Report, No. 2, p. -3. 


\section{The standard of value and the foreign exchanges}

For a country with a depreciated standard there are another set of disturbances: those connected with the foreign exchanges. The rate of exchange may be regarded as a thoroughly good trade barometer, and in normal times it was the signal for corrective measures in times of distress. Thus an unfavourable exchange could be corrected in any of the following ways: (a) raising the rate of discount; (b) restricting imports; (c) increasing exports; (d) shipping gold; (e) Selling securities abroad; and (f) raising loans abroad. During the war Great Britain found that many of these expedients failed. A rise in the rate of discount had little effect, for the country was not on a gold basis; but since such a rise may have led to an increase in the interest necessary for war loans it was undesirable. It was impossible to restrict imports or increase exports, and supplies of gold for shipment were not sufficient to settle international indebtedness. Hence recourse was had to loans abroad and to the sale of securities, more especially to the latter. The story of the efforts made to control the exchanges by acquiring American securities for sale is now available in the report of the British Committee on American Dollars Securities. ${ }^{48}$ When the Committee discontinued operations in April, 1919, securities to the amount of some 1,400 million dollars. ${ }^{48 a}$ had been acquired, but the New York exchange had been maintained at almost 4.76 dollars. After the "unpegging" the rate fell heavily, reaching 3.37 in February, 1920. Now since this situation affects Australia greatly, and is closely associated with the "depreciation" of money, it requires close examination. The tests of depreciation of an inconvertible paper currency are: (i) rising prices; (ii) unfavourable exchange rates; and (iii) a rise in the paper price of gold above the fixed price of $85 \mathrm{~s}$. per ounce for fine gold. All three symptoms were present in 1919. The following table (9.7) shows the movements in the price-level in the United States and the United Kingdom.

In 1918 the average increase of the two index numbers over 1913 was 127.2 per cent for the United Kingdom and 100 per cent for the United States, but in 1920 the increases were 201 per cent and 122.6 per cent respectively. Thus in the two years of free exchange between the countries "paper" prices in England had moved away from "gold" prices in America. This is supported by movements in the index numbers over the period.

48 American Economic Review, Vol. X, 413.

48a It is estimated that the United Kingdom, during the war, sold in and about one thousand million pounds' worth of foreign securities. Keynes: Economic Consequences of the Peace, 258. 
Had the gold standard been maintained in England, or the exchange position regulated, the difference between the movements in the index numbers for the period could not have been so pronounced. The striking feature of the table is the connection between the rate of exchange and the movements in the two price-levels. This connection is shown in columns III and V. Thus the relative movements of prices in England and in America, together with the fluctuations in the foreign exchange, especially in 1920, may be regarded as a sign of paper depreciation. This is true also of Australia, though to a less extent, for prices dropped considerably during the second half of 1920. Now Table 9.8 shows the extent to which the foreign exchange has against England. Do the ordinary trade or financial factors account for this situation? An adverse exchange rate would be produced mainly by: (a) demand for bills to pay for imports; (b) purchase of securities abroad; (c) payment of interest to foreigners; and (d) payment of shipping freights and insurance to foreigners.

Table 9.7: Index numbers of wholesale prices in the United States and the United Kingdom

\begin{tabular}{l|l|l|l|l}
\hline & \multicolumn{2}{|l}{ United Kingdom } & Unites States \\
\hline & Economist & Board of Trade & Bradstreets & Bureau of Labour \\
\hline 1913 & 100.0 & 100.0 & 100.0 & 100.0 \\
\hline 1914 & 98.7 & 100.6 & 97.0 & 99.0 \\
\hline 1915 & 123.1 & 123.5 & 108.1 & 100.0 \\
\hline 1916 & 160.5 & 160.1 & 130.0 & 123.0 \\
\hline 1917 & 204.1 & 208.6 & 172.2 & 175.0 \\
\hline 1918 & 224.9 & 229.5 & 204.0 & 196.0 \\
\hline 1919 & 235.2 & 254.5 & 204.0 & 212.0 \\
\hline 1920 & 283.2 & 318.8 & 201.3 & 244.0 \\
\hline
\end{tabular}


Table 9.8: Comparison of index numbers for the United States and United Kingdom, 1919-20, with the rate of exchange of London on New York

\begin{tabular}{l|l|l|l|l|l}
\hline Month & $\begin{array}{l}\text { I } \\
\text { United } \\
\text { Kingdom } \\
\text { Economist }\end{array}$ & $\begin{array}{l}\text { II } \\
\text { United States } \\
\text { Bradstreets }\end{array}$ & $\begin{array}{l}\mathbf{1 9 1 3} \text { Percentage } \\
\text { USA on } \\
\text { English } \\
\text { prices }\end{array}$ & $\begin{array}{l}\text { IV } \\
\text { Rate of } \\
\text { exchange }\end{array}$ & $\begin{array}{l}\text { Vercentage } \\
\text { market rate } \\
\text { on mint par } \\
\text { of exchange }\end{array}$ \\
\hline $\mathbf{1 9 1 9}$ & & & & 4.76 & 0.98 \\
\hline February & 215.3 & 191.5 & 0.89 & 4.66 & 0.96 \\
\hline April & 214.4 & 190.0 & 0.88 & 4.62 & 0.95 \\
\hline June & 229.8 & 205.7 & 0.89 & 4.27 & 0.88 \\
\hline August & 241.5 & 212.0 & 0.87 & 4.18 & 0.86 \\
\hline October & 252.4 & 216.7 & 0.86 & 3.84 & 0.79 \\
\hline December & 273.5 & 221.7 & 0.81 & 3.7 & \\
\hline $\mathbf{1 9 2 0}$ & & & & 3.50 & 0.72 \\
\hline February & 303.1 & 226.4 & 0.75 & 3.38 & 0.69 \\
\hline April & 305.7 & 225.7 & 0.74 & 3.93 & 0.87 \\
\hline June & 291.4 & 210.7 & 0.72 & 3.95 & 0.81 \\
\hline August & 287.6 & 195.7 & 0.69 & 3.61 & 0.74 \\
\hline October & 266.5 & 170.6 & 0.64 & 3.47 & 0.75 \\
\hline December & 220.0 & 137.8 & 0.62 & 3.50 & \\
\hline & & & & & \\
\hline
\end{tabular}

Now, in 1919-20, the only factor of importance in England was the first, for in respect of the others there was a credit due to England. It is true that imports exceeded exports, but not by more than could be accounted for by "invisible exports," such as services rendered by English shippers and investors, for which they received freights, and interest paid in goods by the foreigner. ${ }^{49}$ But owing to the practice of selling on the continent on long term credits, exports were not all available for payment of imports, and this would doubtless have some effect on the dollar exchange rate. But the trade position was not the only factor

49 "The United Kingdom soon attained, on the face of the trade and shipping figures, a fairly strong position," Pigou: Economic Journal, Vol. XXX, 468. See also an article in the British Board of Trade Journal, January 15th, 1920, where it is estimated that, after making allowance for invisible exports," the United Kingdom will go a long way towards recovering the net surplus of about $£ 200,000,000$ which was available before the war for investment abroad." 
in promoting an unfavourable foreign exchange. After exchange control ceased, important changes occurred in the relative external and internal purchasing power of the currencies of European countries. Under ordinary trade conditions, the external and internal purchasing power of currencies, as measured in the same goods, varies but little, allowance being made for transport charges, tariffs, and other costs involved in foreign trade. ${ }^{50}$

Professor Pigou has made a careful analysis of this problem, and his conclusions are: (i) that the great expansion of the currencies of European countries was accompanied by "pegging" of the exchanges, so that the external purchasing power of these countries rose relatively to their internal purchasing power; and (ii) that the "unpegging" of the exchanges that followed the Armistice, accentuated by trade conditions, promoted a heavy fall in the external purchasing power of European currencies in relation to their internal purchasing power. ${ }^{51}$

In these circumstances the London-New York rate fell heavily through out the whole of 1919 and much of 1920 . The following table will throw further light upon the position.

Column IV of this table is the gold measure of the depreciation of the English paper pound, and is in close agreement with the depreciation of the New York exchange, as shown in column II. This is in conformity with the economic proposition that the depreciation of the exchanges is an approximate measure of the depreciation of an inconvertible paper currency. Thus, speaking of the effect of the depreciated currency in Germany, Professor Taussig points out that "foreign exchange and the specie premium do run together." 52 The above example is rather a striking confirmation of this doctrine.

50 Kinley: Money, 80-6.

51 Economic Journal, Vol. XXX.

52 Proceedings of the American Economic Association, Vol. X, supplement, 39 See also Kinley: Money, 337-9. 
Table 9.9: Foreign exchange and the price of gold

\begin{tabular}{l|l|l|l|l|l}
\hline Date 1920 & $\begin{array}{l}\text { Exchange on } \\
\text { New York }\end{array}$ & $\begin{array}{l}\text { Percentage } \\
\text { below parity }\end{array}$ & \multicolumn{2}{|l|}{ Price of gold } & $\begin{array}{l}\text { Percentage mint } \\
\text { price below market } \\
\text { price of gold }\end{array}$ \\
\hline Feb. 26 & 3.40 & 30.88 & 122 & 4 & 30.57 \\
\hline March 4 & 3.63 & 26.49 & 114 & 6 & 25.76 \\
\hline March 11 & 3.68 & 23.20 & 112 & 1 & 24.16 \\
\hline March 18 & 3.79 & 23.25 & 108 & 4 & 21.54 \\
\hline March 25 & 3.91 & 20.68 & 105 & 8 & 19.56 \\
\hline March 31 & 3.87 & 19.63 & 106 & 2 & 19.94 \\
\hline
\end{tabular}

The three tests - specie premium, rising prices, and depreciated exchanges - were thus in evidence during the past two years. The Australian exchanges are largely controlled by British conditions, and this partly explains our difficulties with America during the past two years. The position has, however, been accentuated by Australian currency and foreign trade in the last twelve months. In general terms, a country with a currency in process of depreciation stands to gain in its export trade. The exchange is rising, and exporters may draw upon their foreign purchasers and sell their exchange to advantage at home. Meanwhile their costs of production have not increased to the same extent as the price-level, and thus "depreciation of inconvertible notes has much the same effect as a protective duty: it stimulates exports but checks imports." ${ }^{33}$ While a country like Germany, with reparation obligations, may benefit considerably by this state of affairs, ${ }^{54}$ it was of no real advantage to Australia. At the time Australia was importing very heavily, and this had the effect of increasing the exchange difficulties Goschen pointed out in his treatment of the foreign exchanges that, despite the above considerations, "a country in which a depreciated currency and a prohibition to export bullion exists is likely to be importing more than it is exporting." ${ }^{55}$ This was precisely the situation in Australia during the latter part of 1920.

53 Clare: $A B C$ of the Foreign Exchanges, 153.

54 Taussig remarks: "It promises to play into Germany's hands in an unexpected way."

55 Goschen: The Foreign Exchanges, 72. For a treatment of the problem see Nicholson: Banker and Money, 38. The Australian position has been fully investigated by Mr. I. Horwitz, and his results were presented at the meeting of the A.A.A.S. in January last. 
These figures speak for themselves. Imports were much greater in 1920-1, and exports had fallen; the position was improving in February of this year. But it is clear that in such a state of affairs the demand for remittances would be heavy and the supply weak; hence the difficulties of obtaining credits in London. No doubt the great increase of imports was due to the trade boom in Australia, as well as to the fact that during the war there was a scarcity of imports, a position which post-war trade sought to rectify. Further, the falling market in other parts of the world encouraged the import trade of Australia. ${ }^{56}$ Here then is the explanation of the exchange position as it developed in the spring and summer of 1920 , and banks in raising their rates for foreign remittances were acting under the compelling conditions of the market. ${ }^{57}$

Table 9.10: Australian imports and exports

\begin{tabular}{l|l|l|l|l}
\hline Month & \multicolumn{2}{|l}{ Imports } & \multicolumn{2}{l}{ Exports } \\
\hline & $\mathbf{1 9 1 9 - 2 0}$ & $\mathbf{1 9 2 0 - 2 1}$ & $\mathbf{1 9 1 9 - 2 0}$ & $\mathbf{1 9 2 0 - 2 1}$ \\
\hline July & 10,543 & 13,063 & 7,543 & 10,408 \\
\hline August & 5,485 & 13,485 & 9,501 & 8,576 \\
\hline September & 6,403 & 15,716 & 14,454 & 9,009 \\
\hline October & 5,785 & 15,019 & 13,669 & 10,353 \\
\hline November & 6,185 & 15,464 & 112,871 & 12,741 \\
\hline December & 8,886 & 15,894 & 11,031 & 10,018 \\
\hline January & 8,005 & 17,420 & 12,868 & 11,588 \\
\hline February & 7,033 & 11,841 & 13,576 & 12,390 \\
\hline Totals & $\mathbf{5 8 , 3 2 5}$ & $\mathbf{1 1 7 , 4 4 5}$ & $\mathbf{9 5 , 5 1 3}$ & $\mathbf{8 5 , 2 6 3}$ \\
\hline
\end{tabular}

Source: This table is derived from the statistics published by the Importers and Exporters' Journal of Australia and may contain slight errors, but it is sufficiently reliable to portray the actual position.

56 Local commerce was the martyr of external suppliers, who had from their overloaded or unsold stocks, poured into this country an unprecedented volume of goods, and complained that they could not pour more. From their files were gathered long past orders, ignored orders, duplicated orders (given because of the declared dearth of goods), delayed orders and orders uncertain, for future delivery. Other markets having weakened, all Australian orders were rounded up and as many despatched as the financial support given to shippers would stand." Australasian Business, March, 1921, p. 10.

57 Importers and Exporters' Journal of Australia, Dec. 4, 1920, p. 1414. 
This digression on foreign exchange has further emphasized the evils of a fluctuating standard. In summarizing these evils with reference to Australian conditions emphasis should be given to the following: (a) rising prices bring prosperity, but may ultimately cause a crisis. Owing to our indebtedness and the nature of Australian exports falling prices produce severe depression; (b) the adjustment of wages according to the cost of living is a painful process at best, and in times of transition from rising to falling prices it may be injurious to industrial stability; (c) contracts are upset and injustices done to debtors or creditors according to the price movements; (d) speculation is encouraged, especially in land values, in a time of rising prices. This is a great evil under Australian conditions; (e) trade cycles are intensified; (f) social unrest is promoted, leading to grave disorder, strikes, and lessened output; and (g) Classes whose incomes are fixed largely by custom suffer in a time of rising prices.

\section{The functions and attributes of money}

Brief consideration of the functions and attributes of good money will show clearly along what lines our present monetary system re quires reform. The functions of money have been classified by Kinley as follows. ${ }^{58}$

a) Essential and necessary at every economic stage: a medium of exchange and a measure or common denominator of value;

b) Derived from the essential functions: standard of deferred payment or a transferer of value from time to time; transferer of value from place to place; and a store of value; and

c) Contingent upon the conditions of contemporary life: distributor of social income; basis of system of credit; and embodiment of generic value, giving a liquid form to capital.

It will be observed that these functions centre round the essential services that money performs, as noted under (a) above. In so far as they are associated with money as a medium of exchange, the present monetary system performs

58 Kinley: Money, 59-68. 
them to general satisfaction. In fact, with the enormous development of the credit system, modern media of exchange are the most serviceable yet devised by man. But most of the above functions imply stability of value in money, and, as we have shown above, the modern monetary system does not possess this attribute. To perform the above functions the following are the necessary attributes: (a) stability of value; (b) general acceptability; (c) elasticity; and (d) uniformity.

To these must be added portability, divisibility, durability, etc. and some economists consider intrinsic value to be necessary also. It is argued that if money is valuable in itself it will be difficult to produce, and will therefore not be issued in abundance. Thus intrinsic value will be a safeguard against over issue and inflation. It is largely because gold has possessed this attribute, together with many of the others noted above, that it has been adopted almost universally as the standard of value. But the intrinsic value of gold has varied considerably during the past hundred years, and the difficulties of procuring it have been no safeguard against fluctuating supplies and consequent changes in prices. Gold for money is not desired because of its intrinsic value, but because it is useful for exchange purposes. For this reason many eminent economists are agreed that intrinsic value is not necessary in the money commodity. ${ }^{59}$ Much more important are the attributes of elasticity and stability of value. Elasticity signifies that the currency should expand and contract in conformity with trade conditions. The credit system at present, and the note issue in some countries, possess this attribute to a limited extent only. Since they are both restricted by the supply of the standard of value their elasticity is largely conditioned by the elasticity of the standard itself. We have already seen that the relationship between gold and trade is really very remote, and that the supply of gold may be altered very materially by new discoveries or new processes of production. It is, therefore, in respect of these two attributes that money requires reform. To many the suggestion that the gold standard should be "tampered with" spells economic and financial disaster. It is supposed that the gold standard has been adopted after much careful thought and that it has served the community so well that any change is not to be entertained. But gold was adopted as the standard of value only because it served that purpose

59 "All commodities in the market become measured a to their value, without regard to the cost of production of the money itself." Palgrave: Dictionary of Political Economy, Vol. II, 793. This view is to be found in the works of Ricardo, Mill, Walker. 
better than any other commodity available. As a matter of fact, England adopted the gold standard in opposition to the advice of financiers. ${ }^{60}$ In practice it has worked better than any other single commodity standard, and better also than a bimetallic standard. Theoretically, bi-metallism is prefer able to mono-metallism. Owing to the supply of money coming from two metals instead of one it is likely that the fluctuations in the supply will be less extreme, but the difficulties of maintaining a stable ratio between the two metals led to the final abandonment of bi-metallism. ${ }^{61}$

It is obvious that the greater the number of commodities forming the standard of value the less will be the fluctuations in the price-level. Gold is by no means the most stable commodity. Thus Fisher observes that "gold, as a standard of general purchasing power, has been more stable than silver, but less stable than eggs or carpets, which last proves to be the best standard of purchasing power during the period (1890-1914)." ${ }^{62}$ A combination of commodities as the basis of the whole currency system would doubtless lead to a much more stable pricelevel. ${ }^{63}$ With the measurement of the general level of prices by index numbers it is now comparatively easy to adopt such a multiple standard as this suggestion implies.

\section{Suggestions for stabilising prices ${ }^{64}$}

Many proposals for the adoption of a multiple standard, such as the tabular standard suggested by Jevons, are open to two serious objections: (a) they necessitate Government action requiring official decisions such as may lead to

60 Thus Sykes considers it due "to an illogical and partial adoption of Sir Isaac Newton's report, a report which was intended to prevent, and not to hasten, the displacement of silver by gold in our currency." Banking and Currency, 30.

61 Professor Marshall has shown that there is very little difference between bi-metallic and mono-metallic prices. See his article in the Contemporary Review for March, 1887, quoted in Parson's Rational Money, 105.

62 Fisher: Stabilising the Dollar, 42. Cf. Giffen: "Viewing a long period dynamically it is beyond all question that the commodities are comparatively steady, and only money changes." Growth of Capital, 61.

63 The multiple standard has been advocated by many economists during the 19th century. Thus Jevons considers that "the purchasing power of the note (based upon commodities) must remain steady compared with that of gold or silver, "Money and Mechanism of Exchange. Among other supporters of the multiple standard are Ricardo, Walker, Marshall, Simon Newcomb, Aneurin Williams, and in more recent times, Irving Fisher, A. C. Pigou, and a great many teachers of economies in England and America.

64 This section is based largely upon a paper prepared for Section $G$ of the A.A.A.S. by Mr. L. E. Giblin, Government Statistician of Tasmania, and the writer. 
danger; and (b) they require adjustments which have a disturbing influence on economic relations. ${ }^{65}$

Recent investigations have shown that these objections may be overcome, and the great merit of the proposal put forward by Professor Irving Fisher, as a result of these investigations, is that it is both automatic and free from serious adjustments. There had been considerable discussion on monetary reform in the nineteenth century and Fisher's proposal was suggested in general terms by economists including Newcombe and Marshall, ${ }^{66}$ but it had not been worked out in any detail until Fisher 's recent investigations. In “ The Purchasing Power of Money," published in 1913, it was briefly described, but it had already appeared in economic journals. ${ }^{67}$ The monetary experience of the war assisted the practical application of the plan, for gold no longer circulates, even in the United States, though it still remains theoretically the basis of the currency and the standard of value, except in countries where the gold standard has been temporarily abandoned. This has enabled Fisher to overcome a difficulty associated with the circulation of gold coin, and the plan, as worked out in his recent publication, Stabilizing the Dollar (1920), is as follows: (a) to maintain the gold standard by providing, as before the war, that gold will be the basis of the currency; (b) to keep gold out of circulation as at present, using notes as the medium of- domestic exchange and gold as the ultimate medium of foreign exchange; (c) to maintain the unrestricted deposit of gold at the mint and the unrestricted redemption of notes in gold, thus ensuring the convertibility of the notes; (d) to measure changes in the general level of prices by means of an index number; (e) to adjust the "gold content" of the $£ 1$ (i.e., the weight of gold which the Treasury would buy or sell for $£ 1$ note) to changes in the index number or vice versa. Fisher summarizes his plan as follows:

We restrain by a rise or fall in the price-level, a fall or rise of the purchasing power of the sovereign, increasing or decreasing the weight of the sovereign, decreasing or increasing the price of gold. ${ }^{68}$

65 These proposals are summarised in Fisher: Purchasing Power, chapter xiii; Barker: Theory of Money, 10520. There is further information on similar proposals in Fisher: Stabilising the Dollar, 288, et seq., and in Kinley's article in The American Economic Review, Vo1. III, 2.

66 Fisher: Stabilizing, 293.

67 Economic Journal, Dec., 1912, 213-35. But see the Bibliography in Fisher: Stabilizing, 294-6

68 Stabilizing, 105. 
"Under the plan about to be presented gold is retained; and there is essentially the same mechanism by which it freely enters or leaves the circulation. But under this plan the gold dollar becomes a standard of value instead of a standard of weight. ${ }^{69}$ The general principle underlying the scheme is brought out in this passage. The price of gold has been fixed by decreeing that a sovereign shall always contain 123.27 grains of gold, but its value fluctuates. The price of gold should vary by varying the "gold content" (weight ) of the sovereign so that its value may remain stable. For all commodities (except gold) price is the expression of value in the money material; but for gold, the money material, there is no such relation between price and value. It is, therefore, not desired that the price of gold should remain fixed, but rather that its value should be stable, even though its price be variable. A sovereign is desired not because it contains a certain quantity of gold, but because it enables its possessor to purchase a certain quantity of goods. If the quantity of goods obtainable varies, the sovereign itself is variable in value. But if the quantity of goods remains stable the value of the sovereign, irrespective of its weight, is a constant. Now apart from controversy on the quantity theory of money, all will agree that more gold will buy more goods, and therefore in a time of rising prices, when the sovereign is depreciating in value, that an increase in the gold content of the sovereign will tend to restore its value. ${ }^{70}$ The variation in the "gold content" or weight in itself is not important, for as Fisher points out the sovereign is a measure of value, not of weight. Any serious objections to varying the weight of the sovereign must be based upon the reactions on exchange conditions caused thereby, and not on the fear that such action is tampering with the currency. "We do not need a sovereign as a unit of weight. We need it as a unit of value, and the trouble is that its constancy in weight makes it inconstant as a unit of value." ${ }^{\prime 1}$ The general principle of the proposal is thus sound, but its working may lead to practical difficulties.

Of fundamental importance is the fact that the plan does not mean Government control. The work will be entirely automatic, being a slight

69 Ibid, 89.

70 "Because I am not a quantity theorist, I am disposed to believe that Professor Irving Fisher's plan of stabilizing the dollar might be feasible." B. M. Anderson, jr., in American Economic Review, Vol III, supplement, 42. Anderson now opposes the proposal on the ground that it will lead to financial disturbances. See his Fallacy of the Stabilized Dollar.

71 Fisher: Stabilizing, 223. 
extension of the present statistical work involved in calculating index numbers. The following are the main details:

a) the calculation of an index number: using wholesale prices, and excluding prices that move very slowly.

b) Varying automatically the "gold content." Thus if the index number rose 1 per cent the "gold content" would be increased from its par weight of 123.27 grains to 124.5 grains. Hence the price of gold would change from $£ 317 \mathrm{~s}$. $101 / 2$ d. to $£ 317 \mathrm{~s}$. $11 / 4 \mathrm{~d}$. per ounce. This would have the effect of bringing notes to the Treasury for redemption, the currency would be restricted, and the price-level would move backwards towards par. The interval between the variations should be just sufficient to show reactions from the previous adjustment in the "gold content" of the $£ 1$ - about two to three months.

c) To prevent speculation in gold there would be two prices for gold, a buying and selling price, differing by a certain percentage, which may be called the brassage fee. A single change in the "gold content" of the $£ 1$ would never be greater than the brassage percentage.

d) The legal tender bank reserves would consist of the notes, and thus bank credits would expand and contract with variations in the "gold content." Hence total currency would be regulated to promote stable prices, and one of the main causes of financial crises (too rapidly expanding bank credit) eliminated.

e) Concerted action by several nations is desirable, but the plan could be adopted by a single nation with advantage, though inconvenient fluctuations in the ratios of exchange might result. This disadvantage would be more than counteracted by the advantage of stable prices.

Space does not permit the detailed examination of the objections made against the proposal. They have been set out in the paper referred to above. I have endeavoured to estimate the course the Australian price-level would have taken during the war had the proposal been in operation on the following conditions: (a) brassage - 2 per cent; (b) adjustment - 1 per cent for each 1 per cent deviation of the index number from par, but no adjustment greater than the brassage. 
Thus for every 1 per cent alteration of the index number the "gold content" of the $£ 1$ would be varied by 1 per cent; (ci) influence - it is assumed that 1 per cent adjustment in the "gold content" would affect 1 per cent change in the price level. Such an assumptions made in the absence of evidence as to what the influence would be; (d) lag - each adjustment to have completed its influence in two months.; (e) tendency - as in the index number of wholesale prices.

Table 9.11 shows the stabilized and unstabilized index numbers on these conditions.

Table 9.11: Stabilized and unstabilized index numbers of wholesale prices since July, 1914

\begin{tabular}{l|l|l}
\hline Date & Index no. unstabilized & Index no. stabilized \\
\hline July, 1914 & $\mathbf{1 , 0 0 0}$ & $\mathbf{1 , 0 0 0}$ \\
\hline September & $1,054^{\text {a }}$ & 1,054 \\
\hline November & $1,108^{\text {a }}$ & 1,086 \\
\hline January, 1915 & $\mathbf{1 , 1 6 2}$ & $\mathbf{1 , 1 1 7}$ \\
\hline March & 1,280 & 1,206 \\
\hline May & 1,453 & 1,343 \\
\hline July & 1,640 & 1,486 \\
\hline September & 1,514 & 1,344 \\
\hline November & 1,328 & 1,156 \\
\hline January, 1916 & $\mathbf{1 , 3 0 0}$ & $\mathbf{1 , 1 0 9}$ \\
\hline March & 1,313 & 1,099 \\
\hline May & 1,315 & 1,079 \\
\hline July & 1,332 & 1,071 \\
\hline September & 1,312 & 1,034 \\
\hline November & 1,321 & 1,021 \\
\hline & &
\end{tabular}


Table 9.11: Stabilized and unstabilized index numbers of wholesale prices since July, 1914 cont.

\begin{tabular}{|c|c|c|}
\hline January, 1917 & 1,330 & 1,008 \\
\hline March & 1,344 & 1,009 \\
\hline May & 1,371 & 1,019 \\
\hline July & 1,483 & 1,080 \\
\hline September & 1,520 & 1,085 \\
\hline November & 1,591 & 1,113 \\
\hline January, 1918 & 1,635 & 1,120 \\
\hline March & 1,668 & 1,120 \\
\hline May & 1,711 & 1,126 \\
\hline July & 1,700 & 1,097 \\
\hline September & 1,720 & 1,088 \\
\hline November & 1,716 & 1,064 \\
\hline January, 1919 & 1,713 & 1,041 \\
\hline March & 1,683 & 1,002 \\
\hline May & 1,715 & 1,021 \\
\hline July & 1,760 & 1,027 \\
\hline September & 1,850 & 1,058 \\
\hline November & 1,987 & 1,114 \\
\hline January, 1920 & 2,026 & 1,113 \\
\hline March & 2,089 & 1,124 \\
\hline May & 2,250 & 1,186 \\
\hline July & 2,341 & 1,210 \\
\hline September ${ }^{a}$ & 2,291 & 1,149 \\
\hline November & 2,072 & 1,011 \\
\hline
\end{tabular}

a. The index numbers for September and November are interpolated, as the figures for those months were not included in the information available at the time. But in 1920 the unstabilized index number had risen to 13 per cent above par, and was still 107 per cent above par in November.

This result is interesting. It was to be expected that there would be a considerable rise in the unstabilized number in 1915, for the very remarkable 
increase in wholesale prices during the early months of that $y$ ear rendered this inevitable. But this was followed by an equally rapid fall, and by January, 1916, the number was only 11 per cent above par. From this till January, 1920, it kept within 12.6 per cent of par, but rose to 21 per cent above par in July, 1920, dropping almost to par at the close of our period.

This proposal would then give us the multiple standard without any rigid Government regulation or inconvenient financial disturbances. It is theoretically sound, and involves no fresh currency machinery, except provision for altering the "gold content" of the sovereign in conformity with movements in the price index number. No fundamental objections have been successfully upheld against the proposal, and the present financial situation in the Commonwealth and elsewhere renders a reconstruction of monetary units vitally necessary. ${ }^{72}$ Thus Australia might take the present note issue as a basis and proceed to regulate it according to the index number of prices, contracting it with a rise and expanding it with a fall. At the same time, if the dollar exchange were "stabilized" it might be possible to avoid the difficulties of a falling price-level, which in present circumstances is inevitable. As an experiment, the note issue might thus be regulated, but it would be desirable to have international action. The following machinery, necessary for carrying out this suggestion, is simple: (i) an index number of responsive wholesale prices; (ii) the automatic variation of the note issue according to movements in the index number; and (iii) the use of notes as legal tender bank reserve and for clearing-house operations.

This machinery exists to-day, and could easily be put into operation. Of course, such details as the method of withdrawing and issuing notes, the amount of variation necessary in the note issue to correct an observed tendency in the index number, would require careful consideration. But the plan would introduce a multiple commodity standard without the use of gold, and would be well worth trial as an experiment.

72 This is what Professor Cassel suggested in his memorandum to the Brussels Financial Conference. European countries should stabilize their mint par to their present market rates of exchange on New York and this would prevent a heavy fall in prices necessary for the restoration of the pre-war mint pars. The same applies, with less severity, to Australia and the United Kingdom. 
The evils of a fluctuating standard are now so obvious to the mass of men that a new standard must be adopted eventually. "The worship of the golden calf" is quite reasonable among those who contrast the movements in war-time and pre-war prices; but the restoration of the gold standard is no panacea, and in view of the serious fall in prices it entails ${ }^{73}$ it is too difficult and hazardous a process for most nations with their present money units. Monetary theory has gone beyond the gold standard, as we knew it before the war, and a simple return to it will be no real advance. On the other hand, the successful adoption of a multiple standard is the next step forward. The course of action for this purpose is already shaping itself. But a better knowledge of the first fundamentals of monetary theory is the supreme need in Australia at the present time, and in anything we may do to promote such a knowledge we are carrying out the wishes of our benefactor, whose name we commemorate this evening. To this task this lecture is dedicated.

73 "The Nation which was to take to gold again would have to go through a very unstable monetary regime and undergo a cost to have it. It would undergo a crisis the reverse of the one it underwent when inflation was going on." Professor Panteleoni in a memorandum for the International Financial Conference at Brussels. 


\section{0}

\section{Money, credit and exchange}

\section{J. Russell Butchart}

Money and credit, the metallic gold coin, and the promise to pay a gold coin printed on a note or written on the page of a bank's ledger - a bank deposit these are the money and credit to which I refer to-night.

\section{Note and deposit identical}

The note, and the deposit payable on demand, are synonymous: they each express the same thing, demand credit, a promise to pay a gold coin on demand to the holder of them. But it is a curious fact, indicative of the very small amount of knowledge of the subject possessed by our legislators, that whilst nearly all democratic Governments have legislated regarding the note they have ignored the deposit altogether. Thus the Commonwealth Government removed from the banks the issue of notes - promises to pay on demand, which was regarded as the function of the Treasury; and yet left with the banks the right to create and issue deposits - promises to pay on demand. But obviously the vital, essential thing is the promise to pay on demand, and not the mere paper on which the promise to pay is expressed, the note or the bank ledger on the page of which the promise is recorded. It is absolutely certain that the reason why the Government legislated regarding the note is that they thought they understood it, and the reason the Government did not legislate regarding the deposit is because they had no clear understanding about it at all.

1 Tenth Joseph Fisher Lecture, 16 May 1923. 


\section{Indebtedness - the tool of exchange}

The discovery that bank demand credit, promises to pay gold coins on demand by a bank, is as efficacious for buying goods or labour and for paying debts as are gold coins themselves, and that this bank demand credit can circulate far more easily than gold coins, was a discovery of immense importance, and the gradual development of the negotiability, or ready transferability of this credit, has rendered possible the vast creation of modern production and exchange built up on the indispensable tool of indebtedness. When we read of Australia's bank deposits being $£ 450,000,000$, it means that the trading and savings banks owe that sum to their creditors, and the banks' debtors owe similar sums to the banks. The debtors owe the banks what the banks owe the creditors. If all the debts due to the banks were suddenly liquidated, deposits would correspondingly diminish. With what else than deposits could the debts be paid? It is with these debts, promises to pay on demand by banks, that 99 per cent of all purchases of goods are effected: and to see clearly how these debts were invented, let us go back to the Bank of Amsterdam, which may be regarded as the first modern bank, and note how the business of modern deposit banking was evolved.

\section{The Bank of Amsterdam}

This bank was founded in 1609 by the merchants of Amsterdam then the first commercial city in the world; and it was founded because of the difficulties experienced through the various kinds of metallic moneys circulating in the city of various issues, weights, metallic contents, and values. The principle on which the bank was founded was that it should receive deposits of these various worn and clipped foreign and heterogeneous moneys, reduce them all by assay and weight to one standard of value, for which the bank should give credit in its ledger. It did not trade with the money left with it, but simply received it, reduced it all to one common value, warehoused it and held it in coins of standard weight and fineness at the disposal of the depositor, who could draw it out in standard coins or have it transferred to other accounts in the bank's ledger. The convenience was great, and met a felt want. Bills of exchange were by Holland law made payable in this "bank money," as it was called, and this compelled every merchant to have an account with the bank in order to have the legal money wherewith to pay his foreign bills, and this 
raised the value of bills on Holland in foreign countries, and the premium on them was called the "agio".

\section{Increase of bank money}

Note particularly the foundation principle of this bank, viz., that the total deposits in the ledger must always equal the money in the safe, because if you clearly understand it, and how the officials broke it, as I will shortly recount, you will see how banks can increase the money available for purchasing in a country by creating deposits - promises to pay; and you will see how the tremendous increases in money and credit were made possible during the war and post-war periods. Professor Copland, in his "Equation of Exchange in Australia," published in the "Australasian Insurance and Banking Record" for December, 1922, finds that between 1913 and 1920 money in Australia increased by 95 per cent, credit currency by 130 per cent, trade decreased by 5 per cent, and the wholesale price index numbers increased by 129 per cent, and he wrote: "How these increases in money and credit were possible is a problem of public and private finance which requires careful analysis. Under the pre-war conditions they would not have been possible, except through a sudden and prodigious increase in the world's supplies of gold. What is relevant at the present moment is that the increases were possible. In them is to be found the real explanation of the rising prices from 1913 to $1920 . "$

Well, I know the facts and think they are worth recording, and if you learn from the history of the Bank of Amsterdam how that bank's officials hit upon the principle by which the money available for purchase could be increased you will understand a principle which was certainly not clearly understood in the early months of the war.

\section{The Foundation Principle}

The officials of the Bank of Amsterdam found, after some years of experience, that the bulk of the metallic money deposited with them did not leave them. What was drawn out by one merchant was generally re-deposited by another. Indeed, the facility of drawing orders on the bank instructing it to make payment by 
transferring credit from one account to another was so convenient that the great majority of the transactions did not affect the metallic money held at all. They simply transferred the record of money deposited from one account to another. They established the rule that release of debt is equivalent to payment. Instead of requiring the bank to pay back actual money, the depositors, or creditors of the bank, released it from that obligation to them on-its transferring credit to another by entries in its ledger. The bank officials could make these internal transfers without breaking the foundation principle of the bank, that the amount of credit in the ledger must always equal the amount of metallic money in the safe. They could only lawfully write fresh deposits, or credit, in their ledger, in exchange for metallic money paid in. They "balanced" by adding up the total balances in the ledger, and they equalled the money in the safe; and although all the money was withdrawable on demand, yet it never all withdrawn because, as I have said, what one merchant withdrew in cash another re deposited, and in the great majority of cases a merchant was paid his deposit by having it transferred to another account.

\section{What did the bank lend: Money, or promise to pay?}

Here then is the position: the bank officials found that in their business of deposit banking they had left with them a balance of metallic money far beyond what was required to meet the drawings of depositors on them. What did they do with this idle surplus of coin? At first thought, one would say that they lent part of it out at interest, and possibly to a small extent they did. But what the customers of the bank wanted was not so much metallic money as credit - deposits written to their credit in the bank's ledger, and against which they could draw their orders to pay, or with which they could meet their acceptances of bills of exchange drawn on them for merchandise which they had purchased. The bank officials broke the foundation principle on which the bank had been founded, in that they allowed the deposits in the ledger to exceed the coin in the safe. They gave deposits without requiring coined money to be paid in. They did this by making "advances" to customers at interest, or by discounting the promissory notes of the customers to the bank itself, which advances or discounts appeared on one side of the bank's ledger - its assets side - and correspondingly increased the deposits - the liabilities of the bank - on the other side of the ledger. There was no variation in the coin held at all. If, in their experience, they found that of every hundred pounds of metallic 
money deposited with them twenty-five pounds was ample to meet the drawings of the depositors upon them, and that seventy-five pounds on average remained in their safes, then they were safe in creating by way of advances at interest, or by discounts, fresh deposits to the amount of about three hundred pounds: because these, with the first hundred pounds of deposits created by lodgment of metallic money, made a total of deposits of four hundred pounds, against which they held the hundred pounds of money, or the required twenty-five per cent of coin holding against liabilities to depositors of four hundred pounds. Now as the three hundred pounds of advances and discounts which created the three hundred pounds of deposits carried interest, it is plain what a profit able business the officials of the Bank of Amsterdam had stumbled upon. They broke the foundation principle on which the bank had been founded, in that they allowed the deposits in the ledger to exceed the coin in their safe, and they were punished for the offence when it was discovered; but they had hit upon the great principle on which modern banking is conducted, and every bank to-day might record over its door, "Here we grant you deposits without requiring you to pay in money."

\section{Australian application of the principle}

Now, with this principle in mind, let us go back to the early days o - September 1914. The Commonwealth Government had pledged itself to support Great Britain in the war, and had enrolled men for the first expeditionary force. It required money wherewith to pay expenses, and for loans to the States suddenly shut out from the London market, and there were two ways of obtaining it. There was the straightforward, expensive way of borrowing what was required at interest from those who had it. This method would have transferred to the Government credit, purchasing power, then existing. Those who had deposits, purchasing power, at their credit, would have transferred that demand credit to the Government in exchange for long-dated credit, debentures bearing interest, payable at a date in the future. Manifestly this method would have created no new demand credit (except to the extent in which patriotic people might have borrowed from banks against securities to subscribe to the Government loans, but as the rate of interest on the advances would have been greater than the rate payable on the debentures such borrowing would have been inconsiderable). 
But there was another way by which the Government could obtain money, and a way by which, at first sight, it seemed as if the Government might obtain the money without paying interest for it. This was by the issue of paper money, which would cost nothing beyond its printing.

\section{Mr. Andrew Fisher, Prime Minister}

Mr. Andrew Fisher was then Prime Minister of Australia, and he flattered himself he was no mean financier, in that he had established the Australian note issue, it being one of the planks of the Australian Labour Party that the issue of notes was one of the functions of the Government and not of banks. Did not the Government have all the wealth of the community behind it, and, therefore, must not its issue of notes be preferable to the issue of banks'? The matter was as clear to Mr. Fisher as the proof of one of the problems of Euclid. Mr. Fisher was also one of the fathers of the Commonwealth Bank, that beneficent institution which, in the glowing rhetoric of its founders, was to "provide for every housewife in the Commonwealth a few sovereigns to jingle in her pocket, and to enable every prospector with his little show out in the bush to get an advance of a few pounds wherewith to develop it."

Here then was the chance for Mr. Fisher to avail of his two creations, the Australian note issue and the Commonwealth Bank, to finance the war.

\section{The $\mathfrak{£ 1 0 , 0 0 0 , 0 0 0}$ gold loan}

On October 2, 1914, Mr. Fisher fired a bombshell into the banks by demanding of the Associated Banks $£ 10 / 15,000,000$ of their gold, free of interest, the banks to receive Australian notes in exchange for them. At first several of the bankers were most emphatic that they would not consent, but after sleeping over it and communicating by cable with their London "Boards," they all agreed, those who had been most positively against the proposal now being quite agreeable to it.

But before this the banks had opened up the way for the Government to get notes into circulation. 
On September 25, 1914, they made the most momentous change ever effected in Australian finance - they gave up settlement of exchanges between the banks in gold and agreed to accept notes instead thereof This momentous change one of the bankers had endeavoured to force upon one of his brother bankers at an earlier date, regarding his agreement to settle balances of exchanges at the Clearing House in gold as not binding on him whenever it suited his purpose to break it. The settlement of exchanges between the banks in Melbourne was held up for forty-eight hours until the Clearing House committee could meet to consider the matter, when they reminded the gentlemen that Great Britain was then at war to uphold the sanctity of signed contracts, and that they could not, under the circumstances, support him in breaking his contract, and that he must settle for the adverse exchanges against him in gold. He had to retreat from the untenable position he had taken up with the best grace he could; but his act had given the cue to his brother bankers, and after general discussion a motion was carried that the banks should settle in notes.

\section{Bankers demand credit limited by gold}

In order that you may understand the tremendous significance of this change, with its far-reaching consequences, through its effect upon prices, upon every individual in the Commonwealth, let me explain how settlement between the banks in gold at the Clearing House definitely limited the amount of credit which a bank could create to a percentage of its holding in gold coins.

A banking system, such as the Australian banks regarded as a whole, creates deposits (as did the Bank of Amsterdam) by making advances, the operations merely increasing both sides of the ledgers. But bankers' demand credit, deposits at call, or current accounts, are drawable by cheque or bill; and when any one bank's customer gets advances, whether by way of over draft, as is customary in Australia, or by discounting his own or other people's bills or promissory notes, he does not do it for fun, but with the serious intent of making payment either for goods bought or for liabilities owed by him. In either case he gives his cheque or bill, which goes in to credit of his payee, and in due course is presented for payment, generally through the Clearing House, to the bank on which it is drawn. Payment of the cheque transfers his deposit to the account of his payee, 
and if the latter banks at another bank it creates an adverse balance against the bank drawn on, which has to be settled at the close of the day, either by setting off claims against the creditor bank in the form of cheques drawn on it, or in gold. Manifestly, as long as settlement between the banks is in gold, the amount of fresh credit which any one bank can create, i.e., fresh advances it can make, depends upon its holding of gold coins, and it is specifically limited by it.

The hanker is in this position: desire for profit leads him to extend his advances as far as possible, for on them he earns interest and discount; but he must preserve the solvency of his bank at all costs, and the fundamental principle of a bank's solvency is that it must always stand ready to pay its demand liabilities at a moment's notice, and its time liabilities, fixed deposits, as they mature. Hence if he makes too large advances or discounts too many bills, Nemesis is sure to overtake him in that the drawings of his customers on him will inevitably drain away his holding of gold. Hence his holding of gold is the brake on the banker, preventing him from over-trading.

\section{A credit cycle}

It is when all the banks are in a mood to expand, when the coin holdings are ample, when the minds of the executive officers are hopeful as to the future, when they are optimistic as to the success of their borrowing customers and their ability to repay, then business is good, prices advance, deposits increase by leaps and bounds; because the coin holdings which lie behind the advances which create the deposits almost automatically adjust themselves, in that what one bank loses through its borrowing customers drawing upon it is compensated for by lodgments of fresh credit, the fruits of advances by other member banks in the system.

But the expansion by the banks in advancing places increased purchasing power in the hands of the public, which exercises it in buying goods, which stimulates imports, which draws money away from the branches of the banks in London. This creates a necessity to replenish the coin holdings in London, which in turn reduces coin holdings in Australia; the percentage of coin to liabilities in Australia is reduced; the minds of the bankers become disturbed; they become pessimistic; not only is fresh advancing sternly stopped, but cruel requests are made for reductions or even repayment in full of existing advances, and at the 
very time when buying by the public is falling off because of restriction of credit. This necessitates liquidation, the forced selling of goods, and business becomes bad. A period of depression ensues until advances have been liquidated with deposits, until the proportion of coin to liabilities is improved by decrease in deposits, and so the cycle is completed.

\section{Credit unlimited on the basis of notes}

But now just consider the position when the bankers gave up settlement of exchanges amongst themselves in gold, and substituted notes therefore. Then the curb on the banks' creation of credit was no longer their holdings of gold - only obtainable by purchase with goods or labour at a price of about $£ 4$ an ounce - but their holdings of Australian notes; and at the outset the Government agreed that the banks might have, in addition to the ten million notes for $£ 10,000,000$ of gold, three notes for every further sovereign they lodged at the Treasury. But this method of obtaining notes was not largely availed of owing to the fear that gold lodged at the Treasury might be difficult to get back again. When the war loans came along the banks could get further deposits of notes in proportion to their own and their customers' subscriptions to the loans, and this method of obtaining notes was largely availed of. These methods of financing made banking easy and profitable - profitable both to the banks and the Government. The notes cost the Government no more than the cost of the paper and the expenses of printing the notes; on the deposits of notes the Government earned interest, and the banks got the needful legal tender, which enabled them to advance freely at profitable rates of interest; borrowers were enabled to obtain advances more easily than ever before; prices of lands and houses, rents, figures of bank deposits and advances, and profits generally, advanced to hitherto unexperienced figures; wages and salaries were largely increased; and the only people who seemed to suffer were those who had to live on the interest of Government loans floated at 3 or 3.5 per cent before the war, university professors, clergymen; and others who had to live on fixed amounts of money incomes.

\section{Effect on London Exchange}

But it has its disadvantages also; for, as I have explained, the free advancing and issue of credit by the banks gave the public command of largely increased purchasing 
power, which they exercised in buying, which led to largely increased imports. Payment for these heavy imports drew money from the banks in London, and with credit based on paper and exportations of gold prohibited, the banks had not the usual means of replenishing their London balances, viz., by shipment of gold. This led to the ludicrous but agitating exchange crisis of 1920, 1921, when the banks were so short of money in London owing to huge importations under their own letters of credit that, although they nominally quoted their selling price of telegraphic transfer at 50s. per cent premium, they would not sell it at all, and unhappy merchants with liabilities to meet on the other side of the world had to pay 120s. in the open market for money in London.

\section{The great inflation of credit}

The table at the foot of figure 3 [Editor's note: Graphs handed out were not made available for publication.] sets out the position, showing the deposit liabilities of the banks, the notes held, and the coin and bullion. The salient figures are that, whereas the deposit liabilities were $£ 159,000,000$ on average during 1914, they were $£ 246,000,000$ in 1922, an increase of $£ 87,000,000$. Against these liabilities the banks held $£ 5,000,000$ in notes and $£ 36,400,000$ in gold in 1914; in 1922 they held $£ 30,000,000$ in notes and $£ 22,000,000$ in gold. The percentage of notes increased from 3 to 12 ; and the gold decreased from 23 to 9 .

If we include the Savings Bank deposits also, the total deposit liabilities of the banks in 1914 were $£ 247,000,000$, as against $£ 410,000,000$ in 1922 , an increase of $£ 163,000,000$ in eight years, during which, as I have said, the gold holdings ran down from $£ 36,400,000$ to $£ 22,000,000$, whilst the note holdings increased from $£ 5,000,000$ to $£ 30,000,000$, showing how absolutely the deposits were created on a paper basis. As Britain is now tending towards resumption of gold payments, it is a great problem how Australia is to follow suit. It can only be by largely reducing the deposit liabilities of the banks, which could only be done by drastic reduction of advances, or by buying gold in America in exchange for interest bearing bonds.

This problem leads naturally to a brief review of the great service of gold in international trade. 


\section{The service of gold in international trade}

Prior to August, 1914, the moneys of Great Britain and Australia were kept from varying in value beyond the cost of shipping gold by the principle of ready convertibility of credit into gold and by the facility of shipment of gold from one country to the other. The great service rendered by gold in thus stabilizing the values of the moneys of Great Britain and Australia was of immense value to the peoples of the two countries trading on a great scale with one another, having borrowed vast sums of money from one another, and with large annual payments to make to one another. It should be manifest to anyone that for the Australian States to have borrowed some three hundred millions of pounds from Great Britain when the pound in London would purchase a pound in Australia, and having to pay interest and finally principal when the pound in Australia will purchase more or less than a pound in London, constitutes a great injustice to one of the two peoples. The service of gold in this respect deserves emphasis also, because it appears to be difficult for the popular mind to under stand how a pound in London can vary in value from a pound in Australia.

\section{Gold, the stabilizer of the values of international moneys}

As I have said, as long as the pound in London and the pound in Australia were readily exchangeable for a gold sovereign containing 113 grains of fine gold, and the gold coin could be shipped from one country to the other, the value of the pound in London and in Australia could not vary beyond the cost of shipping the gold from the one country to the other. But whenever the principle of ready convertibility of the pound into gold was surrendered in either country, then immediately it became not only possible, but inevitable, that the value of the pound in the one country would vary from the value of the pound in the other country; and that is exactly the position to-day, as is known to those who can get behind the artificial exchange rates quoted by the Australian banks to the true market rates determined by the supply of exchange offering by those who have it for sale, and by the demand for it by those who want to remit to London - i.e., the buyers of exchange. To the fortunate few traders who in Australia can and dare buy their exchange in the open market, thus ignoring or defying the close preserve of the banks, there has been for the past ten months a substantial 
premium to be obtained in the value of the Australian pound over the value of the British pound; in other words, London money is and has been at a substantial discount.

\section{Movements of gold}

The movements of gold in international trade are brought about through the rates of exchange, which in turn are determined by the condition of indebtedness between the trading countries. But with free movements of gold exchange rates cannot exceed fairly definite limits - viz., the cost of shipping gold - because if those who have debts to pay in London have to buy bills of exporters drawn on London at a greater cost than the cost of shipping gold, the latter method of remitting money will be adopted. But if gold cannot be freely shipped from Australia, as at present, there are no limits to the rates which importers may have to pay for remitting money to London.

\section{Illustrations from graphs}

When imports into a country are very heavy - as in Australia in 1920-21 - they naturally create a very strong demand for exchange, or debts due to Australians in London, which can be applied to paying for the imports. This causes bills drawn in Australia on London against exports to rise in value, for example of which see figure 2, where, in 1920-21, imports having reached their maximum of $£ 1858$ millions, as per figure 1, the rates for buying bills in Australia payable in London on demand fell from 20s. per cent discount to $7 \mathrm{~s}$. 6d. per cent. Premium - i.e., those exporters who had bills to sell to the banks, instead of being charged 20s. per cent on them, received 7s. 6d. per cent when selling them to the banks. Of course, as the banks were so generous as to allow $7 \mathrm{~s}$. 6d. per cent on bills drawn in Australia on London, they equalized matters by putting up the rates which they charged in London for buying bills on Australia from 70s. to 95s. per cent for sixty days' bills, and from 50s. to 70s. per cent on sight bills; and as the volume of imports was vastly in excess of the exports at the time, you may rely on it that the net profits of the banks did not suffer; on the contrary, it was far more profitable for them to charge the higher rates in London on the vast imports flowing into Australia than to allow the lower rates 
on the much smaller volume of exports flowing from Australia to London. For evidence of which see figure 1, where the line showing Australian bank profits did not fall, but on the contrary rose from $£ 4,973,000$ net profits in 1920 to $£ 5,732,000$ in 1921 .

\section{Imports and exports of Australia, 1900-1914, and exchange rates}

Of the imports and exports of Australia, you will see how from 1900 to 1914 imports and exports followed one another with small variations, the reason, of course, being that when imports exceeded exports a position was set up which called for an export of gold; whilst when exports were heavy and imports less, gold tended to accumulate in Australia, credit was easily obtained from the banks, prices tended to rise, purchasing power was extended, and gold was ready for export to pay for the balance when the next period of heavier imports came along. Similarly, you will see that comparatively only trifling variations occurred, as compared with the violent oscillations from 1914 to 1922. [Editor's note: Graphs handed out were not made available for publication.]

\section{Imports and exports of Australia, 1914-1922, and exchange rates}

The prime reasons for these violent oscillations during 1914-1922 were the paper basis of credit in Australia, with its accompanying absence of a free movement of gold; gold was not permitted to be shipped freely; consequently when there was a large excess of imports over exports during 1913 to 1915-16 exchange rates on imports rose 20s. to 25s. per cent, which means that that tax was levied on consumers in Australia. Then from 1916-17 to 1919-20 there were large excesses of exports, and Australian producers were mulct by high exchange rates on all exports. Then came the phenomenal importations of 1920-21, when exchange went to unheard-of heights, there being a premium in the open market of as much as $£ 6$ per cent on remittances to London, the banks remitting facilities having broken down and partly ceased to function in the business. Then came the swing of the pendulum the other way, as you see in the graph, and money in London went to a substantial discount. Now there are all the signs of a shortage of money in London again approaching. 


\section{Action and reaction in trade}

Now these violent and agitating fluctuations in the volume of trade and in the exchange rates were only possible because there was no gold basis to credit in Australia, and there was consequently no free movement of gold. Consequently time was required before the violent action of the heavy imports or exports was compensated for by re-action of heavy exports and imports. And this permits one to lay down some fundamental facts regarding the fiscal policy of a country, on the basis of which some positive theory may be built up as on a rock, and not on the shifting sand of unfounded opinion.

\section{The appealing doctrine of protection}

The free trader has always asserted that exports can only be paid for with imports, whilst the protectionist champion has always carried the masses of the people of Australia with him by the appealing theory that we should sell our surplus products in the outside world, but retain the money in the country by buying Australian-made goods, and thus we would have both the money and the goods, and so become rich very soon. This doctrine is so appealing to those who have little or no understanding of what money really is, and of the laws under lying trade, that it makes converts by mere repetition, and the Australian public, lacking the incentive to thought on the subject which a harder struggle for existence would create, is protectionist almost to a man.

\section{Law underlying trade}

To such a public nothing can be more uninteresting and unworthy of attention than the trade figures of the country, and they must be served up with most attractive context to catch attention at all Superficially viewed, how improbable that the oversea buying of the populations in Queensland, Tasmania, Western Australia, etc., is dominated by any underlying law: it appears to be determined by mere chance or caprice, or bad calculation on the part of banks in issuing too much or too little buying credits, or on the part of the Flinders Lane and Clarence Street merchants in sending forward too many or too few buying orders. And yet it can be proved that there is a deep underlying law that regulates the amount of the imports that Australia can buy, and that law is that we can only buy with 
the proceeds of what we sell, goods or securities; that imports and exports are reciprocals one of the other; and that if all the factors are included and time given for action and re-action to operate they must be equal.

\section{What tariff laws cannot annul}

The fundamental fact is that exports are paid for with imports, and that we cannot export without setting in motion forces which compel corresponding buying on our part of goods of equal value from the outside world. As the primary industries of Australia grow in productivity beyond the requirements of the home market, their pro ducts must be exported, and can only be paid for with imports of equal value, and no tariff laws or duties can possibly annul that fact. Were it better understood and more firmly held it would save the community from much bad legislation.

\section{Sellers and buyers}

Only a small part of the community exports wool, and wheat, and meat, whereas every individual in the community buys imported goods. Now what is the nexus, the connection between the former few and the latter many? When the former expands its figures of exports, what compels the latter to automatically follow suit in expanding its buying expenditure. The governor of the system is the banks, regarded as a whole. Every export puts money into the London offices of the Australian banks, and every import is paid for with money drawn from the London offices of Australian banks. It is the plenty or scarcity of money in the banks in London that expands or restricts the buying of Australian merchants in Britain and America; and the banks exert pressure (or, shall we say, they should) to expand buying or to contract it, through the rates of exchange and the charge for loans - interest.

\section{Loans and interest}

As the plenty or scarcity of money in the Australian banks in London is the determinant, per the issue of buying credits granted to importers in Melbourne, Sydney, etc., of the quantity of imports, it is manifest that any other factor besides 
exports that places money in the banks in London is equivalent to exports, whilst any factor besides imports that takes money from the banks in London is equivalent to imports. Now money borrowed by Australian Governments in London or New York is paid in to the credit of the Governments in Australian banks in London, from where it is transferred (for a consideration) by bookkeeping entries to the credit of the Governments in Australia. It is, therefore, equal to exports. On the other hand, interest, etc., paid by the Governments to holders of their debentures in Britain is paid for out of money in Australian banks in London, and is therefore equivalent to imports, and is called "invisible" imports. The figures of new money raised abroad, and of interest, etc., paid abroad, have for the purposes of the graphs been obtained from the Commonwealth Year Book and the Statistician's office.

\section{Action in 1919-1920}

Including, therefore, these two additions to the figures of Australian imports and exports since 1901, let us see how, despite the drama tic changes in the Australian trade position during the past few years, the position of equilibrium has been attained. The trade of the past few years is particularly interesting, because in 1919-1920, owing to abnormally high prices for Australian products, money accumulated in London to an embarrassing extent; so much so as to lead Mr. W. M. Hughes to announce that the Commonwealth Government (not too well acquainted with action and re-action in trade) intended to inter pose its mighty hand to relieve the situation.

\section{The reaction to $1920-21$}

But there were forces at work beyond Mr. Hughes' ken, and stronger even than the Commonwealth Government. There was the psychological force of superabundant funds on the minds of the chief bankers of Australia, which, with the desire for gain, led them to issue buying credits on such vast scale that imports jumped from $£ 99,000,000$ in $1919-20$ to $£ 164,000,000$ in $1920-21$, which not only relieved the Commonwealth Government from any need to assist in transferring money from London to Australia, but so embarrassed the aforementioned chief bankers that, as has already been mentioned, their remitting facilities broke down, 
and they could not pay money from London to the outside creditors for goods bought under their own letters of credit. Unhappy merchants with liabilities to meet abroad had, as I have said, to pay up to $£ 10$ ' 6 in Melbourne and Sydney for $£ 100$ to be paid away in London on their account. Harassed bank managers, goaded between autocratic and conscience-convicted chiefs on the one hand, and indignant customers on the other, are not likely soon to forget the months of November and December, 1920.

\section{Another dramatic change}

Again the scene was changed, and again the psychological effect of the evanescent and the temporal on the disturbed minds of the bankers brought forth its inevitable fruits. Just as formerly they had been too lavish in their issue of buyers' credits, so now they went to the other extreme, and were too niggardly in the issue of them. This restriction of credit, combined with large borrowings by the Governments, caused another embarrassing plethora of money in London, and exchange, in the open market, went to a substantial discount, and the Australian importers, who had been bled the previous year in the cost of their remittances to London, got some of their loss back again. The bankers, who had been crying out the previous year that their managers must get rid of the accounts of the importers now were eager to acquire them, for they were in just as great straits to get money out from London as they had been the previous year in difficulty to get it there. To the mere amateur it does look as if there were room for improvement in the conduct of the banks to avoid these ludicrous but agitating convulsions by more intelligent use of the governors placed in their hands in the issue of credits and the rates of interest and exchange.

\section{Equilibrium after violent convulsions}

But now a period of equilibrium is approaching, for the figures on the accompanying figure 1 show that over 22 years and 8 months the imports into Australia, including the "invisible" imports of interest payable abroad, freight, dividends, etc., totalled $£ 1,937$ millions, and the exports, including net borrowings abroad, totalled $£ 1,932.1$ millions. The difference is only $£ 4.9$ millions, which in $£ 1,932$ millions is only one-fourth of 1 per cent. Therefore it is established that imports 
and exports are a moving equilibrium; that when special circumstances cause one to exceed the other, force is set up to bring about a re-action; that imports are the payment received for exports; and that a country cannot export without drawing in imports of corresponding value.

\section{Exchange}

The business of buying and selling exchange is the business of receiving money at one point and paying it out at another, or of paying it out first at one point and receiving it later on at another. For example, the Australian banks sell their T.T. and drafts on London, i.e., they receive money in Australia and pay it out in London; they also buy bills in London on Australia, again paying out money in London and receiving it in Australia; and they buy bills in Australia on London, i.e., they pay out in Australia and receive in London. These are the three chief operations of the banks in London exchange. Of course, they also sell their drafts and T.T. in London on Australia, but such transactions are not large or important.

The aim of the exchange dealer is to create a balance in London and then sell against it at a profit. Before the banks can sell drafts or telegraphic transfers on London, or buy bills in London drawn on Australia, they must have balances in London against which they can sell or with which they can buy. They obtain and maintain these balances by buying the drafts of Australian exporters of wool, wheat, meat, butter, etc., payment for which they receive in London. Also, when the Australian Governments raise loans in Great Britain the proceeds of the loans are paid in to the Australian banks in London and paid out by the banks in Australia. Such money in London constitutes banking funds against which the banks in Australia can sell their drafts or telegraphic transfers, or they can use such money to buy in London bills drawn on Australia by British exporters of goods to Australia. To sell drafts in Australia on London is exactly equivalent in its effects upon banking funds in London as to buy bills in London on Australia. Both operations take money from the Australian banks in London, which money, as I have said, they place in London by buying in Australia the drafts of the exporters of wool, wheat, etc. 


\section{A close combination}

The Australian banks maintain a very close combination for this exchange business; I question if a closer preserve can be found anywhere else in the world. From it they make great profits, and from it they jealously exclude competition. Time after time American and other foreign banks have tried to get a footing in Australia, but so great is the pressure that the banks can bring to bear that time after time the foreign banks have been shut out. The last attempt was by the American Express Company, a wealthy concern, which opened a branch in Sydney about eighteen months ago, and after vainly petitioning for permission to enter the general banking field, closed up, finding it hopeless to obtain liberal treatment. The only way it could have got a share of the exchange business was by giving the public better rates than those fixed by the Australian banking organization, which, of course, the banks were most determined that it should not do, and they could prevent it by refusing to give it any credit in their books or collect its cheques on other banks. The Australian banks have got the extremely valuable exchange business of Australia in their own preserve, and they are naturally determined not to allow any outsiders to share in it; therefore they will not even open an account for any English or foreign bank or company that proposes to do exchange business within the ambit of Australia.

\section{Profits obtained by combination}

The association of the Australian banks forms, as I have said, one of the closest combinations in the world, and whilst it cannot be denied that the close preserve tends to build up strong institutions, yet there is no doubt, on the other hand, that the chief object of the preserve is that of all such combinations - to obtain profits beyond what would be possible were demand and supply allowed to freely operate. By their combination the Australian banks are enabled to obtain rates of exchange beyond what the trading position often warrants, and beyond what would be obtainable were the operations of supply and demand not stifled by the preserve. Sir Robert Anderson, of Sydney, on returning from London last December, commented upon the rates of exchange charged by the banks in London when there was an immense surplus of Australian money in London, and said: "Three London managers of Australian banks admitted that the rates were artificial, but they could do nothing because of the cast-iron agreement 
between the banks"; and "Satisfaction as a shareholder in Australian banks at the large profits being made was tempered by the feeling that their profits, in this direction at all events, constituted a grave imposition on the trade of the country." Kindly note those are not my words; they are the words of Sir Robert Anderson, of Sydney.

\section{The Commonwealth Bank a party to the rates}

You may remember that as recently as $19^{\text {th }}$ April, a Mr. Johnston, a Labour member in the House of Commons, asked Mr. Baldwin (Chancellor of the Exchequer) if he was aware that the Common wealth Bank had cut down rates, and at the same time had facilitated trade and accumulated huge reserves. (There is such a strong aroma of Mr. Andrew Fisher in the sentiment of the question that one wonders if, though the words are the words of Johnston, the thought behind them is not the though of Fisher.) Mr. Baldwin, like a discreet gentleman, replied that he was- not aware that the accumulation of reserves of the Commonwealth Bank had been accompanied by the beneficent blessings to the trading and consuming public which the glowing rhetoric of Mr. Johnston's language would lead hearers to believe. Had he consulted Sir Robert Anderson he would have learned that they had been accompanied by exactly the opposite, for Sir Robert remarked in December last, when commenting on the high exchange rates charged by the banks in London, the Commonwealth Bank included, "When the Commonwealth Bank was established it was hoped that it would wield a strong preventive influence against high charges, but the Commonwealth Bank seemed to have succumbed to the lure of high profits, and followed the line of least resistance." I hope to show you by my graphs a striking instance where the Commonwealth Bank not only failed to cut down exchange rates, but took its share with the other banks of what, I think, can only be regarded as monopoly profits.

\section{Costs should govern price}

For the purpose of this lecture I have prepared the graphs which are in your hands, the first of which shows the import and export figures of Australia for the past 22 and a half years. [Editor's note: Graphs handed out were not made 
available for publication.] It is the exports from Australia that create the credit in London against which the banks sell their T.T. and drafts on London, and with which they buy the bills drawn at that end on Australia and bought or negotiated in London. The cost to the banks of putting the money in London should govern the price at which they can sell against it. If they can buy at little or no cost they should sell cheaply to the public. The business of exchange consists in first putting a balance in London, which is done by buying the bills drawn against exports, and then selling against the balance thus created there. The cost at which you have bought should (and will, if competition is free) govern the price at which you can sell; but with a close combination of all those operating in exchange business high rates may be fixed arbitrarily, and that is the great object of and danger with all combines for fixing prices.

\section{Cost of creating balances in London}

If you will look at figure 2 will see the charges by Australian banks for buying in Australia the 60 days' and sight drafts drawn against exports. These are the drafts that place money in the banks in London when the drafts are paid. Against the great bulk of Australian exports 60 days' drafts are drawn, and these drafts the banks buy in Australia at rates of exchange fixed by the association of the banks. From these rates there is no escape. There is no one in Australia prepared to buy bills on London except the banks, and the banks fix the rates at which they will buy; naturally they see to it that they do not pay too much for the bills.

I have called the bank charges on bills on London cost. But this requires qualification, because, as you will see from the graph where the rates on 1 st December each year from 1901 to 1922 are indicated, that in the case of 60 days' drafts the banks charged or bought the drafts at a discount of their face value of from 17s. 6d. per cent in 1901, to 15s. in 1902, to 20s. in 1903, and so on, the rate being $37 \mathrm{~s}$. $6 \mathrm{~d}$. in $1917,1918,1919$, when, as you see by figure 1 , exports were much greater than imports, causing a great surplus of money in London, and therefore the banks naturally charged more discount on transactions which added to the superabundance. Then in 1920, 1921, when imports were enormous, there was a great scarcity of money in London, and therefore the banks were eager for transactions that would place money there, and they reduced the discount, or 
charge, on the 60 days' bill on London to $17 \mathrm{~s}$. $6 \mathrm{~d}$. per cent; then next year, 1922, when there was again a surplus of money in London, the rate of discount, on the 60 days' bill was raised to $47 \mathrm{~s}$. $6 \mathrm{~d}$. per cent, the highest point touched during the twenty-two years. This high rate is still maintained at the date of preparing this essay, April. 1923.

You will also note from the figure 2 how the charge for buying sight drafts on London follows the 60 days' rate, but at 10s. to 15s. per cent under it. This, of course, is due to interest, for when a bank buys a 60 days 'draft on London it is out of its money for about 90 days (i.e., 30 days in the post and 60 days to run after it is sighted in London); whereas if it buys a demand draft it is out of its money only 30 days. Therefore the exchange rate for buying a 60 days' draft is inclusive of 60 days' interest at the London rate of interest for money over the rate for buying a sight draft, and as 60 days is one-sixth of a year, and the rate of interest in London is generally about 3 or 4 per cent, the bank charges one-sixth of 3 or 4 per cent, i.e., about 10s. or 15s. more discount for buying the 60 days' draft than the sight draft, Australia on London.

\section{Another element than interest in the rate of exchange}

The difference I have just explained between the rates charged on the 60 days' bill and the sight bill, Australia on London, gives us the cue to find the actual cost, if any, to the banks of placing money in London, i.e., of establishing the balances against which they can sell exchange. As I have said, the difference between the rates on the 60 days' bill and the sight bill is about 10s. to 15s. per cent, being purely interest for the extra time the bank is out of its money. But there are notable exceptions to the 10s. or 16s. difference, e.g., during the great stringency in London during 1920, 1921, when the difference was, as you see by the graph, not 10 s., but 25 s., per cent. This extra charge on the 60 days' bill over the sight bill was, I think, mainly due to the anxiety of the banks to get money as speedily as possible to London; therefore they showed their disapprobation of the obstinate exporter who drew against his shipments at 60 days on London by charging him 17s. 6d. per cent discount, whilst the good exporter who came to the aid of the banks in their trouble by drawing at sight they rewarded him with a premium of $7 \mathrm{~s}$. 6d. per cent, the only occasion, so far as I know, on which the Australian banks gave a premium on buying bills on London. You may be pretty sure that 
matters were fairly desperate with them when they behaved in that extraordinary and unprecedented manner. As a matter of fact, they were at their wits' end to get money into London to meet their engagements there.

Now, when buying 60 days' bills on London, the banks are out of their money for approximately 90 days from the date of paying out the money in Australia to receiving it in London. Therefore they are entitled to charge 90 days' interest in the rate of exchange at which they buy the drafts. That is about onequarter of a year, and reckoning interest in London, as above, at 3 or 4 per cent per annum, the charge for interest is about 15s. to 20s.; on a sight draft the interest charge is about 5 s. to 7 s. $6 \mathrm{~d}$. per cent.

Therefore of the rates shown on the figure 2 as having been charged on buying bills on London in Australia about 17s. 6d. and 6s. per cent on the 60 days' and sight bills respectively are average charges for interest, and the balances are charges for exchange. Now if we take the average of the exchange rates shown on the graph for twenty-two years we find that they were 25s. per cent for buying 60 days' drafts and 10s. $6 \mathrm{~d}$. for buying sight drafts on London. Therefore we may conclude that not only did it not cost the banks anything to establish the balances in London against which they sold exchange, but after allowing them interest for the time they were out of their money they made a profit on exchange from $5 \mathrm{~s}$. to 7 s. $6 \mathrm{~d}$. per cent over and above interest.

\section{How the banks use their funds in London}

Now, having created balances in London, mainly by the purchase in Australia of drafts drawn against exports, what do the banks in London do with the money? The great bulk of it is used to pay in London for Australia 's imports. This is done by two methods. First, the shipper of the goods may draw on the purchaser in Australia for the value of the goods, in which case he takes his bill on Australia to one of the banks in London, which buys or negotiates it, giving him the face value of the bill, less the discount, or it adds the exchange to the face value of the bill. If you look at figure 3 you will see in the two top curves the rates for twentytwo years at which the hanks in London bought 60 days' drafts on Australia, and the rates at which they bought sight drafts. Again you see how the rates for 60 days' drafts were generally 20s. per cent over the rates for buying sight drafts, the 
reason, of course, being that in the first case the banks were out of their money for 60 days' longer time than when they bought sight drafts; therefore the banks charge 60 days' interest in the rate of exchange over the sight rate, and as 60 days is one-sixth part of a year the 60 days' rate is about 20 s. per cent. higher than the sight rate, being one-sixth of 6 per cent. per annum, the interest rate in Australia.

\section{Profits on such transactions}

As the difference between the 60 days' rate and the demand rate gives us the rate of interest on which the banks work in negotiating bills in London on Australia, so this rate of interest enables us to see the profit in the exchange which the banks reap; because in buying a 60 days' draft and a demand draft the banks are out of their money for 90 and 30 days respectively; i.e., before the draft is posted to Australia, presented for acceptance or payment, and finally paid. Now 90 and 30 days are respectively the fourth and twelfth parts of a year approximately, and at the rate of interest already arrived at the interest charges are 30s. and 10s. respectively.

Again, taking the averages of the rates for the twenty-two years, we find that the banks charged 62s. and 41s. per cent for 60 days' and sight drafts respectively. Deducting from these average rates 30s. and 10s. per cent for interest, the differences, 32s. and 31s., represent the profits in exchange reaped by the banks. Now, as you will remember, we found that the exchange profit to the banks of placing money in London wherewith to buy bills against imports was on average 5s. to 7 s. 6d. per cent. Therefore we may conclude that, after allowing for interest for the time the banks are out of their money in buying on London and selling against it, there is a net average exchange profit to them of about $37 \mathrm{~s}$. or $38 \mathrm{~s}$. $6 \mathrm{~d}$. per cent.

\section{Specific examples}

To illustrate by specific examples. The banks on $1^{\text {st }}$ January employ, say, $£ 100$ of their money in Australia in buying a sight draft on London against some export of Australian produce. They receive that $£ 100$ in London at about $1^{\text {st }}$ February, and the same day apply the money to buy a demand draft on Australia against 
imports. That draft is paid in Australia and the money back where the transactions commenced by about $3^{\text {rd }}$ March. The bank has been out of its money one-sixth of a year, and it has earned on average, over twenty-two years, 10s. 6d. on buying the draft in Australia and 41s. in London, in all 51s. 6d., of which about 16s. 6d. was interest and the balance, 35s., exchange; thus the total earnings of the bank on the two transactions were 51s. 6d. in one-sixth of a year, which is at the rate of 309 s. per annum on $£ 100$, or $15 \frac{1}{2}$ per cent. per annum.

If we take the case of 60 days' bills, we find that the banks receive 25 s. on average in Australia on buying the bill for $£ 100$ on London, and 62s. on using the money in London to buy a bill on Australia; in all, 87s., earned in one-half year, or $£ 814 \mathrm{~s}$. per cent per annum. Thus the banks, in buying sight drafts and 60 days' drafts, get their interest for the time they are out of their money, and about 35s. and 40s. per cent exchange respectively on top of that. Now, as this exchange profit is so nearly the same whether the bills bought are 60 days' or sight drafts, of course the profit on buying the sight bills is much greater percentage per annum than on buying 60 days' drafts, because six transactions both ways can be completed in the year in sight drafts, whereas only two of 60 days' bills. Therefore it is much more profitable for the banks to employ their funds in buying sight drafts than 60 days' drafts, although I question if many bank officials are aware of it.

\section{The influence of the Commonwealth Bank}

You will notice from figure 10.3 how the charges of the banks in London for negotiating 60 days' and sight drafts, London on Australia (the two top curves) did not fluctuate for the first twelve years of this century. Those were the years before the foundation of the Common wealth Bank; and you will remember how the innocent Mr. Johnston asked the Chancellor of the Exchequer whether he was aware that the Commonwealth Bank had accumulated its large reserves and yet had cut down rates. Well, gentlemen, I leave it to you to say from the graph whether the Commonwealth Bank has had that benign influence attributed to it by the aforementioned member of the House of Commons, or whether he was talking about something he knew nothing whatever about. 


\section{An alternative method of paying for imports}

As I said a little time back, money in London may be employed in two ways in paying for imports into Australia. Instead of being drawn on through London the buyer in Australia may remit the funds to pay for the imports from Australia. To do this he may go to the bank in Australia and purchase from it its telegraphic transfer (which is simply an order to its London branch to pay so much money to his nominee in Great Britain on telegraphic advice), or he may buy from the bank its draft on London at sight or 60 days after sight, which he sends to the seller of the goods in Britain or elsewhere. On figure 3 you will see the curves of the rates charged by the banks in Australia for selling such means of remitting. And you will notice how the selling rate for T.T. was below the rates for buying demand bills in London on Australia, and how the rates for selling demand and 60 days' drafts were respectively below the rates for selling T.T.

Of course, it is the interest charges that account for these differences. In the case of T.T. the bank receives the money in Australia one day and the same days pays it away in London. Hence there is no question of interest at all in the transaction, and the charge may be regarded as pure exchange. If you will remember, we found that the average rate for buying demand drafts in London on Australia was 41s. per cent, of which 10s. was interest, so we would expect to find that the T.T. rate in Australia would be approximately 31s. per cent, whereas if we take the average of the T.T. rates we find them only 24s. per cent. But I am going to show you how the banks, I think, overcharged the importers in 1916, 1917, 1918, 1919, who were drawn on from London, in that the banks in London did not alter their buying rates in London when money was plentiful there, and when the rates in Australia showed the influence of such plentiful money in London by rising for the charges on bills drawn against exports from Australia and falling in the charges on T.T. and drafts sold in Australia to pay for imports.

\section{Buying rates in London, 1916, 1917, 1918, 1919}

If you look at the Graphs Nos. 2 and 3 you will see exactly what I refer to. You will notice how in the years referred to the rates for buying 60 days' and demand drafts on London rose under the influence of the excess of exports shown in Graph 1, and the rates for selling T.T. and drafts in Australia on London fluctuated 
sympathetically, as might be expected. But why were the high rates of 70s. and 50s. for buying 60 days' and sight paper in London on Australia maintained all through those years? That I cannot understand, but I think that there is no doubt of the facts; and I would just point out that in those four years the imports into Australia were no less than $£ 340$ millions, of which a large proportion would be drawn for, and a failure to alter the buying rates in London to correspond with alteration in the selling rates in Australia by $12 \mathrm{~s}$. $6 \mathrm{~d}$. per cent must have meant some one and a half millions of extra profits to the banks. This is what I referred to before as a striking instance where the Commonwealth Bank not only failed to cut down exchange rates, but even took its share with the other banks of what, I think, can only be regarded as monopoly profits. Now, if we assume that the rates for buying bills in London on Australia in those four years should have been about $12 \mathrm{~s}$. $6 \mathrm{~d}$. less than were actually charged, in keeping with corresponding falls in selling rates in Australia and rises in the buying rates as per figures 10.2 and 10.3, then the average of the buying rate of sight drafts in London on Australia should have been, over the twenty-two years, not 41s. per cent, but 38s. 6d. per cent., of which 10s. was interest and 28s. 6d. per cent exchange. This more nearly approximates to what we find the T.T. rate to have been, namely $24 \mathrm{~s}$.

\section{Competition for T.T. in Australia}

But the reason why the T.T. rate in Australia on London is one-quarter per cent lower than the demand buying rate in London on bills on Australia, after making the allowance for interest (which the two operations are exactly analogous so far as they affect London funds), and after allowing for the apparent lapse on the part of the banks to lower their buying rates in London in I916, 1917, 1918, and 1919, is an extremely interesting one. The selling of T.T. in Australia on London is the only exchange operation in which outsiders can in a small way compete with the banks. To explain this. There are a very few exporting firms in Australia sufficiently wealthy to be able to trade with their own money; they do not require to go to the banks for overdraft accommodation, or, if they do, are so strong that the banks dare not refuse it. These firms ship their produce to London, but do not draw for it drafts to be negotiated by the banks; the banks' charges on exporters' bills are so high, e.g., at the present time 4is. $6 \mathrm{~d}$. per cent discount on a 60 days' sight bill on London, that these wealthy firms prefer to send free documents to 
their London branches, so escaping the high exchange charges; then the London branches collect the proceeds of the shipments and place them to the credit of the shippers in London. This creates the balance in London against which, as I have said, the exchange dealer can sell. They become sellers of exchange in the open market, and just as they have beaten the banks by sending their free documents to London, so they can beat the banks by selling their T.T. on London at a better price than the banks. Of course, the banks do not like this, and some even threaten their weaker customers that if they dare buy exchange outside the banks from the outside competitors they will receive no overdraft accommodation - a serious matter for a small man. But my point is this: it is just this little bit of competition that makes the banks ' selling rates for T.T. a little lower than they would be if this small element of competition were eliminated.

\section{Selling drafts on London}

Referring again to figure 3, you will notice how the rates for selling demand drafts by the banks were under the T.T. rate by about 11 s. on average over the twentytwo years, and the rates for selling 60 days ' drafts were again under the T.T. rate by about 22 s. $6 \mathrm{~d}$. on average. Of course, these differences are due to interest, the banks having the use of the money for about 30 days when selling their demand draft on London, and for about 90 days when selling their 60 days' draft, and at 6 per cent the use of the money in Australia for 30 and 90 days is about 10s. and 25s. respectively.

\section{American and Eastern exchange}

The banks not only receive and pay money on account of London, but also to a growing extent of New York. The usual way of paying for imports from U.S.A. is by putting up a credit under which the New York bank is authorized to draw on London, the applicant for the credit undertaking to provide the funds in Australia in time for them to be remitted, generally by cable, to London to meet the drawing from America under the credit.

In the application for such credit (as for all Eastern credits as well, Calcutta, Singapore, Kobe, etc.) the applicant in Australia, i.e., the importer, undertakes to provide the money in Melbourne, Sydney, Adelaide, etc., in time to buy 
remittance to London to meet the drafts drawn in U.S.A. or the East, from the bank which issues the credit, and at the official rate of the day, i.e., the rate fixed and quoted by the combination of the banks. This effectually precludes the importer from obtaining the relief he might obtain were he permitted to buy his exchange in the open market.

\section{What might be done}

I had an example just a few weeks ago, when an importer came to me with his application for a credit under which he had to provide $£ 6,000$ in London that week to meet a drawing under the credit. Had he been permitted to buy his T.T. from me I could have sold it to him at 18s. per cent discount in his favour, i.e., he would have bought the $£ 6,000$ in London to meet the drawing under the credit for $£ 5,946$, whereas by buying the exchange from the bank at the official rate of the day he had to pay 5s. per cent premium, i.e., he paid the bank $£ 6,015$

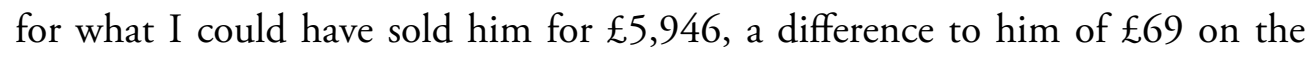
transaction. Regretfully I had to point out to him how he was tied up by his application for the credit, and that he must pay the $£ 6,015$ instead of the $£ 5,946$.

\section{Worse still if drawn on}

But sometimes the American shipper of goods to Australia draws his 60 days' sight draft on the importer, and negotiates or sells the draft at his bank in America, which pays him for it. The bank then sends the draft direct to an Australian bank with the documents attached, which latter on its arrival presents for acceptance, attaching to the bill a slip setting forth the amount of the draft, exchange at 3 per cent added (it was 4 per cent until quite recently), duty stamps, and a collecting fee. But generally the importer wants his goods, and, instead of accepting, pays cash - in which case the bank allows him rebate at 2 per cent. per annum, which is, of course, a very different proposition from 3 per cent on the amount of his draft.

For example, here I have a 60 days' draft in my hands, drawn in New York on 22nd January for $£ 9415$ s. 10d. It reached Australia on 9th March, and was presented for acceptance with slip attached, showing amount of the bill £94 15s. 
10d., exchange at 3 per cent $£ 218$ s. $10 \mathrm{~d}$., stamps 4 s. $6 \mathrm{~d}$., in all $£ 9719$ s. $2 \mathrm{~d}$. The drawee, the importer, wanting his goods, paid cash, and the bank allowed him 6 s. 9d. rebate, i.e., 2 per cent on $£ 98$ for 60 days; so that the importer paid $£ 9712$ s. 5 d. in Australia on 9th March for $£ 94$ 15s. 10d. in New York on 22nd January. Now I sold money in New York within the last fortnight or so at 15s. per cent discount, i.e., the remitter paid at the rate of $£ 941$ s. $7 \mathrm{~d}$. in Australia for $£ 9 ’ 415$ s. 10d. in New York: whereas by being drawn on from New York it cost him - not $£ 941$ s. 7 d., but $£ 9712$ s. 5 d., a difference of no less than $£ 310$ s. 10 d., or more than 3.5 per cent.

I think you will admit that the exchange broker can render his clients in Australia a real service when once he gains their confidence, and thus justifies his existence.

\section{Conclusion}

And now I have to thank you all for your patient hearing of my essay tonight. The matters dealt with are of the keenest interest to me, and if I have in any degree made them interesting to you, I am amply rewarded. I am also deeply indebted to the University of Adelaide, which has given me this great opportunity to render the commercial community of Australia the best service I can, however inadequately I have availed of the opportunity, by explaining how the great inflation of credit in Australia during the war and post-war periods was effected, and the principles underlying the exchange charges on the imports and exports of Australia. Eighteen months ago my banking career was abruptly terminated through the sale of the bank I had served for thirty-seven years to another institution, and I had to seek other means of livelihood. Since then I have received such wonderful kindness and confidence from members of the mercantile community - particularly of Melbourne - as has been a revelation to me of the goodness of many men's hearts; and it is my ambition to serve them faithfully and efficiently with all the knowledge I acquired in my banking career, and with every ounce of my energy. 


\section{1}

\section{The Guilds}

\section{A survey of the old guild system, and a comparison of some of its features with our conditions to-day under our industrial laws Henry Y. Braddon ${ }^{1}$}

Responsible people in Australia realize that all is not well with industrial conditions: but there would be wide divergences of opinion both in diagnosing the trouble and in suggesting remedies. To-night I am concerned rather with diagnosis than with remedies. I think it may be useful to take a glance backward to at any rate one of the systems of the past - to assess the good features and the bad - and particularly to determine whether such a survey suggests some line of action for our own troubles.

The Guilds of the thirteenth, fourteenth, and fifteenth centuries achieved an extraordinary success: a success merited and explained by the fine characteristics underlying their activities. Later on world conditions began to alter with everincreasing rapidity: the Guilds were too inelastic, too jealous of their privileges, to adjust to the change, and in a century or so they passed away. That is the epitomized tale of their rise and fall In their best days they were animated by excellent ideals and they were admirably suited to the conditions of those times; but, like most institutions operated by fallible men, there were less desirable features, gradually these lea to the decay, and finally the obliteration, of the Guilds.

This is neither the place nor the time for any very extended description of the Guilds, nor for my purposes is anything of that kind necessary. I propose to describe very briefly the basis upon which they rested and the reasons for their decay. I will endeavour to place my finger upon those cardinal features which

$\overline{1}$ Eleventh Joseph Fisher Lecture, 25 April 1925. 
deservedly made for success, and then to put the question whether it is possible to revive anything of the kind under modern conditions.

In those older days communities were predominantly agricultural; industries were relatively small and markets were mostly confined to folk living in the immediate vicinity. Political subdivisions (for instance, in Europe) were small and many, and the "free cities" were largely self-contained. In many of these free cities the Guilds rose to their highest pinnacle, sometimes constituting in themselves the local authority - virtual republics. In return for the status they secured the Guilds undertook certain public duties, and paid dues to various authorities. Amongst their duties, for instance, they policed the streets in many cities. In their best days they were animated by a fine sense of civic obligation, and they carried out some wonderful work in architecture, roads, canals, and the like. So much for the general setting: now for some detail.

Guilds were sometimes simple, embracing one craft, sometimes complex. An interesting example of the latter was the Guild which included doctors, apothecaries, and haberdashers, the last named because their wide range of sales often included medicaments. There is no need to assume that Guild officers were angels, or entirely without flaw. They were very human, and occasionally internal dissensions, between this Guild or that, for supremacy or public recognition, became keen to the point of bitterness.

Within each Guild there was much that was admirable. Three grades, the master, the journeyman, and the apprentice, all equal in each grade: all three grades proud of the skill of the particular craft, and all jealous to maintain its reputation. Only an approved master of good character could take in an apprentice, and the former was under incumbency himself to teach the lad: he could not devolve that duty upon anyone else. The apprentice lived in the master's house, at first on a basis of fees paid, and later, as the apprentice became deft, he earned wages. He had to be industrious and obedient, and correction by the master could take the form of beating, provided he did it himself. If a master was inhumane, his conduct could become the subject of enquiry by the Guild officers, and if necessary the apprentice would be released. Human nature being what it is, it may be accepted that there were occasional cases of maltreatment of apprentices by masters, and sometimes outbursts of unruliness on the part of 
apprentices; but the Guild officers on the whole saw to it that the system worked fairly to all concerned.

The journeyman (after completion of apprenticeship) also lived with the master, as a companion, though the one paid and the other received wages. If he had the means to start for himself, the journey-man might become a master at any time; but as the means were often lacking, a journeyman might remain so for life. The master could not dismiss a journeyman until the former had made good his case for dismissal before a mixed tribunal of masters and journeymen. Taken as a totality, the system worked excellently, in the good days of the Guilds, though there were occasional troubles, and even strikes (though rare) were not unknown.

Hours of work were determined by daylight, resulting in long hours in summer and short in winter. Good artificial light was unknown, and daylight was necessary for the fine standard of work upon which the Guilds insisted. The long summer hours were mitigated by many public holidays (something like thirty in the year), and no work was done on Sundays or holidays.

Wages were always difficult to compare, because of the imperfect data of those older days. For that reason it is not easy to establish comparative purchasing powers. Wages were paid partly in money, partly in housing and clothes. There seem to be some fairly valid grounds for the statement that in the thirteenth century journeymen had enough to live on decently, probably, as matter of comparison, rather better pay than in Europe in the days immediately preceding the war.

Masters had to be capable, moral, and patriotic, to the satisfaction of the Guild officers. All masters had equal rights within each Guild, and the rules necessitated fair play between masters. The strong were not permitted to crush the weak; masters were for bidden to buy up raw materials so as to detrimentally affect others. There were in some Guilds regulations for compulsory sharing of raw materials in such cases, and sometimes the Guild itself bought for all. No master could entice a journeyman from another master by the often of a higher wage. No secret discounts or allowances to buyers, and no individual advertisement.

The Guild was a voluntary association of men carrying on a certain trade, and pledged by oath to defend the common interest. In operation the Guild was 
in effect what we would style a corporation - a legal entity. The stronger and older Guilds some times possessed great assets in lands, houses, funds. Power resided in the General Assembly - representing all grades - as regarded the making or the revision of rules; but an executive carried on from day to day, settled internal disputes, and saw to the strict regulation of prices for the particular product. The executive closely watched the quality of each master's output, because the reputation of the entire Guild was at stake; and equally carefully they watched over the interests of apprentices. The Guilds fought strenuously for the virtual monopoly of the trade concerned, and jealously pre served and perpetuated trade secrets and methods. It strove too to limit the number of masters, and mastership was apt to become hereditary - almost an oligarchy.

The sense of unity within a Guild was greatly strengthened by their feasts and entertainments, in which all grades joined. The Guild succoured its members, with medical aid in sickness, and sometimes with monetary assistance to a needy member. Within each Guild the masters were unavoidably competitors for the sale of their products, but they were also allies in the maintenance of the Guild privileges and reputation.

About the middle of the fifteenth century the great epoch of the free cities was about ending, and with it there began a gradual decadence of the Guilds, though another century or two passed before they actually died out. In their best days they had those fine ideals of which I have spoken, coupled with great pride in their city or State. In effect, they guaranteed the quality of the product to the consumer, they watched jealously over its artistic finish, and they kept profits within reasonable limits, by regulating the price beyond which no member master could sell. Journeymen and apprentices shared in the Guild's honourable privileges. Manners were simple, so no discomfort or constraint arose from the housing together of the three grades; while the two lower grades regarded their inferior status as temporary only, and so it did not weigh heavily upon them.

We have no time to go very fully into the reasons which led to the decline of the Guilds. It must suffice to rapidly survey the field, and for that purpose we will separate external from internal reasons. 
Take first the external. As the petty principalities and powers of Europe aggregated into larger political units, the independent cities, where the Guilds had been specially strong, became merged into their respective States. Markets expanded from local to State dimensions, and the State authority began to intervene in the regulation of industry, including the Guilds. About 1700 the Guilds still existed, but largely shorn of their privileges. The power of the Crown had greatly increased, and its demands upon the Guilds were sometimes extortionate: this professedly in the public interest, but the result was to still further weaken the Guilds. India and America came into the field, and markets widened internationally, while the Guilds, with their intensely local sentiment, failed to adjust to the changing conditions. Transport by land and water became safer and speedier; population increased rapidly, partly because improved medical methods saved the world from the more devastating effects of epidemics; a new spirit was abroad, entirely opposed to the narrow conservatism of the Guilds. Public opinion condemned them for their efforts to maintain privilege and exclusiveness, and charged them with lack of consideration for consumers. In the face of a world need for greatly increased production, the Guilds remained conservative and inelastic, with the inevitable result that more enterprising competitors came into the arena - the private merchant and the manufacturer. Great houses based on private capital, whole sale traders in all markets, became extremely active. To them the democracy of the Guild was unknown, and the manual worker was relegated to a lower level. Manufacturers at times imported cheap peasant labour, or utilized child labour in factories; they did not as a rule employ apprentices, and their opposition in the long run was fatal to the Guilds.

Another external reason lay in the growth of invention and the utilization of machinery, wooden or metal fingers displacing the slower hands of the Guilds. While the Guilds weakened, their competitors grew in power and range, with the result of strengthening the movement which made two distinct classes of employers and employed. As the fine human relationships and contacts of the Guilds slowly disappeared, there came upon the scene various new features, attempts at combinations of workers, occasional strikes, destruction of machinery by wage-earners, riots, and on the other hand the denial by the authorities of the right of combination or of public meetings. Then, too, there appeared the foreman, himself a wage-earner, but also the representative of the employer, often crude and harsh in his methods. 
All through the process the Guilds, tragically loyal to their methods and practices, bitterly opposed changes, even when these involved improvements, and so others inevitably came upon the scene who were more adapted to the world's requirements.

The internal reasons may be rapidly scanned. The Guild had no flexibility to meet the growing needs of expanding communities and markets. There gradually developed some lack of solidarity within the Guild, due to favouritism by many of the masters towards sons or nephews; severer tests and fees for journeymen or apprentices who were not related to the masters; increased hours from twelve to sixteen in summer time. Quarrels between Guilds were at times interminable and costly, litigation going on for years, with the result that the Crown sometimes intervened, suppressing the Guild.

Guild monopolies and privileges were over-jealously guarded, rendering these institutions incapable of accommodating their structure to new conditions; and gradually they drifted into a position where they did not even guarantee good work. Meantime the world was advancing by leaps and bounds. The Guild as an institution had outlived its real utility, and in the latter part of the eighteenth century it ceased to exist.

To-night we are mainly concerned with the good features of the Guild, since it is possible that these may suggest some line of action for our own future purposes.

From the mass of material available to the student, certain broad features of excellent quality stand out like good deeds in a naughty world.

1) The direct contact between the masters, journeymen, and apprentices, literally within the home, and the participation of all in Guild affairs, and especially in the maintenance of its integrity and prosperity.

2) Pride in the 'product of their hands, in the honesty of the material and workmanship, and in the artistic finish. If the particular master was inclined to lag behind, the Guild officers saw to it that he conformed to the required standard. 
3) The pride of locality and nationality. The Guild demanded and insisted upon a high standard from its members, and this civic pride evidenced itself in those public works contributed by the Guilds, to which I have referred.

Let us take each in turn, to see what lessons it teaches for modern purposes.

First, as to the lost contact between employer and employed. The old domestic production with its infinitely slower processes, became entirely unable to meet the world's increasing demands, and some other agency and method had to be devised. The big private partnerships, the great trading houses, carried the burden for a while, and in turn were supplemented and to some extent displaced by joint-stock capital. Under this last phase there has been very little possibility of direct contact between the legal owner (the shareholder) and the employed. The shareholders always delegate, and necessarily must delegate, the daily control to directors and managers. The latter are not unusually regarded as themselves the plutocratic owners, whereas in essence they are the salaried servants of the owners, just as are the wage-workers. As they do not own the venture, they do not readily recognize any special obligation towards their co-workers on the lower grades. Furthermore, the active managers of large limited liability companies are usually men who frequently suffer from strain under their unremitting responsibilities, and the fact that their work is at the desk, and not in the factory, does not lessen its severity - quite the contrary. They have little time for setting up direct contact with the operatives, and the channel of communication is often through the foremen, not always the happiest type of intermediary.

Can all this be improved in any way? It is not my purpose to suggest concrete remedies, nor have I the detailed experience to justify any effort of that kind. The trouble is patent enough. Under existing conditions no one is specially to blame, but some remedy is urgently needed. There are some private employers in Australia today who have set up fairly sound relations with their employees, to my knowledge with good results. But this movement is at yet sporadic, and comparatively small in volume. On the other hand, there are other employers who are slow to recognize any claims on behalf of the wage-earners, and their attitude damages the employers' case. With the limited companies it seems to be necessary to awaken the consciousness of the shareholders, so that they may become alive to the obligations of ownership, a phase as yet not realized by the vast majority of them. 
Employers will be able to mention many difficulties, and I do not suggest for a moment that these do not exist. For instance, there are the employers who necessarily depend in part or entirely upon intermittent or casual labour - on the wharves or elsewhere - where the hands so constantly change in personnel that anything like lasting contacts are impracticable. There is also the circumstance that in this country we have set up certain artificial difficulties - under our compulsory arbitration laws. It is not my purpose to-night to enlarge upon our deplorable reputation for multiplied strikes, a reputation which has lost us valuable markets abroad, nor upon the one-sided character of the awards which are necessarily obeyed by employers having easily attachable assets, but are openly flouted by the larger unions when a legal decision is not to their liking. Nor have I one derogatory word to say about the judges who administer these laws, most of them very honestly and capably, though it remains that they are not experts in the trades upon which they adjudicate, and they are at times called upon for widely important decisions which are legislative rather than judicial in character. Nor is it their fault - while the day only contains twenty four hours - that the courts at times become congested, and delayed decisions lead to anxieties of uncertainty for the employer and irritated impatience on the part of the employees. ${ }^{2}$

The serious aspects of our industrial laws, with which I am mainly concerned, are fundamental. The very atmosphere of the court, with its opposed sides and its coldly calculated hostilities, must necessarily work against friendly relations between employer and employee. Evidence tends to be extreme on both sides, because each litigant knows that his opponent will certainly not understand his case. There is here no particle of the round-table spirit, where the parties are all experts, and so are able to discuss the particular issue without exaggeration, and without any design to unduly sway an inexpert tribunal. Our industrial laws force a wide gap between employers and employees at a time when the urgent need on the day is to bring them together.

2 In connection with the above address it is perhaps desirable to mention that the lecturer was concerned with broad effects rather than the experiences of any one State. His address, in $80 \mathrm{far}$ as it related to Australian industrial legislation, was based mainly upon the experiencing of the larger eastern States. and he purposely refrained from making a number of qualifying details in respect of other areas. The industrial experience of South Australia hag been more fortunate in recent years than that of the eastern States, in that there have been fewer strikes, partly, no doubt, due to the fact that industries are smaller and contacts are easier. 
Upon employers the inevitable effect of these laws is unfortunate. A sense of employer responsibility towards employees is, to say the least, difficult to realize when a court fixes most of the detailed conditions of work. The employer, being human, is apt to think, and declare, that the courts have taken the control very largely out of his hands: he has to conform to the rules and regulations they prescribe, therefore he has ceased to have any real responsibility. Furthermore, he is harassed and hampered very often, not merely by one award, but by a multiplicity of awards, not only by the awards of his own State, but often by conflicting and over lapping Federal awards in addition. Valuable time he should be able to devote to expanding his industry is often frittered away in defending his interests against vexatious or frivolous charges in the Industrial Courts. In my own experience, very small compared to the sum total of Australian affairs, I have known a dozen cases of responsible visitors who came to Australia to assess the chances of success if they launched out upon some enterprise here, but who went away completely discouraged by the labour conditions and industrial legislation. The economic loss through these unstarted ventures falls most heavily upon the manual worker.

Upon the wage-earner the effects have been possibly still more unfortunate. Setting aside the communist extremist, whose aim seems to be to substitute an inefficient tyranny of the proletariat for what he terms the tyranny of capitalism, it is unfortunate that unionists have learned to use the industrial laws to the grave detriment of the community. Disputes and disturbances are often based, not upon real grievances, but have the aim of securing monopolies or political ends. Disputes which should be settled within the State originally concerned are artificially extended, if the State award does not suit, into the Federal domain.

In this weird medley of court-made regulations and overlapping jurisdictions the employer is bewildered, and often hesitates to launch out, while the union delegate finds a thousand opportunities for fomenting disputes, and thus justifying both his office and his salary.

To-night I am not arguing that the whole system of industrial laws should be swept away, though there are a number of people who would readily go to that length. For the moment I am merely concerned to point to the obvious circumstance that these laws in several ways have the deeply regrettable effect 
of separating the employer and the employee at a time when it is peculiarly important that they should be brought together into some better recognition of a mutual aim and interest.

To-day few people would argue against a statutory minimum wage, since past happenings showed the need for something of that kind; nor does the reputable employer object to pay a fair wage, as long as a fair day's work is rendered in return. "Go slow" practices are fortunately by no means universal in Australia, but neither are they totally absent. Where they exist, the inevitable deterioration of character must be deplorable. No man can deliberately slur his work, or wilfully idle, without serious loss of self-respect.

Now let us turn to the old-time pride in the product. Unfortunately, conditions to-day do not lend themselves in many cases to that admirable phase as readily as they did in the days when the workman usually himself completed some particular article. Under large or mass production, machinery often takes the place of hand work, and the worker does little more than tend the machinery. His personal contribution may be so small as to yield little possible satisfaction for the creative spirit. I am told that in the construction of a pin some eleven processes are involved, and a different operator attends to each. No one of them can very well feel the elation of the artist who personally achieves. If, then, in many directions we cannot expect to arouse the spirit of the skilled craftsman, can we substitute something else? The mere monotony of the work need not in itself become a serious feature, for an oft-repeated process, done mechanically and unconsciously, at any rate does not necessitate any great nervous strain. On the other hand, if that kind of monotony is not to lead to undesirable results in the form of discontent, there must be some reasonable interest for the wage-earner in the venture.

To-night I do not suggest particular remedies, such as profit-sharing, copartnership, and the like. I am concerned rather to point to the inwardness of our troubles, so that we may take very serious thought towards suitable remedies. In such matters it is difficult for individuals to achieve much; it is probably preferable that a remedial movement should be urged through craft associations. Australia is not entirely lacking in effort of the kind, for a few employers have desirable schemes in operation. The movement, however, needs extension on the craft scale, and it needs to be done quickly, before conditions become still worse. 
Upon the third aspect I will not dwell. I hope both our employers and our employees feel a full sense of loyalty to locality and nationality. If any do not, the sooner they betake themselves to some other country the better. To-day there are no associations of the scale and power to undertake the civic works which the old Guilds often carried out, nor are the conditions of to-day likely to lead to anything of that kind. But if employers and employed frankly inter-worked, to the best of their ability, upon some footing fair to both sides, then there is no telling what some new craft association, representing both sides, might achieve.

Clearly it is not an easy matter to see our way out of the fog with light drawn from our own experience. Can we then borrow helpful light from other countries? Unfortunately, I have no complete up-to-date information about European nations, and in any case, I prefer to keep within the Anglo-Saxon domain.

The United Kingdom has kept clear of compulsory arbitration, and has relied rather upon the round-table method of the Whitley Councils. Her economic position at the moment is grave; she is faced with vastly greater difficulties than is Australia, and direct comparisons of any value are not easily made. Her free trade footing leaves her manufacturers to face extremely keen competition from adjacent Europe, and particularly from Germany. While United Kingdom wages are considerably lower than Australian, they are materially higher than European, and in Europe the working hours are longer, taxation is lower, and there are far fewer industrial disturbances. Therefore the Mother Country, with 1,319,000 unemployed as at December 31,1924, and with the prospect of still more intense Continental competition, is in an extremely awkward situation. Her operatives are asking higher and higher wages, while the prospect seems to indicate unavoidably lower wages. Subject to these radical distinctions, here are some recent details of United Kingdom standard wages:

Engineering shops, basis 55s. 6d. per week.

Shipbuilding (mostly skilled artisans), 45s. 6d. basis. This trade is specially subject to European competition.

Coal-mining: lowest average wages of all, and adjusted by an agreement initiated in 1921, under which wages were made a first charge upon the industry. After standard profits are paid, the excess 
(if any) is shared in certain agreed proportions between owners and miners. German competition is extremely severe, and some of the less advantageously situated Welsh mines have recently closed down.

Railway employees are the best paid of all, and are always claiming more, with the result that other workmen are becoming hostile to the railway hands, because increased rail charges further handicap all other industries.

Contrast all this with German wages of something like 40s. for a fifty-four hour week, backed by fine business organization.

New South Wales minimum or basic wage 82s. for a forty-eight hour week

The United States of America have no compulsory arbitration, and when I met the late Mr. Sam Gompers in New York in 1919, at a time when he was the unquestioned head of American unionized labour, he would have nothing to do with it.

American labour conditions are a little difficult to understand; for instance, in comparison with Australian, until certain broad features are realized. Their labour world is in three tiers: the American born in the industrial box seat, and he is in fairly considerable degree unionized; then the white foreigner, doing the rough work; and finally the black, engaged upon personal service in its varied forms in the home, the hotel, the railways, and the like. These do not readily combine for a big industrial upheaval, the "unions" as a rule preferring to fight out their battles by them selves. Out of some twenty-six millions of paid workers, only about three millions are in the Federation of Labour. Mass production, and a liberal use of the highest class machinery, have led to the greatest per capita production in the world, and the sale of their products is immensely assisted by free trade between forty-eight States, plus the tremendous home market implied by one hundred and twelve millions of people with high individual average purchasing power. This enables high wages to be paid - higher, for instance, than Australian wages, even after allowing for their greater cost of living - higher effective wages, that is. Their unions do not insist upon uniform wages, as do ours, and with them the skilled, rapid worker reaps the reward (through the bonus system) of his greater 
efficiency. They are easily able to pay the high wages, because the increased output bears the cost.

Unfortunately, my brief stay in the States did not permit of my visiting many industrial establishments, but from the few I saw, and all I heard, I came away with a strong impression that American employers, in recent years, were making considerable advances towards setting up better relations with employees, through welfare schemes of various kinds, clinics, libraries, and places for recreation for the wage-earners. I have followed American affairs fairly closely since my return to Australia in 1919, and recent advices confirm my impressions. Employers now seem to be moving in the direction of schemes to interest the wage-earners in the enterprises in which they work, not by any means in opposition to Unions as such, but with the general concurrence of unions. This movement takes many forms, according to circumstances and personal predilections, and here we can only consider the broad outlines. The main idea is to give the employee a voice in the management, so that grievances can be brought up through recognized channels, and can be settled in friendly discussion. There are to-day in the States over eight hundred such employee representation plans in operation, covering $1,177,000$ employees. That is only a beginning, but one-twenty second of all paid workers is not a negligible beginning, especially as the movement seems likely to spread fairly rapidly wherever the conditions are suitable.

These plans are designed to bring about a number of very desirable results, as for instance:

1) To provide a necessary stimulus to otherwise monotonous factory work through the agency of a personal stake in the concern.

2) To remove a natural enough reluctance to increase efficiency and profits when the worker does not share in the profits, and does not appear to have any prospect of ever doing so.

3) To banish suspicions, which readily grow from ignorance of the difficulties which the enterprise has to face, by full information to the employee representatives. 
4) To eradicate the feeling that the employee has no permanent place in the business, that he may be dismissed at any moment on the caprice of owner or foreman, or may fall out because of sickness.

5) To create some sense of personal responsibility towards the venture.

To this end many of the plans, after setting aside a reasonable remuneration for the capital involved, give a portion of the net profits to the wage-earner. In some cases this is done after setting aside funds to enable payment of some dividend for the shareholder during lean periods, and also to provide part wages to avoid unemploy or dismissal of operatives.

Without some such direct contacts the employer rarely under stands the employee point of view, and so disadvantages suffered by the latter lead to discontent and overt trouble. Full information and friendly discussion have been found to remove trouble like breath disappearing from a mirror. When the employees really understand the position they readily meet even reduced wages (in the unavoidably low-profit industries) to surmount momentary stresses.

Under most of the plans the employees are given the oversight of such interests as housing, recreation, and education, and they have a voice in shop methods. It is now a frequent experience that the men volunteer suggestions making for increased efficiency, as, for instance, through the agency of timeclocks, foremen's conferences, and elimination of waste. These plans are said to be revolutionizing the attitude of the employee towards production, while the resultant higher wages are paid from the increased output, with out overstraining the enterprise. Another movement in the same general direction is the buying by workmen of shares in public utilities and corporate enterprise. According to a recent computation there have come into the investment field over 500,000 new employee investors within the last seven years, and "the cry is still they come." Many of those men now have a personal interest in the enterprise from which they draw wages. It is said that prohibition has aided this development, by the diversion of some of the money previously spent on liquor into savings of this kind. Whatever the reasons may be, there are the facts. One of the most significant features appears to be that, in a country where the artificial hostilities of the compulsory courts do not exist, a successful movement is spreading, having 
for its aim the restoration of those personal contacts, and the mutual interest in the product, which so finely characterized the Guilds.

If Australian employers are ready to make the requisite effort wherever the conditions are suitable, and employees are ready to do their part, both sides recognizing that the country's salvation can only be achieved in some such way, then several excellent results would accrue. Grievances would be settled within the craft, and there would be no need to appeal to the courts. The employee would have a voice in shop methods and an interest in the venture, and the increased output would provide funds against sickness and unemployment. Capital and labour frankly inter-working, as they should, the agitator and the extremist, like Othello, would find their occupation gone. The elimination (or a material reduction in the number) of strikes would add an incalculably large sum to the wealth of the community as a whole, and there would be far more funds to devote to the expansion of industry. In that happier condition Australia's trading reputation abroad would gradually be restored, and some of our lost markets, particularly for coal, might be regained. It is, however, an immutable certainty that none of these desirable results will accrue while misunderstandings, aloofness, and artificially hostile conditions keep employer and employee apart. 



\section{2}

\section{The financial and economic position of Australia}

\section{Stanley M. Bruce ${ }^{I}$}

I have chosen as the title for my Lecture the financial and economic position of Australia. I recognize, of course, that it would be impossible within the limits of any one lecture to deal adequately with this subject. I will not attempt to do so, nor do I propose to wander into the realms of controversy. There are probably no subjects which occupy our attention to-day with regard to which more divergent theories are held than in connection with our public finances, and all our economic questions. All I will attempt to do is to set out in broad outline some aspects of these problems, and try to do so in simple language which will be understandable by anyone who will take the trouble to consider what I have said.

It appears to me that the difficulties which the average man experiences in understanding any question are generally not due to the complexity of the question itself, but to the confusion which is created by the differences of opinion of those who are supposed to be authorities upon it. No better example of this fact could be taken than the confusion which exists in the minds of the public with regard to finance, and the difficulties they experience in coming to any conclusion as to our present economic position, and what action should be taken to cure some of the obvious defects that at present exist. I suggest, however, that there are some broad basic facts with regard to both questions that will be readily understandable, and of which it is essential people should have a grasp, as it is to public opinion we must look to guide wisely in the future both the financial policy of this great country and the economic system upon which our future prosperity will depend.

1 Twelfth Joseph Fisher Lecture, 1 July 1927. 
I will deal in the first place with the question of public finance. This conveniently divides itself into expenditure from loan moneys and expenditure from revenue.

The position with regard to loan moneys is that, as a result of the policy which has been pursued in the past, Australia has borrowed large sums, and today has a very great national debt. There is a marked difference of opinion as to what Australia's future course with regard to her national debt, and her further borrowing, should be. One school of thought advocates that Australia should immediately cease borrowing, and devote herself to the repayment of her national debt. Advocates of this view accept the recognized practice of Great Britain in regard to her national debt. I will endeavour to show in a few minutes, however, that the position of Australia is vastly different from that of Great Britain, and that it would not be wise for us to accept the principles of finance which Britain has adopted in connection with her national debt.

The other school of thought contends that Australia should continue a policy of almost unrestricted borrowing, in the belief that the expenditure of further loan money will create prosperity for Australia and increase avenues of employment.

These conflicting views are, of course, the views of extremists, and, as is almost universally the case, such views are not the right ones to be accepted by a sane people.

I will endeavour to set before you exactly what is Australia's present position with regard to her national debt, and what I believe is the proper course for her to follow with regard to future borrowing.

She has a total public debt, both State and Federal, of $£ 1,013,000,000$. This debt represents per head of population a liability of $£ 16714 \mathrm{~s}$. 8d. The total amount of the national debt in 1901 (year of Federation) amounted to $£ 203,500,000$, which represented a burden per head of $£ 5313$ s. 9d. In 1913 the debt had increased to $£ 313,000,000$, representing a liability of $£ 6419$ s. $10 \mathrm{~d}$. per head of population. 
From these figures it will be seen that Australia's national debt, and the liability upon each of her citizens, has progressively grown ever since Federation, until it has reached the substantial amount at which it stands to-day. These figures must give grounds for thought, and it is not surprising that in face of them there is a considerable volume of public opinion which favours the immediate reduction of the amount of our national debt. It is necessary that we should examine this point of view, and determine whether it is right. To do so it is essential to consider the character of the debt which we at present owe, the purposes for which it was incurred, and also at the same time consider the question of future borrowing, and for what specific objects such borrowing would be justified.

The first factor which has to be taken into account in connection with Australia's national debt is that some $£ 305,000,000$ of it was incurred for war purposes. This debt none of us would desire to challenge. We recognize that it was incurred in order to enable Australia to play the great and wonderful part that was hers in support of the Mother Country and the Allied cause. This debt of $£ 305,000,000$ is the only dead-weight debt for which Australia is liable; the remaining portion of her indebtedness was incurred for the purpose of development, and is represented by valuable assets.

The national debt of Great Britain to-day stands at approximately

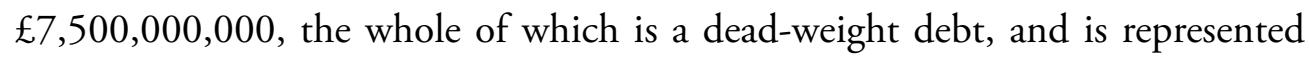
by no assets, except receipts in respect of Allied Debts and Reparations. This dead-weight debt of Great Britain represents a liability per head of population of something in the nature of $£ 170$. The liability of the Australian citizen in respect to the dead-weight debt of Australia is somewhere in the region of $£ 50$ a head. Britain creates a great national debt only during periods of war, and as soon as the period of war is past devotes herself to the redemption of that debt. Australia, with regard to her dead weight war debt pursued exactly the same course; but the only part of Australia's indebtedness which is of the same character as that of Britain, and with regard to which the same course must be pursued, is the $£ 305,000,000$ representing our war debt. With regard to that war debt of $£ 305,000,000$, it is gratifying to remember that $£ 211,000,000$ of it was provided by our own people, and is owed to them. The balance of $£ 94,000,000$ was borrowed from the British Government, an arrangement having been made with the Dominions that none of them would go on to the British market to borrow 
money during the war period, but that Britain would borrow on behalf of all, and make advances to the individual Dominions. In the terms of this policy Great Britain advanced to Australia for the financing of Australia's war effort an amount of some $£ 94,000,000$. Australia was the first of all the countries on the Allied side to recognize her obligation to provide for the repayment of her war indebtedness. We entered into an agreement with Britain for the repayment of the amount of $£ 94,000,000$ before any of the others had come to an arrangement for the repayment of their debts, including Great Britain herself, who only subsequently made the agreement with the United States of America for the redemption of the British debt to that country.

The basis of the arrangement which has been entered into between Australia and Great Britain is that a sinking fund of over 1 per cent is provided, which will redeem the debt in a period of some thirty-seven years. The method which is pursued under this scheme is that Australia pays a fixed amount of 6 per cent upon the total indebtedness, interest being based on an amount just short of 5 per cent., and the balance of the 6 per cent being used for the purposes of redemption. This arrangement was entered into in 1921, and Australia would not, of course, ever think of repudiating or attempting to vary an agreement entered into, save with the consent of the Government with whom the agreement had been made. Since Great Britain came to her arrangement with America for the funding of her debt, and for the payment of interest at a rate of from 3 per cent to 3.5 per cent, I have thought that it would be only just and equitable that the arrangement with Australia should be varied, so that we would pay only the average rate of interest paid by Great Britain upon her war indebtedness. This point of view I have put to three Chancellors of the Exchequer, and have argued strenuously in favour of it. Unfortunately, up to date I have not been able to induce any of them to share the views which I hold. I am confident, however, that in the future some arrangement will be come to, qualifying the agreement entered into in 1921 .

For the redemption of the balance of the war debt of $£ 211,000,000$, a sinking fund of 10 s. per cent is provided, which will redeem the debt within another forty-six years. In addition, out of revenue an amount has during the past five years been found of $£ 7,400,000$, which will further accelerate the time when the total debt will be repaid. 
In addition to providing the sinking fund for the redemption of the loans incurred during the war, an amount of $£ 267,000,000$ was found between the years of 1914 and 1926 for the purpose of financing Australia's war effort. When we remember that this generation fought the war, and bore the great sacrifices and sufferings which it involved, I think it is justifiable to claim that we are doing sufficient towards the redemption of the indebtedness which was incurred, and that we can leave to future generations some part of the burden.

This war debt to which I have referred is the only dead-weight debt which Australia has. The balance of some $\mathfrak{E 7 0 8 , 0 0 0 , 0 0 0}$ is of an entirely different character, and is represented by tangible assets. It may perhaps be well, before dealing with the other portion of Australia's national debt, to make it quite clear what in fact constitutes a dead-weight debt, and what the difference is between it and the balance of Australia's indebtedness. A dead-weight debt is one which is incurred for such a purpose as war, and which is utilized for the provision of munitions, clothing, and food, etc., for the troops engaged. All these things are destroyed, and no assets remain to represent the expenditure which has been incurred. The other species of debt is the debt of the whole of the States and that of the Commonwealth other than the debt incurred for war purposes. Such debt is represented by tangible assets, which have been created by the expenditure of the moneys borrowed. Out standing examples of debt of this character would be debt which was incurred for the purpose of building the great railway system of Australia, or for the creation of irrigation schemes or water conservation.

In 1921 the Commonwealth Statistician estimated that the assets which had been created by the expenditure of borrowed money had a value of $£ 673,000,000$. To-day it is estimated that these assets would represent a value 20 per cent greater than that figure; so that in the result we have assets which are valued at over $£ 800,000,000$ to represent the outstanding indebtedness of the Commonwealth and the States, which to-day stands at $£ 708,000,000$. It is further necessary to remember that of Australia's national debt of $£ 1,013,000,000$ only $£ 500,000,000$ is owed to creditors outside Australia, the balance of $£ 513,000,000$ having been provided by and being owed to our own people.

The question which may legitimately be asked with regard to this amount of $£ 708,000,000$ which Australia to-day owes for purposes other than war is, 
why should the Government of Australia have incurred this great liability, when a country such as Britain has no national debt other than that which is created for the purposes of war?

The answer can be divided into two parts. The first is that in this country certain functions are recognized as being legitimately those for Governments to undertake, which in Britain are not so considered; and the second is that in a new country such as Australia, with its great problems of development, governments have inevitably to incur large expenditure which governments do not undertake in older and more settled countries, such as Great Britain.

Under the first heading of functions which are regarded in this country as being properly undertaken by the Government is the provision of railway facilities. There are in Australia many people who are totally opposed to the Government participating in any activities which can be described as of a business character. Even those people, however admit that it is a proper function of government to conduct and construct railways. I do not propose to deal at any length with the arguments for and against the Government control of railways, because I think the affirmative view is generally accepted in Australia, and very few people hold a contrary opinion. We have in Australia to-day some 26,000 miles of Government-owned railways, the money for the construction of which is included in the national debt with which I have been dealing. The actual amount of the capital expenditure of the whole of the railway system of Australia out of loan moneys amounts to $£ 293,408,000$, which is 41.3 per cent. of the total State and Common wealth debt of a non-deadweight character of $£ 708,000,000$. This mileage of railways is greater than that of the whole of the railway systems of Great Britain. In Britain and America, however, the whole of the railways are owned and controlled by private enterprise. The total capital of the railway companies of Great Britain amounted to $£ 1,161,400,000$ in 1925 , and had the same system of government ownership existed in Britain as exists in Australia, Great Britain would to-day have that amount added to her national debt. It is interesting to observe the growing feeling in most countries of the world that great public utilities, such as the rail ways, should be owned and controlled by the State, and should not be left to depend on private enterprise.

In Canada to-day the position exists that you have the private owned system of the Canadian Pacific Railway, with 15,000 miles of railway throughout 
the continent, and the Government-owned Canadian National Railways, with 25,000 miles. Time will show whether these two systems can work side by side and prosper; and I feel sure that public opinion in other parts of the world will be very greatly influenced by the results that are achieved in Canada.

The Post Office, which controls the whole of the postal, telegraphic, and telephonic facilities of the Commonwealth is another interesting example of Government controlled enterprise. In Great Britain, as in Australia, the post office is controlled by the Government; but in the United States of America, and in Canada, the whole of the telephonic and telegraphic communications are in the hands of private enterprise.

As an illustration of how necessary it is that money should be borrowed for the purposes of great enterprises such as railways and telegraphic and telephonic communications, I might cite my experience with regard to the post office since I have been a member of the Government. I went to the Treasury in 1921, some twenty years after Federation, and the whole of the postal, telegraphic, and telephonic communications had been handed over to the Common wealth. During that period of twenty years only $£ 2,000,000$ of borrowed money had been expended in connection with these facilities, the remainder of the capital work being financed out of surplus revenue. Almost as soon as I went to the Treasury I sent a questionnaire to most of the civilized countries of the world, asking what their practice was with regard to capital expenditure on permanent improvements. The reply I received from almost every country was that capital expenditure was found out of loan moneys, with a sinking fund to redeem the debt within the lifetime of the asset. This principle was introduced in 1922 into the post office finances of the Commonwealth. In the result, during the period since 1922 an amount of over $£ 20,000,000$ has been spent out of loan moneys for capital expenditure in the Postal Department, and even with this great expenditure the necessary facilities have not yet been provided for the people. The whole of the interest upon all the borrowed money, together with a sinking fund to redeem the loans within the lifetime of the assets created, is provided out of the revenue of the post office; and while the post office is not used in any way as a taxing machine to swell the consolidated revenue of the Commonwealth, it is run upon a business basis, and out of its own revenue provides for all the charges which are incurred in the rendering of the services which it gives to the people. 
The post office has a complete monopoly of communication in Australia, and in such circumstances there is an obligation upon the Government concerned to give to the people a proper and adequate service. The borrowing of money for this purpose, provided that the revenue is sufficient to pay the interest and the sinking fund to redeem the loan, is necessary and laudable. Similar action by any private enterprise supplying services to the people would be regarded as conferring a benefit upon the whole of Australia. It is inevitable that in the future, in order to provide proper telephonic and telegraphic communication in Australia, large sums of money should be borrowed.

What I have said with regard to postal facilities applies even more so to railway development and the provision of the necessary railway facilities for the people. There are also great developmental works which have to be carried out in a new country, which it is impossible to expect private enterprise to undertake. They are truly the responsibility of the Government.

The outstanding example of such a work is the irrigation scheme which is being carried out by the co-operative efforts of Governments of the Commonwealth and New South Wales, Victoria, and South Australia. These works will bring into utilization some 2,000,000 acres, which will be available for closer settlement, and also embrace the locking of the Murray for navigation purposes. No direct or immediate return can be received from expenditure of this character, but a more than adequate return will be received indirectly from the new wealth created by the settlement which will be promoted and the improved transport facilities which will be provided.

There are many other great developmental works which will have to be carried out by Governments in Australia in the years to come, if we are to develop properly this great continent and utilize its resources to the fullest extent.

From what I have said it is, I think, clear that it is impossible to accept the view of those who say that we should proceed to pay off our national debt, and should not incur any further obligation by additional borrowing. It is our duty to provide for the redemption of all our existing debt, and this is done in ample measure under the financial proposals which the Commonwealth recently submitted to the States, and of which the States have expressed their approval. Those proposals also 
contemplate the co-ordination of Australia's borrowing in the future in such a way that we will mobilize the whole of our credit, be able to convert our existing loans as they fall due on the most favourable terms, and also issue any future loans for legitimate developmental purposes on the best possible basis.

While it is essential that Australia should continue to borrow in the future for developmental purposes, we must realize that nothing would be more fatal to the future progress and prosperity of Australia than reckless and unwise borrowing.

Australia's greatest problem is that of population, and our future will be seriously endangered unless we bring about a rapid increase in the number of our people. We are all determined that we will do nothing to destroy the standard of living of our people; it is our greatest pride, and we believe that what we have done is an example to the whole world. Only by the wise and prudent expenditure of borrowed moneys can we bring about that increase in our power of absorption which will enable a rapid expansion of our population to take place without any detriment to the existing standard of living. Provided that loan expenditure is limited to works of a reproductive character, or to those which will promote development, and so enable Australia to absorb new people, there is no objection to our pursuing a borrowing policy in the future, notwithstanding the magnitude of our national debt at present. We must, however, be quite clear on this point, namely, that our borrowings are for such purposes, and that we get a full return for the moneys which we expend. How to ensure the wise expenditure of loan moneys is one of the problems for which we have to find a solution.

The recent arrangements which were considered between the Commonwealth and the States in connection with the financial readjustment and the co-ordination of our borrowing does nothing to ensure that moneys will be borrowed only for purposes of wise expenditure. The Loan Council will be able to arrange that Australia will borrow only at rates and upon conditions which are compatible with the position of a first-class borrower. But the Loan Council will have no power to interfere with the purposes for which either the Commonwealth or the States utilize the money so borrowed.

Both the Commonwealth Parliament and the Parliaments of all the States enjoy full sovereign rights, and none of those Parliaments would permit any 
dictation or interference by the Loan Council. Consequently we have to look for some other way in which our objective of careful, prudent expenditure of loan moneys may be achieved. Personally I believe this can only be done by the creation of a public opinion determined that such a position will be brought about.

The Development Commission recently created by the Commonwealth points the way to this very desirable goal.

Under the agreement which has been entered into with the British Government for the provision of cheap money over a period of ten years to the States for developmental purposes, it is provided that the States shall submit their schemes to the Commonwealth for approval. Last year an Act was passed by the Commonwealth Parliament, under which all such schemes are to be submitted to and approved by the Development Commission before the States can receive the advantage of the interest rebate provided under the agreement. Prior to the creation of this Commission it would have been for the Federal Government to determine whether the schemes should be approved or not. It is infinitely better that you should have an outside, impartial body upon whose judgment schemes shall be approved. I suggest that an arrangement similar to this might be made in all the States with regard to all expenditure of loan moneys. If this were done, all schemes for which the Government contemplated the borrowing of money would be submitted to an impartial tribunal, whose report Parliament would have the benefit of when coming to a decision as to the wisdom or otherwise of the expenditure. It is very improbable that any scheme which had been adversely reported upon by an impartial body, on the grounds that it was not a reproductive work, or that it would not promote development or increase the absorption power of the States, would receive the approval of Parliament or the sanction of the general public.

Some who accept the point of view which I am putting forward, that it is necessary and desirable to expend borrowed moneys in future, provided that the expenditure is done on wise and prudent lines, strongly object, however, to any money being borrowed outside Australia. Were it possible for us to be content with an increase in our population based upon past figures - figures which show that our percentage increase of population is the greatest in the world with the exception of New Zealand - the views of those who oppose foreign borrowing 
might be accepted. It is, however, necessary for us to open up and populate this great continent at a very much more rapid rate. If our population increased only at the rate of the past years, our own annual savings might be sufficient to provide for our requirements. If, however, we are to have that necessary acceleration of our numbers, we must inevitably borrow moneys outside our own borders. To provide for all our requirements for development and expansion would mean too great a depletion of the available supplies in the local money market, to the detriment of all private enterprise? and almost of all individual borrowing.

Our experiences during the war, when, in order to finance Australia's efforts, great war loans were issued, showed that in order to raise the amount of money then required it was necessary to deprive extra-governmental enterprise and private borrowers of their requirements.

I am confident, however, that progressively, out of our own national savings, we will be able to provide for our own national loan requirements. Two things have prevented us making as great progress in this direction as we otherwise would have done, although we must remember that our progress had been by no means unsatisfactory. These two factors were the great borrowing during the war period, amounting to $£ 305,000,000$, and the heavy taxation of $£ 267,000,000$ provided out of revenue towards our war efforts. These two factors undoubtedly have put forward the day when Australia can anticipate meeting her own loan requirements out of her own resources.

Notwithstanding the difficulties which have arisen as a result of our war effort, the proportion of Australia's indebtedness which is held locally has progressively improved. In 190114 per cent of our public debt was held by the citizens of Australia; by 1911 this proportion had increased to 29 per cent; and in 1925 it had reached 51 per cent. When the tremendous borrowings of the war period are remembered, the fact that over half our debt is now owed to our own people is even more significant than it would have been under ordinary circumstances. I am confident that progressively we shall be able to find more of our own loan requirements in Australia, but I am certain it would be a grave mistake to try to proceed too rapidly in this direction, as such action would have an effect upon private finance and the expansion of our industries that would be detrimental to our further progress. 
A further fact with regard to the position of our external debt, which shows that the position is not as serious as some of the pessimists would have us believe, is that, even with the great increase in our borrowings, it only requires 16.5 per cent of our exports to meet our interest obligations, whereas in 191516 it required 14.3 per cent. In this connection it is interesting to remember that exactly what is being said of Australias position in connection with her loan indebtedness to-day has been said in the past. In 1893 the public finances of the State of New South Wales were very seriously attacked in Great Britain, and it was freely suggested that that State had been guilty of such extravagance in connection with her loan policy that no further moneys should be lent to her by the City of London. I have been reading an article in the "Investor's Review" of that year, on the finance of New South Wales. The writer declares that the colony's finances were radically unsound, and that its inhabitants were concealing their true position by flattering themselves with statistics about the increase of their public wealth. He throws doubt upon the wisdom of the whole policy of government-controlled development, and launches a particularly virulent attack against the railways. "Sheep tracks and bridle paths," he writes, "converging upon a few well-placed highways, were all that such a territory needed for a generation or more to come." He goes on to make extravagant and very positive prophecies of impending bankruptcy. "New South Wales has sown the wind," he says; "the whirlwind is at hand, and with the whirl wind will come the darkness of a great misery." He concludes with the observation that "twenty years ago only 12 per cent of the value of Australian exports was required to meet interest abroad, and now more than 40 per cent is so required." My best comment on that is to point out that to-day just 16.5 per cent of our export trade is required to meet the interest on our external debt, not withstanding that the amount of the debt upon which interest has to be paid has increased from $£ 203,500,000$ in 1901 , when Federation came into existence, to $£ 1,013,000,000$ to-day, which figure we must ever remember was brought about to a large extent by the abnormal borrowings caused by the war.

To summarize the position with regard to our national debt, as I see it. We have incurred a great debt, one-third of which is of a dead-weight character, and two-thirds of which has been created for developmental purposes, and is represented by assets. Provision must be made for the redemption of the whole of this debt, but particularly for the dead-weight debt. Such provision is made 
under the financial proposals which the Commonwealth recently submitted to the States, and which they have, I am confident, accepted, and will be put into operation. Further borrowings must be undertaken by Australia, but it is essential that such borrowings should be for reproductive works, or for developmental purposes which will increase our power of absorbing new people.

I now desire to turn to expenditure out of revenue. With this question I do not propose to deal at very great length, for the reason that, as I indicated earlier, I do not intend to enter upon controversial questions, and there is probably no more controversial matter than the expenditure of the Government of the day, and the amount of the revenue raised. I do not think any Government has ever held office, or will ever hold office, that does not protest its recognition of the necessity of keeping expenditure on the lowest possible basis, and of the obligation only to take out of the tax payers' pockets the amount that is requisite to meet the requirements of prudent and sane Government.

We have, however, to recognize the fact that, even operating within these principles, large sums of money have to be raised to meet the current obligations of government under a modern democratic system. While no doubt we all hold definite views as to what those requirements of government are, I have never yet heard any suggestion which would so reduce the expenditure, either within the sphere of the Commonwealth or of the States, as to have a material effect in relation to any of the great problems that face us. By a material effect I mean such a reduction of expenditure as would relieve taxation to the point of effectively stimulating industry, or decreasing the costs of production and consequently the cost of living.

I first desire to deal with the position of the Commonwealth. In that sphere there are certain obligations which nobody, I believe, would suggest can be reduced. Let me remind you what some of those obligations are. The first and largest of our obligations is to meet the expenditure consequent upon our war efforts. This represents an expenditure of little short of $£ 30,000,000$ a year, and is made up of interest and sinking fund to redeem our war indebted ness, pensions to our incapacitated soldiers, pensions to widows, and provision for the children of the incapacitated and those who were killed in the war. 
The next obligation is that for defence, which amounts at the present time to something like $£ 5,000,000$ a year, an expenditure which public opinion in Australia is inclined to consider should be increased unless a definite advance is made towards the insurance of the world's peace, which we all so much desire.

Another obligation is with regard to invalid and old age pensions and maternity allowances, which amount to over $£ 9,000,000$ a year, and which, without the reversal of a policy which is generally accepted, cannot be reduced, although we hope to place invalid and old age pensions upon a sounder and more enduring basis by the introduction of a scheme of national insurance, and to improve the manner in which assistance is rendered in maternity cases.

The next obligation is assistance to the States, which under the proposals which were recently submitted by the Commonwealth, will involve an expenditure of over $£ 8,500,000$ a year.

When we also remember the obligations to meet our interest and sinking fund upon the debt of the Commonwealth other than the war debt, and to provide the other services which the Common wealth has to render, it will be recognized that, while it may be possible to reduce to some extent the revenues that have to be raised by the Commonwealth, the amount of such reductions would not be a material factor in solving any of the economic problems which face us to-day.

This question of the Commonwealth expenditure I will deal with in detail from political platforms. To-night I am trying to take a broad survey of the position only, and am dealing with the Commonwealth's expenditure merely to draw the one broad conclusion that the solution of our economic problems cannot be looked for by reduction in the revenues raised by the Commonwealth.

With regard to the States' expenditure, I speak with consider ably more diffidence, because with their affairs I am not so intimately acquainted as with those of the Commonwealth. Certain facts I would, however, point out.

There are certain expenditures of the States which cannot be avoided, nor would anybody desire that they should be. The first is the provision of the necessary moneys to meet the interest and the sinking funds upon their public 
debts. This involves an amount of some $£ 30,000.000$. Upon education is being expended over $£ 10,000,000$; and provision for hospitals, charities, and similar objects requires another $£ 5,000,000$. All these obligations have to be met, and I do not think that the people of Australia would desire that such services should be curtailed.

The total expenditure of the Commonwealth and the States amounts to $£ 170,000,000$. This figure includes post office, railways, and other business undertakings which account for about $£ 70,000,000$. Even under the most rigid system of economy, in view of the obligations to which I have referred, it is obvious that only a fractional part of this expenditure could be eliminated.

For the purposes of the broad survey which I am taking to-night we have, therefore, to recognize that revenues to an amount of little short of what is being at present raised have to be provided for the expenditures of the Commonwealth and the States.

At the time of the creation of Federation it was contemplated that the revenues necessary for the Commonwealth would be found out of customs and excise, and the whole field of direct taxation would be left available to the States. Owing to the expenditure thrown upon the Commonwealth as a result of the war, it was necessary for the Commonwealth to invade the field of direct taxation. The States, under the Constitution, were precluded from providing for any of their requirements from taxes of customs or excise. Experience has shown that it is essential, in the interests of the States, that the Commonwealth should leave to them, as far as is possible, the field of direct taxation. The requirements of the Commonwealth, however, mainly owing to its war obligations, are large, and one point I would stress to you is that it is necessary for the Commonwealth to raise a substantial part of its revenues from taxes of customs and excise, quite apart from the policy of protection which has been adopted in Australia. There is, however, a considerable misapprehension in the minds of the people of Australia as to what is commonly known as the revenue derived by the Commonwealth from the customs. Taking the year 1925-26, this revenue amounted to $£ 39,100,000$. Of that revenue $£ 11,000,000$ was derived from excise duties, leaving a customs revenue of $£ 28,000,000$. Of this amount the Department of Trade and Customs estimates that $£ 9,000,000$ was raised in respect of revenue duties and 
$£ 19,000,000$ from duties which were of a protective character. This fact should be in the minds of the people, because there is a popular impression that the great revenues raised by the Commonwealth under the headings of customs and excise are entirely due to the protectionist policy that has been adopted, and were that policy reversed the obligations on the people would be materially lightened. This impression is an entirely erroneous one, and even if there were no protectionist policy in Australia it would be necessary to raise by means of revenue duties, through the customs, an amount substantially equivalent to that which is being raised to-day. How far the raising of revenue through customs and excise is essential to the finance of a country is shown very clearly in the case of Great Britain, which is the one outstanding example of a free trade country in the world to-day.

The total revenue raised by Great Britain in the year 1925 was $£ 800,000,000$, towards which duties of customs and excise contributed $£ 240,000,000$, or approximately 30 per cent. In the same year in Australia the total revenues raised by the Commonwealth and the States was $£ 165,000,000$, including about $£ 65,000,000$ post office, railways, etc., and of this duties of customs and excise contributed $£ 39,100,000$, or approximately 24 per cent. These facts, I think, somewhat seriously conflict with the general impression that exists in the minds of the majority of the people of Australia.

On this question of expenditure out of revenue the points which I desire to make may be summarized as follows.

Great revenues must be raised in Australia by the Common wealth and the States to meet the interest and sinking fund obligations upon borrowed money, and to carry out the social services which it is the accepted policy of an overwhelming majority of the people should be provided by the respective Governments; that while it is possible that the amount of revenue to be raised might be reduced by more prudent and efficient financial control, the amount of such reduction would not be a material factor in solving any of our economic problems; and finally, that whether there were a protectionist policy in Australia or not, revenues practically equivalent to those to-day being raised by duties of customs and excise would have to be provided from the same source. 
I now pass to the question of the economic position of Australia to-day. This is governed by the policies pursued in the past and maintained as part of what we call our social system.

Two great policies stand out. The first is the tariff, which is designed to build up our own industries and protect them against unfair competition from other countries. The second is the legal fixation of the living wage, and the adoption of a definite high standard of living for the whole of our people. It is well that we should remember that the protective policy applies both to our primary and secondary industries. In its operation, costs of production have increased and prices have risen. The position has, however, been met by an advance in wages, so that the purchasing power of the people is such as to maintain the desired standard of living. No serious problem arose as a result of these two linked policies so long as our exportable surpluses which had to be sold in the markets of the world in open competition with other countries were small, or were of a character such as wool, where competition was limited and a market always available. In recent years, however, an increasing population and a larger production have swelled the volume of our exportable surpluses, and we are now confronted with the important problem of how to meet the world's competition at world's prices. We must maintain our own standard of living and at the same time compete against all-comers in the open markets of the world. This problem, which is already acute, must become more intensified as the years go on. Our population must increase, our production will most certainly be augmented, and we will have to increasingly rely upon overseas markets.

We are also faced with the necessity of increasing our exports, in order to meet our external obligations and preserve a favourable trade balance.

Many solutions of the problem with which we are confronted have been advanced. Some people consider that we should depart from our protectionist policy and allow free imports. Others say that we should raise our tariff barriers higher and stem the tide of imports. Many other courses of action have been advocated, but to deal with any of them is to be inevitably thrown into the field of controversy, which I am studiously endeavouring to avoid to-night. 
The free-trader, the protectionist who flirts with prohibition, the economist, the banker, the man of commerce and the man of industry, the pastoralist, the agriculturist, and even the politician, however, are all agreed that something is wrong, and that we have a problem which it is vital we should solve.

I venture to suggest that, while there may be something in the solutions proposed by the various theorists, the fundamentals of the problem which confronts us are improved efficiency and a greater measure of co-operation between all who are engaged in production. Ever since I have been privileged to be Prime Minister of this country I have preached these things as the vital necessities of our national life. Once we recognize the need for greater efficiency and cooperation the solution of our financial, fiscal, economic, and social problems is in sight. Such a recognition, however, must be nation-wide. We must improve our methods of production and our methods of marketing. Employers must recognize the obligation that rests on their shoulders to employ the most efficient methods of management and finance; they must provide up-to-date machinery and plant; they must bring to the assistance of their workers adequate supplies of power, and all the aids that science can render. Every individual worker must recognize his obligation to give efficient service and a fair return for the wages which he is paid.

Such a recognition of its obligations by every section of the community, and the creation of a true spirit of co-operation, is the starting-point towards the solution of our economic and social problems.

The pressure of circumstances will inevitably impel us to take this road, or see our much-vaunted social system perish. Only with efficient production, distribution, and finance, and co-operation between employer and employed, can we maintain our high standard of living and meet our competitors in the markets of the world. This is the task which lies to the hand of every individual citizen, and the greatest to which any democracy could call its people. On its successful achievement depends not only the future of Australia, but the maintenance of those things we have so far achieved and regard so highly. 


\section{3}

\section{Public finance in relation to commerce}

\section{Richard C. Mills ${ }^{1}$}

The title of my lecture this evening is: "Public Finance in Relation to Commerce." This covers a wide range of topics, and is capable of treatment from many points of view, for the operations of public finance are manifold, and the manifestations of commerce are various. I shall be unable to do more than select for discussion certain aspects. In the Commonwealth, and in most of the States, acute problems of public finance now confront us, but I do not intend to attempt any original analysis of the financial situation in Australia, still less to propound any startling solution. I shall rather attempt to discuss the nature and meaning of the operations of public finance and the economic effects of the system as a whole and in its various parts. These latter aspects are less exciting and controversial than the former, but they concern matters which are too often lost sight of in public discussion of the former aspects, to which discussion they are, indeed, an essential preliminary.

\section{Public finance}

The State is a form of social organization to which every man must belong, and it is usually recognised that the chief activity of the State is government, which includes both legislation and administration.

In order that the State may fulfil its purposes, in order that it may be enabled to exercise its functions, it must have money to expend, and it raises this in the form of annual revenue, or at times, by borrowing. Hence we get the operations of public finance which may be conveniently considered under the heads of revenue, expenditure and debt.

1 Thirteenth Joseph Fisher Lecture, 28 May 1929. 
To get an accurate picture of the nature of public finance it is necessary that we survey its operations as a whole instead of concentrating our attention upon one of its aspects. Public finance is concerned with the economic effects of the fact that public authorities raise income from various sources and expend it in various ways. In each case many competing methods present themselves, and different economic consequences follow from different methods.

"Most of the operations of public finance," as Dr. Dalton puts it, "resolve themselves into a series of transfers of purchasing power." In the typical case, the State, on the one hand, takes from some of its citizens by divers methods portion of their incomes which otherwise they would have been able to spend for themselves, and, on the other hand, transfers this revenue as income to another set of people. The latter may be those who render in return certain services to the State, such as judges, military and naval men, and other civil servants; or they may be those who render no such return, such as old age pensioners.

As Professor Pigou puts it: "Every completed act of public finance is alike in form. $£ 100 \mathrm{~m}$ are obtained by the Government from the public - and are paid over to certain other persons. This money is purchasing power. When it is taken away, those persons from whom it is taken are constrained to give up certain things (including perhaps some leisure) which they would have had if it had not been taken away. The Government then spends the $£ 100 \mathrm{~m}$. It is evident that there is a great number of different ways in which the providers of taxes or fees or loans can modify their purchases and activity in order to furnish the $£ 100 \mathrm{~m}$ : and a great number of different ways in which the $£ 100 \mathrm{~m}$ can be spent, and in which the output of different sorts of things and services can accordingly be affected. ${ }^{3}$

Practical problems of public finance turn largely upon the question whether on balance of advantages and disadvantages it is better to allow a public authority to spend in ways which seem good to it, a little more of the income of individuals, or to allow those individuals to spend that income in ways which seem good to them. To concentrate our attention solely upon the revenue aspect of public finance, or the expenditure aspect, may lead us into misconception, for instance, there is a current notion that every tax is an evil, an exaction with no return. The

2 Public Finance, 1923, p. 9.

3 Public Finance, 1923, p. 4. 
old view of J. B. Say still commands much popular assent: "The very best of all plans of finance is to spend little and the best of all taxes is that which is least in amount". It is not uncommon to find the view expressed that because a taxpayer suffers a diminution of his income by a tax, because he loses some purchasing power, that therefore all taxation is a net loss. To this there are two answers. In the first place, his loss, which is admitted, is some one else's gain; in the next place, this transferred purchasing power enables the State to exercise functions in the absence of which his income would be at least precarious and, indeed, might not exist. It is true that not all taxes go to provide for the maintenance of internal order and external defence, but this kind of expenditure at least appears to be such a positive good to the taxpayer as to offset some at least of his loss. As might be expected, primitive peoples, when faced with the fact of a tax imposed by their more civilized governors, take this view of the evils of taxation. In Papua, as Sir Hubert Murray writes, there is a tax on all male natives between certain ages. Village councillors are selected to explain that this apparently meaningless exaction has another side. "A Government officer explains to the councillors, and they pass on to the rest, the real meaning of the tax; he tells them, for instance, that the tax does not go into the pocket of the tax collector, but that it is used to build hospitals, to equip schools, to provide for the travelling medical assistants, and so forth." ${ }^{4}$

But the idea that all taxation is an evil is difficult to eradicate even from more civilized minds. Connected with this is the idea that if the money taken were left in the hands of the individual it would be spent more wisely than when spent by the Government. Adjectives such as "lavish" and "wasteful" are often applied to Government expenditure, sometimes with good reason, but whether Government or private expenditure is wiser depends, not on its form, but on the circumstances of each case. "Our public expenditure is so lavish," said a chairman of a Sydney bank, "it is easy to pass this unpleasant subject over: so much more pleasant to ignore it, so infinitely comfortable to be a public man of the bold courageous, optimistic order and squander money." 5 To much the same effect wrote an American banker: "Money in the hands of the Government cannot possibly be anywhere near as productive and fructifying and active as

4 Studies in Australian Affairs, 1928, ch. xii: Australia’s Policy in Papua, p. 257.

5 Mr. Thomas Buckland, S.M. Herald, 30/5/1923. 
in the hands of individuals." "The answer to such contentions is that private individuals do not necessarily and always spend their incomes more wisely than public authorities. To hold this is not to go so far as Sir Leo Money when he stated that his taxation was the best expenditure that he made and that for which he got the most satisfaction. ${ }^{7}$ Nor is it necessary to accept Mr. Sydney Webb 's view that "Government expenditure is, in fact, far more wisely done (on any view of wisdom) than the average of private expenditure." ${ }^{\text {All that is contended for }}$ is that government expenditure is not always and everywhere worse than private expenditure. "Since," says Mr. Hartley Withers, "there is so much bad spending in all classes, we have no right to assume, as is often done, that all the money taken by the State and spent, well or ill, by it, would have been well spent if left to 'fructify in the pockets of the people.' It might have gone in race meetings, tango teas, picture palaces, fashionable fripperies, strong drink, or trashy 'literature,' all of which things have their uses in amusing people who do not know how to amuse themselves better, but do not lead to much 'fructification'."'

Public finance and private finance are often contrasted, and it is a matter of common complaint that the principles which govern sound private finance should be applied to public finance, but are not. But there are differences between the two which render difficult the application of principles of private finance to public finance. ${ }^{10}$ The first difference is that the State may and does exercise compulsory powers over those within its jurisdiction. The limits to State action are to be found in the practical difficulties of compelling its subjects to obey, but within the limits of its own sphere of action the State is independent, and in time of need may claim the property or even the lives of its citizens. The next difference arises from the fact that the State normally has a longer existence than that of any of its citizens. This means that its attitude to the more distant future may well be different from that of an individual whose views normally do not extend to a period much beyond his own life. For instance, a reason able time for a return from private expenditure will be shorter than for public expenditure. Lastly, an individual is apt to judge a financial transaction by the pecuniary test.

6 Mr. Otto Kan: Ibid., 15/1/1922.

7 Stamp, Fundamental Principles of Taxation, 1921, p. 51.

8 Preface to R. Jones: Nature and First Principle of Taxation, 1914.

9 Our Money and the State, 1922, p. 75.

10 See generally Bastable, Public Finance, 1903 bk. i, ch. i; and Adams. Finance, 1899, pp. 26, et seq. 
According to whether or not there is a direct monetary return, so he will assess success or failure. While a State, too, may use this test, yet from its very nature a State may also judge a financial operation by the test of indirect or non-monetary return. The general duty of the State being to promote social welfare, it may expend money on such services as education or public health, from which it neither expects nor receives monetary return, but which produce very important indirect returns in social welfare.

\section{Commerce and its relation to finance and public finance}

Commerce and industry are frequently contrasted, and a distinction is drawn between the production of goods and their exchange. But the "making" and the "sale" of a motor car are both part and parcel of the same process of changing the form and place of goods until they reach the hands of the final consumer. There is no essential difference between the services rendered to society by commercial men, such as merchants and retailers, and those rendered by manufacturers or "primary producers." Commerce in a narrow sense covers the process of buying and selling goods and its attendant services. But for this discussion we may use the term "commerce" widely enough to cover the whole of what is commonly called "business." Business is conducted for gain by private individuals or groups of individuals. Men are induced to provide goods or services in the hope of the gain arising from their exchange with other goods and services. Success in business is measured, in the main, by the objective test of money income. Commodities and services are thus bought and sold, and the prices which result from these transactions are an indicator at once to producers and consumers. Economics is concerned with explaining why individuals or groups of individuals are as well off as they are, and why some are better off than others. It treats of the prosperity of individuals and of nations, and examines the meaning and causes of that prosperity. Many of the topics with which economics has to deal come within the survey of the businessman, e.g., money, banking, international trade, taxation. The point of view, however, is rather different, that of economics being social, that of business being individual. The practical application of economics is to be found in public problems, rather than in the private problems which beset the businessman. Economic theory, as it has been said, throws light upon "the business of government rather than the government of business." 
Commerce, therefore, is not to be taken to be the practice of economic theory. A man does not make a success of a business by merely applying to it principles of economics. But economics has a practical relation with commerce, because it is constantly dealing with the same field, although from a different point of view. Its study provides the student with a "clear vision of the social goal of business activity," ${ }^{11}$ and makes him realize that the social function of business is the efficient production and distribution of goods.

The science of public finance has an intimate association with economics on the one hand and politics on the other. The subjects included in the study lie, as Dr. Dalton has remarked, "on the border line between economics and politics." 12 The problems that face us in public finance cannot receive a complete solution merely by the application of the principles of economics. We cannot simply decide on economic grounds alone at what rates an income tax should be levied, or even what is the most appropriate form of such a tax. But every problem of public finance has an important economic aspect, and to neglect this is to set sail on an uncharted sea. Nevertheless, public finance does not, any more than any other branch of economics, lay down a series of practical maxims for the guidance of the harassed statesman. "Finance" may be, as some have put it, "great policy," but policy is dependent upon more things than economics. It is, however, one matter to lay down the principle that the economist should be chary of offering advice outside his own sphere, and another matter to put it into practice. To give advice and not to take it is one of the marks of our common humanity. The very close association of public finance and politics gives to the subject at once its interest and its danger. "Public finance," as Dr. Dalton has put it, "lies very close to practical politics. It is, in this sense, the most live branch of economics. Its precepts and its formulae may change, at the wave of a politician's wand, into the clauses of an Act of Parliament. Here, more easily than anywhere else in economics, theory and practice may play into each other's hands."13

It is obvious that the operations of public finance, such as we have described, bear an intimate relation to commerce.

11 R. C. McCrea, Journal of Political Economy, April, 1926, p. 222.

12 Public Finance, 1923, p. 1.

13 Economica, June, 1928, p. 221. 
The State normally contents itself with regulating industry and commerce, though in many countries public authorities have gone much further than mere regulation, and have entered into the field of ownership and management, whether of monopolistic concerns, or of those carried on in competition with private enterprise. The success or failure of these enterprises, and the financing of them, and of State regulation, are matters of deep concern for every businessman. He is, for example, vitally affected by taxation, which he usually looks upon as a hindrance to industry and commerce. At first sight taxation is a deterrent to enterprise, for it reduces incomes and may lessen incentives to work and to save. In so far as taxation, in particular, makes extensive inroads upon the savings of the community, all production is affected. It is to be borne in mind that all income, private or public, comes out of one source, viz., production. The operations of public finance may leave unchanged, may lessen, or may even increase the flow of production, but there is no mysterious source of public income like the purse of Fortunatus or the widow's cruse of oil. Rather does it come from the stream of production, whose sources may dry up if drawn upon in a wasteful fashion. Public expenditure, too, is of vital interest to the businessman. Waste or inefficiency in Government expenditure represents a wasteful diversion of the community's resources. It is true that production is not the only factor to be considered. Some forms of social expenditure may be justified, even though the provision for them may somewhat lessen production. ${ }^{14}$ But the true test of expenditure is whether, on balance, the advantages which it brings outweigh the effect upon production. And unless this is taken into account it is impossible to pronounce expenditure good or bad.

\section{Public revenue}

The most convenient classification of public revenue appears to be into: (a) Economic receipts, or quasi-private income; (b) Compulsory receipts, of which the most important part is taxation.

In each case it is the national dividend which provides the revenue, but in the first case the State, or its agents, produces part of the revenue, while in the second case the State merely compels its subjects to hand over what would otherwise go to them as receivers of the national dividend.

14 Compare Colwyn Committee Report, 1927, pars. 284-5. 


\section{Public revenue in the form of economic receipts}

State undertakings, generally speaking, although they serve to swell considerably the volume of gross public revenue, yet contribute little, if anything, to net revenue. It is rare to find net economic receipts from such undertakings providing help in any marked fashion towards meeting the ordinary expenses of government. There are some exceptions, but on the whole State undertakings either produce a deficit which has to be met from some other source of revenue, or they just manage to cover their own working expenses, depreciation, interest, and sinking fund on any borrowed capital. This is a matter of common knowledge in the case of Australia, which has gone to greater lengths than most countries in State enterprise. It may be convenient to examine for a moment the reasons for this state of affairs. It is often alleged that State ownership and control of industrial and commercial enterprises is less efficient than private ownership and control. But although this may be true in certain instances, it cannot be accepted as necessary. Comparison is often made between a small well-run private enterprise, with all the advantages of careful and individual supervision, and a State enterprise on a large scale, where many difficulties arise, not so much from the fact of State ownership and control, as from the very size of the operations. Again, State enterprises are subject, as private enterprises even on a similar scale are not, to politically imposed policies, which aim, not at the production of revenue, but at service to the consumer at, or even below, cost. So, in the case of railway management, "developmental lines" may have to be built and operated at a loss by a State railway, when under private management this loss would be cut, if ever incurred.

In so far as State enterprises are less efficient than similar under takings would be in private hands, there is a net loss to production. To borrow money publicly for the purpose of establishing inefficient State enterprises, whether they are monopolies or in competition with private enterprise, is a wasteful diversion of resources from private industry. But, generally speaking, allowing for reasonable efficiency in Government industries, the effects of raising public revenue in this way will depend upon what price policy is pursued. If the enterprise chooses to charge prices high enough to cover its expenses and make a profit, this is, in effect, a transfer of purchasing power from the users of the service to the State. If, on the other hand, the prices charged are not high enough to cover expenses, the amount of the loss represents a subsidy to the users of the service as a class, from the general body of taxpayers. 


\section{The nature of taxation}

Taxation and exaction are often used as synonymous terms. Every Treasurer realizes the truth of Burke's saying, "To tax and to please, no more than to love and to be wise, is not given to men." To most people the payment of taxes is at best a grudged necessity. Few share the opinion of the dignitary of the Church who found the payment of his income tax "an exhilarating duty." ${ }^{15}$ Sir Josiah Stamp relates that when he was a Surveyor of Taxes he often felt inclined to put up a prominent notice in his office to this effect: "Please don't say you would be pleased to pay the tax if you'd only got the income, because you wouldn't." ${ }^{16}$

We need not try to distinguish very carefully between taxes and other forms of compulsory State revenue. Indeed, the distinction is not always easy to draw. For our purposes it is enough to recognize broadly as taxes those payments to the State which are compulsory, not voluntary, for which no direct quid pro quo to the contributor is contemplated, and which are intended predominantly to raise revenue. Such a payment is typified by an income tax, where the willingness or unwillingness of the contributor is legally immaterial, where the payment does not bring a direct return, proportionate to it, and where the predominant intention is that a contribution should be made to State revenues. On the other hand, a fare paid to a State railway is voluntary, in that the contributor is not compelled to use a State railway in the same sense that he is compelled to have an income, and the payment is proportioned to the service which is a direct return for the expenditure. Again a penalty for a breach of traffic regulations is compulsory; and gives no direct return, but its purpose is not so much to raise revenue as to deter people from certain forms of anti-social conduct.

But taxation may be used in such a way as to be hardly distinguishable from a penalty. This raises the broader question of the legitimate aims of taxation. Should taxation be "for revenue only," or are other aims allowable? It should first be noticed that taxes undoubtedly do have other aims than merely revenue. Much of the taxation upon various forms of alcohol and tobacco aims both at producing revenue and lessening the consumption of commodities considered socially undesirable. The Federal Land Tax, according to the late Mr. Andrew Fisher, who

15 R. Jones, op. cit., p. 6.

16 Fundamental Principles of Taxation, 1921, p. 54. 
introduced it into the House of Representatives, had a two-fold object: "While the incidence will tend to break up large estates and help to develop the country from an economic point of view, it is a proper kind of taxation for the purposes of raising Commonwealth revenue. "Stern critics of other people's vices have found further examples in Amusement Taxes. How prominent the repressive aspect of taxation can be may be seen from an American example of some years ago: A liquor licence in a certain Western town cost 100 dollars. A tax of 100 dollars was put upon banks. The bankers held up their hands in horror; ' the people think the banks are as undesirable as the Saloons."'17

The outstanding example of the use of taxation for other than revenue purposes is to be found in the almost universal use of import duties for the purpose of giving a definite direction to the economic development of a country. Moreover, the effects of the tax may be very different from what were intended. Some of the effects of a tax may be foreseen and intended, others not, and a tax may fail even in its object of producing revenue.

Opinion is divided as to whether "ulterior aims" in taxation are legitimate. On the one hand there is the view that taxation should be "designed with the sole intention of producing necessary revenue." ${ }^{18}$ On the other hand there is the view that taxation may be used "as the means of effecting specific social or political purposes." ${ }^{19}$ Mr. Stephen Mills, who draws a distinction in these terms, holds that the latter view treats taxation "as a system of morally persuasive penalties" to induce society "to follow the path which leads to the imagined elysium of Socialism," while the former view is correct in maintaining that any other object than revenue "is an alien, unassimilable, and injurious ingredient." 20

But this contrast is too strongly drawn. Those who hold it legitimate to use taxation to promote social welfare are not necessarily socialists, and few even amongst free traders would question the right of the Government to use import duties as a method of directing the economic development of a State. It may be noted that the late Alfred Marshall wrote, in 1917: "The State is under obligation

17 Plehn, Public Finance, 1919 ed., p. 315.

18 Stephen Mills, Taxation in Australia, 1925, p. 1.

19 Ibid.

20 Ibid., p. 2. 
.... to use its powers for promoting such economic and social adjustments as will make for the wellbeing of the people at large. A chief place amongst these powers is held by its control of the distribution of the burden of taxation." ${ }^{21}$

Our conclusion is that taxation may legitimately have other aims than merely the production of revenue, but that the effects of a tax are much more important than the ascertained or presumed intention of those who are responsible for its imposition.

\section{Taxes}

A common classification of taxes is into direct and indirect taxes. The distinction between these is sometimes made to turn upon the incidence or burden of the tax, those taxes being direct whose burden cannot be shifted. Sometimes it is made to turn upon the intention of the public authority which imposes it, a tax being indirect if it is intended that the burden should be shifted. Neither of these distinctions is satisfactory. In the first place, the question of incidence in any given case is a difficult one to be determined, so difficult, in fact, that we could not be safe in distinguishing at first sight, by this means, between a direct tax and an indirect tax. In the next place, the intention of public authorities is no safe guide, for their intention is sometimes undiscoverable and always irrelevant to the question of the incidence of a tax. A distinction may be made between direct taxes of which the burden is open and unconcealed, and indirect taxes whose burden is disguised by being concealed in a transaction or a price. An income tax, for example, exhibits an obvious burden, while a tax on a commodity may be obscured by a price change. In other words, an indirect tax is a comparatively painless extraction from the taxpayer's pocket. But indirect taxes, if less painful, are not always endured in silence, if Walpole is to be believed: "Landed gentlemen," he said, "are like the flocks upon their plains, who suffer themselves to be shorn without resistance; whereas the trading part of the nation resemble the boar, who will not suffer a bristle to be pluckt from his back without making the whole parish to echo with his complaints." ${ }^{22}$

21 Memorials of Alfred Marshall, 1925, p. 347. Compare Delisle Burns: Government and Industry, 1921, p. 156, "The principles of adjusting social differences by differential taxation can be used also for remodelling the industrial and economic life of a nation, and there is no reason against such remodelling, since economic life, as it now is, is not necessarily good and is largely the effect of the desires of past generations."

22 Quoted by Seligman, Essays in Taxation, 1911, p. 33. 
The rate of taxation may be progressive, regressive, or proportional. A progressive tax is one in which the rate usually increases with the amount, e.g., of income, taxed; a regressive tax is just the opposite, where the rate decreases as the amount of income increases; while in a proportional tax the rate remains constant.

Regressive taxes, from their very nature, bear more hardly upon those with lower incomes. In practice, too, regression may arise although the form of the tax is proportional. Most taxes on commodities have this effect, not that it is unavoidable, but that in order to raise much revenue from commodity taxes it is advisable to place them upon articles of necessity and of staple consumption. It would be possible to impose such taxes merely upon commodities used by wealthy people, and then the effect would be progressive and not regressive. But while they are imposed, instead, upon articles of common consumption they are regressive in effect, because a greater proportion of a smaller income is spent upon such articles than is spent of a larger income." The man who possesses an income of $£ 1,000$ a year," wrote Sir D. Barbour in 1896, "does not, as a rule, drink ten times as much whisky, tea, or beer, or smoke ten times as much tobacco as the man who possesses an income of $£ 100$ a year." ${ }^{23}$ This aspect of regression really arises from the fact of inequality of incomes which is characteristic of most societies, and, in its absence, taxes on articles of general consumption would be much less regressive in effect.

\section{Income taxation}

To illustrate the effects of taxation upon commerce we may select the income tax for two reasons. In the first place, it is the most important and typical direct tax, and is usually looked upon by business men as a hindrance to production and a deterrent to enterprise. In the second place, the Colwyn Committee recently investigated the effects of the income tax upon the British business community. Its conclusions are interesting, for they fortify economic reasoning, and they were arrived at by a body consisting not merely of economists, but of taxation experts and leading industrialists and commercial men.

23 Quoted by Pigou, Public Finance, 1928, p. 142. 
In dealing with the effects of a tax upon income it may be remarked once more that the total effects of a given system of public finance will be different from those of taxation alone. Until account is taken of the use made of the proceeds of taxation the effects of raising revenue in this way remain isolated for purposes of analysis, and likely to mislead if attention be concentrated upon them alone.

A payment made by a taxpayer in the form of income tax is a transfer of purchasing power, a deduction from the taxpayer 's income, a lessening of the amount which he otherwise would have at his disposal to spend or to save. Production may be affected, because as a result of the tax, work or saving, or both, may be reduced. This will depend upon how capacity to work and to save, and willingness to work and to save are affected. Usually an individual's capacity to work is unharmed by an income tax unless its payment is such that he is unable, out of what is left to him, to provide the necessaries for efficiency. Saving, however, is in most cases reduced, because the lessened income means a reduced capacity to save. As Professor Pigou puts it: "A considerable part of the money taken from the public in taxation is likely, especially if the rate of taxation is high, to come out of what would otherwise have been, or become, capital in the widest sense." ${ }^{24}$

We may now consider the effects of the tax upon willingness to work and to save, or more generally the way in which taxpayers react to an income tax. This is a question upon which it is difficult to make accurate generalisations. Dr. Dalton says: "At this point, perhaps, the economist looks hopefully into the eyes of the psychologist, but the latter is apt to return a stony and uncomprehending stare, and to talk of other things, such as the inadequate psychological basis of modern economic theory." 25

It is commonly held that taxation always reduces willingness to work and to save. But this does not seem to be universally true. Those who are concerned to provide for themselves and their dependents, those with a fairly rigid standard of life, accustomed to "living up to their income," ${ }^{26}$ or those who are attempting to save for a fixed amount of income at the end of a definite period of life, are not

24 Economics of Welfare, 1920, p. 598.

25 Public Finance," 1923, p. 84.

26 cf. Pigou, Economics of Welfare, 1920, p. 593. 
likely to work or to save less when faced by an income tax. On the other hand, the view that taxation "acts as a spur" to industry and to saving appears to have no general validity. It may apply in the case of those who desire wealth as an evidence of power and success. Taxation to them may be merely an obstacle, and the higher the obstacle the higher they will jump. ${ }^{27}$ But Lord Leverhulme's view can hardly be generally shared: "Every raising of the rate at which income tax is levied has been followed by increased efforts, successfully made, to increase incomes out of which to pay the increased tax." 28

It would appear that the truth lies somewhere between these views, but possibly nearer to the. first than to the second. Income taxation may tend to reduce both willingness to work and willingness to save, but it depends upon the circumstances of the case, and particularly upon whether the tax is moderate or heavy. We may go a little further with this matter, and distinguish between the effects upon willingness to save and those upon willingness to work.

\section{Saving}

A great deal of saving in modern times is done vicariously by companies on behalf of their shareholders in withholding from distribution current profits and placing them to reserve. "The saving, while effected on behalf of the shareholders, is done without any volition on their part; it is collective and impersonal." ${ }^{29}$ The effect of a tax upon those who have the decision as to whether profits should be put to reserve, or distributed in dividends, has been considered for the United Kingdom by the Colwyn Committee. Their general conclusion is that "when a concern is well managed it will not be deflected by high income tax from a sound policy in the matter of reserves." The statistical evidence available to them showed no signs of reserves having been sacrificed to dividends. While admitting that income taxation absorbs much of the savings of companies, and to that extent is a hindrance to accumulation and an obstacle to development, the Committee thought that no great damage had been done to company savings in general even by the high rates of income taxation. ${ }^{30}$

27 Dalton, Public Finance, 1923, p. 85.

28 Quoted by Dalton, Public Finance, 1923, p. 85.

29 Colwyn Committee Report, par. 392, p. 145.

30 See generally pars. 392-402. 
A great part of saving, too, is done by wealthier people, and is to a certain extent automatic, ${ }^{31}$ so that in these cases willingness to save is not affected to the same extent as in the case of less wealthy savers. Professor Pigou's view is that an income tax means that the less important uses of an income are curtailed first. These uses may be either consumption or investment. Commonly both are lessened, and, if the taxation be moderate, roughly in proportion to the respective expenditure upon each. In the higher ranges of income, therefore, where the proportion invested is greater, taxation will reduce saving more than in the lower ranges of income. Where the taxation is heavier there is more likelihood that saving will be the main source from which the taxpayer meets the tax, so that the higher the taxation the more likely it is to reduce the amount of what would otherwise be capital. ${ }^{32}$ This view is reinforced by the opinion of the Colwyn Committee on the effect of income taxation in the United Kingdom: "The savings of the income tax paying classes have suffered; the effect has been most severe in the larger incomes liable to high effective rates of tax." ${ }^{33}$ In this connexion the Committee makes an interesting classification of individuals according to income, concluding that the willingness to save differs in each class, so that the resultant effects upon saving will be different. In the lower range of incomes, up to $£ 500$, where the rates are also low, willingness to save is such that probably the tax is paid out of money which would otherwise be spent on consumption, and saving is to this extent unaffected. In the middle range, between $£ 500$ and $£ 2,000$, where the rates are much heavier, the savings of some will be unaffected, but in spite of economies in consumption, savings will be reduced in the majority of cases. In the higher ranges of incomes the deterrent effects upon saving are still more marked. ${ }^{34}$

\section{Enterprise}

A similar classification is adopted by the Committee in its discussion of the effect of the income tax on work and enterprise. ${ }^{35}$ In all ranges of incomes for employees and professional men, they consider income taxation has no important effect upon work or enterprise. The case is different with public companies, and still

31 Colwyn Committee Report, par. 429, p. 161.

32 See generally Economics of Welfare, 1920, pt. iv, ch. ii.

33 Report. par. 441, p. 166.

34 Pars. 365-377.

35 See Pars. 343-364. 
more so with private traders. In so far as the tax tends to restrict the supply of capital, it tends to depress the outlook both of those directing public companies and of those in charge of private concerns. This may lead to a tendency to avoid risks which would otherwise be taken, and therefore "to damping down industrial activity, particularly of the more speculative kind." ${ }^{36}$ The most important effects, however, concern private business, where the individual controllers are the only ones financially interested, and have to bear the burden of taxation without the possibility of transferring it to the shoulders of the shareholders.

A private trader is in a different position from an employee or a professional man. He neither works for a fixed salary, nor does he carry on largely without material capital. He is lured by the hope of gain arising from his own hard work and initiative, and affected by the ever-present possibility of loss. To him saving and enterprise are of great importance, and the individual motive is dominant. "In the struggling business the necessity for fresh capital may be no less urgent than the necessity for hard work and initiative; the trader may have to save in order that the business on which he depends for a livelihood may survive. Again, in the prospering, go-ahead business the will and the ability to expand require to be backed by a continual flow of savings, if they are to be effective." ${ }^{37}$ In the Committee's opinion work and enterprise are not adversely affected in the lower ranges of income generally speaking, we should regard the psychological effect as neutral for traders with profit up to $£ 500$ per annum." ${ }^{38}$ In the middle range of incomes, and for some distance beyond, although effects will vary with individuals, probably income taxation "definitely increases the business man's output of effort. ${ }^{39}$ In the higher range of incomes, however, the burden of the tax is formidable, and enterprise is likely to suffer, especially the undertaking of more risky and speculative business. But such statistical evidence as was available led to the conclusion that "it would be difficult to maintain the view that as a whole the enterprise of the wealthy business man is very seriously damaged." 40 
These effects upon enterprise and upon saving constitute the real argument against high rates of income tax. It is not merely that individuals dislike paying such taxes, but that the payment reduces savings and lessens enterprise, and consequently tends to a reduced national income and a lessened prosperity. Once again it is to be remembered that we are looking at the question apart altogether from how the revenue is spent. The effect upon saving, for example, will be very different, according to whether the proceeds are used in waging a war, or in paying interest to holders of Government loans, who promptly proceed to invest the money.

Before leaving income tax it will be convenient to examine for a moment the question whether the income tax is "passed on" by traders to consumers in the form of higher prices. This question has often been hotly debated, economists, as a rule, holding the view that the burden of an income tax cannot be shifted, while business men, as a rule, hold that it not only can be, but actually is, shifted in the form of an addition to the price. The Colwyn Committee, whose discussion of this question is most recent, sided with the economists, and were fortified by a statistical analysis prepared for them, which showed, inter alia, that the distribution of profit rates in a year of low taxation was almost identical with that of a year of high taxation, although, if the "business" view be right the rate of profit before payment of the tax should be higher in the year of high taxation. It is, however, of little importance which view is right. There is no doubt that the view that all income taxes are simply "passed on" and reflected in prices is untenable. As Mr. Robertson says: "If you throw enough taxation mud at the business man a good deal of it will stick." ${ }^{41}$ But, on the other hand, prices may increase as a result of income tax, and it matters little whether this is described as resulting from "passing it on" or, more correctly, from a contraction of supply owing to the effect of the tax upon saving and enterprise. The question of the effects of an income tax upon individuals, and consequently upon production, far exceeds in importance the barren question of whether the tax can be passed on. But the possible effects of taxation are often exaggerated. Not long ago the proposal to tax property incomes at a higher rate than work incomes was described by an American writer as "apparently intended merely as an entering wedge leading at

41 Economic Journal, December, 1927, p. 581. 
best to socialism; at worst to Bolshevism, or anarchy." ${ }^{22}$ Again the adoption of progressive taxation in Australia has falsified the fears of the alarmists, for neither has the institution of private property been weakened, nor has capital been driven out of the country. ${ }^{43}$ The truth is that, although the current burden of taxation always appears heavy, people have a way of getting used to it, much as they grow accustomed to a new price level after a period of inflation, or adjust themselves to an increasing tariff. "It is quite possible," writes Mr. D. H. Robertson, "that as a result of a prolonged high level of taxation business men as a class should revise their conceptions of what constitutes a reasonable rate of reward for enterprise, and it is not impossible that ... something of the kind has already happened." ${ }^{44}$

One problem of income taxation which has become more prominent with the growing economic interdependence of communities is that of double taxation, ${ }^{45}$ which occurs when the same income is subject to taxation by two taxing authorities. Its chief importance lies in the effects upon investment, for an investor in a foreign country is deterred by the fact that he will have to pay on his investment income a tax in his own country and a tax in the country of investment. This is of special moment to a country like Australia, which is a borrowing country, because double taxation, in the words of Sir Josiah Stamp, tends to prevent "liquid resources flowing from the places where they are most abundant to the places which need them most." 46 The obvious method of overcoming the difficulty is for taxing authorities to select either the principle of origin or the principle of residence as the basis for income taxation, either to tax only income of residents wherever arising, or to tax only income arising within its borders irrespective of who receives it. The trouble arises often because taxing authorities try to tax incomes of all residents, and in addition all income arising within its borders. If one principle alone is to be selected it appears that residence is the better, on the ground that the true subjects for taxation are the inhabitants living within the area subject to the taxing authority. This was recommended by the League of Nations Committee on Double Taxation and by the Committee of the International Chamber of Commerce, though the practice as yet is by no means uniform.

42 W. I. King, Annals American Academy of Political and Social Science, May, 1921, p. 259.

43 Seligman, Progressive Taxation, 1908, p. 124.

44 Economic Journal, December, 1927, p. 580.

45 See generally Report of League of Nations Committee on Double Taxation, 1923.

46 Current Problems in Finance and Government, 1924, p. 190. 
But the problem is not as easy of solution as this, for, as Professor Pigou points out ${ }^{47}$ not all States are equally strong as tax leviers, and in practice somewhat arbitrary arrangements have to be made so as not to work injustice to the weaker States. In Australia the Commonwealth and the States, generally speaking, adhere strictly to the principle of origin, and do not tax incomes of their residents derived from sources outside their boundaries. But this means that income arising in Australia from foreign investment is taxed by Australian Governments, and therefore double taxation may arise. As far as the United Kingdom and the Dominions are concerned, mutual arrangements were made a few years ago whereby each authority agreed to give some relief to taxpayers subject to both Imperial and Dominion taxation. It has been recently reported that the Federal Government had under discussion an amendment of the Income Tax Act to provide for the taxation of money earned overseas by Australian companies and individuals. ${ }^{48}$ So far no official announcement of a change of policy has been made, but if this were done it would add considerably to the difficulty of adjusting the burden of double taxation. ${ }^{49}$

\section{Public expenditure}

Public expenditure is the other side of the shield from public revenue. It is well to distinguish between gross and net expenditure. An analysis of the annual expenditure of the Australian States shows that, for long, approximately 60 per cent has been due to two items, (1) Public Debt, interest and sinking fund, (2) Railways and Tram ways working expenses. ${ }^{50}$ Neither of these is a purely net expenditure. In the case of the railways there is to be set against the expenditure the revenue from freights and fares, etc., while in the case of the debt there is to be set against the interest the revenue derived from various public works established by public loans. Taking the two items together, for railways and tramways have been the principal forms of loan expenditure, the net annual expenditure consists in the deficit on all public enterprises, including the interest on loans, from which there has, for one reason or another, been no direct monetary return.

47 Public Finance, 1928, pp. 191-2.

48 Melbourne Stock Exchange Record, 30th June, 1928.

49 Double taxation in another form arises in Australia from the exercise of the concurrent powers of direct taxation shared by Commonwealth and States. Space does not permit of treatment here, but reference may be made to articles in the Economic Record, November, 1926, by Prof. Giblin, and May, 1928, by myself.

50 Commonwealth Year Book, No. 21, 1928, p. 380. 50 See generally Dalton: Public Finance, 1923, part iii. 
Many of the effects of public expenditure upon production operate in the reverse direction from those of taxation. ${ }^{51}$

In the first place, it is to be borne in mind once more that some Government expenditure is essential to production, and without this expenditure the national dividend would obviously be much reduced. In the next place, a great deal of expenditure in modern States is mere "transfer" expenditure, as Professor Pigou calls it, where those who receive the money raised by taxation have a purchasing power exactly equivalent to that which has been surrendered by the tax payer. ${ }^{52}$ The most important example of this is the expenditure in the form of interest on war loans held internally. The receivers of this interest get from the taxpayers, less cost of collection, a sum which they may use in any way they choose, for spending or for saving. In the third place, a great deal of public expenditure takes the form of services which are directly aimed at improving production. Typical examples may be found in expenditure upon education and training of all kinds, and that upon public health and allied services.

Over and above these forms of expenditure there is that which may be called social expenditure, or expenditure upon various forms of social amelioration, which is becoming increasingly characteristic of governmental policy. It is not easy to measure this kind of expenditure by any economic test. Sometimes, it is true, it has unforeseen effects upon production by increasing the efficiency of the recipient or his family, although the intention was rather to improve the quality of the life of the recipient, or to lessen existing inequalities of income. Cases of this kind of expenditure may be found in widows' pensions, and possibly in schemes of child endowment. The practical problem of the desirability of such expenditure, and of the amount of such expenditures, may be stated in this way. Given a certain form and amount of State expenditure, which has been determined by historical conditions and previous policy, the spending of more on existing social services, or upon new forms of social services, necessarily involves the raising of more revenue by means of taxation or otherwise. So the problem becomes one of balancing the advantages expected to accrue from the expenditure against the disadvantages of raising the necessary revenue. It is easy enough to state the problem in this way, but this kind of balance is in practice peculiarly

51 See generally Dalton, Public Finance, 1923, part iii.

52 Pigou: Public Finance, 1928, p. 20. 
difficult, for it is not merely a balancing of economic effects one against the other, but of economic effects against social effects, and there is no certain criterion for this. When the balance is struck it is usually done roughly on an estimate of social good against economic loss, and the economist has no right to complain if the statesman chooses, as a matter of policy, to incur economic loss.

Expenditure may affect production through its effects upon capacity to work and to save, and upon willingness to work and to save. Here it is obvious that some forms of public expenditure, such as provision of free education, may act in the opposite direction from taxation by improving both capacity to work and capacity to save. The effects upon willingness to work and to save are more difficult to estimate. A common argument is that to the extent to which free grants are made by the State to individuals their willingness to work and to save will be reduced. But this does not follow as a general rule any more than, as a general rule, does taxation always act as a deterrent to enterprise. Some forms, for example, of old age pensions have been so devised as to offer direct inducements to individuals to work and to save less than they otherwise might do..$^{53}$ Others appear to have no serious effects one way or the other, and others again directly induce further willingness to work and to save.

Another way in which public expenditure may affect production arises from the fact that the goods and services produced by means of public expenditure are different from those which would have been produced if the individual taxpayers, instead of the Government, had had the choice of how the money should be expended. This was obvious enough in war time, when belligerent Governments diverted resources from normal channels of industry into those which were better calculated to supply the needs of modern warfare. But even in peace time such a process is always going on, just as, for example, by protective customs duties a Government may divert resources from one channel of production into another. In either case production will be different, but not of necessity less. Broadly the effect upon production depends upon whether the collective wisdom of the community as expressed in Government is greater than the sum of individual wisdom of those who would otherwise expend the money, and we should not assume that Government action is always less wise. The case against

53 Cannan, Economic Outlook, 1912, p. 19. 
protection, for example, is sometimes put on the ground that there is always a presumption that Government action will not be as wise as individual action. But if this presumption is to be accepted it is only a prima facie presumption, and may be rebutted by evidence such as, for example, that the Government is looking to returns in a more distant future than the individual has in mind. Similarly with expenditure, for example, upon education. This will often produce services different in amount and kind from those which private individuals would have obtained had they not been taxed for this purpose. But we can accept no presumption that one expenditure is necessarily wiser than the other.

It has been said that "the possession of a national debt is one of the first signs of civilization." ${ }^{54}$ The truth of this saying may be gauged from the fact that the most important cause of public debt has been borrowing for purposes of waging war. The next important cause, which has special relevance for Australia, has been borrowing for the purpose of public works. In form a public loan, whatever be the purpose for which it is used, is a transfer of wealth from private owners to the State. As a result of such transfers there may arise benefits and burdens. If the loan is external, i.e., if the lenders are not members of the borrowing State, the loan represents a benefit, because it means an addition to the total resources of the State, although when the time comes for repayment a similar burden is imposed. If the loan is internal, i.e., if the lenders are subjects of the borrowing State, the total resources of the State are unaltered. It is a mere transfer within the community, and the same is true when repayment is made. In each case payment of interest has to be made during the period of the loan. The payment of interest on an external loan is a burden, because it is a deduction from the national dividend, but there is no similar burden in the case of an internal loan, because the national dividend remains unchanged.

The burden and the benefit will also differ according to how the proceeds of the loan are spent. If they are spent wastefully in such a manner that no economic assets are created out of which an income arises to meet the interest charges, the burden consists in the taxation which has to be levied for the purpose of meeting interest payments. If, however, the proceeds are spent wisely, and an income results large enough to cover interest and other charges, then it is impossible to

54 Quoted by C. K. Hobson, Export of Capital, 1914, p. xxi. 
say that the loan has imposed any net burden, for even if it is an external loan, the burden of interest payments is offset by the addition of income producing assets created by the loan.

When a loan is spent for war purposes it is difficult to say that it has been wasted in one sense, because it may have been necessary to preserve national existence, but it has clearly been wasted in another sense. On the other hand, a loan used for purposes of establishing public works may also be wasted in the latter sense. It is not, of course, the form of borrowing which decides whether or not wealth is destroyed by public borrowing, but the use to which it is put. "The evil that arises is from the waste of war, not from the borrowing." 55

The "burden" of public debt, therefore, will differ according to whether a loan is external or internal, and according to whether its proceeds are economically or wastefully used.

We may now briefly apply these principles to Australian loan expenditure. ${ }^{56}$

Approximately one-third of the total debt of Commonwealth and States on June $30,1927, £ 333,000,000$ out of $£ 1,044,000,000$ was classified as war debt. In so far as the interest on this sum is payable abroad it is a loss to the national dividend. If this obligation did not exist it would be possible either to reduce taxation or to provide services which now we are forced to go without. In so far as the interest on this sum is payable to Australian holders of war loan there is no such net loss. As in the former case, the money has to be raised by taxation, but the money so raised is, in this case, transferred from taxpayers to stock holders, and, while it reduces the purchasing power of taxpayers, it correspondingly increases the purchasing power of the stock holders.

The remaining two-thirds of the debt has been incurred, for the most part, both by the Commonwealth and by the States, for the purposes of establishing public works. In so far as the net earnings of these enterprises cover interest charges, depreciation, and sinking fund, they involve no burden, for, if the interest goes abroad the capital came from abroad. Actually, however, there is

55 Plehn, Public Finance, 1919, p. 380.

56 For a fuller discussion see my article "Australian Loan Policy": Studies in Australian Affairs, 1928, ch. v. 
a margin between interest and net revenue, and the difference has to be made up out of taxation. It is not possible to estimate accurately the amount of this margin, for public accounts are not usually presented in such a way as to show beyond doubt the net monetary return from loan expenditure, but it is large enough to warrant the belief that some of the borrowed money has been wasted. ${ }^{57}$ At times loan money has been spent in such a way as to produce indirect or nonmonetary returns, that is, the national dividend, out of which taxation comes, has benefited by the expenditure, but no direct governmental revenue has arisen. Examples of this are expenditure upon harbours, roads, and bridges. There is no way, of course, of adding indirect returns to monetary returns, but the former operate to reduce the margin between interest and revenue. It is not suggested that the borrowing policy of Australia has been unsound; external borrowing for the development of a country in the economic stage in which Australia is can clearly be justified. The principal test is whether the money has been spent in such a way as to produce adequate returns. But that the policy might have been wiser is shown by conspicuous examples of waste.

Finally, I may be allowed to quote my conclusions written in 1928: "The knowledge that there has been some waste in the expenditure of loan moneys, and the suspicion, unallayed by satisfactory figures, that it has been great, have together probably caused much of the adverse criticism of our financial policy from outside investors or their representatives. It may also account for any differences in rates of interest on Australian as compared with other Dominion loans. To overcome this two things are necessary. First, a more careful scrutiny of the proposed objects of loan expenditure and greater economy in spending the loan. Next, more careful estimation and publication of returns to this expenditure, so that our financial situation should be made plain. The Loan Council can do something to achieve the first of these objects, but for both together some further common action on the part of the States and Commonwealth is necessary. In view of our industrial needs, and indeed of our commitments to certain projects and enterprises, Australian public borrowing is not likely to stop suddenly, but more care could be exercised to promote economy and to prevent waste. This involves a searching examination of the public projects which compete for the expenditure of loan money, and a discriminating selection of those only which are justified,

57 See Report of British Economic Mission, 1929, pp. 7-8. 
either from their expected direct return in the form of Governmental revenue, or from their no less desirable, though less easily measurable, indirect return in the form of social welfare. In the face of political considerations these decisions are difficult to make, but they are none the less essential to the prosperity and welfare of Australia." 58

58 Studies in Australian Affairs, 1928, p. 117. 



\section{4}

\section{Current problems}

\section{in international finance}

\section{Theodore E. G. Gregory}

I am very conscious of the fact that lecturers on this endowment have in the past been chosen on the ground of their personal distinction, and I cannot hope to address you with that particular qualification; but I can claim at least this, that at no time in the history of Australia did those eminent men have to discuss problems more immediate and more urgent than those which form the material of what I have to say this evening. What I want to discuss I have labelled Current Problems of International Finance, but what I really want to deal with are the problems which arise, and have been arising in the last ten years, out of the peculiar monetary organization of the modern world.

Now it has long been held up against economists of all schools that they are unnecessarily abstract in dealing with the problems of life, and in particular of business organizations. If we have been abstract, it is nothing in comparison with the actual abstractness of the monetary systems of the modern world. We are all of us in a way the creatures of an illusion. We see around us, in Australia as elsewhere, magnificent cities and still more magnificent buildings. Wherever we go we are faced by the tangible and by the concrete, and we naturally think that a body of men who spend their time reducing these great realities to abstract ideas are not in touch with the realities which they describe. But that, ladies and gentlemen, is a complete illusion. The real world, the world which matters in modern business, is not the actual physical structure at all. The real world which matters in business, as in economics, is the balance sheet, which those physical structures actually represent. In other words, whether we like it or not, in every state of society in which money is used all those concrete phenomena - farms and

1 Fourteenth Joseph Fisher Lecture, 25 August 1930. 
farmhouses, and human beings, and buildings, and equipment of one kind and another - are in the final analysis plotted down in a balance sheet.

And that balance sheet involves a conception of a monetary unit. It may be the pound sterling, it may be that object of worship the American dollar, it may be the franc, or it may be the mark, but, nevertheless, whatever the particular symbol we care to employ in the modern world, the whole of the economic activities of mankind presuppose and rest upon a monetary symbol and upon a monetary system. Not only that, but all business, the business of the small peasant farmer, as well as the business of the greatest banking firm in the world, is based upon the assumption that these symbols have a certain stability of value; that is to say, that the local unit of money, whatever it may be, will purchase both over space and over time a certain fixed quantity of goods. If it does not do so, some very important consequences follow. All business, I repeat, the business of a socialist community as well as the business of an individualistic community, is based upon the inherent assumption that the standard of value and the unit of account represent over time and over space a certain fixed quantity of goods, or, if not absolutely fixed, at any rate fixed to the extent that their purchasing power does not vary very much over reasonable periods of time. If their value in terms of goods does alter very much over space and over time, all business, the largest to the smallest, becomes simply a gamble with the future value of money.

Let me begin, therefore, by making quite clear what an enormous significance all changes in the value of money have even to the humblest individual in any part of the world. We all of us have to make provision for the future, and that provision takes the form of setting aside out of our income, voluntarily or compulsorily, certain sums of money. Whenever you and I are invited by an insurance company to take out a policy on our own life, or for a fixed number of years, we are gambling unconsciously, and in some cases consciously, on the future value of money. I constantly keep worrying as to what the value of money is going to be in twenty years' time, when some of my insurance policies begin to mature, whether the pound sterling is then going to buy a larger or smaller collection of commodities compared with what it would have bought when I took out that particular policy; and every banker and every business man who makes any investment, the return from which accrues over future periods of time, ought, although a large number of them do not do so, to take into account the 
fact that, as things actually are, he does not know what the purchasing power of money is going to be in the future. Most of the problems which form the content of modern international finance arise from, and are determined by, the instability of money in the past, the instability of money in the present, and the probable or possible instability of money in the future. I want to drive these points home if I possibly can, because you will not understand the preoccupations of modern finance unless it is perfectly clear that modern economic society rests upon a monetary foundation, and that this monetary foundation rests upon the almost unconscious assumption on the part of everybody that money is not going to differ in its purchasing power in the future very violently from the purchasing power of money in the past.

That is the first point. Now we may ask what happens if the purchasing power of the pound sterling, the dollar, or the franc, varies very much. What are the consequences of extreme instability in the purchasing power of money? In the last fifteen years, broadly speaking, the purchasing power of money first fell and then rose. Between 1914 and 1920, roughly speaking, the pound sterling and the Australian pound, and all other units of account, bought each year less than they did before; and since 1922, particularly since about 1925, the pound sterling and all those other units of currency have been buying more each year than they bought the year before. Economists are only just beginning to be aware of the fact that alterations in the purchasing power of money are perhaps the most powerful of all agencies of social change that one can possibly imagine, because until quite recently those alterations which they produce in the social fabric have not been completely understood. The way in which alterations in the purchasing power of money work themselves out is simply this, that any change in the price level produces a most profound change in the distribution of the social income of mankind. In producing changes in the social income of mankind it completely upsets the equilibrium of social classes and the equilibrium of social institutions which are in existence at any particular time.

These changes in the purchasing power of money can take one or other of two forms. As I said, up to about 1920 the purchasing power of money was falling. Each pound of one's income bought less and less, which is the same thing as saying that the price level was going up. Since 1920 each pound of one's income has bought more. Of course, the speed with which each pound of one's income 
bought more has varied in different parts of the world, and I may mention in passing that the increase in the purchasing power of the pound in Australia has been very much slower than the increase in the purchasing power of the pound in almost any other part of the world, and a great many of your problems at the present time are derived from the fact that alterations in the purchasing power of the unit of account outside Australia have been proceeding much more rapidly than they have been inside Australia. But that is by the way. The point merely is this, that since the outbreak of the Great War, the unit of account the pound sterling, or the dollar, or the franc - has never in any two succeeding years bought even approximately the same quantity of goods. What follows? In periods in which the purchasing power of a particular currency has risen, the distribution of the national income alters in favour of those particular groups, and of those particular institutions, that have fixed rights in terms of money. If I am a bondholder at a time of falling prices, I get the same quantity of money, and each unit of my income buys more than it did before. If I am a bondholder in a period of rising prices, each pound that I get buys less than it did before. Now, if you make the enormous assumption, because it is an enormous assumption, that the real things which are produced re main the same, whether prices are rising or whether they are falling, it is easy to see, is it not, that in periods of rising prices those particular people who have fixed income rights of any kind suffer, and in periods of falling prices those people who have not got fixed income rights suffer. Economists express that by saying that in periods of inflation, in periods in which the price level is rising rapidly, the recipients of fixed incomes suffer, and that in periods of deflation the residual recipients of income suffer, that is, all people without definite legal right to a fixed amount of income.

What are the ultimate social consequences of this state of affairs? We in Europe have been privileged to see an enormous economic experiment carried out upon a vast scale, because through out the greater part of Europe, between 1919 and 1925, we saw the purchasing power of money falling literally not only from day to day, but almost from hour to hour. I have been in at least three countries in which one did not know at the end of the day what to-morrow's rate of exchange would be, nor, therefore, what to morrow's purchasing power of money would be. Consequently what I am about to describe is no figment of the economist's imagination, because international economists are not allowed to possess imaginations. What I am about to describe are the actual facts, as 
they have been experienced by a whole group of European and extra European countries. If the purchasing power of the unit of currency keeps on falling, which is the same thing as saying that if the price level goes on rising, you ultimately get to a state of affairs in which production breaks down completely. If you ask me why this is so, the answer is perfectly simple. If I possess something, namely money, the value of which is being reduced not only from day to day, but even from hour to hour, the time will come when I will refuse that money, or, what is even more important, the time will come when I cannot pass this money on to anybody else, when I cannot use it to go into a shop and buy anything with it, for the very simple reason that the shopkeeper will not accept my money, and will say: "Oh, no; I do not know what the future value of this money will be; I prefer to hold my goods, and, if you like, you can hold your money." When the stage comes where nobody is willing to accept the local currency, the productive system breaks down, because we live in an extraordinarily complicated world based upon the division of labour, based upon private property. If nobody is willing to accept local money the entire productive mechanism breaks down. But the same result will also follow, not only if money is constantly falling in value, but also if money is constantly rising in value. In other words, the ultimate effects of deflation are very much the same as the ultimate effects of inflation. Put yourself in the position of somebody who possesses a piece of property, the value of which rises day after day and hour after hour. The longer you wait the more valuable your property becomes. Under these circumstances you refuse to part with it as long as you can. In other words, if prices are constantly falling, production breaks down, because everybody says, "Prices are going to continue falling, and therefore I will not do anything until they have fallen some more." If everybody says that, no one can sell anything at all, and prices will go on falling; in which case the productive machine breaks down just as it broke down in the case of inflation. In the case of inflation it breaks down because no seller is willing to sell, and in the case of continuous deflation it breaks down because no buyer is willing to buy. In both cases the whole cash nexus of society entirely disappears.

Therefore, however unwilling one may be to face ultimate consequences, there can be no doubt whatsoever that violent changes in the value of money, either upwards or downwards, do result in very considerable alterations in the distribution of the national income, and do result in inflicting very considerable damage to the entire productive machine. My friend and colleague on the 
Macmillan Committee, Professor Keynes, once said that the average person divided the world up into little inflationists, who believe you should go on reducing the value of money, and little deflationists, who insist on raising the value of money all the time. He did not see why he should belong to either category. I have to face this problem from rather a different angle when I ask the question, "Which is ultimately worse, to go on constantly raising prices and reducing the value of money, or to go on lowering prices and raising the value of money." I do not know, because I have tried to explain that the ultimate consequences of either are to destroy the productive machine. If you ask me to choose, as it were, between two hells, the hell of inflation on the one hand, and the hell of deflation on the other, I am not sure, being, I suppose, a little deflationist, that I would not choose deflation as the preferable hell to the hell of inflation. When the value of money is altered from hour to hour, everybody is insecure. When the value of money is rising, that is, when prices are falling, at any rate the people who have got the money know they have a good thing, whereas in periods of rising prices people who have money know they have a thoroughly bad thing. The social consequences of inflation on the one hand, and deflation on the other, can be summed up shortly, perhaps rather inaccurately, in this way. An endless period of rising prices destroys two very important social things; it destroys the value of saving, and it destroys the worker's standard of living. On the other hand, deflation, if endlessly pursued, destroys the business man's chance of success, and thereby aggravates the problem of unemployment. In the country in which prices are constantly going up, what is the use of saving $£ 100$ to-day when it may be worth, putting an extreme case, only one penny to-morrow? That is perhaps exaggeration, but let me remind you that the German insurance policy which was worth perhaps $£ 50,000$ in 1913 was in 1923 worth rather less than the one-thousandth part of an English farthing, because at that time the mark was being quoted, if I remember correctly, at something like thirteen billions to the pound. I never was a mathematician, and could never grasp what thirteen billions was, but it made the $£ 50,000$, which was the value of the policy in 1913 , look rather small in 1923. Similarly, inflation must destroy the worker's standard of living, because wages in the modern world are paid in terms of money. If you have got an indefinite inflation it must end by destroying the desirability of saving and the desirability of working. On the other hand, if you have an endless deflation, no business man will go on producing; he will not produce something 
which is worth $£ 100$ at the beginning of the morning and only $£ 95$ by the end of the afternoon. He will much prefer to keep his capital intact in the shape of a bank balance and to dismiss his workmen. Consequently, if you have to choose, and these choices are sometimes forced on mankind, between inflation on the one hand and deflation on the other, you have to choose between the destruction of savings and the destruction of the worker's standard of living on the one hand, and the destruction of business enterprises and increased unemployment on the other. I do not know which is worse, except that I have a sort of feeling that in a period of rapidly rising prices all sorts of other things, which do not enter into the business man's calculations at all, are destroyed: the ability, for instance, of the middle classes to educate their children, the ability of civil servants to have anything like a decent standard of living. All these elements, which do not enter into the business man's calculations, are more affected in a period of inflation than in a period of deflation.

I hope I have made it quite clear that money is a very much more important element in modern economic life than is thought at first sight, and than was thought by all those middle Victorian economists who lived in a period of great peace and prosperity, and used to say that money was only the disturbing veil which hid the realities from mankind. Money is more than that. It has an extraordinarily potent tendency both for good and evil in the national life of any particular country and in the international life of all countries taken together.

That brings me more directly to the problem I have to discuss ultimately this evening. Why is it that international finance is in such a difficult position today? There are certain people in my country, and in yours, whose conception of an international financier is that of a gentleman with a considerable waist protuberance, always smoking a very fat cigar, and wearing nothing but white waistcoats and diamond studs. That is not the international financier as you actually know him, or as you actually meet him. The international financier as you actually meet him is a very worried gentleman, who sits in an office with twenty-five telephones around him, receiving depressing messages from every part of the world. What is wrong with international finance at present? In the first place it is suffering from the economical and psychological effects of the period of extreme instability, which came to an end in Europe, and the rest of the world, roughly about 1925. I want to describe what these psychological and economic effects are and have been. 
In the first place there is the problem of the liquidation of the accumulated balances in the international short loan fund. That seems very terrifying. It is, in fact, a very simple thing to grasp. When in the period in which the German mark, the Belgian franc, the French franc, the Italian lira, the Hungarian crown, the Austrian crown, and the currency of all the other European countries were melting before the eyes of the miserable populations of those countries, a few people began to realize earlier than the rest that they were melting, what did they do? They tried to escape from the consequences of the falling value of their currency by buying something which did not fall in value; and the simplest thing to buy, apart from attaché cases and other things which they could buy in their local shops, but which they could not go on buying because the shop keepers frankly refused to go on selling them, was a dollar note, the ordinary notes of the Federal reserve system. In 1926 and 1927, for instance, the Federal reserve system suddenly discovered millions upon millions of small notes returning as physical entities from the interior of Poland, Czeckoslovakia, parts of Germany, and other parts of Europe. There took place what is nowadays popularly called a flight from the currency, and, in the particular case of the London money market, a flight from the currency was especially important in the case of our nearest neighbour, France. Between 1924 and 1926 the French escaped the consequences of their local inflation by refusing to return to France the proceeds of their exports to England and to other countries. They left these sums - very large sums - on deposit in London banks. The same thing had taken place in Holland and in Switzerland in the case of Germany. All of these countries had also accumulated large balances in New York. What was the result? As soon as these currencies became stabilized again, local populations started drawing some of these sums back, and, owing to the peculiar organization of money markets, you cannot withdraw immense sums from one money market to another without actually, if you have fixed rates of exchange, taking part of the proceeds in gold. It would take me too long to explain why, but it is so. Consequently the London money market in 1927, 1928, and particularly in 1929, when other things were happening as well, which I intend to explain, was faced with the enormous problem of the French balances, the so-called bad money, about which you will find every English banker complaining and grumbling at the present time. In other words, the first of the consequences of inflation from the standpoint of the London money market (I make no apology for mentioning London, because, after all, 
it is the centre of international financial machinery), was the presenting to the London money market of a very difficult and serious problem, namely, what the central bank was to do if a single country had it within its power, as France certainly had it within her power, to withdraw something between a moderate $£ 50,000,000$ and $£ 100,000,000$ in gold at any particular moment. That is the problem of withdrawal, the liquidation of accumulated balances - balances which had largely accumulated as a result of previous inflation, and as a result, therefore, of an attempt to escape from the consequences of that inflation.

The second consequence of this period of extreme instability all over the world is something which I can describe only in technical language. The second consequence has been an exaggerated spread, as a technical banker would say, between short and long-period rates of interest. All over Europe you earn relatively little if you leave your money on deposit at a bank; but if you take your courage in both hands, and invest in a long term bond, you get proportionately more than you would have got in comparison with deposit rates of interest before the war. In other words, the margin between the deposit rates of interest paid by banks, and long period rates of interest paid by various Governments, municipalities, and business enterprises has increased considerably over the last ten years. Why is that? It is a remarkable thing. It presents many grave difficulties to the financing of long period enterprises; but the fact remains that the spread between long period and short period rates of interest is much greater than it was before the war. That is a direct consequence of the psychological effects of inflation. Everybody in Europe outside the Scandinavian block, Holland, Switzerland, and Great Britain has witnessed - actually physically witnessed - the savings of the community being literally wiped out: so far as those savings were expressed in terms of money. Naturally the temptation to anyone who has seen that is to say, "I will put my savings into such a form that I can convert it from money into something else at a moment's notice." Now, a deposit payable within seven or fourteen days is the most liquid form of investment known to mankind, and consequently all the nervous investors of Central Europe have been deliberately piling up their savings in the form of deposits, and have been refusing to take up on the normal scale the long-dated, interest bearing bonds of Governments and municipalities, and other enterprises. If you read the reports of that highly gifted officer, the Agent-General for Reparations Payments, an American, you will find that he constantly points to the spread, the difference, between long period and short period rates of interest 
as one of the most difficult problems which German and French bankers have to face at the present time. This difference, this distortion of the rates for money in one department and in another, is entirely the consequence of psychological disturbances created by inflation in the past.

The third consequence of inflation is this: Nobody in Europe has forgotten the war; still less has anyone forgotten the period from about 1919 to 1925 . What is the consequence? The consequence is that people are liable to be very panicky when anybody suggests that a little dose of inflation would not do us any harm. I remember the situation in Great Britain on the eve of the general election of 1923, when a certain Conservative Minister suggested that the situation was so desperate that it might be as well to see what the effects of a little inflation would be. What was the consequence? The consequence was that within twenty-four hours of the making of that speech every international banking firm in the world was beginning to withdraw deposits from London. They said in effect, "If you are going to inflate we shall take time by the forelock." That is not only true of bankers, who ought to know their business. Over large parts of the Continent it is true of the average man and the average woman, who have been through the period when local money literally would not buy the same amount from hour to hour. The result is that the European money markets, and all the money markets affected by Europe, are very sensitive to any suggestion of a movement intended to reduce the value of money; that is, to raise prices.

The fourth consequence of the inflationist period in Europe was one which was hardly suspected until it came to an end. The fourth consequence was to make very popular among European investors the idea that at all costs they had to invest their money in something which had a real value. The business man's way of expressing that is to say that they wanted to invest their money in something which gave them an equity in an actually existing enterprise. The most prosperous country in the world in the last few years has undoubtedly been the United States of America, and therefore the tendency has been for European investors to refuse to invest in the long-dated bonds of their own enterprises and their own bonds, and to put all their money into those American enterprises which seemed to yield an endless prospect of expansion and profitability. The New York Wall Street boom of 1926-29, which came to a very sudden and very disastrous end last October, was fed by the fears of the European investor, and 
by his desire to invest his money in a way which gave him a real, aliquot part of the ownership of some definite industrial enterprise. The Wall Street boom - you probably never heard of it in Australia, because you had one of your own - was not only caused in part by European conditions, in part it was caused by American conditions; but, however it was caused, it has in itself been a factor in creating some very serious problems, both for the money markets of Europe, and for the money markets of the rest of the world. In the first place, it accentuated the problem of the flow of international balances. There was a time in the early part of 1929 when anybody, by which I mean any bank, any investment trust, any insurance company, having an amount of over 100,000 dollars, that is to say, $£ 20,000$, could earn with perfect safety 12 per cent per annum by putting its money at the disposal of Wall Street. The New York Stock Exchange has always said with perfect truth that no investor in call money to the New York Stock exchange has ever lost a cent. In other words, you could at that time earn 12 per cent and get your principal back without any difficulty by simply calling it. What was the consequence? It was perfectly simple. Instead of the European investment trust, or the European insurance company, taking up, I shall not say Australian securities, but the securities of the Argentine, or of Brazil, or of some West Indian island, which was risky, they put their money into Wall Street, which was not at all risky. Consequently the whole equilibrium of international investment, which was already being affected by the peculiar mentality of the European investor as regards short and long investments, was being further accentuated by this enormous drain on the funds of the New York Stock Exchange. How it worked out was briefly this: All the time the American banks and American issue houses were taking up long-dated securities in various parts of the world; but it really makes no difference to the net result if J. P. Morgan lends fifty million dollars to Canada, and Canadian banks and insurance companies lend fifty million dollars to Wall Street, for in the end no money is being lent to Canada at all; in consequence of the enormous out burst of speculative activity in the United States the total quantity of money invested in sustaining the industry and the governmental equipment of the newly developing countries of the world fell off, and fell off very sharply. What consequences this had there I need not enlarge upon at this meeting. Let me go further into the question. From the standpoint of the banking systems the flow of funds to Wall Street had the effect of causing a drain of gold to the United States; and, when central banks lose more than a 
certain amount of gold, they are almost inevitably driven, under central banking practice, to put up their bank rates. What is the consequence of that?

It can be very simply described. In the years 1927,1928 , and the early part of 1929, all over the world raw materials of one kind or the other, such as copper, zinc, spelter, wheat, and cotton, were being financed by means of bank credits, etc. As soon as the money market rates rose, as soon as the banks were short of funds, they began to put a squeeze on all the various instrumentalities, which were preventing the prices of raw materials from being depressed by keeping a certain proportion of the aggregate world output of those things off the market, therefore producing the slump of raw material prices of all kinds, which has been a characteristic feature of the world in the last twelve months.

I come back to 1929 , as being directly and inevitably associated with the reactions of the money markets of the world, to the great spectacular boom in New York in those three years. The consequences of the fall in the prices of raw materials is again a matter on which I need not enlarge to this audience. I may mention, how ever, that the fall in the price of raw materials has been accentuated by the fact that various countries - I shall not mention them - thought that they could keep up the prices of these things by valorization schemes of one kind or the other. Rubber producers, for example, thought that if they could only keep rubber off the market they would keep the price up, and copper producers thought the same thing. That sort of game is all very well so long as banks are willing to finance the pools, but, as soon as the banks are not willing to do so, the whole structure comes down with a tremendous thump. As everyone knows, the whole structure has come down with a tremendous thump during the last few years. Of course, that does not end the matter, as banks all over the world have been advancing to producers in anticipation of those prices being maintained. So you see that, just as when you throw a stone into a pond, the resulting disturbance stretches out in an endless series of ripples, so a stone thrown into the international monetary organization, in the shape of the immense Wall Street boom, has had repercussions of a most difficult and far-reaching character.

Finally, I want to draw your attention to one very important and significant consequence which has not in the least been realized either in this country or in others. Inflation in Europe had the very bad effect of destroying the average 
man's belief in the virtue of buying Government bonds. That is inevitable. The Wall Street crash has destroyed the average man's belief in the virtue of buying ordinary shares, because shares he bought last year at 100 are now standing in the neighbourhood of 40 . Consequently the whole process of investment on which, in the last resort, our entire economic civilization depends, is being held up in all countries at the present time by the destruction in the minds of ordinary investors of any faith in the virtues of investment, either in bonds or in ordinary securities. What effect that is going to have in the long run nobody knows, but at the moment it is exceedingly difficult to present a convincing case for investing in bonds, and it is obviously an exceedingly difficult thing to present a convincing argument for investing in ordinary shares, as the average man you talk to has had experience in both directions. He has either put money into pre-war German 3 per cents and got nothing out of them, or put it into United States steel, or something of that sort, and lost 50 per cent. He now asks what he is to do, and the answer is, Nobody knows.

That brings me back to the ultimate question which I want to discuss this evening. These money market problems are very fascinating, but there are ultimately more fascinating problems still. These questions are only facets, only sidelights, if you like, on a very much deeper problem still, the problem of what is going to happen to the purchasing power of money, and what is going to happen to the price level in the future. The price level at the present time is being affected by two rather dissimilar series of causes. There is first of all the backwash of the Wall Street crash. That is very serious. In 1928 and in the early part of 1929 I was in New York. Up to the end of August, 1929, very few people indeed believed me when I said the crash was going to come before Christmas. In 1928 and 1929 it is true to say that, although there was some, and perhaps very considerable, unemployment in the United States, unemployment as a national problem was hardly conceived by even the most pessimistic of American observers. Nobody knows how many unemployed there are in the United States to-day, but it is pretty safe to put the number down in the neighbourhood of 5,000,000 people. There are more than 2,000,000 unemployed in Great Britain, and nearly 3,000,000 unemployed in Germany, if not more. It would be fairly safe to estimate that the total number of unemployed workers all over the world at the present time, including Russia, is some where in the neighbourhood of $10,000,000$ persons. That is a part of the problem of price level at the present 
time. We are face to face with one of the most serious and difficult of any of the economic problems we have had to face in the lifetime of any man now living. Part of it is backwash from the Wall Street crash, but some portion of it has to be associated with the general tendency of prices to slide downwards, which has been in progress since 1920. If anybody asks me what the future of prices is going to be I do not like to answer; I am not a journalist; I am an economist. However, I shall put it something like this. I say that, in so far as present world prices have been depressed in consequence of the Wall Street slump and its various sequelae, I am inclined to think that prices by, say, the end of 1931 will be somewhat higher than they are at the end of 1930 . Nevertheless, 1931 prices will be lower than 1929 prices, and the general trend will be downwards. That is to say, there will be a bit of a recovery, and then the general trend will be to slide down again, because there are at work two entirely different sets of factors. The first is the backwash from Wall Street, and the second is the problems and difficulties which arise from the general gold and central banking position as it is in the modern world. I am surrounded by some brother economists, and I ask their forgiveness for talking about reactions from the Wall Street slump, instead of saying, as I ought to say, in purely technical language that we are now suffering from one of the effects of a cyclical movement of prices. That is what I really mean. These cycles, of good and bad trade, existed in the nineteenth century, and presumably from all we know after the Wall Street crash, will go on existing in the twentieth century. Prices are, however, practically the result of the long period movement, the effects of which are slower. The short period movement varies between years of good trade and years of bad trade. I venture to express the opinion that, enormous as has been the amount of statistical work and economic study put into the elucidation of these cyclical movements of trade, although we know a great deal more about their details than we did before, we do not know a great deal more about their causes than was known in the middle of the nineteenth century. However, we do know that there are these two sets of factors: long and short.

For the remainder of this lecture I want to discuss possible remedies, not for the short period fluctuations, but for the long period fluctuations. I hope I may say one thing perfectly frankly to an Australian audience. Since I have been in this country, which is not so very long, I have noticed a distinct tendency to argue that a little amount of local inflation would not do Australia very much harm. I hope I may be permitted to say at least this about Australian problems, that 
local inflation in Australia will not help Australia in the very least, for two simple reasons. In the first place, you remember the attitude of the man Dickens used to describe rather frequently, who used to take off his coat and announce in a very loud voice to all and sundry that when he had taken off his coat he was prepared to fight, but who never did fight. Why did he not do so? It was because the other fellow knew, of course, that he had not the faintest intention of doing it. If you take off your coat, and announce to all and sundry that when you get into office, or when your friends get into office, you propose to double the Australian note issue, you will not secure the slightest success when you do get into office, because unfortunately you have told everybody of your good (or bad) intention. If you are going to announce beforehand to every man, woman, and child in Australia, that, when you get into office, you propose to cut the value of money in half, everyone with sense is going to take jolly good care that his own particular property will be exempt from the consequences of cutting the value of money in half. You see, in the modern world, it is not very much use to talk about the bondholder and the international financier as if those persons were high and mighty individuals living in elaborate palaces in Park Lane, Fifth Avenue, or anywhere else. It is quite ridiculous to talk in that way about Fifth Avenue, anyhow, as all the palaces there, except picture palaces, disappeared long ago. If you announce that you are going to inflate, what is the consequence? It is that everybody who has any sense - and a large number of people who have no sense like to follow their neighbours - will escape from the consequences of inflation by converting their holdings of money, which will fall in value if inflation takes place, into something which will rise in value in the event of inflation occurring. Now, of course, the simplest way by which you did that in the good old days of European inflation was that you went to an innocent banker and bought dollars, and you paid for them two or three months afterwards when the value of your local currency had gone down. Those were the people who used to be called "Valutaschweine," or speculators, in the German press, the people who speculated in exchange. Of course, you may say to me, "Well, Australian bankers are not going to sell exchange to weak-kneed persons of that sort, who try to convey money out of the country; Australian bankers are going to pursue a policy of rectitude." That will not save you in the least, because no one has yet been elected to Parliament, even in Australia, by saying that if I have $£ 100$ I may not use that $£ 100$ either to buy wool, wheat, lollypops, or a bit of garden, or what not. On the first day you announce beforehand you are going to 
inflate, people will escape by withdrawing deposits from the banks, and using the proceeds of those withdrawals to buy goods in Australia. In other words, the price level will rise before you have inflated, and, if that is so, you have either to inflate a great deal more than you intended to do, or, if not, you cannot inflate at all. In other words, if the people know you propose to lower the value of money, you cannot lower the value of money by fiat. As far as I can observe, the inflationists in Australia have been so busy explaining what they propose to do, when they have the chance, that everyone has been forewarned from the beginning. It seems to me that inflation in Australia would be a very risky and a very dangerous expedient. You are, of course, a great many miles away from the nearest land. I do not know how far you are from New Zealand, but everybody in this country appears to forget New Zealand. You are, at any rate, a great deal further away from the other great centres of population than any other part of the world, but that does not save you from being a part of the world. If you are going to depend in the future, as in the past, on the great international money markets to supply you with part of the capital you require for the further equipment of this country, you cannot possibly inflate; and if you ask me why, the answer is simply that the psychology of European and American investors is such at present that if you announce your intention to inflate on the one hand, and borrow on the other, they will, in fact, have nothing to do with you. There fore, although I say that the little dose of inflation which some people recommend in this country has a very attractive air, I believe that its ultimate consequences would be fatal, not only to the stability of Australian banking institutions, but fatal to the ordinary progress of this country in every direction. That is all I want to permit myself to say on the subject of your own local problems.

Let me get back to the wider problems. What can the world do as a whole to prevent this instability in the purchasing power of money? The problem of prices is primarily a problem of how to manage the gold standard. In its essence, looking at it as an economic problem, it is simple enough. The gold problem rests upon the three following foundations. In the first place you have a certain visible volume of gold production. Every year the gold-mines of the world turn out so much gold. If the price level falls, as it is falling now, the quantity of gold which can be turned out goes on increasing. If it rises, the quantity of gold goes on falling, but ultimately gold production is governed, as various critics of the gold standard state, by the chances and fortunes of nature 
over which no man has any control. On the other hand, there are two other elements in the situation, over which human beings have some control. One is the industrial consumption of gold in such things as dental fillings, earrings, and other impedimenta of that kind; the other is the consumption of gold in Eastern countries for the purpose of hoarding. From the present standpoint, whether I buy earrings, and give them to my wife, who sometimes wears them, has no direct effect on the price level, though a powerful indirect effect. If people were to give up wearing gold as ear-rings, or using it as dental fillings, and if the Eastern potentates ceased to keep the cellars beneath their palaces stocked with gold, there would be so much more gold for the third use, which is monetary. Before the war gold was actually in circulation as an everyday part of the stocks of the world, but in the modern world the only monetary use which gold possesses is to be stacked in the cellars and vaults of the various central banks of the world. The quantity of gold which the central banks need keep against their liabilities is a matter over which the central banks, taking them altogether at any one particular moment of time, have complete control. In the modern world, in which gold is no longer in circulation, all central banks would recognize that the whole of the gold which they possess is required only for one reason, namely, to settle those temporary deficits in the international balances of payments which sometimes arise. If you have a panic in Australia, in England, or the United States of America, you do not meet that panic by the banker unlocking all his vaults and throwing sovereigns over the counter. You meet the panic in the modern world by paying out notes of the central bank, and you cannot do it in any other way. You want the gold for one purpose, and one purpose only: if French creditors of the Bank of England, for instance, demand payment of their indebtedness, they can be paid in gold at a moment's notice; or, if the London money market is on balance a debtor to New York, the only real function of the gold reserve of the Bank of England is to enable the bank to ship gold to New York at a moment's notice. In other words, the gold stocks of the central bank have one purpose, and one purpose only. There are certain people who think that unless the bank holds a certain amount of gold its notes will not circulate. That is absolute nonsense, because during the war they circulated perfectly freely. The only function that gold reserves serve in the modern world is as a medium by which you can settle temporary deficits in the balance of payments. 
But very important consequences follow that. If you look at the balance sheets and the constitution of the majority of the central banks in the modern world, you find they are required to keep a certain minimum reserve ratio against liabilities. For instance, the Federal Reserve System is required to keep actually in gold against any note issue a minimum of 40 per cent, and against deposits 35 per cent; but, in fact, if ever there were an internal panic in the United States, it would be met, not by paying out gold over the counter, but by paying out more notes. The only reason why the Federal Reserve System wants to keep all that is in case it has to make payments, or in case the American money market as a whole has to make payments, to other parts of the world. It does not require it for internal purposes, but for international payments.

Upon these very simple facts we economists rest the whole of our case for the international functioning of the central banks in the sphere of monetary regulation. We say that if only they will adjust the value of credit to the price level, instead of adjusting the price level to the value of credit, they can exert a pressure in the direction of stabilization. You may ask how can they do it. They can do it by not worrying if they happen to hold only 25 per cent of gold against the liabilities, instead of 35 per cent. In other words, as the price level falls, you work it back towards a position of greater stability by increasing the volume of credit against a given gold basis. That is the only way in which the central banks can affect the problem; but, if they were to do it, it would affect the problem in the shortest possible way.

Why do they not do it? The answer to that is a very complicated one. Let me indicate two reasons at least why this is not so easy as it looks at first sight. In the first place, there is a very large number of central banks in the world, and some of them are governed by persons of very much less economic intelligence and foresight than others. It is no use grumbling about that, but the fact remains that the degree of intelligence possessed by central bankers is not evenly distributed amongst all of them. There are some of them, like the governor of the Bank of France, who think that it is the aim of a central bank to accumulate, in the course of the financial year, more gold than is actually produced in the year, and avail able for addition to the monetary stock. If you have that kind of central bank, it is quite clear it is no good for economists to go around preaching the virtues of disgorging the quantity of gold you possess. If all the central banks behaved like the 
Bank of France, you simply could not attempt co-operation at all. In the second place, even certain central bankers who possess a high degree of intelligence, and are friendly towards other countries, are responsible to populations not so highly educated as themselves. One of the difficulties of the modern central banking world is to secure the co-operation of the Federal Reserve System with the rest of the world in a combined and definite way. This reflects no discredit, say, upon the directors of the New York Reserve Bank, who are assisted by a highly competent economic and statistical staff, who are perfectly normal and well-educated human beings. Unfortunately, they are surrounded by hordes and masses of voters, who are neither intelligent nor highly educated, and who very strongly object to what they would describe as the entanglement of the Federal Reserve System, with the nefarious complications of European central banking. So long as the average middle-western voter holds this opinion we are not likely to get very much further with co-operation. If all central banks were agreed, it is not clear that the population which surrounds the central banks would fall in with the views which the central banks desire to express, and the policies they would desire to carry out. Therefore, although it is as clear as daylight that the problem of the stabilization of the price level can only be achieved, if it is going to be done at all, through the intimate co-operation of the central banks of the world, we think it is not clear as yet that we have reached a stage when central banks can effectively cooperate to secure this particular end.

Even if you had the whole of the central bankers of the world unanimous on this particular subject there is still one difficulty to which I want to draw your attention - the last of the many difficulties to which I have drawn your attention to-night. You can, as an international group of central bankers, do your best by the expansion of credit - in other words, by the reduction of reserve ratios, by the reduction of bank rates, the purchase of securities in the open market, and what not to increase the volume of credit, and therefore raise the price level, but it would be mere affectation to pretend that this is not a process which may take much longer than people think. For instance, the New York slump is already eleven months old. It came at the end of October, 1929; nevertheless, in spite of the fact that every central bank in the world has been pushing its bank rate down ever since, and that bank rates are still falling, prices are still falling too. In other words, there is a time lag in these things, and it is sometimes of very long duration. In other words, again, you have not only to face certain technical difficulties 
of co-operation between the central bankers, but you are face to face with the difficulty that you must not expect a very intricate, a very highly integrated and complicated modern economic system, to respond to the efforts of central bankers as easily as a modern liner responds when you turn the wheel a little bit one way or the other. If economic life were as easily adjustable as that, it would be a highly delightful and very satisfactory thing; but, unfortunately, economic systems are much more rigid and less amenable to direct control than one would think at first sight. I am convinced in my own mind that the problem of prices, if it is going to be solved at all, must be solved by the agency of central bankers; but I am bound to admit that the process of solving this particular problem is much more heartbreaking than it appears at first sight. For all these reasons it is just as well that there has been created one agency, which, in the course of years, certainly not in the immediate future, certainly not in the next twelve months, but in the long run, may help to overcome some of these difficulties. That is the institution that was created under the last definitive reparations settlement, namely, the so-called Bank of International Settlements at Basle. The Bank of International Settlements, in the first instance, was created to take the place of the old reparations machinery, by which Germany transferred reparations to her European and her American creditors; but the Bank of International Settlements contains the germ of a very fruitful institution, namely, it contains implicitly the idea that the central banks of the world should have for themselves a central bank with which they should all bank. Just as the commercial banks of a country, by banking with their central bank, can economic reserves, so, if all the central banks of the world were to keep their entire gold stocks with the Bank of International Settlements at Basle, in the end they could practise a highly desirable and highly useful economy of gold reserves. Of course, I need not conceal from you that we are very far from the day when the governor of the Bank of England, and particularly the governor of the Bank of France, will be willing to transfer the whole of their gold reserves to the keeping of a new institution in Swiss territory. There is the germ of a new international central banking order in the creation of the Bank of International Settlements, but it is only a germ. Mean while, the Bank of International Settlements serves a highly desirable purpose, because it represents a private meeting place for the heads of the various central banking institutions all over Europe. One of the difficulties connected with getting conferences of central bankers together is that everyone begins to ask, Why do they want a conference 
at this particular moment? And at once you have a renewed wave of uncertainty and unrest; but through the creation of the Bank of International Settlements the heads of the central banks can meet at Basle, and nobody takes too much notice. Of course, astute journalists all over Europe invent explanations of what central bankers say and do; but, in the course of time, every one will accept it as a perfectly normal thing that, once a month, or once every two months, Mr. Norman and the president of the Reichsbank should go to Basle and discuss the affairs of the Bank of International Settlements. To sum up, the problem of prices has not been solved. Even the problem of how to tackle the question has not been solved; but we have done two things in Europe. We are beginning to see the way in which the problem of prices must be solved, and we are beginning to understand the kind of machinery which will help us to solve it. 



\section{5}

\section{Australia's share in international recovery}

\section{Alfred C. Davidson ${ }^{1}$}

Having read the list of previous lectures under this Foundation, it is with the greatest diffidence that I address you this evening. Not only must I follow men of high academic distinction. My old chief, Sir John Russell French, during whose tenure of office as General Manager I joined the service of the Bank of New South Wales, delivered the fourth Joseph Fisher Lecture. He spoke in 1910 on the subject, "Banking as a Factor in the Development of Trade and Commerce". Those were halcyon days, when bankers, in common with other Australians, viewed their task as one of assisting in an expansion to which imagination set scarcely any limit. Much has happened since to dispel the mirage of infinite development. We no longer take it for granted that these Southern Dominions live in a happy world of their own, remote from Europe's wars and America's racial hates. Indeed, the remark of my immediate predecessor, Professor T. E. Gregory, that we in Australia had probably never heard of the Wall Street boom because we had one of our own, seems to-day almost savage in its irony. It was a little unkind even when it was uttered in 1930. Your own State of South Australia had emerged from its latest boom long before the middle of 1929, when some in Wall Street were still speculating on a "new era" of permanent prosperity and the rest were speculating on their fellow speculators.

I would not even concede that Australians outside this State (South Australia) were unaware in 1929 of what was happening overseas, nor did they miss its immense significance to Australia. It was in January of that year that the last of our long-term loans was raised on the London market. It was in September, 1929, that the Bruce-Page Administration fell in a first attempt to adjust the Australian economy to its changing task. We were early aware that in the absence

$1 \quad$ Fifteenth Joseph Fisher Lecture, 14 July 1932. 
of easy borrowing we would have to meet our commitments overseas by increased production at lower costs. But the change over was not easy.

In taking as my subject to-night, "Australia's Share in International Recovery," I shall confine myself to our island story, avoiding any discussion of the causes of the world-wide depression. I do so merely in order to mark out a subject-matter capable of treatment within the time at our disposal. All of us are painfully aware of our dependence on the prosperity and adversity of the big world. We sell in its markets nearly a third of the value of our production, even after reckoning export values at free-trade prices and our home consumption at the prohibitive prices that "protection" inflicts. But as a people we are too small a toad under the harrow of adversity that torments the world to control the forces that draw the harrow. We can but watch its sharp spikes and dodge them as best we may.

In the graph before you (Figure 15.1) is depicted the course of American wholesale prices, a convenient record of the change which occurred in 1929 in the trend of the purchasing power of gold, then the international money of the world. From 1923 to the middle of 1929 there was, on balance, a slight sagging in gold prices, but, substantially, the restored and extended gold standard fulfilled the hopes of those who, at Genoa in 1922, recommended its restoration. The essential condition of the satisfactory working of this system was the flow of investment from creditor countries to debtor countries. During the period 19241929 inclusive United States investment abroad averaged 1,070 million dollars per annum and Great Britain 118 million pounds sterling per annum. It was when this investment ceased that the system threatened to break down. The international trade facilitated by the gold standard gave until 1929 a reasonable stability in price levels as well as in exchange rates between the moneys that were linked by it. Since then the very opposite has been true. Monetary stability and expanding international trade have given way to shattered prices, discouraged enterprise, and universal unemployment. Gold prices, as you may see by this graph, based on Bradstreet's Index of Wholesale Prices, have fallen in United States dollars, one of the two great currencies still convertible into gold, from a level of 98.3 in September, 1929, to 53.2 in April, 1932. Taking Irving Fisher's Index of Wholesale Prices, the fall between the same dates has been from a level of 98.3 to 62.4 . In both instances these are the latest figures available. Steeply falling prices always and inevitably mean unemployment. Buyers hold off, intending 
to enter the market only when bedrock is reached. Producers fear losses, which, indeed, are all too likely when costs are incurred at one level and goods are sold at a later and lower one.

When, less than two years ago, Professor Gregory delivered the last preceding lecture under this Foundation, he estimated the total number of unemployed all over the world, including Russia, at about ten million persons. "That," he said, "is a part of the problem of price-level at the present time, ... one of the most serious and difficult of any of the; economic problems we have had to face in the lifetime of any man now living". Professor Gregory was then in hopes that prices would be somewhat higher by the end of 1931 than at the end of 1930 . They proved to be lower both in gold and in sterling. In fact, gold prices fell a further 18 per cent, and even sterling prices, in spite of the departure from gold, were lower (about 3 per cent). And the number of unemployed is now at least twice, probably nearly two and a half times what it was in 1930, viz., between twenty and twenty-five millions.

\section{Figure 15.1: United States wholesale prices}

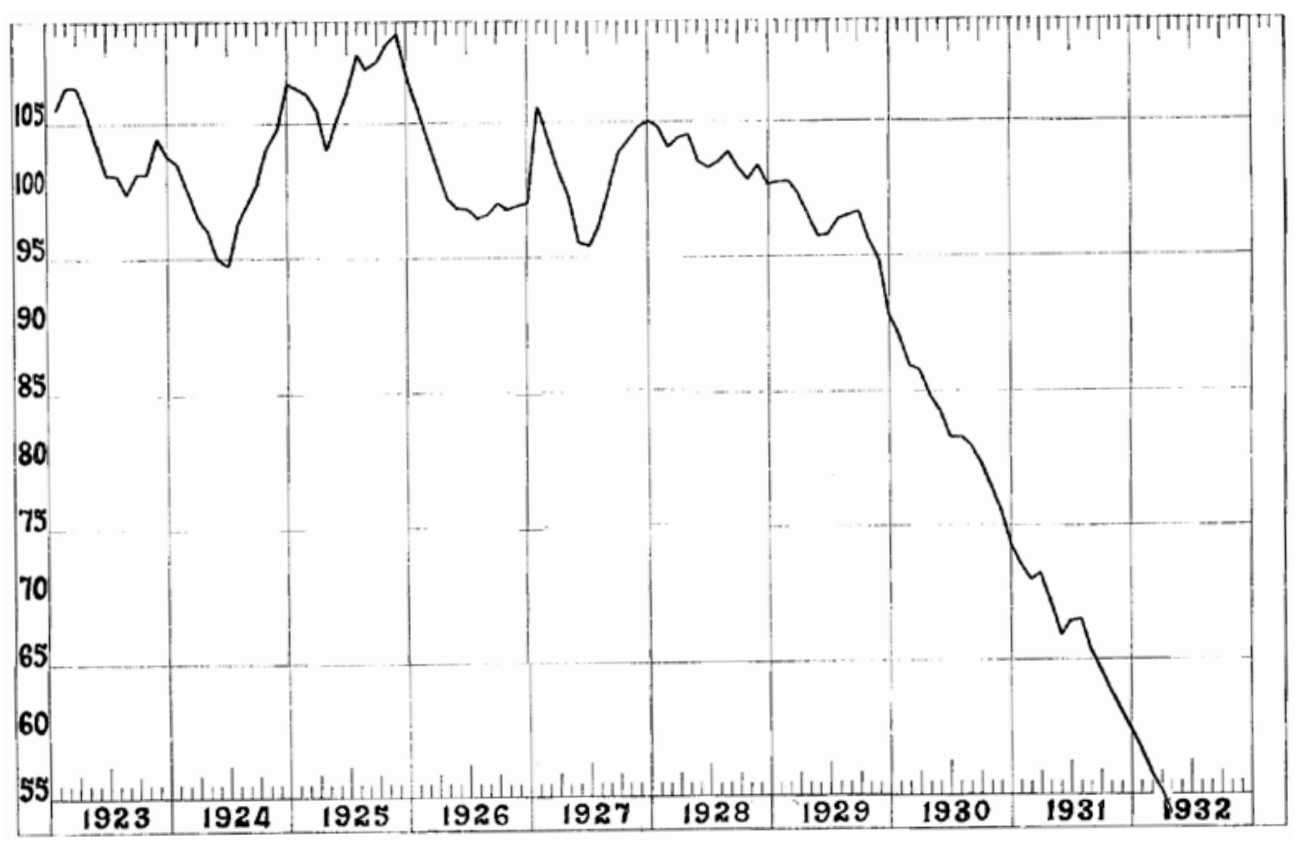


Figure 15.2: Wool prices, showing divergences of Gold, Sterling and Australian

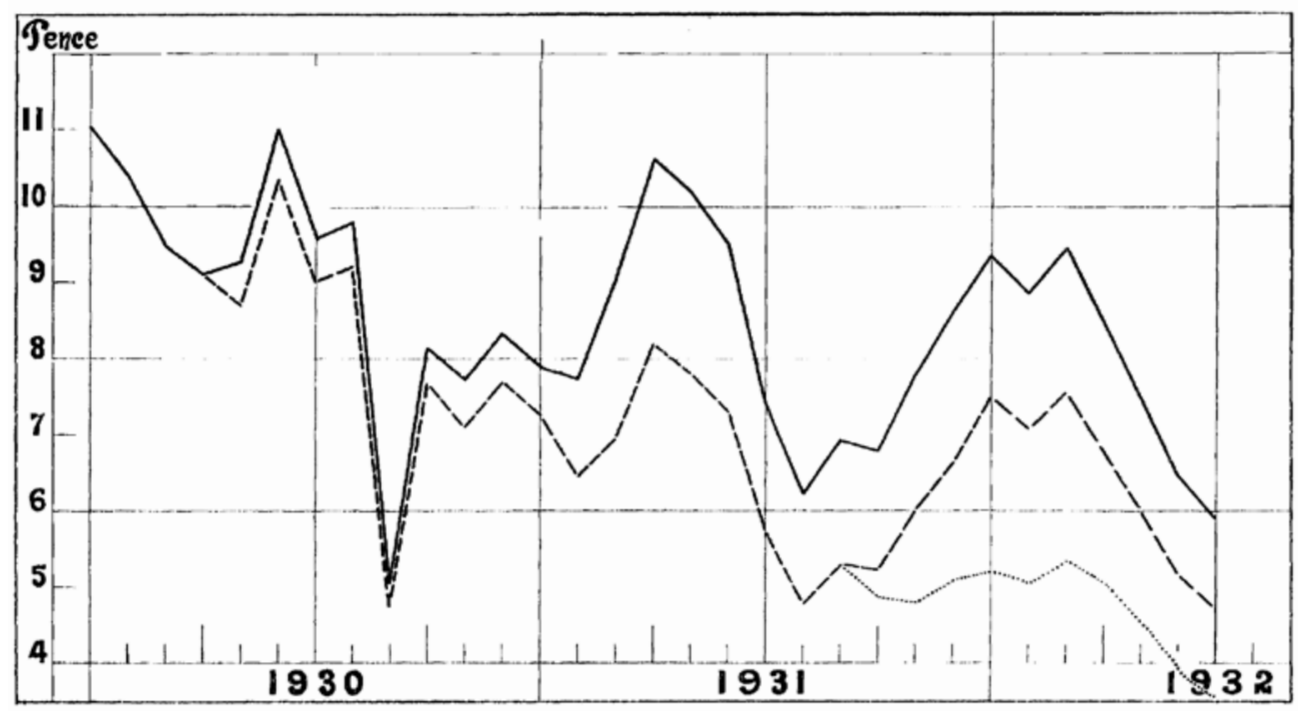

Figure 15.3: Wheat prices, showing divergences of Gold, Sterling and Australian

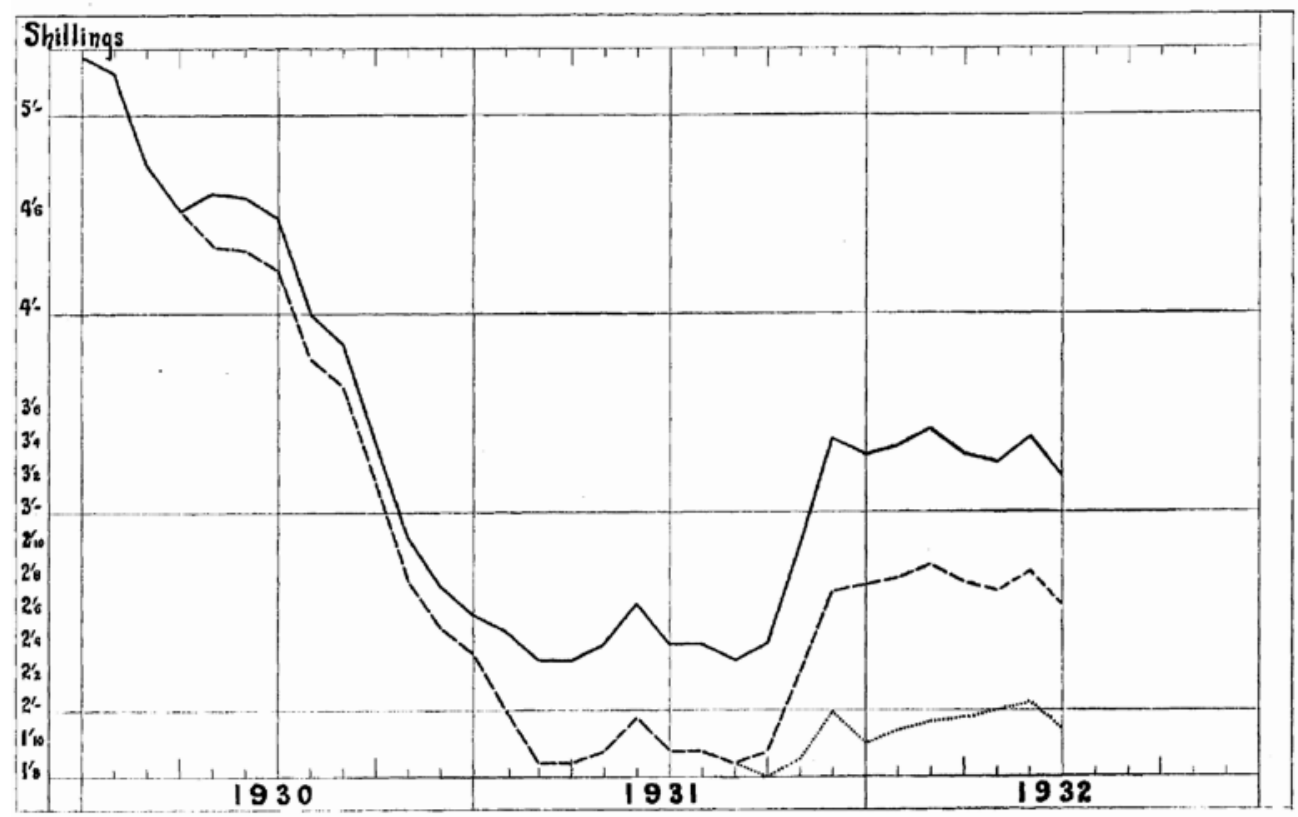


Figure 15.4: Lead prices, showing divergences of Gold, Sterling and Australian

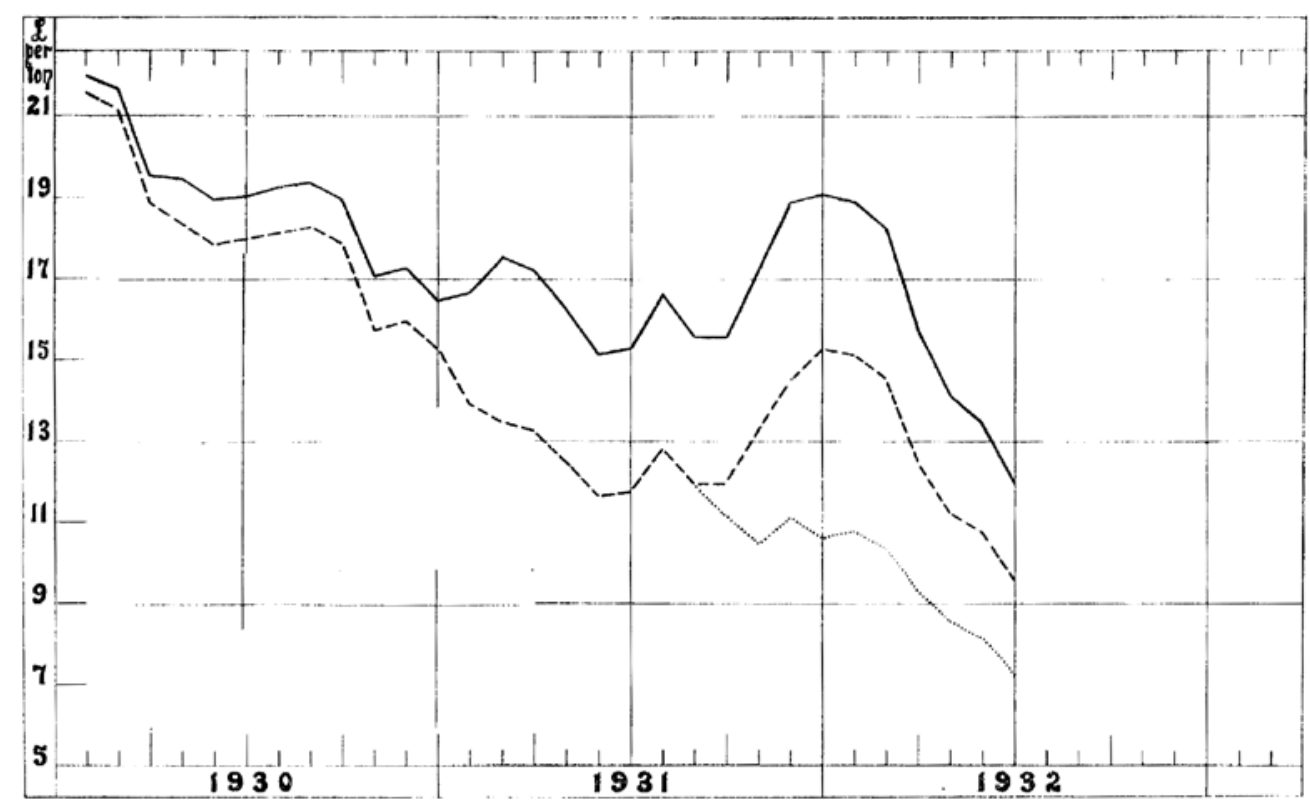

Figure 15.5: Wholesale prices

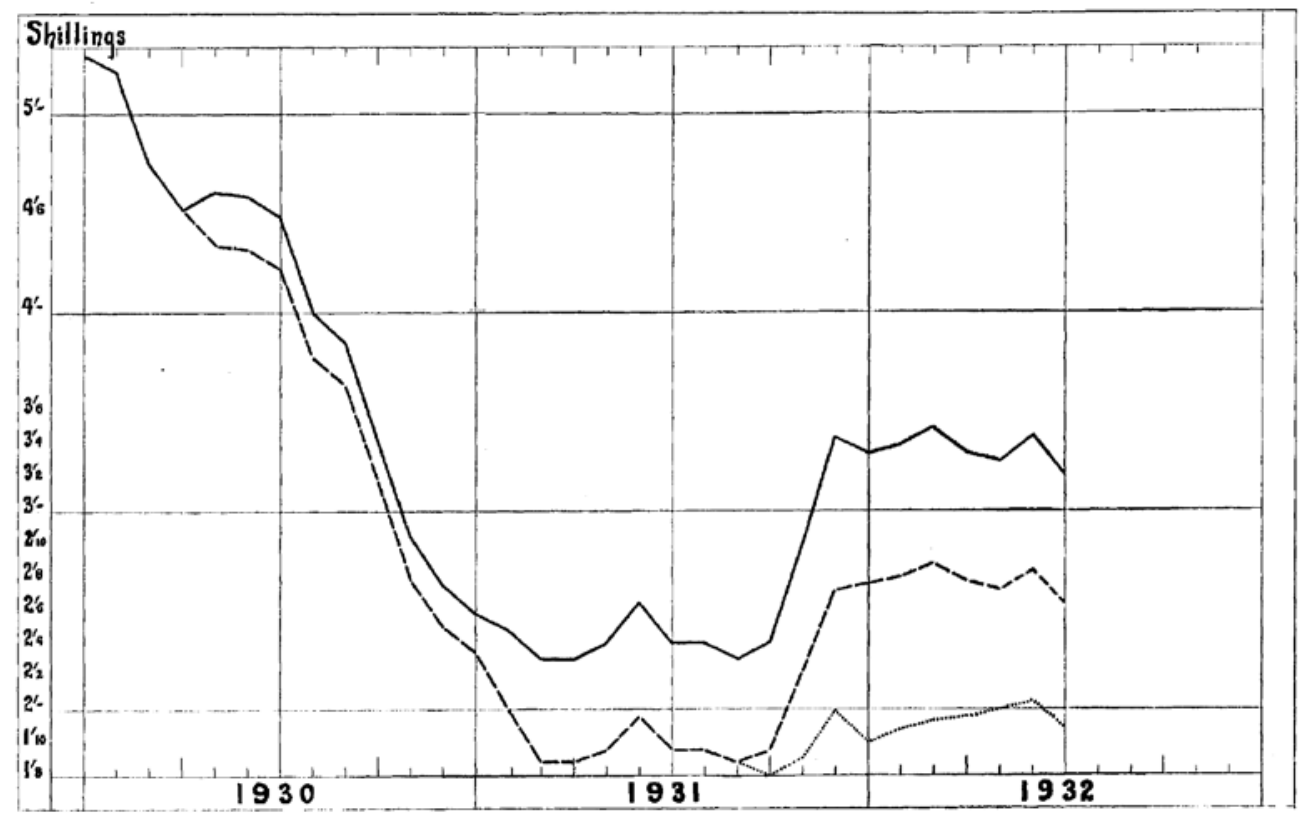


It would take me too far into the field of international economic history to trace in detail the reasons for that disappointing drift. The main reason for it was the financial crisis from June to September of last year. This was an inevitable consequence of the unstable financial and economic position of Central Europe, and was precipitated by the revelation that the big Austrian bank, the Credit Anstalt, was in an insolvent condition, and by the runs on the German banks and on the Bank of England which this set going. The financial crisis deepened the economic crisis by causing almost all nations to redouble their efforts to sell exports and to limit imports, thereby forcing prices still lower and raising fresh barriers to international trade.

Professor Gregory was convinced that the problem of falling prices, "if it is going to be solved at all, must be solved by the agency of central bankers; but I am bound to admit", he added, "that the process of solving this problem is much more heart-breaking than it appears at first sight". The events of the last two years have lent a gloomy emphasis to my learned predecessor's admission. In Australia, however, the intervening years have witnessed a not unsuccessful resistance to what at one time seemed overwhelming odds against us. We have hung on. We have even made some headway, notably in this State (South Australia). Men of every political party and of every calling have played their parts in this truly national effort, but I trust you will pardon a banker for claiming first rank for the leaders of his own profession, the Chairman of the Commonwealth Bank Board and the Governor of the Commonwealth Bank. We are not out of the wood, and therefore we owe them still our active support and counsel in the still difficult and doubtful contest.

For two reasons the initial impact of the collapse in prices was more severe upon our Australian economy than on almost any other. To one of these reasons I have alluded already. The depression made an end, for a time at least, of our public credit as borrowers overseas. We had thus to make a sudden right-aboutturn. Instead of borrowing some $£ 30,000,000$ a year, a sum roughly offsetting the annual interest owing on all earlier loans, we were called upon to meet that interest burden by a surplus of exports over imports. To make that transition feasible under conditions of individual production and trading, we needed a change in the relation of costs to prices sharp enough to attract substantial numbers out of capital construction-trades into the production of additional exports or of consumption 
goods that would supplant imports. Capital construction-trades may be taken to be trades which produce "buildings, factories, machines, equipment for transport and public-utility enterprises and the like." For the major part of our economic activity we are still organized on individualistic lines. Only under the attraction of a wider margin of profits in the appropriate industries could the re shaping of our national economy be achieved.

The other reason which made the collapse in gold prices more severe in Australia than elsewhere was the especial severity of the fall in the prices of wool, wheat and base metals, our principal ex ports. (See Figures 15.2, 15.3 and 15.4). Professor Melville, whose accuracy and industry in statistical work is not unknown to you, has reckoned the fall in the gold prices of our exports since 1926-27 at no less than 68 per cent, and I understand that Professor Giblin, the Acting Commonwealth Statistician, confirms that calculation. Very evidently heroic measures were needed to prevent the collapse of our whole economic structure under such a bludgeoning by fortune. We have taken heroic measures and we have held on. Only just held on, it may be. What more could be expected while the world depression was deepening? World gold prices of our exports have fallen nearly a third since the Premiers' Plan (10 $0^{\text {th }}$ June 1931) was drawn up. Yet as a nation we are entitled to draw from a retrospect of what we have achieved courage to continue the fight.

The first aim of the Premiers' Plan was to preserve the credit of all the Australian governments. This was done by concerted economy in expenditure on wages, salaries, pensions and interest, and by increased taxation. But for these measures deficits in all the States would have mounted up as did that of New South Wales when the Lang Government evaded its part of the task. Uncontrolled deficits would have caused a flight of capital and a collapse in the value of securities of all kinds, endangering the whole financial structure and all the savings of the Australian people.

But the Premiers' Plan, as I need hardly remind an Adelaide audience, went beyond the problem of government finance. It dove tailed with other measures set on foot earlier in 1931 to reduce costs throughout the Australian economy. The imperative need of reduction in costs stood out from the figures that I quoted as to falling overseas prices and from our inability to raise those prices. If production 
and employment were to continue even to the degree that remained after the first slump in 1929-30, a margin or hope of profit had to be left to the producers of exportable goods. In January, 1931, the Commonwealth Court of Arbitration had given a lead to all our wage-fixing tribunals by reducing the wages covered by its awards by ten per cent over and above the cost-of-living adjustment of the basic wage. Equity suggested that this cut in real wages should be balanced by corresponding reductions in interest and in rents. But it is obviously dangerous to break into contracts save under the clearest mandate of national necessity. Perhaps the highest merit of the Premiers' Plan is that it succeeded in this difficult task, co-ordinating action by the banks, other financial institutions and private creditors to effect these reductions and that in the result it strengthened rather than injured the confidence of investors in Australia. Not without legislative pressure but mainly by voluntary action interest rates have been reduced on an average by well over 20 per cent.

Even so, had wages and salaries, interest and rentals been cut by twenty per cent., and nothing else done, the adjustment of Australian costs would not have restored a margin, nor even a hope of profit to the exporting industries. The reductions directly made were supplemented, fortunately, by an indirect reduction universally and smoothly achieved by the fall, between October, 1930, and January, 1931, in the exchange value of the Australian pound. This meant that all Australian prices were re-stated in a unit of smaller and, incidentally, of more stable purchasing power than the pound sterling. Reference to Figure 15.5 (Wholesale Prices) shows that the wholesale price level in Australia since January, 1931, has been relatively stable during a period of acute decline in all other whole sale price levels. The fall in the exchange value of the Australian pound made no direct increase in the national income. It merely translated the sterling incomes of exporters into more numerous Australian units and in so doing redistributed the real income of local products and imports somewhat more favourably to exporters, somewhat less favourably to sheltered industry and to consumers and taxpayers generally. Indirectly, however, the fall in the ex change value of the Australian pound did increase the national income. It maintained production at record volume in the all-important industries, thereby preventing the appalling increase of unemployment throughout the community that would have followed the collapse of the wheat-growing and the grazing industries. Collapse is by no means too strong a word for the position into which rural production would 
have been forced had wheat and wool continued to fetch prices at the Australian seaboard as low as their gold or even sterling prices. (See Figures 15.2 and 15.3).

It is true that Australia has been faced with serious budget deficits in the past three years. Thanks to the Premiers' Plan these were brought under control.

Table 15.1: World prices of Australian exports, 1929-32

\begin{tabular}{l|l|l|l}
\hline & $\begin{array}{l}\text { Sterling and Gold March } \\
\mathbf{1 9 2 9}\end{array}$ & Sterling May $\mathbf{1 9 3 2}$ & Gold May 1932 \\
\hline Wool & $16.67 \mathrm{p}$ per pound & 5.18p per pound & 3.92p per pound \\
\hline Wheat & 5 s 3.5d per bushel & 2s $8 \mathrm{~d}$ per bushel & 2s per bushel \\
\hline Lead & $£ 2510 \mathrm{~s}$ per ton & $£ 1015 \mathrm{~s} 5 \mathrm{~d}$ per ton & $£ 83 \mathrm{~s}$ per ton \\
\hline Zinc & $£ 273 \mathrm{~s} 6 \mathrm{~d}$ per ton & $£ 1211 \mathrm{~s} 1 \mathrm{~d}$ per ton & $£ 910$ s per ton \\
\hline
\end{tabular}

* Wheat figures for December, 1929

They have been financed by short-term Treasury Bills discounted by the Commonwealth Bank. To make these Treasury Bills a negotiable money market security which can be dealt in by the trading banks the Commonwealth Bank has under taken to re-discount them at all times should the ordinary business requirements of a trading bank make such desirable. This arrangement makes it possible for the trading banks to take quantities of these Treasury Bills off the hands of the Commonwealth Bank as their liquid funds become available for such forms of investment. The effect of this type of finance, provided it is rigidly controlled and budget equilibrium is in sight, is to increase both the liquid reserves and deposits of the banks and to sustain internal prices. The changes in the cash position of the Banks during the past two years are worthy of mention. The first column in the table below shows the effect of Treasury Bill finance. The second column shows firstly the effect of the transfer of the gold of the trading banks to the Commonwealth Bank acting as the Central Reserve Bank for Australia, and secondly that the Banks are using their balances at the Commonwealth Bank to supplement their holdings of Australian notes in place of their holdings of coin and bullion as was done previously. In a time of depression we should expect to find a considerable shrinkage of the total deposits of the trading banks. That deposits have increased during the last nine months is due largely to Treasury Bill finance. 
That these measures have resulted in an enlightened banking policy in Australia is confirmed in a statement made by no less an authority than Professor T. E. Gregory. Writing in the Royal Bank of Canada's Circular of October, 1931, he remarked: "The efforts of the politicians must be seconded by the central banks - a concerted effort must be made (primarily through the financing of budgetary deficits through central bank credit) to cause a rise of prices."

Equilibrium, in the sense of a balance of prices and costs which admits of continued exchange between various commodities and services is the very essence of economy. To restore it is to restore purchasing power. Every approach to such a balance of prices maintains employment in the sense that it slows up the decline in spending power that goes with losses. In this way the three Australian adjustments to which I have referred, all made in 1931, viz. (i) Wages and salary reductions, (ii) Interest and rental reductions, and (iii) the fall in the exchange value of our pound, made up a well co-ordinated plan to restore industry and employment.

They were favoured and eked out by the luck of two excellent seasons in succession, taking the Commonwealth as a whole. Wheat, wool, and butter products the volume of which is markedly affected by drought make up 70 per cent of our exports. In the twelve years after the war there were five good wheat years, three under average, and four decidedly bad. In wool production three of the last ten years were good, five poor, and two bad. I am generalizing for Australia as a whole. In butter production only one year prior to 1930, viz., 1924, saw a volume of output comparable to those of the last two years. They say in New South Wales that you may expect one good, one fair, and one bad year in three. Both 1930 and 1931 were, on the whole, excellent seasons. But such luck cannot continue indefinitely, and an average season would cut a fifth off our volume of exports, a bad season two-fifths or more.

Far be it from me to minimize the degree of success achieved by Australians in adjusting our economy to the apparently hopeless task that faced us in 1930 . Let me rather emphasize again what we were called upon to do and the big thing we have done. 
Table 15.2: Cash position of the trading banks

\begin{tabular}{|c|c|c|c|c|c|c|}
\hline Quarter & $\begin{array}{l}\text { Balances due } \\
\text { by Cwlth. } \\
\text { Bank to } \\
\text { Trading Banks }\end{array}$ & $\begin{array}{l}\text { Coin and } \\
\text { bullion }\end{array}$ & $\begin{array}{l}\text { Australian } \\
\text { notes }\end{array}$ & $\begin{array}{l}\text { Total } \\
\text { cash }\end{array}$ & $\begin{array}{l}\text { Total } \\
\text { deposits }\end{array}$ & $\begin{array}{l}\text { Ratio of cash } \\
\text { to deposits }\end{array}$ \\
\hline & Em. & $\mathfrak{E m}$. & Em. & Em. & Em. & $\%$ \\
\hline \multicolumn{7}{|l|}{1929} \\
\hline Dec. & 8.4 & 21.3 & 13.0 & 42.8 & 277.6 & 15.4 \\
\hline \multicolumn{7}{|l|}{1930} \\
\hline March & 13.5 & 14.6 & 14.4 & 42.5 & 274.7 & 15.5 \\
\hline June & 16.9 & 4.6 & 16.0 & 37.6 & 268.6 & 14.0 \\
\hline Sept. & 15.7 & 2.7 & 17.4 & 35.8 & 262.5 & 13.6 \\
\hline Dec. & 20.8 & 2.1 & 16.8 & 39.8 & 263.4 & 15.1 \\
\hline \multicolumn{7}{|l|}{1931} \\
\hline March & 29.7 & 2.1 & 17.1 & 48.9 & 263.3 & 18.6 \\
\hline June & 32.2 & 2.0 & 18.9 & 53.1 & 259.9 & 20.4 \\
\hline Sept. & 23.0 & 2.0 & 20.3 & 45.3 & 255.8 & 17.7 \\
\hline Dec. & 22.2 & 2.1 & 18.6 & 43.0 & 268.5 & 16.0 \\
\hline \multicolumn{7}{|l|}{1932} \\
\hline March & 32.1 & 2.2 & 18.9 & 53.2 & 282.3 & 18.8 \\
\hline
\end{tabular}

For these three tables I am indebted to the Acting Commonwealth Statistician, Professor Giblin. From 1923 to 1929 the balance of our annual payments was roughly this:

1923-29 Average yearly $\mathfrak{E m}$. gold

\begin{tabular}{l|l|l|l}
\hline Imports & 151 & Exports & 147 \\
\hline Interest and Sinking Fund & 26 & Loans & 27 \\
\hline & & "Deficiency" & 3 \\
\hline & 177 & & 177 \\
\hline
\end{tabular}


The deficiency was probably covered by imports of private capital. The onset of the depression created this prospect for 1931-32, if we had gone on as from 1923 to 1929:

1931-32 Hypothetical (Em. gold)

\begin{tabular}{l|l|l|l}
\hline Imports (at 1923-29 volume) & 83 & Exports (at 1923-29 volume) & 48 \\
\hline Interest and Sinking Fund & 30 & Loans & 0 \\
\hline & & "Deficiency" & 65 \\
\hline & 113 & & 113 \\
\hline
\end{tabular}

To maintain our position as in pre-slump years we should have needed, therefore, an added $£ 65,000,000$ of exports (i.e. a total of two and a third times the old volume). To the extent that we failed in that impossibility, we had to make some equivalent adjustment by reduced imports or reduced oversea payments. It seems an incredibly difficult undertaking to achieve against such odds a favourable balance of payments, but it has been done. This is our actual tally for 1931-32:

1931-32 Actual (Em. gold)

\begin{tabular}{l|l|l|l}
\hline Imports & 36 & Exports & 64 \\
\hline Interest & 21 & & \\
\hline "Surplus" & 7 & & \\
\hline & 64 & & 64 \\
\hline
\end{tabular}

Dividends to oversea shareholders and payments for services, such as shipping and insurance, must come off the "Surplus," leaving perhaps an addition to London balances of $£ 4,000,000$ gold on income account. It would be foolish to minimize that achievement, but we must not claim that it has been done by hard work alone. Reduction of imports has accounted for $£ 47,000,000$ (gold prices) out of the improvement of $£ 72,000,000$ in the actual as compared with the hypothetical position. (From a deficiency of $£ 65,000,000$ to a surplus of $£ 7,000,000)$. That cut in imports has been largely at the expense of Britain, lessening her market here. An increase in the volume of exports, by one third, has added a more constructive $£ 16,000,000$ at gold prices. Britain's depreciation of sterling has reduced the cost to us of interest payments overseas by about $£ 6,000,000$ in terms of gold. Her postponement of interest and sinking fund on the war debt has let us off another $£ 4,000,000$ at gold prices. 
Taken by and large, the change-over is an astonishing achievement. But foresight and experience join in warning us that it is as yet a precarious one. The most highly regarded statistical service in Britain, published by the London and Cambridge Economic Service on April 20, 1932, sums up the general business position there as one of "continued and perhaps accentuated worldwide depression, in which the only favourable features are the improving financial positions of Australia and India." Considering how we stood two years ago, our position certainly has improved. But we shall need, I submit, to fight to maintain that improvement. Yet we may draw courage from the fact that we have learnt to use the weapons at our disposal.

In sizing up the further action needed in Australia it will help if we recall the atmosphere in which the Premiers' Plan was adopted in June last year. During March, April, and May, 1931, the fall in world prices had slackened and ceased. Hopes were entertained of a settlement of Europe's political tangle over reparations and war debts. The long-expected recovery in prices seemed close at hand. There was thus the fullest justification for the reluctance of the Premiers to impose on the Australian people any sacrifice heavier than that needed to hold the fort until oversea prices rose. Unhappily the hopes then held were disappointed. President Hoover's bold move towards a settlement of reparations and war debts was frustrated by indecision and delay. Financial crises followed in Austria, Germany, and Britain. The prices of our exports, after a short-lived rise in October and November, have tumbled afresh. Even so the Premiers' Plan succeeded remarkably in restoring the public credit of Australia and in checking the growth of unemployment. Under more favourable auspices it is plain that it would have put us well on the road to recovery.

Our present position is, I suggest, precarious. The trend of sterling, as well as of gold prices, has been again sharply downwards, and we cannot count on the indefinite continuance of the run of good seasons and exports at new record volumes year after year. The pending stabilization of sterling at a low rate at some future date, the decline in money rates in London, the recent central bank policy of America, and the remarkable success of the British Conversion Loan offer some hope that this downward trend of prices is coming to an end. But the recovery required to place Australian export production on a sound basis is so great that we cannot hope for immediate relief from this source. A mediocre 
season would work havoc among the marginal wheat farmers and pastoralists, who have hung on at the cost of some deterioration in their properties and of growing indebtedness. Nor is there wanting evidence of the decline of profits in all businesses. The severity of the depression in our main industries would lead one to expect this.

Of the 266 Australian companies whose profits and losses for 1929, 1930, and 1931 were collated recently by my friend, Mr. A. E. Heath, of Sydney, only 8 showed losses in 1929. In 1930, 20 showed losses, and in 1931 some 83 did so. In 1929 these 266 companies, belonging to all the chief cities in Australia, and including many of its leading commercial and financial houses, declared a total profit of $£ 16,775,264$. In 1930 the corresponding figure was $£ 13,807,941$, and in 1931 it was $£ 7,023,501$. There is probably no one in this room who has not instantly reflected that for 1932 the position disclosed in the published accounts will be worse. And while I have been saying that you have been thinking that not all the leeway will be disclosed.

Another effort is therefore needed to stop the rot, to restore the hope and chance of profit throughout Australia, and thereby to sustain the very creditable effort we have made and are making. The Premiers' Plan of June, 1931, so far succeeded that it paved the way.

The new effort which will be shaped at the present or at subsequent conferences of the Premiers may be expected to broaden and straighten out that way. But the events overseas since June, 1931, have warned us against too heavy a use of the method of reduction, of forcing down. To bring and to keep Australian costs below prices that are continually falling would require continual cuts in wages and in interest. Such a process would condemn business to the depressing prospect of further falls in prices. As costs fell the desperate competition to maintain turnovers would mean further price reductions and further cost-of-living adjustments. The result would be a vicious spiral into abysmal and indefinitely prolonged depression. For employment cannot revive so long as every enterprise must face the sale of its products at price-levels constantly undermined by further cuts.

There are evident reasons, partly of a budgetary origin, partly in relief of rural costs, for the rounding out in all States and industries of the reductions 
already made in interest and wages. But if we attempt to rely on deflationary measures alone to restore equilibrium we shall run grave risks of a financial crisis in Australia similar to that which occurred last year in Austria, Germany, and Britain, and has been avoided only with great difficulty in the United States. Indeed, a crisis in America has been averted only by the reversal of central bank policy through the action of the Federal Reserve Banks in buying large quantities of securities, and thus increasing the cash reserves and reducing the indebtedness of all member banks. Even this action has had to be supplemented by legislation creating special institutions to provide additional relief to weak banks and other institutions. A halving of prices means rather more than a halving of values. Financial institutions are borrowers as well as lenders. As their securities shrank in value so would their solvency. Not even the strongest of them could regard as wise a policy which forced the weakest to the wall.

Sir Wallace Bruce's committee of business men and economists showed, therefore, sound foresight in recommending that a limit should be put to the fall in wages and prices. They held that this could be done simultaneously with the rounding-out of wage reductions in New South Wales and of interest reductions throughout industry by setting in operation a force tending in itself to raise prices. That force has been tried and tested in Australia under conditions of confidence less favourable than those now ruling. I refer to the raising of the rate of exchange. If used in a measure and degree calculated to offset the price-dropping effect of wage and other reductions it would give us in Australia what we so urgently need as a basis for renewed investment and the employment it would bring, namely, a cessation in the fall of prices.

Interest is still falling, and will, I believe, continue for a time to do so if lenders continue to repose faith in the future of Australian industry. To ensure this a return of conditions that will admit of profit is essential. As interest rates fall under the pressure of a plethora of capital seeking security, we may look for an equitable balancing of reductions in labour costs and in fixed charges. But we cannot afford to wait indefinitely upon the grinding pressure of blind forces. We need very urgently the restoration of a stable equilibrium between prices and costs generally. Within our own economy a very considerable measure of adjustment can be made with safety under the monetary conditions that our struggle to pay our way has created. 
We may well regard an independent paper currency as less desirable in many ways than a currency linked by a stable rate of exchange with an international gold standard. but we were forced off the gold standard in November, 1929. Sterling, the mother currency, to which our own is linked by strong though elastic ties, was forced apart from gold in September, 1931. Being in possession of an independent paper currency, we shall do wisely to use the power that it confers of "adjusting the exchange to the level of costs." The phrase is Professor Gregory's, and I call him to witness to the merits of exchange management in a crisis like the present. In his latest book, written in November last, on "The Gold Standard and its Future", he argues for an ultimate return by Britain to gold at a devalued par. In the course of his argument he gives his considered judgment that, while a paper standard is in use, "the process by which, in the event of maladjustment, the position is corrected interferes less with the pecuniary status of individuals, and gives rise, therefore, to a smaller degree of social friction than is the case with a fixed exchange when the necessity for a downward revision of the scale of money incomes and fixed charges makes itself felt".

Candour and caution alike bid me underline Professor Gregory's warning that "the superior merit", in this regard, "of the paper exchange must not be overstressed". We in Australia have all along refused to rely on it alone. But, again quoting Professor Gregory (page 84), "it remains true that the method of adaptation which the paper standard permits is well adapted to the exigencies of a complicated society, in which changes in the general scale of money incomes in a downward direction are bound to be very unpopular".

At the moment Australia has the opportunity to restore a profit able basis to industry and investment by the middle way recommended by Sir Wallace Bruce's Special Committee. This includes action along three lines:

The completion of the cuts in interest and wages contemplated and assumed in the Premiers' Plan of June, 1931;

A drive for efficiency in all industries, enforced upon the protected secondary industries by a downward revision of the tariff; and

The prevention of a fall in prices consequent on these measures by an upward movement of the rate of exchange under the control of the Commonwealth Bank. 
For the successful operation of this policy certain conditions precedent may be stated: (a) It is highly desirable that the Commonwealth Bank, as the central reserve bank of the nation, should be in command of a large fund of London money, as a means of deterring speculators and of ensuring the accurate adjustment of the rate to the purpose of a stable economic equilibrium in Australia. (b) It is imperative that the autonomy of the Commonwealth Bank, as an institution seeking simply and solely the welfare of the whole nation, should be respected and safeguarded in every way. (c) It is equally necessary that the Commonwealth Government should stand behind the central reserve bank and relieve it from the fear of loss or the hope of gain as a result of its activity in managing the exchange.

The second and third of these conditions precedent are matters within the decision of our financial and political leaders. The first is an economic condition, and is therefore not wholly within the control of the human will. At the moment, and probably for nine months to come, the Commonwealth Bank has within its reach the power to build up such a London reserve. In the event of reasonably good seasons it may by wise action extend that power further into the future. But in order to do so the profitable character of production and industry, without which an individualistic economy slows up and ceases to function, must first be restored. This calls for higher efficiency, of course. But the costs of the efficient producer may be stated in terms of an appreciating unit of money or in a stable unit of money. To appreciate a monetary unit is to increase its value, or purchasing power. This is the same as saying that it lowers the general commodity price level. With falling or stable world prices at a low level, the value of the Australian monetary unit is appreciated by reducing the exchange rate on London. This means that the returns in Australian currency for our exports are reduced, the burden of costs of the exporting industries is increased, and their capacity to maintain and expand production weakened. As the whole Australian community is dependent upon these industries, it necessarily weakens the economic structure of Australia, both public and private, and asset values cannot resist the downward pressure.

Australia, Britain, and the Argentine have made a better showing than any other countries during this depression, largely because their price-levels have been more stable than those of the countries faithful to gold (Figure 15.5, Wholesale Prices). The suggestion which I am supporting is that we should follow up that hint as to the way out. To seek a more profitable basis for Australian industry by 
reductions alone would condemn us to falling prices, insolvencies, further forced conversion of the internal debt, and an all-round writing-down of obligations. The end would be chaos. Industry and investment would remain paralyzed. The time-lag of costs above falling prices would mock each successive cut. The first mediocre season would find the Commonwealth Bank in a vulnerable position. Its London balances would shrink. The buying pressure on the rate of exchange would drive it, in the absence of an exchange stabilization reserve, to uncontrollable levels. If attempts were made to stop the rise by further arbitrary restrictions on imports and exports these measures would aggravate the collapse of the chief industries of the country. Import restrictions would further raise their costs. Export restraints would hold down their returns from sales overseas. The effect aimed at by restrictions is defeated by the loss of confidence and increased panic which they engender.

It is not the role of a central reserve bank to stand by consenting to the destruction of the economic life it exists to guard. In contrast with so suicidal a policy the extension of the Premiers' Plan suggested by the Special Committee would encourage exports while the seasons are still favourable. In so doing it would build up the power of the Commonwealth Bank to control the exchange rate and the future stability of our economy.

The spirit of the doleful post-war period has been one of strident nationalism. If the policy under discussion were aimed merely at the stimulation of exports from Australia it would carry the seeds of its own destruction by hostile tariffs or other market restrictions. The necessary counterpart of progressive Australian development of Australian resources is therefore continued activity in international trade. To sell our exports we must find, as we have found hitherto, willing buyers overseas. At this point, therefore, I must remind you that my subject is "Australia's Share in International Recovery". If we are to recover our internal balance we must adopt policies that, as a whole, chime in with the efforts of others overseas.

Taken by itself, a policy of maintaining and increasing Australian exports would, like the departure of Britain from the gold standard, accentuate the competition for a shrinking volume of international trade. It may be true, as the "Westminster Bank Review" for May of this year confesses, that "British policy, in 
any new and difficult set of conditions to which the lessons of the past afford little guidance, is normally based upon inspired opportunism in the light of progressive experience". In other words, we like to "muddle through". But the chaotic state into which the industry, trade, and finance of the whole world have been thrown by post-war muddling, from Versailles onwards, should give us pause. This is a time for the application of first principles in the criticism of every step proposed.

The greatest emphasis should therefore be laid on a section of the Special Committee's report which has hitherto received very little notice. I refer to section 55, and, with your approval, I shall read it in extenso:

"To some small extent Australia may help to raise world prices. She is part of the world economy, and any action reviving her prosperity accelerates that of the rest of the world. In particular, she can assist herself and the rest of the world by negotiating treaties with other countries for mutual reductions in tariffs. In addition to the probability of improved terms of trade within the Empire, as a result of the Ottawa Conference, it is common knowledge that the Governments of important European countries are at this moment ready to respond to overtures from Australia for reciprocal treaties. The removal of barriers to trade and international investment offers the most hopeful way out of the depression."

If we are to continue to sell overseas an increasing proportion of the products of a prosperous Australia, we must so reshape our fiscal policy as gradually to restore the market here for British and other imports. In this there need be no menace for the efficient secondary industries we have built up in Australia. The world is entering upon a period of planned reconstruction of industry and trade. Few countries have made a more auspicious entry into that era than our own, and, as I see it, the task of our representatives at Ottawa and at later conferences will be to pave the way for policies both in currency and in trade which will dovetail together the interests of the Dominions and Great Britain in the mutual service of a freer trade. 



\section{6}

\section{Gold standard or goods standard}

\section{Leslie G. Melville}

In recent years there has been a remarkable change in the attitude of business men towards the problem of the price level. In 1928 Sir Josiah Stamp wrote:

"With business men there is still a sneaking feeling that references to the price level or index numbers are academic and highbrow, not practical or immediate ... And yet it is the most bitterly practical of all questions."

To-day, in English-speaking countries, the price level has come to be the chief preoccupation. Indeed, there are many business men who are beginning to have a sneaking feeling that perhaps it is the gold standard which is academic and highbrow.

It is easy enough to understand the impatience of the Anglo-Saxon world with the gold standard. It has about it something of the logic and precision which appeals to the Latin rather than to the Anglo Saxon temperament. Your AngloSaxon distrusts a solution which appears simple, and looks askance at logical arguments, feeling, perhaps, how inadequate is logic to grapple with the problems of a complex world.

Perhaps it is for this reason that the Latin countries - France, Italy, Switzerland, and Belgium - continue to cling, with Holland, to the beautiful simplicity of the gold standard, while the Anglo-Saxons have started off on a voyage to discover a new currency. It may not be merely a coincidence that the countries which have lightly set out on this quest are those which have had less experience of inflation. Yet, surely, the real explanation lies deeper. Anglo-Saxon countries believe that this depression is connected with gold. You may turn

1 Sixteenth Joseph Fisher Lecture, 26 September 1934. 
them aside from their cruder fallacies, but of this much they remain convinced. So, to-day, the greater part of the world rejects the gold standard and pledges its adherence to some kind of goods standard. By a goods standard is meant a monetary system under which the quantity of money would be regulated rather with reference to the prices of a selected group of goods than with reference to the quantity of gold.

The President of the United States has announced that America aims to restore the price level (presumably of 1926) and will then seek the kind of dollar which a generation hence will have the same purchasing and debt-paying power as the dollar value they hope to attain in the near future.

At the Ottawa Conference the countries of the British Common wealth of Nations declared that they desired to see a rise in the level of wholesale sterling prices.

After the failure of the World Economic Conference these countries stated that the problem with which the world is faced is to reconcile stability of exchange rates with a reasonable measure of stability, not merely in the price level of a particular country, but in world prices.

In Sweden, as early as September, 1931, the Swedish Government and the Board of Directors of the Riksbank both declared that the aim of the country's monetary policy would be to preserve the internal purchasing power of the krone in the hands of consumers.

\section{A monetary babel}

A number of countries in Europe follow the sterling bloc, and hanker after a goods standard. Nevertheless, the countries remaining faithful to gold, though few, are important. Only four or five countries have anything like a genuine gold standard, France, Belgium, Switzerland, Holland, and Lithuania. These countries permit free conversion of their currency into gold, and gold into currency, but otherwise they do not play the gold standard game. One of the functions of the gold standard was to give countries adhering to it a warning when their prices, costs, and wages, were out of line with prices, costs, and wages in other countries. 
The theory was that when domes tic prices were too low, gold would flow into a country, and by causing a domestic inflation, raise wages and prices; when domestic prices were too high, gold would flow out of the country, and, by causing a domes tic deflation, lower wages and prices. The countries now adhering to gold will have none of that. If there are signs that prices are so high as to make the balance of payments adverse, and cause gold to move out of the country, they take steps to correct the balance of payments rather by means of higher tariffs and quotas than by lower wages and prices. But tariffs and quotas disturb the economies of other countries. The gold standard is intended to resemble a tuning fork, by means of which a country can discover whether its economy is in tune with the economies of other countries. The raising of tariffs and quotas gives countries their own tuning forks, each with a different pitch, and leads to economic dissonance.

The gold standard is supposed to act as a regulator of the economic system, moving resources to those places where they can be put to the best use. If nations refuse to allow it to operate in this way, its principal virtue is lost. There is little merit in a gold standard operated as it has been in France and Switzerland in recent years. Until the last few years Holland and Belgium have kept the tenets of the gold standard more faithfully. Their recent imbibing of economic nationalism is easily forgiven in a world drunk with the doctrine of self-sufficiency, particularly when the one time sober John Bull is more than a little intoxicated.

There is a second group of countries, such as Italy and Poland, which keep their currencies at parity with gold, and take pride in being on the gold standard. Their exchange rates are stable, and they are ready to accept gold at a fixed price. But they are not so ready to convert their currencies into gold. They use quotas, tariffs, ex change controls, and even the police force to protect their gold reserves. Anglo-Saxons will scarcely be attracted by a gold standard of this kind.

A third group, including Germany, Roumania, and Bulgaria, claims to be on the gold standard, but nobody outside the countries concerned takes the claim very seriously. These countries make use, like group two, of tariffs, quotas and exchange controls to protect their gold reserves. In addition they divide their currency into two sections - sometimes into a number of sections. One part is kept at parity with gold and used to meet certain Government obligations and 
other external charges. There are strict foreign exchange regulations to prevent anyone from making payments abroad. Foreigners are not supposed to remove their deposits or liquidate securities in the debtor country. In so far as they are permitted to remove their assets, they have to take a loss, just as they would if the currency were depreciated.

Some countries, such as Czecho-Slovakia, Austria, Hungary, Estonia, Yugoslavia, Spain, and Portugal, have allowed the external value of their currencies to depreciate, but nevertheless keep foreign money frozen by standstills and moratoria. The removal of assets from these countries involves a greater loss than that due to the depreciation of the currency alone.

The currencies of the British Empire, the United States, and Scandinavia are strikingly different from these grim ghosts of the gold standard. They are heavily depreciated, but are practically without exchange restrictions. Tariffs, it is true, have increased, and quotas have made their sinister appearance, but so far the extraordinary excesses of the gold bloc and the imitation gold standard countries have been avoided.

The United States has returned to a gold standard of a kind, but not the gold standard of former years. The gold contents of the dollar may be altered by the Executive within the limits of 60 per cent and 50 per cent of its pre-1933 value. Thus it is still possible to lower or raise the gold value of the dollar by as much as twenty per cent. Taking this together with the declaration of the President that the United States wants a dollar of constant purchasing power, and the past record of the Administration in raising prices, or attempting to raise them, by monetary means, we may conclude that the United States has to-day a commodity dollar. That is to say, the United States is on a goods standard rather than a gold standard. We cannot be certain of this conclusion. The President has made it clear on many occasions that he looks on all his measures as experiments to be discarded if they prove unsuccessful. Possibly monetary experiments are now in the discard, and the United States is on a real gold standard, with an invariable weight of gold in the dollar and fixed rates of exchange with countries on the gold standard.

The currencies of the British Empire and Scandinavia are frankly on a paper standard. They are not properly on a goods standard, although much influential 
opinion is deeply tinged with its philosophy. The official policy of the British Empire, at the moment, is to raise prices to a level which restores the normal activity of industry and employment, which ensures an economic return to the producer of primary commodities, and which harmonizes the burden of debts and fixed charges with economic capacity. The influence of the goods standard philosophy is to be found in this aim. It is also to be found in the declaration that "international co-operation with a view to avoiding, so far as may be found practicable, undue fluctuations in the purchasing power of gold" 2 is a condition precedent to the restoration of the gold standard. Again it is suggested by the statement, "the problem with which the world is faced is to reconcile the stability of exchange rates with a reasonable measure of stability, not merely in the price level of a particular country, but in world prices." ${ }^{3}$ The British Empire, then, is prepared to return to a gold standard, but only if that gold standard is a kind of gilded goods standard. For Britain the reign of the gold standard as an absolute monarch is officially over. Gold may be restored to its throne, but only as long as it is pledged to follow the guidance of some selected representatives of the world of goods. Some liberty, however, is to be allowed the re-instated monarch. He must follow the guidance of prices, but only in a "reasonable measure." His subjects in the world of goods will overlook a mild intoxication, but would look askance at any serious insobriety. Only time will show whether the limited monarch of the British Empire is really different from the monetary republic of the United States, with its dollar which a generation hence will have the same purchasing and debtpaying power as the dollar value they hope to attain in the near future. Perhaps both countries will restore an absolute monarchy.

\section{The conflict of opinions}

However official policy may change, there can be no doubt that there is much unofficial support for a goods standard in Great Britain, as in the United States.

In 1931 the committee headed by Lord Macmillan wanted to raise world prices and then stabilize them. In 1932 the Federation of British Industries

\footnotetext{
2 Joint declaration of the Governments of Great Britain, Canada, India, Australia, New Zealand, and the Union of South Africa, made after the World Economic Conference, 1933.

3 Op cit.
} 
wanted to do this with sterling prices. On April $4^{\text {th }}$, 1934, a group of business men, representative of the London Chamber of Commerce, wrote to the Times. They had "come to the conclusion that gold is not essential as the basis for the issue of national money, and that nations should not be under obligation to make payments internationally with gold." Even the Times thinks that the issues raised by the London Chamber of Commerce "are worthy of serious, unprejudiced, and searching discussion."

The Midland Bank wants a monetary standard based on the general commodity price level. It is prepared to seek stability of purchasing power, even if this means that sterling remains with no fixed attachment to gold. On the 7th June, 1934, the Financial Editor of the Manchester Guardian wrote: "A few reactionaries do, indeed, demand a return to the gold standard system as before 1931 - even if with a reduced gold content of the pound. But they are not listened to. What are heeded are the voices urging a definite and formal acceptance of a more modern currency system, providing for the control of prices by banking and general financial technique, and giving assurance that though the pound is permanently detached, or at all events detachable, from gold, we are safeguarded none the less against those inflationist excesses into which sooner or later some Government is pretty sure to lead us."

While these and other important groups in Britain are fighting for a goods standard, the conservatively-minded are cautiously saying they do not want a gold standard - yet. When many improbable things have happened, they will be ready to return; but in the mean time they are making good progress, and do not want to take any action which might possibly delay recovery. An attitude of this kind might conceivably result in Great Britain, more or less accidentally, establishing a goods standard, just as she accidentally established a gold standard about 1717 .

In contrast to this attitude in Great Britain, the Board of the Bank for International Settlements, composed of the Governors of the principal central banks of the world, has unwavering faith in the gold standard. It is true, that on 11th July, 1932, it laid down certain conditions for a general return, which, if they are to be at all strictly observed, would indefinitely defer that event. But in its report for the year ending 31st March, 1934, it affirms: "There can be no 
doubt about a general return to gold as the basis for the monetary system" ... it is evident that there has been a real advance on the part of public opinion, on the part of Governments, and on the part of Central Banks in appreciating how indispensable is the restoration of the gold standard."

In spite of the further growth of economic nationalism and the retrograde financial and monetary developments - "more moratoria, more transfer impediments, more artificial clearings, more gold hoarding than during any year on record" - the Board sees in the increased annual production of gold, its better distribution between central banks, the reduction in international shortterm indebtedness and the approach towards a better equilibrium between prices, costs, and debts, grounds for believing that the time when the gold standard will be restored is approaching.

In March, 1934, the important group of business men which assembles in the International Chamber of Commerce unanimously approved a resolution calling for the stabilization of currencies without further delay, and the restoration of a monetary system based on gold.

In spite of much influential opposition in Great Britain and the United States, it is probable that the Bank for International Settlements correctly interprets the present situation, "prevailing public and governmental opinion preponderatingly support the conclusion that the gold standard constitutes the best available monetary mechanism." It seems likely that the course of events will bring increasing pressure to bear on those countries still on a paper standard to force them back to gold. Dr. Coates may be right when he argues that "the natural process of recovery must proceed some way further before the nations as a whole will be willing to admit that each has sufficient internal strength to take some of the risk which must inevitably attend a greater freedom of international trade," and that "a larger measure of home prosperity will in time form the basis of that greater confidence which is a condition precedent to the stabilization of exchanges." It may be, too, that some adjustments, either of the present relative valuation of the pound, the dollar, the franc, and the reichmark, and various adjustments of prices and costs in the different countries, will be necessary before the gold standard can be restored without intolerable strains. 
There is, then, much opposition in Great Britain to the restoration of the gold standard, and some reason for believing that official opinion has been influenced by the philosophy of the goods standard. Government pronouncements may not convince one that Britain will not return to the gold standard as soon as the time seems propitious; but they do suggest that the event will be postponed. It must be remembered, however, that the dollar was again linked to gold in January, 1934. It is significant that the Secretary of State explained on $23^{\text {rd }}$ April, 1934, that "we should favour a policy that will result as early as may be practicable in permanent exchange stabilization and permanent monetary arrangements." This seems to suggest that the opinions of the President of the United States have greatly changed since he broke up the World Economic Conference, meeting in London, with his declaration, "what is to be the value of the dollar in terms of foreign currencies is not and cannot be our immediate concern."

It is significant, too, that Great Britain and the United States, two countries in which there has been much talk of a goods standard, to-day hold more gold than ever before. Popular belief in gold as the monetary standard of the future is demonstrated by the great hoarding of gold and the ready sale of gold shares. If there were any reason to suppose that gold would cease to be used as the monetary standard, we should expect it to fall heavily in price at some future date, just as the price of silver was depressed when it ceased to function fully as money. The accumulation of gold by central banks and individuals is evidence that, in responsible quarters, there is not the slightest distrust of the position which will be assigned to gold in the future. We can, then, infer that a gold standard and not a goods standard will be the basis of the monetary system of the future.

\section{Gold standard and the depression}

Evidence showing that the restoration of the gold standard is probable does not, however, prove that it is desirable.

In some minds there is a suspicion that the gold standard prevents consumers from enjoying the potential output of production. This idea is based on a fallacy which is fairly easily exposed. More important and more difficult are the contentions that the gold standard causes or aggravates booms and depressions, and either cannot function, or is futile, in a world of reparations, war debts, quotas, and tariffs. 
There are many who contend that the present depression is, in large measure, due to the gold standard. To argue that the depression is solely or mainly due to the gold standard shows a singular lack of proportion. There were factors present before 1929, in no way connected with gold, which must necessarily have caused dislocation, and are sufficient to explain the depression. Amongst these are reparations, war debts, tariffs, quotas, valorization schemes, rigid wage rates, unwise foreign loans, an ill-conceived expansion of credit in the United States, the rapid growth of some new industries, and the over-growth of some old ones.

While we can find here a sufficient explanation of the depression, a prima facie case can, nevertheless, be made for the theory that gold played some part. We know that the quantity of gold in the world in 1929 was not sufficient to support the level to which prices had risen in Great Britain and the United States under the influence of the war and post-war inflation. At least it was not sufficient without drastic economy in its use as compared with the pre-war era. Important economies had been made. Gold was withdrawn from circulation in most countries and, apart from the commercial demand, was used in those countries only by central banks as a reserve against the larger amount of credit needed to support the higher price level. In addition the gold exchange standard was developed, which enabled many countries to substitute for gold, as a reserve against their note issue, liquid claims to other currencies which were readily convertible into gold.

Whether these economies were sufficient to prevent the gold standard causing some tension in the money markets, we have no means of knowing. The following points, however, are relevant. The rise in prices in the United States and other countries, which remained on the gold standard during the war, was made possible by the flow to them of new gold from the mines, and stocks of gold from the reserves of countries which had abandoned the gold standard. It is clear that the price level so induced could not be sustained in the United States, nor in other countries such as Great Britain, which returned to the gold standard at their pre-war parities, if the pre-war demand for gold was to be revived. Great Britain was followed in her return to gold in 1925 by a procession of other nations. 
Table 16.1: Date of return of countries to the gold standard

\begin{tabular}{l|l|l|l|l|l}
\hline $\mathbf{1 9 2 5}$ & $\mathbf{1 9 2 6}$ & $\mathbf{1 9 2 7}$ & $\mathbf{1 9 2 8}$ & 1929 & 1930 \\
\hline England & Chile & Bulgaria & Estonia & Roumania & Japan \\
Hungary & Czecho- & Denmark & Norway & & \\
Danzig & Slovakia & India & Greece & & \\
Holland & Canada & Ecuador & France & & \\
Java & Belgium & Argentina & & & \\
Australia & & Poland & & & \\
$\begin{array}{l}\text { New Zealand } \\
\text { South Africa } \\
\text { Albania }\end{array}$ & & Italy & & & \\
Finland & & & & & \\
Switzerland & & & & & \\
\hline
\end{tabular}

The return of these countries to the gold standard would lead us to expect an increasing demand for gold and a consequent tension in the money markets. This expectation is strengthened by the new monetary law passed in France in June, 1928, repealing the law of $7^{\text {th }}$ August 1926, which empowered the Bank of France to buy foreign exchange. Actually the following movements occurred in the gold reserves of a number of important countries. Reserves of countries not included show no significant movements.

Table 16.2 makes it clear that some countries did begin to accumulate gold between 1925 and 1929 after their return to the gold standard, but only in the case of France was the movement really large. Out of a total of $\$ 1,600$ million added to the reserves of central banks between 1927 and 1930, France absorbed \$1,300 million, and Italy, Belgium, and Switzerland \$169 million. Everyone who studies these figures interprets them according to his preconceived ideas. To me they seem a flimsy argument on which to base an explanation of the fall in prices and the depression. It would have required very little management on the part of central banks outside France to meet a movement of this magnitude. I should hesitate to assume that the control of our currency was-in hands so inept that they did not pro vide the requisite degree of management. A study of the statistics of bank deposits and central bank credit confirms this first impression. The flow of gold to France may have been symptomatic of other troubles, non-monetary in origin, which were shortly to emerge in the depression. But that is something for which the gold standard cannot be held responsible. 


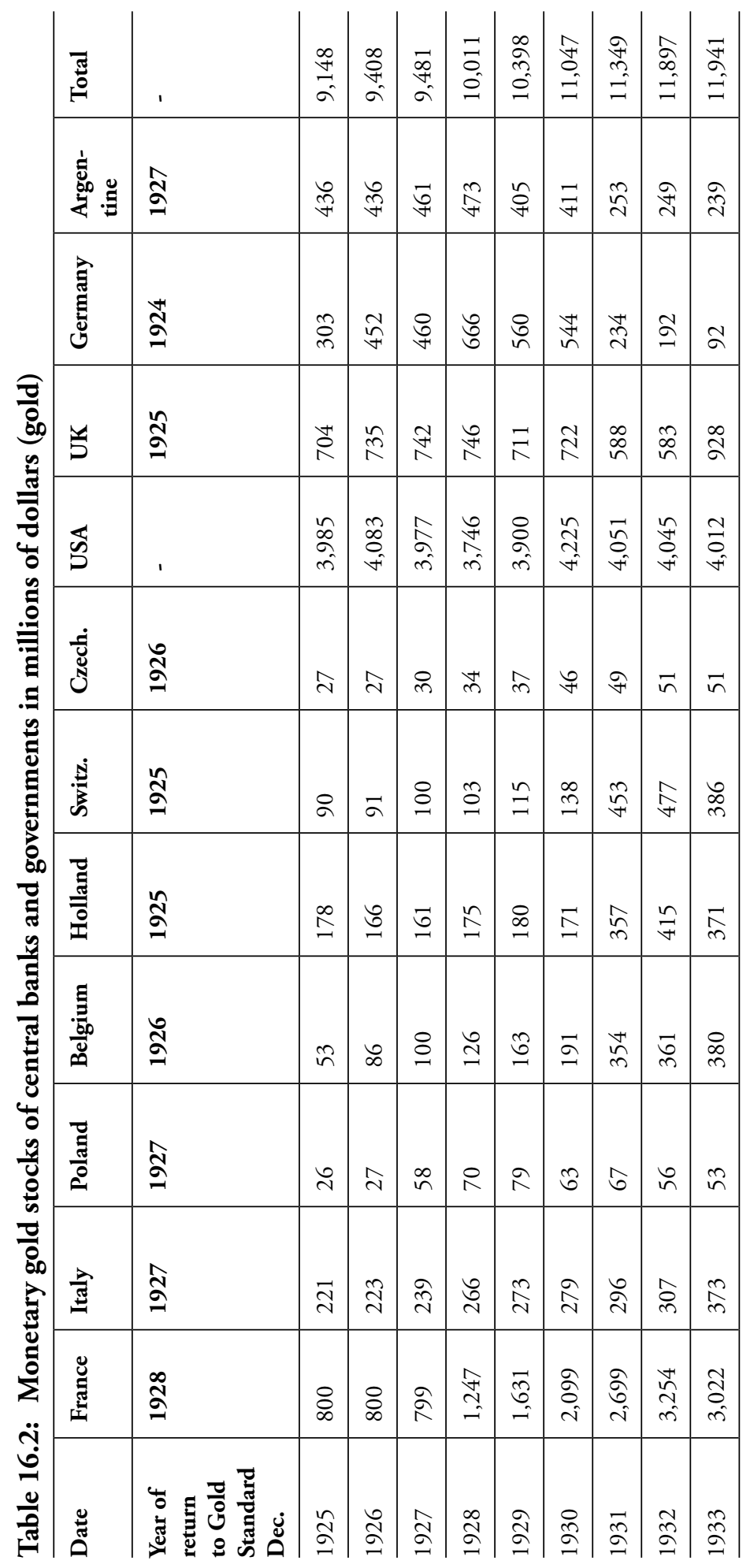


Turning our attention to another line of criticism, we find it argued that the quantity of money must expand at a rate of 3 per cent per annum, if consumers are-to enjoy the potential output of production. This argument is based upon calculations which seem to show that the output of commodities increases at a rate of about 3 per cent per annum. If there is no increasing economy in the use of gold, then the quantity of gold must also grow at this rate, in order to prevent prices from falling. Falling prices, however, do not have a depressing influence, when they reflect increasing efficiency. In such a case, a given number of people produce a constantly increasing output. Wages, salaries, and overhead costs may remain fixed and yet permit units of output to be sold profitably at falling prices. It would appear sufficient, therefore, for the quantity of gold to increase at about the same rate as the population. We cannot determine this rate exactly, but the following rough estimates of rates of increase in the population of the constituent continents of the world show that it is well below 2 per cent:

\begin{tabular}{l|l}
\multicolumn{2}{l}{ Increase, per cent per annum } \\
\hline Europe & 0.75 \\
\hline America & 1.50 \\
\hline Africa & 0.75 \\
\hline Asia & 1.00 \\
\hline Australia & 1.50 \\
\hline World & 1.00 \\
\hline
\end{tabular}

A rate of increase of 2 per cent per annum, in our monetary gold stocks, should suffice, even if the growing complexity of industry calls for some increase in the quantity of gold in addition to that required by the growing population.

From 1925 to 1929 the gold reserves of the central banks increased at a rate of more than 3 per cent per annum. It can scarcely be con tended, therefore, that the annual production of gold was inadequate. The above tables, and any other statistics one cares to examine, give little support to the contention that the gold standard was responsible for the depression. It is possible that there was, nevertheless, an unseen scramble for gold before 1929; central banks bidding for supplies with high rates of interest. Gold would not move from one market to 
another if, in the attempt to gain gold, rates of interest in all countries were raised together. If such were the case it would be difficult to explain why the boom lasted until late in 1929. I do not reject out of hand the argument that the gold standard may have played some part in causing the depression, but it seems to me that we can find much more probable explanations.

\section{The supply of and demand for gold}

The above table does, however, bring out clearly the scramble for gold which commenced when Britain was forced off the gold standard in 1931. There can be little doubt that the events of that year greatly increased the demand for gold, both by central banks and individuals. Whatever may have been the case before 1931, monetary causes probably intensified and prolonged the depression after that year. Not only did the depreciation of sterling, and many other currencies, result in an increased demand for gold and a fall in prices in gold standard countries, but it caused them to protect their balance of payments, and gold reserves, with tariffs, quotas, and exchange restrictions. It was not the gold standard but its abandonment which worked all this mischief.

In some ways the monetary chaos after 1931 has made the restoration of the gold standard difficult. Countries which were content to economise gold, by holding claims to gold in foreign money markets as note issue reserves, will not be so ready to do this after the loss they sustained by the depreciation of sterling. It is, nevertheless, surprising to find that the short term claims on London are to-day nearly as great, in terms of sterling, as they were in 1930. This is largely due to the fact that countries of the sterling bloc, South Africa, Australia, India, Egypt, and the four Scandinavian countries, are content to hold sterling instead of gold as primary or secondary cover. These countries actually hold more foreign exchange than they did before the depression. It is not certain, therefore, that the gold exchange standard will not come back into favour. Still it is unlikely to be as popular as in the past. Another danger is that central banks will be come nervous holders, and their demand for gold may be subject to violent fluctuations which could not fail to dislocate industry. Thus we have reason to suppose that there will not be the same economy in the use of gold as there was before the depression. 
On the other hand the heavy fall in prices, measured in terms of gold, has been so great since 1929, that it will in future take a much smaller quantity of gold to support a given volume of production and business. In countries such as Holland, Switzerland, France, Belgium, Italy, Germany, and Poland, which either did not build up large internal and external debts during the war, or else drastically reduced them by the post-war depreciation of currencies and recent defaults, it has been possible to reduce prices measured in their own currencies. These countries are far from having completely solved their problems, but a substantial reduction in prices has been achieved. In other countries, such as Great Britain and the Dominions and the United States of America, where the volume of debts was too great to make it practicable to reduce prices in this way, a similar but greater result has been secured by the depreciation of currencies. You can look on the rise in the price of gold in these countries in either of two ways, according to your particular prejudices. You can imagine gold as some thing fixed like the polar star, and suppose that the depreciation of the currency has reduced all prices and costs measured in gold. This method of reducing costs is much more complete than the alternative, and more direct, method of cutting costs, forced on countries which keep their currencies at parity with gold. The latter countries must concentrate at first on wages and salaries, and the reduction will spread only slowly to interest rates as contracts are renewed. Other relatively fixed charges, such as fares and freights, handling charges, distribution costs, and rates and taxes, will gradually fall into line, though it may be many years before the reduction spreads right through the community. Some people will be left unscathed. The reduction in prices and costs secured by a depreciation of the currency is much more searching. Fixed charges as well as wages and salaries are immediately reduced. The same money payments are made, but in gold they are worth less. Some individuals will again escape, but relatively few, and there are none of those distressing delays in the fall in fixed charges which cause so much social friction.

If you do not regard gold as something immutable against which the value of all other commodities is measured, you can look on the increase in the price of gold as an increase in its quantity. While neither view is wholly right, the latter is possibly the more useful for our present purpose.

Countries which have met the crisis by cutting costs and reducing prices, will, in future, be able to support a greater volume of production and business 
with a given volume of gold. Those countries which have met the crisis by depreciating their currencies will have a greater quantity of gold - if you take the second view - and so can support a greater output. Thus the events of the last few years have, in effect, greatly increased the supply of gold. Since the pound and the dollar have fallen about 40 per cent, the quantity of gold in Great Britain and the United States has been increased about 67 per cent. It is more difficult to estimate the increase in the supply of gold due to the fall of prices in other countries, but it is clear that the increase has been substantial.

Thus, against the anticipated increased demand due to the loss of popularity of the gold exchange standard, and the possible increased nervousness of central banks, there can be set a large increase in the supply due to a fall in prices and a depreciation of currencies. There will, doubtless, be some rise in prices as business revives; but, as far as one can judge, the increased supply is more than sufficient to take care of the increased demand. We need not hesitate to return to the gold standard, therefore, on account of any fear of a shortage in our stocks of gold. Neither need we fear that the annual production will be inadequate. Ill the following table are given the annual additions to monetary gold stocks, expressed as a percentage of the total monetary supply, and the annual production of gold as a percentage of total world stocks.

The fall in prices and the depreciation of currencies has not only increased the existing supply of gold, but it has also made new production more profitable. A glance at table 16.3 will show that, with the higher output, there is no reason to fear that the increase in monetary gold stocks will fall below 3 per cent per annum, or the increase in total world stocks below 2 per cent per annum, for some years to come. With a tendency for the growth of population to decrease, this should be sufficient to prevent any pressure on the money markets or prices. There is no need, therefore, to defer our return to the gold standard on that account. Then there is the mal-distribution of gold, of which we have heard so much, and in which there seems to be so little. Provided the parity at which we return to the gold standard is chosen more carefully than in 1925, France will have lost her power to attract gold. Nevertheless, as compared with other countries, France and the United States do hold too much gold. It might be well to seek some reduction in the gold holdings of these countries, and an amendment in French monetary laws, before we agree to return to the 
gold standard. But these points are of no great moment, and I do not think we should necessarily insist upon them.

Table 16.3: Annual additions to monetary gold stocks

\begin{tabular}{l|l|l}
\hline Year & $\begin{array}{l}\text { Annual increase in monetary gold } \\
\text { stocks as a percentage of total } \\
\text { \% }\end{array}$ & $\begin{array}{l}\text { Production of gold as a } \\
\text { percentage of world stocks } \\
\text { \% }\end{array}$ \\
\hline 1924 & 3.7 & 2.3 \\
\hline 1925 & 0.2 & 2.2 \\
\hline 1926 & 2.6 & 2.2 \\
\hline 1927 & 3.9 & 2.2 \\
\hline 1928 & 4.8 & 2.1 \\
\hline 1929 & 2.8 & 2.1 \\
\hline 1930 & 5.9 & 2.2 \\
\hline 1931 & 3.4 & 2.3 \\
\hline 1932 & 5.4 & 2.4 \\
\hline 1933 & 0.4 & 2.4 \\
\hline Ten years average & 3.3 & 2.2 \\
\hline
\end{tabular}

\section{Gold and the price level}

The fear that there is likely to be a shortage either of monetary stocks of gold, or of the annual output, can, I think; be dismissed. We have still to consider the objection that the gold standard is responsible for booms and depressions. The advocates of managed currencies, a commodity dollar or goods standards argue that, if by suitable expansions or contractions of credit the general level of prices could be stabilized, booms and depressions would be no more. I reproduce a graph submitted to the League of Nations Gold Delegation by Mr. Joseph Kitchin. This graph compares variations in the supply of gold with changes in the level of wholesale prices. The graph makes two things clear. First that there is a remarkable similarity between the secular trend of prices and monetary stocks of gold. It can only be supposed that this similarity is a matter of cause and effect; increasing supplies of gold cause prices to rise; decreasing supplies of gold cause prices to fall. The second fact that the graph demonstrates is that there are 
short period movements in the price level extending over from five to ten years which have little or no relation to the supply of gold. To deal adequately with the difference between these two movements would take far too long, and would carry us into technical matters about which there is much dispute amongst economists. I can, therefore, only give you my own views on this matter. It seems to me that it is both desirable and possible, by monetary management, to eliminate the secular movements in the general level of prices; but that it is impossible by monetary means to eliminate the short period fluctuations, and that it would be undesirable to try. Unfortunately, it is the short period fluctuations in the general level of prices which are associated with booms and depressions. I am afraid, therefore, that a goods standard will not prevent booms and depressions. As for the secular trend of prices, it does not seem to me to matter much whether the trend of prices is slightly upwards, stable, or slightly downwards. The practical difficulty is to decide whether a tendency for prices to fall is a short period movement or a secular trend.

Having in mind the controversies of the last few years about the cause of the fall in prices, and the inadequate statistics on which enthusiasts have based wholly conflicting conclusions, it seems to me to be impossible for us to see clearly, at any time, under what influence prices are rising or falling. Unless we can see our way clearly, any action taken is as likely to land us in difficulties as to avoid them. Remembering that there will always be outside pressure present, political and other, to persuade the monetary authorities to take some course of action against their better judgment, the probability is considerable that any attempt to manage the currency, so as to minimize short period fluctuations in the price level, will cause serious trouble. On theoretical grounds, I believe that a gold standard, with the supply of monetary gold increasing at a rate of about 2 or 3 per cent per annum, will give us quite as good results, if not better, than any managed currency or goods standard, and it will avoid a host of political difficulties. I shall have more to say about that later.

Perhaps there are some, who, even to-day dislike references to the price level and index numbers, and move uneasily amongst these discussions of secular trends of prices and short period fluctuations. To them I have merely this to say. Central banks are exhorted by one group of eminent economists to raise the price level and then stabilize it. Unless they do this, central banks are earnestly 
assured, they will run the ship of state on the rocks of rigid wages and fixed charges. Another equally eminent group, just as earnestly, assures central banks that if they do attempt to raise prices, and then stabilize them, they will be overwhelmed in a tempest of heaving prices. Is it surprising that central bankers should conclude that on this matter economists are all at sea? It is only to be expected that economists will differ widely about the application of their science. That is because they must take account of factors which, strictly speaking, lie beyond their scope, and which cannot be resolved by ordinary scientific methods. But in their arguments on what to do with the price level, they differ profoundly on a matter of theory. In the circumstances their proper policy is to return to their studies and common rooms until they have thrashed this problem out to their own satisfaction. When they can speak with an almost unanimous voice, it will be time for central bankers to decide whether their theories can be applied. Meanwhile, can we expect central bankers to pursue any other course than what seems to be the common sense one of supplying the world with a currency which will expand at about the same rate as the output of commodities?

\section{Figure 16.1: The relative stock of gold money}

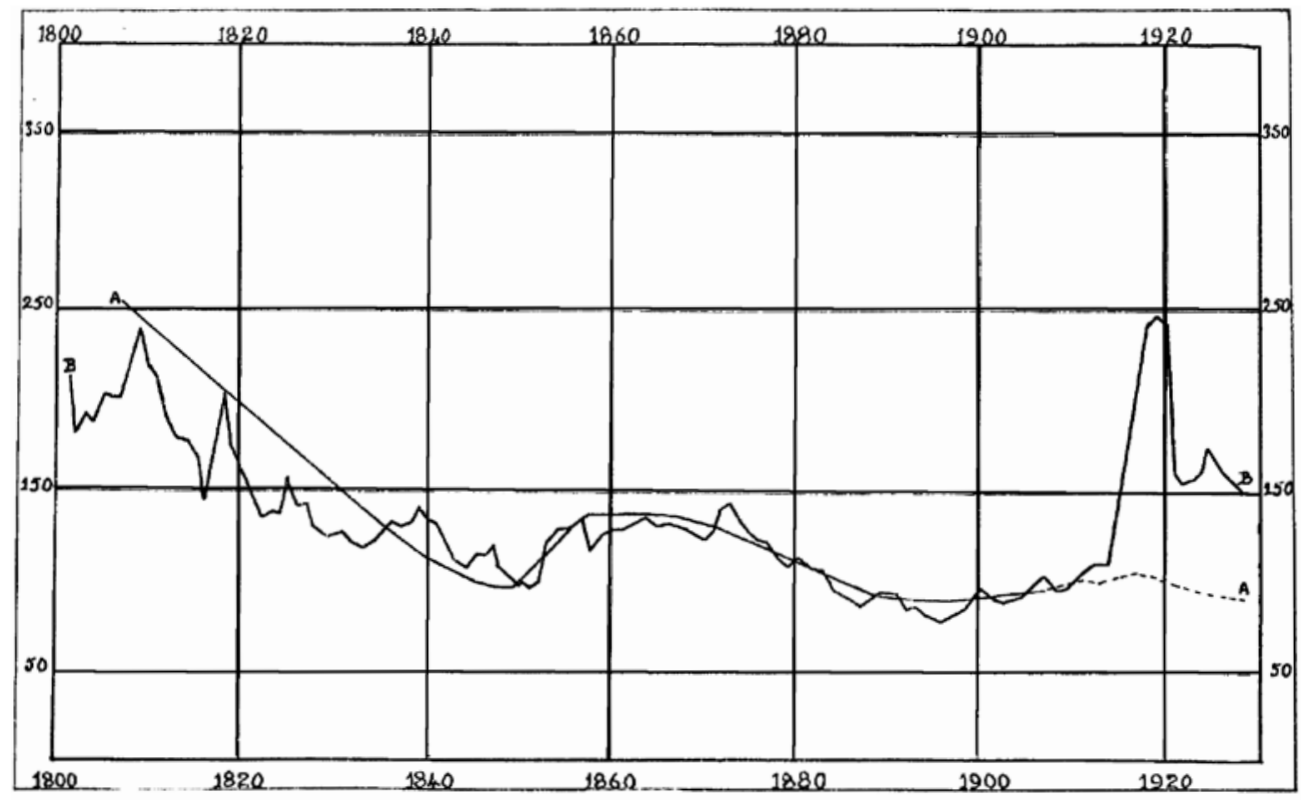




\section{A paper substitute for gold}

There is still another argument against gold that we must face. Let us assume that, theoretically, the best monetary system is one which provides, as does the gold standard, for a constant rate of in crease in the supply of money. It is not necessary, according to this theory, for the currency to be supported by gold. All that is required is that the quantity of money - and this includes coins, bank notes, and bank deposits - should expand at the constant rate. Why, then, it is asked, have any gold? Let us arrange that the supply of money should increase at a constant rate, and avoid all this expensive business of digging gold from deep holes in the ground, only to transfer it to other less deep holes in the vaults of central banks, where it is jealously guarded from contact with the man in the street. If certain views now being expounded in Holland and the United States of America find general favour, the protection of gold from contact with common fellows who are not central bankers will be made complete. Apart from industrial uses, gold will only move from one central bank to another, and can never more be buried in back yards or hoarded in safe deposits. Is then gold really necessary? May we not replace it by paper money or book entries?

This sounds attractive. It would be an economy - about $£ 150$ million of effort could be diverted every year to producing food and shelter. Moreover, it might be easier - once we had rid ourselves of gold, and the rigidities and prejudices which surround it - to adapt our monetary system more intelligently to its task of permitting the production and exchange of goods to proceed at the maximum possible rate. Other attractive possibilities now begin to appear. Could we not go further and manage this system in each country so that nations everywhere would solve the problem of how best to organize their national housekeeping? Could we not have national money instead of cosmopolitan money - national goods standards instead of an international gold standard? To a country such as Australia this prospect may appear particularly attractive. We are subject to violent fluctuations in our output as a result of seasonal conditions. Our exports are raw materials which change greatly in price with the passing of booms and depressions. We are confronted by difficult social and political problems. Should we not have a money which would enable us best to meet all these complex difficulties? If we could alter the quantity of our money, and our exchange rates on other countries, without reference to a rigid gold standard, would we not have 
a system which could meet, with more resilience, the economic earthquakes to which we are exposed?

It sounds attractive; but it would work very badly. Every country must keep a reserve against a rainy day. Its rainy day might, of course, be a drought, or a war, or a violent upheaval of prices. A re serve of its own paper currency would be of no use, for in an emergency a country wants to buy goods from abroad, and the sellers will want to be paid in their own money. Thus countries must hold re serves either of foreign currencies or of some commodity which people in other countries will readily accept as payment. Were foreign currencies suitable for this purpose, then there would, indeed, be no need of a gold standard. Unfortunately, they are not suitable. Currencies can depreciate as sterling has done in the last few years, or, more sobering thought, a nation might find itself at war with the country where its reserves were held, and its reserves would vanish in its time of stress. It is apparent that in the present unsettled political and monetary state of the world, foreign currencies could not be widely adopted for reserves. Reserves of some commodity, or commodities, which can be readily sold are essential. And of all commodities, what could serve this purpose better than gold?

\section{National or international money}

This is sufficient, I think, to dispose of the, suggestion that there can be any monetary substitute for gold, or, at any rate, for precious metals. Even so, we have not finished with the critics. Gold might be treated as a commodity held in reserve to meet emergencies, but the relation between the value of the unit of currency in a country, and an ounce of gold, could be varied according to circumstances. These variations would be evidenced by rises and falls in the price of gold.

Here, it seems to me, theoretical and applied economics part company. Theoretically there is much to be said for each country having a currency which reflects its particular circumstances. Rubber currencies and elastic exchange rates, under wise management, could give short cuts to that relationship between prices in individual economies, and between the price structures of different economies, which would make possible the maximum output of goods and services. The difficulty is to make sure that the management will be wise. The determination of 
action which would give the best result is an extraordinarily complex task to set our monetary authorities. It will be necessary to develop our theory further, and to do much more research work, before we can safely embark upon an experiment of this kind. I imagine, too, that there are few countries where the monetary authorities have the technical knowledge for the task.

Were the technical difficulties the only ones, however, it would be worthwhile experimenting with goods standards of this kind. We could trust that the conservatism of central bankers would cause them to err rather on the side of rigidity in exchange rates than the reverse. Their experiments with flexible exchange rates, and the local printing press, would be very tentative, until they had learnt how to get the best results. I imagine that the difference between such a currency and the orthodox gold standard would not be great, except in periods of exceptional stress. And, at these times, it is, even now, not unusual for countries to abandon the gold standard and reach much the same result by allowing their currencies to depreciate. Indeed, during the present depression, it has been the exception, rather than the rule, for countries to keep their currencies at parity with gold, while the pre sent currencies of the British Commonwealth of Nations are very like the goods standards described above. Australia has gone rather further, and, to-day, holds its reserves in the form of deposits with banks in England, and short term sterling securities, instead of gold.

The real objections to the development of goods standards of this kind are not technical. With as imperfect a theory of the management of goods standards as we have to-day, the monetary authorities cannot know exactly what actions they should take in any given situation. Whatever they do will have important political consequences. In such circumstances, it is almost impossible for them to act on their better judgment. They are bound, in view of their uncertainty, to be influenced by political considerations.

Whatever they do will also have important effects on the welfare of other countries. If they depreciate their currencies more than circumstances warrant, they will gain a temporary competitive advantage in international trade. Can we really expect Governments and central bankers to resist a temptation of this kind? Just as countries, after hundreds of years of experiments with tariffs, have failed to realize that economic warfare, more often than not, harms both the attacker and 
the attacked, so I imagine it would be many years before nations would cease to seek some advantage, albeit only temporary, from undervalued currencies. Even if a country depreciated its currency by an amount which it sincerely believed its circumstances warranted, the probability is strong, where calculations are tentative, that it would exaggerate its necessities and underestimate the difficulties of other countries. The difficulty of persuading other nations that the depreciation was justified, and preventing them from retaliating, either with greater depreciations, or with tariffs, quotas, and restrictions on trade, might prove insuperable. Competition in the depreciation of currencies, and in the erection of economic defences against the trade of other countries, could only lead to monetary and economic chaos. These arguments are graphically illustrated by the events of the last few years. No one, who looks at the table on the opposite page, showing the amounts by which the currencies of different countries have depreciated, will believe that the differences correspond to national necessities.

There can, I fancy, be little doubt that the pound is undervalued as compared with the franc, and the dollar as compared with the pound, while the yen is probably undervalued as compared with them all. I do not claim that these countries, with the possible exception of the United States of America, have deliberately undervalued their currencies; they have merely not regarded it as one of their inter national obligations to prevent their currencies from becoming undervalued. It is true that Great Britain, and those countries which followed her off the gold standard, are prospering relatively to countries still on gold, while Japan is surprisingly active. But the recovery so won has been at the expense of incredible barriers to trade, and grave political tension in Europe.

To claim that all the difficulties of Europe are due to the under valuation of the pound, the dollar, and the yen, would be a wild exaggeration; but it would be foolish not to recognize that the blowing in of blast furnaces in England has had something to do with the insecurity of Governments in Europe. Whether Great Britain and the United States have gained absolutely, as well as relatively, is dubious. That the gain, if it exists, will rapidly vanish is certain. Undervalued currencies only reshuffle trade without adding to the stream of goods. As the undervaluation passes, so do the benefits gained by the reshuffle; and currencies cannot be permanently undervalued. It is true that the present time is exceptional. But the tendencies which have provoked the present excesses will always be present. 
There is not wanting evidence to show that it is only a step, in thought, from the idea of a national managed goods standard, to a belief in autarkie. Nations which take the first step, willingly or unwillingly, take the second.

It is true, of course, that in a world where there was no inter national trade, there would be no need for international money. Those who urge this as an objection to the restoration of the gold standard, however, overstate their case. International trade has been sadly reduced by the present epidemic of economic nationalism; but what is left is worth preserving. The volume of world trade is still about 75 per cent of the peak of 1929 .

So far as the restoration of the gold standard is concerned, it is the changes in tariffs and quotas, and not the existing obstacles, that matter. With prospects of a tariff holiday, we could make tentative calculations of the parities at which it would be safe to restore the gold standard. While tariffs are growing we cannot; but tariffs will only cease to grow when there are reasonable prospects of a return to the gold standard at suitable parities.

\section{Australia and the gold standard}

These issues are of great importance to Australia. She is an important producer of gold, and consequently has a substantial interest in the continued use of gold as the basis of the world's monetary system. Australia, also, exports from onequarter to one-third of her total out put of commodities; there are, therefore, few countries relatively so interested as Australia in the clearing out of the channels of trade. There was a time when Australian Governments lightly imposed embargoes and tariffs on imports from abroad, imagining that the injured nations could not retaliate. Was there not always a world market for Australian wool and wheat, and would not the United Kingdom continue to absorb unlimited quantities of meat and butter? Recent embargoes on wool and wheat, and talk of quotas on imports of Australian origin into the United Kingdom, are beginning to teach us otherwise. Australia, therefore, is vitally interested in the removal of the monetary chaos, and other restrictions, which are strangling trade, by turning men's minds to thoughts of self-sufficiency. 
Table 16.4: Depreciation of currencies - ratio diagram

\begin{tabular}{|c|c|}
\hline $\begin{array}{l}\text { Present gold value } \\
\text { of currency as } \% \text { of } \\
1929 \text { gold value }\end{array}$ & Country \\
\hline \multirow[t]{2}{*}{100} & $\begin{array}{l}\text { France, Holland, Switzerland, Belgium, Poland, Lithuania, Albania, Hungary, } \\
\text { Latvia, Germany, Italy, Roumania, Bulgaria }\end{array}$ \\
\hline & Venezuela \\
\hline \multicolumn{2}{|l|}{90} \\
\hline & Czecho-Slovakia \\
\hline \multicolumn{2}{|l|}{80} \\
\hline & Austria, Yugoslavia \\
\hline \multicolumn{2}{|l|}{70} \\
\hline \multirow[t]{2}{*}{60} & $\begin{array}{l}\text { India, Estonia, Straits Settlements England, Portugal, Egypt, South Africa } \\
\text { Canada, USA }\end{array}$ \\
\hline & $\begin{array}{l}\text { Sweden } \\
\text { Norway } \\
\text { Spain } \\
\text { Finland }\end{array}$ \\
\hline \multirow[t]{2}{*}{50} & Denmark, Chile, Australia, New Zealand, China, Uruguay, Hong-Kong \\
\hline & Greece, Persia, Bolivia, Brazil \\
\hline \multicolumn{2}{|l|}{40} \\
\hline & Japan \\
\hline & Argentine, Columbia, Peru \\
\hline \multicolumn{2}{|l|}{30} \\
\hline & Ecuador \\
\hline
\end{tabular}

In other ways, Australia has learnt that currency depreciation leads to unexpected consequences. The depreciation of the Australian pound, was, we thought, justified and necessary. We were followed by New Zealand, Denmark, and the Argentine. The heavy depreciation of the currencies of all these countries, producing primary products has been an important factor in helping to glut the markets of the world with exports of wheat, butter, and meat, forced out by the assistance so given to export production. This is now leading to proposals for restrictions of imports into Great Britain. The working out of quotas, 
and the restriction of the production of individual producers by Government fiat, is involving us in serious difficulties, and may, perhaps, result in a radical modification of our existing social structure.

The decision as between a gold standard and a goods standard must be made after weighing imponderables and forming some practical judgment about the costs and the benefits involved. Amongst the costs to Australia of the restoration of the gold standard would be the larger liquid reserves we should need to hold than with a flexible exchange rate. Individual industries and exporters would also need larger re serves to tide them over periods of difficulty. Exporters, who had not had the time to build up sufficient reserves before depression overtook them, would suffer more under a gold standard than under a goods standard manipulated so as to provide them with a cushion in times of depression. On the other hand, importers and overseas investors in Australian industries would suffer more from a goods standard.

The benefits Australia would secure from the restoration of the gold standard are substantial. She is an important producer of gold, and is greatly interested in the revival of some reasonable freedom in international trade.

The question whether or not we are to return to a gold standard is one which Australia, in common with other countries, will some day have to face. There are strong arguments for both points of view. Unfortunately, it is often the emotional rather than the rational arguments that prevail in discussions of this kind. One can detect, in England, the United States, and Australia, an irrational distrust of the gold standard now taking the place of the earlier equally irrational worship. The picture of "mankind crucified on a cross of gold" is striking and moving. We must beware lest our judgment on a matter which is essentially technical be deflected by such false metaphors. I have attempted in this paper to outline the principal arguments for and against the gold standard, though perhaps not altogether impartially. Nevertheless, I believe it is on those arguments that the case for gold should stand or fall. 



\section{7}

\section{Some economic effects of the Australian tariff}

\section{Lyndburst F. Giblin ${ }^{1}$}

The free trade controversy has had many vicissitudes in Australia. It has nearly always divided political parties. We used to think of England as the inviolable stronghold of free trade. That thought on the one side and the growing call of nationalism on the other made a clear-cut decision difficult. For many years the Labour Party was in a serious dilemma with the tradition of passionate free trade inherited from British democracy to be balanced against the obvious advantage of a growing industrial electorate; and the official attitude was one of indifference. The safe answer to a heckler was that the difference between protection and free trade was precisely the difference between Tweedledum and Tweedledee: they were equally capitalistic devices for exploiting the worker.

On the other side the country producers maintained a faith in free trade which was at first fully justified by their economic interests, and was only gradually sapped by the discovery that many of them could get as much out of protection as the factory-folk. To this day the Country Party has been disinclined to admit that when its interests are at stake it can give lessons in high protection before which the efforts of the manufacturers sink into mediocrity. The left wing of the Conservative side had, however, its roots in the cities, and was pushing national ideals more strongly than the Labour Party, hampered as it was by the British tradition of its pioneers. These two elements of the forces opposed to Labour were sometimes in opposition, sometimes in uneasy alliance. So it has come about that this question of free trade versus protection, though of supreme economic importance, has seldom been the dominant issue at elections and, at any rate during the last twenty years, no Australian government has come into power with

1 Seventeenth Joseph Fisher Lecture, 25 June 1936. 
a definite mandate for or against protection. Gradually the cause of free trade has weakened. The sudden and complete abandonment of free trade by Great Britain during the depression has put the last nail in its coffin as a pure policy, and only a handful of Elijahs are left reaffirming their faith to an uninterested world. The practical questions now are - as they have always been for the economist - the degree of protection, the direction and the form in which it can most usefully be applied. From this field comes my subject to-night. My aim is to put before you some of the conclusions which can, perhaps rather tentatively, be reached from the examination of our experience with protection in recent years.

I must not be understood as dismissing the theoretical argument for free trade. A convincing case can be made for its operation in an ideal world. In the nineteenth century, in the first fine careless rapture of industrialism plus international trade, that ideal world seemed not so very remote, though I think there were always reasons for thinking its apparent nearness a mirage effect. The vision of it at any rate has faded, and we have now a fairly unanimous conviction that it can, at least for this generation, be disregarded in the practical conduct of affairs.

Up to 1927 neither parliaments nor press had taken much interest in the broad problem of the economic effects of a protective tariff. All parties were as a rule content to see the immediate and partial effect which supported their views, and to be blind to all others. The Commonwealth Government, however, in 1927 began to feel some uneasiness about the effects of the policy they were carrying out, and the Prime Minister (Mr. Bruce) asked a number of economists and statisticians to form a committee and report on the economic effects of the Australian tariff. The members of this committee had to confess that though they had discussed this problem for years, theoretically or practically, they had never arrived at a definite judgment on the Australian position. They applied themselves therefore to the task with an open mind, and in 1929 produced under some difficulties a joint report, which was published under the title of The Australian Tariff.

Let me remind you of some of their conclusions. It was called an economic enquiry. It began, however, by postulating the very uneconomic condition that population could not be allowed to leave Australia - that in fact population must 
grow at, at least, the rate of natural increase. It was thought possible that Australia might have had a maximum income per head under free trade - with perhaps only half the population devoting itself to working the richer natural resources in wool and wheat and metals. That was rejected as an impracticable alternative. The committee found that without protection it would have been impossible to maintain the same population at the same standard of living. Protection no doubt was strictly uneconomic; it imposed a cost which was the price that had to be paid to maintain a growing population at the Australian standard of living.

The problem was one of balancing two possibilities. Protection no doubt made everything dearer, and in particular raised the costs of production of export industry. With the lower costs under free trade would it have been possible to expand export industry - wool and wheat and butter - so as to balance the loss of protected industry? Expansion of rural industry meant expansion into worse land with higher costs. It looked as if wool had reached about its limit, and in some places over passed it. A good deal of wheat-growing had certainly passed it; while butter had gone so far that heavy protection by means of a home price was required to maintain production. Even with lower free trade costs the expansion of export industry to the required extent was judged to have been impossible. That judgment was made in the days of high export prices, and at the time it seemed a bold one. It surprised, indeed, the authors of it. Now-a-days it is an obvious common-place. Even in 1928 the future of export prices - particularly wheat - was looking very dubious. This was, however, kept resolutely out of the argument, because the authors were concerned with what had happened or what could have happened up to that date. Now, looking back over seven years of depressed export prices, we can easily appreciate how much we owe to the growth of secondary industries. As it was we came near to a breakdown in 1931-32. Free trade would have meant doubling our wheat acreage and large increases in our other exports. Export prices would have fallen still lower, and we should have been much more dependent on them. External default would have been the least of our penalties for backing the wrong horse.

For it was a gamble. The reasons for which most people (and their Parliaments) backed protection were probably quite unsound-demonstrably false. But it turned out a winner. 
There is, then, little disagreement about the necessity of the protective policy to-day. The general principle is admitted, but its application is still controversial. How hard should the policy be pushed? And in what directions? How can we get the greatest advantages at the least cost? Then we should like to know the cost even if it is a necessary cost. And we want to know how the cost is distributed between classes, and particularly between States. On some of these matters I wish so far as time will permit to review the state of our knowledge - or ignorance.

The committee in 1928 based their consideration on an estimate of what they called the excess costs due to protection. Let us be quite clear what this means. Excess costs were defined as the amount by which the prices of Australian products were raised by the policy of protection, above those of duty-free imports. No account was taken of the increase in price of imports on account of customs duties. These duties went into revenue used for the presumedly necessary expenses of government, and it was presumed further that if this revenue had not been provided incidentally by protective duties, it would have been raised deliberately by revenue duties or other indirect taxation. The duties on imports therefore did not raise prices for the community as a whole more than they would have been raised in any case. ${ }^{2}$ The incidence of these duties might have serious effects for different classes of the community-perhaps in their final effect for the whole community - but that was a question of wise taxation, not of protection. The excess cost due to the policy of protection was the excess above free trade prices for the Australian products only.

Let us look a little more closely at this excess price and its effect on the community. It will be convenient to consider separately two classes of goods which at this stage we may describe roughly as luxuries and necessaries. The more precise definition of luxuries will be goods of which the price does not enter into the costs of production.

$2 £ 1 \mathrm{~m}$, raised in customs duties would of course raise retail prices by much more than $£ 1 \mathrm{~m}$; but equally so would $£ 1 \mathrm{~m}$ raised by excise or sales tax which must be assumed to be the alternatives. In respect to the excess costs of Australian production due to protection, the total excess costs, as measured in The Australian Tariff is in reference to prices at the factory door. The further additions to retail prices were taken into account by reckoning "retailing" as a separate sheltered industry, and estimating the excess costs which fall on it and were eventually passed on to unsheltered incomes. 


\section{Protection of luxuries}

For a sample luxury take a motor car used for pleasure. I recognize the difficulty that every individual can make a convincing and often heart-rending case for regarding his or her motor car as a strict necessity-but you will, perhaps, concede that some of the other people's cars are luxuries. However, the conscientious objector may think alternatively of wireless apparatus, cigars, lipstick, or top hats, according to fancy. Top hats perhaps arouse the fewest passions, so let us express it in terms of top hats.

Let us suppose that top hats can be imported at one pound, duty free, and there is a duty of 50 per cent. Then the wholesale price of imported hats will be roughly 30s., and the Australian maker can then keep his price a little under 30s. and displace imports by home-products. The excess cost will be nearly ten shillings for every hat.

(Internal competition and other factors may reduce the price and the cost, but we are concerned for the moment only with the maximum excess cost.) Let us suppose that Adelaide requires 400 top hats every year. They will now cost $£ 600$ instead of $£ 400$, in addition to the cost of retailing, which will be the same in both events. The making of these hats will employ, let us say, three men in Adelaide, and put out of employment two men overseas. If Adelaide insists on its top hats - if the demand is very rigid then the purchasers will pay the $£ 600$ instead of the old $£ 400$ for imports, and have $£ 200$ less to spend on other things-probably clothes. So one man will lose employment on making those other clothes, and the net result on employment will be two more employed in Australia, two less employed overseas. If, on the other hand, Adelaide prefers to have fewer hats and spends only the same $£ 400$ on them, it will employ only two additional men, and no others will be displaced. Whatever response in fact Adelaide makes to the new conditions of supply, the first net effect will be two more men employed in Australia, two less overseas, and Adelaide will have to get along with fewer top hats or other things. For the world as a whole employment is the same as before, and the standard of living in Adelaide has been reduced. This is the essential loss, incidental to all protective policy.

These statements imply in both countries concerned a reserve of unemployed people. With full employment in either country, some modification 
of the statement would be necessary, but the net cost of protection would be even greater with full employment in Australia.

I have said "the first net effect", and there will of course be further effects - repercussions of increased or decreased income and employment. The new men employed will give employment to others, and these again to others in a diminishing series. The total will depend on many circumstances - the proportion of new income spent on imports or overseas interest, and particularly on the extent to which the factors of production are already employed. In Australia in recent years, with much unemployed resources in labour, land, and capital goods, it may be reckoned that one additional man re-employed in unsheltered industry ${ }^{3}$ would be followed ultimately by the re-employment of two others. So the total net new employment in Australia on account of displacing $£ 400$ worth of imported top hats would be six men. The total unemployment caused in the country which supplied the top hats would depend on conditions in that country, and might be more or less than for Australia. Roughly, one may say that the greater the unemployment and the unused capital equipment, the greater will be the secondary effects of an increase of employment. On account, however, of the relatively large unused natural resources of Australia, repercussions of increased income will tend to be greater here than in most countries.

From the purely Australian standpoint, we should have an increase in employment by perhaps six, at the cost of some lowering of the standard - some loss of consumption goods. At the present time it may seem a very reasonable price to pay for increased employment-the going without a certain amount of luxury expenditure. It does not help the world depression, but as a defensive, self-protective measure, it is clearly justified in emergency, with the hope that a growing efficiency in Australian production will in course of time make up the loss in the standard of consumption, which must be its immediate sequel.

3 i.e. export industry or industry competing with imports. The fall in imports of top-hats will of necessity be balanced by the consumption of imports of the six men re-employed (or of six men of additional population), 80 that the balance of external payments will not be altered. I have for simplicity kept the balance of payments out of the main argument, but it may be useful to remind the reader on occasion that protection does not of necessity improve the balance of payments, except in so far as it leads to an abnormal restriction of consumption. The ratio of imports to consumption is lowered, but this is balanced immediately by the increased consumption of imports due to new employment (or population). 
Coming back to the net first effect on employment, from which the secondary effects can be deducted by multiplying by about three, we see that the higher the protection required or used, the less will be the resulting new employment. The excess costs always stand for a loss, a certain amount of consumption foregone. Corresponding to this loss of consumption will be, in general, a loss of employment to be set against our first gain. (This is the man making other clothes who lost his job in the top hat illustration. $)^{4}$ It will be seen that the net new employment will correspond to the total new production less its excess cost, or in other words to the free trade value of the new protected production. The greater the excess costs the less the net gain in employment. For the same excess costs - for the same loss - it will be seen that the net new employment will vary inversely as the degree of protection required and used. Suppose we are prepared for excess costs of $£ 1 \mathrm{~m}$ - to go without consumption goods to that amount. If certain new production requires duties of 50 per cent, then for an excess cost of $£ 1 \mathrm{~m}$, we should have $£ 3 \mathrm{~m}$ of this new production, with $£ 2 \mathrm{~m}$ as the cost of displaced imports, and the net new employment would be (say) 10,000 men.

But if new production could be found which could carry on with 25 per cent protection, then the resulting new production would be $£ 5 \mathrm{~m}$, the cost of displaced imports $£ 4 \mathrm{~m}$, and the net new employment on the same basis of calculation would be 20,000, or twice as great. For the same cost-for the same loss in consumption - you get twice the benefit on account of the lower degree of protection required. Halve the percent age of the protective duty, and you double the resulting net employment. Double the percentage, and you halve the resulting employment.

Now a country at any time is able and willing to make a certain effort, to stand a certain loss, to put up with excess costs to a certain total amount. It is therefore of the highest importance to make the effort go as far as possible. It is absurd to fritter it away on protecting industries that require 50 or 60 per cent protection, when it would go twice as far with industries that could live with subsidies of 25 or 30 per cent.

4 This will not be true if the consumption of the protected goods is reduced, but we must assume that the aim of protection is to supply the same quantity of home products as was previously imported. 


\section{Protection of necessities}

The effect of protecting necessaries is not so simple. In Australia it is more farreaching and at the same time more measurable than in most countries, by reason of our methods of wage-determination. Australia is unique in fixing most wages and many salaries in accordance with an index number of retail prices, which takes account of nearly all ordinary food and clothing, housing, household gear, and other miscellaneous expenditure. Anything covered by this index is for our present purpose a "necessary", and you see that through rent it covers all kinds of building materials. (There are other necessaries not covered by the index number, as we shall see.) It follows that any alteration of price over a very wide range of goods in common use affects wages almost at once under Australian conditions, and will therefore have immediate and far-reaching effects on the cost of production.

The only large exception to this close relation of wages and retail prices is with farm employment. Most farm wages are not so related, and they vary rather with the income of the farmer, which itself depends mostly on export prices. We may therefore rather broadly regard the farm labourers, who number about 10 per cent of total bread winners, and the farmers, who also number about 10 per cent, as making one class which is affected for better or worse in the same way by all variations in prices, whether internal prices or export prices.

Let us now consider the effect of the protection of some necessary such as sugar, or butter, or working boots, or dungarees, or teapots, or galvanized iron. But there is a further distinction between factory goods and primary products, and we will take factory goods first - say, teapots.

\section{The passing on of costs}

Suppose teapots are made here with 50 per cent protection, so that $£ 600$ is paid for teapots that could be imported duty free for $£ 400$, and we have as the first effect the employment of three more men. But here there will be little question of cutting consumption on account of higher prices. The great majority of the people using these teapots will have wages or salaries depending on retail prices, and the added expense of teapots will be repaid - or in practice on the average 
more than repaid - by an increase in wages. Most of this excess cost of $£ 200$ will therefore be added to the cost of other production of goods and services. Of course it will not stop there. If all butchers or all boot makers or all lorrymen have their costs increased, they try to put up their prices and make good their loss. If they can do that without fear of competition from outside, we call them sheltered industries. Those that are exposed to outside competition are the unsheltered industries, and they cannot put up the price, but have to stand the extra costs and suffer the loss of consumption - the same loss of consumption which befell the immediate purchasers of top hats in our first example.

Let us consider the unsheltered industries. They are in the first place broadly the export industries. Some exporting industries - sugar and butter and dried fruits - are indeed themselves protected, and receive in effect a heavy subsidy. That subsidy might be increased - e.g. the fixed price of sugar might be raised-so as to relieve them of the excess costs of other protection. But in the short run these industries also have to carry excess costs and suffer a cut in their living standards.

Then there are the industries competing with imports - mostly themselves protected. If imports are actively competing these industries cannot raise their prices, and so they are unsheltered. Like sugar and butter they might be given additional protection, but in the mean time they must bear excess costs. However, at the present time, as we shall see later, most protected industries are working well within the limit of the protection offered by law, so that they also can raise their prices and pass on excess costs. There are important exceptions, but for the most part the protected manufacturing industries are also at present sheltered.

There are also the people who are not producing goods or providing services, but live on fixed incomes from interest. These cannot pass on higher prices, but bear the loss of consumption. These are not numerically very important.

So that we can very broadly regard the export industries as those which bear the excess costs of protection of necessaries, and cannot pass them on.

Let us now trace the journey of the excess costs of protecting teapots. Some of it will fall at once on export farmers and their farm labourers, whom we agreed to count as one. (I shall refer to them for brevity as farmers, but you 
will understand in this connection I do not mean sheltered farmers like milk dairymen, who are in an intermediate position, and I include all people working on the farms or stations which produce wool and wheat and other exportable produce, the price of which depends on the world price.)

Some of the first excess cost then falls directly on the farmers, and stays there. Most of the rest goes through higher wages into the costs of sheltered industry, and is passed on through higher prices. Some of these higher prices are paid by the farmer, and he has to carry this dose also. A little may fall on Governments through railway services, for example - and be carried by the general taxpayers. Some will go into the price of luxury goods, and will rest with the purchaser of those goods. A little will fall on fixed incomes. The rest, which will be the greater part, will fall on the wage-earner in the shape of higher prices for all his necessaries.

Retail prices will go up again, and wages follow them, and the higher costs will be passed on again in higher prices, some of which will stick with the farmer, and a little with the taxpayer and fixed incomes. So the process goes on until sheltered industry has entirely got rid of excess costs. Every $£ 100$ of excess costs may now be distributed something as follows:

\begin{tabular}{l|l}
\hline & $\boldsymbol{E}$ \\
\hline Taxpayers & 5 \\
\hline Fixed Incomes & 10 \\
\hline Buyers of Luxury goods & 15 \\
\hline Unsheltered Manufacturers & 10 \\
\hline Farmers & 60 \\
\hline Total Excess Costs & 100 \\
\hline
\end{tabular}

All these elements of the community bear some such share of the excess cost of the protected production of teapots, and suffer a corresponding fall in their living standards. But the burden is very unequally divided. All the community buys the protected teapots, but they do not bear the excess cost, as the buyers of top hats did. Some part of it falls on fixed incomes, and some part on the 
purchasers of luxury goods having no connection with teapots. This incidence, though it may be unjust to individuals, is not economically harmful. But the greater part falls on the export farmer and his men, who are of very great economic importance to the community at all times. When export prices are high, they may carry a good burden of excess costs without distress; but not during the low prices of the last few years, when much export farming has been unprofitable. ${ }^{5}$

We have then a large proportion of the cost of protecting necessaries falling on unsheltered industries. So far as this is manufacturing industry relief is likely to come either by increased tariff protection or by improved efficiency, for which there is in general plenty of scope. For export industry there is no obvious relief. Costs of production are increased, and some export production becomes unprofitable. It was reckoned in The Australian Tariff that relief from tariff costs would be equivalent to adding about 10 per cent to the price of export produce. The percentage to-day is probably, on the whole, rather less.

I will not stop to discuss the effects which these higher costs have had in restricting export production. In earlier years that question was very important. Under the present conditions of export industry, there would be no substantial expansion at free trade costs. The chief effects of relief from tariff costs would be an increase in land values for the more favoured producers, and some relief to the community from the burden of supporting the less favoured ones. On the other hand, production in the protected export industries would fall away. Sugar

5 The protection of necessaries also will not of necessity affect the balance of external payments. There will be the same repercussions of increased income and employment with teapots as with top-hats, but here they may be partly offset by a decrease of employment and income, mostly in export industry, which will also have their repercussions. The fall in imports will then be partly balanced by a decrease in exports, and for the rest by the increased consumption of imports due to the net increase in employment. Theoretically the decrease in export production and employment might be greater than the increased production of tea pot, so that the net increase of employment would be negative. Normally, however, with farm production, which is very rigid-and particularly 90 in recent years with the marginal farmer supported at public expense-the tendency will be for export production to be maintained. So far as that is achieved by a lowering of the living standard of the farmer (or of the taxpayer), there will be decreased imports. The decrease of imports of teapots will be balanced by the increase of imports due to new employment and its repercussions. The decrease (if any) on account of lower standards of the farmer will give a net fall in imports as a final result, and a consequent improvement to this extent in the trade balance. (Export production, by hypothesis, is not affected.) Generally it is only in so far as the protective policy results in an abnormal restriction of consumption and a consequent lessened demand for imports, that the net result in the short term will be an improvement in the balance of trade. 
production would cease, and in butter and dried fruits, the lower costs would not on the average compensate for the loss of protection, so that the tendency would be towards a lower output.

It is of interest to note that this passing on of costs which leaves most of the burden with the export farmer, occurs equally in Australia when the price of necessaries is raised in any other way. When the price of butter is raised sixpence a pound to provide a bounty to dairy farmers, or a home price is imposed on flour or wheat to give a bounty to wheat growers, the added cost is passed on, just as with higher prices due to protection. Most of this assistance given to butter or wheat by means of a home price or "marketing control" is provided in the last resort by the export farmers themselves.

It has been noted above that there are other "necessaries" besides those covered by the retail price index. Anything which enters into the cost of production of goods covered by the retail price index or of export goods is a "necessary" for our purpose. Under this heading we have many kinds of machinery, farming implements, tools, some fuel, and a good deal of raw material. Protection of these also will give rise to excess costs which will be passed on through wages, and fall in the end mainly on unsheltered industry. The distribution of these costs will be much the same as that suggested in the table above for teapots. There is not, however, a great amount of excess costs due to protection of goods of this kind.

\section{The protection of primary products}

We come now to the distinction between factory goods and primary products as the subject of protection. For primary products, the incidence of costs is the same as for factory goods-for luxuries on the first purchaser, for necessaries mostly on the export farmer. But the benefit - the effect on employment - is very different.

In general, all factories start level in competition. If there are particularly favourable locations as regards climate or transport facilities, all factories can share them. Their costs will depend wholly on their efficiency and the size of their output. In primary production, costs depend mostly on the natural advantages of the farm (or the mine), and with the same efficiency of management vary enormously in different localities. Average yields of wheat vary from 6 bushels 
per acre to 30 bushels per acre, according to district. Average yields of apples vary from 100 bushels per acre to 600 bushels per acre. The Wheat Commission found that current costs of production (i.e. excluding land values) averaged about 2s. per bushel in the Wimmera, against more than 4s. in the outer Mallee. For factories, then, the whole of the production of a certain class of goods - top hats or teapots - is dependent on the higher price due to protection, and the tariff creates or maintains the whole of the employment in that industry. For farms and mines, on the other hand, it is only the marginal production which is essentially dependent on the tariff, and the employment created or maintained by protection is only a part - it may be a small part - of the total employment in that industry. But all producers get the benefit of the protection, which is therefore, over a large part of the field, an unnecessary bonus, inflating land values. The costs, and their distribution (as we have noted), are the same as for factory products. But the benefit in employment which we get in return for a given cost may be only a half or one-quarter of what would be obtained from the same cost spent in protecting factory products.

To summarise our conclusions:

All protection imposes a cost on the community or some part of it, and the costs of protecting necessaries falls mostly on the export farmers. In return for this cost we get the benefit of increased employment, which in normal times means increased population. The lower the rate of protection required the more employment is gained for a given cost, so that it is important to avoid as far as possible industries that require high protection. Protection of primary products gives only a fraction of the additional employment (or population) that is given by protecting factory production. It is therefore in general to be avoided, even when the rate of protection is low. High protection of primary produce is then the maddest of all forms that protection can take. The highest peak of insanity in Australia is reached by the protection of the tobacco industry under a protective duty which in 1934-35 averaged 265 per cent. It is a characteristic and significant feature of the new trade policy recently promulgated from Canberra that this monstrous duty is raised still higher.

It may be noted also that while the cost of protection takes the form of a definite lowering of living standards by a loss of consumption goods, which can reasonably be expressed in $\mathfrak{E}$ 's, the benefit is primarily and normally an increase 
in population (or of employed population) on which no monetary value can be put. In times of depression, however, some monetary benefit can be estimated for the relief of unemployment, but this is not an adequate measure of the benefit. In general, protection only makes possible the maintenance of additional population at a given standard-it does not add greatly to existing incomes. The exception is in the protection of primary products where, as we have seen, the greater part of the cost may be taken out, not in greater employment, but in adding to the incomes (and land values) of the more productive farms.

\section{The total of excess costs}

Having now discussed the meaning and significance of excess costs, let us turn to the question of their magnitude. The estimate made by the committee for $1926-27$ was $£ 36 \mathrm{~m}$. $£ 26 \mathrm{~m}$. on account of factory goods, and $£ 10 \mathrm{~m}$. on account of farm production. It still seems probable (as the authors judged at the time) that this estimate, though it could not pretend to high accuracy, was within 10 per cent of the true figure. In the years that followed, the protective tariff was heightened, and excess costs probably increased. Then came the heavy duties and embargoes imposed by the Cullin Government in 1930-31. These were designed, however, not so much to protect Australian goods as to stop quickly a flow of imports which we could not pay for. At the same time, they must have had some effect on diverting consumption from imports to, Australian products, and this diversion even without higher duties, means an increase in total excess costs. About 1931, then, excess costs were no doubt relatively higher than in 1926-27, but on account of the greater fall in income and consumption, total excess costs were probably a little lower.

With the depression came a gradual but strong improvement of competitive power by Australian factories, so that even when duties remained unchanged, less protection was used. This came about partly as a result of greater economy and efficiency induced by the depression and the keen competition of Australian factories for the reduced market.

A still more powerful factor was the fall in wages relative to wages abroad. This came about primarily through our peculiar method of adjusting wages to prices. The 10 per cent additional cut imposed by the Federal Court affected 
perhaps half the field of wages, but was offset by the slowness of some of the States, particularly New South Wales, to allow wages to be adjusted to lower prices. The net effect over all Australian wages has been a reduction almost exactly equal to the fall in prices. Wages in the three years 1930 to 1932 fell 21 per cent, and retail prices 22 per cent. In England, in the same time, the cost of living fell 15 per cent, and wages only 5 per cent. Wages now in Australia are 18 per cent lower than in 1930, but in England only 2 per cent lower. This fall in w-ages relative to the movement in England took place in the face of a depreciation of the currency in relation to sterling; it may be said at the present time that sterling wages have fallen 34 per cent in Australia since 1930, and practically not at all in England.

This change in relative wages had, of course, a very great effect on the relative cost of production in the two countries, since wages, directly or indirectly, account for half the costs of factory production in Australia. With the added spur to economy and efficiency given by depression conditions, Australian factories as a whole have moved much nearer free trade conditions. Some important manufactures, such as iron and steel and agricultural implements, can now face world competition without any protection at all, and their prices in Australia are for the most part free trade prices. This movement must have greatly decreased the degree of protection required, and reduced excess costs. This reduction will, however, be in some extent offset by a further diversion from imports to home products, and by the rising level of all consumption. On the whole I think we should expect excess costs in 1932-33 to have been appreciably less than in 192627 for manufacturing industry, and to have decreased further to the present time.

The costs of protection of rural industry, on the other hand, which are much more easily measurable, have continued to increase during the last ten years.

These conclusions can be tested by results obtained from inquiries carried out in Adelaide and Perth in response to suggestions made by the Commonwealth Grants Commission. Your Auditor-General, Mr. J. W. Wainwright, is chiefly responsible for the very able investigation of tariff costs in 1932-33, which was presented last year to the Commission. Mr. W. L. Wilson, the Assistant Statistician at Perth, took the leading part in examining the same problem from a different 
angle on behalf of the Government of Western Australia. (I will for convenience refer to these two inquiries by the names of Mr. Wainwright and Mr. Wilson respectively.)

Mr. Wainwright found for 1932-33 that the excess costs of protected manufactures was about $£ 19 \mathrm{~m}$ - $£ 7 \mathrm{~m}$ less than the estimate for 1926-27-and for the farm products nearly $£ 11 \mathrm{~m}$, or $£ 1 \mathrm{~m}$ more than at the earlier date.

Mr. Wainwright's investigation was carried out on similar lines to that of the earlier Committee. Neither was able to attempt a full investigation, but I should judge that Mr. Wainwright's enquiry was at least as thorough as the earlier one. On the other hand the problem is now rather more difficult than it was in 1926-27. At that date most of the protected industries were using the full amount of the protection afforded by the tariff, so that excess costs could be estimated for them with some confidence. The chief difficulty was with industries that were not using the full protection allowed, but perhaps only a half or a quarter of it. This more uncertain field has increased greatly relatively to the more certain field, so that I think Mr. Wainwright's estimate must be liable to at least as much error as the estimate for 1926-27, which was put at 10 per cent. I think, then, we may take excess costs for $1932-33$ as being between $£ 27 \mathrm{~m}$ and $£ 33 \mathrm{~m}$, and since there can be little doubt about the figure for farm protection, the total for factory protection may be taken to be between $£ 16 \mathrm{~m}$ and $£ 22 \mathrm{~m}$.

Mr. Wilson's results are for the year 1933-34, but they are not directly comparable, because they deal primarily with tariff costs as they affect the State of Western Australia. We shall see presently that some indirect comparison can be made, and that this comparison suggests that Mr. Wainwright 's estimate is too high rather than too low.

Let us, however, provisionally take $£ 30 \mathrm{~m}$. as the measure of excess costs in 1932-33. The meaning of that is that Australia as a whole is foregoing consumption goods to that value for the sake of additional population and employment. It seems a stupendous cost - hardly credible.

If, however, we estimate the amount of increased population or employment which we get in exchange, the balance seems not unreasonable. The additional 
population made possible by protection corresponds with the free trade value of protected production.

If we put protected production at $£ 100 \mathrm{~m}$ in $1932-33$, and excess costs at $£ 30 \mathrm{~m}$, then we get a free-trade value of $£ 70 \mathrm{~m}$, which might directly support a population at the Australian standard of 900,000, and indirectly nearly three times as many, or certainly over two millions. ${ }^{6}$ On this reasoning, at least a third of our population is only there by virtue of the protection policy, and $£ 30 \mathrm{~m}$ does not seem an excessive price to pay. If it was spread uniformly over all consumers, making 5 per cent all round, and still more if the cost could be distributed in the same way as income tax, the cost would not be very heavy. The trouble is that most tariff costs are on necessaries, and so fall with concentrated weight on the export farmer. It is on this account that we have to be very jealous of any increase in tariff costs, and welcome any reduction with very warm appreciation.

The proportion of tariff costs that falls on necessaries is therefore a vital consideration. With necessaries must be grouped, as we have seen, not only the commodities which enter into the index of retail prices, but all producers' goods used in the production of these commodities. These would include raw material like cotton, wool, etc., and also machinery and plant used in manufacture and transport. The remaining protected goods which do not enter into costs of production, we are calling luxuries.

For 1926-27 the excess costs of protected "luxuries" were estimated at $£ 7 \mathrm{~m}$, and the estimate was very conservative. As far as factory goods go, the movement has been towards protection of luxuries, and it may be now that not more than half the excess costs of factory goods are on account of necessaries. On the other hand protected farm products are mostly necessaries, and excess costs have increased for farm products. On the whole I estimate that a slightly smaller pro portion of excess costs falls on the export farmer than in 1926-27, so that there has been some relief on that account, as well as from the reduced total. On the other hand, he has been less able to bear added costs of any kind.

6 Against this of course is to be set the increase in export industry possible at lower free-trade costs, with its repercussions. Before the depression, this would have been considerable, though it was judged in The Australian Tariff that it would be a good deal less than production dependent on the tariff. Under the recent conditions of export industry, it may for the present be regarded as roughly negligible. 


\section{The states and the tariff}

We come now to the vexed question of the unequal incidence of the tariff among the States. Modern factory industry in all countries tends to concentrate in chosen positions in relation to raw material, coal, power, transport, and markets, and have a natural concentration here in Victoria and New South Wales. These States therefore receive the benefit of increased population and employment which result from protection of factory goods. On the other hand, the price paid for this increased population falls predominantly on unsheltered industry, which in Australia is mostly export industry.

It happens that all the States are largely interested in export production, so that the burden is widely spread. But some States, Western Australia particularly (and to a less degree South Australia), have a larger proportion of export industry, so that they bear too large a share of the cost, as well as getting too small a share of the benefits. It is clear that South Australia and Western Australia are at a disadvantage in respect to tariff policy.

Is it possible to measure the relative disadvantage? It may be possible to make a reasonable estimate of the distribution of costs amongst States. But can these costs be regarded conversely as subsidies paid to protected production, and distributed as benefits amongst States in proportion to the amount of protected production. The payment of these subsidies makes possible the increased population and employment which is required in the interests of Australia as a whole. But the subsidy may be - in fact should be - entirely used up in making it possible for this new population just to subsist. It cannot be regarded as an addition to existing incomes in the same way that the costs paid are a definite subtraction from the real income of those who pay them. We are essentially comparing a loss of income on the one hand with increased population on the other. The two things cannot be compared in numbers. They are incommensurable. No doubt there are monetary advantages accruing to a State from increased factory employment. In times of depression and great unemployment, they may be very great. In times of full employment they may be comparatively small. At no time are they adequately measured by the amount of subsidy to protected production. 
With protection of farm products, a good deal more of the subsidy is a definite increase to existing incomes, as I have pointed out earlier. There is therefore a better case here - but still not a good one - for balancing subsidies against costs.

Estimates of costs and benefits among States have been made on the lines I have indicated, but I do not think they are valid. I am afraid that I was the first to offend in that way, but it was nearly ten years ago, and I quickly recanted. Mr. Wainwright, in his enquiry, was particularly concerned with the unequal effect of the tariff in States, and has made a calculation on these lines, not perhaps with entire conviction, but for want of a better way.

I will mention his results in a moment. Here I want to say first that I do not think this method of distributing benefits is valid; and secondly, that his distribution of costs according to population could be improved upon. It is fundamental, in the position as I have put it to you, that excess costs fall predominantly on unsheltered industry. A better way would be to distribute onehalf of total excess costs in pro portion to the value of unsheltered industry in each State, and the other half in proportion to its population. ${ }^{7}$

I have said that I do not think that "benefits" can be measured crudely by the subsidies to protected production. I want, however, for the moment to assume that they can be, in order to make some comparisons of Mr. Wainwright's results and those of Mr. Wilson's for Western Australia.

If we revise Mr. Wainwright's figures by distributing one-half the costs in proportion to unsheltered export industry and the other half in proportion to population, we get the following results for net gains or losses by States in 193233, which we may compare with the original estimate:

7 In protection of necessaries, 75 per cent of excess costs is taken as falling on unsheltered industry; for luxuries perhaps 20 per cent. Protection of necessaries accounts for about two-thirds of the whole, so that 50 per cent is a conservative figure for the proportion of total excess costs falling on unsheltered industry. 


\begin{tabular}{l|l|l}
\hline & $\begin{array}{l}\text { Original } \\
\mathbf{E m}\end{array}$ & $\begin{array}{l}\text { Revised } \\
\mathbf{E m}\end{array}$ \\
\hline New South Wales & -1.74 & -1.95 \\
\hline Victoria & +1.43 & +1.82 \\
\hline Queensland & +3.28 & +4.05 \\
\hline South Australia & -1.11 & -1.30 \\
\hline Western Australia & -1.30 & -2.15 \\
\hline Tasmania & -0.50 & -0.47 \\
\hline
\end{tabular}

The revised estimate increases the loss of South Australia a little and of Western Australia greatly, and leaves Tasmania untouched. This is what we should expect. Western Australia has by far the greatest proportion of unsheltered export production. Much of Tasmanian farm production has a sheltered market, and the State gets great benefits from interstate free trade.

Now let us look at the Western Australian results. There they tried to get a net measure of the total effects of the tariff for that State alone, by comparing the price of all interstate imports and exports with the price of duty-free goods, and counting the excess price of imports as a loss and the excess price of exports as a gain. They were able to do this because they have a complete record of interstate trade, which no other State has. This result will take into account the extent to which excess costs are passed on to unsheltered industry. It will also take into account any greater cost falling on Western Australia, because inter state freights are higher to that State than to any other from the manufacturing centres of the east. I am not sure that the result should be exactly comparable with that derived from Mr. Wainwright's, but I think it should be at least roughly comparable. Here are the two figures for net effects on Western Australia:

\begin{tabular}{l|l}
\hline Mr. Wainwright 's revised & $-£ 2.15 \mathrm{~m}$ \\
\hline Mr. Wilson's & $-£ 1.19 \mathrm{~m}$ \\
\hline
\end{tabular}

Here is a rather serious discrepancy. To what extent can they be harmonized? 
Mr. Wilson's is for 1933-34, and we might expect tariff costs to have fallen a little in the year, but not much. That might account for $£ 100,000$ and reduce the difference to, say, $£ 1 \mathrm{~m}$.

Mr. Wilson's estimate, however, includes the amount by which factory goods from the east are raised in price by customs duty (including primage) actually paid on raw material and machinery used in production. This is excluded by our definition of excess costs, and is excluded from Mr. Wainwright's estimate.

Mr. Wilson's figure will be exaggerated on this account, and the discrepancy increased. I am not at present prepared to offer any estimate of the amount of this error.

On the other hand, Mr. Wilson has left out certain elements of excess costs. Sheltered goods received from other States will be raised in price by the passing on of tariff costs, though by definition the price will not be raised above that of duty-free imports from overseas. I have made a tentative estimate of the error on this account, and make it about $£ 150,000$. There is one other respect in which Mr. Wilson's estimate will be low. His comparisons are in general with the price of British goods, and these are not always the potential competitors in the Australian market. Mr. Wainwright's estimates, like those of the earlier enquiry, were based on the average duty paid, and not on the British preferential tariff. If Mr. Wilson had compared Western Australian prices with goods duty-free from the cheapest source, his excess costs would have been increased.

To make his figures comparable in this respect with my revision of $\mathrm{Mr}$. Wainwright's, I would very doubtfully add 10 per cent.

I am afraid we cannot make much of these deplorable confessions of ignorance, but I am inclined to think that if all these corrections were properly made they would not raise Mr. Wilson's figure to more than $£ 1.5 \mathrm{~m}$; and if $\mathrm{Mr}$. Wainwright's is assumed to be 10 per cent too high (and I know he believes it to be conservative), we still have it over $£ 2 \mathrm{~m}$. There is still an unexplained discrepancy to be cleared up. 
I am, however, the less concerned to clear it up, because (as I have said above) I do not think that the benefits to States are properly measured by the subsidies to protected production. Even if the two estimates considered above could be made to agree, the harmonized results would have no validity. The "benefit" is primarily an increase of population - a political end which cannot be measured in terms of economics.

\section{The lowering of tariff costs}

Let me in conclusion return to the question of the reduction of tariff costs and the prospects of the movement continuing. The strongest argument for protection in general is that it is necessary to support new industries, until they have acquired experience and skill and are able to stand on their own legs. In practice, we have found in the past that this growing-up process has been very protracted-the infant industries have refused to grow up, and have gone on requiring increasing doses of baby food. Some advance was made in the years just before the depression, particularly in consolidating small businesses into larger ones and getting rid of surplus capacity.

With the depression, as we saw earlier, came a steady reduction in costs, not only absolutely but relatively to the costs in other countries from which our imports were drawn. This greatly improved competitive power is reflected in the reports of the tariff board. For most factory products, the need for protection is found to have become much less in recent years. Even for such highly skilled manufactures as agricultural implements, the question is raised whether they could not and should not be put on the market at prices substantially below free trade prices in return for protection from dumping.

The tariff board has played an important part in this encouraging development. The board offers a remarkable instance of the delegation (in effect) of a highly specialized job to experts, with very satisfactory results. In this business of tariff protection in the interests of the community as a whole, there were in fact no experts ready-made. The members of the board had to learn their job by doing it. Naturally enough, the board's earliest efforts were crude, and its authority consequently slight. It applied itself, however, diligently and intelligently to its work, studied, gained experience, broadened its outlook, built up a technique, 
and as a result has become very competent. The consequence has been that it has to a large extent gained the confidence of all the interests concerned, and established its authority.

The present Government has contributed greatly to that end. Its declared policy has been to refer all questions of protection to the tariff board, and to give great weight to its recommendations. That policy has up to the present been carried out in very fair measure, in spite of the obvious political difficulties which it entailed. There have been at times hesitations and postponements, but in the end the tariff board's recommendations have been substantially carried out. It appeared likely that this policy if pursued would give the board a status in public confidence that would be increasingly difficult to upset; so that even a diehard free trader or protectionist in the Ministerial chair, though he might impede, would find it impracticable entirely to frustrate the board's guidance to a sane and balanced protective economy.

\section{The new trade policy}

This pious hope has been somewhat rudely dashed by the new trade policy recently promulgated from Canberra. On two most important items of tariff policy (the protection of textiles from Japanese competition, and the protection of motorcar manufacture) the Government has taken drastic action, without, so far as the public has been informed, even referring these highly technical questions to the board. On another item (the increased protection of tobacco), action has been taken directly contrary to the board's findings, without any reason being offered for rejecting them. By this action the Government appears to have undone the good work in the past, to have destroyed the promising building it has been patiently erecting, and to have exposed the whole structure of our tariff policy to the vagaries of future political expediency, and the log-rolling of interested parties.

This aspect of the new trade policy bears directly on my subject to-night. There are other aspects, not so closely related, on which I feel bound to make some comment. This new policy has startled and bewildered a great many people, and particularly the economists. I have no authority to speak for them, but I have no doubt that most of them are as much troubled as myself. It has been a pleasant 
feature of the years of depression that we have felt ourselves in broad agreement with the trend of Government policy on economic questions. Now for the first time comes a divergence which most of us will feel very deeply.

The first disturbing feature of the new trade policy is the absence of any rational principle behind it. The need of placating "good customer" countries is put forward as a principle, with Great Britain as the one "good customer" to whose interests all other countries, whether good or bad customers, must be sacrificed. Attempts to balance the trade between two countries are now one of the greatest obstacles to the revival of international trade on which Australia is particularly dependent. Apart from this important consideration, the fundamental assumption of the argument is not supported by the facts. The United States is a "bad customer" country, we are told, because we have a heavy adverse balance of trade with her. The facts are that we have an even heavier adverse balance with Great Britain.

Let us look at the balance of payments for $1934-35$. We had $£ 31 \mathrm{~m}$ to pay for imports of British goods, and about $£ 26 \mathrm{~m}$ for interest, sinking fund, and other services (beyond those included in the valuation of imports). To our credit were about $£ 38 \mathrm{~m}$, the value of imports from Australia retained by Great Britain. So the balance sheet for Australia in 1934-35 runs thus:

\begin{tabular}{l|l|l|l}
\hline Cr. Exports & $£ 38 \mathrm{~m}$ & Dr. Imports & $£ 31 \mathrm{~m}$ \\
\hline Adverse balance & $£ 19 \mathrm{~m}$ & Interest, etc. & $£ 26 \mathrm{~m}$ \\
\hline Total & $\mathfrak{£ 5 7 m}$ & & $\mathfrak{£ 5 7 m}$ \\
\hline
\end{tabular}

So the year ended in a balance of $£ 19 \mathrm{~m}$. against us. We paid about $£ 6 \mathrm{~m}$. of this balance with gold, and the remainder $(£ 13 \mathrm{~m}$.) had to come out of favourable balances with other countries or London reserves. We should, however, set against this the capital investment from Great Britain, which is not accurately known but may have been of the order of $£ 5 \mathrm{~m}$.

If, then, we are going to talk about "good customers", Britain is no doubt, in one sense, a good customer of Australia, but Australia is a much better customer of Great Britain. If we are going to adopt this vicious system of balancing trade 
between two countries, it is for Britain to buy a great deal more to make the balance even. But in any event trade of different kinds has different values. Other countries must get their wool from us, just as we must get petrol from America, regardless of the other trade between the countries concerned.

Apart from the principles involved, the most dangerous feature of the new policy is the threat to wool, on which our whole economy is based. Japanese imports were already subject to very severe customs duties, and this new savage discrimination against Japan can be expected to stir national resentment to a frenzied dance, whenever it suits the Japanese authorities to call the tune. I am not so much concerned with any immediate disturbance of the market. That might be very costly to the wool-grower, and disastrous to our balance of payments; but on the other hand, it may not suit Japanese policy to withdraw too quickly from the wool market. It is the long run effect on wool prices which is more certainly to be feared. Wool is faced with the increasing competition of substitutes. If only a quarter of present wool consumption was replaced by other fibres, the effect on prices and on Australia would be disastrous. The wool-growers themselves would be troubled by prices rising much above the level reached this year, because high wool prices encourage the development and use of substitutes, and imperil the future price of wool. But high prices for wool would not be nearly so effective in encouraging substitutes as the passionate national sentiment of a people devoted to taking any and every means to overcome their dependence on wool. That is the prospect before us. Japan was buying wool in large and increasing quantities. She is showing ability to make textiles of wool so cheaply for export as to open up new markets for wool, which neither Great Britain nor Australia could attempt, and so make up, and more than make up, any loss on account of substitutes. This promising development we have nipped in the bud. Further, when Japan has shown the way to a comparative independence of wool, there is a possibility of other countries of a supersensitive nationalism, such as Germany and Italy, following her example. (Flocks suggest Abraham and a non-Aryan taint.) The tragic possibilities are endless. In return, there seems a prospect that Great Britain will buy a little more inferior Australian beef at unprofitable prices in place of the better product of Argentina.

More broadly, looking at the gloomy international situation, one would have expected a conciliatory foreign policy for the next few years, until international 
relations are improved, or we have at least lone something adequate for defence. Two leading features of such a policy would be to enhance in every way our friendly relations with the USA, and to avoid with particular care any action calculated to provoke Japan. Both these important considerations appear to have been deliberately flouted.

I have already referred to the project for making motor car chassis in Australia. This is the most important and difficult application of the protective policy that has ever been attempted in Australia. If ever there was a tariff item which required full public investigation and criticism, it is this. Yet this is the item on which, apparently, depart mental advice is regarded as so competent as to make quite superfluous any reference to the experienced tariff board, until after the Government is committed to the project, and the industry, in fact, has been launched with the support of a heavy tariff and a large bounty.

From every angle, the new trade policy inspires the gloomiest forebodings, and the prospect is the worse, because it seems to have been launched with the mild approval - I was tempted to say, connivance - of all political parties. One can only hope that its operation will be carried out with quietly diminishing vigour until in a year or two it passes into deserved oblivion. Failing that, one can only be reminded of the old Euripidean tag, more familiar in its Latin form:

"Quem Juppiter vult perdere, dementat prius". 


\section{8}

\section{Australian economic progress against a world background}

\section{Colin Clark ${ }^{1}$}

To regard economic progress as the normal and natural condition of human affairs is to betray the limitation of one's mind in both time and space. of the continents of the globe, Northern Europe, America, Australasia, and Japan have, during the last century, made genuine and striking economic progress. But in Southern and Eastern Europe the evidences of progress are much more dubious. The great bulk of Africa's population remains in an entirely primitive stage of economic development; while in Asia, other than Japan (in which continent over half of the world's population is to be found) there is evidence of actual economic retrogression during the period which we are pleased to call "the century of progress". Even within the favoured minority of countries where genuine economic progress has been made, the rate of this progress is often grossly exaggerated. Alleviating the colossal total of the world's poverty will take much longer than some people think.

The attention devoted to statistics by certain economic historians, particularly that great pioneer Thorold Rogers, is now enabling us to see that our economic history in past centuries by no means consisted of that steady improvement in standards of living which some would have us believe in. Sufficient figures indicative of wages and retail prices in England are available to give some indication of the real standard of living of artisans in England from the beginning of the eighteenth century onwards. ${ }^{2}$ From an index figure of 67 units early in the eighteenth century, these standards of living had shown, by the end of the century, a catastrophic decline of more than one-half to 33

1 Eighteenth Joseph Fisher Lecture, 9 August 1938.

2 See for example Tucker, Journal of the American Statistical Society, March, 1936. 
units. There was little improvement in standards of consumption of the English population between 1800 and 1850 , though of course capital goods were being rapidly accumulated during this period. The "hungry "forties" are more than a popular legend. It was not until the eighteen-seventies that the British working population resumed the standards of living which had prevailed at the beginning of the eighteenth century.

Computations of real wages alone would be inadequate to support these statements. But they are also confirmed by statistics of industrial production. The marshalling of the available information regarding industrial production in England in the eighteenth and nineteenth centuries has (to the shame of English historians) been left to a German statistician, Dr. Hoffman. ${ }^{3}$ The available evidence goes to show that throughout the whole course of the eighteenth century the expansion of industrial production was only about adequate to keep pace with the increase in population, while it is almost certainly the case that the expansion of agricultural production definitely failed to keep pace with the growth of population. The glittering facade of civilization and learning of the much belauded eighteenth century conceals from view the intensified sufferings of the hungry poor who have left no records of their lives.

These impressions are confirmed when we collate the computations of English national income made by Gregory King for 1688, by Beeke for 1800 , by Colquhoun for 1814, by McCulloch for 1837, and by Smee for 1847. In the earlier years of the nineteenth century real income per head was far below the level of 1688. Finally, to take a concrete illustration, meat which (according to Thorold Rogers) was a staple element in working class diet in Elizabethan times, was in shorter supply in the seventeenth century, and had virtually disappeared from the working class table by the time of the Industrial Revolution, only to reappear in the English working class diet at a comparatively recent date.

History, as well as geography, provides for those who are willing to see it, quite as much evidence of economic retrogression as of economic progress. Some indeed ${ }^{4}$ have gone so far as to point out that the level of economic productivity

3 Weltwirtschaftliches Archiv, September, 1934.

4 For instance, F. B. Jevons, Economic Journal, 1896. 
in classical times was not far different from that which prevailed in the middle nineteenth century. It took the world over twenty centuries, and heaven knows what discoveries of applied science, simply to recover the level of economic welfare which had prevailed at the earlier date.

The colossal mass of human misery and hopelessness summarized in the few paragraphs above, whether in eighteenth century England or in presentday India or China, can be explained in terms of one single phrase, well-known to economists, "the pressure of population upon the means of subsistence", as expounded in the so-called law of diminishing returns and in the Malthusian laws of population. The fact that neither of these laws is applicable in wealthy modern communities is an important truth. But we must not let it blind us to the more important truth that these laws are applicable still at the present day in countries containing more than half the world's population, and were applicable in Europe at the time they were first propounded. Economists of the early nineteenth century earned for their science the name of "The Dismal Science", and for themselves great unpopularity; but this dismalness was no more than a reflection of the objective facts of the situation of that date.

The law of diminishing returns is more frequently mis-stated than any other proposition in economics. It can be cogently and concisely stated in a single sentence. With a given amount of land, and a given state of productive technique, there is no necessary limit to the amount which can be-produced from it; but to produce a large output will re quire more labour per unit of output than to produce a small output. Thus (assuming a given amount of land and a given level of productive technique) a small population enjoys a better standard of living than a large population. Improvements in productive technique do not destroy the validity of this law, as is sometimes supposed. After such an improvement the law again starts to operate, but at a higher level of real income per head (which is the same thing as a lower labour requirement per unit of output). With all the resources of chemical and bio logical science at their disposal, the proposition that from a given area of land a small population can obtain a higher standard of production per head than a large population, remains as true to-day as it was in neolithic times, even though the effect of technical improvement has been to feed the dense populations of to-day better than the sparse populations of those times. 
It is only in primary production that this law of diminishing re turns is universally true. In secondary and tertiary production this law is occasionally applicable, but more often the reverse, or law of increasing returns, is applicable. This law requires more care in its statement, but may best be stated in the form that a community engaged in industrial production, the state of industrial technique being given, will require to exert less labour per unit of output for a large output than for a small output. This law is not applicable to industries which are dependent on relatively scarce and unsubstitutable natural products, or under certain other circumstances. As will be shown below, the operation of the law of increasing returns in Australian secondary industry seems to be less marked than elsewhere. Most tertiary industries (precise definition of which will be discussed below) are carried on subject to increasing returns.

In the primitive and unprogressive economies which are still found over more than half the earth's surface and were universal until a century or so ago, the bulk of the community will be engaged in primary production, and diminishing returns will be the natural economic law. From this situation sprang the Malthusian law of population and the Ricardian law of rent, denounced by humane men of that period as a gloomy conspiracy to perpetuate the poverty of the human race and the grossly unjust distribution of what little wealth was produced, but in fact not more than objective statements of the economic trend of that time. Neither Malthus nor Ricardo foresaw the advent of the good fairy of Increasing Returns who, in the subsequent half-century, was to chase away gloom and to inspire mankind with the hope of economic progress.

To escape from the power of diminishing returns - and much of the world is still subject to that evil control - it is necessary that, in the first instance, capital should be accumulated. With this capital secondary and tertiary industries are established. At this stage, the problem of markets is not important. The rural population, and the gradually growing industrial population, readily consume the entire output of these industries. Once these industries are established on a substantial scale, income rises rapidly and the amount of capital available to facilitate further economic progress increases still more rapidly. By these processes the pace of economic advance is, in the first instance, an accelerating one. To make the first few paces is exceedingly hard, but with every step progress becomes easier. "To him that hath shall more be given." But even in the modern world, 
the initial stages of economic progress are of exceptional difficulty and slowness. It has indeed been argued that in England, France, and Holland - the three countries where the trend towards modern economic organization began, in the seventeenth century - the capital accumulated from the spoliation of the Indies and the Americas was the source from which all economic progress sprang, and without which no progress would have been possible.

To measure the absolute levels of economic progress so far reached in different countries is a difficult statistical task. In essence the task consists of measuring the real national incomes of the countries concerned, which amounts to the same thing as the actual equivalent of goods and services produced, whether for consumption or investment, measured at an international price level. I have published the details and methods of this determination in a recent article in Weltwirtschaftliches Archiv (January, 1938). The world moves fast, and many of the figures given there are already out-of-date. I have brought the figures up-todate $^{5}$ for the principal industrial countries of the world and table 18.1 below gives the true level of the real income per head of the working population in these countries in 1936 or 1937.

Australia, it will be seen, now holds fourth place on the list. Other countries among the first half dozen number Canada and Switzerland; up-to-date figures for them are not available, but they are probably below Australia at the present time; the Argentine also appears to be running closely up to Australia. Contrary to the belief of some, Australia does not enjoy higher average real income per head than Great Britain, though a less equal distribution of income in Great Britain, and the glaring poverty of certain districts, create the impression that Britain is the poorer country. The highest standards of living in the world are found in New Zealand, which country (taking into account the fact that she enjoys a shorter working week) is now slightly ahead of the USA There has been a tremendous upward surge of economic progress in New Zealand during the last six years.

Attention is drawn to the fact that this represents the average productivity per person in work. The extent of unemployment may reduce the average standard

5 These and all other figures subsequently quoted are extracted from the manuscript of a book which I am now completing, entitled The Conditions of Economic Progress, in which the detailed calculations and sources are given. 
of living of the whole population seriously below these levels. This point is dealt with later.

Table 18.1: Average real income produced per year per occupied person in work in various countries (On a 48-hour week basis measured in international units of purchasing power, 1936 or $1937^{*}$ )

\begin{tabular}{l|l}
\hline New Zealand & 2,040 \\
\hline U.S. America & 1,948 \\
\hline Great Britain & 1,402 \\
\hline Australia & 1,363 \\
\hline Sweden & 851 \\
\hline Germany & 848 \\
\hline Italy & 399 \\
\hline Japan & 362 \\
\hline USSR & 345 \\
\hline
\end{tabular}

*(1 international unit $=$ amount of goods and services purchasable with 1 American dollar over the average of the period $1925-34$, or $£ 0.26$ Australian in 1938).

Even between these countries we see a tremendous difference of economic fortunes. Italy, Japan, and Russia are all close together, and very low on the scale. Inside the USA there are the widest divergences between States. The average income per head of the working population of New York or California is at least four times as great as that of Georgia or Carolina. In Australia and New Zealand these great geographical inequalities are absent.

Table 18.1 however, gives very little idea of the dispersion of the world 's population as a whole. As is shown in table 18.2 below, more than half of the world 's population is living at a level of poverty more desperate than we can even imagine. An income of 200 international units represents fairly closely the standard of living which would be enjoyed by an Australian wage-earner, buying food at Australian retail prices, trying to keep a family on $£ 1$ a week. In India and China the situation is even worse. The average productivity is only about 120 units, corresponding to the standard of living which would be enjoyed by an Australian wage-earner with an income of 12s. 6d. per week. 
Attention is drawn to the fact that table 18.2 relates to an earlier period, namely the decade 1925-34, than table 18.1; and also relates to in come per head of population, working and unemployed. On both these grounds the figures are considerably lower than those quoted in the previous table.

Nothing could bring out more clearly the limited extent of economic progress, even in the present-day world. Standards of living approaching those to which we are accustomed are found (besides in Australasia) only in North America and Northern Europe, and in three of the States of South America. As many as 500 million people are living in conditions of what might be called incipient industrialism, of which Japan and the USSR are the most marked. They have a long way to go before they approach the standards of living of the richer countries, though we have grounds for thinking that their progress will be accelerated with time.

Table 18.2: World's population, distributed in income categories, 31 st December 1935 (Incomes in international units of purchasing power per head of occupied population, working and unemployed. Period 1925-34, hours actually worked)

\begin{tabular}{l|l|l}
\hline Incomes per head & & Millions \\
\hline Over 1,250 & USA, Canada & 139 \\
\hline $1,000-1,250$ & Great Britain, Switzerland, Argentine, New Zealand & 65 \\
\hline $700-1,000$ & Australia, Holland, Eire & 18 \\
\hline $600-700$ & Germany, France, Sweden, Denmark, Belgium, Uruguay & 137 \\
\hline $500-600$ & Spain, Chile, Norway & 32 \\
\hline $400-500$ & Czechoslovakia, Jugolavia, Brazil & 72 \\
\hline $300-400$ & $\begin{array}{l}\text { Rest of South America, Japan, Egypt, Algeria, Philippines, Italy, } \\
\text { USSR, Poland, Finland, Hungary, Greece, Portugal, Latvia, } \\
\text { Estonia }\end{array}$ & 451 \\
\hline $200-300$ & $\begin{array}{l}\text { Rumania, Bulgaria, Albania, Lithuania, Turkey, Syria, South } \\
\text { Africa, Morocco, Tunis }\end{array}$ & 68 \\
\hline Below 200 & India, China, East Indies, rest of Asia, Africa, and Oceania & 1,113 \\
\hline & & 2,095 \\
\hline
\end{tabular}


Over the last quarter of a century, however, economic progress throughout the world has been very uneven. It is difficult to disentangle the underlying economic factors from the effects of the war and its aftermath. Even in countries which took no part, or only a small part, in the war of 1914-18, its economic effects were still marked. In Great Britain, pre-war productivity has been restored by 1924, and from that date progress was resumed; while in USA, Japan, the Scandinavian countries, and Australasia,-the effects of the war were even more quickly overcome. But in continental European countries, where the devastation of war was much greater, and the almost equally devastating effects of inflation were subsequently felt, recovery was much later delayed, though rapid when it came. By the year 1930 we can take it that the economic effects of the war and inflations had disappeared, and that underlying economic forces were again in charge. The extent of economic progress throughout the world between 1913 and 1930 is measured by the following table 18.3 .

In this table we measure real income produced per head of the occupied population in work; that is to say, we take no account of the effect of unemployment on real incomes. If we did so, many countries would appear in a still more unfavourable light than they do in this table.

To illustrate the importance of diminishing returns, even in the modern world, the countries are ranged in the order of their rate of population growth over that period. It will be seen that in the case of Germany, Italy, Russia, Holland, Rumania, Greece, and Bulgaria, all largely agricultural countries, rapid growth of population has been accompanied by a marked decline in standards of living. In the new world and in industrial Europe, however, the reverse is the case. At the same time, it cannot be maintained from the evidence that the countries which have in various ways kept down their population growth (e.g. Great Britain, France, and Austria) enjoyed a particularly marked rate of economic development, or low unemployment in consequence.

The rate of economic progress in Australia has only been surpassed by Japan, Switzerland, and Yugoslavia. The corresponding figure for New Zealand (not shown in the table) is a 28 per cent increase in real income per head of the working population between 1913 and 1930 . 
Table 18.3: Changes in workforce, per worker real income, and working hours, 1913 to 1930

\begin{tabular}{|c|c|c|c|}
\hline & $\begin{array}{l}\text { Percentage increase } \\
\text { in working } \\
\text { population 1913-30 }\end{array}$ & $\begin{array}{l}\text { Percentage change } \\
\text { in real incomes per } \\
\text { person in work } \\
1913-30\end{array}$ & $\begin{array}{l}\text { Percentage fall in } \\
\text { working hours } \\
1913-30\end{array}$ \\
\hline Bulgaria & 41.2 & -18 & $*$ \\
\hline Germany & 38.8 & -22 & 23 \\
\hline Holland & 38.2 & -7 & 20 \\
\hline Canada & 34.8 & +22 & 15 \\
\hline Greece & 31.8 & +4 & $*$ \\
\hline USA & 24.5 & +16 & 9 \\
\hline Norway & 24.1 & +13 & 20 \\
\hline Finland & 23.9 & -1 & $*$ \\
\hline Australia & 21.0 & +39 & 7 \\
\hline Sweden & 18.8 & +23 & 17 \\
\hline Russia & 17.1 & -4 & $20 ?$ \\
\hline Denmark & 16.8 & +9 & 17 \\
\hline Japan & 14.5 & +105 & 10 \\
\hline Italy & 14.1 & -12 & 30 \\
\hline Hungary & 11.4 & +31 & $*$ \\
\hline Britain & 10.0 & +13 & 11 \\
\hline Rumania & 9.8 & -20 & $*$ \\
\hline Switzerland & 8.6 & +38 & 12 \\
\hline Spain & 8.2 & +39 & $*$ \\
\hline Yugoslavia & 6.7 & +64 & $*$ \\
\hline Czechoslovakia & 4.5 & +16 & $*$ \\
\hline France & 3.4 & -8 & 20 \\
\hline Belgium & 0.7 & +1 & $*$ \\
\hline Austria & -9.0 & +1 & * \\
\hline
\end{tabular}

* Unknown. 
The influence of the old enemy of diminishing returns can be clearly seen in many parts of the world. It is indeed the principal factor holding back economic progress in Soviet Russia, where the Malthusian devil remains unexorcised by Marxist dialectic. The dense and rapidly increasing population attempting to make a living out of a rather infertile agricultural land was bound to lead to a decline in the standard of living of the rural population, which offsets the somewhat spectacular achievements of Russian industry.

Another striking feature is the extent to which hours of work have been reduced all over the world during the last twenty-five years. Since 1930 this tendency has been accentuated. In one respect, at any rate, this is an important form of economic progress, in which nearly every country has had some share, and at the same time has acted as an important palliative of over-population in Russia and Italy. It will be noticed that by no means all countries have succeeded in raising their average annual real income per head, while at the same time reducing hours of work, though every country has increased its average hourly income per head.

The grievous effects of diminishing returns must not, however, lead us to suppose that primary production is a source of weakness in the Australian economy. The level of real income obtained by the worker engaged in primary production in Australia is exceedingly high, largely because the Australian land is more sparsely populated than that of most other countries. The high level of this figure is shown in table 18.4 below. What the law of diminishing returns tells us is that any attempt to increase the numbers engaged in primary production would probably lead to a serious fall in their average real output per head.

Table 18.4 analyses the production of national income from primary, secondary, and tertiary sources in the principal countries. Secondary production covers manufacturing industries; tertiary production all forms of economic activity not included under primary and secondary. These figures refer to income "currently produced", and exclude the rents of houses and external investment incomes. They are thus distinctly lower than the figures of average income per head previously quoted. It will be seen that secondary workers made the greatest contribution per head to Australian real national income, but that primary workers are not far behind. This is in marked contrast to the situation in USA, 
where primary producers contribute per head less than one third of the amount of secondary and tertiary producers. In New Zealand the magnitude of productivity per head of primary producers is even more marked. In general, however, we can say that Australia and New Zealand are the only countries in the world where the average real income per head of primary producers comes anywhere near that of secondary and tertiary producers. The relatively poor position of the primary producer is particularly marked, for instance, in Germany, Sweden, and Japan. In Great Britain and Switzerland the real income per head of the primary producer approaches that of the secondary producer. But in each case here we have a limited number of primary producers supplying a densely populated industrial home market and enjoying both natural and fiscal protection. The primary produce of, Australia and New Zealand, on the other hand, is, in the former case mainly, and in the latter case entirely, sold at world prices.

Table 18.4: Average productivity in international units per occupied person in work per annum in primary, secondary and tertiary industries

\begin{tabular}{l|l|l|l|l}
\hline & $\begin{array}{l}\text { All income } \\
\text { currently } \\
\text { produced }\end{array}$ & Primary & Secondary & Tertiary \\
\hline USA (1935) & 1,945 & 736 & 2,410 & 2,340 \\
\hline New Zealand (1935-6) & 1,481 & 1,872 & 1,653 & 1,296 \\
\hline Australia (1935-6) & 1,277 & 1,408 & 1,461 & 1,148 \\
\hline Switzerland (1929) & 1,123 & 816 & \multicolumn{2}{|c}{1,183} \\
\hline Great Britain (1930) & 1,095 & 827 & 1,151 & 1,072 \\
\hline Germany (1928) & 760 & 440 & 810 & 935 \\
\hline Sweden (1930) & 740 & 278 & 1,109 & 886 \\
\hline France (1930) & 618 & 469 & 1,170 & 433 \\
\hline Norway (1934) & 603 & 268 & 1,123 & 650 \\
\hline Italy (1928) & 426 & 328 & 471 & 541 \\
\hline Japan (1934) & 365 & 146 & 959 & 374 \\
\hline
\end{tabular}

In the same way the high figure for secondary production per head in Australia is partly accounted for by the high degree of tariff protection enjoyed by Australian secondary industries. This table is based on calculations which show the amount of real income received per head by each type of producer. In a free 
trade country this corresponds to the value of goods or services which he can produce, measured at world prices. The effect of tariff protection is artificially to enhance real incomes of secondary producers, and to a less extent primary producers, and to diminish the real incomes of tertiary producers, for they have to pay more for their primary and secondary produce without having their own incomes in any way enhanced. Few people have drawn attention to the fact that protection of either primary or secondary producers tends to keep down the real income of that hitherto neglected person - the tertiary producer.

The true productivity per head of primary and secondary producers can, to some extent, be measured directly. Two special investigations have been conducted, in which the average output per head of primary and secondary producers in different countries of the world is expressed at American prices (tables 18.5 and 18.6). In this way the genuine productivity of each is measured without the disturbing element of tariff protection.

Table 18.5: Agricultural and pastoral production per male occupied

\begin{tabular}{l|l}
\hline \multicolumn{2}{c}{ \$ at American 1934 Prices } \\
\hline New Zealand & 1,930 \\
\hline Australia & 1,144 \\
\hline Uruguay & 1,123 \\
\hline Argentine & 900 \\
\hline Canada & 598 \\
\hline Switzerland & 566 \\
\hline Denmark & 550 \\
\hline USA & 549 \\
\hline France & 307 \\
\hline Germany & 266 \\
\hline Sweden & 183 \\
\hline Italy & 160 \\
\hline Poland & 75 \\
\hline
\end{tabular}


Table 18.6: Net output per operative employed in secondary industry

\begin{tabular}{l|l}
\hline \multicolumn{2}{|c}{ \$at Amercian 1925 prices } \\
\hline USA & 3,420 \\
\hline Norway & 1,700 \\
\hline Great Britain & 1,530 \\
\hline Japan & 1,345 \\
\hline Australia & 1,250 \\
\hline France & 922 \\
\hline
\end{tabular}

Broadly tables 18.5 and 18.6 confirm the calculations given in table 18.4, but they show some striking features of their own. In the sphere of primary production, the predominance of New Zealand is truly outstanding. Australia falls far below the New Zealand level, high though her standing is compared with other countries. High figures for the Argentine and Uruguay are also of importance. Many will be surprised to see the low level of productivity in Canada and the USA, which is no higher than that of the most agriculturally advanced countries of Europe, namely, Great Britain, Denmark, and Switzerland.

International statistical comparisons of industrial production are much less easy. Table 18.6 gives figures for six countries. When the value of goods produced is re-expressed at international prices, Australia makes a very poor showing. Production is indeed carried on more efficiently in Japan than it is in this country; in other words, the Japanese manufacturer could afford to pay Australian wages and still undersell us.

New Zealand, with a lower degree of tariff protection than Australia, shows a much higher value of net output per worker in manufacturing industry, while Canada has an output per head (measured at international prices) as high as that of USA. The comparatively poor showing made by Australian industry is not due to inefficiency on the part of the basic industries of this country, the productivity statistics of which compare fairly well with those of Great Britain or New Zealand. The fault lies in the profuse extension of manufacturing activity into a large number of hitherto unexplored fields during recent years, under the 
protection of the tariff and the exchange rate. So far these extensions have proved uneconomic. If the claims of their sponsors are true, that they will eventually prove themselves to be efficient and economic industries, Australia has a tremendous industrial improvement to look forward to during the next few years, without any further tariff protection.

Returning to the figures given in table 18.4 , it can be said at any rate that Australia does have the appearance of being more evenly balanced between primary, secondary, and tertiary production than is the case in other countries. The level of real income in the three types of industry is approximately the same. Where primary incomes are very low relative to secondary and tertiary, as in the USA or (to take a very different example) in Japan, this leads to rural impoverishment and discontent and a rapid drift of population away from the land. Where secondary incomes are abnormally high, as in pre-Blum France, this is indicative of excessive profits and mal-distribution of income. Norway and Sweden also are open to this same criticism. Or where primary incomes are abnormally high, as in New Zealand, this leads to inflation of land values, speculation, mortgages, and other concomitant troubles. From each of these difficulties Australia is relatively free.

That desirable thing, an economic balance between different forms of production, must be interpreted to mean equality of real income per head in different types of activity, rather than that equal numbers should be engaged in them. It will be seen (in table 18.7) that the distribution of Australian working population at the last census was 24.4 per cent in primary industry, 29.4 per cent in secondary industry, and 46.2 per cent in tertiary industry.

In table 18.6 the countries have been ranged in order of their average real income per head in 1925-34. Only 19 per cent of the American population are engaged in primary production, but their incomes are hopelessly low, and show a tendency to fall further. A tremendous further migration away from the land will be necessary to restore economic equilibrium in that country. Many people will be surprised to see that even in France and Germany only one- quarter of the working population is engaged in agriculture. For any higher proportion of the population than that to be engaged in primary production is indicative of extreme poverty. In a progressive modern community, adequately supplied with natural resources, the labour of 10 per cent, or less, of the population ought to 
suffice to produce the community's whole requirements of primary produce. If the proportion of primary producers in the working population is much above that, the country will have to export a large part of this primary output. Australia, employing only 24 per cent of its population in primary production, exports half its output of primary produce. New Zealand exports as much as two-thirds of her output of primary produce, while only just over 20 per cent of her working population are engaged in primary production (the figure given in the table is for the last census, that of 1926, and has fallen heavily since that date). Great Britain supplies more than half of her food requirements with only 6.4 per cent of her population engaged in agriculture. The large proportion of America's population engaged in primary production is associated with a very low figure of average output per head. In future years, further population will leave the land and the average output per head of those remaining on the land will increase till in America too we shall probably find that 10 per cent of the population can supply all the primary produce required by the remainder.

Even so the high proportion of tertiary workers may come as a surprise to some. New Zealand by 1926 already had the highest pro portion in the world, and now has a higher figure still. To find low proportions of tertiary producers among the population we have to go to Italy, India, China, or Soviet Russia. Even in Japan the proportion is 38 per cent.

It was an Australian professor, Professor A. G. B. Fisher, who first drew the world's attention to the fact that a rising standard of living and economic progress were ineluctably associated with an increasing proportion of tertiary producers and a declining proportion of primary producers. Many of us have still failed to learn that lesson.

The extent of the movement away from primary production during the last thirty years is indicated in table 18.8. The proportion of primary producers in the principal countries at that date may be compared with the present-day numbers given in table 18.7 .

In case any of you find these figures hard to accept I would ask you to reckon up how much you spent altogether last year, and how much of that you spent on primary produce. Bearing in mind the fact that less than half of the retail price of 
primary produce goes to the producer, you will probably find that you have spent about 90 per cent of your income on goods and services other than primary produce.

Table 18.7: Distribution of occupied population (excluding unemployed) as shown by latest census

\begin{tabular}{l|l|l|l}
\hline & Primary & Secondary & Tertiary \\
\hline USA & 19.3 & 31.1 & 49.6 \\
\hline Great Britain & 6.4 & 43.9 & 49.7 \\
\hline Switzerland & 21.3 & 44.9 & 32.8 \\
\hline Australia & 24.4 & 29.4 & 46.2 \\
\hline New Zealand & 25.7 & 24.3 & 50.0 \\
\hline France & 25.0 & 39.7 & 35.3 \\
\hline Germany & 24.3 & 38.5 & 37.2 \\
\hline Japan & 36.4 & 25.0 & 38.6 \\
\hline Italy & 42.9 & 31.1 & 26.0 \\
\hline India & 62.4 & 14.4 & 23.2 \\
\hline China & 80.0 & $($ approx $)$ & 20.0 \\
\hline
\end{tabular}

Table 18.8: Percentage of working population engaged in primary production about 1901

\begin{tabular}{l|l}
\hline USA (1900) & 37.4 \\
\hline Great Britain (1901) & 8.4 \\
\hline Switzerland (1888) & 37.4 \\
\hline Australia (1901) & 32.8 \\
\hline Germany (1895) & 33.3 \\
\hline France (1901) & 33.1 \\
\hline Italy (1901) & 59.4 \\
\hline Japan (1897) & 71.8 \\
\hline
\end{tabular}

Even in Great Britain where the proportion was already low in 1901, the decline has continued. Particularly marked has been the de cline in Japan. The 
Australian figure has fallen from 32.8 per cent to 24.4 per cent. In our case this means that the absolute number of primary producers has increased very slightly, while, relative to the whole population, their numbers have fallen heavily.

We are now in a better position to approach the dynamics of the general problem of Australian economic progress. In our book, National Income in Australia, just now being published, Mr. J. G. Crawford and I give the following figures of real income produced per person in work on a 45-hour week basis, as a measure of the true trend of Australian economic progress since 1886.

Table 18.9 gives evidence of very uneven progress. The earliest figures are based on computations by Sir Timothy Coghlan for New South Wales, then containing about 40 per cent of the Australian population. The figure for 1898 is a little uncertain, but the evidence appears to show that up to about that date economic progress was exceedingly rapid. From 1898 to 1914 was a period of stagnation.

Table 18.9: Real income produced per person in work on a 45-hour week basis

\begin{tabular}{l|l|l|l}
\hline \multicolumn{5}{c}{ E per week at 1923-27 prices } \\
\hline $1886-87$ & 172 & $1924-25$ & 301 \\
\hline 1888 & 186 & $1925-26$ & 308 \\
\hline $1889-90$ & 203 & $1926-27$ & 328 \\
\hline 1892 & 217 & $1927-28$ & 330 \\
\hline 1998 & 231 & $1928-29$ & 337 \\
\hline 1901 & 201 & $1929-30$ & 341 \\
\hline $1901-03$ & 207 & $1930-31$ & 335 \\
\hline $1914-15$ & 226 & $1931-32$ & 343 \\
\hline $1916-17$ & 216 & $1932-33$ & 350 \\
\hline $1917-18$ & 204 & $1933-34$ & 343 \\
\hline $1918-19$ & 210 & $1934-35$ & 360 \\
\hline $1920-21$ & 223 & $1935-36$ & 364 \\
\hline $1921-22$ & 269 & $1936-37$ & 355 \\
\hline $1922-23$ & 280 & $1937-38$ & 360 \\
\hline $1923-24$ & 282 & & \\
\hline
\end{tabular}


Followed as this was by the disturbing effects of the war; it was not until 1921-22 that Australia recovered to the level of average real income per head which it had enjoyed thirty years earlier. From 1920 to 1926-27 came a rate of economic progress which has never been equalled at any other time in Australian history, or scarcely in the world. From 1926-27 to 1935-36 progress was resumed though at a slower pace. The great depression had little effect on productivity, that is to say, on the average income produced per person in work. During the last two years the number of people in employment and the aggregate money national income have shown a marked expansion, but the figures of average real income per head have declined. There are some grounds for saying that Australia has been, since 1935-36, in a situation of decreasing marginal returns, or of rising marginal costs.

It will pay to examine in more detail the astonishing spurt of Australian productivity between 1920-21 and 1926-27. In many other countries there have been short, or sometimes prolonged, periods of very rapid economic growth, and from the available statistics of national incomes I have selected all the available figures (table 18.10). It will be seen that this period when production per head in Australia was expanding at the rate of 91 per cent per decade, nearly constitutes a record. The record rate of growth is that shown by Japan between 1920 and 1928, during which period the real national income per head was doubled. The New Zealand figure is not entirely comparable though undoubtedly growth has been exceedingly rapid during this period. Owing to certain technical difficulties, my calculations of real income for New Zealand do not eliminate the effects of changes in the terms of trade, but do eliminate them in the Australian calculations. As a result, the New Zealand figure was, to some extent, unduly low in 1931 and unduly high in 1937.

To throw further light on Australian economic progress, we will examine the average real income produced per head per year in primary, secondary, and tertiary industry at four critical dates (table 18.11). These are 1889-90, the first year for which information is available; 1921-22, or the beginning of the rapid upward movement; 1926-27, after which date it slowed down; and 1935-36, the year of maximum real income per head so far reached. 
Table 18.10: Maximum rates of growth of real national incomes per head of working population in world

\begin{tabular}{l|l|l}
\hline \multicolumn{2}{|c}{ Per cent increases per decade } \\
\hline Japan & $1920-1928$ & 125 \\
\hline New Zealand & $1931-1937$ & 115 \\
\hline Australia & $1920-21$ to 1926-27 & 91 \\
\hline Russia & $1925-1937$ & 33 \\
\hline Canada & $1911-1928$ & 31 \\
\hline Norway & $1891-1937$ & 27 \\
\hline Switzerland & $1900-1930$ & 26 \\
\hline Germany & $1854-1881$ & 25 \\
\hline Japan & $1897-1920$ & 22 \\
\hline Italy & $1901-1934$ & 22 \\
\hline USA & $1920-1936$ & 22 \\
\hline Great Britain & $1865-1937$ & 17 \\
\hline
\end{tabular}

Table 18.11: Average real income produced per worker in Australia

\begin{tabular}{l|l|l|l|l|l|l|l}
\hline & & & \multicolumn{3}{|l}{$\begin{array}{l}\text { Distribution of working } \\
\text { population (per cent) }\end{array}$} \\
\hline & $\begin{array}{l}\text { Primary } \\
\text { producers }\end{array}$ & $\begin{array}{l}\text { Secondary } \\
\text { producers }\end{array}$ & $\begin{array}{l}\text { Tertiary } \\
\text { producers } \\
\text { (incl. } \\
\text { building) }\end{array}$ & $\begin{array}{l}\text { All } \\
\text { currently } \\
\text { produced } \\
\text { income }\end{array}$ & Primary & Secondary & $\begin{array}{l}\text { Tertiary } \\
\text { (incl. } \\
\text { building) }\end{array}$ \\
\hline $1889-90$ & 948 & 341 & 674 & 693 & 32.0 & 20.5 & 47.5 \\
\hline $1921-22$ & 1,122 & 1,155 & 795 & 943 & 26.2 & 17.3 & 56.5 \\
\hline $1926-27$ & 1,393 & 1,341 & 1,000 & 1,159 & 23.6 & 18.6 & 57.8 \\
\hline $1935-36$ & 1,408 & 1,461 & 1,148 & 1,277 & 24.3 & 20.0 & 55.6 \\
\hline
\end{tabular}

During the period 1921-22 to 1926-27, all three forms of industry expanded their output per head, but the rate of expansion was most marked in tertiary industry. Since 1926-27 productivity in primary industry has shown little further advance. Tertiary industry has continued to expand most rapidly, and as has been pointed out above, would have made a better showing still if it had not been for tariff protection to secondary industries. 
The most striking feature of table 18.11, however, relates to the longer period of comparatively slow advances between 1889-90 and 1921-22. During this period of over thirty years, real income produced per head rose by 36 per cent only, and in primary production by only 18 per cent. But there was an astonishing advance in the productivity of secondary industry, accompanied - this is the remarkable feature - by a decline in the proportion of the population engaged in it. It appears that Australia suffered from a premature over-development of secondary industry, with a very low level of productivity in the 1880's.

Climatic and financial crises in the eighteen-nineties, though they produced tremendous unemployment and distress, had at any rate the beneficial feature of forcing out unsound secondary producers and very much raising the average level of efficiency.

Though we have advanced much since those days in the efficiency of our secondary industries, the figures quoted previously show that there is much still to be desired. We should not rest content until we have raised their productivity to the American or Canadian level, which is almost double that of present-day Australian manufacture. We are better off than those two countries in respect of the well-being of our primary producers, but that is no reason why we should rest content until we have achieved the same abundance of manufactured goods as they have achieved in those countries.

Those who attribute the high productivity of American industry to the abundance of natural resources there, show themselves very poor analysts. These same primary products obtained from natural resources are available in Australia, or, for that matter, in Great Britain, at much the same cost as in the USA. In some cases, as for instance the motor industry, the high productivity of American industry is attributable to the enormous scale on which they can work. But this is by no means always the case. Many examples can be found of American industries with very high productivity and very low labour costs, where the average size of plant is definitely smaller and employs fewer men than in Australia or Great Britain.

The high figure of productivity per head in Canadian industry shows that smallness and sparsity of population are no bar to the development of efficient 
industrial technique. The next steps in Australian industry progress can only be illumined, I suggest, after an intensive study of the industrial economics of Canada and the USA; eschewing generalizations and concentrating on the essential technique whereby such high average output per head has been obtained in these countries.

In the field of tertiary production, particularly in the transport and distributive industries, Australia has made remarkable progress, for which considerable commendation is due. Though measurement is not easy in this sphere, it appears that the Australian tertiary producer now has a real productivity above the level of Great Britain or of Europe, though still below the high figures reached in the USA. The economics of tertiary industries are almost a closed book throughout the world - many people have a reluctance even to mention their existence - except that in the USA a certain amount of work has been done on the economics of retailing and of transport. In view of the fact that half our national income comes from tertiary production, intensive study of applied economics in these fields is also called for.

Though the average level of productivity per head in Australian primary industries enables them to contribute very substantially to our present-day national income, it certainly does not follow that any further employment of labour in these industries would make a proportionate contribution. Indeed rather the reverse, owing to the niggardliness of nature in our geological make-up, the extent of good agricultural and dairying lands in Australia is very limited, and any further extension of production in marginal lands is likely to be hopelessly unremunerative. As Professor Richardson has pointed out, we may indeed expect to see further abandonment of marginal lands, where cultivation was too optimistically undertaken in the past. Agricultural progress in the future, he has pointed out, will lie in a steady improvement in technique and in biological strains on the part of farmers in the existing high-grade lands, with comparatively little expansion of employment.

The future of Australian export trade in primary produce lies in the politics of trade agreements rather than in the economics of comparative costs, and cannot therefore be foreseen. As the standard of living of the Australian public rises in the future, its consumption of primary produce will scarcely increase at all except in 
the case of milk and fruit. Its demand will be for secondary goods and for tertiary services, and to the provision of these we must bend our productive efforts.

So far, I have been dealing almost entirely with productivity, or the amount which the average man is able to produce, rather than production. In other words, I have ignored the wastage of economic resources occurring in all places and at all times, in the form of unemployment. In a real picture of modern economic progress we can no longer do this.

The best way by which this can be taken into account is in the series of diagrams given below. These diagrams illustrate the pace of economic progress in a number of principal countries since 1900 (since 1860 in USA). In each diagram three lines are drawn. The first illustrates what might be called the maximum productivity of the community per head if there were no unemployment and if the maximum length of hours were worked. The second line shows the potential productivity in the hours actually worked. That is to say, the difference between the first line and the second measures the amount of new economic productivity which is "taken out" by the worker ill the form of shorter hours; and in nearly every country it has been substantial.

Finally, the third curve shows the productivity actually realized. The difference between the second curve and third, therefore, represents the extent to which economic productivity has been wasted in the form of unemployment.

For Australia, we see that there has been a marked increase in realized standards of living as well as a reduction of hours. In the worst years of the depression much productivity was wasted in the form of unemployment though, at the present time, unemployment is no worse than it was at the beginning of the century.

Sweden is interesting in several respects. Here the rate of economic progress has been very substantial, and a surprisingly large proportion has been taken out in the form of reduced working hours which were very long at the beginning of the present century. Unemployment has been kept within moderate limits, and there is no great wastage of productive resources in this way. 

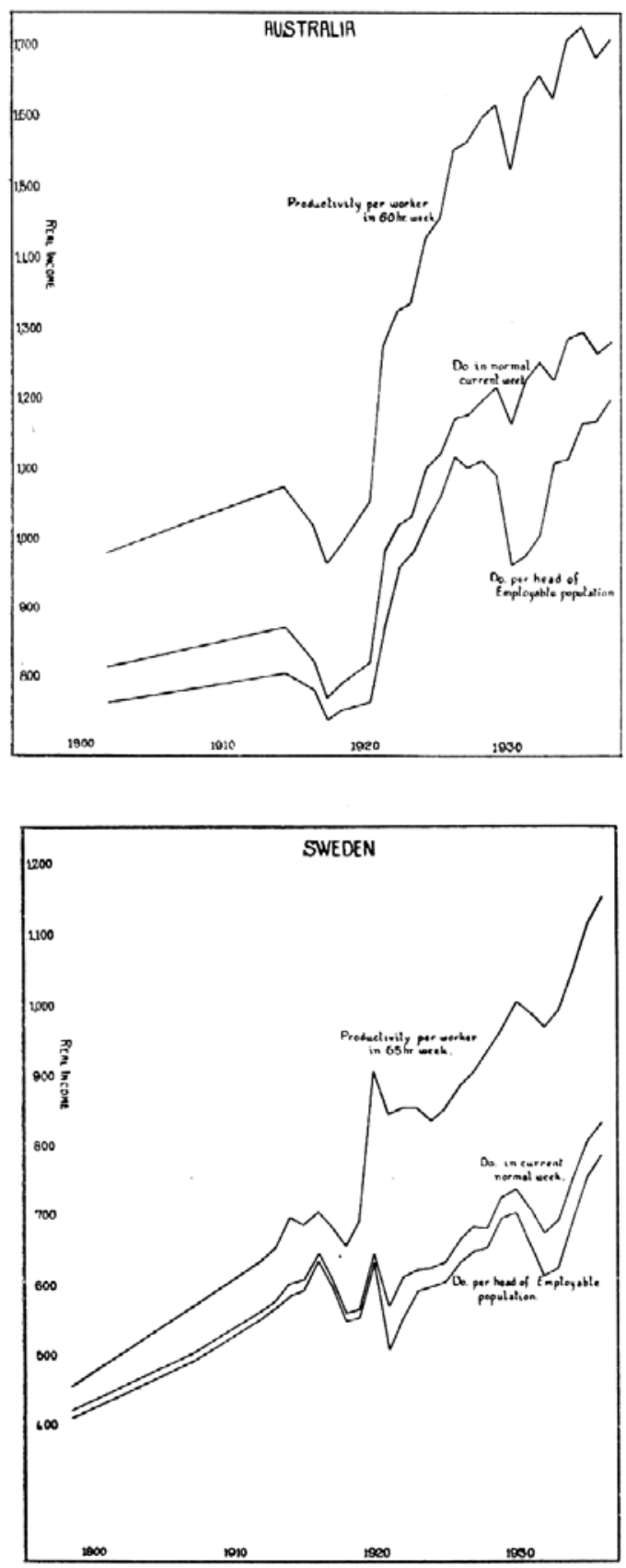

Please note: the figures on the following pages are of poor quality due to their age. 

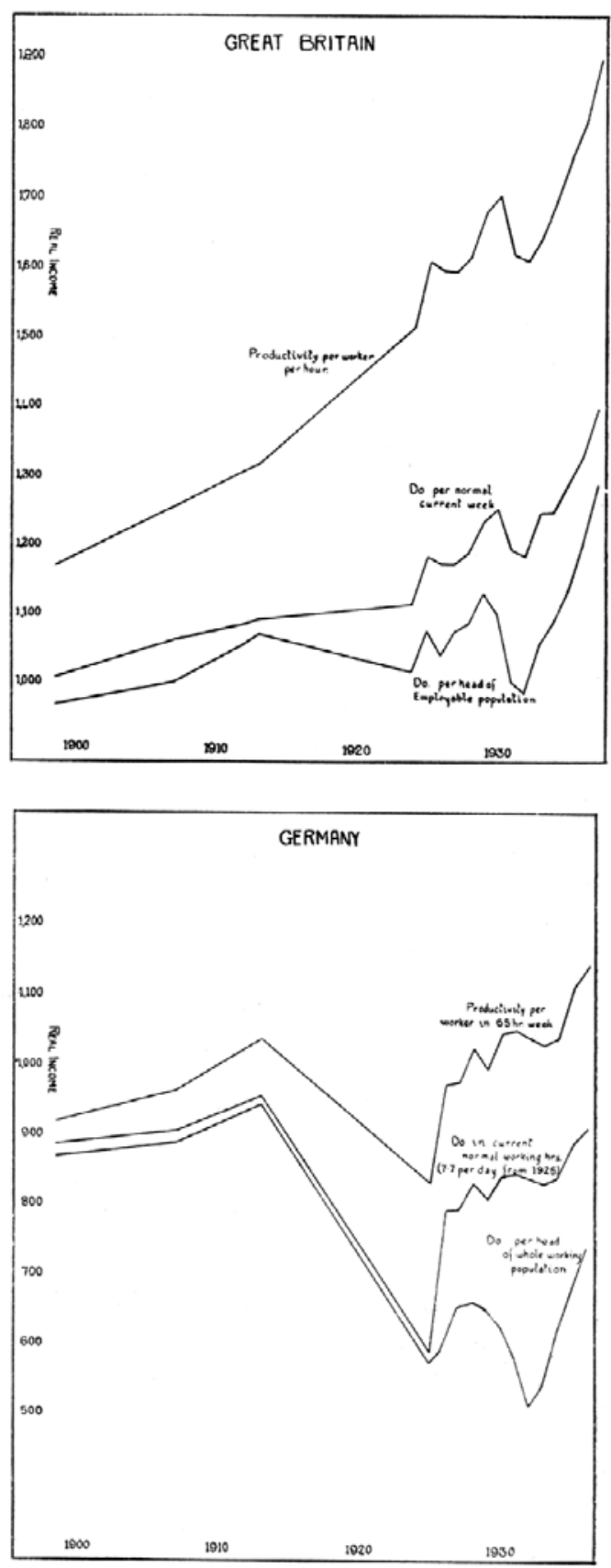
Colin Clark
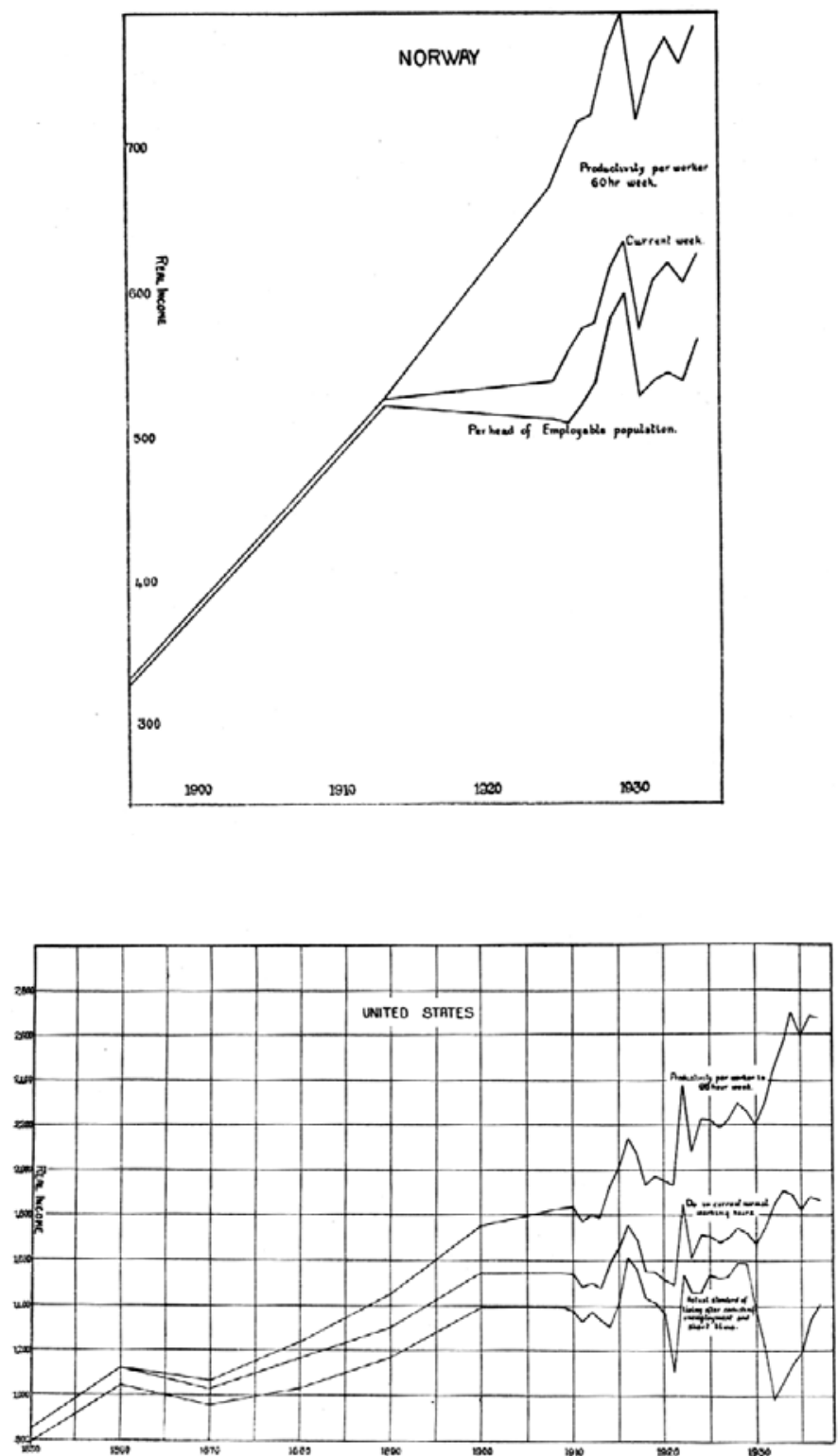
In Great Britain the expansion of economic productivity has been fairly uniform from the eighteen-sixties to the present day. Between 1900-14, however, it was comparatively slow. A marked reduction of working hours in this country also absorbed a large part of the fruits of economic progress, and substantial postwar unemployment for some years kept the achieved standard of living below the pre-war level. The expansion of British national income between 1932-37 has been exceedingly marked, though some of us are of the opinion that the drop from the present peak will be equally marked.

In Germany productivity, as a result of the combined effects of the war and of inflation, showed a catastrophic decline. Notwithstanding, there was substantial reduction of working hours, with the result that the standard of living of the population in 1925 was very much below that of pre-war years. After 1925 the expansion of productivity was largely offset by rising unemployment, and only now is the realized standard of living tending to rise back to the pre-war level.

In Norway, where economic progress has also been substantial, the effects are about equally divided between reduction of hours, and in crease of unemployment; and the realized standard of living has risen little from the 1913 level.

But it is in the USA that this situation is most marked. From 1850 to 1900 the three graphs rose together, although working hours were gradually being reduced. But the amount of economic productivity which was wasted in unemployment was not great. But since 1900, remarkable though it may seem, the realized standard of living of the American people, employed and unemployed taken together, has shown no tendency to advance, but has fluctuated with the movements of the trade cycle round about the 1900 level. The whole fruits of that country's magnificent technical progress were used up partly in reducing hours (which at any rate conferred some benefit upon the people) but mainly were wasted in the form of unemployment or short time.

One of the most essential facts of the world in which we live is the trade cycle. In spite of efforts to understand and control it, it shows signs of becoming more violent and destructive as time goes on. Its causes lie very deep in our financial and economic system; my point at the moment is that so long as we continue to live in a world of which the trade cycle is one of the main factors, 
it is inevitable, even if we work our labour force up to the limit during boom periods, that there will be a considerable surplus of labour throughout the rest of the trade cycle. In engineering parlance, our economic system has a bad load factor. In that sense, a considerable fraction of the unemployment with which tile modern world is afflicted should be directly blamed upon the trade cycle, and would disappear in its absence.

But to regard the trade cycle as all-important is also a serious mistake. There is much unemployment which is apparently not attributable to the trade cycle. In Australia, during the last three years for instance, the trade cycle has been in its topmost phase, and the demand for labour has been very active. Nevertheless, we have been left with some 7 per cent of our working population, as measured by trade union returns, still unemployed. These returns are only partial, and such further investigations as can be made seem to indicate that the true figure is distinctly worse than that indicated by the trade union returns. To what can unemployment of this nature be attributed? The only answer in this case is "occupational mal-distribution". Public and private lack of foresight have built up an Australian working population containing a huge surplus of unskilled labour. Employers have been unable to obtain almost any type of skilled labour for the last two years, while in every State thousands of unskilled men are engaged on relief work or are unemployed for the greater part of the year. Only as a new generation grows up is it possible to rectify this mistake.

Australia does not err alone in this respect. Indeed it is impossible to find any industrial country where this is not the case, namely, a surplus of unskilled labour and comparative scarcity of skilled labour. In Great Britain the problem of occupational mal-distribution is augmented by the existence also of geographical mal-distribution. A large surplus of unemployed population is congregated in some of the older industrial districts such as Clydeside, South Wales, and the North-East coast. Such problems are not serious in Australia, mainly owing to the greater mobility of the Australian population.

But it is only fair to point out that the analysis is not quite so simple as has been indicated above. There is not an inescapable division of the working population into so many thousands of skilled and so many thousands of unskilled. There is no doubt that the length and severity of the last depression served very 
much to accentuate the problems of occupational mal-distribution. Parents could not afford to give their children apprenticeship or technical training, and as a result an in creased number of boys were thrown on to the unskilled labour market. Skilled men themselves, finding themselves unemployed at their normal vocations, sought jobs as labourers, and generally obtained preference over men already in the unskilled labour market. Putting it the other way round, it is permissible to say that if booms were longer and stronger, depressions shorter and less intense, the problem of occupational mal-distribution would not be so serious as it is at the present moment.

Finally, we have the position in the USA, where at the peak of the trade cycle in August, 1937, there was still 11 millions of unemployed. A very large proportion of these were unskilled, but the skilled trades were by no means in a condition of full employment at that date.

In other words, we still have to account for this mysterious tendency which seems to be operating most powerfully in the USA, but which is to be found to some extent in all countries, tending to bring down the average level of national income and throw an increasing pro portion of the labour force into unemployment. The movements of the trade cycle are, of course, superposed on this underlying force. But this force tends to make depressions longer and more severe, booms shorter and less marked. This in itself, as we have shown above, tends to create a substantial part of this occupational and geographical mal distribution of the working population which is the proximate but not necessarily the ultimate cause of much of the unemployment which we find to-day.

More and more it is coming to be agreed among economists that the basic factor at work is the inability to find remunerative investment for all the potential savings of a wealthy modern community. The dilemma is a simple one. As an economy progresses and as national income rises, ever larger sums tend to be saved. Even where labour obtains a large fraction of the total product (as, for instance, in the USA) this difficulty remains. At the same time, as economic resources become more fully developed, the number of available outlets for capital, able to pay a reasonable rate of interest, rapidly diminishes. In the parlance of theoretical economics the marginal productivity of capital must fall rapidly as the amount of capital increases. This is more than a theoretical proposition, for it 
has been clothed in actual figures by Professor Douglas' studies of the growth of capital in the USA and other countries. It is a basic economic principle to which many economists and men of affairs have so far paid only lip service. They fail to recognize that an essential, and perhaps the most essential, condition of economic progress is a steadily declining rate of interest.

Another important fact concerning the accumulation of capital, of which few people are aware, is the extent to which industrial investment tends to retire into the background, and investments of the housing and public utility type tend to occupy the field. In Australia, for example, during 1937-38 the amount of net new investment was about $£ 80$ millions. Investment in plant, machinery, and vehicles for the whole of manufacture, mining, and agriculture only amounted to $£ 20$ millions of this. The whole remaining $£ 60$ millions represented buildings, public works, and dwelling houses. A very large proportion of investment of this kind must be undertaken by, or financed through, public bodies; and, moreover, it is investments of this kind which are most sensitive to changes in the rate of interest.

Australia being still a comparatively new industrial country, there are more opportunities for industrial investment here than in the USA or Great Britain. The investment of new capital in manufacturing industries in these countries has virtually ceased, and the steady replacement of obsolete plant offers all the opportunities which are needed for introducing technical improvements. Furthermore, even in Australia, the opportunities for new industrial investment are rap idly being used up, and it is evident that investments of the public utilities, public works, and dwelling houses type will be the main out lets for investment for capital in the future.

But will not the natural working of the capital market, we are entitled to ask, bring about the necessary re-adjustment? Will not these abundant supplies of capital cause the interest rate to fall to the level where they can all be economically absorbed Unfortunately, we have to answer - No.

The determination of interest rates is one of the most difficult branches of economic theory, but the doctrine that they depend simply on the supply and demand of capital has been very widely impugned. It has been clearly shown that two other factors at least are present, namely, "liquidity preference", or the extent 
of the desire on the part of investors and business men to hold their capital in liquid form, and the available amount of liquid money. Further, it appears that the supply of savings is, in the last analysis, more a consequence than a cause of changes in the rate of interest. An illustration and an analysis of the Australian interest rates during recent years is given in the July issue of Economic News.

It may at first sight seem far-fetched to claim that a change in interest rates can actually cause a change in the supply of savings. But so far as a change in interest rates is instrumental in causing a change in the investment of new capital this will literally be the case. It has been established very clearly, both statistically and theoretically, that any change in the rate of investment of new capital will cause a corresponding change in the national income of considerably greater amount than the originating change in investment. The ratio between these changes, known as the multiplier, is a matter of considerable interest. So far as Australia is concerned Mr. Crawford and I have shown that movements in the level of Australian national income are almost exactly determined by a multiplier of 2.08 applied to changes in the level of investment and of exports. The multiplier in England has varied during recent years, and for the USA is about 3 .

These figures mean that for each increase of $£ 100$ in the amount of capital invested in Australia, the national income will rise by about $£ 208$, and for each decrease in investment there will be a corresponding decline in the national income. It is not hard to see how any expansion in the investment of capital tends to create additional incomes, a substantial part of which will be saved and thus will itself provide a further source of capital. In the same way, if for some reason the investment of current savings is checked, the disparity between savings and in vestment will have the effect of forcing down the national income till the source of the savings is itself destroyed.

Thus, in a short compass, I have attempted to describe the basic trouble of many wealthy industrial communities in the world to-day. Science and management continually increase their potential productivity; the seemingly inevitable discrepancy between the tendency to save and the willingness to invest forever keeps down national incomes and wastes the fruits of technical progress in the form of unemployment. In the complex workings of the banking system 
is lost the hope of a self-adjusting mechanism whereby the rate of interest could be called into play to equate the supply and demand of savings necessary for the maintenance of maximum national income.

Australia to-day, having brought her national income up to its highest recorded level, is now threatened with a serious decline. The level-of internal investment has so far been maintained, but the rapid fall in export prices is threatening the whole stability of our structure. To maintain the level of economic activity it is now essential that internal loan expenditure should be extended at the same pace as export income declines. Repugnant though heavy loan expenditure may be to the pre-conceived ideas of many of us, there is no other expedient which will enable us to meet the present situation without wholesale unemployment, reductions in wages, of an unattainable degree of severity. Those who refuse this safeguard will be guilty of throwing hundreds of thousands of their countrymen into unemployment, and again flinging to waste the fruits of technical progress.

But I, for one, am confident that Australia will courageously meet and overcome these difficulties. As a returning migrant from the old world, and knowing many European countries, I would say that other than Sweden I know no country in the world for which I have such high hopes as I have for Australia, as a country in which the resources of economic science should suffice to counter depression. In Australian Universities, as in no others, economics is taught and studied as a true applied science, seeking practical remedies for depressions and other ills which confront us, eschewing on the one hand the theoretical scholasticism of European universities, or any partisan adherence on the other. In no country is the public so well informed and so critical on economic questions as in Australia, thanks largely to our press, which, with one or two exceptions, maintains the highest standard of fair and adequate comment on economic problems. With all these things in our favour, we shall indeed be lacking in courage if we cannot face and conquer the issue of depression and unemployment. 



\section{9}

\section{Economic coordination}

\section{Roland Wilson}

\section{The meaning of economic coordination}

I fear the Australian public has given so little thought to the subject of economic coordination that I may profitably spend a few moments discussing just what it means.

There is no need for me to dwell on the word "economic", even though its normal content is somewhat expanded in time of war. As for "coordination", it will be sufficient to remind you that the dictionary defines it as "the harmonious combination of agents or functions towards the production of a result". Taken in conjunction, however, and with special reference to their application in time of war, the words acquire a special significance.

If economic coordination is to be regarded as the deliberate combining into one harmonious whole of the diverse forces that constitute an economy, it becomes obvious at once that the term is inapplicable to an economy which relies on a system of completely free enterprise. It is, indeed, the chief justification of the system of free enterprise that market forces will automatically bring about their own coordination through the operation of the profit motive, producing those "economic harmonies" of which Bastiat wrote so enthusiastically in the middle of last century. Under a system of completely free enterprise, therefore, economic coordination can have meaning only if applied to the activities of a single profit-seeking unit in the economy, or to the governmental framework within which the profit-seeking units are compelled to operate.

1 Nineteenth Joseph Fisher Lecture, 11 November 1940. 
Immediately some element of control enters into the economy the scope for coordination widens. It is precisely as the automatic regulators diminish in effectiveness, and the field in which they operate is restricted, that the need for conscious and deliberate coordination in creases. In a completely authoritarian economy, while coordination is still required in that each part of the general plan must be consistently related to the other parts, the achievement of consistency is facilitated by the very fact that all decisions emanate from a single authority. It is otherwise in an economy in which, on the one hand, the freedom of enterprise has been limited and curtailed in considerable degree for the better achievement of some special purpose, such as the conduct of war, but in which, on the other hand, many decisions in fields related to that purpose are left for determination independently of any central authority. In this type of "mixed" economy special difficulties arise from the division of responsibility, and it is here that the need for coordination becomes most acute and its practice most difficult.

This is the situation which our Australian economy has reached to-day, and it is coordination in this sort of economic environment that I propose to discuss. The problem has both general and particular aspects, and appears in comparable if not in exactly similar form in most of the remaining democracies fortunate enough to be still fighting. I shall be concerned in the first place with the general aspects of the problem, but I hope to conclude with such reference to the particular circumstances of Australia as my official connection permits.

In an environment of the type to which I have referred the term economic coordination may be used in two senses, a wide sense and a narrow sense. In the narrow sense it assumes that planners and directors are already at work in their own special fields, and refers more particularly to the "coordination" or harmonious combination of their separate endeavours. It aims at facilitating and guiding their work so that a general plan may be carried through by subsidiary measures that will be consistent with one another and conformable in the highest degree to the general plan. In the wide sense it comprehends not merely the nervecentre of a system of control designed to implement a general plan determined by higher authority, but extends in some measure to the formulation of the plan in the light of the ultimate objective of the economy. In the narrower sense economic coordination has some affinity with, though it is not quite the same as, "applied economics", or the application of solutions to economic problems. 
This has been de fined as the rational allocation of scarce resources to given ends, but for economic coordination in the wider sense the ends - or the elements of the general plan - are not necessarily completely or permanently de fined. This is particularly likely to be so when the term is applied to the management of an economy at war, and under these conditions the coordinators must be constantly looking ahead to see that the plan itself remains appropriate to the ultimate objective towards which the economy is striving.

It is thus necessary to emphasize that economic coordination in he wide sense must concern itself both with the making of the general plan and with the direction or persuasion of economic resources into channels that will accord with the plan. Though a better description might be found for this more comprehensive type of coordination, in what is to follow I shall be using the term "economic coordination" sometimes in the narrow sense of the nerve-centre in a system of control, and sometimes in the wider sense I have indicated. This may help to explain my failure to draw a strict distinction between the traditional functions of Cabinet, the executive kernel of the elected Parliament, and the functions of the appointed administrators who are responsible to Cabinet - a distinction which, as I shall have occasion to point out, becomes increasingly blurred under war conditions. In some contexts "coordination" will include the work of Cabinet, and in others it will refer more particularly to the work of one or a group of subcoordinators. To save words, however, I will speak of "a coordinator" and trust to the context to make my meaning clear.

The term coordination must be applied in yet another sense in relation to the economic war effort of the Empire. This is being carried on by a number of loosely-knit economies, responsibility for the conduct of which remains, under our present political arrangements, in the hands of each economy. The chief emphasis here falls on the formulation of joint plans to reach a common objective and, to a somewhat lesser ex tent, on the methods by which the plans may best be put into effect. The actual application of the resources of each economy in pursuance of the plans must remain a matter for each contributor to the joint effort.

The results of the conference of the Empire Eastern Group now being held in Delhi will afford an interesting example of the extent to which the economic 
war activities of a group of countries can be coordinated in the face of a sudden and unprecedented danger. The conference has been called to discuss the complementary production and interchange of munitions and other war supplies in most of the dominions and colonies of the East and the southern hemisphere, with the general object of making the group as self-dependent as possible, and relieving the pressure on Great Britain. The achievement of this object will require a skilful use of the combined resources of the members of the Group, and in particular the avoidance of needless duplication of expensive equipment. The outcome of the conference will be of particular interest to Australia, for whose industrial future it may hold considerable significance.

\section{The task of the coordinator}

In any single economy the first task of coordination has to do with the formulation of a general plan through which economic activity may be guided into those channels most likely to realize the ultimate objective of the economy. We may perhaps express the objective for a democracy engaged in a desperate fight for freedom as the greatest possible contribution by the economic machine to the military effort, "possible" being limited in practice by the amount of interference with the material welfare of the civil population now and in the future that the people are prepared to accept. Before such an objective can become the basis for economic action, however, it must be reduced to a general plan from which will radiate a series of concrete programmes for guns, aeroplanes, battalions, and so on. Although the determination of the main lines upon which this physical embodiment of the war effort will be built is finally a matter for political decision, it is here that the first task of coordination appears.

Many brains will contribute to the formation of such a plan, and unless care is taken different parts of the plan and its subsidiary programmes may express different and perhaps inconsistent theories and views about the war. First of all, therefore, the coordinator must consider the basic assumptions about the nature of the war. For how long a war must we prepare? If it will be over in two years it is obviously useless to prepare for the production of war equipment which cannot be realized within that period. What kind of war will it be? Hand grenades are no good against bombers, and tanks will not break a blockade. Who will be our 
enemies? Where the theatre of operations? When? These questions are, perhaps fortunately, not the sole concern of the economic coordinator, but the answers to them or the assumptions made about them will vitally affect his decisions.

In the mad world of to-day such questions cannot be answered even by the best-informed in advance of actual events, but without some weighing of the possibilities and assessment of the probabilities preparations for war could not go on. It is obviously unwise to attempt to prepare for all possibilities, for this would ordinarily involve a dissipation of effort which would defeat its own purpose. Each possibility must be carefully weighed, not only in the light of its probability and the seriousness of its potential consequences, but against the amount of resources which would be drained away in providing against it, and which would, therefore, be no longer available for guarding against other possibilities. Thus, using money figures as a crude measure of resources, if the chances of a certain event happening are assessed at one in a hundred, and the consequences if it did happen are not likely to be very disastrous, we might decide that it was definitely worth guaranteeing ourselves against the risk if it could be done for $£ 5,000$, doubtful if it would cost $£ 500,000$, and definitely not worth the certain loss of resources if the cost was $£ 1,000,000$. But if the consequences were more serious, or the chances less favourable, our judgments would be correspondingly altered. This, of course, is a somewhat over-rationalized rendering of the mental processes by which such judgments are formed, particularly when the possibilities are numerous and ill-defined. The best that can be done in such circumstances is to reduce the possibilities to a relatively few general contingencies which can be viewed as a whole and adjusted from time to time in the light of events.

Granted the basic assumptions, it is then the task of coordination to ensure that the general plan is consistent with the assumptions and that the physical programmes based upon it are within the capacity of the economy.

The next step is the elaboration of detailed plans for making possible the realization of the military programmes. In what directions and to what extent will this be facilitated by the continued free play of market forces, and to what extent must free enterprise be subordinated to direction from the centre? Here the coordinator must take under review the whole of our ordinary economic life. He must consider not merely the physical problems of the production of war 
materials and equipment, but must think in terms of the vast transfers of resources - real and financial - which will be required to make that production possible. And, since our economy fortunately remains in relatively free communication with other economies, notably those of other Empire countries and the United States, he must concern himself not merely with local resources but also with the exchange of the product of local resources for the product of oversea resources.

There is thus no end to the ramifications of the coordinator 's work, and much of it lies in fields which are commonly thought of as belonging exclusively to government "policy". Ordinarily the coordinator will not be responsible for making final decisions between alternative ways of achieving a desired result, and where alternative ways are open there remains a field within which the government can impress the mark of its own distinctive "policy" on the economy. But under war conditions this field is constantly contracting, and in the elaboration of measures required to implement the general plan the coordinator must play an important and sometimes a decisive part. It is easy for those accustomed to draw a sharp distinction between politics and economics to miss this gradual but important change in the normal relations between the technical adviser and the elected representative. When a dominant objective has been decided on, the ordinary freedom of the makers of policy is very much curtailed. Freedom of choice in many matters - often even irrelevant at first glance - is found to be limited by the realities of the economic environment. It is one of the coordinator's tasks to assess these realities and to demonstrate how a particular combination of subsidiary measures will best contribute towards the attainment of the predetermined objective. Above all, he must ensure that there is no actual conflict between these measures, and that any inconsistent between the several parts of the general plan from which they spring is realized and removed.

It is not difficult to give instances of the potential conflict between measures which on the surface appear complementary. The "export drive" in the United Kingdom, for example, was admirably conceived as a method of increasing sales of British products in "non-sterling" markets and replacing the goods of nonsterling countries with British products in Empire markets. But were it not closely coordinated with the demands of British industry for materials and labour for war production at home, its net effect might easily be to prejudice the war effort as a whole. Again, to take an example nearer home, while the control of prices is 
generally regarded in war-time as a necessary and laudable policy, there have been occasions when an unduly rigid control of prices, or the fear of it, has tended to restrain importers from laying in the stocks of essential goods which prudence would have dictated. Another and more important example of conflict would be that between a war production policy which called for the transfer of enormous quantities of labour from industries producing goods for civil consumption, and a financial policy which made insufficient provision for the taxes and public loans required to reduce public demand to a level consistent with the reduced quantity of goods available for civil use.

It thus becomes clear that economic coordination calls not only for an embracing mind but for an encyclopaedic knowledge of the facts of the economy. If coordination is to be successful it must not be based on the rule-of-thumb methods which are appropriate enough to the mainly self-directing economy of peace-time, but on as exact an appraisal of all the factors in the situation as can be made. Hence the necessity for comprehensive and frequent surveys of the community's real and financial resources. Though I am crying my own wares, I think it will be agreed that such surveys are far more important in time of war than at any other time. Economic statistics, after all, occupy much the same place in the national economy as the books of account of the private trader, and I am quite sure that the most unregenerate "practical man" would hesitate to suggest that production can be carried on efficiently without the assistance of appropriate financial and cost accounting methods. If the individual business concern cannot get on without exact knowledge of its resources and operations, how much less possible is it for a state at war to manage its affairs intelligently without similar kinds of information.

When the broad lines of the plan have been laid down and the de tailed measures required for its completion have been elaborated, it remains to put these measures into effect. This is not the task of the coordinator but of the executive agents of the government. Nevertheless, it is in connection with the execution of policy that the coordinator will come up against some of his toughest problems.

I have drawn a somewhat over-rationalized picture of the actual process of operation of the governmental machine. In practice there is no clear-cut division between the elaboration of measures and their execution. The two are 
conducted together, and frequently the executive agents themselves suggest, even though they do not determine, the lines which policy should follow. In this way policy, or at least leads to policy, tend to become the product not of one single or grouped intelligence but of a number of separate intelligences each working in a subordinate sphere. If I may use a military analogy, the objective and the points of penetration are determined by the central intelligence at headquarters. The general staff must stand by while the defences are pierced by the active agents, which then begin to spread out in a fan like pattern dictated by physical realities and the pressure of events. Some of the lines indicated by the blades of the fan may be inconsistent with the ultimate objective, and at this point the general staff, or coordinating intelligence, again steps in, closes up some of the blades, and redirects the general line of advance. Our economy is not as disciplined as an army, however, and it is sometimes necessary to use a "pincers" movement against our own troops. Parliaments become wonderfully adept at this.

From the method of operation of the machine, it follows that the coordinator must maintain close touch with the executive agents as well as with those formulating general policy. He must be the confidant of Cabinet and the alter ego of the administrative head. Without frequent and cordial contacts with the executive personnel he is likely to find himself toiling along in the rear of the fait accompli For he can be easily submerged beneath a mass of detail with which ideally he should not be concerned, and equally easily cold-shouldered by those who may wish to stick to the old tradition that a department is sovereign within its own sphere and as much of another 's as it can get away with.

Without wishing to lay undue emphasis on a tendency which is now rapidly disappearing, or to impugn the good sense and public-spiritedness of a body of men who, all things considered, rub along together amazingly well, it is profitable to consider the appropriateness to war conditions of the existing and traditional organization of government departments, and especially of those concerned with economic affairs. In the old view the functions of government could be split up into watertight compartments, each administered by a permanent head responsible only to his own Minister and, through him, to Cabinet. While the system had its merits in the environment in which it developed, it some times came up against the difficulty that the affairs being administered obstinately refused to separate themselves into the pigeon-holes of the departmental 
organization. The very obstinacy of facts thus contributed in some measure to the tendency for departments to vie with one another in a competition for the border-line responsibilities, and a system which bases remuneration partly on the mere enumeration of duties does little to offset such a tendency. Progressively as the state has been forced to take an increasing part in the everyday economic life of its people, so have the border-line cases multiplied; whilst there has been a simultaneous growth in the inter-connection of those functions traditionally regarded as the sacred preserves of particular departments. This was happening even in peace-time, but its development has been spectacular since the outbreak of war. What has come to be called "economic warfare" furnishes a good example of functions which impinge on the work of many departments. While a special department has been formed in Great Britain to deal with this matter, the varied nature of its activities will be sufficiently illustrated by the fact that in Australia economic warfare is the responsibility of an inter departmental committee on which is represented the Departments of the Treasury, Trade and Customs, Commerce, External Affairs, and Supply and Development. It is true that the Committee has not met frequently since war broke out, but that is merely another illustration of the weakness of present organization.

As with "economic warfare", the expedient of inter-departmental committees has been used in many other directions in an effort to over come the deficiencies of the departmental organization. In no case, it is fairly safe to say, have they provided a perfect solution. Sometimes they produce good and speedy results, but perhaps as frequently they merely provide a sounding-board for the reiteration of "the views of the Department" when these are acceptable to the Government and a de fence from criticism when they are not. The old problem of final authority usually obtrudes, and we have the spectacle of busy men arguing fruitlessly over which Minister a committee is to report to.

The chief weaknesses to be overcome are, first, the tendency of departments to regard themselves as sovereign bodies within their own spheres; second, the difficulty experienced by two or more departments jointly concerned with a single problem in coming to an agreed decision on all but the more important points of policy before bringing their recommendations before Cabinet; third, the lack of a suitable machinery for submitting to Cabinet recommendations on the more substantial matters jointly affecting several departments; and, fourth, 
the lack of suitable machinery for securing a continuous oversight of inter-depart mental problems by Cabinet.

A solution to the first difficulty could be found in part through the elaboration of new administrative machinery, but, more effectively, by a change of heart in those primarily responsible for such matters. It is gratifying that such a change of heart has been in evidence for some time, and the bonds of fellowship which war insensibly produces have done much to further it. If the other problems could be solved I am sure this one would become quite insignificant.

The second difficulty is that of coming to agreed decisions outside Cabinet on all but major policy matters. This is partly the result of the first difficulty, but in part it is due also to an inability to see through the special aspects to the central core of the problem at issue. It must be confessed that this inability is sometimes due to the fact that in the stress of war-time expansion problems of great magnitude must necessarily be handled by men whose training, experience and aptitude do not fit them uniquely for such responsibilities. Some improvement is to be expected, therefore, as the administrative personnel is strengthened and shaken down into its new duties. At the same time I cannot help feeling that some advantage would accrue from the establishment of a small inter-departmental committee of permanent heads of the economic departments which would meet frequently and regularly, and act as a sort of minor Cabinet on inter-departmental economic problems. Geographical dispersion is a difficulty, of course, and one to which there is no obvious solution; while lack of time - which in some cases is trace able to an inability or reluctance to delegate authority - is an even greater one. The members would require, therefore, to be relieved of some of their more pressing routine functions, and to regard the work of the committee as of at least equal importance with their own depart mental business. This would enable them not only to overcome the pre sent tendency for inter-departmental discussions to be pushed into the few odd moments that busy officials can "take off" from pressing departmental duties, but also to take a more objective view of the proposals advanced by their own enthusiastic officers. The chief advantages of the proposal, however, would lie in the improved coordination of executive action and the release of Cabinet from detailed discussions of matters on which political direction is not necessary. 
At the same time while retaining those existing committees which have proved their usefulness, there is room for a considerable increase in the use of small ad hoc inter-departmental committees, preferably on no very formal basis, but giving an opportunity to the officers actually handling a problem to come together for joint discussion of those aspects which cross departmental boundaries. They do not need to be formally "representative" of departments; in fact, they would be better not, for the officers should not attend to put forward fixed views which may have been formed on an incomplete knowledge of the facts, but to assist in the formulation of views which will take into account all aspects of the problem at issue. Moreover, it should be possible in these circumstances for less senior officers to take part in inter-departmental discussions. A department need not be "committed" to a particular decision, if one is made, and in the event of any serious divergence of opinion the committee of permanent heads I have suggested would usually be capable of settling the difference.

The third difficulty, that is, the lack of suitable machinery for making to Cabinet recommendations on some of the more important matters of interdepartmental concern, might be overcome by using this committee of permanent heads as a direct vehicle for joint submissions to Cabinet. The mere fact that recommendations were being submitted through such a channel would in itself conduce to a greater measure of unanimity, while a department which remained dissatisfied with the joint recommendations would still be able to appeal against them through its own Minister. In this way it would be possible to ensure that important proposals placed before Cabinet were not over-coloured by the particular views of the department making the submission.

The fourth difficulty - the lack of machinery for securing continuous oversight of inter-departmental problems by Cabinet - is somewhat outside my scope, but one attempt at a solution was the creation some months after the outbreak of war of the Economic Cabinet. While this body was never conspicuously in the news, it might under more favourable circumstances have become a suitable instrument for dealing with some of the problems I have outlined. Now that it has been abolished a solution must be sought in some other direction.

So far I have referred only to the more obvious tasks of coordination. An equally important field for the exercise of the coordinator's genius is that of 
timing each part of the whole economic programme to fit in with the other parts. Organization of the flow of materials and parts to the production-line in a modern factory is mere child's play compared with the complexity of fitting into space and time the intractable elements which go to make up a maximum economic war effort. The industrialist may have to cope with strikes and breakdowns, but he is relatively free from the interruptions and frustrations to a considered and continuous programme which result from propaganda, elections, selfishness, vested interests, and the pure "cussedness" of human beings. Appropriate timing, despite its difficulties, is all-important to the economic effort. Without it we may get production programmes running ahead of the supply of skilled labour and material resources, essential imports being restricted before local substitutes are available, or heavy taxation being imposed either too soon or too late in relation to increased defence expenditure, with all that this implies in the shape of deflation or inflation. These are merely a few of the many examples of inter connection between the various phases of the war effort in the economic field where appropriate timing calls for skill and judgment of a high -order.

\section{The difficulties of coordination}

I have said enough about the tasks of economic coordination to demonstrate that its practice is by no means as simple as critics of government policy sometimes imagine it to be. It will be seen to be even less simple when we have considered a few of the special difficulties under which the coordinator must labour.

In the first place, one must remember that, from the very nature of his task, the coordinator must work with the tools and technique of a semicapitalist democracy, and in these days with the emphasis on democracy. $\mathrm{He}$ is, therefore, debarred from adopting many expedients, logical and effective though they may well be, that are open to the economic practitioner in the authoritarian state. He is compelled some times to indulge or to acquiesce in methods that any business-man would regard with horror if applied to his own business, for his task is to persuade the wayward elements of the economy into the right patterns rather than to force them there. It is true that a free Parliament has enacted legislation which grants almost unlimited powers over the life and property of its citizens, but it is tacitly understood by 
governors as well as governed that such powers must be exercised in the spirit of democracy. Anything else would defeat the purpose for which the powers were granted.

For the coordinator this limitation is even more serious than it is for the government. A government can always find some reason for justifying its acts, if only by reference to the fact that a majority of freely-elected representatives of the people has tolerated if not actively willed them. The coordinator, on the other hand, is responsible to his government, which is in a position to be a little more definite and a little less tardy in its signs of disapproval. But this is not the worst of it. As I have already pointed out, much of the coordinator 's work must of necessity be conditioned by an estimate of future probabilities, and must be based on plans to meet contingencies which have not yet arisen. If he is to succeed, therefore, his plans for the solution of future problems must be such as will be likely to gain acceptance from the government of the day when these problems emerge as concrete realities. The unfortunate coordinator, therefore, must not merely forecast his problems and provide solutions in advance, but must also forecast the readiness of the government and the people to accept them at some future time. To some extent he is thus forced into politics - not to practise them in the accepted sense of the term, but most certainly to take cognizance of them, and to persuade the government for which he works that some of his longer-term plans should provide even for the contingency of its own defeat and the possible reversal of some of its own particular policies. With some form of assured nonparty government, of course, this type of difficulty becomes much less acute, even though it continues to exist. In the absence of such a government, the only sound course for the coordinator who would see his work endure is to base his plans on what L. F. Giblin has called "the highest common factor of the policies of alternative governments".

In the second place, one must remember that we have no school for coordinators, and a very limited reservoir of discovered natural talent on which to draw. The practical coordinator must in large part learn his job by doing it, and this in a sphere in which every mistake will count - not merely for himself but for the whole community. It is all the more necessary, therefore, to start with the right material. 
It is obvious that a mere knowledge of economics is not enough, though it might well be defined as a prerequisite. You will doubtless remember J. M. Keynes' remarkable description of an economist in his Memoir on Alfred Marshall:

" ... the master-economist must possess a rare combination of gifts. He must reach a high standard in several different directions, and must combine talents not often found together. He must be mathematician, historian, statesman, philosopher - in some degree. He must understand symbols and speak in words. He must contemplate the particular in terms of the general, and touch abstract and concrete in the same flight of thought. He must study the present in the light of the past for the purposes of the future. No part of man 's nature or his institutions must lie entirely outside his regard. He must be purposeful and disinterested in a simultaneous mood; as aloof and incorruptible as an artist, yet some times as near the earth as a politician".

That, one might say, is enough, but it is only a beginning.

It is equally obvious that a mere knowledge of business is not enough, though an acquaintance with the commercial and industrial organization of the country can also be classed as a prerequisite.

It is again obvious that mere experience of administration, business as well as governmental, while not enough in itself, is a decidedly useful and even essential requirement.

On top of all this the successful coordinator must be capable of cutting himself free from the limits which his own special background and training have hitherto enforced; of scrapping accepted business principles designed merely for the limited objectives of profit-making; of dispensing with the routine methods and red-tape of what the Australian public persists in calling traditional public service methods; and of adjusting the logical beauty of an academic conception to the sometimes hard and ugly reality of a world which is never still. He must have tact and courage, and frequently exercise both; be able to succour the weak, to encourage the strong, and not always to suffer fools gladly. 
This sounds a somewhat formidable list of accomplishments - and it is. A Solomon or a Stamp is not born every day. But we need not despair. As I have already warned you, I have been talking of "a coordinator" when in fact I have usually meant "those whose duty it is to coordinate". For no single individual, however gifted, can hope to bring within the compass of his own mind the endless ramifications of the economics of a modern state at war. Cabinet, as the sun about which the whole system revolves, is the ideal coordinator, but its light cannot reach into all the dark places. This has been recognized by those who, particularly in England, have urged the creation of a super-minister who would bring all the multifarious threads of economic and financial policy into one pair of hands. But their solution is only a solution in theory. If the harmony of the spheres is to prevail there must be a whole constellation of lesser luminaries to collect and reflect the rays from the central source of energy. Some may shine with a little more brilliance than others, but each must be adjusted to the common wave length. Let us cease searching for the super-man, therefore, and recognize that economic coordination, like any other achievement of the democratic state, must be the joint product of many minds.

There is one special difficulty to be faced by the coordinator, whether he be one or one of many, which perhaps merits a word at this point. That is the difficulty of making the mental adjustment which is demanded by the transition of an economy from a state of more or less permanent under-employment to one of full and even potentially over full employment. The modern democratic state has never completely solved the problem of unemployment, whose results constitute our greatest social evil. In consequence, we have tended more and more in practical affairs to regard the increase of employment as an end in itself, whereas in a perfectly ordered society one would regard employment - in the normal sense of enforced and possibly uncongenial economic effort - as an evil to be reduced to a minimum. These ingrained habits of thought, which can hardly be regarded as unreasonable in the atmosphere in which they develop, are very hard to get rid of because of the infrequency with which they do actually become unreasonable. But in a state of war, if the economy is not grossly mismanaged, we are faced not with a perennial surplus of labour and machine capacity but with a very real shortage. There will, of course, be localized surpluses and "hard cores" of unemployment which persist for special reasons, but any slackness of demand for resources in a general sense will not be present. The pressure will be all in the 
other direction, and the familiar (even if sometimes misguided) touchstone of peace-time economic policy - "Will it increase employment?" - becomes quite inappropriate and even dangerous unless applied with a full appreciation of the type of resources to be employed and the alternative demands for them. As Keynes has pointed out, if the war effort is to be conducted on the scale required, there must be a constant race between the disemployment of dispensable resources and their re-employment in essential services; and as Sir William Beveridge has sagely qualified, the re-employers should at least keep their noses in front in the race.

Another lesson the coordinator must learn is not to attempt to do too much himself. This is the prerogative of the very young and the very old, the young because of their enthusiasm, which excuses much, and the old because of their disillusion. The wise coordinator will keep some of his illusions or lose his sanity; he will keep some of his enthusiasm or lose his power to inspire those whose work he seeks to guide.

\section{Economic coordination in Australia}

I have been concerned so far with economic coordination in the abstract, and my remarks have been but little concerned with our own present condition. If I have raised problems without solving them, I have not failed in my intentions, for I have endeavoured merely to rough-in a background against which the work of coordination may be more clearly seen. If I have brought you to realize the amazing complexity and very real difficulty of the coordinator's work, I may at least have earned the gratitude of those whose duty it is to grapple with these problems.

Before considering the extent to which provision has already been made in Australia for economic coordination, it will be convenient to make a brief survey of the measures which have been taken since war broke out to limit and control the free play of economic forces. It is well to remember, however, that the classical conception of a system of completely free private enterprise had little application in Australia even before the war. The state had already laid its hand on commerce and industry, sometimes deftly and sometimes heavily, but always with the effect of limiting still further that area within which decisions as to the direction which economic activity shall take are left solely to the guidance of the 
profit motive. The resultant mass of legislative requirements and administrative formulae provided a great potential field for the cultivation and exercise of the coordinative genius. While there was little sign of the need being realized - and much less satisfied - the very fact that control had developed so far before the war made it all the more essential that the administration of the new war-time measures should be harmoniously related to the other features of our economy.

At bottom, the problem of waging a modern war is one of production. We thought we had realized this in 1914-18, but the experience of the first year of Hitler's war has given us what is almost a new conception of the relation of arms and equipment to mere man-power. It is this new conception which has brought a true realization of the vital part that economic organization must play in the present titanic struggle, and it is the imperative demand for maximum economic efficiency that makes the proper coordination of our errant economic system so very important for the prosecution of the war effort.

The basis of production is men, machines, and materials. The immediate problem of production for war purposes is to bring these together in the right places, in the right proportions, at the right time and in the greatest possible quantities. The bringing together of the available resources of men, machines, and materials is part of what might be called the technical machinery of production. This, I believe, is in very competent hands, and as it has little relation to my central theme, I must pass it over lightly, despite its great importance and the magnitude and vigour of the effort which is being put into it.

If it is to be a maximum effort, however, the use of what we are pleased to think of as "available" resources is not enough. Resources must be made available, and unless they are made available the technical planners of production programmes may very soon find themselves beating the air.

In general, there are two ways of making potentially available re sources actually available for war purposes, and both are being used to some extent in Australia to-day. The first is by restricting their use for non-war purposes, whether voluntarily or compulsorily; the second is by positively directing them into the desired channels. The emphasis in Australia up to the present has been on the negative or restrictive method, with only limited resort to the positive method of 
direction. The balance has accorded not only with the requirements of our situation, but also with the deep-rooted instinct which makes democratic communities accept restraints with resignation and positive orders with resentment.

The restrictive controls may be either general or specific, according to whether they are designed to free resources in general or to free some specified kind of resources. Among the general controls are financial measures such as increased taxation and borrowing, which are really designed to reduce consumption and investment for non-war purposes. The popular view which regards taxes and loans as means of raising money, is, of course, a mere delusion. The state has the power to mint all the money it wants, but all the printing-presses in the world are of no avail to produce war equipment unless men and materials can be diverted from other uses. It is true that some help can be obtained by diverting men and machines from idleness, but we need not delude our selves that we can win a major war by the efforts of those who were unemployed in peace-time.

Compulsory loans, as advocated and popularized in England by Mr. J. M. Keynes, also fall into the category of general purpose controls, though in origin the emphasis was placed on their utility as a safeguard against inflation rather than as a means of freeing resources. The one is consistent with the other, however, and in an economy in which it can be assumed that all the resources needed for war purposes will be taken for war purposes, regardless of consequences, the emphasis is rightly placed on the anti-inflationary effect of the loans. Nevertheless, they can achieve their avowed object only by inducing a reduction in civil demand for resources, even if the demand is one which is destined not to be satisfied. They remain a subject for official scepticism in England and newspaper speculation in Australia, but our enterprising neighbours in New Zealand have recently introduced a scheme of compulsory loans on a limited scale.

Another control which is somewhat similar in type, though not quite so general in its aims, is that exercised over capital issues. The immediate object of the regulations is to prevent the raising of capital on the public market for nonessential or otherwise undesirable enterprises, but the real object is to prevent new calls being made on the physical resources which would be required to build up the new undertakings. This form of control is particularly important, as the type of resources used in the investment industries is generally very similar to the type 
required for war purposes. The control is also cumulative in effect, for it not only directly frees the resources that would be required for the original investment but prevents the subsequent wastage of labour and materials that the unnecessary enterprise would currently consume.

It is not my purpose to discuss here the relative merits of alternative forms of control, but it is perhaps of interest to refer in passing to the caution with which general restrictive controls should be used in time of war in an economy which has not reached a high stage of industrial development, particularly in those directions which are of importance for war production. Unless the resources which are freed are capable of being diverted, either immediately or after some re-adjustment or re-training, to war purposes, the restrictions may result in economic dislocations which contribute nothing to the war effort. It is fruitless, for example, to disemploy labour even in the luxury trades which cannot, even if training facilities are available, be re-employed in war industries or other public services; though it may not be so in exceptional cases if continued employment of such labour involves heavy demands on scarce essential materials. Yet by its very nature the general form of restrictive control must ignore this kind of consideration. The only alternative, however, would be such a mass of particular restrictions that the attempt to enforce them would probably break down of its own weight. The general controls must remain, but they must be carefully proportioned and carefully timed.

Much more specific in character is the control exercised over machine tools and their uses. These are now in world-wide short supply, and form one of the most important bottle-necks in munitions supply, not only in Australia but also in Great Britain, the United States and the Soviet Union. A census of machine tool equipment was conducted some time ago by the Department of Supply and Development, and a Machine Tools Committee was set up to advise the Minister on the acquisition of metal-working machine tools and control of their sale or use in Australia. Exports are prohibited except under licence, and all imports must be licensed by the Department, while active steps are being taken to increase Australian production of this class of equipment. The civil demand on machine tools - and more importantly on toolmakers, who form another serious bottle-neck - has also been reduced by regulations which require the consent of the Minister for Munitions before any factory may "tool-up" for new products or old products of new design. 
The machine tool control has many affinities with direct rationing of commodities, which is the most specific form of restrictive control. The rationing may be applied either to the use of the commodity itself in excess of a determined quantity, or to its use for one or more particular purposes. In the case of petrol, the most conspicuous rationing experiment in Australia up to the present, the use of petrol itself is limited to certain quantities, while the danger of substitution of other petroleum products as a means of defeating the rationing scheme is met by banning the use of certain other liquid fuels, e.g. solvents, lighting and heating spirits, and turpentine substitutes, for the special purpose of operating motor vehicles or locomotives with internal combustion engines.

Direct rationing of goods to consumers on a compulsory basis is familiar enough in countries nearer the main theatres of war, but in Australia it has not yet been applied to goods other than petroleum pro ducts. Rather more has been done on a voluntary basis, however, and this method is to be preferred as less costly and cumbersome, if the desired objectives can be achieved effectively. Cases in point are the agreement with newspapers and periodicals to restrict the consumption of newsprint, which, contrary to common assumption, continues on a voluntary basis, although the import licensing power stands behind it as an ultimate sanction; the motor car import "holiday" which was arranged by the motor vehicle industry itself; and the arrangements now being made by the Department of Trade and Customs to conserve paper of other types, particularly in the packaging of goods for retail distribution. Much more has been done through the co-operation of manufacturers with the Department of Supply and Development in limiting deliveries to private customers of goods and materials urgently required for the production of munitions and other military equipment for export to other parts of the Empire. The comparative ease with which such arrangements can be made in Australia is due largely to the concentration of production of most of the commodities in question in relatively few hands, so there is at least one small benefit to be derived from a monopolistic or semimonopolistic organization of basic industry.

While most of the controls already referred to indirectly affect the demand for labour, direct action to secure a balanced allocation of man power between the competing demands of the fighting services, munitions supply and civil 
industry has not yet reached the proportions which it must inevitably assume if our attempt to turn this country into a vast munitions reservoir for the Empire is to succeed. The desirability of greater efforts in this direction is beyond political dispute, though in administration there is unfortunately a fertile field for misunderstanding and prejudice on the one side and misconception and mistake on the other. It is not to be expected that the new Department of Labour and National Service, which has just been established, will avoid all the errors which must beset its path, but we may hope that it will avoid the major ones. If it is to succeed in bringing about a rational and effective use of our labour resources it will have to win and retain the confidence and willing co-operation of those whose lives it must so closely affect. I am sure it will be your fervent wish, as it is mine, that it may not fail in this great and onerous task.

Until the formation of the new department was announced, the most notable action taken was the appointment of a Director of Labour supply and Regulation to the Ministry of Munitions, and the establishment of trade union advisory panels. Direct measures of control have been limited so far to regulations limiting the right of employers not engaged in the manufacture of munitions to engage certain categories of skilled workers without the consent of the Director of Labour Supply, and fixing their marginal rates of pay. A great deal of excellent work has, of course, gone into other phases of labour policy, such as technical training schemes, the labour dilution agreements in the engineering industry, and other activities of a comparable nature. Mention must also be made of the work of the Man-Power Committee in connection with the list of Reserved Occupations and the general problem of allocating skilled workers between industry and the fighting services.

The controls I have enumerated up to this point have all been de signed to free resources for an increased production of war materials in Australia. There is another series of controls which is concerned mainly with the conservation of our oversea financial resources, which must be strained to the limit to provide essential materials not produced in Australia and war equipment to supplement what we can produce for ourselves. I refer, of course, to the import and export licensing schemes, and the Monetary Control and Securities regulations.

The general object of all these measures was to give the government control over all oversea exchange transactions. This appeared most obviously in the 
Monetary Control regulations, which centred all authority in the Commonwealth Treasurer. The regulations dealing with export licensing were designed chiefly to strengthen the effect of the monetary control regulations, by providing that the proceeds of sale of all exports should be routed through the Australian banking system, while the securities regulations were similarly directed to building up the oversea exchange resources at the disposal of the government.

Whereas the export licensing scheme and the control of foreign securities were designed to add to our supplies of oversea exchange, the import licensing scheme was designed to reduce demands on the Empire's supply of non-sterling exchange. The import of certain classes of goods from non-sterling countries is entirely prohibited, while licences must be obtained for the import of all other classes. Except for goods and materials required for defence and other urgent national purposes, the licensing scheme operates in such a way as to reduce the quantities imported well below the pre-war volume.

Yet another series of controls is being exercised at present, but they are concerned rather more remotely with the problem of freeing resources for war purposes. Nevertheless, they are important not only in their own right but in their influence on other aspects of the war-time economy. I refer particularly to the control of prices, and to the control over interest rates which is incidental to the control of capital issues. There is no need for me to refer to these in any detail, since the scope of price control is generally understood, and it would lead me too far afield to describe the exact way in which the Capital Issues regulations facilitate the control of interest rates. It is perhaps relevant, however, to mention the recent extension of the Prices Commissioner's powers to include the fixing of minimum prices. This is of great potential importance, particularly in relation to problems that may have to be faced at the end of the war; and it is also of immediate interest from its association with the problem of building up security stocks of essential goods.

I have not attempted to make a complete survey of the various ways in which the State has stepped in to guide and direct the functioning of the economic system, but merely to indicate the general nature of the more far-reaching controls which have been instituted in the first year of war. It remains to review briefly the present organization for securing the coordination of activity in an economy 
which is now consider ably less dependent on ordinary considerations of profit and loss for its chief motivating force.

Apart from the creation of new executive bodies concerned only in part with coordination, the first important step taken was the establishment of the Advisory Committee on Financial and Economic Policy, composed of economists who were already fairly closely associated as advisers with Commonwealth and State Governments and the Common wealth Bank. This committee really grew out of a smaller investigating committee that had been set up much earlier by the Prime Minister, and which was subsequently taken over by the Minister for Supply. On the outbreak of war it was reconstituted and enlarged by the Treasurer, and Professor L. F. Giblin was invited to give his full time to the duties of chairman. While the committee reports on many matters of special interest to the Treasury, its most important function is to coordinate the basic economic policies of the various executive arms of the government. It is in no sense set over the departments and other committees concerned with economic affairs, and its power to co-opt Commonwealth officials for joint discussions is the only one it possesses. It is thus entirely advisory in capacity, and is dependent in the main for its effectiveness on moral suasion and the power of reasoned argument. It re ports formally to the Treasurer, who consults with other Ministers or with Cabinet on recommendations affecting matters not within his personal control. The financial and Economic Committee is professional rather than inter-departmental in character, and does not consist entirely of public servants; though its proceedings are facilitated by the fact that several of its members hold advisory or executive positions in the departments.

There are two types of inter-departmental committee, the first being more or less permanent in character, the second coming together for a special purpose and dissolving when that purpose is accomplished. In each case, as the name implies, the committee is representative of departments rather than individuals, and the personnel may vary from time to time.

Of the permanent variety, the Inter-departmental Committee on Seaborne Trade is probably the most important. It is composed of representatives of the Departments of the Treasury, Trade and Customs, Commerce, and Supply and Development, and was established just before the outbreak of war, on the 
recommendation of the Financial and Economic Committee, to take over part of the original planning activities of the latter body. In actual practice it has been concerned al most exclusively with problems of oversea trade, and particularly with the question of conserving non-sterling exchange through import licensing and similar devices. To some extent, however, and particularly in its earlier stages, the Committee was used as a kind of general purpose inter-departmental committee; and was responsible, incidentally, for advising the Government on the initial price control regulations and the form which future control should take. Its powers and functions remain somewhat nebulous in consequence of its slightly unorthodox birth under the Minister for Supply and Development, but its character as an independent inter-departmental committee was strengthened when its chairmanship was assumed by the Director of Economic Coordination.

It is unnecessary to refer in detail to inter-departmental committees of the more strictly ad hoc variety, as I have already discussed their functions in general terms. Examples are to be found in the committees dealing with local security stocks and the censorship of statistics.

Because of the rapid growth after the outbreak of war of problems affecting more than one department, the necessity for joint discussions by ministers outside Cabinet soon became more evident. This was particularly true of matters coming within the scope of the Sea-borne Trade Committee. It was not long, therefore, before a special sub-committee of Cabinet composed of the ministers whose departments were represented on the Sea-borne Trade Committee came into fairly active being. This Cabinet sub-committee was really the forerunner of the Economic Cabinet, which was formally established at the same time as the War Cabinet. As the Economic Cabinet has now been abandoned, it may perhaps be anticipated that greater reliance will in future be placed on special sub-committees of Cabinet to give preliminary consideration to economic policy measures.

Along with the establishment of the Economic Cabinet went the creation of the office of Secretary to the Economic Cabinet and Director of Economic Coordination. This post is occupied by Sir Ernest Fisk, a distinguished radio and electrical engineer, and Chairman of Directors of Amalgamated Wireless of Australia. The Director is an ex officio member of many of the economic planning and other special war committees, and is also assisted in his work by the members 
of the Tariff Board, whose normal functions have become somewhat attenuated under war conditions.

The direct coordination of a number of activities in the economic field is also undertaken by the Department of Supply and Development. In addition to its more obvious duties, it has the task of coordinating from day to day a hundred-and-one activities of its own branches and affiliated organizations whose work impinges closely on the general economic life of the country. Despite the ramifications of the Department, the public sees little of this work which goes on the more effectively for its very unobtrusiveness. By way of example, I may mention the co ordination of the activities of the numerous State and Commonwealth authorities concerned with the safeguarding of civil supplies and transport from the point of view of both national requirements and the requirements of particular localities which might be threatened in an emergency.

In the financial relations of the Commonwealth and States the need for more adequate coordination was felt long before war conditions made it imperative. So far as these relations are concerned with the raising of loan moneys, the need has been filled by the recent decision of the Loan Council to appoint a Works Coordinator in the person of Sir Harry Brown, until lately Director-General of Postal Services. The main function of the Coordinator is to examine, in collaboration with State Works Coordinators, the loan proposals to be submitted to the Loan Council, and to report to it on the relative urgency of the works included in the proposals and the relation of the whole programme to the defence works being carried out by or for the Commonwealth Government.

These necessarily brief references to the machinery that has already been devised for securing coordination of the economic system under war conditions may perhaps make it appear sketchy by comparison with the tremendous range and importance of the matters with which economic coordination is concerned. It should be remembered, however, that many of the new boards, committees and departments which have been established since war broke out, in addition to carrying out executive and advisory duties, are charged with some responsibility for coordinating activity in certain subordinate spheres. Moreover, the interlocking of personnel, as, for example, between the Commonwealth Bank Board, the Treasury and the Capital Issues Advisory Committee, is another important 
factor which contributes to coordinated activity in many different directions. Coordination does not necessarily involve the creation of elaborate machinery, and in some circumstances can be secured more effectively without it. We must beware, therefore, of assuming too readily that chaos must prevail merely because we do not see any obvious means of achieving order.

It is also to be remembered that the need for coordination, while it existed in some measure before the war, has only become acute in the last twelve months. That is a comparatively short period in which to switch over from a peace-time economy of a fairly normal capitalistic type to a war economy from which the freedom of certain important forms of enterprise has been banished. In these circumstances it should hardly occasion surprise if the creation of new economic machinery to undertake particular tasks occasionally outruns the provision of means to harmonize its work with that of the existing organization.

Though I have no desire to adopt the role of apologist, it is difficult to see how this could be otherwise in a democracy such as ours. Economic coordination implies control, and, while it is possible to persuade people that particular measures of control may be in their own interest and conducive in the long run to the preservation of their liberty, it is not quite so easy at first to persuade them that the essential interdependence of the various parts of the economic machine requires a planned and orderly arrangement of those parts. The necessity for this must be demonstrated by the logic of facts, and until some disharmony becomes apparent there is an inclination to resent what is frequently regarded as an unnecessary incursion of authority. Provision for coordination in the economic sphere must therefore develop gradually, and must be made with a full appreciation of the vital need for safeguarding those very rights for which we are fighting.

At the same time, let it be clearly understood that the vigour of our fight depends more closely now on the skill and ability with which we organize our economy and our industrial man-power than at any previous time in our history. Let us, as a people, therefore, make more willing surrender of our comfort, our convenience, our old ways of thought, and even our liberty, in the confident belief that what we forgo for a time will be restored eventually in ampler measure. 


\section{0}

\section{The Australian economy during War}

\section{Robert G. Menzies ${ }^{1}$}

This is not a lecture by an economist for the guidance of politicians; rather perhaps the reverse.

When I was an undergraduate there was a topic of study appropriately named "Political Economy", the lecturers in which were commonly lawyers who appeared to regard as somewhat menial the task of expounding a science and art less accurate than that of the Law. True, they imparted to us with due vigour any principles which could reasonably be called "laws". Thus it was that I encountered "Gresham's law" and "the law of diminishing returns" and the "law of supply and demand" - the first of which I have sometimes suspected to be a law of politics, the second of which I have never quite under stood, and the third of which my friend Professor Copland has now abolished.

But two things were always clear, and have become no less clear in the passage of time; that laws are made to be broken, and that any law may be changed by Parliament.

With this precious stock of first principles, let me apply myself to the task in hand, that of explaining how a man who was Prime Minister of Australia for the first two years of this war sees and remembers some of the economic problems and experiments of that period, and anticipates the problems to come.

I use the word "experiments" because it was in many cases the true word. In the first two years of this war, the greatest and most dislocating war in history, much devising had to be done; foundations had to be laid, an attempt at longrange planning made, and all in the presence (or, if your prefer it, behind the

$\overline{1}$ Twentieth Joseph Fisher Lecture, 6 July 1942. 
back) of a public but little interested, a Parliament collectively distrustful of professional, that is, trained economists, and a newspaper press condemned to make daily, and there fore superficial, judgments without much evidence and without argument.

In spite of all, there is cause for satisfaction in the minds of those who worked with me in the knowledge that the economic, financial, and productive policies established in the opening years of the war have not been abandoned or substantially altered, and that the Australian economy, broadly speaking, has taken a strain unprecedented and unimagined, with notable stability and success.

\section{The function of the economist}

In the economic history of the last fifteen years nothing will be more notable than the rise to influence and authority of the professional economist.

In previous years he had been regarded as the professor rather than the practitioner of a somewhat dismal art. As his audience consisted of students rather than of financiers and business men, he was tried and convicted on the discreditable charge of being an academic person.

When, at the conclusion of the last war, John Maynard Keynes sought to expound the economic consequences of the peace, his words were, one fears, regarded as a somewhat scholastic intrusion upon the labours of men of the world. He has lived to see the tables turned; to take his seat in the House of Lords, and to find his economic theories accepted and translated into fact by a war-time Chancellor of the Exchequer.

In any consideration of economic policy it is, I believe, necessary to determine the function of the expert adviser. Some economists - as we know to our profit in Australia - have shown marked administrative ability. But the prime function of the economist is not to be an administrator and not to provide the ultimate answers to questions which must always be mixed questions of economics and politics, but constantly to keep before the minds of those who have to determine these questions, the scientifically collated objective facts, and the normal operation and trends of the related economic principles. 
I sometimes think that we fall too readily into two groups, those who, professing and calling themselves "good practical men," ignore and even despise the wealth of knowledge which the economic investigator has in these later years placed at our disposal, and those who, having themselves soft and uninformed minds, slavishly follow the advice of economists without testing it in relation to the human factor which, while it is imponderable and elusive, is still the most important economic factor in the world. The true task of economic statesmanship is not to follow the text-books blindly. The problem of the economic statesman is, after all, political and, what is more difficult still, democratic.

It is always essential to say: "What is economically pure and sound?" but it is not sufficient to say that and no more. The statesman must go on to say: "How much of what is economically sound and pure will the people accept and obey"? As democrats we need to remind ourselves that this does not mean that the appeal is constantly to be from knowledge to ignorance, or that immediate and superficial reaction is to be allowed to determine profound questions of fundamental policy.

The task of a democratic Parliament, one which it has not always appreciated, is not to follow but to lead. But the fact will still remain that any leader must remain in contact with his army if he is to lead it effectively. The statesman, therefore, will not simply say: "What will the people accept"? but he will modify that question so that it reads: "What will the people accept after proper instruction and reasonable pressure"?

If his policies are, however sound, out of touch with instructed public opinion, he will create a black market in economic ideas, and false ones at that, which may easily bring his plans to nothing. Moreover, as Edmund Burke reminded us a long time ago, we must constantly mould our principles to the facts and circumstances.

In a work-a-day world there is a good deal to be said for the traditional English practice of trial and error; the inductive method rather than the deductive method; because, after all, the purpose of government is the good of the citizen, and what is socially and industrially and economically good for the citizen is a problem which must admit of a variety of solutions. 
We must adapt our economic schemes to a social philosophy, and to concept of practical wisdom.

Let me take a topical example. The economist may tell me that there are various ways and means of putting a certain limit upon the profits of companies.

He may tell me that according to the method employed so may certain conclusions be expected to follow. Armed with this advice, I will then address myself not only to the particular effect which any specific proposal will have upon the joint stock system, but I will also consider whether the result will be generally to weaken or strengthen that system; I will then have to consider, according to my own conception of social betterment, whether the joint stock system is an asset to the community or no. I will need to consider whether it is a good thing to have companies building up reserves so as to provide continuity, capacity for expansion, and a stabilizing factor amid the fluctuations of employment, or whether, on the other hand, the existence and activities and strength of large companies are inimical to the interests of the ordinary citizen whose ultimate well-being it is the duty of democratic statesmanship to serve.

As in most things, therefore, we go back to the middle course. The expert will be ignored at our peril.

But he will be made our master only at the risk of disastrously applying purely objective standards to a world of men whose judgments are almost invariably subjective and whose emotions, prejudices, and passions are just as vital elements in our economy as any of the economic laws.

\section{The general problem}

No war has caused such a heavy economic burden as the present one. There was a time when civilians went about their ordinary lives in time of war while mercenary armies fought for them; when taxes were low and borrowing small, and wars were relatively cheap. Even the last war, ruinous though its cost was thought to be, pales into financial insignificance beside this one. It cost Australia, for example, in terms of money, something under $£ 250 \mathrm{~m}$. The present war cost Australia more than that in the financial year just closed. 
When a war goes to the root of national existence all our conceptions of it have to be reorganized. Our ideas, our lives, our resources, all must be reorganized to one end. Many thousands of men must go into the Army, the Navy, the Air Force. Many thousands more must make munitions; build aircraft; manufacture equipment and clothing; grow, prepare, and transport food; take their place in an enormous mechanism which may start with the ploughing of 300 acres of land in the wheat country and end with the distribution of bread to the fighting man in the battle front.

The immediate problem presented by war was and is, since the problem is continuous, to determine what resources of men and materials can be devoted to fighting, and equipping and maintaining the fighters, and how those resources can be set free; and to organize behind it all a community which performs its tasks and bears its burdens justly and equitably.

This is not primarily a question of money, though for convenience we often express the task in terms of money. Monetary and credit systems can, of course, be used as instruments of policy so long as it is understood that while money and credit may make active idle resources of men and materials, they cannot of themselves create either men or materials.

I will say something later on about the credit and financial policies pursued and to be pursued in this war.

But the financial experts have only part of the task. Ultimately the great problem is the organizing of man power, for it is man power that produces not only armies and navies, but the materials which they employ. Up to that point at which war expenditure and war finance do not go beyond the absorbing of unemployed men and materials, the man power problem is not acute. But at that point there comes the tug-of-war: "pull devil, pull baker."

The Army, the Navy, the Air Force, begin to grow.

In the case of Australia, at the end of less than three years of war we find them, between them, absorbing the better part of 600,000 men. The munition works grow; from a few thousand of employees they expand to scores of thousands 
of employees. The Americans arrive. They must be provided with camps, with aerodromes. Works Councils are set up. Thousands of men are needed for military construction, for the servicing and maintenance of military vehicles.

All this crescendo of events imposes unheard of strains upon transport systems, both of land and water.

A country which before the war had to export practically half of the whole of its primary production in order to maintain its primary industries finds its overseas markets threatened, and in many places gone; and at the same time its food-producing industries find themselves in the paradoxical position of finding it hard to supply our local requirements, not because they cannot physically be grown, but because, by reason of the unexampled drain of man power it is difficult to transport and distribute them, and sometimes actually to produce them.

All these factors are familiar to you, and I need not deal with them. For to-night 's purpose the point I want to emphasize to you is that we reach a point where our needs must be adapted to our capacity. Australia cannot produce an unlimited supply of fighting men, nor can she provide an unlimited supply of material. Our physical resources are limited not by our goodwill but by their own nature. The limit to the number of sailors and soldiers and airmen we can use militarily, is to be found not merely by taking the total numbers in the various age groups, but by determining as scientifically as possible how many men can be effectively trained and adequately equipped, and kept clothed and supplied in front of a civil population itself sufficiently clothed, fed, and housed, and discharging its supply obligations to its allies.

Experience in this war has repeatedly shown that victory is not a mere matter of numbers, but of toughness, training, and equipment.

It would be thoroughly bad policy to make a great gesture and put another 100,000 men into camp unless we were satisfied that our facilities for training and equipping them were so adequate that the strength they brought to the fighting forces would more than offset the effect of their subtraction from productive and distributive activity. 
These problems are all delicate problems. Those who deal with them should, as far as possible, be able to see the picture as a whole. Their decisions should be based not upon emotion but upon reason. There should be as little interference as possible by the amateur, and by the exigent demands of publicity.

But when all these things have been considered we will find our selves going back to this basic truth: that the economic problem of war, which is my special subject to-night, is the problem of transferring men and materials from peace to war, making the best possible use of the men and materials transferred, and distributing the community burden involved in the transfer equitably over every section of the people.

The problem of transfer includes many things. The controlling of the production of certain goods; the controlling of investment; the controlling of the exchanges; the raising of funds; the rationing of commodities; the diverting of spending power by appropriate means; each of these things required and requires earnest and close and vigorous attention if economic policy is to pursue identifiable lines and bring us to some more or less foreseen conclusion.

Within the brief space of an hour it would be plainly foolish to attempt to cover the whole field. What I propose to do, therefore, is to put before you some aspects of some only of those problems which my own personal experience has enabled me to consider at first hand.

\section{Banking and fnancial policy}

Wars are fought with men and materials, and not with money. The function of money is to set free for war purposes the men and material needed for armies, navies, air forces, munitions, supplies.

The prime purpose of war finance therefore is the diversion of resources, though its secondary and extremely important function is fairly to distribute the burden of the total defence programme. To this we must add, in my opinion, that war-time financial policy must, as far as possible and without subtracting from the war effort, keep an eye on the impact which it will have upon post-war economic reconstruction. 
The achieving of these results involves the use of three elements: taxation; borrowing (that is, non-inflationary borrowing); and the use of Central Bank credit.

It seemed to us at the outbreak of war that our immediate problem was to use each of these three things with care and judgment. Australia had moved a considerable distance out of the depression, but recorded unemployment was still around 10 per cent. This meant that we had unemployed resources of man power and unemployed resources of material. There were still considerable State borrowing programmes for Public Works, some of which were of a nonreproductive character. An immediate expansion had to occur in both the armed forces and the production of the necessary equipment. This meant a constant increase in Commonwealth expenditures, and led naturally to a consideration of how soon a War Loan should be floated, and what steps should be taken to tone up the business community so that it could withstand increased taxation and at the same time give additional employment.

A consideration of these factors, in consultation with the Common wealth Bank and thereafter the Trading Banks, in the closing quarter of 1939, led to a decision, which was admirably justified by the results, that there should be no Loan flotation until 1940, and that the Commonwealth Bank as the Central Bank, should make available to Governments what was then a considerable sum, $£ 10 \mathrm{~m}$, the somewhat inflationary effect of which would tend to increase the money in circulation and reduce unemployment.

What had been anticipated in fact happened. By the first quarter of 1940 unemployment had substantially fallen, the National Income was increasing, a Loan could be successfully floated, and the community was ready for increased taxes in the following Budget.

There has been some criticism of the fact that at this opening stage of the war I urged people to carry on business as usual. I still think it was good advice. If the entry of Australia into war, with unemployment still high, had been immediately accompanied by increased taxes and Loan appeals, with a jittery condition in the markets and exchanges, there might have been a serious setback in the important work of preparing Australia's economic machine for the enormous strain which it was to encounter. 
I have been interested recently to read in a valuable monograph printed this year in the Harvard Law Review, on "American Economic Mobilization", this passage (Vol. 55, page 478):

"In accordance with the principle that, since loans are less likely to retard production they are preferable to taxes in the early part of the war effort, the Treasury Department, through its Defence Savings Bonds drive, has been trying to reach savings while preventing the creation of new credit by commercial banks."

Once the ship was launched and steadied on its keel, with employment rising and business conditions improving, the special problem of war finance could be attacked.

Taxation was obviously one great means, not only of putting the Government in funds, but of reducing the demand for civil goods which, as unemployment disappeared, were bound to be powerful competitors with munitions of war. Similar purposes were achieved by loan issues made on the internal market.

It is necessary to remember in considering these things that local borrowing is not, as some observers lightly imagine, a passing of our burdens to posterity. The truth is that the war generation finds both men and effort for war because, if your borrowing is internal, future generations will owe the money only to themselves.

At the same time, the immediate effect of large borrowing is large taxation to meet the debt service. And on our steeply graded scales of taxation, this inevitably means a far-reaching and speedy social redistribution of wealth.

Borrowing and taxation thus impose and properly impose great burdens on those with large resources. But, at the other end of the scale, the proceeds of both loans and taxes go into circulation through expanding payments to men and for materials, and the result is that the diminution of purchasing power at the upper income levels is accompanied by an ever greater cumulative increase of purchasing power in the lower income groups.

You thus encounter what is politically the most difficult problem of war finance. The vast expenditures of war, setting up great purchasing power, will 
defeat the war effort unless a sufficient proportion of that purchasing power can be drawn off to reduce civil demand and civil production progressively as military demand and military production increase.

How are you to draw it off? Broadly speaking, you may do it in one of three ways:

1) You may tax it off by carrying fair but substantial rates of tax into the lowest income groups;

2) You may inflate the currency, in which case you will in substance impose a flat rate tax upon everybody's pound;

3) You may, either by voluntary effort or by compulsion, divert into public loans a substantial proportion of everybody's annual income.

Let me say something by way of elaboration of these propositions:

It is difficult to get up-to-date figures, but in 1940-41 it was estimated that the total of individual incomes in Australia was $£ 800 \mathrm{~m}$, and that of that sum the total of individual incomes up to $£ 400$ a year was $£ 560 \mathrm{~m}$, that is, 70 per cent of the total.

The whole movement of income groups in the first two years of the war deserves notice.

In 1938-39 the total of individual incomes was estimated to be $£ 690 \mathrm{~m}$, subdivided as follows:

\begin{tabular}{|c|c|c|c|}
\hline & Under $\mathfrak{£} 400$ & $£ 400-1,000$ & Over $£ 1,000$ \\
\hline $1938-39$ & $£ 490 \mathrm{~m}$ & $£ 120 \mathrm{~m}$ & $£ 80 \mathrm{~m}$ \\
\hline $\begin{array}{l}\text { In } 1939-40 \text { these figures had } \\
\text { become }\end{array}$ & $£ 520 \mathrm{~m}$ & $£ 135 \mathrm{~m}$ & $£ 90 \mathrm{~m}$ \\
\hline $\begin{array}{l}\text { while in } 1940-41 \text { it was } \\
\text { estimated that they were }\end{array}$ & $£ 560 \mathrm{~m}$ & $£ 145 \mathrm{~m}$ & $£ 95 \mathrm{~m}$ \\
\hline
\end{tabular}


This means that over this relatively short period the total of incomes under $£ 400$ a year has increased by $£ 70 \mathrm{~m}$; of those in the middle register by $£ 25 \mathrm{~m}$, and of those in the upper register by $£ 15 \mathrm{~m}$.

Having regard to the enormous increase in munitions production and the very substantial rise that has taken place through over-time and war loadings in the actual weekly earnings of those on wages, it seems probable that the under- $£ 400$ group is to-day more than 70 per cent of the total, and that its increase since the middle of 1939 is probably of the order of $£ 100 \mathrm{~m}$.

Now, as a matter of better distribution of wealth, no enlightened person can take any objection to this movement. The purpose for which I am referring to it to-night is to consider what effect it should have on our taxation policy. For the truth is that you cannot leave substantially untouched over 70 per cent of your individual purchasing power and at the same time expect to avoid inflated prices and fierce competition between civil and military production for your available men and materials.

This problem is brought into high relief when one considers that in the current financial year it is estimated by the Uniform Tax Committee that the total Commonwealth and State tax contributions made by the over- $£ 1,000$ group, with incomes totalling $£ 95 \mathrm{~m}$ is $£ 42 \mathrm{~m}$, or 44.4 per cent of the income; that of the $£ 400-£ 1,000$, totalling $£ 145 \mathrm{~m}$ is $£ 20.7 \mathrm{~m}$, or 14.2 per cent of the income; whereas that of the under- $£ 400$ group, totalling $£ 560 \mathrm{~m}$ is something like $£ 21.8 \mathrm{~m}$, or 3.9 per cent of the income.

This comparison is likely to be aggravated unless new policies are pursued, because the proposed limitations of dividend rates, the partial stifling of an open stock exchange, the rigid control of profits on public contracts, and the low interest rates on public securities, coupled with the decreased incentive to the earning of large incomes which results from steeply increased taxation, will all tend to reduce the available net taxable resources on the higher income levels, while the steady increase in the volume of war work, carrying a good deal of over time and loaded rates of wages, will tend steadily, and perhaps rapidly, to increase the net taxable resources of the lowest income group. 
I believe that to any detached observer it must be abundantly clear that while it may be politically popular and even, having regard to the acute unemployment of earlier years, historically just to leave the lower income groups relatively untouched, it can very well be economically disastrous to pursue such a policy.

It is true that rationing, which has now been quite properly introduced in respect of some commodities, should tend to limit civil expenditure, and therefore to increase savings available to the Government. But if rationing is to operate as a real diversion of spending power, it will need to be made substantially universal. Otherwise it may merely divert civil expenditure from one civil avenue to another; from clothing to carpets or furniture, for example.

I cannot feel satisfied that we have yet faced up to the stark realities of this problem.

If we are ultimately to direct 40 per cent or 50 per cent of the national income to war, then it follows almost mathematically that we must subtract that percentage from our civil requirements. This does not mean, in a country like Australia, that anyone need go short of the necessities of life. But it does inevitably mean that there must for some time to come be far-reaching changes in our standards of living.

If we ration clothes and leave other things to run free, if we decline to use the compulsory weapon of taxation to draw off some of the purchasing power of the mass of the people, if we are constantly appealing for war loans to the geese who have lost their capacity to lay the golden eggs and are unwilling to put real pressure upon the geese who could lay the silver eggs, then I can see no escape from such a use of central bank credit as will produce a real inflation in Australia, and will thereby impose the most unjust of all taxes: the flat rate tax upon everybody's money whether he be rich or poor.

It is indeed unfortunate that the consideration of thesefar-reaching economic problems which should, in an ideal community, be carried on with detachment and without passion, should so constantly be clouded by considerations of a short-sighted and selfish kind. 
Even the assumed political basis of the resistance to adequate taxation upon what I may call for this purpose the "wage earner" seems to me to be erroneous. I find it difficult to believe that there are many wage earners in Australia who would refuse to pay a substantial wages tax for the carrying on of the war. In the depression most States imposed unemployment relief taxes running up to $18 \mathrm{~d}$ or more in the $\mathcal{E}$; in other words taxes which even at that rate would produce from $£ 560 \mathrm{~m}$ no less than $£ 42 \mathrm{~m}$, instead of the existing yield of about $£ 20 \mathrm{~m}$.

I simply do not believe that wage-earners who out of their own precarious depreciated earnings were prepared to contribute to the relief of the unemployed would refuse at a time like this out of their relatively abundant and sustained earnings to contribute to a national security which is the real protector of every industrial condition that they enjoy, and to much more poorly paid fighting men who are the guardians of that security.

The great thing to be avoided is rigidity of mind with its accompanying catch-cries.

André Maurois in his book, The Family Circle, has a pertinent paragraph:

"In action there are no rules, no unvarying doctrine. One has to devise the means whenever one comes to an obstruction. Always. And it will always be true. Humanity will never be able to go to sleep in a Capitalist or Bolshevist paradise saying, 'this time we've hit on the right way'."

\section{Price control}

"Although large wars have never been financed without some inflation, the resulting redistribution of wealth and increased war debt justify its use only to the extent the other two methods fail to raise the necessary funds. Government price control is designed to check inflation from operating to any greater degree through its self-generating characteristics." (Harvard Law Review, Vol. 55, p. 477).

This passage clearly states one of the prime objectives of price control in time of war. It involves and includes all those matters of social justice which are involved in the suppression of the profiteer, in the laying down of the cardinal 
maxim that nobody should be personally advantaged as a result of the nation's danger.

In the last war, in Australia, price control never acquired more than an elementary and spasmodic character. In this one we were armed with a great deal more knowledge, and with more skilled advice. The result was that the price problem was attacked within a few days of the outbreak of war.

War was declared on $3^{\text {rd }}$ September, 1939.

A Sub-Committee of Cabinet, on the $7^{\text {th }}$ September, recommended that the Commonwealth should take power to control the prices of all commodities and services, and the recommendation was adopted.

On $8^{\text {th }}$ September an order was issued pegging certain prices at the level ruling on $31^{\text {st }}$ August.

On $9^{\text {th }}$ September the whole question of price control was discussed at a Premiers' Conference held at Canberra, when arrangements were made for the utilization of State officials and price-fixing authorities.

On $28^{\text {th }}$ September the National Security Prices Regulations were proclaimed under which a Commonwealth Prices Commissioner was appointed, and the whole elaborate business of scientific price control began.

It will thus be seen that the matter was attacked promptly. From the outset it was made clear that price control was to be non-political. The Minister could suspend and remit a price ruling, but could not reverse it.

We were fortunate in choosing as Prices Commissioner Professor D. B. Copland, an economist of unusual administrative capacity and with a shrewd understanding of the general social sense of the people. The work done by and under him has been not only one of the most interesting experiments in Australian economic history, but one of the most successful attempts at price control in the history of the world. 
Prices rise in time of war for two principal reasons:

One is the pressure of purchasing power on goods which are in short supply because of shipping difficulties, interference with overseas production, diversion of labour, and other causes.

The other is increased costs brought about sometimes by the in creased costs of importations and sometimes by rising wages internally.

It is clear that no Prices Commissioner can simply suppress these factors and prevent them from operating. But our experience has shown that a close scrutiny of costs, an averaging system designed to take into account stocks purchased at a lower level as well as newer stocks purchased at a higher level, and a strict, even if sometimes irritating supervision of the business community, can have real results in keeping the price level within bounds.

That this is so will be clear when I point out that between August, 1914, and the end of 1915, retail prices in Australia rose by 40 per cent, and wholesale prices by 60 per cent, whereas between September, 1939, and the end of July, 1941 , retail prices had risen only, by 9 per cent, and wholesale prices by only 15 per cent.

When one takes into account that the chief factors in the increases from 193 to 1941 (a period when I had some personal opportunity of close acquaintance with them) were an increased cost of imported articles, increased prices of primary products, and increased wages, it will be seen that price control had substantially prevented an inflationary rise in the price level.

Direct price fixation is of course not the only mechanism available to government. At least three methods suggest themselves:

a) You may, as we did in Australia, decide to impose ceilings on certain prices, putting the onus upon the trader desiring to raise the price to show cause for the increase;

b) You may, without imposing specific ceilings, endeavour to limit the rate of profit on any commodity to a certain percentage (not a very satisfactory method this, in my opinion, because it reduces the incentive to efficiency which is produced by the normal search for reduced costs, while in the other 
direction it reduces the incentive to efficiency by making the reward equal whether the efficiency is high or low);

The Government may, as it has to a considerable extent in Great Britain, and as I foresee it may in relation to some matters in Australia, become a mass buyer and seller of commodities. This is referred to in the Harvard Law Review supra, at page 501, as follows:

"Not only is it convenient for a government to take over imported goods, since they must go through the customs anyway, but a single buyer is likely to obtain a better bargain in the world market than numerous importers competing for the supply; this saving could be passed on to the consumer. In the present war the English Ministry of Food has be come the sole importer of most important foodstuffs, and parts with title to the majority of these at the wholesale stage, leaving the later stages of distribution either free of price control or controlled by maximum prices."

In all this consideration of price control, however, we must not lose sight of the fact that the price controller cannot relieve us from all the consequences of an otherwise badly conceived financial policy.

It appears to be thought in some quarters, for example, that a vast and inflationary use of central bank credit could easily be counteracted by price control, and that inflation therefore need have no terrors for us.

It is just as if you endeavoured to counteract a high fever by taking artificial steps to reduce the colour of the patient's skin.

Whatever means we may adopt for retarding rises in the price level, our monetary and fiscal policies will still be of the first importance. Price fixing aims at preserving pro tanto the purchasing power of the citizen's money. But without taxation, borrowing, rationing, and well balanced Treasury control, it can never bring about that diversion of the public resources from peace to war which is the prime object of war-time policy.

It seems clear, in spite of much legendary chatter to the contrary, that price rises so far in Australia are certainly not due to increased rates of profit. On the 
contrary, profit rates have undoubtedly fallen. There have, of course, been many examples of increased aggregate profits made by companies, but where these have occurred they have been due to increased turnover and not to an increased profit rate. Indeed, one of the paradoxical things in the political discussion which went on a few months ago was that while some people spoke ardently, first of the scandal of increased profits on the profit and loss accounts of certain large retail trading establishments, and second of the injustice of increasing taxes upon the lowest income group, they were apparently quite unable to see that what had produced these increased profits was not an upward move in the profit rate, for that had been adequately controlled by the Prices Commissioner, but a very large increase in turn over, which in turn had been almost entirely produced by the fact that the vastly increased purchasing power in the lower income group had been practically unreduced by either taxation or borrowing, and so flowed freely into the great retail emporiums of the cities.

Under the system established at the outset of the war, a system which still continues, the profiteer, that bloated monster who produced a new word and a new hatred in the last war, has been curbed, if not eliminated.

Four weapons have been available against him, and all have been freely used: His prices have been fixed; his taxation, both of his company and of himself as a shareholder, has been raised to almost astronomical proportions; he has been the recipient, in suitable eases, of orders to reduce prices; he has occasionally had his business "declared" so that it came under control as a whole.

It is not possible in a lecture of this kind to discuss these factors elaborately. I can do no more than state them. But I should add this: that after a few months' experience it became clear that as a matter of common justice, if the Government was protecting the consumer on a rising market, traders themselves would be entitled to some protection if, following the war, a collapse in prices took place.

Accordingly, on $9^{\text {th }}$ March, 1940, I made an announcement that the Government proposed to continue import licensing and price control for a sufficient period after the war to avoid heavy losses by importers or producers holding stocks purchased at high war-time prices. Subsequently, power was taken for the Minister for Trade and Customs to declare certain commodities for the 
fixation of a minimum price. As you w ill readily see, this may prove to be highly important.

Where reserve stocks have been built up at high prices for national purposes, where long-term contracts have been made at increased price levels, the utmost confusion and possibly business disaster would occur if a price collapse followed the Treaty of Peace.

Minimum price fixation, is thus designed to steady down what would otherwise be the effects of dislocation, just in the same way as maximum price fixation is in the war designed to steady down what might otherwise be sharp and ruinous oscillations in the price curve.

\section{The impact of the War upon living standards}

The two phases of war economic organization are now probably widely understood.

The first is that in which we bring idle resources into active production. The second is the subsequent one in which we divert labour and resources from one type of production and service into another.

When the war began we had an unemployment rate in Australia of approximately 10 per cent, and there was same sluggishness in business conditions generally. Plainly, then, as I have previously pointed out, there was room for an active central bank policy and a stimulation of business morale which would take up the slack.

By the middle of 1940 the problem of diversion began to manifest itself fairly clearly. I well remember going to Cabinet, after that week end in May 1940, when the collapse of France looked imminent, with two proposals: one, that munitions production should be made an entirely different department from that of Supply, and second, that the Managing Director of the Broken Hill Proprietary should be asked to take charge of it, with direct access to myself as Prime Minister, and to the War Cabinet, with unprecedented financial authority, with practically an open charter to marshal men and machines and resources for the manufacture in the shortest possible time of the greatest possible amount of the requirements 
of the Fighting Services, such requirements to be liberally stated by them for a programme of several years.

This departure, which has led to such astonishing results in Australia - and with which two South Australians, Senator McBride and Mr. N. J. O’Makin, have since been honourably associated as Ministers - marked the first big inroad into the normal production and consumption requirements of the Australian civilian.

For we must not forget that a transfer or diversion of resources means that the community as a whole will have less civil goods available for its own enjoyment.

It is still true, though we have not yet learned it, that you cannot have your cake and eat it, too. If there were no expenditure on war goods we would be paying for the labour and resources employed for our benefit by the purchase of the resultant goods.

When the diversion to war takes place and labour and resources have been extensively appropriated to war purposes, the community does not buy the resultant goods as so many millions of individuals; it buys them through its government, and it must pay for them not as a price handed over a counter but by means of diverting to the government great quantities of purchasing power through loans, taxes, and credit expansion.

But - and here is the point to emphasize - whichever of these three means we may employ, the ultimate source of the capacity to get these war goods is the income of the country as a whole. We cannot enjoy the same expenditure for civil consumption or normal investment and at the same time divert our resources to the production of war goods. This is not merely an economist's theory; it is a hard matter of physical fact, and no monetary doctrine, new or old, can overcome it.

Unfortunately, we have for a generation acquired the bad habit of thinking, if it be thinking, in terms of slogans and catch-cries. One of them has been that our standard of living is sacrosanct. For years we went on saying this while Germany and the German people were willing to make inroads upon their living standards so that they might develop the national power for war. 
The plain truth is that to-day we are paying the price. It is not merely the Generals who are to blame for our troubles. Nobody knows better than I do how dangerous it is for a politician to discuss matters of this kind frankly and honestly. His words are torn from their context, and he is at once represented as a man who wants to "grind the faces of the poor". But the time has gone by for loose thinking and sloppy talk.

\section{What do we mean by "reduced standards of living?"}

If the expression means a reduced average capacity to spend the same amount on the same things as in times of peace, then clearly the answer must be that our standard of living must be reduced. It is mere pretence to say that the country can spend 40 per cent of its national income on war and still have the same capacity to satisfy the immense variety of its civil needs. But if, on the other hand, we mean by the expression "standard of living" that standard which is regarded by our social and industrial philosophy as the reasonable and adequate maintenance provision of the wage earner and his family, then all I can say is that the frugality which must be imposed upon all of us before this war ends is by no means inconsistent with such a provision. If it becomes so, we must be prepared to face it.

But that brings me to the ultimate question, which is, whether a reasonable and adequate maintenance provision for the wage-earner and his family relates to the real necessaries of life, or to those minor luxuries and comforts at which we once wondered but which we now take so much for granted.

If our attitude is that, however the war goes, and whatever suffering our fighting men may encounter, we must as a condition of supporting those fighting men and saving our own country, be guaranteed a substantial absence of deprivation, then the plain fact is that there is no reason why we should win the war at all, since we will be fighting an enemy prepared to do more and sacrifice more than we are.

The further fact is that while the enormous diversion of resources now going on has unquestionably altered the whole living standard of many thousands of people who were relatively well-off before the war began, it has substantially raised the purchasing capacity of many hundreds of thousands of others. 
In a word, there has been, and I re-emphasize this, a real and remarkable redistribution of wealth, so much so that I would think that at this stage of the war, striking an average on mere numbers, the average civilian's living standard in Australia has risen and not fallen.

In any event, many things stand between us and any real hardship in relation to our standards of living. We have many means of protecting ourselves against a speedy reduction of our standards.

These include such matters as greater skill in management, greater effort and efficiency, and less absenteeism by those in employment; the full use of equipment to the limit of its capacity, the absorption of people and resources not normally used, such as, for example, the woman power of the country; the steady diversion to the war effort of labour and resources still used in the production of investment goods or durable consumer goods. But none of these things can in a great and sustained and long continued war effort indefinitely shield us from sacrifice and loss; the time must come when we will fight for our country with our hands or our brains or our money or Our lives because we love our country, and not for what we can be paid for doing it.

In terms of money it must be recalled that in 1938 -39 we spent $£ 4 \mathrm{~m}$ on defence and some of us, incidentally, were thought to be "war mongers" for doing it, whereas in the current financial year we will attack the problem of spending between $£ 300 \mathrm{~m}$ and $£ 400 \mathrm{~m}$ on the same purpose. If this great enterprise is to be financed without excessive resort to financial methods which, if ever used, can bring ruin and in justice to millions of our people, it will be necessary for us not only to pay our taxes and place our savings at the disposal of the Government; it will be essential for us to accelerate our rate of saving, to go without things which we took to be commonplace, in order that we may not be forced to go without everything. It is in the light of that great truth that every discussion of living standards must be conducted.

\section{The primary industries}

It has been impossible, within the compass of one lecture, to deal with the economic and financial matters which I wanted to discuss, and at the same time 
make any adequate statement on the basic and therefore important problem of the impact of the war upon our primary industries. This is a matter which I hope will some day be developed by my South Australian colleagues, Senators McLeay and McBride, who had, in the early months of the war, the political responsibility for the primary industries, and whose work I believe must have made all primary producers their debtors.

It is probably sufficiently known that, partly as a result of pre-war AngloAustralian trade discussions and arrangements, partly because of tentative agreements sketched in before the war, and partly because, through various Boards, several of the Australian primary industries were in a fair state of organization, it was possible in the early months and indeed in the early weeks of the war to give a high degree of stability to our major industries by bulk contracts, chiefly with the United Kingdom, by controlled marketing, and in some instances by local or home consumption prices.

As I have said, the full story deserves to be told in detail. To summarize it in a bald fashion would be unilluminating and unjust.

But as I am concerned to-night with the enunciation of principles and not merely with a factual or statistical record, I would like to state in a few paragraphs what seemed - and still seems - to me to be the true view of war-time primary production policy:

First, no section of the community can hope to be completely insulated from the shocks of war, and therefore we must not be so much concerned with endeavouring to preserve our profits or advantages, as with endeavouring fairly to distribute the burden of war.

Second, in time of war the primary function of primary production is to feed and clothe and equip warring populations. Where, as in the case of many of our primary industries, production far exceeds local consumption, and there are substantial exportable surpluses, those surpluses should primarily be available to our sister nations who need them, and secondarily available, as they were in earlier stages of the war particularly, to neutral countries prepared to buy them. 
I mention this almost obvious point because at present there may be a temptation to regard our moral duty, reinforced by healthy self interest, to keep up supplies to Great Britain as of lesser importance than it was before our own local security became relatively closely threatened.

I will not need to remind this audience that for years before the war we got from Great Britain a preferential market for many foodstuffs, which was the principal factor in our general economic stability.

The wool industry to-day rests upon the foundation of a bulk purchase by Great Britain in which the real risks are with her, not with us. Other primary industries to a lesser, but still great, extent enjoy advantages which she has given us. I do not need to emphasize this matter any more than to say that our experiences of the last few months increase rather than diminish our duty to make available to her everything that our own capacity and the available shipping will permit.

Third, what I have already said does not impair our obligation to maintain adequate local supplies. There is no reason to believe that such supplies cannot be easily maintained, provided that man power is scientifically allocated and economically used.

Those authorities who are controlling man power and its distribution, and those who are controlling the primary industries, need the most intimate contact with each other, and a clear understanding of principle.

It is, for example, as you will agree if you accepted my second proposition, a quite inadequate conception of the man power requirements of the primary industries to think that all that is needed is sufficient farm labour to keep Australians fed and clothed, and to perform a similar service for such Allied forces as may be within our boundaries.

We have to go further than this. We must keep up that supply over and above our own needs which is so urgently required on the other side of the world.

Fourth, internally, in the interests of the individual producer - which means in the interests of the majority of individual producers - we must recognize 
that in some productions, such as, for example, apples, overseas markets have substantially disappeared. There is an inevitable glut of production, and there must therefore be a wise control of local marketing in order to avoid a ruinous collapse of prices, and to spread losses.

Fifth, in doing all these things we must realize that the producer him self must live. His right to avoid bankruptcy is no less real, though perhaps not so clearly recognized, as that of the man who makes guns or shells.

We therefore encounter the most complex and delicate problem of how to reconcile reduced exports and interrupted markets, with their inevitable consequence in some cases of controlled or reduced production with some fair stabilization of the producer's financial position.

The Commonwealth Wheat Stabilization Scheme is, I venture to say, a splendid example of how this can be done when the problem is seriously attacked and competently and practically handled.

Let me add that when that happy day arrives when we really enter the post-war period of which we speak so much, the problem of Australian primary production will be one of the most acute of a series of economic problems which we shall undoubtedly encounter. At that time it will be (of immense value to us to have had not only a vast amount of war-time experience in dealing with emergencies, but also a substantial force of Board Members, Committeemen, and Administrators with wide knowledge and intensive training.

It is unfairly fashionable to speak ill of the civil servant. The out side world thinks of him as a strange and bloodless being, entirely swathed in a cocoon of red tape.

A striking illustration of the falsity of this picture is to be found in the expansion and work of the Department of Commerce before and during the period of this war. Most ably stated, it has performed services to all primary industries with a breadth of policy and comprehensiveness of outlook which would probably have been impossible if each industry had been left to set up its own organization and to fend for itself. 


\section{Munitions of War}

In a country in which manufacturing development had been comparatively rudimentary, such as New Zealand, the impact of war upon the national economy is great enough, and produces problems which are difficult enough. But both the problem and the impact are magnified where you have a country like Australia, in which manufacturing development had been very considerable, and the manufacture of iron and steel well-established, so that the essential foundations of expansion were laid, but in which no occasion had arisen for any substantial manufacture of precision tools, of internal combustion engines, of a dozen and one things which relate themselves to a modern munitions effort.

In the previous war Australia had been called upon to produce little more than small arms, and she was on balance an importer of munitions, relying primarily on British production. The greatest number of people she had required to subtract from civil engagement for munitions production was under three thousand.

When this war began we were in substantial production of rifles and machine guns, and of various types of ammunition; we were on the way to producing our first aircraft, the Wirraway, and our first aeroplane engine, the single row Wasp; but the total number engaged in munitions production of all kinds was still only a relatively few thou sands, and therefore no problem of diversion from civil to military production had arisen.

Admirable foundational work had been done by such outstanding public servants as Mr. N. K. S. Brodribb and Mr. J. K. Jensen but, beyond the establishing of some annexes, no levy had been made upon industry as a whole.

When, in the middle of 1940, France fell, and the skies of our world were darkened, all this was changed.

The most remarkable board of industrialists ever assembled in Australia was brought together under the leadership of Mr. Essington Lewis. Chemicals, gun ammunition, ordnance, aircraft, materials, machine tools, were all organized under men who were beyond question the leaders of their craft in this country. 
The Government factories were expanded; a great policy of decentralization into the outer States was put in hand. New and difficult productions, such as that of the 25-pounder gun, were organized through principal and sub-contractors who turned willingly, though from a financial point of view unprofitably, from civil to war production.

The system of munition annexes to private factories was further developed; the aircraft programme became more ambitious; the world was scoured for machine tools, and yielded far too few for our needs, with the result that under great pressure of time and circumstances the production of machine tools in Australia had to be improvised, and the mechanical genius of the Australian worker fully employed.

There were no political hold-ups; there was an unlimited financial backing; there was, I am happy to record, a prompt co-operation by such unions as the Engineers' Union, in schemes of training and dilution.

The results were astonishing, and will grow steeply on the original programmes laid down.

To the casual observer there is no miracle about manufacturing some particular type of weapon. He under-estimates or is simply un aware of the technical difficulties of engineering production on a mass scale, and to a degree of precision to which much Australian industry had never needed to adapt itself.

But when I remind you that every single subject of mass production in this war requires initial decisions of policy and layout, the getting or preparation of blue prints, the erection of factories, the purchase and assembly or, in many cases, the manufacture of engines, presses, machine tools, jigs, gauges, and the like, the training of staffs in new forms of process work, the production in many cases of a prototype, the testing of it, the ironing out of its eccentricities and defects, and finally the coming into real line production, you will have some perception of the magnitude of the industrial revolution which war is working in Australia.

In the last two years of the war, with no previous experience in artillery manufacture, with experience only in a limited range of other munitions, Australia 
was able to go into production of anti-tank guns, anti-aircraft guns, 25-pounder field artillery, mortars, machine gun carriers, Bren guns, pistols, bombs, depth charges, mines, pyrotechnics, between 20 and 30 different types of shell, gas masks, assault boats, pontoons, bridges, vastly to increase its production of machine guns, and so greatly to increase its production of that vital war-time requirement, small arms ammunition, that its production of September, 1939, which was at the rate of 25 million rounds per annum, had by August of 1941 become 400 million rounds per annum, and should by now, on the programmes laid down, and the factories and facilities put under construction, be nearly double that total.

Side by side with all these things you have the manufacture of cordite, of T.N.T., of scores of different chemicals, the construction and equipment and staffing of filling factories.

Like everything else of a developmental kind, munitions production cannot develop its top speed from the beginning. The foundational work is intensely difficult and sometimes painful, and almost invariably unappreciated. It may be that for a year or eighteen months after the decision has been taken to manufacture a particular item, no production whatever takes place. Establishment, equipment, and training are going on. And when production begins, it begins as a trickle. But the trickle grows, and the longer it grows the faster it grows, so that all schedules of production tend to illustrate a geometrical and not arithmetical progression.

I saw interesting evidence of that during my own period of office, for in the last eight months preceding my resignation we commenced the construction of no less than ten vast rifle, ordnance, ammunition, explosives, and allied factories? some of which are only now coming into full production.

A perfect illustration of the almost incredible complexity of these war manufactures is to be found in the Bren gun, which looks so relatively simple as you see it in the hands of the soldier. When we decided to manufacture the Bren gun in Australia all the gauges and many of the tools were to have been made in England. But in the result many, if not most, had to be hurriedly and yet accurately improvised in this country. 
It will perhaps surprise those of you who are laymen like myself to know that for the mass production in Australia of the Bren gun we required to get together from one source or another seventy-three thousand separate tools, gauges, jigs, and fixtures.

Side by side with all this, the shipyards of Australia have been coping with a large and growing programme of naval construction, including destroyers, corvettes, anti-submarine vessels, and the like and, in later months, some civil production, while aircraft construction in a country which, I remind you, had never before the war produced even the simplest type of motor car engine, has successfully produced not only the Wirraway, which is fundamentally an advanced trainer, but also the Beaufort bomber, large numbers of elementary trainers, and three different types of aircraft engine, but is also about to give us our first Australian designed and built dive bombers and fighters.

Side by side with all this we have seen new metal productions, such as that of magnesium, a vast development in chemical production, and a growth both in volume and quality - of that most vital of all industrial productions, the machine tool.

I give you one illustration to indicate what has been done: At the outbreak of war we had in Australia one lathe manufacturer, two firms who made a few power presses, three excellent Government factories making machines for lathes, and a few other private makers on a very small scale. By August, 1941, which was the period at which my direct contact with the matter ceased, there were no less than 75 firms engaged in quantity production of high grade machines, while in the manufacture of tools, gauges, jigs, and fixtures, in which 5 firms were engaged at the outbreak of the war, no less than 181 were engaged by August of 1941 .

That this astonishing growth is primarily due to the masterly work of Mr. F G. Thorpe, the Director of Machine Tool Production, I promptly and happily acknowledge. But the point that I want to make about the whole of this munitions development in Australia is not that it is even now intrinsically great enough, which it is not, or that I look back upon a personal association with it with some pride, which I hope is pardonable, but that it represents and illustrates the revolutionary impact which war can make upon a nation's entire 
economic structure. For this munitions programme, you will at once realize, not only gives us something which is vital to us in war; it provides the foundation for a post-war development of Australia in a manufacturing sense which should, wisely understood and handled, make us a real force among the manufacturing and exporting nations of the world.

My memory can go back to the great Free Trade and Protection arguments which took place when I was a boy. My adult memory covers a period when the manufacturer was suspect; when it was thought that for Australia to balance its economy by developing secondary industries was to risk our entire economic security.

But those times have changed. We have seen that the development of manufacturing resources, technique and experience has literally saved us in this war. We have lived to see such States as South Australia become vital manufacturing centres, and so develop that capacity for standing on two feet instead of one, which every community wants to have.

This industrial mobilization and growth has involved the over coming of many difficulties. We should not forget that there will be just as many difficulties in transferring this enormous potential to civil production when the war is over and, as we hope, peace has once again come to the world.

Time will not permit me to discuss these problems in any elaborate fashion, but I think it is important that I should point out that many of the things which were properly and gratefully welcomed in time of war must produce peace-time problems which good minds ought even now to be considering. Let me give you one important illustration - the Lend-Lease Act of the United States, and its inevitable significance in post-war relations.

In itself the Lend-Lease Act was a triumph for Mr. Roosevelt's statesmanship, because it did overcome the American Neutrality law at a time when that great country was still neutral, and it was a sincere and spectacular attempt to obviate the creation of those vast international debts which occasioned so much trouble at the end of the last war, and which, by the recriminations to which they gave rise, did something to embitter international relations. 
As you know, the Lend-Lease Act, passed in March of 1941, gave to the President power to authorize the manufacture or procurement of defence articles for the government of any country whose defence the President deems vital to the defence of the United States. Though the Act is called "Lend-Lease" it provides that:

"The terms and conditions upon which any such foreign Government receives any aid shall be those which the President deems satisfactory, and the benefit to the United States may be payment or repayment in kind or property or in any other direct or indirect benefit which the President deems satisfactory."

What this means is perhaps best illustrated by the supplementary agreement which the United States made with Great Britain in February, 1942.

After providing that the Government of the United Kingdom will return to the United States at the end of the war such lend-lease defence articles as shall not have been lost or consumed, and as shall be deter mined by the President to be of use to the United States, the agreement goes on to say that in the final determination of the benefits to be provided to the United States by the United Kingdom in return for Lend Lease aid, the terms and conditions shall be:

"Such as not to burden commerce between the two countries, but to promote mutually advantageous economic relations between us and the betterment of world-wide economic relations. To that end they shall include provision for agreed action by the United States and the United Kingdom, open to participation by all other countries of like mind, directed to the expansion of appropriate international and domestic measures of production, employment, and the exchange and consumption of goods which are the material foundations of the liberty and welfare of all peoples; to the elimination of all forms of discriminatory treatment in international commerce, and to the reduction of tariffs and other trade barriers; and, in general, to the attainment of all the economic objectives set forth in the Joint Declaration made on August 12, 1941, by the President of the United States of America and the Prime Minister of the United Kingdom.” 
Now, that means that payment is not being thought of in pecuniary terms, but in terms of post-war economic arrangements minimizing the acute economic nationalism which preceded the war.

\section{What effect will this have upon us in Australia?}

Our industrial development is something of great importance to us. But the LendLease Act warns us, and we cannot disregard the warning since we have accepted the benefit, that our industrial development is to he reconciled with general world trade after the war, and is not to be thought of as something designed to make us an entirely self-contained community.

Here we undoubtedly have a difficult future problem which we should have in the back of our minds even while we are making our war-time arrangements.

As a convinced believer in sensible protective tariffs for a nation which is a developing and debtor nation, I extract some comfort from the recollection that the industrial development of Australia in the past did not eliminate trade with or import from other countries; it merely changed its character and type.

But there can be no doubt that when at the end of this combat, the United Nations sit down in conference with the defeated Axis powers, every nation will need to be prepared to make its contribution to the solution of the post-war economic difficulties. If any one of us stands selfishly aloof, we will to that extent restore some of those prejudices and suspicions which in the ten years before this war persuaded so many nations to become purely nationalistic and aggressive, and to develop an instinct and readiness for battle. 



\section{1}

\section{Problems of a}

\section{high employment economy}

\section{H. C. Coombs ${ }^{1}$}

Governments of democratic countries during the war have accepted a new responsibility - that of maintaining a high and stable level of employment within their borders.

It is of course not a new thing for governments, as far as lies within their power, to seek governmentally determined results from the workings of the economic system. The writings of those early economic thinkers, the Mercantilists, show that it was generally believed that the course of trade, in addition to enriching the individuals who carried it on, should lead to the accumulation of "treasure" within the nation and increase its economic and therefore its military strength in relation to that of its actual and potential rivals.

Gradually, however, these beliefs gave way to the general view that the economic system could generally be left to run itself, and that governments should confine their intervention to making the rules, and to some extent to protecting the weak and succouring the injured. This non-interventionist attitude of governments of course had its exceptions - defence and the promotion of industrial development have long been recognized as at least plausible excuses. And of course during wars the workings of the economic system have always been subordinated to a greater or less extent to the over-riding purpose of winning the war.

1 Twenty-first Joseph Fisher Lecture, 29 June 1944. 
The new objective, however, is different in character. In the past where intervention has been positive, it has been associated with power - military and economic. Where it has been social, for example concerned with the welfare of the members of the community, it has been merely protective, that is, negative. Now, however, intervention is proposed which is both positive and social - it is designed to influence the processes of the economic system so as actively to increase human welfare - to subordinate the workings of that system to the purposes of welfare as it has been subordinated during the war to the purposes of war.

This change in the attitude of governments is due, I believe, to two main causes. The first, a growing belief that it is not enough for the State to provide merely protection from destitution. Second, the belief that increasing understanding of the economic system and improving techniques of economic management have made possible, technically at least, successful positive social intervention.

It is not my purpose to discuss whether governments should accept this responsibility of maintaining employment or whether the objective itself is a desirable one, but rather - accepting the objective as given - to attempt to answer three questions:

a) Can a high and stable level of employment be maintained by deliberate actions?

b) If so, by what means?

c) What are the main problems which will be created by the action taken?

\section{Basic assumptions}

Before passing to a consideration of the questions I have set myself, it is necessary to outline the basic assumptions upon which my analysis is based. Clearly the practicability, the techniques, and the problems of a high employment economy would be different in the different economic systems of, say, the USSR, the United States, and the United Kingdom. For the purposes of this paper, I have assumed that in post-war Australia: (a) the great bulk of production, distribution, and exchange will be carried on by private enterprise, (this does not preclude some increase in public and joint public and private enterprise); and (b) the Government will continue to limit the rights of property to a greater extent than it did before the war, but will abandon its war-time control of persons. 
I should perhaps add that the selection of these assumptions does not indicate approval or disapproval but merely a judgment that they are the most realistic that can be made in the light of existing knowledge.

\section{Definition of "high employment"}

It is necessary first to examine the meaning of the objective of a high and stable level of employment - to make clear both what it does not mean and what it does mean. Firstly, it will be clear from the second assumption I have outlined above that it does not mean compulsory employment or employment only in occupations by authority. Secondly, it does not mean the continuation of labour at the level of intensity which has been general during the war. There will be less overtime, more regular holidays, and so on. Thirdly, it will not be merely work for work's sake. It will, or at least can, mean employment directed to worth while purposes, to the raising of living standards, to the improvement of the physical environment, to the increase of individual and family security, and to the development of our economic resources. Fourthly, it does not mean everybody in a job. There will be some who do not need to work. There will be the sick, those moving from job to job, those who prefer seasonal occupations with periods of idleness between them. There may even be some unemployment due to the decline of particular industries or occupations, although it should be the objective of policy to reduce this form of unemployment to the minimum.

A high and stable level of employment means, therefore, that there will be a few more jobs available than men and women to fill them, that there will be a slight but persistent shortage of labour.

\section{Means of high employment}

\section{Maximum production}

Employment is dependent upon production, and we can only hope to have the highest practicable level of employment if production itself is at a maximum. In examining, therefore, the means to high employment, it is useful to assess the maximum production of which the economy is capable, since this will be the aim, 
if maximum employment is to be achieved. The production possible is dependent upon: (i) the raw materials available; (ii) the capital equipment available; (iii) the quantity and character of labour available for employment; and (iv) the efficiency with which these resources are employed.

In making an estimate for any given year, only the changes which will take place in these determinants compared with the preceding year are significant As a general rule, the materials and equipment factors can be ignored since they are unlikely to have changed significantly. Attention can be concentrated, therefore, on the increases in the labour force available either by natural increase, immigration, or from labour previously idle, and upon changing efficiency. Fortunately there does seem to be a fairly steady trend about changes in efficiency as measured by the real value of production per head which has been estimated for various parts of the world at figures which range between 2 per cent and 4 per cent per annum. So far as can be judged the lower figure seems more applicable to Australian conditions.

It is possible, therefore, for any given year, to estimate roughly the value of production which it will be necessary to achieve if our human resources are to be employed to the full. In this estimation the available labour and the changing levels of efficiency will be the most significant factors to be taken into account, and the value will be expressed in terms of prices current in the year upon which the estimation is based. If, for instance, we were estimating the maximum production possible in 1945-46 by estimating changes in the available labour force and in efficiency from 1943-44, our answer would be in terms of production at the levels of prices generally current in 1943-44.

\section{The maintenance of expenditure}

Production is dependent upon expenditure, and maximum production will be achieved only if expenditure by private individuals and public authorities is equal to maximum production. It is of course not sufficient merely for total expenditure to be adequate; it must be distributed geographically roughly in accordance with the distribution of the physical resources used in production, and, furthermore, it must be directed into industries so as to conform broadly with their capacity to produce. In other words, it should not impose upon industry changes in the 
type of production or the distribution of its resources which are too great to be effected in the time.

\section{Types of expenditure}

Consequently, if the Government accepts responsibility for the maintenance of employment, it must accept responsibility for the maintenance of total expenditure and for its approximate distribution between industries and between areas.

Expenditure can be classified into the following broad classes: (i) private expenditure on current consumption, for example, on food, clothing, housing, health and other services, entertainment, etc.; (ii) private expenditure on investment, buildings, machinery, durable equipment, stocks of materials and of goods; (iii) public expenditure on current consumption goods and services, for example, education, defence, etc.; (iv) public expenditure on investment goods, buildings, roads and bridges and other public works, machinery, and equipment, etc. (v) Net expenditure overseas, that is, the difference between exports of goods and services and imports.

It is necessary to add the last-named factor, for some of the above expenditure by Australians is on goods produced overseas, and this of course produces employment in the countries concerned. On the other hand, however, some expenditure by people in other countries is on goods produced in Australia, and this of course produces employment in this country. The balance between these two items will depend upon whether our overseas trade results in a net addition to employment in Australia or vice versa.

\section{Methods of control}

\section{Private expenditure on consumption}

These various classes of expenditure vary both in their liability to fluctuation and in the ease with which they can be controlled. Private expenditure on current consumption is on the whole the most stable of the various classes of expenditure. So long as people's incomes do not change greatly, they will continue to spend roughly the same proportion of their income on current consumption. The maintenance of this class of expenditure is, therefore, dependent upon the 
success in securing stability in other classes of expenditure. There is, however, an important exception to this conclusion.

Many Australian incomes are derived from the production of goods for sale overseas, and are dependent upon variations in seasonal conditions and in the prices commanded by Australian exports. In the past these incomes have, therefore, been subject to wide fluctuations, and as a consequence private expenditure on current consumption has been relatively unstable. Any measure, therefore, to bring about greater stability in the incomes of export producers would have a stabilizing effect on the level of expenditure, and therefore on production and employment. From this point of view a strong case can be made for stabilizing the prices received by producers for the main export commodities provided that these prices are adjusted progressively to long term changes in the level of world prices of these commodities.

\section{Private expenditure on investment goods}

Private expenditure on investment goods is probably the most variable form of expenditure, and, furthermore, the most difficult to influence by any form of public action. Business men must necessarily be guided in their plans for investment expenditure by their judgment of the prospects of their own industry. Greater stability in expenditure and employment generally will of course give greater stability to their markets, and therefore to their prospects. This may be expected to reduce the amplitude of fluctuations in private investment expenditure, but there will remain wide fluctuations which will derive from such things as: (i) the appearance of new commodities requiring extensive capital equipment; (ii) the development of new methods and techniques rendering existing capital equipment obsolete; and (iii) the uneven incidence of replacement of existing capital equipment.

\section{Public expenditure on consumption goods and services}

Public expenditure on consumption goods and services is relatively stable, although it is likely to experience sudden increases if governments assume new social responsibilities. It is, furthermore, to some extent capable of being adjusted to offset fluctuations in other types of expenditure. There are disadvantages about this practice, however. Expenditure undertaken to offset a threatened decline in 
private expenditure may well tend to become permanent. It seems preferable that this class of expenditure should be determined largely in the light of the purposes which it is intended to achieve.

\section{Public expenditure on investment goods}

Public expenditure on investment goods in the past has been a very variable factor. This has been due predominantly to the tendency of public authorities to restrict this expenditure at times of falling incomes when their revenues were uncertain and economy seemed to be the right policy. It has, however, for some time been accepted by economists and in general by governments and other public authorities that it is desirable to pursue almost the reverse policy, that is, that times of falling expenditure generally are times when public expenditure on investment goods should be stepped up. This expenditure is particularly well suited to control. There are always a number of projects of a public investment character associated both with the provision of services to industry, for example, in transport, and with the improvement of amenities to the civilian population, for example, schools, hospitals, for which resources could usefully be employed. Intelligent planning should make it possible to adapt the volume of this form of expenditure to economic policy decisions.

Such an adaptation is, however, not quite so easy as it may at first appear. Firstly, before any work can be undertaken, much preparatory work is necessary, and unless this is carried out well in advance it may prove impossible to step up actual expenditure on investment quickly enough to meet a threatened decline in other parts of the economy. Furthermore, work once commenced is not easy to slacken off or to stop without increased cost to the public authority concerned.

\section{Net expenditure overseas}

For a country such as Australia, which is largely dependent upon international trade, the net expenditure overseas is the most usual and the most difficult cause of fluctuation in total expenditure. Everybody will recall how the depression of 1929 was precipitated on Australia from overseas, showing itself first in a sharp reduction in our export income, and a check to the inward flow of capital to which we had become accustomed. 
Action by the Government to control this source of instability is difficult, since the factors determining the demand for our exports and overseas investment in Australia are substantially outside our control. Appropriate policy would seem to be to seek agreements with other countries by which they, too, will follow domestic policies aimed at a high and stable level of expenditure and employment. If this is done, their demand for our products will be maintained at a relatively high level and fluctuations in our domestic situation arising from changes in that demand correspondingly reduced. Furthermore, it is of course possible to control our expenditure overseas on imports and on services so as to prevent its exceeding the export income available. To do this, however, means limiting Australian expenditure in other countries, and this is not likely to be welcomed by them.

\section{Conclusion}

The conclusion seems to be, therefore, that the government can, if it so desires, influence the various types of expenditure so as to maintain expenditure equal to the maximum production of which the economy is capable. This it can do:

a) by providing more stable incomes for export producers;

b) by determining public expenditure, particularly on investment goods, by the need to maintain total expenditure at the desired level.

In controlling public expenditure on investment the government will be faced with a difficult choice. Firstly, it can estimate what private expenditure on investment is likely to be, and can adapt public expenditure to that estimate. Secondly, it can fix public investment at a level sufficiently high to make it practically certain that public investment and investment which private industry would wish to carry out would exceed what is practicable, and then to seek to control private investment so that it does not go beyond the level necessary to maintain total expenditure. The difficulty about the first method is the extreme uncertainty of any estimates of private expenditure and the danger, therefore, that public investment may be fixed at a level insufficient to maintain expenditure, and that the government will be unable to adjust it quickly enough to offset a possible deficiency in private investment. The difficulty about the second alternative is that it will frequently require limitation of the freedom of activity 
of private enterprise. Such a limitation is undesirable unless it serves a sufficiently important social purpose.

This problem arises from the absence of knowledge of the plans of private industry. Rational planning of total investment is impossible unless the government has earlier and more complete information about the plans which private enterprise itself is preparing. An appropriate policy for the government would appear to be:

a) to determine a basic public investment programme, including all works which it considers of sufficient urgency to be undertaken whatever the level of private investment;

b) to discover from private enterprise the scope of their plans;

c) if these two programmes are judged insufficient, to supplement them by:

d) (i) further investment plans by private enterprise prepared at the request of and perhaps assisted by the government; and/or

e) (ii) the inclusion of projects for public investment of less urgency than the basic programme already included;

f) to have ready numbers of emergency works which could be readily put into operation to supplement the planned programme if it proves insufficient.

In this discussion emphasis has been placed upon the problem of maintaining total investment. As I mentioned earlier, however, it is not enough that total expenditure should be sufficient. It should also be distributed both geographically and between industries roughly in accordance with the availability of resources. This may well affect the government's planning. The traditional fields for government investment are public works and buildings. Plans now being prepared by the Commonwealth and State Governments will extend this field to include housing - perhaps the most important single item of investment. There will, however, be substantial investment, particularly in machinery, plant, and equipment, which it will be difficult for the government to influence. There may be a danger, therefore, that in seeking to increase public investment to maintain employment, the government may not be able to distribute that investment geographically and industrially in accordance with available resources. This problem places particular importance on the need for the government to 
have some fore-knowledge of plans of industry, and for methods to be worked out by which the government itself can influence investment in industry. This it could do by direct participation, by joint participation with private enterprise, or by assistance to private enterprise to undertake forms of investment in which a deficiency is anticipated.

\section{Application to 1938-39}

It might be of interest to consider what the effect would have been in a past year had the government pursued a policy of seeking the highest practicable level of employment. In 1938-39 net income produced at market prices was $£ 877$ million. There were, however, roughly 10 per cent of our labour resources idle, and maximum production, allowing for only unavoidable unemployment, might reasonably have been estimated at $£ 940$ million. The main items of expenditure are set out in the first column of the following Table 21.1.

Table 21.1: National expenditure, 1938-39

\begin{tabular}{l|l|l}
\hline & $\mathfrak{f}$ million & $\mathfrak{£}$ million \\
\hline Private expenditure on consumers' goods and services & 638 & 665 \\
\hline Private expenditure on investment goods & 97 & 115 \\
\hline Net expenditure in Australia from overseas* & 20 & 2 \\
\hline Public expenditure on goods and services: & & \\
\hline From revenue & 88 & 114 \\
\hline From loan & 34 & 44 \\
\hline Unemployed resources & 63 & - \\
\hline Maximum production & 940 & 940 \\
\hline
\end{tabular}

* Export of goods and services minus imports, excluding government imports.

In estimating the additional public expenditure which would have been required of the government to bring expenditure to the desired level, it is necessary to bear in mind that any increase in public expenditure will itself raise private incomes, and therefore private expenditure on consumption, and by maintaining markets for consumption goods will stimulate the desire of private enterprise to maintain its own investment. 
In the second column of the table figures have been set out to indicate the scale of action which would have been required by the government. In preparing these figures it was assumed that private expenditure on consumption and on investment would increase roughly in proportion to private incomes. This is a reasonable assumption in relation to private expenditure on consumption, but some doubts have been expressed as to whether an increase in public expenditure would not intensify the fears of private enterprise and lead to a further contraction of private investment. There is some evidence in other countries where government expenditure has in the past played a relatively minor part in the economy, for example, the United States and France, that an increase in public expenditure can have this effect. There is little reason, however, to expect such a response in Australia, where public authorities have normally been responsible for a substantial section of total investment. In the figures given it has been assumed also that the rise in incomes consequent upon the increased expenditure would have shown itself roughly proportionately in increased receipts from taxation, and in increased expenditure on imports.

The detailed effect on the public accounts and on the balance of payments is set out in the following tables 21.2 and 21.3.

The following interesting conclusions emerge from the figures: (a) that to bring about a total increase in expenditure and therefore of production of $£ 63$ million, it would have been necessary to increase public expenditure by only $£ 36$ million, and of this increase it was necessary to finance only $£ 10$ million from loan, the balance being covered by increased revenue receipts; (b) that the rise in incomes would have brought about a corresponding increase in expenditure on imported goods, and consequently reduced a surplus of exports by $£ 18$ million.

The same results could have been obtained by an increase in public expenditure balanced by a corresponding increase in taxation sufficient to prevent an increase in the expenditure to be financed by loans. Because of the adverse effect such an increase in taxation would have had upon private expenditure, it would have been necessary to increase public expenditure to a correspondingly greater extent, and consequently to increase the severity of taxation considerably. Alternatively, public expenditure could have been left unchanged but a reduction made in rates of taxation, leaving more income in the hands of individuals to be 
spent on private consumption and investment. This method does not in fact seem practicable since politically it would be impossible to vary taxation rates in this way. Taxation policy must be determined with due reference to equity and the need for stability rather than by the requirements of economic policy.

Table 21.2: Effect on public accounts

\begin{tabular}{|c|c|c|}
\hline & 1938-39 actual & 1938-39 High unemployment \\
\hline & $£ \mathrm{~m}$. & $£ \mathrm{~m}$. \\
\hline \multicolumn{3}{|l|}{ Expenditure: } \\
\hline Goods and services & 122 & 158 \\
\hline Interest and exchange & 58 & 59 \\
\hline Sinking funds & 2 & 9 \\
\hline $\begin{array}{l}\text { Pensions and cash benefits (including } \\
\text { unemployment relief) }\end{array}$ & 30 & 25 \\
\hline Total & 219 & 251 \\
\hline \multicolumn{3}{|l|}{ Revenue: } \\
\hline \multicolumn{3}{|l|}{ Direct taxation: } \\
\hline Individuals & 32 & 37 \\
\hline Companies & 16 & 18 \\
\hline Indirect Taxation & 89 & 100 \\
\hline Net government income & 48 & 52 \\
\hline Total & 185 & 207 \\
\hline Government loan Expenditure: & 34 & 44 \\
\hline Total & 219 & 251 \\
\hline
\end{tabular}

\section{Application to post-war years}

It is of course relatively easy to speculate about what would have been the result of a different economic policy in the past. Such speculation has the outstanding advantage that it cannot be proved to be incorrect. But if economic policy is in fact to be based upon considerations of the kind which I have outlined, it will be necessary to apply them in advance. I propose, therefore, to examine the problem of planning for a high level of employment in an early post-war year in order to 
bring out more clearly the nature of the problems which would be encountered, and to obtain some rough numerical impression of the various factors to be taken into account.

Table 21.3: Effect on balance of payments

\begin{tabular}{|c|c|c|}
\hline & 1938-39 actual & 1938-39 High unemployment \\
\hline & $£ \mathrm{~m}$. & $\mathfrak{E m}$. \\
\hline Imports & 125 & 141 \\
\hline Excess freight & 16 & 17 \\
\hline Interest overseas & 27 & 27 \\
\hline Net income payable overseas & 20 & 20 \\
\hline Total debits & 188 & 205 \\
\hline Exports & 137 & 136 \\
\hline Sundry credits & 24 & 24 \\
\hline Total credits & 161 & 160 \\
\hline Overseas disinvestments & 27 & 45 \\
\hline
\end{tabular}

In this section I will be using estimates of many items which have yet to be determined by public and by private policy. The figures I use have no official standing whatsoever, and in their preparation no inside knowledge has been used. They have been prepared upon assumptions in many cases arbitrary, but which I have judged to be the most reasonable possible in the light of information which is available to the public.

\section{Maximum production}

The first question to be answered is: What is the maximum production possible? Taking the year 1947-48 as the post-war year with which we are concerned, we have first to take account of the increase in the labour force available. Compared with the last pre-war year there has been some increase in the working population, and, furthermore, it should be possible to reduce the level of unemployment which existed in that year. We can, therefore, start by assuming that on these two counts, it should be possible to increase the value of production in 1947-48 by about 13 per cent compared with 1938-39. 
During the war years efficiency measured by output per worker engaged has increased by about 16 per cent. This has in part been due to overtime and to the stimulus which the war itself has given. These factors will to some extent disappear with peace and there will, it is presumed, be some reduction in hours. Furthermore, the concentration of war-time production on special types of industry, and the fact that costs have been regarded as at least a secondary factor, may have reduced the normal improvement in efficiency which might have been expected during this period. It would, therefore, be reasonable to assume an increase in efficiency, compared with 1938-39, of about 12 per cent. This would be less than the average of some pre-war years, and substantially less than in certain other countries, but, in view of the distortion of our productive organization for war, may be regarded as reasonable. Price levels of course have risen substantially since 1938-39. It is assumed for the purpose of these calculations that prices and wage rates will remain constant at their present levels, that is about 25 per cent above 1938-39.

On the basis of these factors it would appear probable that the maximum net production at market prices possible in $1947-48$ would be about $£ 1,380$ million.

\section{Level of investment}

It is mainly through control over the level of expenditure on investment that the government can influence total expenditure, and so production. The question immediately rises, therefore, as to what level of investment will be necessary in our post-war year to ensure the necessary total expenditure. In 1938-39 total net investment was 14.9 per cent of the net national income at market prices, but if the action we have described above had been taken by the government in order to ensure a condition of high employment, it would have been necessary to raise this percentage to about 19 per cent. This might be taken, therefore, as an indication of the level of investment necessary. In order to be on the safe side, it would perhaps be as well to aim at 20 per cent as a minimum.

There is, however, some uncertainty as to whether expenditure on investment equal to this percentage would be sufficient in an early post war year. Firstly, consumption goods industries have been seriously restricted during the war, and some time may elapse before they have recovered to an extent which 
will enable consumers to spend as much on current consumption as they would desire. It is possible also that the habit of saving a larger proportion of current income which has been imposed upon people during the war may tend to persist.

Another factor to be taken into account is that there will be strong incentives to invest. As far as private enterprise is concerned, many firms will feel the need to re-equip their production units, and generally to overhaul their capital equipment. In addition there has been serious deterioration of plant due to the impossibility of carrying out normal maintenance expenditure. This applies both to private and to public investment. Furthermore, there has been serious restriction upon public investment expenditure so that substantial arrears of urgent and essential works are known to exist. It is clear, therefore, that both public authorities and private firms would desire to spend on investment goods larger amounts proportionately than in pre-war times. Furthermore, many of them, because of accumulated funds, are in a position to meet such expenditure. In what follows, therefore, I consider two post-war possibilities: (a) an investment programme based upon urgent projects which it is likely that public and private authorities will wish to carry out: this gives a figure for net investment expenditure equal to about 24 per cent of the national income; and (b) an investment programme equal to approximately 18 per cent of the national income.

These two alternatives would require investment expenditure of $£ 325$ million and $£ 255$ million respectively.

\section{Public investment}

The amount of these totals required for public investment depends upon government expenditure programmes on the one hand, and the yield of revenues on the other. These are examined in Tables 21.4 to 21.6. Both programmes A and B provide for:

a) expenditure on housing in accordance with the proposals recently made by the Commonwealth to the States;

b) expenditure on defence at a substantially higher rate than pre war - at roughly 4 per cent of the national income: this is less than the normal peace-time proportion in European countries, and may well prove a conservative estimate; 
c) continuation of expenditure on subsidies designed to prevent the cost of living from rising;

d) higher expenditure on interest and sinking fund;

e) greater expenditure on pensions and cash benefits consequent upon the national welfare programme being introduced by the Commonwealth Government;

f) Australian contribution to post-war relief of war-devastated countries.

Table 21.4: Government expenditure on goods and services 1943-44 prices

\begin{tabular}{|c|c|c|c|c|}
\hline & \multirow{2}{*}{$\begin{array}{l}1938-39 \\
£ \mathrm{~m} .\end{array}$} & \multirow{2}{*}{$\begin{array}{l}1942-43 \\
£ \mathrm{~m} .\end{array}$} & \multicolumn{2}{|c|}{$1947-48$} \\
\hline & & & $\begin{array}{l}\text { "A" } \\
\qquad \mathrm{m} .\end{array}$ & $\begin{array}{l}\text { "B" } \\
£ \text { m. }\end{array}$ \\
\hline \multicolumn{5}{|l|}{ Buildings } \\
\hline Dwellings & 1 & 1 & 40 & 40 \\
\hline Other & 5 & 3 & 7 & 5 \\
\hline Public works & 65 & 32 & 108 & 80 \\
\hline Defence* & 12 & 534 & 50 & 50 \\
\hline Post-war relief & - & - & 5 & 5 \\
\hline Administration & 26 & 32 & 30 & 30 \\
\hline \multirow[t]{2}{*}{ Social } & 43 & 37 & 50 & 50 \\
\hline & 152 & 639 & 290 & 260 \\
\hline
\end{tabular}

* Including defence works

The main difference between the programmes is in expenditure on public works other than housing. Alternative "A" provides for works programmes which would enable States and local and semi-governmental authorities to catch up arrears of maintenance, and to carry out works which they judge to be urgent and essential, within the first three post war years. The "B" alternative on the other hand provides for works programmes little in excess of pre-war levels (after allowing for changes in prices) and would fall far short of the programmes which the authorities concerned would regard as urgent. Neither, it should be noted, provides for any of the imaginative large-scale development projects which have received a good deal of attention during the war. 
Table 21.5: The public accounts

\begin{tabular}{|c|c|c|c|c|c|}
\hline & $\begin{array}{l}1938-39 \\
\text { Actual } \\
1943-44 \\
\text { prices }\end{array}$ & $\begin{array}{l}\text { 1938-83 High } \\
\text { unemployment } \\
1943-44 \text { prices }\end{array}$ & $1942-43$ & $\begin{array}{l}1947-48 \\
\text { "A" } \\
1943-44 \\
\text { prices }\end{array}$ & $\begin{array}{l}1947-48 \\
\text { “B” } \\
1943-44 \\
\text { prices }\end{array}$ \\
\hline Goods and services & 152 & 197 & 640 & 290 & 260 \\
\hline Interest and exchange & 72 & 74 & 70 & 110 & 110 \\
\hline Sinking fund & 11 & 11 & 17 & 30 & 30 \\
\hline Cost of living subsidies & - & - & - & 25 & 25 \\
\hline Pensions and cash benefits & 37 & 31 & 49 & 100 & 100 \\
\hline Total & 272 & 313 & 776 & 555 & 525 \\
\hline \multicolumn{6}{|l|}{ Revenue: } \\
\hline \multicolumn{6}{|l|}{ Direct taxation: } \\
\hline Individuals & 40 & 46 & 107 & 120 & 120 \\
\hline Companies & 20 & 22 & 57 & 45 & 45 \\
\hline Indirect taxation & 111 & 125 & 144 & 155 & 160 \\
\hline Net Government income & 60 & 65 & 83 & 50 & 50 \\
\hline Total & 231 & 258 & 391 & 370 & 375 \\
\hline Government loan expenditure & 41 & 55 & 385 & 185 & 150 \\
\hline Total & 272 & 313 & 776 & 555 & 525 \\
\hline
\end{tabular}

In estimating the revenue which will be available against this expenditure, I have assumed reductions in the current rates of taxation of the following proportions: direct taxation of individuals 25 per cent approx.; companies 16 per cent; indirect taxation 20 per cent.

Lest I should raise false hopes, perhaps I should repeat that I have no authority for these assumptions.

On the basis of these estimates we have figures for public expenditure on investment of $£ 185$ million and $£ 150$ million respectively, compared with $£ 56$ million at comparable prices pre-war and $£ 385$ million in a recent war year. 


\section{Private investment}

This would leave $£ 140$ million and $£ 105$ million respectively for private investment compared with $£ 121$ million at comparable prices in 1938-39 and probably a net disinvestment during recent war years.

It is more difficult to guess the lines on which these totals will be distributed, but an attempt is made in Table 21.6. The estimates are of course very tentative, but they take into account what is expected of private housing in the general housing plans being prepared by the Commonwealth and State Governments, the need for stocking up by retail stores, the deficiency of motor transport, and so on. It should be noted, however, that programme "B" does not reach pre-war levels of expenditure in any group.

Table 21.6: Net private investment

\begin{tabular}{|c|c|c|c|c|}
\hline & $\begin{array}{l}1938-39 \\
\text { Actual } \\
1943-44 \\
\text { prices }\end{array}$ & $\begin{array}{l}\text { 1938-83 High } \\
\text { unemployment } \\
1943-44 \text { prices }\end{array}$ & $\begin{array}{l}1947-48 \\
\text { “A” } \\
1943-44 \\
\text { prices }\end{array}$ & $\begin{array}{l}1947-48 \\
\text { “B” } \\
1943-44 \\
\text { prices }\end{array}$ \\
\hline $\begin{array}{l}\text { Machinery: plant and equipment for industry } \\
\text { and commerce }\end{array}$ & 15 & 19 & 26 & 10 \\
\hline Farm machinery, plant, and equipment & 6 & 7 & 8 & 5 \\
\hline Motor cars and commercial vehicles & 30 & 35 & 42 & 28 \\
\hline Other transport equipment & 10 & 11 & 9 & 8 \\
\hline Building: business and residential & 60 & 71 & 51 & 50 \\
\hline Livestock & -1 & -1 & - & - \\
\hline \multirow[t]{2}{*}{ Stocks and stores of materials and equipment } & 1 & 1 & 4 & 4 \\
\hline & 121 & 143 & 140 & 105 \\
\hline
\end{tabular}




\section{The balance of payments}

We have seen that after investment expenditure the demand for exports is the most important variable affecting the levels of expenditure, production, and employment in Australia. How far is it possible to forecast this and other factors in the balance of payments?

There is for any economy a fairly stable relationship between imports and incomes - people tend in the short run at least to spend a fairly constant proportion of their incomes on imported goods. Imports in the three pre-war years averaged 16.2 per cent of the net national income produced at market prices. There are, however, a number of factors to be taken into account: (a) supplies of many imported goods in Australia have disappeared, and there will be some "arrears of demand" and the need to build up stocks; and (b) many industries are in serious need of imported plant and equipment.

On the other hand: (a) some time must lapse before overseas production of many civilian goods gets under way, and supplies are likely to be difficult; (b) war-time restrictions on imports may not be entirely lifted; and (c) any shift in expenditure towards construction would probably reduce demand for imports.

Export prices are higher than pre-war, and may possibly go higher. On the other hand it may take some time for our staple export industries to get back to full production. Some secondary industries expanded during the war may, however, have the opportunity to enter export markets. 
All this is very speculative, and the following figures are correspondingly tentative:

Table 21.7: Balance of payments

\begin{tabular}{|c|c|c|c|c|}
\hline & 1938-39 Actual & $\begin{array}{l}\text { 1938-83 High } \\
\text { unemployment }\end{array}$ & $1942-43$ & $\begin{array}{l}1947-48 \\
\text { "A" and } \\
\text { "B" } \\
1943-44 \text { prices }\end{array}$ \\
\hline & $£ \mathrm{~m}$ & $E \mathrm{~m}$ & $\mathfrak{E m}$ & $E \mathrm{~m}$ \\
\hline Imports & 125 & 141 & 110 & $190^{*}$ \\
\hline Excess freight & 16 & 17 & 19 & 20 \\
\hline Interest payable overseas & 27 & 27 & 27 & 25 \\
\hline $\begin{array}{l}\text { Net income payable } \\
\text { overseas }\end{array}$ & 20 & 20 & 25 & 25 \\
\hline $\begin{array}{l}\text { Net overseas war } \\
\text { expenditure }\end{array}$ & - & - & 1 & - \\
\hline Total debits & 188 & 205 & 182 & 260 \\
\hline Exports & 137 & 136 & 144 & $200^{* *}$ \\
\hline Sundry credits & 24 & 24 & 29 & 30 \\
\hline Total credits & 161 & 160 & 173 & 230 \\
\hline Overseas disinvestmrnt & 27 & 45 & 9 & 30 \\
\hline
\end{tabular}

* Assuming some import replacement and probably some import restriction.

* Assuming a good season and expanded exports of iron and textiles. Excludes "relief" exports.

There is one factor which it may be desirable to take into account. One of the most difficult problems which will arise in the transition to peace will be the shortage of goods in relation to demand. If our over seas balances warrant it, and supplies are available, it would be a welcome aid to that transition to use part of our reserves to finance a temporary import surplus greater than that contemplated here.

\section{Total expenditure}

It should now be possible to complete the Expenditure Budget by treating the remaining item - private expenditure on consumption goods and services - as the residual amount necessary to bring the total of expenditure up to the value of 
maximum production. Provided goods are available there seems little doubt that private expenditure on consumption will reach this level. In both approaches the proportion of income devoted to consumption is less than was customary before the war, and in addition consumers have many "arrears of demand" backed by accumulated purchasing power from past savings.

Table 21.8: Expenditure budget

\begin{tabular}{|c|c|c|c|c|c|}
\hline & $\begin{array}{l}\text { 1938-39 } \\
\text { Actual } \\
1943-44 \\
\text { prices }\end{array}$ & $\begin{array}{l}\text { 1938-83 High } \\
\text { unemployment } \\
1943-44 \text { prices }\end{array}$ & $1942-43$ & $\begin{array}{l}1947-48 \\
\text { "A" } \\
1943-44 \\
\text { prices }\end{array}$ & $\begin{array}{l}1947-48 \\
\text { "B" } \\
1943-44 \\
\text { prices }\end{array}$ \\
\hline & $\mathrm{Em}$ & $\mathfrak{E m}$ & $\mathfrak{E m}$ & $\mathfrak{E m}$ & $\mathrm{Em}$ \\
\hline $\begin{array}{l}\text { Private expenditure on } \\
\text { consumers' goods and services }\end{array}$ & 798 & 831 & 704 & 930 & 1,000 \\
\hline $\begin{array}{l}\text { Net private expenditure on } \\
\text { investment goods }\end{array}$ & 121 & 144 & -20 & 140 & 105 \\
\hline \multicolumn{6}{|l|}{$\begin{array}{l}\text { Public expenditure on goods and } \\
\text { services: }\end{array}$} \\
\hline from revenue & 110 & 143 & 254 & 105 & 110 \\
\hline from loan & 42 & 55 & 385 & 185 & 150 \\
\hline $\begin{array}{l}\text { Net overseas expenditure in } \\
\text { Australia }\end{array}$ & 25 & 2 & 44 & 20 & 20 \\
\hline Unemployed resources & 79 & - & - & - & - \\
\hline Maximum production & 1,175 & 1,175 & 1,367 & 1,380 & 1,385 \\
\hline
\end{tabular}

"A" Investment 26.3 per cent of available gross income.

"B" Investment 21.7 per cent of available gross income.

Since both investment programmes contemplate an encroachment on consumption in order to sustain a higher level of investment, it may be as well to make some examination of the levels of consumption for which they in fact provide. Relevant figures are set out in Table 21.9.

Despite the "limitation" of consumption, production on the programmes contemplated should, therefore, provide for average levels of consumption 8 per cent and 16 per cent respectively higher than pre war. 
Furthermore, the increased public expenditure on social services (education, health, etc.) and on cash security payments should ensure greater equality of consumption standards.

Table 21.9: Expenditure levels (1943-44 prices)

\begin{tabular}{l|l|l|l|l}
\hline & $\mathbf{1 9 3 8 - 3 9}$ & $\mathbf{1 9 4 2 - 4 3}$ & $\begin{array}{l}\mathbf{1 9 4 7 - 4 8} \\
\text { “A” }\end{array}$ & $\begin{array}{l}\mathbf{1 9 4 7 - 4 8} \\
\text { “B” }\end{array}$ \\
\hline & $\mathbf{f m}$ & $\mathbf{f m}$ & $\mathbf{f m}$ & $\mathbf{E m}$ \\
\hline $\begin{array}{l}\text { Private expenditure on consumption } \\
\begin{array}{l}\text { Index of consumption per head of } \\
\text { population }\end{array}\end{array}$ & 798 & 704 & 930 & 1,000 \\
\hline
\end{tabular}

From the foregoing attempt to plan post-war expenditure with the aim of ensuring maximum production and employment, the following conclusions emerge:

a) that the investment programmes contemplated, while adequate to ensure maximum production, are less than public authorities and private firms seem likely to want and to be in a position to finance;

b) that planned expenditure on current consumption, while providing for higher and more equitable consumption than pre-war, would require individuals to save a higher proportion of their current incomes than they did pre-war, despite the great increase in their holdings of liquid assets;

c) that a high level of production and expenditure seems likely, in the short run at least, to involve us in some depletion of our international reserves.

These conclusions point to the problems that will confront Australian governments in their pursuit of high employment.

Before considering these problems, however, it is necessary to refer to another set of quantities which must be watched if our objective is to be achieved.

\section{The resources budget}

It is not sufficient merely to plan expenditure in broad categories. This expenditure must be distributed so that physical resources will be employed in a way conforming 
closely to their distribution both geographically and industrially. There will of course need to be changes in this distribution with the changing character of production, but if shortages are not to appear locally and for particular industries, too great pressure should not be placed upon the mobility of resources. At the same time the difficulties of change should not be magnified. In the first years of the war we brought about a revolution in the organization of our production and in the allocation of our resources. The problems of peace-time adjustment are unlikely to be as difficult.

\section{Industrial distribution}

The resources to be watched are materials, capital equipment, and labour. Of these labour is the most important, and the most readily measured. In tables 21.10 and 21.11, I set out for males and females a comparison of the distribution of labour between principal industrial groups as it was in 1939 and 1943, and as it will be required to carry out the production planned under the two programmes of expenditure.

In preparing these target distributions I have taken the following factors into account:

Primary Industries. The general trend is for a decreasing proportion of the population to be engaged in these industries There may, however, be some expansion in dairying, vegetable production, and forestry.

Mining. Some time must elapse before gold production is fully restored, and increased mechanization will probably reduce demand for labour on coalmining.

Manufacturing. Some war-time industries - shipbuilding, air craft production are likely to persist. A higher population with higher real incomes will increase demand more than proportionately in this field. materials for the greatly expanded construction industry will be an additional cause of growth.

Building and Construction. Labour requirements of the planned private and public investment programme will be considerable, but changing methods may prevent the increase being proportional to the increase in production. The trend is definitely for more to be done in the factory and less on the job. 
Commerce and Finance. War-time rationalization will probably persist to some extent.

Public Administration and the Professions. War-time employment on administration will, it is hoped, decline, but it is unlikely that it will return to pre-war levels. Social welfare plans will probably result in increased numbers of doctors, dentists, nurses, teachers, etc.

Defence. It is assumed that substantial peace-time strength will be maintained in the Services. (There is no authority for the guess given.)

Women in Employment. It is assumed that the numbers of women in employment will decline from war-time levels, but remain substantially above pre-war numbers.

Unemployment. Taking into account the types of unemployment which I outlined earlier as being consistent with a slight but persistent shortage of labour, I have assumed that on the average 4 per cent of males and 2 per cent of females seeking employment will be unemployed.

It will be noted that the industries which it is expected will absorb the greater part of the released service personnel are building, public construction, commerce, and finance, and amongst women personal and domestic service, although the numbers in this group are well below pre-war figures, while the number of women employed in all other industries is expected to be higher.

The relative stability of employment in manufacturing conceals a difficult transfer problem within the group. 
Table 21.10: Estimated number of males engaged in principal industries, Australia

\begin{tabular}{l|l|l|l|l}
\hline Industry & June 1939 & June 1943 & June 1948 \\
\hline & & & $\begin{array}{l}\text { Est. demand } \\
\text { "A” }\end{array}$ & $\begin{array}{l}\text { Target distribution } \\
\text { "B” }\end{array}$ \\
\hline Fishing and trapping & '000s. & '000s. & '000s. & '000s. \\
\hline $\begin{array}{l}\text { Agricultural, pastoral, and } \\
\text { dairying }\end{array}$ & 15 & 10 & 17 & 17 \\
\hline Forestry and forest saw-milling & 29 & 374 & 525 & 525 \\
\hline Mining and quarrying & 67 & 18 & 35 & 33 \\
\hline Manufacturing & 450 & 573 & 550 & 567 \\
\hline Building & 97 & 103 & 150 & 120 \\
\hline Public construction & 103 & 135 & 130 \\
\hline $\begin{array}{l}\text { Gas, water and electricity } \\
\text { production and supply }\end{array}$ & 28 & 31 & 33 & 33 \\
\hline Transport and communication & 231 & 232 & 260 & 260 \\
\hline Commerce and finance & 371 & 214 & 320 & 340 \\
\hline $\begin{array}{l}\text { Public administration and the } \\
\text { professions }\end{array}$ & 133 & 144 & 155 & 155 \\
\hline Entertainment and sport & 21 & 12 & 25 & 25 \\
\hline Personal and domestic service & 53 & 38 & 55 & 55 \\
\hline Defence & 15 & $680+$ & 70 & 70 \\
\hline Total occupied & $\mathbf{2 , 1 1 0}$ & $\mathbf{2 , 4 7 6}$ & $\mathbf{2 , 3 9 0}$ & $\mathbf{2 , 3 9 0}$ \\
\hline Unemployed & $\mathbf{2 6 5}$ & $\mathbf{1 9}$ & $\mathbf{1 0 0}$ & $\mathbf{1 0 0}$ \\
\hline Total industry & $\mathbf{2 , 3 7 5}$ & $\mathbf{2 , 4 9 5}$ & $\mathbf{2 , 4 9 0}$ & $\mathbf{2 , 4 9 0}$ \\
\hline & & & & 60 \\
\hline
\end{tabular}

\section{Geographical distribution of resources}

In addition to this survey of employment by industries, it would be desirable to maintain a similar survey by regions. This would be in valuable in ensuring that total expenditure was so distributed as to avoid the development of depressed areas and in throwing into relief the indirect effects on employment of declining and expanding industries. Furthermore, it could be a valuable factor in influencing the direction of housing, migration, and development policies. Unfortunately, I have not been able to assemble facts on this matter. 
Table 21.11: Estimated number of females engaged in principal industries, Australia

\begin{tabular}{|c|c|c|c|}
\hline Industry & June 1939 & June 1943 & June 1948 \\
\hline & & & "A" and "B" \\
\hline & ‘000s. & ‘000s. & ‘000s. \\
\hline Fishing and trapping & - & 0.1 & - \\
\hline Agricultural, pastoral, and dairying & 18.0 & 39.8 & 20.0 \\
\hline Forestry and forest saw-milling & 0.1 & 0.3 & 0.2 \\
\hline Mining and quarrying & 0.2 & 0.6 & 0.4 \\
\hline Manufacturing & 158.0 & 252.8 & 205.0 \\
\hline Building & 0.4 & 1.6 & 1.3 \\
\hline Public construction & 0.3 & 0.8 & 0.6 \\
\hline $\begin{array}{l}\text { Gas, water and electricity production and } \\
\text { supply }\end{array}$ & 1.0 & 3.1 & 2.0 \\
\hline Transport and communication & 13.0 & 35.0 & 20.2 \\
\hline Commerce and finance & 124.0 & 163.7 & 144.0 \\
\hline Public administration and the professions & 115.0 & 143.8 & 138.0 \\
\hline Entertainment and sport & 5.0 & 7.3 & 7.5 \\
\hline Personal and domestic service & 209.0 & 107.3 & 175.0 \\
\hline Defence & - & 44.8 & 1.0 \\
\hline Total occupied & 644.0 & 801.0 & 715.0 \\
\hline Unemployed & 36.0 & 6.0 & 15.0 \\
\hline Total in industry & 680.0 & 807.0 & 730.0 \\
\hline
\end{tabular}

\section{Can there be a manpower policy?}

In the above tables I have set out the allocation of labour at which we should aim in order to achieve given production programmes. It might well be asked what the use is of having a "target" of this kind if the government will not exercise any authority of direction over persons. In other words, is a man power policy possible without some powers of compulsion? 
In my opinion the answer is definitely "Yes". It should be recalled that the major war-time shifts in the industrial distribution of our man power were made before the power of direction was used, and that in fact it has been used surprisingly little, even if allowance is made for its indirect use - as an unstated sanction for persuasion.

The problem of securing a changed allocation of our labour force is that described in economic text-books as increasing the "mobility of labour". Labour in the aggregate is not very mobile. Its units are human beings, with lives to live outside their jobs - with families, homes, associations, and loyalties which make transfers a real hardship. But mass transfers are rarely required, and at the margin labour is much more mobile. From any industry there is a steady stream of withdrawals - because of death, retirement, attraction to other occupations, marriage, and so on. This wastage is repaired by a corresponding stream of recruits - youths, people attracted from or leaving other jobs, and so on. To some extent this stream of recruits is specialized in the sense that the persons who compose it have definite wishes about the job they want to do, have definite capacities which should be made use of, or definite limitations which restrict the field of the* usefulness. But within fairly wide limits the direction in which it flows can be influenced without compulsion. The existence of opportunities itself will exercise quite an important influence, and this can be made much more effective by conscious action which might include:

a) the establishment of an Australia-wide employment service which would bring to the notice of those seeking jobs the whole range of opportunity throughout the country, and would bring to employers effective recruitment from the whole field of available labour;

b) the provision of financial aids to overcome some of the costs of transfer advances or gifts to meet fares, costs of moving furniture, and so on;

c) assistance in securing housing or other accommodation;

d) the preparation of special plans for growing industries which would include: (i) special assisted courses of training for skilled occupations within the industry; (ii) improvement in working conditions, etc., to render industry more attractive; and (iii) possibly improvements in wages - this might be given in the form of a temporary bonus; 
e) the preparation of special plans for declining industries which would provide for: (i) limitation of entry by apprenticeship, etc.; (ii) provision of assistance to enable earlier retirement; and (iii) introduction of retraining plans for younger people in the industry.

This series of measures would, I believe, be capable of giving effect to any man power policy arising from specific production plans, unless we were faced suddenly by the collapse of a major employing industry or new demands for labour of the order created by war. Furthermore such measures would generally be welcomed by employees and their organizations and by employers because of the services provided.

There may be some doubt as to the attitude of trade unions of skilled workers to special plans to recruit new workers for the industries in which they are engaged. The war has shown, however, that Unions are willing to accept recruitment where need can be established. This is being confirmed by the attitude of the Unions to the Reconstruction Training Scheme for special training to assist in the re-establishment of Servicemen. It is necessary, however, that Unions should be taken into consultation on the labour needs which arise from specific programmes of production. Provided recruitment is based on definite production plans, and workers already in the trade are protected against recruitment being used merely to weaken their bargaining position, there is reason to expect the cooperation of Unions in such special plans.

\section{The problems of a high employment economy}

\section{Excess expenditure}

The policy described in this paper might be described as one of a Government underwriting expenditure to ensure that it does not fall below the level required to sustain production, and therefore employment at a maximum. The obvious questions which arise are: Is it possible for expenditure to rise above that level? and what would be the consequences if it did so rise?

It is clearly possible for expenditure to rise above the planned level. Public expenditure may have been planned on the assumption that private expenditure 
on, say, investment goods, would be $£$ x million, but unexpected opportunities may arise which persuade firms to use reserves or borrow from banks to increase their expenditure above this level. What would be the result?

Firstly, production (with certain minor qualifications to be referred to later) cannot be increased, since it is already planned to be at the maximum. If total expenditure rises, therefore, it can show itself only in increased prices for the goods produced and in some change in the character of production. This then is the nigger in the woodpile. Planned expenditure rules out deflation and ensures high employment, but it must be recognized that a high employment economy always carries within it the seeds of inflation. How serious is this danger, and by what means can it be controlled or mitigated?

\section{Sources of excess expenditure}

Expenditure habits are relatively very stable, and for any given level of income it is possible to predict on the basis of past experience what private expenditure on consumption will be. But where investment plans (public and private) are on a scale which leaves for the production of consumption goods and services less than would be required to meet the consumption expenditure which private individuals would desire to make the goods available for consumption would be less than the money being spent on them, and rising prices would be threatened. This would be the situation under the planned expenditure described above in programme "A".

In the foregoing paragraph I have not considered the possibility that consumers might wish to spend from accumulated reserves of purchasing power. Past experience suggests that people in fact draw upon such reserves only in times when incomes are falling. Provided that in comes generally are sustained we can, therefore, generally ignore this source of spending. The immediate post-war years will, however, be very exceptional. Holdings of cash reserves in Savings Bank deposits, and other liquid assets, have risen during the war to unprecedented heights. Furthermore, people have been forced to forego much of their customary expenditure, and their stocks of durable goods will have fallen to low levels. It is not unlikely therefore, that many people will draw upon their reserves, or at least refrain from adding to them, and a higher than normal level of private consumers' expenditure may, therefore, result. 
Private investment expenditure, depending as it does upon fluctuating opportunities, business confidence, etc., is a much more uncertain factor than private consumption expenditure. Ignorance on the part of the government of the plans of private industry may lead to excess expenditure on investment. This danger is particularly acute in the post-war years when both industry and public authorities will have arrears of investment work to catch up, and when many private firms and some government and public authorities have large accumulations of cash resources.

Excess spending will follow also from successful pressure from wage earners for increased wage rates greater than that justified by rising productivity. Insofar as such increases lead to higher costs, and are permitted to be passed on in higher prices, there will again be higher money incomes without any corresponding increase in goods available for purchase.

\section{Stabilizers}

Insofar as expenditure above the planned level is temporary, and of modest proportions, there are stabilizing factors - elements in the economy which can absorb the shock of this expenditure and prevent its showing itself in higher prices. Firstly, there are the stocks of goods within the system which can be drawn upon, and so increase the goods available against expenditure. Secondly, it is possible, if reserves of international currency are held and the necessary goods are available on international markets, to increase imports, so increasing the volume of goods available without a corresponding rise in incomes. This obviously cannot continue for long. Thirdly, there are within the economy some reserves of unused labour. Overtime can be worked, and persons who would normally not be seeking gainful employment drawn into production. This will increase the flow of goods produced and will also increase incomes, but provided some of the new incomes are saved there will be some net gain.

These stabilizers taken together could have appreciable effects, and with involuntary saving resulting from occasional inability to buy precisely what is wanted, would probably be sufficient to prevent inflation in a high employment economy with normal reserves of purchasing power and a total expenditure which had been planned without any attempt to devote a higher proportion of available 
resources to production of investment goods than people are generally prepared to save from current incomes. They are, however, clearly inadequate: (a) if there is any widespread expenditure from accumulated purchasing power; and (b) if it is desired to concentrate resources on investment.

In these circumstances it would be necessary to supplement them with more conscious controls of prices and of wages.

\section{Price policy}

The objective of price policy should be to stabilize prices at their existing level or at least to prevent their rising at rates much in excess of the rate at which productivity is increasing. In Australia, with its strict relationship between prices and wages, any other policy could readily deteriorate into the notorious spiral of inflation.

How can this be achieved? In the years immediately following the war some form of price control similar to that current during the war may well be necessary, involving the maintenance of ceilings over a substantial part of production, and the continuance of subsidies where necessary for this purpose. The field covered should include at least all articles normally entering into wage earners' expenditure, and legal price control might well be supplemented by the government's underwriting production by private firms of essential classes of goods of satisfactory quality at reasonable prices. There seems little reason why the government should not operate as a check to prices by competition at the margin in the same way as the central bank does in controlling interest rates.

An additional phase of price policy will be concerned with monopoly prices. Without some control of the prices of monopolies, rising expenditure to ensure employment may be absorbed in rising prices and profits of monopoly goods, and the objective of the expenditure defeated. This problem is likely to remain when the need for general price control passes.

\section{Wage policy}

It must be recognized that with high employment the wage earner will be in a strong bargaining position to seek concessions. This shift in the balance of strength must be recognized as a real factor. 
There are two phases of the wage problem: (i) the general level of wages; (ii) relative wages.

The first problem is embodied in Australia in the task of determining the basic wage which is fixed in real terms by the Arbitration Court at irregular intervals in accordance with "industry's capacity to pay". If wage earners are not to take advantage of their increased bargaining strength to exact higher wages, it is necessary that they should be satisfied that their wages do pass on to them the increasing productivity of their labour. This could be done by having a periodical review, to which Trade Unions would be a party, of the changes in real production per head, as it was influenced by rising efficiency and by changes in the terms of trade, and to have the basic wage re-assessed in the light of that review.

The problem of relative wages is partly one of assessing appropriate margins for skill - a task for which our Arbitration Court system is reasonably well adapted, and partly one of relative scarcities of labour of different kinds. Local or industrial shortages create conditions in which pressure for relative increases can be effectively exerted. To prevent such conditions occurring, the whole policy of ensuring mobility of labour outlined earlier in this paper is essential.

\section{Balance of payments}

We have seen that a high level of expenditure includes a high level of expenditure on imported goods and services, and that it seems likely that in our early postwar years our requirements from overseas may well exceed the proceeds of our exports. We will, therefore, have to draw upon our reserves. The circumstances are to some extent temporary export industries imperfectly recovered, and heavy accumulated demands for imported goods, including building up of distributors' stocks. But when we recall that pre-war our export industries did no more than pay for our import requirements on much lower levels of income, there is clearly cause for concern as to our capacity to continue to pay for the imports a high level of expenditure will require.

A good deal, of course, turns on the domestic policies of other countries. If they, too, are pursuing policies of high expenditure, production, and employment, then we can expect a high demand for the products of our export industries. 
Indeed if the United States, the United Kingdom, and the major European countries maintained high levels of employment, it seems probable that the wartime shortages of internationally traded foodstuffs and raw materials will persist.

There may, therefore, be no problem, but it is clear that if other countries do not maintain levels of employment comparable with our own, we shall face a persistent tendency towards adverse balances of payments which, if we are to maintain internal employment, would have to be met by internal measures designed to limit imports.

An additional problem is the changing values of our exports. We have seen that fluctuating seasons and prices have in the past been responsible for many fluctuations in Australian employment generally, and I have suggested that this effect can be mitigated if stable prices (adjusted progressively to overseas prices) for our major export commodities can be paid to producers. This does not solve the problem of a permanent change in the relative value of our exports. Suppose, for instance, the price of wool fell to half its normal level and stayed there.

This would mean a permanent reduction in our capacity to buy overseas and would mean a real reduction in our standards of living.

In the past the procedure of adjustment would have been as follows. First a fall in the incomes of exporters, and then in the incomes of those from whom they bought. This would lead to unemployment, falling incomes over a wide field, and falling demands for imports. This would bring the balance of payments into line, and gradually the prevalence of unemployment would bring about a lower level of wages, costs and incomes.

It should be recognized that if we consciously aim at a high level of employment this method of adjustment will not be possible, and other measures to secure a balance in our international payments must be sought.

\section{The problem of efficiency}

One of the most serious criticisms levelled at the policy of high employment is that it reduces the incentives to efficiency. There are three aspects to this problem: 
labour efficiency; managerial efficiency; and efficiency in the broad industrial organization of our resources.

\section{Labour efficiency}

In the past labour discipline was based primarily upon the threat of dismissal, with its consequent fear of unemployment. If that fear is removed there may be reduced output, increased labour turnover, absenteeism, and so on. If we are incapable of finding other incentives to efficiency, these results will follow. They may follow at any rate while we build up new attitudes and incentives. We cannot expect to transform the basis of labour discipline over night after a hundred and fifty years during which it was based essentially on a threat.

What can these new incentives be? In the broadest community sense we can educate people to understand the relationship between efficiency and national income as a whole, and consequently its effect on wages, and on communal services, education, housing, public utilities, hospitals, clinics, etc. We can interest workers in figures of production, costs and efficiency for individual plants, and for production as a whole. We can educate them in the relationship between wages and profits on the one hand, and national income on the other.

In the more detailed sense we can build up a consciousness in the worker that his work is significant to production as a whole, and a sense of participation in the total achievements of the economy. We can provide a progressively improving physical environment on the job and at home, better housing and community facilities, effective safety measures and industrial welfare services, adequate opportunities for training and transfer to other jobs, and an understanding and acceptance of the principles on which his wages are based.

Furthermore, we can develop those measures used during the war which bring the worker and his representatives increasingly into the tasks of production planning, wage determination, and labour control. Briefly, we must build up the worker as a partner in the tasks of production and of management, and thus establish the cooperation which can come only from a sense of common responsibility. 


\section{Management}

Examination of some Australian industries has revealed that the higher costs compared with overseas production derive not from higher wage rates or less zeal or intelligence on the part of the workers but from defective organization as a result of which best use is not made of the labour. Australia has much to learn in this field. This is due in part to the absence of opportunities for training managers and lesser managerial staff, but in part also to the fact that much of our industry has been content with much below the best, sheltering behind the natural for artificial protection of the Australian market.

We cannot afford this. Industries receiving protection for which the public pays, have an obligation to improve continuously their methods, and the government has the right to ask questions of them to ensure that they reach the highest possible efficiency and the lowest level of costs.

\section{Efficient use of resources}

In the past industries and firms no longer providing efficiently the goods required, have been eliminated in the purges of periodical depressions. The maintenance of high employment may permit the inefficient and the obsolete to linger on. This is perhaps the most serious inefficiency of all, since it will prevent resources being used more effectively for more urgent social purposes.

This problem requires the development of consciously planned machinery. When evidences of decline appear, an appropriate authority might overhaul the whole industry, determine the causes of the decline, and submit specific plans to the government for its reorganization. If it was necessary to provide for substantial reduction in output, plans should provide for the absorption elsewhere of the labour, and other resources so released. Permanent commissions of investigation in the fields of primary and secondary industry would be of value for this purpose. 


\section{Conclusion}

In conclusion may I summarize by reminding you of the three questions I set myself, and of the answers this analysis suggests.

a) Can a high and stable level of employment be maintained by deliberate action? I think the answer is clearly: yes.

b) If so, by what means? Our analysis suggests the following means:

c) (i) the stabilization of exporters' prices;

d) (ii) the planning of public expenditure, particularly on investment goods, so as to ensure that total expenditure does not fall below the level necessary to sustain production at a maximum.

e) What are the main problems which will be created? The main problems are:

f) (i) the inherent threat of excess expenditure which may lead to inflationary price rises; this will be particularly acute in the post-war period because of the desire to concentrate on investment production and of the accumulation of war-time purchasing power;

g) (ii) the tendency of high employment to unbalance our international payments; and

h) (iii) the difficulty of maintaining efficiency of labour and management, and in the broad use of our resources.

These problems are difficult, and to build up a complete technique for their solution will certainly require years, if not generations, of trial and error. However, their difficulty need not deter us. To avoid them is not to avoid difficulty but to return to the difficulties of a world where mass unemployment is a commonplace, where businesses are wrecked in the alternating boom and slump, and where the shock absorber for the vagaries of the economic system is the health, happiness, and lives of human beings. 


\section{2}

\section{Necessary principles for satisfactory agricultural development in Australia}

\section{S. M. Wadham ${ }^{1}$}

This evening I want to present a brief survey of those basic principles which seem to me to be the foundations for sound agricultural advance in Australia. Some of these principles have often been ignored in the past development of our countryside - to our increasing national discomfiture as the years go by. I must, however, prefix my discussion of the main theme by a rather lengthy consideration of world agricultural history.

In these days of change, it is fashionable for nations to review their agricultural policies. There is every reason why they should do so, for in many respects the inter-war period was one of agricultural transition. The Great Depression which occurred in the middle of this period brought about the end of one epoch in the history of world farming. This epoch opened in the latter part of the last century with the steady exploitation of vast new areas of farm lands in various countries and brought about large increases in the volumes of many farm products entering international trade; it witnessed the modern agricultural development of the United States, Argentina, Canada, Australia and New Zealand. Economically, it was somewhat disastrous to the agricultures of some older regions, but it supported in food stuffs a great expansion of population in many European countries as well as in the regions of expanding production themselves. Financially, its rapid development was possible only because of the progressive policy of overseas loans and credits pursued by European financial organizations, notably those of Britain.

1 Twenty-second Joseph Fisher Lecture, 5 July 1946. 
If the present problems and prospective developments in agriculture are to be understood correctly, it is necessary to examine those features of land use in this epoch which, though they scarcely appear in the statistics of production or of acreages or prices, are yet of prime significance in the future of agriculture in these new areas of world farming.

\section{Agricultural features of the epoch of expansion}

In the newly-developed countries, little thought was given to the basic soundness of the agricultural practices adopted during the stage of primary exploitation. There was plenty of land, and some of it, such as part of the North American prairies, was extremely fertile in character. As long as there were new areas to be brought in, practices which were wasteful of soil resources went on. The results were similar to those likely to follow from putting a number of energetic young children, removed from parental control, into a room full of new mechanical toys. The process of soil degradation went on more or less rapidly according to the type of soil and climate in each area. Its more obvious results in the various forms of erosion began to show in a quarter to half a century in many places. Apart from this outward visible sign of an ill-balanced use of land, there was a less obvious, but equally sinister, change going on within the soils themselves. Systems of farming which are solely exploitative, especially those primitive types which involve the continuous cultivation of the same crop on the same land and do not encourage the return of residues to the soil, gradually bring about a variety of troubles. The time which must elapse before these troubles become evident depends on the type and inherent fertility of the original soil. Every time a paddock is cropped, some change occurs in the physical condition of the soil. Every time a crop is grown and carted off a paddock, a certain amount of mineral matter goes with it and this comes out of the soil's reserve. Sometimes that reserve is so large that the results are not noticed for many years, as has been the case of potash in many Australian soils in our drier areas. Sometimes, when the soil's reserves of a particular mineral are slight, the result becomes apparent very quickly as was the case with phosphate in most of the soil in southern Australia. The number of mineral elements which a plant requires is large - consequently, the chances of one or other gradually coming to be in short supply is considerable when a particular crop is grown year after year and happens to require a large amount of one or other of them. 
The physical changes which occur in soils as a result of ill-balanced agricultural use, often make the land less retentive of moisture, in other cases they make it much less tractable from the point of view of the cultivator trying to reduce it to a satisfactory physical state for the crops he is planting. When the Australian farmer states that droughts are worse than they used to be and crops aren't what they were, he is often referring to the results of these two effects.

In my opinion, the great majority of cases quoted by that enthusiastic band of writers in Britain, whom we may call the "composters", are explicable on these grounds. To that extent I agree with much of their thesis, although I disagree with many of their interpretations and most of their remedies. It seems clear that the degradation of soil fertility has been considerable in some regions of Australia as in other countries which are, agriculturally speaking, new.

During this exploitative phase of land development, other disastrous features of land utilization occurred in this country as in others. Those departments of the states to which the task of settling farmers on the land had been allotted, focused their attention on the immediate problem of providing more farms with little thought as to the wisdom of their policy in the long term. Most of our lands with high rainfall were originally covered with fairly dense forest which had to be destroyed if it was to be farmed; and destroyed it was. Often the timber was not of much value so no lasting harm was done. In other cases the timber species were really valuable or worse still the land, when cleared, was too steep for farming. In the former case a valuable potential asset was destroyed, in the latter the settlers lost their battle and walked off leaving a miserable scrub vegetation from which the regeneration of a cover of useful timber species will take years. We have not been alone in these errors; wherever man has gone and whatever his colour, as soon as he has tried to settle on steep, densely forested country, the same results have occurred in the early stages.

Development was too rapid; it often became a scramble. It was so uncoordinated that it could only result in production in excess of market capacity with resultant price levels which were, at times, disastrous to the farmers. The cost of developing and equipping the new farms was usually such that the operator contracted a load of debt which was more than he could easily support from his returns. Virtually, he made a real success only-under one or other of four sets of 
conditions. Firstly, if he happened to be lucky enough to start on a really rich patch of soil. Secondly, if he was one of the first to adopt some new discovery which made the process of production more profitable than it had previously been. Thirdly, if he started at a time when costs of development and equipment were low and he continued in operation through a period when inflation of the price structure occurred so that his capital burden became relatively light. Fourthly, when he and his family were well above average in ability, strength and endurance. As instances of the first, one may mention some of the early pioneers who obtained land on specially good soils as occur in some parts of the Adelaide plains. Those who acquired sheep grazing land in the South-East along the Victorian border before the development of the practice of top-dressing pastures may be cited as examples of the second. The third type was fairly frequent between 1903 and 1918, when the prices of farm commodities were generally rising. Of the fourth type, any observer who knows his countryside will be aware of instances.

\section{Adjustments following the Great Depression}

The depression of 1929-35 ended the epoch of exploitative expansion. Its demise was gradual, as are most changes of a social character. The political and social needs of that unhappy period - the Depression - were of such force that governments were bound to take action. Attempts at improving the efficiency of marketing, debt adjustment, moratoria, improvements in farm practice, amendments to the credit mechanism in relation to farming, some readjustment of land use on the marginal areas where farming had been pushed too far - these were some of the various methods used to improve the lot of farmers and cultivators in most countries. In the United States the menace of erosion was used as a means of attracting popular attention to the destruction which was going on and, incidentally, became a convenient way of providing employment. Australia can show instances of every one of these devices; some have been adopted in every State, others only in some.

It became clear that a state of virtual overproduction had been reached in some commodities, notably wheat; while in others markets were certainly saturated at the price levels which would enable producers to pay their way. From the realization of these facts, those responsible for agricultural policy in many countries came to the 
idea of matching supply with demand for farm commodities, but it would be far from the truth to suggest that the general run of farmers adopted this attitude. In a great number of cases they were imbued with the memory that things had been more or less satisfactory before the depression, and they did not quite realize why they should not return to the same condition once more.

Two new lines of thought came to the fore in the middle 'thirties. First, the campaign for better nutrition launched in the League of Nations by Mr. Bruce in 1935 and advocated strongly by Sir John Orr of the Rowett Institute and Mr. F.L. McDougall of Australia House, London. This campaign was seized on in the United States by Mr. Wallace and spread throughout the world by propaganda and such films as World of Plenty. The second was the need for studies of conditions of farm life and of living conditions in the countryside generally. This had a considerable vogue in the United States and certain phases of it were popularized and filmed, as in Steinbeck's The Grapes of Wrath and many other books, which are paralleled for other countries by Red Bread, The Good Earth, and the novels of A. G. Street and Adrian Bell. Intensive studies, designed on scientific lines, have been made in many districts in the United States, while Doig's account of the sociology of dairying in New Zealand, the McIntyres' Country Towns in Victoria and Holt's recent sociological survey of the wheat industry in Victoria, are nearer home. This line of approach, though indirect, has tended to focus attention on the real problems of farm life in the districts or industries surveyed.

This period between the Great Depression and the Second World War was one of steady readjustment. Governments gradually realized the need for a halt in expanding the agricultural areas; farmers were not yet accustomed to the idea of a need for moderating production in some lines, in others they increased it. Even the need for changes in farm practice so as to avoid erosion was not accepted wholeheartedly; but the lessons were being learnt, slowly and painfully.

\section{Effects of the War}

The war naturally changed everything. Whole areas of supply went out. Channels of trade were severely disorganized or blocked. Demands increased or changed and the waste inevitable in any war became an important factor. The farming mechanism was severely handicapped in many ways. I need not go into details; 
most of them are more or less familiar to you. In the national interest it became necessary to stimulate extra production of some farm goods and high prices were paid for many commodities for that reason. How far this will cause farmers to forget the lessons of the preceding decade remains to be seen.

I would like to stress the point that the difficulties of the immediate postwar period were fairly clearly foreseen by those responsible for world agricultural policy. The Hot Springs Conference, which received such scanty publicity in this country, endeavoured to draw up a plan for world agricultural development so as to be ready to deal with the inevitable shortages of the immediate post-war period and also with long term problems. Among the latter was the need for improving the nutrition of many peoples and of raising the standards of living for farmers and farm workers. These objectives could only be based on an increased international exchange of foodstuffs and the raising of certain levels of production and of standards of farm life through the development of improved methods of farming, the revision of credit systems of land tenures, and the provision of better educational and technical services.

Actually the worst fears of the agricultural planners in regard to shortages of foodstuffs, have been more than realized by the events of 1945 . The starvation which has stalked through many lands in the northern hemisphere during the last four months was the inevitable result of the sequence of events. If the last stages of the war in Europe had not ended exactly in the season when the potato crop should have been put in in Germany, the disaster would have been smaller. As it turned out, there was no time to replace the "slave" workers on the farms by German labour, and parts of the potato and other spring crops were doubtless unsown. If the destruction of the north-western European transport system had not been so complete, distribution of relief supplies would have been practicable and fewer would have suffered from the effects of hunger in those countries. Similarly in Asia, if the Japanese collapse had been a little less sudden, there might have been time to get rice supplies more effectively reorganized. On top of all this, the Australian drought of 1944-5 and the failure of the Indian monsoon in the past season have made the problem almost insoluble.

What we now face is the rebuilding of the structure of world food supply which is in the same sort of condition as a house which has been shaken and partly 
shattered by an earthquake and whose inhabitants, being extremely impoverished and not particularly intelligent, naturally patch the structure by their own efforts as far as they possibly can. In fact, the memory of the disaster will make all European nations most anxious to be as self-sufficient in foodstuffs as possible. The tendency will be to reduce the international trade in foodstuffs as fast and as completely as practicable and at whatever cost.

The disturbance to international trading relations of various countries caused by this sort of disaster would have been great enough in times of peace; its repercussions just at the end of a war, at a time of high world prices and depreciated currencies are likely to be even more severe. In some cases the food is being supplied by UNRRA, but the price which is being put on it by the countries providing it makes this scheme expensive. In other cases it has to be purchased with what remains of overseas credits until export trade can be built up. The present price of wheat at Chicago is of the order of 198 cents per bushel, equal to 12s. 3d. in Australian currency, compared with about 75 cents in 1939. The effect of prices of this type must be to stimulate a very rapid recovery- of European agriculture as far as grain is concerned, and let us remember that in normal times Continental Europe is very nearly self-supporting in cereals.

The high prices which rule are partly the result of increasing prices to encourage production during the war; partly because, in all countries, farmers are endeavouring to obtain higher prices for their produce as their costs have risen, and are probably going to rise even further; and partly because they feel it is their turn to explore the pockets of consumers who had it all their own way during the decade preceding the war.

In my opinion, some of those who are forecasting years, or even a decade, of food shortage, particularly cereal shortage, are likely to be surprised. Recovery will be slower in meat and dairy products but the latter will be replaced largely by margarine. If my surmise is correct, the future market for the products of our farming industries is going to be enormously influenced by the success which is achieved, not only by Britain but by all other countries, in getting their export trade moving as soon as possible. The fewer the obstacles to trade in general, the better the chances of maintaining markets for our produce. The policy of the USA in relation to imports is probably the most important single factor in this regard. 
The fact that in Australia the prices of most agricultural products (dairying excluded) have not risen as much as they have in other countries should mean that the amount of readjustment required here will be less than in countries such as the USA, where the prices of farm products have advanced more rapidly.

\section{The general prospect for markets for produce}

This question of international markets for our products will naturally determine the extent to which we shall find it necessary to make adjustments in our farming economy. One hopes that it will be unnecessary to adopt measures of production control in any commodity. Given a freer international trade in all types of goods, it is reason able to hope that for some years our chief lines of production will find markets at reasonable prices, but the lessons of the inter-war period certainly are that this will not continue if schemes of unlimited expansion of farming are set on foot in this and other countries. I need not enlarge on the difficulties which are inseparable from production control and the need for any scheme to be such that the farmers' methods of farming are not unduly interfered with thereby.

So far I have endeavoured to set before you the agricultural aspects of the historical background against which agricultural policies must be reviewed. I apologize for he length of this survey but it is absurd to separate the agricultural problem of the Australian farming from those of the larger world outside. We are exporters of primary products on a scale which in most industries is large in relation to our home consumption.

\section{The desirable principles}

I will now consider the principles we should adopt if we are to have a better development of our countryside and an agriculture more soundly based than heretofore. These will be important, no matter whether world events result in more trade or otherwise.

\section{Land allocation}

First and foremost, I would place problems of proper land usage. It seems to me automatic that any self-respecting nation must ensure that its land resources are 
used with regard to the needs of future generations and not merely for those of the present. Two separate principles are involved: the first, that the available land is properly allocated; the second, that the soils are conserved. As regards the first, water catchments must be safeguarded; the allocation of land between forestry and farming must be in accord with a sound timber policy; national reserves and parks must be set aside on a plan which caters not merely for a population of the present size. Naturally these reserves when so set aside must be properly managed. Various efforts have been made to establish such policies in the past, but no one who examines the present situation can be satisfied with the result. The Australian people are probably in favour of the policy, but they have not always been prepared to face the political and administrative problems involved.

\section{Erosion control}

On my second point, soil erosion must be reduced to a minimum, not by lip service but in fact. Erosion control needs to be taken very seriously and competent staffs organized to deal with it. For a time these staffs may be large and may cost a great deal. This State of South Australia seems to me to be due for some congratulation on its energetic start and plans in this direction, but I cannot say the same of all. In some States, which shall of course be nameless, an ostrich like attitude towards erosion, which is little short of marvellous, has been adopted by some of those who have been responsible for directing its so-called control. Such control is first a matter of education, but where this fails, the State must pass coercive measures to permit interference with the right of the individual to do what he likes with his land if it is being eroded. Such measures will, however, be useless unless the administration of the law is firm. Too often the Statute Books of the Australian States contain wise measures on various matters, which, however, are seldom put into effect because of the continuous pressure exerted through political channels by offenders who would be inconvenienced if they observed the law. Similarly, in connection with the conservation of water catchments, reserves and the allocation of land for these and for forests, in the past departmental, and even ministerial, jealousies and disagreements have often prevented action of the right type; but this can be achieved only by transferring the responsibility for developing general plans from the departments to a coordinating body which must be given a high status in the public service and must be constituted of 
departmental heads and not of their subordinates. Those who are familiar with the working of the machinery of government in some States will be aware of the need for the emphasis.

\section{Maintenance of soil fertility}

Closely associated with my first two principles is the third, the need for the maintenance of soil fertility. We are here confronted with some very awkward problems which are common to those regions of most new countries where soils are not exceptionally rich. Australia has few large areas of soils of remarkably high fertility and accurate knowledge of the problem of trends in fertility is gradually accumulating. In some districts, farmers have worked out on their own account methods of management which achieve this objective. The better farmers in the various parts of the wheat belt in the southern States, e.g. on the Adelaide plains, have developed an improved technique of ley-farming practices which are gradually coming into vogue. But over enormous areas of our better rainfall country fertility is still being exploited and systems of farming which will maintain soil fertility at higher levels than those which exist at the moment, require to be devised. These must be of such a nature that the extra expense they involve is more than paid for by the extra returns.

This is a task for agricultural scientists, but much of the work re quires planning on lines somewhat different from those employed in the past. In some regions it will be necessary to get new varieties of crops, sometimes new machinery and usually some new method of using new products, for instance, higher protein diets are an urgent necessity for many livestock industries, especially in northern Australia. At present there is little call for these because they cost too much. They could be produced more cheaply given more knowledge of varieties, of how to grow them to the best advantage and of how to harvest them mechanically, so as to keep labour costs down. These need both research and an educational campaign to encourage farmers to grow and use the product. This means team work for a plant breeder, an agronomist and an agricultural engineer. In the past much of our agricultural experimentation seems to me to have been far too spasmodic and lacking in coordination. The plant breeders breed new varieties, or the introduction specialists bring new types from overseas, a few people try them, 
mostly in the wrong places, but even if successful they find markets difficult to establish or they expect too much. Finally, they give up and return to the old methods. Insufficient attention has been given to the planning of projects referring to groups of workers.

In no section of our agriculture is the need for active scientific work in the direction of raising soil fertility more important than in irrigated pastures and their management. The old idea that irrigation water, because it makes up for lack of rainfall, should be turned on to native pastures must be stamped out. Irrigation gives a grazing farmer an opportunity to introduce new pastures with levels of fertility and production altogether different from those of the surrounding dry country.

This third principle, that of the need for raising soil fertility, is bound up with extension work to which I shall refer later. It is also connected with rural credit.

\section{Rural credit}

Compared with many other countries, Australia has usually been relatively well supplied in the credit available for farming. Interest rates, although not always low, have been moderate when compared with the 10 per cent to 30 per cent charged in some countries. One criticism which can be justly levelled, is that at times credit has been afforded too lavishly to some farmers without thought as to whether the immediate circumstances which seemed to warrant it were likely to last. In most States, the liaison between the assessor of the long-range agricultural position and the credit authorities has been wanting.

Further, agricultural credit, to be efficiently used, needs to be closely associated with agricultural knowledge of the individual property. Credit can then be made available with discrimination. Too often has State money been advanced by settlement authorities, most of whom were Lands Department men, or others whose outlook was characterized more by their desire to establish more farmers than by their understanding of the economic bases of agriculture. In the case of private financial institutions a similar principle has applied. It may be good enough to make advances to a farmer merely on the ground that he asks for them 
and his margin of equity in his property is wide, but if the money be unwisely spent, it means less credit is available for other purposes; in addition, when the day of depressed prices or of agricultural disaster dawns and the borrower is in difficulties, he usually criticizes the bank.

The general adoption of debt adjustment and moratoria in the farming districts during the depression must, in my view, mean that many organizations and individuals who were ready to advance money to farmers in the past will not be prepared to do so in the future. I suppose most of us have personal knowledge of individuals, institutions and organizations who were far too badly bitten as creditors during the period 1931-9 ever to want to repeat the experience. In some districts large sums are still tied up in unsatisfactory rural loans. If it is generally true that agricultural credit is likely to be in short supply in future, then the State will have to undertake the task, but it is to be hoped that the lessons of the past will be assimilated and the necessary liaison will be established between an agricultural adviser with an economic mind and the credit authority before much assistance is given.

A controversy exists as to whether the provision of rural credit should be a Commonwealth or a State function. Although it would be necessary for the Commonwealth Bank as a Central Bank to have an overriding voice as far as general credit policy is concerned, yet for two reasons it seems to me most undesirable that it should endeavour to become the main rural credit organization. First because it can scarcely achieve the necessary liaison between agricultural practice and credit in the individual case as readily as can a State authority. Secondly, because the system needs to be decentralized in order to be rapid and I doubt if it would succeed in this. Whoever provides the service, let us remember it is not the man with the 40 per cent equity or better, who requires assistance, but the struggling farmer with ability and energy who needs that extra $£ 100$ at a moment of crisis to enable him to make that extra purchase which will save the crop or let him take advantage of a sudden favourable turn in the season. I need hardly remark that any authority affording credit, needs to be completely "insulated" from political pressure - a state of affairs which has not always prevailed in the past.

My fourth principle for effective agricultural progress is there fore a credit system linked with an agricultural advisory service. A rural credit system of such 
a type would exert a valuable corrective influence in re-orientating some of the uneconomic farms which are numerous in some country districts.

\section{Size offarms}

Nowadays, under Australian conditions, a reasonable amount of mechanization is essential in many farm processes if those who work the farms are to obtain a reasonable standard of living, otherwise the volume of production per worker will be insufficient. Mechanization means considerable overhead costs and the volume of production must be reasonably large to bear them. Farms which are too small should either be amalgamated into larger holdings or their owners must be prepared to work in with one another in the use of machinery. A wise financial organization with agricultural knowledge could invent schemes in which all the difficulties associated with the joint use of machinery could be explored, understood and overcome. An enlightened group of educated farmers can do just as well by free association as the regulated and formalized peasants of the USSR. The financial organization could then adjust its loan programme with the farmers so as to ensure that they would appreciate the advantages of joint operation, although it is true that the local finance manager might have to have some of the wisdom of Solon, coupled with the tact of Solomon. The question of the size of farms is the most important one from many points of view. For most farming industries (some types of horticulture excepted) there is little to be said in favour of a one-man farm. All the political ideas which have dominated Australian land settlement in the past have been based on the assumption that the one-man farm is the right objective. I notice that my friends of the National Catholic Rural Movement, although they are insistent on the family farm as being ideal, recognize that it is not to be a one-man farm but one which can give full-time employment to at least two and preferably three able-bodied men. Surely it is time that all political parties recognized the folly of setting up farms of such a size that they are uneconomic at the outset. It costs millions which we cannot afford.

\section{A rural wage system}

However, if we agree that the economically desirable form of farming is one which will employ several men, then whatever the size of the family, experience shows 
that there will be many cases in which labour will have to be employed for wages and this necessitates consideration of my sixth principle - the establishment of a recognized wage system for farm workers. There is no more important matter to-day. In many districts farmers are finding it most difficult to get satisfactory labourers. On the other side of the picture there are thousands of men who left farms to go into the forces. They have served in well-organized units, been adequately fed and looked after; they have been in many places and talked to many people, comparing ideas, and they are not going back to the farms under the old conditions. Until there is some certainty that farm wages will not drop to old levels as soon as the present acute world food problem passes, until there is some evidence that the problem of farm housing is being faced realistically, and a man going after a farm job knows that he will be housed under conditions in which he can have family life, there will continue to be a shortage of farm labour of a type which is worth good wages. Some sort of wage award is necessary. It needs very careful framing so that the particular features of farm work are allowed for and undue difficulties are not put in the way of the farmer. I rather think I should have made this my first principle instead of my sixth.

\section{A ladder of progress}

A farming system employing wage workers calls for a ladder of progress up which the really efficient worker can mount to ownership. Such a rise is very difficult for a farm worker now that the minimum capitalization for an effective farm unit is, in most industries, not less than $£ 5,000$. If we assume a 30 per cent equity as a basic necessity, this means a capital of at least $£ 1,500$ which has to be accumulated by the man who is to start farming on a fair basis. It might be done by share-farming or by farming under a long leasehold, but it will not be possible unless steps are taken to control the conditions under which these forms of tenure operate. I need not go into the hopelessness of the past position of many share farmers or short term leaseholders. legislative action in connection with such tenures becomes a matter of necessity where it has not already been taken. The satisfactory construction of the ladder referred to is my seventh principle. 


\section{Avoidance of unwise settlement or subdivision}

The rough estimate of $£ 1,500$ as the sort of minimum capital asset required by a farmer starting out on his own, emphasizes the financial difficulties of land settlement under government auspices unless the nation clearly understands the cost. The tradition that farming is a reasonable basis for the rapid expansion of our population and that the land is a place for young people to try to establish themselves has over a century of glamorous propaganda behind it. It may take all other decade or two and the writing off of another $£ 50$ million or so of national capital - that is, the incurring of further debt burden to be borne by you and me - before we learn that the days of wholesale expansion are over. It is interesting to note that in the USA the exhortation, "Go west, young man" now has a sinister interpretation; apparently Britain learned her lesson after the first world war; she has steadfastly refused to have anything whatever to do with small holding settlement for returned men to-day. In Australia so wide spread is the ignorance about the economic prospects of farming that we shall be very lucky if the authorities concerned are able to resist pressure to settle far more of our returned men on the land than it is justifiable to put there. Subdivision of large estates may be all very well when the land is being effectively used, but the spectacle of acquiring a large well managed station employing profitably perhaps eight men and housing them and their families well, and of replacing such a unit by perhaps ten or a dozen smaller properties by considerable capital outlay and risk, seems to me plain foolishness. My eighth principle then is that land settlement and subdivision should be based on the agricultural need for it and on the individual case and should not be regarded as inevitably desirable.

\section{Realism towards the facts of tenure systems}

While dealing with this type of land problem we might as well examine another fallacious dogma which is current in some States. This is the view that crown leasehold is a far superior form of tenure to freehold. The basis of this idea seems to be twofold. First, that as the settler doesn't have to pay for his land by instalments but only pays a rental, he has a better chance of establishing himself. Secondly, that under crown leasehold it is possible to prevent land values from rising because the crown can reclaim for itself any increment by altering the rent. 
As regards the first of these, the cost of the unimproved land itself is usually only a small part of the cost of establishment, so that buying the land is not a great extra burden provided the payment is spread over a long enough period.

As regards the second, experience shows that, at least as far as farm land is concerned, the State is not, in fact, in a position to raise the rent, and the farmers knowing this very well are prepared to pay large premiums for goodwill when leases are transferred. These premiums represent a rise in land value, probably as great as would have occurred under a freehold system. Finally, experience in some States has shown that at times when farming meets adverse conditions, economic or otherwise, political pressure to reduce rentals cannot be resisted and that when better times return the rents are not raised. Under leasehold systems as at present administered, therefore, not only does the nation fail to retain to itself benefits from increased land values, but it ends up by losing some of the value of its land. My fifth principle then is that we face the real facts of land tenure systems and get rid of preconceived notions on the subject.

\section{Better rural education is essential}

Coming back to the main trend of my argument, which you will remember, involved greater mechanisation, more efficiency in farming and a better appreciation of those nice points which distinguish the good farmer and his high yields from the average, it will be quite apparent that we shall not reach these higher standards unless we have a better system of rural education. My tenth principle involves better technical training and also a better general education, for without improvement in both of these directions farmers will find it difficult to understand the application of more advanced techniques, without which they will not be likely either to develop the capacity to think of farming as a business enterprise or to understand the relation between it and the nation as a whole.

During the last few years much has been written and said about the need for raising educational standards in Australia. As far as country education is concerned, there seems to be a general realization that the system of large, centralized schools is better than the system of larger numbers of smaller teaching units. Personally, I have no doubt of this, not only because the pupils stand a better chance of getting a wider education at the larger schools but also because they 
obtain the added advantage of bringing them into contact with a wider variety of their fellow human beings. If members of my audience do not appreciate the need for this, I can only recommend them to go and stay in a few remote districts and make judicious enquiries about the general atmosphere in single-teacher schools.

However, centralization is not the end of the story. I very much doubt whether the full benefit of a centralized system will be obtained unless opportunity is taken to use it to alter the curriculum. The Tasmanian authorities, who were probably the first in the field among the Australian States in this direction, claim that it has proved possible to devote nearly half the school time of the children of twelve years and over to useful crafts, without prejudicing the standards which they reach in the ordinary educational subjects at the age of fourteen. Looking back as clearly as I am able to my own school days and realizing the amount of time we used to waste, either through boredom or through an incapacity to do more at ordinary subjects, I can well believe that this is true. At present, a proportion of the children's time is used rather unproductively on bookwork subjects which the average child merely endures. How far the various States are prepared to introduce crafts and applied work for about half the time-table of both boys and girls I do not know, but I feel fairly certain that unless some steps are taken in this regard, the raising of the school leaving age to 15 or 16 will be found to be useful only in the case of a rather small percentage of the country students.

I think it necessary to say something about our agricultural colleges. In this connection I would, at the outset, remark that I think South Australia is extremely fortunate in the development of Roseworthy, but I do not think that all the other agricultural colleges in Australia are in quite the same position. When considering the specific function of agricultural colleges, I think we should start by considering what a boy who is going to become a proficient and progressive farmer needs in the way of knowledge. First, he has to learn the technique of handling animals and farm machines and what each one does ill the practices of the farm. Secondly, he has to learn a certain number of crafts connected with farming. He will be a better farmer if he can be a bit of a blacksmith and is able to do rough carpentering, concrete work and the more elementary repair jobs on machinery. Thirdly, he ought to know the reasons for the various procedures which are carried out on the farm, why this kind of soil is to be worked with 
that succession of implements, what governs the proper time to sow, what preparations are necessary for organizing machines, labour and materials for a harvest, and so on; and with this should go some account of the principles of feeding animals. Finally, he must have an acquaintance with elementary bookkeeping and should understand something of farm economics. While it is true that all this can be done at an agricultural college with its large farm and its specialized staff, yet such institutions are expensive, and if we expect that they are going to be multiplied many times so that every potential farmer is going to pass through one, we are going to have to foot a very large bill. Of the four groups of subjects mentioned - farm practices, farm crafts, agricultural science and agro-economics - the potential farmer can get the first on the farm from which he comes, while the other three do not necessarily need a farm for teaching purposes but can be taught in a properly staffed and equipped technical school in a country district. America has had a wide experience of agricultural colleges and has gradually come to the conclusion that the proper place to learn farm practices is on a farm and the function of the colleges is more in connection with the other three groups of subjects which I have mentioned. If we are to improve our general level of agriculture, every farmer's son who wants to be a farmer should spend two years at an agricultural technical school during which most of his time will be spent at the subjects mentioned. This virtually makes the agricultural college a technical high school of a special type, unless it also takes its training further and aims at producing men for the simpler specialist positions in industries connected with farming, as I believe it should.

\section{An effective technical extension service}

My eleventh principle concerns extension work. At various stages I have referred to the need for more technical assistance to farmers on their farms through welltrained district officers who will have gone through a course of high standing at an agricultural college and, preferably, a University course as well. These extra services would cost a good deal, but if for the whole of Australia the extra sum involved were about $£ 1$ million a year, I think it would be a sound investment always provided the right type of man is appointed. We have to realize that, agriculturally speaking, most parts of Australia are difficult farming areas, although many may be easy places in which to scratch along. I suggest we have 
scratched along quite long enough and it is high time we faced our problems both by increasing the amount of soundly-based scientific research and by providing adequate extension services to promulgate their results.

\section{Administration services}

My twelfth principle deals with administration on which something needs to be said. The complex constitutional structure of Australia means that there must always be considerable difficulty in arriving at a common policy in connection with agricultural matters. It is common knowledge that the past has shown how difficult it is to arrive at such a policy, yet the failure to do so has meant embarrassing delays and sometimes the loss of opportunities. If we admit that there is need for an organization through which the States may come together and develop this common policy, then we must also add that as long as Australia is a Commonwealth of self-governing States, those who constitute the Commonwealth department which deals with agricultural affairs must recognize that their function is to collate ideas and promote agreement rather than to dictate the former and enforce the latter. The dictatorial line of action may have a magnificent appeal to the bureaucratic mind, but is legally and physically impracticable.

\section{Amenities on farms and in country centres}

Finally, I come to the question of farm amenities. Before the war many people living in cities and towns had almost come to think of country folk as a race apart which did not need some of the conveniences which those in the city regard more or less as their everyday right. It is true that life in the country must always be somewhat different from life in the city, but it is quite certain that if we are going to have an efficient countryside staffed by effective people, the gap between the amenities of the city and the amenities of the country must be reduced.

Improved education, better housing, better water supplies, rural electrification, more effective health services, better amenities in country towns, are directions in which improvement can be made. Of course, it will be impossible to bring electricity to every homestead, and large water supplies cannot be made available to every farm without enormous expense. I suggest there are two 
underlying principles. First, some of these amenities will mean national assistance; secondly, it is not much use providing community centres and libraries and rest rooms and so forth unless the country people want them. The community efforts in various parts of this State are most interesting; even more interesting will be the observation of how far the demand for such organizations spreads to other centres.

\section{Conclusion}

I have traversed in a somewhat sketchy way a great number of topics this evening. The very nature of my title made it inevitable that I should do so. In so far as this has resulted in my giving you a confused picture. The result is a failure. On the other hand, I took that risk deliberately, because the agricultural progress of any country where people have the right to try for any type of employment they choose is bound to be a complicated affair. Thus wage regulation, conditions of life on farms and the amenities the countryside offers, influence the average level of intelligence of those who choose agriculture as a livelihood. The degree of intelligence of those who elect to stay in the country, their standard of education and the system of spreading new knowledge largely determine the readiness of farmers to try other methods and to take advantage of new discoveries. Progressive methods often mean a need for more capital which is available on reasonable terms only if a satisfactory rural credit system exists. This in its turn must be backed with economic services in two directions. First, as regards the farms and secondly, as regards the prospects for markets without which agricultural expansion is an unwarranted diversion of the national resources.

I am aware that the principles I have enunciated are thirteen in number, which some people might regard an unlucky chance. I am not worried by any thoughts of chance as deciding our agricultural future. Our task is to realize that sound farming seeks to eliminate chance or to provide reserves against its effects as far as is humanly possible. The days when it seemed good to many to "try anything once" or "to give any proposal a fly" ought to be over as far as agriculture is concerned. Our success in the future will largely depend on how far we face our problems coolly and with a determination to think them out; only by such procedure shall we make progress in the development of the resources of our continent which are agriculturally some what meagre in everything but size and sunlight. 


\section{3}

\section{The importance of the iron and steel industry}

\section{Essington Lewis ${ }^{1}$}

\section{Introduction}

It is a great honour to be invited by the Council of the University of Adelaide to deliver the 1948 Joseph Fisher Lecture on "The Importance of the Steel Industry to Australia." It is a subject which is all-absorbing and is especially interesting to South Australia, the State which supplies the Australian steel industry and allied works with two of their major raw materials, iron ore and limestone, and some of their lesser known requirements, dolomite, salt and gypsum. Mr. I. McLennan has largely assisted in the collecting of data and facts for this lecture.

\section{Early history}

The early history of the industry is interesting. Iron Smelting was first established in 1848 , just one hundred years ago, in the vicinity of Mittagong (then called Nattai) in New South Wales. This was a small enterprise and despite several attempts achieved little success. It was finally abandoned in 1886. In 1874, Mr. James Rutherford in association with other well known colonists set about establishing a blast furnace at Lithgow, New South Wales, and in 1875 the Eskbank Iron Works commenced operations. Mr. William Sandford was the lessee of the Mittagong Works in the 1880's and when in 1886 he abandoned them he took over the Works at Lithgow. Under his direction the plant was extended and on January 15,1894 , the first sheet rolling mill in this country was started. On the $24^{\text {th }}$ April, 1900 , an important milestone in the history of the industry was passed when the

1 Twenty-third Joseph Fisher Lecture, 10 June 1948. 
first heat of open hearth steel made in Australia was tapped from a newly erected 4-ton furnace at the Lithgow Works. The firm of William Sandford Ltd. became financially embarrassed and the Works closed down on December 10, 1907, to be purchased by Messrs. G. and C. Hoskins Ltd. of Sydney who took possession in January, 1908. Mr. William Sandford was a stout-hearted pioneer to whom the country owes a great deal.

\section{The importance of the iron}

The initiative of Messrs. G. and C. Hoskins in taking over the Eskbank Iron Works opened up a new phase in the history of the Australian steel industry. They threw their energies into the venture and it progressed greatly. With great vision, Mr. Charles Hoskins purchased a 400-acre site at Port Kembla and in January, 1927, the firm commenced the erection there of a modern blast furnace. Mr. Charles Hoskins, however, did not live to see his Port Kembla plans come into being. By his passing Australia lost a great industrialist.

The plans he had initiated kept moving. His two sons, Messrs. Cecil H. Hoskins and A. S. Hoskins, took over the direction of the enterprise. The great possibilities of this Port Kembla development were fully recognized, and in 1928 Hoskins Iron and Steel Ltd. in association with Dorman Long and Co. Ltd. and Baldwins Ltd. of England and Howard Smith Ltd., formed Australian Iron and Steel Ltd., which company acquired all the interests of Hoskins Iron and Steel Ltd. On 29th August, 1928, the new blast furnace at Port Kembla was blown in, to be followed quickly by other plant. Then in 1935, another most important event in the annals of this undertaking occurred. The Broken Hill Proprietary Co. Ltd., at that time the other major steel producer in this country, acquired all the ordinary shares of Australian Iron and Steel Ltd. This brought the two steel plants, one at Newcastle and the other at Port Kembla, into close association with resultant benefit to both. Modern steel plants are made up of units with large producing capacities and the advantages of rationalizing to individual plants those products for which their equipment is most suited, are obvious.

It is necessary now to go back to 1885 to the discovery of the silver-leadzinc ore bodies at Broken Hill. At that time and for many years thereafter, no one could have foreseen any connection between this discovery and the development 
of the steel industry in Australia. There are two fundamental connections. It was the wealth won from Broken Hill that provided much of the finance which initiated the B.H.P. steel industry at Newcastle and carried it through the difficult formative years. Secondly, iron ore was necessary as a flux in the smelting of the Broken Hill ores at Port Pirie and the ironstone deposits leased at Iron Knob for this purpose in 1899 , later became the source of raw material for iron and steel making.

It is appropriate to consider the tremendous value to a country of its mineral deposits. Perhaps the best way to do this is to give a few examples.

What a great debt Australian industry owes to Broken Hill. Its ore bodies have provided the basis for large and important industries directly connected with lead and zinc. The wealth it has made available and the great financial and technical organizations that have sprung from it have helped materially other Australian industrial development, such as iron and steel, paper, aircraft and nonferrous metal fabrication.

Gold deposits at Gympie (Queensland), and Bendigo and Ballarat (Victoria) were the basis of great cities which, long after gold mining has languished, have prospered and remained centres of flourishing communities. It was the finding of gold in the 1850's that led to the first big inflow of population to this country. The Golden Mile in Western Australia, in fact the whole vast area of the Western Australian goldfields, has been the means of opening up country which otherwise must have remained undeveloped. Mt. Isa (Queensland) is producing wealth and sustaining a community in another remote area, as is also Mt. Lyell on the west coast of Tasmania.

It is possible to mention others, but sufficient has been said to illustrate the points: firstly, the benefits accruing from the exploitation of ore deposits by truly bringing about decentralization, and secondly, the wealth and raw materials so unlocked make possible other manufacturing industries.

It would be wrong to say that the end has been reached of great mineral discoveries in Australia. It is necessary to press on with all manner of prospecting work, using the best scientific means to further examine the country. 
The tragedy of it is that mines are wasting assets and no matter how great an ore deposit may be, its life is limited. Vast and rich as were the leases held at Broken Hill by The Broken Hill Proprietary Co. Ltd. they were not inexhaustible, but long before they were reaching depletion the far-sighted men who controlled the destinies of the Company were considering how they could best employ its resources to the country's advantage. On $25^{\text {th }}$ August, 1911, the Chairman of Directors of the Company, the late Mr. John Darling, made the following announcement:

"With so large a concern, the Management is always fully taxed to keep well ahead of the times, and after careful consideration, having in view the necessary extension of your industrial operations, irrespective of mining, it has been decided that your General Manager (Mr. G. D. Delprat), in the interests of your Company, shall visit Europe and America, so as to have all the latest information, and if necessary, secure the service of experts, for the development of industries kindred to our resources, as yet barely touched upon.”

Mr. Delprat made his visits to England, Sweden, Germany and America. In USA he engaged Mr. David Baker, a consulting engineer with wide iron and steel works experience, to visit Australia and advise the Company on developments. After a thorough investigation Mr. Baker submitted a favourable report to the Board of Directors on June 29, 1912, and recommended Newcastle as the site.

These Directors were men of high courage. They wasted no time. On July 17, 1912, they sought, and on September 27 obtained, the sanction of the shareholders for the establishment of a steel plant at Newcastle. The project developed under the guidance of Messrs. Delprat and Baker. Australia owes a great debt to the wisdom, fore sight and skill of these two men.

In March of 1914 Mr. John Darling, Chairman of Directors of the Company since 1907, died. He was a man of great vision, ability and courage, and it was most deeply regretted that he did not live to see the commencement of operations of the works, in the initiation and development of which he had played such a major part. Mr. John Darling was a South Australian and his son, Mr. Harold Darling, later also became Chairman of Directors and has occupied that position for over twenty-five years. To the Darling family Australia 
is indebted for the foresight, energy and pluck that they have carried into the industrial development of this country.

The first shipment of iron ore from Hummock Hill (as Whyalla was then called) was made on January 8, 1915, when the S.S. "Emerald Wings" lifted a cargo of 2,500 tons, and on March 9, 1915, No. 1 Blast Furnace at Newcastle was blown in and the manufacture of pig iron commenced. Steelmaking in the open hearth plant started in the following month, as did also the rolling of the ingots to blooms, billets and rails.

The advent of the Newcastle Steel Works during the First World War was indeed providential. This plant made a valuable contribution to the production of munitions and other sinews of war.

\section{Location of operations}

\section{Whyalla and Iron Knob}

Whyalla, on the western shore of Spencer's Gulf, is the port of shipment for iron ore. The ore occurs in a series of hills running generally in a North and South direction - roughly parallel to the Gulf and distant some 30 miles from it. There are several deposits, the major one of which is known as the "Iron Monarch," and it is from this that most of the ore has been quarried. Quarrying operations are on a highly mechanized scale, electric power being supplied by a high tension transmission line from the power station at Whyalla. The foundations of the present mechanized operations were laid in 1928 and so suitable was the original conception that all subsequent developments have followed the same pattern.

From 1915 to 1937 Whyalla developed as an ore shipping port, but its growth was greatly accelerated in 1937 when a decision was made to erect a blast furnace there. Work was put in hand on August 17, 1938 A harbour was built, together with a deep water approach channel, and the blast furnace was erected adjacent to it. It commenced operations on May 26, 1941. Coke is shipped from Newcastle or Port Kembla and at present pig iron is supplied for the foundry trade of Australia and New Zealand and for export. 
The establishment of the harbour made possible another great development. On December 15, 1939, it was decided to establish a modern shipbuilding yard with five slipways. From this yard four naval vessels and twelve merchant vessels have already been commissioned. One of its more recent achievements was the launching on September 1, 1947, of a 12,500 ton turbine-driven orecarrying vessel, the S.S. "Iron Yampi," which is very largely Australian in design and construction. She completed her sea trials in May, 1948, and will shortly be commissioned. Three sister ships are now being built.

Whyalla has developed to a thriving community of some 8,000 inhabitants, based fundamentally on its adjacent ore deposits. It is a dry area, the average rainfall being of the order of 8 inches per annum. The necessity for an assured and adequate supply of fresh water, for both township and industrial purposes, was before the Company when it was making plans for the developments mentioned. The relatively small needs when the town was only an ore shipping port were taken care of by evaporation of sea water and catchment of the sparse rainfall in large dams and, more latterly, by the shipment of fresh water as ballast in ore steamers returning from Newcastle and Port Kembla. These methods could not cope with the greatly enlarged demands envisaged, and following negotiations between the Company and the South Australian Government, a 223 mile pipeline was laid from the River Murray at Morgan to Whyalla.

The idea of using water from the River Murray for supplying some of the drier areas of South Australia had occurred to many, but the achievement of this dream waited until the decision of The Broken Hill Proprietary Co. Ltd. to develop substantial industry at Whyalla. This water scheme is the result of cooperation between the State and private industry.

The importance of this assured fresh water supply to Whyalla can hardly be over-estimated. Additionally, much of the country traversed by the pipeline has an uncertain rainfall and water is now supplied to many of the towns and districts en route and the scope of this supply is being continually widened. This line provides a concrete example of the importance of water conservation to Australia and the results that accrue from well-planned schemes. 
Whyalla was pioneered and developed by The Broken Hill Proprietary Co. Ltd. which provided the usual municipal services. With the rapid growth of the township which came with the industrial developments mentioned, the need of a form of control which would give the townspeople a democratic interest in civic affairs was recognized. The Whyalla Town Commission Act was passed by the South Australian Parliament on December 14, 1944. Under this, the town is governed by a Commission of seven members - three elected by the townspeople, three nominated by the Company, and a Chairman appointed by the South Australian Government.

One other feature of the Whyalla township development worthy of mention is the "Employee Building Scheme" under which approved employees are assisted to build their own homes. This assistance is given if necessary to the full extent of the capital value. Over 500 homes have already been built under this scheme and more are now under construction.

The war effort of Whyalla was outstanding. The basic importance of its industries is obvious. The winning and shipment of iron ore, the production of pig iron and the building of ships were all pursued. Other work was done including the forging and machining of 25-pounder shells, the production of aero engine cylinders and a wide variety of tools and gauges. Towards the end of the war a modern electric steel plant and forge shop was erected on behalf of the Commonwealth Government to produce ordnance forgings. This plant did not come into actual operation, as hostilities were nearly over when it was ready; subsequently it has been taken over by the Company to form the nucleus of marine engine and boiler shops as an addition to the shipyard facilities. It is proposed to make reciprocating steam engines, steam turbines and reduction gearing, boilers, and diesel engines. Equipment for making turbine blading has been installed and a heavy machine shop provided with large modern gear-cutting equipment is being erected.

\section{Yampi Sound}

On the north-west of Australia is Yampi Sound. There on an island (Cockatoo Island), distant four miles from the mainland, occurs another of Australia's iron ore deposits. This is just being developed to the production stage by Australian Iron and Steel Ltd. 
Quarrying practice will be similar to that which has proved so successful at the "Iron Monarch" and the method of loading ships will be along the same lines as that at Whyalla, but the length of conveyor belt is much shorter as deep water is obtainable close along side the shore. There is a rise and fall of thirty-five feet in tide, and in order to minimize the drop of the ore into ships, the end section or boom of the loading conveyor is hinged and counterweighted so that it can rise and fall in unison with the tidal effect on the vessel. The whole of the jetty, including piles and superstructure, is of steel. This is an interesting development and represents the first all-steel marine structure in Australia.

The equipping of this deposit for fully mechanized operation is rather a triumph for Australian industry. Practically the entire plant is Australian made, the only major exceptions being diesel generating sets for power supply and the chassis of diesel quarry trucks. The 84 inch by 60 inch jaw crusher, built entirely at the Newcastle Steel Works, is the largest crusher ever made in the British Empire. The two 4-cubic-yard electric shovels are also entirely Australian made.

Situated 500 miles inside the Tropic of Capricorn, Cockatoo Island has an annual rainfall of about 32 inches, most of which occurs from November to March, and the climate is generally pleasant but warm. Houses for married men have been built and each has a mechanical refrigerator. Quarters for the single men include a fine mess-room and recreation block. Practically no flat areas are available, but tennis courts and a swimming pool are being provided, and in a garden, soil for which has been obtained from the mainland, vegetables and tropical fruits are being produced. Thus a community of some 250 people has been established in this remote area, based on this country's mineral resources.

\section{Rapid Bay}

Limestone is obtained from a fully mechanized quarry at Rapid Bay on St. Vincent's Gulf, 65 miles south of Adelaide. Work started on this deposit in 1940 as sufficient limestone from the Company's Melrose quarry near Devonport, Tasmania, was unavailable. The first shipment from Rapid Bay was made in September, 1942, and since then the major portion of the limestone requirements of Newcastle and Whyalla have been supplied from this source. It is an extensive deposit, forming part of the coastline, and after the stone has been quarried and 
crushed, it is delivered to a storage bin and thence by conveyor belt over a 1,600 feet jetty direct into steamers.

Rapid Bay is a rich pastoral district and a splendid village has been established adjacent to the quarry.

\section{Ardrossan}

A new venture has been started at Ardrossan on St. Vincent's Gulf to supply dolomite for the steel industry of Australia. The deposits are large and mechanized quarries and loading appliances are at present being developed.

\section{Coal}

Despite the many developments that have taken place and are proceeding in fuel and power generation - fuel oils, hydro-electric power and, more latterly, atomic energy - coal is still the "king" and an adequate and assured supply is vital to the maintenance and development of healthy industry. This is very true in steel-making, in which coal is not only the basis of the vast amounts of power and heat required, but is also essential for supplying the coke used in the blast furnaces. Not all coal is suitable for making good metallurgical coke, but Australia is fortunate in having reserves of coking coal located close to the eastern seaboard of New South Wales.

The coal deposits in other areas of Queensland, Western Australia and Victoria are in many cases excellent for steam raising and heat generation, but so far have not been used very much for making metallurgical coke. For some years after their establishment, the Newcastle Steel Works depended on purchases from outside sources for its coal requirements, but an adequate and steady supply was so essential to the Company that it was realized it would have to develop and control its own mines. In 1922 an exhaustive geological survey of the Newcastle and Maitland coalfields was undertaken and as a result of the information assembled a programme of colliery acquisition and development was commenced.

In the Newcastle field, two seams of coal suitable for coking occur - the Victoria Tunnel seam and the Borehole seam. In this area a holding of just over 
10,000 acres was obtained, and in 1925 work preparatory to the establishment of a modern colliery on this holding was started. It was named John Darling Colliery after the late Chairman of Directors of the Company, and now produces over 2,000 tons of coal per working day.

About the same time, the development of Elrington Colliery on the Maitland field was undertaken. This colliery is owned by B.H.P. Collieries Pty. Ltd. and is a joint enterprise of The Broken Hill Proprietary Co. Ltd. and Hebburn Ltd.

In furtherance of the policy of winning its own coal; the Company purchased in 1932 from the Scottish Australian Mining Company, Burwood and Lambton Collieries on the Newcastle field. They lie immediately to the north of John Darling Colliery. Burwood now has an output of about 3,500 tons per day and is the largest producing colliery in Australia. Similarly, Australian Iron and Steel Ltd. has acquired and developed collieries in the Southern Coalfield of New South Wales. In this field also, two seams of coking coal have been exploited - the Bulli or No. 1 seam and the No. 3 seam.

Until the early 1930's practically all coal won in Australia was hand mined. It was about that time that ideas for winning coal by machinery were being crystallized in USA, where conditions in some coal mines were quite similar to those in Australia. It was decided to develop Lambton Colliery along the lines of the then most recent American practice and in 1935 operations commenced in the Victoria Tunnel seam of this mine on a fully mechanized basis. Following the successful application of those methods at Lambton, similar practices were introduced at John Darling and Burwood Collieries. A large programme of reorganization and development is now under way in the coal properties of Australian Iron and Steel Ltd., involving an expenditure of over $£ 4$ million in opening up new collieries and modernizing some of the older mines.

The benefits of mechanized coal-mining are very clear and the day is not far distant when practically all the coal required by the steel industry will be won by machines. This colliery mechanization has had to take place during the war years, when procurement of equipment from USA has been virtually impossible. Consequently, machines and equipment have been developed and manufactured 
locally to such an extent that a modern mechanized colliery can be established in Australia fully equipped with locally made equipment.

Mechanization has enabled the winning of more coal per employee, but other important benefits to the industry have followed. Firstly, mechanized mining is safer. The winning of coal quickly has reduced the possibility of falls of rock and the dust problem is more easily controlled, thereby overcoming any health hazard from this source.

Secondly, mechanized mining has changed the whole conception of the miner 's craft. He has become a skilled operator of a high grade machine, and tribute must be paid to the adaptability Australian miners have exhibited in this change over. In order to train young men entering the coal industry, the steel companies have taken the lead in establishing miners' schools. In September, 1947, a school was commenced at Burwood Colliery and soon one will be opened on the southern New South Wales coalfield. Youths about to enter the industry are given three months' theoretical and practical instruction in their craft and are paid Award wages during the training period. The initial success of the Burwood school is most heartening.

\section{Other raw materials}

Apart from iron ore, limestone and coal, there are other raw materials essential to steel-making, although their usage in quantity is not very great. Most of these raw materials are obtained in Australia and in this respect this country is as selfcontained as practically any other steel-producing nation. These other raw materials include dolomite, magnesite, quartzite, refractory bricks and bauxite, which are all obtained from Australian sources. Many alloying elements are required in the steel industry. Of these tungsten, zirconium and titanium are available in abundance from local deposits. Manganese, chromium, molybdenum, nickel, aluminium and vanadium are all usually imported, although some deposits of the first three occur in Australia, which, while not large, can be of use in times of stress. 


\section{Newcastle Steel Works}

With a productive capacity of 20,000 tons of steel ingots a week, the Newcastle plant is one of the largest steelworks in the British Empire. Included in the Works are facilities for making the rolls for the rolling mills, ferro alloys, magnesite bricks and a substantial proportion of the machinery and equipment. In the more highly industrialized countries, such as England or USA, specialized separate firms exist for performing these services.

The plant embraces 161 by-product coke ovens, three blast furnaces, 14 basic open hearth furnaces in the main open hearth shop, a 35 inch blooming mill and various other rolling mills capable of producing a wide variety of structural sections, plates, merchant bars and rods, and also a cold rolling plant producing cold rolled strip in narrower widths.

There are also several engineering shops which serve to maintain the production departments, to build new equipment for the Works and for associated companies and in some cases where help is needed, to supply the needs for other Australian industries. These shops include a large machine shop, a tool room, a fabricating shop, an electrical shop as well as a complete range of other auxiliary service shops.

In the steel foundry which is equipped with two 35-ton open hearth furnaces, one basic and one acid, steel castings in size up to the largest made in Australia are produced. These furnaces also provide steel for the manufacture of rolls. As a result of this development of the manufacture of rolls in this country, Australia is completely independent of overseas sources for its roll needs. Iron and brass foundries are also operated to supply castings used in operation, maintenance and construction.

Prior to 1939 all the ferro alloys required in Australia were imported, but it was realized that disruption likely as a result of war would place requirements in jeopardy. As a result of preliminary steps taken in 1939, a ferro alloys plant commenced operations towards the end of 1940 and has since supplied all the major ferro alloy needs of the country, as well as quantities for export to Allied nations during the war. 
The fundamental connection between the main products of the Newcastle plant - iron and steel - and the war effort is obvious. Suffice it to say that during the war years the Steel Works produced record tonnages. Without them there could have been no shells, no guns, no ships, no armoured vehicles, in fact without them there could have been very little munition effort. Many other projects were undertaken, including the manufacture of magnesium, machine tools, shot and shell, steel barges and ocean-going tugs.

Early in the war a world shortage of magnesium occurred and all local manufacture became a necessity, the Company installed a plant at Newcastle which commenced operations on July 21, 1941, and during the war years produced over two million pounds of magnesium and magnesium alloy ingots and over half a million pounds of magnesium powder. This achievement was made possible by the generous co-operation of Murex Limited of England who supplied designs and operating data. The plant has since been demolished, but the technique of magnesium production has been mastered and the foundations for an industry laid.

As a large number of the machine tools for the munitions programme were not available from abroad, plans were made to produce them in Australia. The Newcastle Steel Works made a valuable contribution, including the production of 40 precision milling machines for which drawings had to be made for each individual part from prototype machines, three large plano-millers, 10 optical profile grinding machines, and many parts for tools and presses made elsewhere.

The machine shops and foundries made a great range of other machines and parts, including 3,500-horsepower marine engines, large hydraulic heading presses, one 2,000-ton forging press and many other items.

Prior to the war, in 1936, the Company considered it advisable to secure experience in shell production and to have a plant ready in the event of emergencies. Entirely at its own expense it equipped a machine shop at the Newcastle Steel Works and in 1938 work commenced on 18-pounder shells. A production rate of 4,000 shell bodies per week was achieved before this shop was replaced in May, 1941, by a new annexe which made 25-pounder shells. 
The Company provided the building and services for this new plant. A production rate of 30,000 shells per week was achieved and when the annexe ceased work on June 25, 1943, a total of one and a half million shell bodies had been produced.

In January, 1941, the Ministry of Munitions asked the Company to undertake the manufacture of armour-piercing shot. Again the Company provided at no cost to the country the building and services, and in addition, evolved the manufacturing procedure and designed and made much of the equipment needed.

To assist in meeting the need for barges and other small craft required in the Pacific war theatre, the Company undertook the manufacture of steel lighter barges of welded construction and having a displacement of 80 tons. A total of 164 barges was supplied. The Company was also asked to manufacture 75 foot all-welded ocean going diesel tugs. The first tug was commenced in September, 1944, and launched in December, 1944. Fifteen tugs were completed, eight for the U.S. Army and seven for the Royal Navy.

Another achievement was the development of a process for the manufacture of tungsten carbide, and the installation of a plant for its production. Tool tips from this plant were required in munitions annexes for machining shells and other armaments.

\section{Australian Iron and Steel Limited}

The history of the Hoskins Iron and Steel Co. Ltd., of the establishment of a Works at Port Kembla, and the subsequent merger with The Broken Hill Proprietary Co. Ltd. has already been outlined.

The Port Kembla Steel Works have an annual ingot capacity of 700,000 tons. There is a battery of 72 by-product coke ovens with an additional 48 now in the course of construction, two blast furnaces, having a combined capacity of 14,000 tons of pig iron a week, and seven basic open hearth furnaces ranging in capacity from 150 to 240 tons per heat. The rolling mills include a 42 inch blooming mill, a 36 inch structural mill, a 21 inch billet and sheet bar mill and 
a 10-13 inch merchant bar mill. A new merchant bar, rod and strip mill which will produce light merchant bars, narrow strip, coiled rounds and rods for wire drawing is being built. There is also a spun pipe plant which produces centrifugally cast iron pipes. Ancillary shops and services along somewhat similar lines to the Newcastle Steel Plant are also provided.

The Port Kembla Works' special contributions to the war effort included the establishment of a forge shop which produced approximately 22,000 tons of forgings consisting largely of gun barrels and other ordnance parts, and marine forgings. An electric steel plant was erected, its primary purpose being to supply forging ingots for the forge plant. A special machine shop was installed for machining and testing gun barrels. Most of the machines for this shop were made by the Company. The normal steel plant machine shop was greatly expanded and many machine tools, marine engines and ordnance parts, as well as a great number and variety of tools, and gauges were produced. Some of the outstanding items produced in the machine shops were: eight 1,500-ton hydraulic presses, eight cold rolling mills for non-ferrous strip, 239 lathes of various descriptions and sizes and four large triple expansion marine engines.

\section{Subsidiary and allied industries}

There are several other companies closely associated with the principal steel producers. They play an important part in national development and their war effort was no less valuable.

Rylands Bros. (Aust.) Pty. Ltd.: Located at Newcastle, this plant has a capacity of 1,400 tons of wire products a week ranging from fencing wire, barbed wire and wire netting to special alloy wires and wire for wire ropes. It also produces nails and star steel fence posts. Rylands products were in great demand for the war effort. Barbed wire and fence posts for entanglements, wire for wire ropes and numerous naval and marine uses, aircraft control wires, landing mats, core wire for armour piercing bullets, wire for ball bearings, spring wire and bolt and rivet wire were manufactured. The Company also installed equipment and undertook the manufacture of bren gun magazines, cleaning rods for rifles and machine guns, and 2-pounder ammunition links. 
Lysaghts Works Pty. Ltd.: This Company manufactures galvanized and black steel sheets at both Newcastle and Port Kembla and their combined capacity is in excess of 250,000 tons of sheets per annum. Steel sheets played an important part in most phases of war production and defence. Their uses ranged from air-raid shelters and sheets for buildings to bullet-proof sheets for armoured vehicles and aeroplane and naval uses; also such highly technical products as special silicon sheets for electrical equipment. In meeting these needs, Lysaghts Works produced record tonnages. In a shop erected for the purpose, the Newcastle plant produced 480 aircraft spinners for Lincoln and Mosquito aircraft. Newcastle and Port Kembla plants were responsible for the production, in special annexes, of 45,000 Owen sub-machine guns. An outstanding achievement was the production in conjunction with The Broken Hill Proprietary Co. Ltd. of 23,780 tons of bulletproof plate in thicknesses from one-sixth of an inch to one inch and a quarter for armoured fighting vehicles.

Commonwealth Rolling Mills Pty. Ltd.: The sheet rolling plant of this Company was established at Port Kembla in 1939 to produce high quality sheets for such uses as motor car bodies, refrigerator cabinets and enamelled ware. Plans are in hand for the extension of these works to include an 80 inch reversing cold mill, so that these cold reduced sheets may be supplied for modern motor car bodies.

Stewarts and Lloyds (Aust.) Pty. Ltd.: Established in 1934 to produce buttwelded tubes up to 3 inch in diameter, this plant has expanded rapidly. In 1940 a push bench plant went into operation for the production of seamless tubes for such purposes as high pressure steam and boiler tubing, bore casing, oil line piping and feed for the tube drawing industry. In 1945 this Company installed a second push bench plant at Adelaide.

Believing that war was becoming imminent, the Company, entirely on its own initiative, in 1938 undertook the installation of special equipment for the manufacture of shell forgings. When operations finally ceased, this plant had produced over 3,000,000 25-pounder shells and over 750,000 other types. In addition, about 122,000 forged steel aircraft cylinder barrels were produced in the Newcastle push bench tube plant. This was a great contribution to the development of aircraft engine production in this country. 
British Tube Mills (Aust.) Pty. Ltd.: In February, 1939, this Company established works in Adelaide for the production of cold drawn tubes, electrically welded tubes, bicycle rims and manipulated tube items. It also installed equipment for the manufacture of gas "bottles" such as containers for compressed oxygen and acetylene. The production of these works proved of tremendous value to the war effort and without it many of the Australian wartime munitions projects could not have been accomplished.

Commonwealth Steel Co. Ltd.: Normal productions of this Company are diverse and varied, including steel castings; steel forgings; railway axles, wheels and tyres; forged steel balls; a wide range of special alloy steels in bar and sheet form, including tool, stainless and heat resisting steels; and hollow drill steel.

An astonishing number of defence items were produced during the war. Although its normal operations are closely related to any defence programme, the Company encompassed a much wider field. One of the most important contributions was the production of ordnance forgings including nearly 14,000 gun barrels in various sizes from 2-pounder to 8 inch naval guns and almost 15,000 forgings for breech rings and breech blocks. A special annexe produced armour piercing shells - the first of their type made in Australia - and other equipment was installed for the manufacture of nearly two million protective steel helmets, requiring 4,290 tons of bullet proof manganese steel.

The Australian Wire Rope Works Pty. Ltd.: This Company's products range from small, fine wire strands to the large heavy ropes used in the mining industry. These products played an important part in the war effort, and it was also necessary to make many new products including aircraft cables of which 17 million feet were produced, strand for field telephone cables, mine mooring rope, mine sweeping rope, camouflage net rope and strand for harbour defences.

Newcastle Chemical Co. Pty. Ltd.: Established at Newcastle in 1940, this Company manufactures certain chemicals essential to the steel industry and utilizes products of that industry for the production of other chemicals. Phthalic anhydride is an important product. During the war it was used as a plasticiser for nitro-cellulose lacquers for aircraft and also for making di-methyl phthalate used as a mosquito repellant. 
Lysaght Bros. and Co. Pty. Ltd: Located in Sydney, these Works produce wire netting, barbed wire, nails and also zinc oxide for rubber manufacture and paints.

B.H.P. By-Products Pty. Ltd.: Normal products marketed by this Company include various grades of road tar, tar oils, pitch, pre mixed tar macadam and napthalene. During the war an important part was played in the construction of aerodromes and landing strips throughout the Commonwealth.

Titan Nail and Wire Pty. Ltd.: This Company produces nails and barbed wire from its South Melbourne and Hobart factories. At Hobart a factory has been established for the production of wood chisels and other hand tools, including auger bits and screw augers. Plant was installed early in the war for producing aluminium and other non-ferrous rivets for the aircraft industry.

\section{The aircraft industry}

Commonwealth Aircraft Corporation Pty. Ltd.: The steel industry has a very close association with this Company. Early in 1935 discussions took place with representatives of some large Australian companies which resulted in the formation of a syndicate, the purpose of which was to investigate the establishment of an aircraft manufacturing industry in this country. A technical mission was sent overseas early in 1936 to study manufacturing technique and to select a suitable type of plane for manufacture. In October, 1936, the syndicate formed the Commonwealth Aircraft Corporation Pty. Ltd. at the specific invitation of the Commonwealth Government. This Company successfully achieved its objective in establishing in Australia the mass production of aircraft and aero engines.

The initial aeroplane manufactured was an American type and the first machine was flown on 27th March, 1939, five months before the outbreak of war. The Australian machine was known as the Wirraway. 1,316 planes have been produced, made up of 757 Wirraways, 200 Wackett Trainers, 250 Boomerangs and 109 Mustangs. Pratt and Whitney engines were made for many of these aeroplanes.

The initial selection of an American type of aircraft proved to be a happy choice, since the US Army Air Force was able to have a large number of its aircraft 
and engines overhauled and assembled in this country. Without these services they would have been severely handicapped in their Pacific war effort.

Were it not for these Australian-made planes, Australia could not have turned out more than a fraction of the number of air crews actually trained for the R.A.A.F. and the R.A.F. The Corporation's pioneering of aero engine manufacture in this country was an outstanding effort of the war.

\section{Other associated industries}

In addition to those Companies already mentioned, others with which the steel industry is associated and which it has assisted to develop are: Structural Engineering Co. of WA Pty. Ltd., a steel fabricating company with works on the outskirts of Perth, WA; Wiltshire File Co. Pty. Ltd., manufacturers of files and cutlery, near Melbourne; Southern Portland Cement Ltd., manufactures cement at Berrima, NSW; Rheem (Aust.) Pty. Ltd., manufacturers of steel drums and pails and household appliances, with works in Sydney, Melbourne, Brisbane and Fremantle.

In outlining the history of the steel industry and in describing it as it is today, it is hoped that many of the factors making for its importance have been made apparent and give some idea of its usefulness in peace and war.

\section{Employment and wages}

The steel industry is Australia's greatest provider of employment. For the year 1947, there were some 29,000 employees engaged by the major steel companies and their allied and subsidiary industries. The pay-roll for that year amounted to almost $£ 12.5$ million and the average weekly earnings per employee was $£ 83$ s. $0 \mathrm{~d}$. The figures represent only the direct employment of the industry and would be much expanded if those who gain their employment indirectly were added.

\section{Government revenue}

The steel industry contributes greatly to Government revenue, both State and Federal, and it does this in many ways, but chiefly in the form of taxation and as royalties on the various raw materials. During the past ten years the industry, 
as described in this lecture, has borne an aggregate of over $£ 19,000,000$ in direct taxation, this figure not including sales tax paid on purchased goods. Taking the case of The Broken Hill Proprietary Co. Ltd., the incidence of income tax has increased from $£ 420,000$ in 1938 to $£ 1,475,000$ in 1947 . When other direct taxes are added, the total tax contribution by this Company alone in 1947 is about $£ 1,605,000$. This is equivalent to $£ 115$ s. $4 \mathrm{~d}$. per ton on marketable iron and steel products made in that year. In addition, over the past ten years the steel industry has paid as royalty on raw materials which it has won itself - coal, iron ore and limestone - the sum of $£ 865,000$. If steel were imported none of this money would be received by the Government.

\section{Purchases}

The annual value of purchases by the steel industry under current conditions is:

\begin{tabular}{l|l}
\hline Direct imports & $£ \quad 938,927$ \\
\hline Local purchases & $11,627,296$ \\
\hline & $£ 12,566,223$ \\
\hline
\end{tabular}

These purchases include materials, freights, services, etc., but inter-company transactions between the Companies within the group are not included. It is not difficult to see the great importance of the steel industry as a customer within Australia.

\section{Prices}

It is well known that Australia is provided with low-priced iron and steel. To illustrate that point, the following typical examples are quoted: in January, 1948, the price of Foundry Pig Iron in the United Kingdom was $£ 12$ 3s. 6d. per ton, in USA $£ 11$ 5s. per ton, and in Australia $£ 6$ 15s. per ton. Merchant Bars in England cost $£ 24$ 9s. 5d. per ton, in America $£ 20$ 6s. per ton, and in Australia $£ 14$ 2s. 8d. per ton. The English prices are delivered prices at consumers' works in the United Kingdom. American prices are for delivery F.O.B. at various basing points, whilst Australian prices are C.I.F. main Australian ports, and all figures have been reduced to Australian currency at current rates of exchange. That Australian prices for steel products are low is due to a variety of factors including grade and 
location of raw materials, efficiency of operations, and skill and application of technicians and workmen.

It is necessary, however, to give thought to the future and seriously consider where present trends may lead. Shorter hours of work are now the order of the day and in a young country like Australia with so much to be done it behoves everyone to increase efficiency and counteract the loss in productivity and increase in costs that must inevitably follow these tendencies.

Taking the year 1947 as an example and assuming that there was no production of iron and steel in this country, the Australian consumer would have had to pay $£ 15,000,000$ more for his steel supplies if those actually produced at the Newcastle and Port Kembla Steel Works had been imported from the United Kingdom. This is purely a hypothetical example because, in point of fact, supplies were not available from overseas and the local user would have had to go without.

\section{Availability of steel products}

The importance of the availability of steel products for both normal and special demands is not always realized. When requirements must be imported the supply position is relatively inflexible because it is difficult to carry large stocks. With the source of supply near at hand, special requirements can be catered for at much shorter notice. The price structure and availability are subject to Australian conditions and not to factors quite separate from the Australian economy.

It is of interest to consider a few statistics of world steel production. The annual capacity of various nations for the production of steel ingots and castings at the end of 1947 was estimated to be:

\begin{tabular}{l|l}
\hline & Million tons per annum \\
\hline USA & 84.5 \\
\hline Great Britain & $14-15$ \\
\hline Canada & 2.7 \\
\hline Australia & 1.75 \\
\hline India & 1.3 \\
\hline South Africa & 0.6 \\
\hline
\end{tabular}


The estimated world production of steel in 1947 was 140 million tons. Therefore, USA produces more steel than the rest of the world put together. This is indeed a marvellous achievement - USA has only 6 per cent of the world's people and 7 per cent of the land area, but she produces over one-third of the marketable goods of the world and does this under a system of free enterprise.

Some figures showing various countries' annual steel-producing capacity per head of population are also interesting. These are as follows:

\begin{tabular}{l|l}
\hline & Tons per head \\
\hline USA & 601 \\
\hline Belgium (1939) & 445 \\
\hline Germany (1939) & 306 \\
\hline Great Britain & 300 \\
\hline Australia & 246 \\
\hline Canada & 229 \\
\hline
\end{tabular}

These figures indicate that Australia is well to the fore in its industrial development.

At present there is a world shortage of steel. Germany and Japan, both substantial producers pre-war, are producing comparatively very little. Belgium and Luxemberg are exporting relatively small quantities. A recent letter received from the USA contains the following paragraph:

"The steel companies in the States are right up against it and not able to take care of their customers for any line of their products and especially pig iron."

Without its steel industry, Australia would have practically no supplies of steel and, relatively speaking, it is better off than other countries. It is true that Australian demands for steel are now very heavy and the steel producers could do much more to meet these were it not for shortages of coal and labour. Producing facilities are there and the coal mines are capable of producing all the necessary coal with some to spare. Instead of operating at a rate of 1.75 million tons of ingots per annum, the steel industry in 1947 produced only about 1,200,000 tons of ingots. 


\section{Export potential}

In view of its favourable price structure and of Australia's proximity to the Eastern markets which are importers of steel, this country is in a sound position for the development of a strong export trade in iron and steel.

New Zealand is an important Australian market, but so natural is it to supply the needs of that dominion, that it is not considered as an export market - rather as a development of the domestic market. New Zealand is dependent on Australia for a high proportion of her steel requirements and her needs are given special consideration.

During 1939, approximately 155,000 tons of steel were shipped to the United Kingdom and this quantity included 118,000 tons of sheet, bar and finished sheets for use in the construction of Anderson air raid shelters. During the early years of the war, approximately 225,000 tons of re-rolling billets were shipped to the United Kingdom to supplement her steel supply. Since the war, Australia has been able to assist Great Britain in the need for steel by supplying approximately 112,000 tons of blooms, billets and slabs. Enquiries are constantly being received from all over the world.

It is interesting to note, that 30,000 tons of pig iron from the Whyalla blast furnace have been sold to USA this year, forming a source of much-needed dollars. Already a substantial portion of this order has been shipped and further orders are likely.

There is little doubt that this export business will increase and flourish as the years go on, thus adding to the wealth of this country. It is not only in pig iron and steel products that this can be anticipated. The fact that Australian secondary industry can secure its requirements at favourable prices, is a substantial factor in aiding the export of manufactured goods.

\section{Defence}

In describing the various activities of the steel industry, many references have already been made to the part played in the war effort, and the importance of 
regular supplies of iron and steel to a nation at war has been mentioned. Truly, the steel industry is fundamental to the defence of the country.

Mr. J. K. Jensen, Secretary of the Ministry of Munitions, delivered an address to the Institute of Industrial Management in Melbourne on June 1, 1943. The title was "The Development of Munitions Production in Australia." In it he said:

"The basic material in our munitions industry is, of course, steel, without which it simply could not exist, and there is consequently a close collaboration between the steel industry and the Department of Munitions. Details of the production cannot be given, but it can be said that we are almost entirely self-contained, and that byproducts of the steel industry help to meet very important chemical requirements. The Australian steel industry has also assisted in the war effort abroad by its exports to the United Kingdom, to the Dominions, and to the United States.”

A little later on in his address Mr. Jensen went on to say: "Our shell steel was invoiced to us at $£ 9$ per ton, but we were getting a rebate of $17 \mathrm{~s} .3 \mathrm{~d}$. per ton when all the costs had been worked out, so that until quite recently we were paying only $£ 82 \mathrm{~s}$. $9 \mathrm{~d}$. for our shell steel. Consequently, notwithstanding the march of time and the change of conditions since 1915, we were paying nearly two pounds per ton less for shell steel than in the last war.

However, the Prices Commissioner stepped in a few months ago and ruled that as all steel now being produced was being used in the war effort, the munitions orders should not be getting preferential rates, and that all steel prices should be equalized. Concurrently a general advance in steel prices was ordered, the first since the outbreak of war, and thus our shell steel was now to cost us $£ 111 \mathrm{~s}$. $7 \mathrm{~d}$. per ton. But if comparisons are desired, the equivalent British shell steel is costing $£ 19$ 15s. 11d. in Australian currency; hence we are better off to the extent of $£ 814 \mathrm{~s}$. $4 \mathrm{~d}$. for every ton we purchase. American prices are about $£ 2$ per ton higher." 
One major factor of the munitions war effort was the establishment of large factories which are now engaged in useful peace-time production. Notable advances were made in the skill and technique of Australian industry generally and these are being applied to the benefit of normal peace-time industry. It has made possible a much wider range of manufacture and there has been a more diversified spread of scientific and technical knowledge. With the building of these modern factories, great improvements in working conditions were attained.

\section{Other phases of the steel industry}

It is natural that there are many activities which, while in themselves not directly connected with the processes of making steel, are essential to the smooth functioning and development of the industry.

Education: The steel industry has fully recognized the benefits to the nation of adequate and well-staffed educational facilities. Perhaps the contributions that have been made to the betterment of education can be divided into two categories, the things that have been done to aid education generally, and the Staff Training Scheme of the industry itself.

Wherever The Broken Hill Proprietary Co. Ltd. has operations it has regarded itself as having a trust to foster the facilities for the youth of the district to gain in knowledge. At Newcastle there is a fine technical college, one of the finest in Australia. Towards the cost of this college, the steel industry has donated handsomely. Senior officers of the Company assist in the administration of the college and many of its staff assist by teaching. At Whyalla there is a very fine Technical High School which was opened in 1943, towards the cost of which the Company contributed its full share.

In the no less important spheres of schools for the boys and girls, the Company has done much to foster and assist the State Schools at Whyalla, Iron Knob and other centres. At Yampi it provided the school building, and just now a modern permanent structure is being erected.

In the broader spheres, the Universities of the Commonwealth have been assisted. There is also the "Staff Training Scheme" of the industry. It has been 
the policy of the Company for many years to encourage its officers to prepare themselves for promotion and to afford them opportunities for wider experience. In furtherance of this policy a staff training scheme was inaugurated in 1926.

There are four main categories into which employees under this scheme may be divided. These are Cadets who are young men holding either University Degrees or approved Technical College Diplomas, Trainees who are young men with Leaving Certificates and undertaking an approved Technical College Diploma course, Commercial Trainees and Trade Apprentices. The Company gives those young men in its Staff Training Scheme the utmost encouragement to progress and refunds tuition fees provided the trainees maintain a certain standard. At the present time there is a total of 1,883 young men undergoing training. It is very pleasing to be able to record that, practically without exception, every high administrative position in the Company in recent years has gone to a graduate of this Scheme.

Housing: From the description of the Employees' Building Scheme in operation at Whyalla given earlier, it will be appreciated that the steel industry recognizes the necessity for good homes for its employees. Different methods of providing homes are adopted to suit different circumstances and localities, but always the principle is that the homes should be of good standard and not just houses.

At Port Kembla a somewhat similar housing scheme to that at Whyalla has recently been inaugurated. At some other places a scheme of this nature is not quite so applicable. Thus at Rapid Bay the Company is providing all the necessary houses and these are made available to employees at relatively low rentals. The houses at Rapid Bay are of the same type as those described for Whyalla and they make quite a picture in a fine setting on the shores of St. Vincent's Gulf. Similarly, at Cockatoo Island, the Company is providing the homes at low rental terms to employees, and here they have been built having in mind the semitropical conditions on the island. Each home at Yampi Sound is provided with a mechanical refrigerator and also an electric stove.

Amenities: The steel industry has taken great interest in the well-being of its employees and to this end many steps have been taken to improve working conditions and to provide amenities, both on and off the job. In the provision of well-equipped change houses, the industry has been to the forefront. 
Safety: The steel industry has a carefully organized safety campaign which is maintained by Departments specially set up at the various Works for this purpose. Constant effort is made to focus the attention of all on "Safety First" principles and, in addition, attention is given to the design of all buildings and equipment from a safety angle. Some accidents do happen, and to do everything possible to minimize their effect, suitable ambulance and first aid stations are set up.

Tree Planting: Another thing that the steel industry has fostered is tree planting, and it has done this particularly at Whyalla and Iron Knob. The same pattern is being followed at Rapid Bay and Yampi Sound. At Newcastle and Port Kembla the planting and tending of trees and shrubs has greatly added to the beauty of the Works and the district.

Good Housekeeping: Cleanliness, orderliness and pleasant surroundings have a definite place in industry, leading as they do to efficiency and better working conditions. In these matters the Australian steel industry has set a high standard. The old idea of dirt and smoke being unavoidable adjuncts of steel-making has vanished. Operations are carried on in clean and tidy conditions more often associated with the gentler arts.

Service: This word covers a wide field, but here it is used in the restricted sense of service to industry outside the normal business of supplying iron and steel products. The major producing companies of the steel industry maintain staffs of trained metallurgists whose sole duties are to assist users of steel and, in fact, industry generally.

Mention should be made of service in a still wider sphere. Due to its varied activities the steel industry has built up a staff of specialists in many industrial arts - mining, both metalliferous and coal, shipping, engineering, metallurgy and commerce. Frequently assistance is freely given in response to calls received from other industries and from Governments. It is regarded as a pleasure and a duty to help in the development of Australia.

Suggestions: Comprehensive schemes are in operation at most of the Works for encouraging suggestions from employees. Special committees consider all suggestions put forward and where they are adopted, bonuses are paid. 
Research: The steel industry has a staff of skilled metallurgists, chemists and engineers. In addition, an eminent scientist from England has been engaged and he has been given the charge of developing research activities. A fine large building at Newcastle is planned, equipped with modern tools and instruments.

\section{The future}

This year is historic, as it is the centenary of the establishment of iron smelting in this country. It was in March, 1848, that the first iron was produced at Mittagong. A lot has been achieved since that time.

Long-term planning is necessary for the progress of the industry and great capital expenditure is necessary for the development of raw materials, and the provision of coke ovens, blast furnaces, open hearths and rolling mills to bring about substantial additions to ingot tonnage. Private industry, with its continuity of policy, has made possible this long-term planning.

One of the principles of democratic government is change. The people must have their say at regular intervals and this makes impossible continuity of planning for industrial development. Many confusing statements are made about public ownership and nationalization and perhaps this point is one of importance in assessing the benefits of what is termed "private industry".

The steel industry has its plans for the future and some of them have already been mentioned, including the building of four 12,600-ton "Yampi" class ore vessels, the equipping of the Cockatoo Island iron ore deposits, the development of collieries on the southern New South Wales coalfield and the building of coke ovens and a merchant bar and strip mill at Port Kembla. All these projects are in hand.

The greatest undertaking of all - in magnitude and complexity - is the plan for the erection of a hot and cold strip mill and tinplate plant at Port Kembla.

In Australia, the rolling of sheets was undertaken by hot methods then in vogue overseas and the plants of Lysaghts Works Proprietary have been developed with this practice. Developments overseas, particularly in USA, since the early 
1930's have been in the direction of continuous rolling of flat products. The steel is first rolled into a long band or strip in hot mills and then further reduction is done cold, after which the strip is cut to length to individual sheets.

This project at Port Kembla means that this new method of rolling will be introduced into Australia. It will add greatly to the country's capacity for plate and sheet products and will make possible the production of the only major steel item not at present produced here - namely, tinplate.

This plant will require steel to feed it, power to drive it, and facilities for handling and shipping the finished products. It is a very large undertaking and its completion date cannot yet be estimated, but designs have been obtained from America and the project is now under way.

At the Newcastle Steel Works, additional rolling facilities to cater for the expanding demands for pipe skelp and rods for wire are in the planning stage. These are large installations and are dwarfed only by the big developments at Port Kembla.

Stewarts and Lloyds (Australia) Proprietary Ltd. are now installing another butt-welded tube plant at Newcastle, thus practically doubling their capacity to produce this type of pipe.

A modern wire mill is to be erected at Geelong in Victoria by Rylands Brothers (Australia) Proprietary Ltd. This is planned to augment the output of wire for both primary industry and for manufacturing purposes. The Commonwealth Steel Co. Ltd. is planning a new forge shop at Waratah, near Newcastle, in which will be installed a 5,000-6,000 ton forging press obtained by the Commonwealth Government as reparations from Germany.

The Broken Hill Proprietary Company is now planning a development of peculiar significance to South Australia, namely the establishment of a steel works at Whyalla, thus further aiding the scheme of decentralization.

When the Newcastle Steel Works were established, it took approximately one and a half tons of ore and three tons of coal to make a ton of finished steel. 
Obviously, the economics were in the direction of taking the ore to the coal. In the intervening thirty years, tremendous strides have been made in the art of fuel conservation and nowadays an Australian steel works takes about one and a half tons of ore and one and a half tons of coal to make a ton of finished steel. The economic situation has therefore changed and it becomes a practical proposition to carry the coal to the ore under some circumstances.

This Whyalla development will involve the erection of coke ovens, open hearth facilities and rolling mills - in fact, a completely integrated Steel Works. The nucleus already exists in the wharf facilities, blast furnace and machine shops and, with a large clear area of land available, there is the opportunity to lay out a fine modern plant. Before the works can be built it will be necessary to conduct negotiations with the South Australian Government for further supplies of fresh water.

The planning of this works will take some years, and in any case, other more urgent work has to be undertaken at present. With the present dearth of men and materials it is impossible for any active erection to commence; indeed, at Whyalla today there are insufficient men to maintain the shipbuilding programme.

The South Australian Government is always most co-operative in industrial progress and tribute is paid to the part played by the Premier, the Honourable Thomas Playford. He has taken a great interest in Whyalla and has been most helpful in its development.

\section{Conclusion}

In concluding, praise should be given to the pioneers, Australian executives, technicians and workmen who have played their great part in building up this industry, which is mainly manned, from the highest executives to the youngest apprentice, with native born and educated Australians. The workman in the industry is an excellent man and there is no better workman than the Australian. $\mathrm{He}$ is well endowed with initiative and a sturdy independence of spirit which augers well for the country's future. 
In giving recognition to what Australians have done, it is a source of pleasure to acknowledge the great debt owed to the older nations, particularly Great Britain and the USA They have been truly generous in their aid. Designs, technical assistance and equipment have all been forthcoming when needed and the friendly help and advice given to officers who have visited abroad are truly appreciated. In fact, one of the highlights of Australia's industrial development is the kindly relations with overseas friends.

The industry is largely Australian owned, largely managed and staffed by Australians, and finds its major raw materials in this country. Perhaps it will be agreed that its products and services are of first-rate importance to the country, both in peace and in time of war. 



\section{4}

\section{The economic consequences of scientific research}

\section{John B. Condliffe ${ }^{1}$}

The invitation to deliver this Lecture on the Joseph Fisher foundation came to me in California. The honour and privilege of delivering such a Lecture in the land of my birth moved me very deeply. I was so pleased to have my name added to the list of those honoured by the University of Adelaide that I wrote at once to accept the invitation. In my haste I sent a title which I do not find easy to justify. If I had taken more time to reflect, I might not have ventured upon such a title; but once sent, I could hardly recall it.

I must begin, therefore, with a series of limiting definitions. Economists have been tempted to talk of the economic consequences of something or other ever since Mr. Keynes, as he then was, used the phrase to describe some unfortunate aspects of the peace treaties that ended the first world war. A young Frenchman who was killed in the second world war turned the phrase on Keynes himself. Before that, Keynes had entitled one of his most effective tracts, "The Economic Consequences of Mr. Churchill.” I submit to you that in 1925 no one could have foreseen the consequences of Mr. Churchill - political, literary, oratorical, strategic or economic. There are some phenomena whose consequences are incalculable. Mr. Churchill is one of them. Scientific research is another. The best one can do is to single out some of the more obvious influences such phenomena seem likely to exert in specific fields of human action. Keynes wrote his pamphlet to stress some economic aspects of a particular decision by Mr. Churchill: the decision in 1925 to restore sterling to its old parity with the dollar. I use the phrase economic consequences in this Keynesian sense. What I am concerned

1 Twenty-fourth Joseph Fisher Lecture, 8 September 1950. 
with is the tremendous recent spurt in scientific research and some of the more immediate consequences of its application to the working and living conditions of people particularly in the United States of America.

As words go, research is very new, and the particular meaning given to it in our own time is even newer. This is because the operations described by the word have changed. Research has come to mean the systematic pursuit of new knowledge, particularly in the experimental sciences, and usually by cooperative groups or teams of trained specialists. In any great university one soon becomes aware of these specialist groups. They are mostly young men working under the leadership of a scholar whose researches have led him into a promising field of inquiry and who in consequence has been able to secure funds to pursue it. These young people not only work together, they form a recognizable group outside the laboratory. Much of their shop talk is in a jargon incomprehensible even to those who work in allied fields. They invent their own scientific language. They even write their own mathematics. In nuclear physics, for example, the symbols that served to elucidate the relations between quantities of a limited range are being supplemented by a new mathematics designed to handle the infinitely great and the infinitely small.

One characteristic of the new research, therefore, is that it calls for relatively large numbers of younger men trained beyond the undergraduate level and grouped in teams pursuing specialized investigations in rather narrow fields. Such a development is possible only in universities which are able to spend money sustaining large numbers of graduate students over a prolonged period of advanced training. On the Berkeley campus of the University of California, there are 6,000 such graduate students of whom about 1,000 come from out side the United States. Not all of them are engaged in organized research, but in the experimental sciences, graduate instruction tends more and more to be organized around the development of such teams of researchers. This is expensive. The annual budget of the University of California, exclusive of building grants, is now very close to fifty million dollars a year.

I do not wish to make invidious comparisons; but it is obvious that expenditure at this level - about $£ A 20$ millions for a community of ten million people - is of a different order of magnitude from that which is deemed adequate 
for higher education in Australia and New Zealand. The University of California, moreover, is not the only, though it is the biggest, university in the state. There are several private universities as well as fifteen four-year state colleges and numerous smaller liberal arts private colleges, and junior colleges. This is the true secret of American productivity - a liberal investment in human capital. It is not regarded either as a luxury or as a privilege. Education at the state universities and colleges is free because it is regarded as an investment that pays hand some dividends. Agriculture, business, and industry support the university generously because they realize that without large numbers of highly trained young people they cannot continue to expand. It would seem to me of the utmost importance to the development of Australia that the level of expenditure upon higher education, and particularly education beyond the undergraduate level, should be lifted. A democracy cannot afford the false economy which deprives potential leaders of the best possible training and the greatest possible opportunities for research. Until there are large numbers of the best graduates kept for some years of specialized training beyond the undergraduate level the universities will not be able to do their duty to the community.

I hasten to add that, in my judgment, there are narrow limits to the usefulness of this research technique in the social sciences. I do not believe that we can solve our economic, social political and moral problems by laboriously piling fact on fact, statistic on statistic, equation on equation. My own view of these very human problems was aptly phrased by the college librarian, himself a classic, who issued to me the first book I ever tried to read on mathematical economics. As he gave lit to me he urged me for- my own intellectual integrity to read it thoroughly and master it. But when this was done, he begged me to remember that $(a+b)^{2}$ made $a^{2}+2 a b+b^{2}$, only on one condition, that $a$ was not stronger minded than $b$.

When I first went to the United States, twenty-five years ago, and was introduced to Allyn Young at Harvard as the Research Secretary of the Institute of Pacific Relations, Professor Young drew from his breast pocket the manuscript of a commencement address he had just prepared and read to me the opening sentence. It was to the effect that in the nineteenth century men reposed their faith in something they called Reason: the twentieth century has the same blind faith but for the word Reason it substitutes the word Research. I have no such faith. 
I yield to no one in the belief that we ought by all means to learn more of the intricacies of our economic, social, and political structure; but the more we learn, the clearer it becomes that human conduct in all its manifestations is primarily a matter of ethics and of will. We do not solve social questions by know ledge, though knowledge is essential for their solution. In the last resort, the solution lies in the direction indicated by James Russell Lowell in his Ode to Freedom:

"Freedom is re-created year by year

In hearts wide-open on the Godward side,

In souls calm-cadenced as the whirling sphere,

In minds that sway the future like a tide;

No broadest creeds can hold her, and no codes;

She chooses men for her august abodes,

Building them fair, and fronting to the dawn.”

I should not wish the emphasis in this lecture on scientific research to be misconstrued as an advocacy of material values and accomplishments. It does seem to me highly desirable in a democracy, and particularly in a young democracy, to foment scientific inquiry. Where government undertakes such a large role in the direction and regulation of economic activity as it does in Australia, the responsibility lies on government to pro vide adequate opportunities for scientific training and research. It is not enough to create government departments of specialized research, which indeed soon become sterile if they are not nourished by university-trained recruits. The universities must be the centre of research and must be equipped to function effectively. But the researchers must be subjected to the discipline of the humanities and of history, or their values will be distorted.

We are always in the dilemma described by Shelley in The Defence of Poetry: "We have more moral, political, and historical wisdom than we know-how to reduce into practice; we have more scientific and economical knowledge than can be accommodated to the just distribution of the produce which it multiplies ... There is no want of knowledge respecting what is wisest and best in morals, government, and political economy, or at least what is wiser and better than what men now practise and endure ... The cultivation of those sciences which have enlarged the empire of man over the external world, has, for want of the poetical faculty, proportionally circumscribed those of the internal world; and man, having enslaved the elements, remains himself a slave." 
The new knowledge must be used for social purposes, and an understanding of social purposes cannot be gained without a study of the social heritage. We need always to bear in mind the wise admonition that with all our getting, we should get wisdom. This is all the more important because the universities now provide the only environment where the research worker is likely to be exposed to other than material values.

The research work of the universities, however, is only the foundation of organized research. It is supplemented by the work of foundations, government laboratories and private industry. This raises large questions of educational policy. It becomes difficult for a teacher to win promotion, or even to keep abreast of his subject, unless he is actively engaged ill research. Much of the graduate instruction in American universities is carried out in connection with research contracts paid for by government departments, by foundations, or by industry. Necessarily these contracts are for research in specific fields. While university teachers are usually given a free hand, there is some risk that advanced teaching will run along the lines determined by research contracts. The training of recruits at the undergraduate level is not conducive to research opportunities and therefore needs to be emphasized lest it be neglected. The dissemination of specialized knowledge even in one subject or group of subjects needs to be carefully organized. There is keen competition by industrial and government laboratories for promising graduates, and still more for those who have successfully completed three or more years of graduate study for the Ph.D. degree. Fortunately the academic life retains its appeal to idealists. Otherwise it would be difficult for the universities to replenish their teaching faculties. It is already difficult for smaller institutions to retain their good men. Moreover there is a danger that teaching may become divorced from the new research knowledge, particularly when much of this, in our modern euphemism, remains classified and restricted. This is at least as great a danger in the social, as it is in the experimental sciences. The only remedy that seems possible lies in the frequent interchange of personnel between teaching and applied research.

It has been estimated by the National Research Council of the United States that in 1949 a total of $\$ 1,930 \mathrm{~m}$ was spent on scientific research and development. Of this, no less than a third went for military purposes. Another third was industrial. One-sixth was for medical research, and the remaining 
sixth for academic research. These are significant, and somewhat frightening proportions. If the sums allocated for economic, social, and political studies could be estimated, they would not amount to more than a tiny fraction of the vast amounts devoted to material and destructive studies. We shall not escape from the suicidal tendencies of our age unless some way can be found to divert to the study of peace and humanity, a larger fraction of the material and intellectual resources now devoted to the potentialities of their destruction. It is true that we are confronted by a new and threatening system of organized power masquerading under the camouflage of social reform. It is inevitable that we must gird ourselves lest this new despotism conquer us by default and from within. But there is a nice question as to how far power can be met effectively solely by greater power, if this entails restrictions on the freedom and moral values which we seek to preserve.

The tremendous sums now being spent on military, industrial and even on medical research emphasize another point. It is difficult any longer to draw a clear line between pure and applied science. It is probable that a greater proportion of the research work outside the universities is directed towards immediate practical use or even routine testing, rather than to the pursuit of new knowledge for its own sake. But even the military and industrial laboratories recognize that they get better practical results from minds that are left free to range widely. And there is increasingly close liaison between the universities and industry. It has indeed been argued force fully that the British tendency to concentrate on pure science and neglect its industrial applications reinforces the technical leadership of the United States which has a highly developed industrial apparatus eager to seize upon and develop the new discoveries of British laboratories. The very excellence of British science, in default of adequate industrial applications, may increase, instead of decreasing, the already wide gap between British and American industrial efficiency. ${ }^{2}$

I have spoken of industrial laboratories, but the application of new scientific knowledge involves much more than laboratory experiment. It is one thing to demonstrate a discovery in a test-tube. It is quite another to develop

2 Cf. R. I.. Meier, "The Role of Science in the British Economy," The Manchester School, May 1950, pp. 101-127. 
the process and adapt it to routine standardized large-scale production capable of semi-skilled, or unskilled, operation by mass-production methods. Increasing importance attaches to what has become known as process-development. This is a species of scientific engineering, calling for mechanical ingenuity as well as scientific insight. It is very expensive and economically hazardous. Hundreds of thousands of dollars may be spent in developing a single new product or process only to find that a rival product has won the race. Usually a pilot-plant is required, but even when the process has been demonstrated in this way, much remains to be done before the investment necessary to large scale operations on a commercial scale can be justified.

What I have said so far is necessarily general. I do not pre tend to understand the machinations of the experimental scientists and their engineering associates. Most of the talk that I hear from my scientific colleagues of new products and processes goes over my head. They seem to me to be engaged in a loose international conspiracy to pry open the secrets of energy and of life, taking bits of nature to pieces and reconstituting them in different combinations. We dined with one of my colleagues less than a month ago, just before we left home. He is a Chinese biochemist, who shuttles by air between California and Sweden and has teams of young assistants working in both places. His special interest lies in breaking down the molecular structure of the hormones which he extracts in minute quantities from the lining of animal glands. His theory is that the body builds up these substances and if they can be unbuilt into their simpler components it may become possible to create them from their constituents - synthesize them - in the laboratory. Up to this point it was relatively easy to follow him, but when he launched into more technical descriptions of his methods, the language soon went beyond my comprehension. All that a layman can dimly perceive is that this kind of research on the frontiers of knowledge - in physics and chemistry and biology and in their interrelations - is bound to bring vast and at present unpredictable changes in our way of life. Already the expectancy of life has been lengthened and this presents us with what in California we call the problem of our senior citizens. When should a man retire from active work? What is the test of working age? How should a community make provision for an increasing proportion of retired people?

This lengthening of life expectancy is an economic consequence of scientific research too vast to do more than mention in passing. The biological 
sciences, which now press forward even more rapidly than the physical sciences, will present us with many more such economic consequences. But I am more concerned to-night to draw your attention to some economic consequences of earlier discoveries, mainly in chemistry and physics, which can already be discerned, and with which we already must grapple.

I do not have the knowledge or the foresight to attempt anything in the nature of an exhaustive catalogue of the economic consequences of scientific research. The best that I can do is to explore some of the more obvious consequences, mainly those concerned with the structure of industrial production, that already force themselves upon one's observation. In particular I am concerned with some international economic consequences of the fact that these changes in industrial structure are furthest developed in the United States. It was an Australian industrialist who remarked to me some years ago that the United States had become the industrial laboratory of the world. He went on to talk about the necessity of coming to the United States for new processes, and therefore for design and construction, even for preliminary lessons, in the operation of these new processes. In so far as this remark holds true, the United States now is in the position of technical leadership that Great Britain held after the Industrial Revolution. For a time in the latter part of the nineteenth century it seemed likely that German science would displace British commercial and financial power. The United States has borrowed heavily from both. If a new system of world trade is to be created, as Britain created the trading system of the nineteenth century, it must be centred upon the technical leadership of the United States and must be adapted to the pattern of its industrial structure. I do not say that this development is inevitable. There are many difficulties, both inside and outside the United States, that complicate its realization. But I believe any alternative to its realization is a poor second-best both for the Dominions and for Britain. Mr. Churchill spoke prophetically when he declined any sharp clarification of the status of American naval bases in the British West Indies on the ground that the more mixed up our affairs get, the better for all concerned.

Clearly one consequence of scientific research has been that industrial establishments grow larger. Some of them, it is true, have grown to their present dimensions as a result of financial manipulation rather than technical convenience. But the optimum size of industrial operations tends to increase markedly. It is not 
possible for the small-scale, family business or limited partnership to carry the overhead cost of research and process development that are now necessary if a manufacturing business is to survive. The ramifications of this development are farreaching. They amount to a commercial revolution. It is not possible to-night for me to do more than mention some of the more outstanding of these ramifications. I confine myself therefore to noting those concerned with the ownership and managerial direction of industry, with the parallel large-scale organization of labour and agricultural interests, and with the relations of large-scale business to government. None of this may seem especially novel to Australians, whose economic development has paralleled, or even anticipated, that of the United States in many essential respects. Australia is a highly industrialized country.

But there is a difference of degree between Australia and America and a difference of degree that amounts in this case to a difference in kind. The size of American industries does not depend entirely upon the development of scientific research; but the applications of scientific research pervade the whole situation. The great market which enables American industries to operate on a large scale could not be organized without road, rail, and air transport, electrical communications and business machines that are the product of scientific research.

Obviously the development of giant industry has freed, or if you like has displaced, labour. Energy is the secret of production. What has been happening was recently described as shifting the burden of labour from the shoulders and muscles of men to the waterfalls. Much of the incessant research and invention is directed towards saving labour costs where such costs are high. The low unit-costs of production result from the intensive use of capital equipment which is economical only if it can be applied to very large, continuous and repetitive operations. The principle of the assembly line or of the stream-flow process can be applied not only to complicated manufactures such as automobiles and refrigerators, but to a wide range of chemical products, and also to food-processing. As we passed through Hawaii we took the opportunity again to visit the pineapple cannery which is the largest food-processing plant in the world. From the time the pineapple is tipped on to the long conveyor belt till it emerges naked and cored on the sorting tables, it is subjected to the economic consequences of scientific research. Indeed, the research reaches backward into the pineapple fields and forward through the packing and marketing processes. 
But this is an economical operation and the released labour finds employment in a wide variety of tertiary industries and services, many of which are necessarily small-scale. The strategic key industries of a modern economy are large-scale, but by their very efficiency they make possible a proliferation of smallscale industries and services. The economic consequences of this fact have yet to be fully explored. The stability of the economy is largely based upon the effective and continuous operation of the key industries at something approaching full capacity production. If these fail to operate at full efficiency the effect is felt throughout the whole economy. In Australia I need hardly do more than mention coal. Conversely, if we can find the means to stabilize and maximize these key industries, we shall have gone a long way towards stabilizing and maximizing the whole economy. The most significant recent advances in economic theory are concerned with such subjects as overhead costs, the price-policy of large corporations, and, to quote a recent significant title, "Competition Among the Few?" There is much work to be done before we can estimate the possibilities of regulating the smooth expansion of a national economy by developing stability in its key industries. If the United States can be kept going at maximum efficiency, the rest of the world has a chance to do likewise. If it falters, as it did for a few months in 1949, there are severe repercussions throughout the trading world. But the key to stability in the United States is not to be found any longer in the smooth working of a dispersed marketing process. It must be found in negotiations among organized power groups in the great strategic industries such as steel and automobile manufacture.

It was inevitable that the power of the great corporations should be countered by attempts to organize the more dispersed factors of economic activity. The most obvious of these factors are labour and agriculture, both of which tend to work through government, which is itself an economic factor of increasing importance in these days of high taxation and enlarged government activities. The basic pattern of economic relations is no longer determined by competitive forces registered through prices and the monetary mechanism. Negotiations between organized groups set the pattern. For example, the five-year contract recently negotiated between General Motors and the United Automobile Workers' Union seems likely to stabilize wages, working conditions and employment not merely in one of the largest corporations, not merely in the industry of which this corporation is a part, but for industry as a whole. It is true that there are 
complications. The steelworkers may feel that they must go one better than the automobile workers. Agreement between management and labour may prove untenable if it has been made at the expense of the consumer. There is a new pulling and hauling between the different segments of economic activity. Power and prestige factors enter into this bargaining. Political factors enter also, because as between organized management, organized labour, and organized agriculture, government necessarily becomes something of an arbiter. The impressive capital structure of the big industries does not necessarily carry with it the power of economic decision. There are economic limits which bargaining power may not transgress with impunity; but within those limits the bargaining is an aspect of politics and votes count. It is fair to say that organized labour and organized agriculture have used their ability to mobilize votes as an effective bargaining instrument.

Implicit in this situation is the fact that economics and politics, which were never so sharply distinguished as academic text-books have sometimes assumed, tend to become more confused. There was good reason to analyse economic questions apart from politics when economic activity was organized in a multitude of small establishments, no one and no group of which was capable of effectively controlling the dispersed forces of demand and supply. The theories of prices, wages and interest worked out on the assumption of free competition among dispersed producers and consumers must now be modified. Among the changes that must be reckoned with is the increasing importance of political factors, both in the sense that organized groups use their bar gaining power in negotiations, and in the sense of government intervention. So far has this gone that the sharp distinction which the nineteenth century drew between private enterprise and state socialism has become anachronistic. To approach modern economic problems with a desire to show that a certain course of action would promote either state socialism or private enterprise is a waste of breath. The great modern industries have to reckon with social responsibilities, and government intervenes without necessarily operating.

To emphasize this point on the industrial side one need only point out the shift in the location of power in the economic system that has come about as the result of the large scale upon which the key industries are organized. It is still the fashion in some quarters - notably in the Kremlin - to belabour Wall Street as the 
symbol of financial power; but this betrays an intellectual lag. In the nineteenth century the merchant bankers who controlled the City of London did exercise real power. But one has only to watch the gyrations of the Stock Exchange to realize that effective power has now passed from financial to industrial leadership and within industry to a new class of managers. The ownership of a large corporation is widely dispersed, in many cases among hundreds of thousands of stockholders. It is true that there are instances where effective ownership is tightly held in a small group which dominates management. It is also true that there are many other cases where minority holdings supplemented by the routine proxies of passive small owners suffice to maintain control over large enterprises. But the trend is unmistakable. Ownership becomes more and more divorced from active management. Dividends are stable and often do not vary from year to year, and therefore become more and more in the nature of a fixed return. The numerous small dividend-receivers have little or no say in the selection and still less in the operations of management.

Those who rise to power in the management of large corporations travel by varied routes, seldom now by acquiring majority ownership and less and less often by legal acumen. The corporation lawyer does not become president as readily as he did, and the accountant or banker almost never. Often the best way up is salesmanship. Always it is organizing ability and often this is displayed by men who by sheer will power have fought their way up to the top. What is even more important is the fact that large-scale enterprises necessarily develop a kind of general staff. No one would deny that great power lies in the hands of the executive leader, but that power is to some extent shared and is certainly conditioned by the group with whom and through whom he must work. This executive group is composed of men of diverse qualifications and experience and skills - financial, technical, personnel, public relations, scientific research and other experts. There is a great deal of committee work and clearing of policies among those who must both formulate and execute them. The executive decides, but in some measure his decision is conditioned by the alternatives and the evidence put before him by the various specialists. The execution of policy is as important as its formulation.

"For forms of government let fools contest

Whate'er is best administered is best." 
I have heard one of these powerful executives remark that he spent the largest part of his time like a professor in a seminar, explaining decisions to his staff so that they understood and went along with full understanding of his policies. I have ventured to put these facts before you briefly be cause I am convinced that they represent a most significant shift in the location of power in the economic system. Three aspects of this shift need to be emphasized. The first I have already mentioned. It can be summed up by a phrase which I borrow from Dr. Edwin G. Nourse, who for some time acted as Chairman of the President's Council of Economic Advisers, when he wrote that the office of the executive rather than the market-place had become the birthplace of prices. We have moved a long way from the semi-automatic competitive determination of the prices which govern the relations between commodities and also those between the factors of production. This means that wages, farm prices, and even interest rates are determined by negotiation rather than by impersonal market forces. When New Zealand first introduced its experiment in compulsory arbitration and the determination of wages by judicial decision, Sir Robert Stout remarked that this constituted a reversal of Sir Henry Maine's famous dictum that the progress from medieval regulation to nineteenth century laissez-faire had been a change from status to contract. If this evolution had continued along the lines of state socialism, Stout's observation might have been justified. We might indeed have entered upon a new phase of social stratification. But it seems to me that the work of the experimental scientists which has resulted in the organization of these great enterprises which are essentially social in character has given a new twist to the aphorism. Contract has become more important again, but it is a new kind of contract entered into by organized groups of approximately equal bargaining power.

The second aspect of this shift of economic power relates to the displacement of the financier as the industrial manager gains strength. The giant corporations are for the most part self-financing. They do not distribute the major part of their earnings in dividends; but provide for replacement and expansion. When Standard Oil of California secured tor a small payment the oil concessions in Arabia that have proved the richest strike in the world, it cost at least two hundred million dollars to develop the concession before oil was found. This venture capital was neither borrowed from banks nor from the general public in the form of share flotation. It was set aside from the earnings of the parent enterprise. The Texas 
Company was associated with Standard of California largely to take advantage of the Texaco distributive organization in Europe. Recently Standard of New York and Standard of New Jersey have been brought in largely to draw upon their resources to begin a development programme estimated to cost two billion dollars over the next five years. Much of this investment will in fact be provided by ploughing back anticipated profits. Neither American-Arabian, the producing company, nor Caltex, the selling company, floated new shares. The decisions regarding expenditure and the financial means of implementing those decisions did not depend either upon the general public subscribing capital or upon bank loans, but lay within the power of the management of the oil enterprises. The essential decisions were in respect of the prices that could be charged for the new production, and of the proportion of profits to be devoted to expansion.

The third aspect to be noted in this shift of power is concerned with the relations of such great enterprises to government. There is in my judgement much foolish talk of their influence. In a democracy political power is always greater than economic power - when it is exercised. If it comes to a test government can compel industry or any other organised group to do its will. Nor can industry, by advertising, newspaper editorials, radio publicity, or any other means, control elections. If proof of this were needed the last Presidential election should suffice. In the confusion of business, labour, agricultural and other propaganda, and the personal campaigns of candidates, the voter has much the same function as a juryman. To argue that he can be hoodwinked by special interests on any question which is the subject of active controversy seems to require a degree of naive ideological belief in the crafty wickedness of capitalism that is possible only to a prejudiced mind. The Wall Street of the communist cartoons exists only in the imagination of the Kremlin.

But there is a large area of economic policy upon which elections are not fought and upon which public opinion is seldom aroused because few can be aware of the decisions taken and of their results. Within this area the great corporations obviously exercise a great deal of power. They work within a framework of existing law and their actions are carefully watched by increasingly alert and highly organized labour groups. Much of the law doubtless was written when economic activity was organised along simpler lines. This is true, for example, of the antitrust legislation which in recent years has been vigorously administered with dubious 
results. But the fact must be accepted that within the area of their operation many great enterprises now constitute organs of administration which may be compared with feudalities. They possess many of the attributes of government, in a limited sphere and subject to the overriding power of the central government and to the law of the land, but nevertheless powerful. Some of these feudalities cross state and even national boundaries or make alliances over these frontiers. There are some who would argue that when they become so powerful and deal with the public as directly as do the public utilities and many enterprises in fields which tend to become public utilities, they should be nationalized. Ownership, however, is not the real issue. It makes little difference whether an enterprise is owned by a very large number of absentee shareholders or by the state. The real issue is management policy. It has not yet been demonstrated that public ownership results in vigorous management that in the long run serves the public interest better than the management provided by widespread private ownership. It is true that some experiments such as the Tennessee Valley Authority have demonstrated that public ownership may be almost as divorced from politics as is private ownership, that power may be dele gated for defined periods and within prescribed limits. But it is also true that political interference has been markedly detrimental to managerial efficiency in many public enter prises, notably in the Atomic Energy Commission. Public enterprise need not result, but often does result, in the bureaucratic centralization that Harold Laski once described as producing apoplexy at the centre and anaemia at the extremities.

One other fact is obvious. The men who have proved their ability to control large private enterprises move easily and effectively into the public service in emergencies. Many examples might be cited. It is even more significant that many who have risen to prominence in the public service, move just as easily into high management positions in private enterprise. The fact is that new forms of organization for specific purposes, both economic and political, are in process of experiment, directed by new types of organizers. It is inconceivable to me that we shall continue to be bound by the stereotyped forms of organization developed in the nineteenth century. An economist who is sceptical of these experimental types of organization would do well to recall Adam Smith's low opinion of joint-stock companies which not long after his death proved instruments of more effective organization than he had visualized for purposes he could not foresee. It would 
be my guess that the twentieth century has many more such surprises in store for us. The reason for my guess is that the experimental scientists keep on working to undermine the foundations of our economics and equally of our politics.

If there is any substance in what I have said so far, it follows that the advent. to technical leadership of a United States whose economic organization is already so different from that of nineteenth century Britain and is evolving so rapidly, must profoundly affect not only the world's trade, but the economic life of all countries which have trading contacts with her. And which country does not? If world trade is to be restored it will not function as it did in the nineteenth century through a monetary mechanism. Its architects will be neither the bankers nor the specialized traders, but the industrialists. As an instance that comes close home let me cite the fact that the apparently insoluble problem of quotas and exchange control, with its counterpart of petrol rationing, yielded to direct negotiation between the oil companies and the British Government. I am aware that the Australian Government fulfilled its election pledge and abolished petrol rationing; but this unilateral action did not solve the payments problem. Indeed, it aggravated that problem. The action of the oil companies in guaranteeing adequate supplies against sterling payments which they agreed not to convert into dollars did provide a solution.

This was an important action. Petroleum now constitutes the most important group of commodities entering world trade. The British western European markets were supplied with petroleum products mainly from the developing resources of the Near East. When Britain imposed further severe restrictions on the import of dollar oil, it became necessary to throttle down the production of Arabia. This recoiled upon the economic development programmes of the whole Arab world. Moreover, these repercussions extended to the Caribbean, since Venezuelan oil was diverted from Europe to the United States market. This caused alarm among the small independent producers of Oklahoma and Texas and caused an agitation for higher protective duties, as well as grumbling about countries in receipt of dollar aid whose actions were causing such difficulties in the domestic oil market. This agitation was a contributing factor to the renunciation of the reciprocal trade agreement with Mexico - the first breach in the lower tariff programme initiated in 1934 - because Venezuelan oil came into the United States at the low duties imposed on Mexican oil and extended to Venezuela by most favoured-nation treatment. 
It was therefore an exceedingly complicated situation that was precipitated by the increased British restrictions on dollar oil. This situation was eased when the American oil companies agreed to accept sterling payments. But in doing so, the companies did far more than safeguard their markets in the sterling area. They must use the sterling they receive and use it within the sterling area. Tankers will be built in British yards. Steel for Arabian pipelines and other supplies will be bought in Britain or Sweden. These are important determinants of a new pattern of international trade. More over, there will be more automobile production and British exports of cars, buses and trucks will be facilitated. Domestic patterns of production, as well as the direction of international trade, will be affected in many countries. There will still be competitive trading, but the conditions of that competition are altered by the agreement between government officials and corporation executives.

International investment too, has changed its character. The portfolio lending characteristic of the British nineteenth century system did not survive the freedom and stability of the foreign exchanges that was guaranteed as long as the international gold standard worked effectively. It is now rare for a foreign loan to be offered for public subscription. But investment in foreign countries has not ceased. It is now primarily of the type of direct investment. Apart from government loans, the amount of United States direct investment abroad is now nearing twenty billion dollars. A large part of this is in oil. The largest industrial investments are just across the border in Canada. But there is a great variety of direct investment widely spread in many lands, in transport, mining, manufacturing, public utilities.

What is even more important is the export of what Americans call knowhow. I had occasion recently to see the work of a graduate student who combed the pages of a few trade journals for two post-war years and uncovered many hundreds of cases of United States companies engaged in engineering-economic surveys, constructing roads, railroads, airports, pipelines, dams and other public utilities on a commission basis. The pattern of such undertakings is familiar within the United States. Many of the great hydro-electric dams of the western states were constructed by joint ventures formed by several construction companies joining in a specific under taking. Six firms joined in building the Boulder Dam. The plans were drawn and the contract was let by the government. The builders were paid 
for their construction. The dam and power plant remained public property. One of these firms now has about half a billion dollars worth of construction contracts in the Near East alone. Similar firms build roads in Afghanistan ironworks in Brazil, hydro-electric installations in Chile, sawmills in the Cameroons, tunnels in Australia, and a great variety of manufacturing enterprises all over the world. One such enterprise in India is being built to American design for the application of new chemical processes to deposits of natural gypsum. It will cost the equivalent of fifty million dollars, some of which will be provided in rupees and some by drawing upon blocked sterling balances to pay for British materials. When completed soon it will double the production of artificial fertilizer in India. The American firm receives a fee for designing and superintending the construction and for training Indian engineers in the operation of the plant. Presumably it will receive royalties on the use of its patents. But it will not own the enterprise and if it continues to operate it after construction, it will do so as the agent of the owner, in this case the Indian Government. This American firm has on hand hundreds of foreign contracts, some small, some large, in many countries, and there are many such firms.

I do not mean to imply that such enterprise is confined to the United States. Cases could be cited of British, and indeed of Australian, enterprise of the same sort. But because of the leadership of the United States in the industrial applications of scientific research the export of know-how has developed on a great scale.

Necessarily in the limited time available in a single lecture I have telescoped much of my argument. If I have jumped from point to point and drawn my illustrations from too wide an area, omitting many of the steps in the reasoning and much of the descriptive background, I can only plead that what I have been trying to indicate is a revolution in the methods of organizing economic activity, a revolution that is world-wide in its implications. There is at least as much reason to label these developments of scientific research a scientific revolution as there was to call the consequences of steam power and mechanical invention an industrial revolution. The agents, or instruments of this scientific revolution are those who are in a position to apply the results of scientific research to industrial production. 
At the present time, in the western democracies, the industrial applications of this new scientific knowledge are largely in the control of great corporations. It is possible, and in my judgment probable, that new types of economic organization will emerge, but here and now the patents, and above all the men capable of operating the new methods, are grouped in these great enterprises. Effective reconstruction, the economic development of backward industrial areas, and the restoration of world trade depend in large measure upon effective means being devised to harness their constructive ability to purposes consonant with national plans. It does not seem likely that private enterprise will be as free to operate in the twentieth as it was in the nineteenth century. On the other hand, governments have not developed initiative and enter prise on anything like this scale - at any rate they have not done so in the international field. One of the most promising aspects of the present confused situation, however, lies in the fact that the contracts made by corporations with governments have gone far towards solving the conundrums which governments themselves have not been able to solve. A new Law Merchant may be in the making, practical solutions for new situations being worked out in particular cases. These solutions may gradually be generalized until a code of international law more suitable to the new conditions of our time is gradually built up.

The forces which impel the managers of American business enterprise to extend the scale of their operations are strong. There has been a great shift away from isolationism and from reliance upon the great domestic market sheltered behind a tariff wall. The shift is far from complete and it would be naive to expect either that the extraordinary upward surge of productivity will continue unbroken or that the forces of national protectionism will not rally. The United States has the industrial leadership that Britain had after the Napoleonic Wars; but it is in a very different position. It need not import a large proportion of its food. And its dependence upon imported raw materials is limited. The vitality and exuberance of its economic activity, and the resistance of large groups to the discipline of authoritative regulation, is always likely to result in straining the economic mechanism. But it is permissible to hope that such strain will not again be allowed to develop into the paroxysms of economic depression that occurred between the two world wars. And it seems certain that whatever setbacks may occur, the United States will not turn back from the road of international cooperation to narrow isolationism. 
Economic cooperation with the United States, therefore, while not without risks and annoyances, is not an unhopeful prospect. But such cooperation entails some degree of adaptation to the needs and to the outlook of what is now the dominant industrial community in the world. Insofar as other peoples wish to obtain access to the products of American industry, or to the secrets of their production, they must secure the necessary purchasing power by sending the kind of exports that the United States can use. That other peoples do desire such access is obvious. The so-called scarcity of dollars or dollar gap is simply the reflection of a demand for American exports greater than the American demand for foreign imports. This dollar scarcity is in fact the most obvious economic consequence of scientific research to be observed internationally. The best definition I have heard of its size is that it amounts to the sum that Congress is willing to vote so that American exports may exceed imports. Obviously this sum is capricious. In the future it is likely to be correlated more closely with military aid and therefore with military commitments. The capacity to purchase from the United States will be determined largely by the ability to sell there.

There are two broad classes of goods the United States will buy in large quantities. The first is specialty goods of fine quality or novelty. The second is raw materials. The market for both is expansive, but only on condition that care is taken to prepare the goods for that market. The day has gone by when a big industry will bother with odd lots of material of uncertain quality. Its continuous operation demands that materials of standardized quality be fed into it in large quantities and continuously. This means that the raw material supplier must adapt his methods to those of the manufacturer. Wool is a typical raw material likely to be in great demand. Australian wool is graded so that it fits easily into the processes of American manufacture. The wool growing industry has long followed such methods and this accounts for its success in the American market. Having lived to see the tariff on wool reduced after the President had vetoed a Bill by which Congress had virtually given the United States woolgrowers power to control imports, I do not despair of seeing further tariff reductions on other products. As demand breaks down the barriers to imports, those countries which produce to meet American needs will gain an obvious advantage. This is as true of novelties and fine quality consumers' goods as it is of raw materials. But it would be wrong to conclude that all the world must make itself over on the American pattern and become dependent upon the fluctuations of the American economy. Indeed, it is 
improbable that the United States can or will balance its trade bilaterally with the sterling or any other area. Nothing short of multilateral trade over a wide area, as wide an area as the free world, will suffice to ensure both prosperity and stability. The contraction of space and time as barriers to international cooperation is the greatest of all the economic consequences of scientific research. It would seem to me the merest common sense for all the countries which share the common traditions of our civilization to bind themselves together in specialized division of labour utilizing all the scientific research possibilities of the free world to build mutual prosperity and security. 



\section{5}

\section{Australian agricultural policy}

\section{John G. Crawford ${ }^{1}$}

It is tempting to assert that the most striking thing about Australian agricultural policy is that there isn't one. However, the Oxford Concise Dictionary defines policy as "courses of Government action," and of these there have been, and are, a great many. So many decisions of Government affect agriculture that in this sense of the word there must, willy nilly, be policies. What is far more open to question is whether the innumerable activities of Commonwealth and State authorities conform to a consistent set of policy objectives.

It is the purpose of my paper to-night to review the principal policy objectives which now seem to be emerging and to review also some of the "courses of action" which are in process of being developed. Not less important, I propose to draw attention to the necessity and scope for further action in a number of matters vital to our achievement of stated policy objectives. I believe I will show that, while there is now apparent a clear set of policy aims, broadly acceptable to all Governments and political parties, these have not yet been fully translated into effective "courses of action", although progress is in the right direction.

Clear and complete statements on agricultural policy have not been a marked characteristic of any political party in Australia. Political platforms, as printed and uttered, are prone to mix policy ends and means with cheerful abandon. This is partly because the farmer electorates are not homogeneous, one with another. Each electorate is apt to be interested in a particular commodity and the "courses of action" proposed for it, rather than in the total or comprehensive role of agriculture in the community. Even welfare concepts such as equality between the living standards of farm and urban families - are translated into the price of

1 Twenty-fifth Joseph Fisher Lecture, 15 October 1952. 
butter or wheat. This is one explanation of the non-appearance until recently of a single organization representative of the "farm bloc" outside Parliament. To-day the National Farmers' Union, comprised of representatives of various industry organizations, is assuming this role and is displaying a keen interest in policies couched in terms wider than those of any particular industry.

There is another good reason why completeness in the statement of policy objectives is not frequent. The division of constitutional powers is such that State policies are likely to be couched in terms of different objectives from those of Common wealth parties. Commonwealth policies have developed largely through export activities while State policies are more closely related to the farm unit itself, particularly the problems of production. Nevertheless, while the constitutional divisions are no less real, there is apparent now a decided converging of Commonwealth and State policy objectives. This will be more evident as this paper proceeds, and is less surprising than may at first appear.

\section{Policy objectives: 1952}

It would be an interesting historical exercise to trace the story of agricultural policy making in Australia in some detail. It will serve our needs better, however, to seize upon, as our starting point, the most recent authoritative statement of policy. I refer to a statement made by the present Minister for Commerce and Agriculture, the Hon. J. McEwen, when addressing the Australian Agricultural Council in February this year. Two extracts will suffice:

"The Commonwealth Government has, therefore, decided to adopt as its policy objective a Commonwealth-wide programme of agricultural expansion, not only to meet direct defence requirements, but also to provide food for the growing population, to maintain our capacity to import, and to make our proper contribution to relieving the dollar problem."

"Out of a consideration of all these circumstances the Commonwealth Government has decided that activities directly concerned with the production of essential items of food and agricultural products in this country shall be classified in importance with defence and coal production.” 
Lest you discern in this choice of policy spokesman a rather highly favoured bouquet, let me say at once that his statement is not without its forerunner.

The late Mr. J. B. Chifley, in a special statement on rural policy issued in 1946, covered somewhat the same ground as the first extract, although defence was not mentioned. ${ }^{2}$ Moreover, Mr. McEwen refers to agricultural production while Mr. Chifley explicitly recognized higher farm living standards as an objective. This latter, however, is clearly an objective common to the platforms of all parties, and this apparent difference between the two statements need not concern us here. The more important difference is in the sense of urgency. The 1946 statement was couched in terms of a post-war world expected to be characterized by peace and the opportunities for the leisurely pursuit of economic progress. The setting of the 1952 statement is altogether different. Actual war is taking place in certain areas, but for the most part "cold war" rather than peace describes the international scene, while economic developments within Australia have brought agricultural policies into a prominence hardly to be foreseen in 1946.

It is to the sense of urgency about our policy of 1952 that I wish particularly to address myself. While I will have occasion to comment on the incompleteness of the Commonwealth's policy objectives, my greater concern will be with the reasons for the Commonwealth's particular choice of objectives and the courses of action contemplated or thought necessary to achieve them. Except where I find it necessary to do so, I will not be concerned to examine in any detail the relation between agricultural policy objectives and programmes and wider objectives of economic and social policy for the economy as a whole. Yet my audience will have noticed already, I believe, that the 1952 policy is really one which makes

2 A Rural Policy for Post-War Australia: A Statement of Current Commonwealth Policy in relation to Australia's Primary Industries. (1946). The relevant extracts are: "The Government feels that certain general objectives may already be clearly stated:

(i) To raise and make more secure the levels of living enjoyed by those engaged in and dependent upon the primary industries.

(ii) To secure a volume of production adequate to meet domestic food requirements, to provide the raw materials for our developing secondary industries, and to enable an expanding volume of exports to pay for necessary imports.

(iii) To encourage efficient production at prices which are fair to the consumer and which provide an adequate return to the producer.

(iv) To develop and use our primary resources of water, soil, pastures and forests in a way which conserves them and avoids damaging exploitation." 
enhanced agricultural production a matter of urgency because it is a principal means to the wider ends of national interest.

The Commonwealth policy objective as stated by Mr. McEwen is clearly a production one - normally regarded as the province of the States. Yet the policy aim is one acceptable to the States, which resolved in Council in February as follows:

"The Australian Agricultural Council recognizes the serious need for expanded agricultural production and notes with approval the Commonwealth's decision to accord high importance to agricultural production, and, to achieve this objective, recommends a cooperative Commonwealth and State effort in close association with the industries concerned."

At a subsequent meeting in April, the Council adopted some production aims of which more will be said later. Meanwhile it will be useful to note that the production aims for the next five years amount, in aggregate terms, to a 20 per cent advance on early post-war production levels or 28 per cent in terms of prewar performance. ${ }^{3}$ The States continue to approve the "high importance" given to increased agricultural production, but this question of status presents some very real problems for Commonwealth and States which will be reviewed in later sections.

The very statement of policy and the terms of its endorsement by State Ministers imply that recent trends have not been satisfactory. These can be summed up in one sentence. From the pre-war period agricultural production in Australia increased up to 1951 by only some 10 per cent or 11 per cent compared with a 22 per cent increase in population.

\section{Post-war disappointment}

It is of some importance to our task to look briefly at the reasons for the apparent failure of primary production to keep pace with total economic needs in the last five or six years. ${ }^{4}$ There is little doubt that farmers expected, in 1945, a fairly early

3 Estimates by the Bureau of Agricultural Economics using the method of the Quantity Index of Rural Production as prepared by the Commonwealth Bureau of Census and Statistics.

4 I have drawn heavily from portion of a book of which I am a joint author to be published by Stanford University Press in 1953. 
return to normalcy, although wool growers were forgivably some what fearful of the large accumulation of stocks which had taken place. Normalcy meant a return of men from the armed forces and from defence industries. It meant an end to short ages. True, it meant perhaps, a return to problems of over production - but the new system of long-term contracts with the United Kingdom and a prospective international wheat agreement seemed likely to contain that enemy. Altogether, their expectation was to get on with production, first making up for the dilapidation of farms becoming obvious after six years of war; and then to march forward with new practices and new equipment known to the country but impracticable to apply under war conditions.

The war ended in drought and most farmers felt that given a break in the drought and a removal of shortages, all would be well on the production front. By 1947-48 food production was up by 9 per cent over pre-war and hopes were still high. In fact, however, this percentage was only exceeded once in the next four years.

By comparison with other countries the result was most disappointing. In the three years 1948-49 to 1950-51, the average percentage increase in food production over a pre-war base was 10 in Australia, 10 in New Zealand, 6 in Argentina, 35 in South Africa, 28 in the United States, and 27 in the United Kingdom. ${ }^{5}$ The explanation is not to be found in better seasons - they were good in Australia - but rather in more adequate supplies of fertilizer and equipment and possibly a more liberal price policy in the Northern Hemisphere countries.

An illuminating comparison of the Australian position with the position in the United Kingdom and the United States has been given by Mr. T. Strong, Director of the Bureau of Agricultural Economics. ${ }^{6}$

"In England and Wales the number of combine harvesters has risen from fewer than 1,000 in 1942 to more than 10,000 in 1950. During the same period, combine drills increased from 7,000 to 24,000 and between 1939 and 1950 tractors on farms in Great Britain increased from 55,000 to more than 300,000 . The increase of about 40 per

5 Data drawn from FAO Production Indices.

6 Quarterly Review of Agricultural Economics, April, 1952, page 45. 
cent since before the war in agricultural production in the United Kingdom is largely the result of this heavy investment in farm machinery. However, we must also take into account an increase of 18 per cent to 20 per cent in the employed rural labour force, an increase of more than 150 per cent in fertilizer consumption, and perhaps not least, the favourable price policy enjoyed by British farmers at a cost of some $£ 330$ million in subsidy expenditure on home produced foodstuffs.

"In the United States of America a similar increase in agricultural output has been obtained, despite a declining labour force, with the aid of 170 per cent more tractors, 310 per cent more milking machines, 320 per cent more grain combines, 350 per cent more corn pickers and 144 per cent more fertilizers.

"In striking contrast to developments in the UK and the USA, is the Australian supply position. It has been estimated that there are actually fewer ploughs, fewer headers, and fewer reapers and binders in working condition on rural holdings in this country than in 1943. Farm machinery surveys which have been conducted by State authorities strikingly reveal that much of our machinery is old. For example, in one important typical farming region, the average age of twin disc ploughs is 14 years, of combines 13 years, of headers 12 years, and of reapers and binders 16 years. So rapid have been world technical advances in agricultural engineering, that a considerable degree of obsolescence in our agricultural machines can be inferred from these figures."

To this could be added that fertilizer usage (limited by availability) has increased only 50 per cent in Australia since pre-war, compared with the higher percentages given by Mr. Strong for the United States and the United Kingdom. Only in wheeled tractors has the increase been comparable - the worst shortages are in the implements which go with the tractors.

There can be no doubt that the continual shortages of materials and equipment were a major factor, probably the greatest, in the stagnation of 
production. Far from overtaking the backlog of demand, local production of wire, galvanized iron sheets and pipes, steel posts and most agricultural machines fell below current requirements and, in most cases, below pre-war production levels. By 1946-47 superphosphate supplies regained pre-war levels and actually expanded by about 30 per cent in the next three years. From 1949 on, however, the capacity of the industry to meet additional farm requirements - particularly for pasture development - has lagged.

In this period, it is to be noted that it was not lack of financial resources that inhibited production. In the early post-war years the farmers' share of total national income improved compared with war years. Moreover, this improvement was widespread: wool did not become a seriously distorting factor until 1949-60 and later. ${ }^{7}$ The financial opportunities for expansion were there and it was this fact, taken in conjunction with the lack of adequate physical resources, which led me to conclude in January, 1950:

"It is, in my opinion, one of the real agricultural tragedies in Australia's history that since the war the farming community has not been able fully to exploit its financial strength in the interests of soil improvement and land development. Over the last 10 years, American agriculture has been characterized by very marked advances in productivity. These have been based on adequate supplies of labour, materials (including fertilizers), and equipment with which to carry out improved techniques of production. Australian agriculture has been less fortunate, finding it difficult to repair the shortages accumulated during war years, let alone make the advance which is its due in the light of the much-improved 'state of the arts'."

Whether price policy was also a factor inhibiting early post war expansion in production is open to argument. For the most part farmers supported the type of price policy operating in the late 'forties, including the pegged home consumption price for wheat and the United Kingdom contract prices for meat and dairy produce. As already noted, the prices paid actually improved the farmers' relative

7 Conclusions derived from farm and national income data provided by the Bureau of Agricultural Economics and the Bureau of Census and Statistics.

8 Page 29 of The Economics of Conservation, by J. G. Crawford, written in January, 1950; published in 1952 by the Commonwealth Bureau of Agricultural Economics. 
share of the net national income. It has seemed to me that any different price policy would have yielded no better result in production while the shortages of capital equipment, material supplies and labour persisted as they did.

Whatever the verdict on early post-war price policy, there is little doubt that in the decisions of Governments and of private investors the dice were loaded against a successful agricultural expansion. In general terms, there has always been a clearer purpose behind the expressed policy of developing secondary industries than in respect of agriculture. Secondary industry, too, had a better base from which to jump off. Whereas farm production was significantly at the expense of farm capital in time of war, secondary production received a great impetus from the needs of war. Much of the gains of war development were held in the peace. Considerable attention was indeed given to market security for primary products, but it has always seemed reasonable to Governments to let production expansion in agriculture take care of itself. This attitude was readily enough reinforced by the fear of the recurrence of burdensome surpluses already noted. In short, there was no clearly recognized driving necessity behind the policy of expansion professed by all parties. In this setting, the voice and pressures of the comparatively unorganized farm bloc were weak alongside the better equipped secondary industry groups.

The very troubles of secondary industry expansion after the war seemed to tell more heavily against the farmer than most other consumers. As already noted, the output of wire, galvanized iron, wire netting and agricultural machinery fell very substantially in comparison with pre-war output. Shortages of coal, steel and labour were undoubtedly responsible, yet many farmers felt that their needs were not given the priority treatment they deserved. It is difficult to decide this issue adequately, but, rightly or wrongly, the suspicion of farmers that they were the Cinderellas of the national effort increased their reluctance to respond to subsequent appeals for more production. Even import policy seemed to go wrong. Import restrictions were eased in 1949-50 and imports of scarce farm sup plies began to flow freely and helpfully - but at prices increasingly high by comparison with local production. Consumer resistance set in: farmers needed materials but not at any price.

Employment policy - forty-hour week, prosperity wages, and very full employment - added to the lure of the city. Potential farm workers and farm owners went to the metropolitan areas. Despite some new settlement, total 
holdings began to fall and the permanent farm labour force (including farm owner operators) was barely sustained at the 400,000 level. Moreover, new farms were costly to establish and this fact, combined with the shortage of structural materials, discouraged private development on any significant scale. This was the more disheartening in that tax concessions of considerable significance were available for those who adopted a generous array of soil conserving practices. ${ }^{9}$ As we have seen, too, even the fertilizer position failed to sustain the bright hopes of early post-war recovery.

All this may explain why agricultural production failed to expand as rapidly as it might have and, incidentally, exonerate the farmer of any charge that he has fallen down on the job. It doesn't explain why the failure to expand at a faster rate began, at the turn of the decade, to assume in many minds the proportions of a national disaster. The explanation lies principally, but not solely, in the much faster growth of population.

\section{The need for exports: Requirements and aims, 1957-58}

This problem of a growing population has been given useful, although probably exaggerated emphasis by projecting it forward. In the table which follows (table 25.1), from which I will cite a few items, it is clear that the country is not faced with early starvation. It is, however, apparent that a policy of inaction would spell trouble for our balance of payments position, not to mention British food supplies. It will also be apparent just how modest are most of the production aims adopted by the Australian Agricultural Council.

\section{Export income in relation to imports}

It is in relation to the desired volume of imports that export income has become of great economic importance. The failure to expand exports spells trouble, not only for Britain's food requirements, but also for Australia's capacity to pay for the volume of exports likely to be necessary to develop its resources and maintain consumption standards for a growing and fully employed population. It is not possible for me lo say precisely what volume of imports these general economic

9 See Crawford, Economics of Soil Conservation, Appendix III. 
objectives call for. ${ }^{10}$ It is possible, nevertheless, to pose the problem in reason ably effective, albeit somewhat crude terms.

Let us assume that the volume of exports and imports were in reasonable balance in the three pre-war years and that import requirements in 1957-58 will advance simply in proportion to population. In these circumstances, the volume of imports required would, if population is then 97 millions, be 40 per cent in advance of the pre-war level. Ignoring foreign loans and sources of credit other than from the export of goods, this suggests the expansion in export volume required - unless export prices remain high relatively to import prices. At the present time (June quarter, 1952), the aggregate terms of $\operatorname{trade}^{11}$ are about 108 , having dropped from 177 in 1950-51. The distortion due to the abnormal increase in wool prices in 1950-51 has disappeared: wool is back among the main pack of exports in its present values. If export prices lose their present advantage, then the increase in export volume on our fixed assumptions would be 40 per cent. If, however, they retained an 8 per cent price advantage, a 40 per cent increase in volume of imports could be financed with about a 30 per cent increase in exports. Clearly the price level for our exports is of great importance.

Before commenting on this result, it is worth noting the recent changes in volume of imports and exports.

10 The actual level will depend upon the number, tastes and incomes of people in Australia, import prices, the capacity of local industry to replace imports, the level of the investment programme and the type of capital goods required. We really do not know from any past experience what continuous full employment means for import demand. Certainly it could be expected to increase domestic demand for goods not produced in Australia, as well as for exportables.

11 Pre-war base = 3 years ending June, 1939. Data used are drawn from paper by I. A. Butler to Section C of the Meeting of the Australian and New Zealand Association for the Advancement of Science, Sydney, August, 1952. 


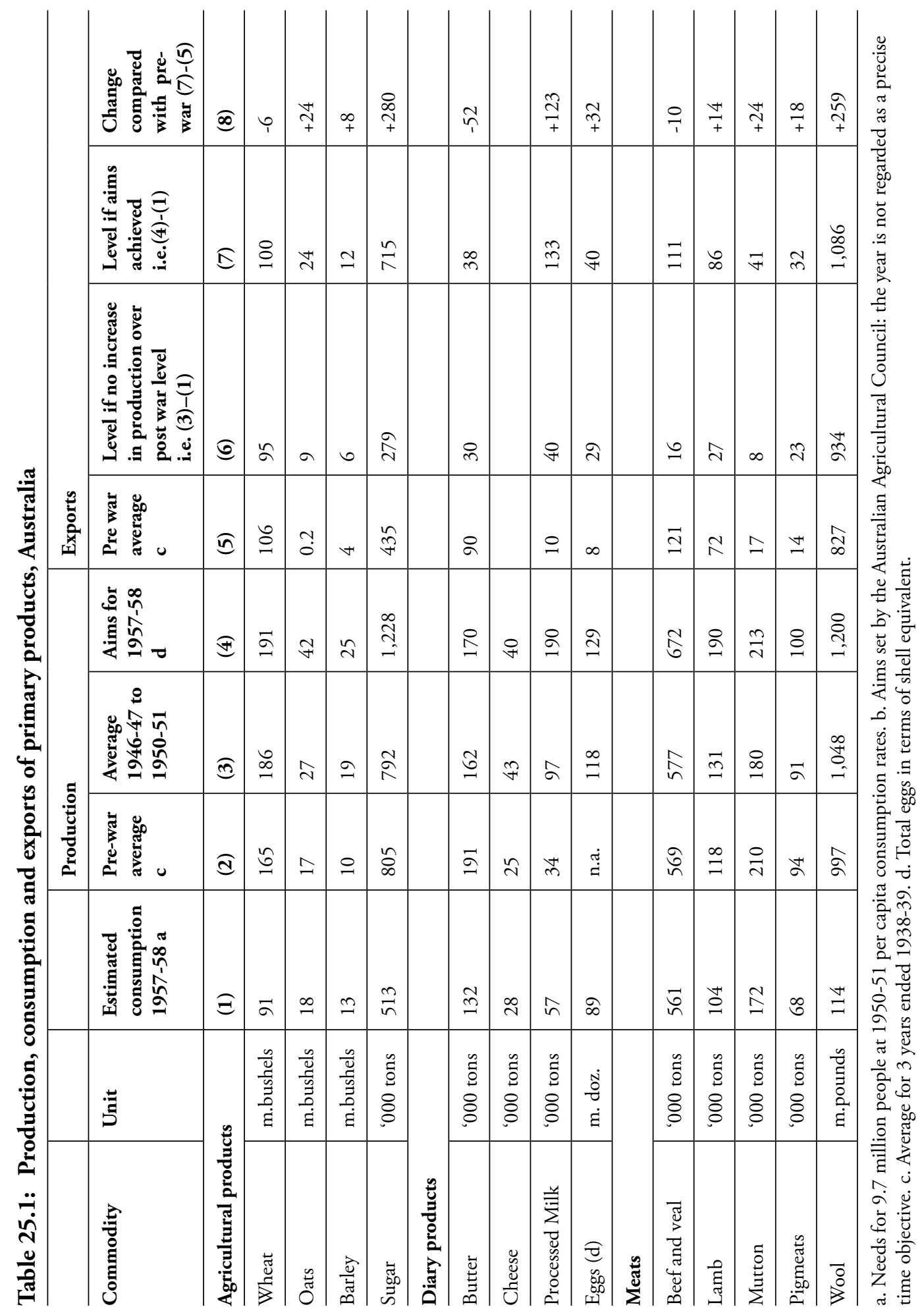


Table 25.2: Indexes of volume of exports and imports

\begin{tabular}{l|l|l|l}
\hline 3 years ended 1938-39 & $\begin{array}{l}\text { Export volume (excl. } \\
\text { gold) }\end{array}$ & Import volume $^{\mathbf{b}}$ & Terms of trade $^{\mathbf{c}}$ \\
\hline $1945-46$ & 74 & 76 & 73 \\
\hline $1946-47$ & 104 & 77 & 89 \\
\hline $1947-48$ & 103 & 108 & 109 \\
\hline $1948-49$ & 122 & 126 & 122 \\
\hline $1949-50$ & 126 & 151 & 130 \\
\hline $1950-51$ & 112 & 172 & 184 \\
\hline $1951-52$ (est.) & 10 & 21 & 118 \\
\hline
\end{tabular}

Notes: a As calculated by E. Hoffman, Bureau of Agricultural Economics (See Quarterly Review of Agricultural Economics, January, 1952). b Total value deflated by use of Commonwealth Bank import price indices. c Ratio of export prices (Commonwealth Statistician) to import prices (Commonwealth Bank). A ratio higher than 100 means that fewer exports are required to pay for a unit of imports compared with the base period (Taken from The Australian Balance of Payments, Commonwealth Bureau of Census and Statistics ).

The extraordinary influence of high wool prices in 1949-50 and 1950-51, and of the maturing in 1950-51 and 1951-52 of a heavy backlog of overseas orders (government and private), is to be seen in the heavy volume of imports in those years. Equally apparent if we use our crude estimate of the volume of imports required in 1957-58, is the need for a greatly expanded volume of exports. Recent levels of imports cannot be sustained without heavy recourse to borrowing or a drain on reserves. Nor are we entitled to expect another boom in wool to get us out of our payments problem. The task ahead is the unspectacular one of endeavouring to expand exports, and probably to diversify them, to reduce the adverse effects of down swings in wool prices. Until we succeed in this we are likely to have import restrictions - although possibly less harsh than those now operating, since these seem likely to reduce import levels to about a 10 per cent to 15 per cent advance on the pre-war base.

It is pertinent to observe at this point that the Australian Agricultural Council's production aims would make possible increased exports over pre-war levels of the products concerned averaging about 35 per cent. ${ }^{12}$ These do not

12 Estimates by the Bureau of Agricultural Economics, using five pre-war years as basis. The estimates include wheat, although the export goal for wheat actually somewhat less than the pre-war level. 
cover all exports, and it must be concluded that unless the terms of trade remain in favour of exports, the production programme will not itself finance a volume of imports moving no more than proportionately to population. It is therefore encouraging to note that the Agricultural Council does not regard its programme as the maximum of which Australia is capable. The programme is modest, and while it certainly appears that the sights will have to be raised, it is probably right to do this only after the programme gains actual momentum.

We now have an explanation of the urgency attaching to agricultural policy which is not in terms of an emotional expression of Britain's food needs, but rather in a projection of Australia's own import requirements. These have to be paid for with exports, and so far no-one has come forward with major alternatives to primary products as export earners, al though mineral development may well add considerable sup port. Primary products, including minerals, now account for 95 per cent of exports. It becomes of very great importance, therefore, to devise policy programmes or "courses of action" which will result in greater production and I will shortly turn to a review of these.

\section{Other reasons for expanding export production}

Before doing so, however, it is worth noting two other reasons for the Council's production objectives and commenting briefly on some of the more obvious omissions from the policy statements of the Commonwealth Government. The two principal objectives behind the expanded production programme are the food requirements of a growing Australian population (with which may be coupled British requirements), and the need for oversea earnings with which to finance imports. Two other objectives may be stated.

I do not intend to dilate much on the defence aspects, which involve considerable specialist detail beyond the scope both of my liberty and of the needs of this paper. Suffice it to say that without an expansion in our food production we cannot expect to play as effective a role in meeting the needs of our Allies in a total war as we have in the past. It is fair to comment, too, that the peculiar needs of defence forces present fewer difficulties to us, important though these be, than the much larger needs of dependent populations in strategic areas of the world. 
The other objective - dollar earnings for the sterling area - is really part and parcel of the total balance of payments problem already canvassed at length. There is no scope in this paper for a review of the dollar problem; but it should be noted that primary products are the great dollar earners for Australia and, indeed, for the sterling area. Wool is in the van in this respect, and it is rather sad to know that a considerable body of opinion in the United States considers our wool now to be too cheap! The plans of the Australian Agricultural Council look to a steady expansion in wool output - to an important degree as a result of rising fleece weight per sheep and of the greater carrying capacity of improved pastures. It is to wheat, however, that the nation is entitled to look for quickest results in the short-run, for wheat is not only of peculiar importance to the sterling area but it is a crop the acreage of which can be stepped up quickly if farmers will it. In recent years, imports of wheat and flour have been the major item of United Kingdom dollar expenditure on foodstuffs, the dollar cost in 1951 being equivalent to $£ A 161$ million. Sugar cost the United Kingdom $£ A 81$ million, and sterling sugar is therefore important. Other commodities do not save dollars in the same way as wheat and sugar. Thus, every bushel of wheat exported saves a dollar purchase, but shortages in supplies from Australia of other grains and meats to the United Kingdom are not as a rule replaced by purchases from North America. It follows that wheat policy is of more than ordinary importance in our affairs. Likewise a successful expansion of tobacco and cotton production has its importance for the dollar earning cum dollar saving objective.

\section{Other policy objectives}

One of the most commonly quoted and widely but uncritically accepted of policy objectives is the idea of equality between agricultural and non-agricultural producers. As Professor J. D. Black has put it: ${ }^{13}$ "While it is the role of farmers in civilization to produce food and fibres cheaply so that all peoples are well fed and clothed, they cannot be expected to produce them at prices that buy them a poorer living than obtained by other groups." American legislation has this objective explicitly in view but, to the extent that price supports are the means to this end, serious difficulties have arisen because of the conflict with the other function of price which is to allocate the use of land, labour and capital resources between

13 Black, Sayner, Clawson and Wilcox: Farm Management, p.86. 
the various demands of consumers. It is a characteristic of progressive economies (that is, economies with rising production and living standards) that agricultural incomes fall relatively to non-agricultural incomes. Thus Dr. Ojala ${ }^{14}$ has shown that agricultural incomes have risen in absolute terms in the United Kingdom, Sweden and the United States, but not as fast as other incomes. This was certainly happening in Australia, too, before and during the war; but since the war, largely owing to the influence of wool prices, agricultural incomes have risen faster than others - to a point in the period 1947-48 to 1950-51 when average agricultural incomes appeared to exceed the average for the rest of the community. When one commodity so dominates the picture as does wool it is rather dangerous to deal with aggregates. If wool be excluded, agricultural incomes have improved since the war, but not relatively to other incomes. ${ }^{15}$ (See Table 25.3.)

It is doubtful whether in Australian utterances on the concept of equality for primary producers there has been much attempt to assess the full implications of it, and most proponents have been content with improvement in agricultural incomes and economic opportunity for farm families as a satisfactory interpretation of parity for farmers. Likewise, more and better farm and rural town amenities and industrial decentralization form part of the concept of equality for farmers; and these matters defy precise measurement.

Altogether, welfare concepts are not less important although less precise in federal policy statements in Australia than in the United States - a reflection not only of stronger political group organization in the United States but also of the greater part played by the federal agricultural authorities there. To the extent that adequate family farms, more population in rural areas, more amenities for the country and the like welfare goals have a place in federal policy, they do so both as ends and means. Means, because they do affect the production objective which for the moment takes pride of place. Thus in the setting of a production drive, family farms are important if they are commercially efficient units. Amenities are important if they entice the necessary labour to farm areas. Their intrinsic social and political values are not denied but here the emphasis is certainly on their contribution to the expansion of export production.

14 E. M. Ojala: Agriculture and Economic Progress.

15 Inferences drawn from official data in which a considerable margin for error exists - particularly as to the number of income earners in each category. 


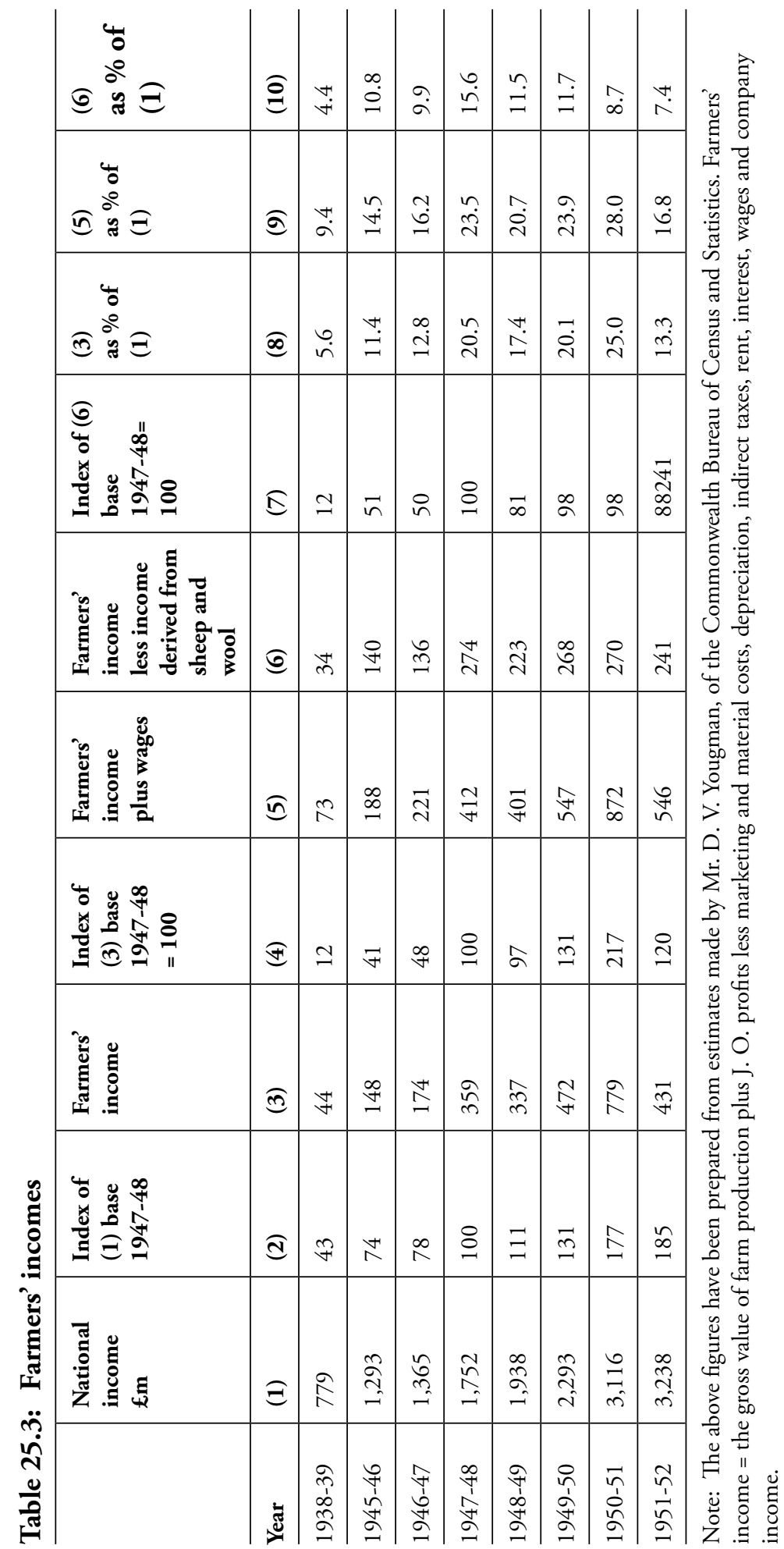


To conclude this Part then we may well admit an incompleteness in the policy objectives as at present explicitly sponsored by governments. However, this fact is of less importance than the single fact developed at some length, namely, the existence of a production programme behind which there is the driving force of considerable urgency. Yet a production objective requires "courses of action" or "action programmes" for its achievement. We must therefore turn to the questions: on what grounds and with what means do we expect to add to our agricultural output? In trying to answer these questions we must run the gamut of a host of policy issues, ranging from market outlook through price and taxation incentives to closer settlement and public transport - all difficult and contentious and all of importance to the welfare of the non-rural community as well as to the farmer or grazier.

\section{Courses of action}

\section{Land resources available}

In the short run, and possibly in the longer run too, more results may be expected from a more intensive use of existing holdings than from the development of new farms, but there is no doubt in my mind that it is necessary to look to both sources. Moreover, it is a mistake to assume that there is no scope for further land development. The number of holdings has fallen from 246,895 to 243,626 since 1945, despite a net addition of some 3,000 soldier settlement holdings allotted in the same period. This could suggest some amalgamation of small units which may be a good thing from the viewpoint of efficiency. It does not necessarily mean the end of development or that farm holdings will not again increase in numbers.

That there is room for further development is implicit in the declared programme of agricultural expansion. Scope for future development - given the necessary confidence in scientific research and the economic outlook - is also implicit in two authoritative statements by leading scientists. Both are cautioning, but both indicate the considerable, even if limited, scope for further productive effort. 
First, Professor Wadham, ${ }^{16}$ who has concluded:"Reviewing the whole historical sequence, it becomes evident that the phase of primary exploitation of the country for agricultural purposes is over. It is now clear that expansion towards the dry centre, except where irrigation is possible, is unwise. Future progress will be made in the better rainfall areas and here virtually all the areas of good soil, particularly in southern Australia, have now been brought into use. Greater production will result from increased efficiency in the industries already established. At the same time a wider diversification of crops is desirable, but this must be guided by the availability of markets for the produce. There are still many millions of acres of land in reliable rainfall regions where development awaits the discovery of methods of soil fertility improvement which can be applied economically. This field of research is receiving much attention at the present time."

Recent advances in pasture development and in soil treatment with minor elements give grounds for optimism, as do the quite major developments in mechanised land clearing operations.

Our second authority is the late Dr. A. E. V. Richardson who indicated something of the quantitative limits of future land use development in Australia. A summary of his Presidential address to ANZAAS, Perth, 1947, is reproduced from The Australian Environment: ${ }^{17}$

"Of the total area of 2,974,581 square miles (rather more than 1,900 million acres) . . . Thirty-four per cent (approximately one million square miles) of the continent has a rainfall of less than 10 inches per annum, which is erratic in its incidence. Since rate of evaporation is high, the major portion of this area is true desert and uninhabitable, whilst the remainder is capable of carrying only the sparsest population of stock.

"Forty-two per cent (approximately one and a quarter million square miles) of the continent surrounding the central arid area receives sufficient rainfall to provide fair to good grazing, but insufficient for

16 In The Australian Environment (CSIRO, 1949), p. 65.

17 At pp. 127-128. 
the growth of farm crops. It is likely, therefore, to remain for the most part as extensive sheep or cattle country, with a sparse to moderate population of stock.

"Full development of Australia's irrigation resources have been estimated to be able to irrigate not more than one-quarter of one per cent (five million acres).

"Twenty-four per cent (approximately 464 million acres), located chiefly on the outer fringe of the continent, has a length of growing period (P/E 0.3) exceeding 5 months, and is suited to agriculture and intensive stock raising. After allowing for mountains and barren highlands, which occupy considerable areas in Victoria and New South Wales, and for unsuitable areas of poor sandy or lateritic soils in northern Australia, it has been estimated that some 144 million acres could reasonably be regarded as suitable for cultivation. Intensive cropping, such as is practised in higher rainfall areas of Europe, is, however, not possible in Australia, where, even in this more favoured area, it is customary to precede our chief winter cereal crop - wheat - with a period of fallow. Moreover, on the better soils in this area, pastures for dairy cattle and fat lambs are often more profitable than field crops. The proportion of the area-of cultivable land, therefore, that can be put under crop each year would probably lie between one-quarter and one-third? i.e., about 36 to 48 million acres. It thus ap pears that the yearly crop acreage might possibly rise to nearly double the average acreage under crop during the last decade."

It is not unreasonable to assume, therefore, that increased crop and livestock production is possible and that a great deal of it will come from a more intensive use of land already in the hands of individuals and, probably rather less, but still quite significantly, from low fertility lands in the hands of the Crown or held in large under-developed blocks suitable for sub division into farm units.

The decisions of the individual farmer are thus of great importance. What will-induce him to produce more from an established unit or make him anxious to develop an entirely new holding? The short answer is that he must 
have confidence in the outlook, be satisfied with the incentives offered, possess the financial and material wherewithal to utilize his land re sources and, in the interests of maximizing his profits, possess the best available "know-how" of production. There is much that is hidden in this short answer and it is high time I brought some of it out from hiding.

\section{The outlook for agricultural production}

A well known Missouri farmer, Thad Snow, a visitor not so long ago to Australia, is responsible for the following caution: ${ }^{18}$ "The bad guesses of the dead economists of the slow going past ought to warn living economists against over-sureness in these swift changing times."

It is not only dead economists who have made bad guesses. Some of us living did not see in 1939 a future full of expansion in agriculture. Not all of us do yet, but most would agree that the outlook taken in the sense of "demand" for agricultural produce is very good. I hold this view quite strongly: yet, with an eye on Thad Snow's warning, I do see some trouble looming up in the shape of rising costs. This problem to which I will again refer, emphasizes the inter-dependence of agriculture and the rest of the economy.

The view that the market outlook for Australian agriculture is favourable is most important in the light of the fact that before the war and certainly during and immediately after it, an important question in agricultural discussions was the problem of "burdensome surpluses." Allied with this problem was the notion that agriculture was a declining industry. ${ }^{19}$ The future was not rosy and, therefore, policies which aimed at the expansion of agriculture were thought to be largely misguided.

On the contrary, it was considered that the thing to do was not to discourage the decline in farm employment since this offered the best hope for improving

18 Quoted by Dr. W. J. Topp in Journal of Farm Economics (United States), November, 1949, p. 792.

19 Although it is related, I am not using the technical concept which defines decline in terms of the falling share of total national income available for those dependent upon agriculture, but rather in the more absolute sense of actual decline in farm income for which the only remedy was considered to lie in curbing production and rural employment. 
the lot of those remaining. Nor was this view as silly as may now seem. It is still probably a fundamental element in economic progress in under-developed thickly populated countries such as India. But even in Australia it was fair to argue that if the world didn't want our produce at payable prices, then fewer farmers would suffice to produce what was required. This was the more true since rising production per person engaged in agriculture meant that as much output as before was possible with fewer people. The case for an enlarged agriculture today is that more production is in fact needed.

Behind the pre-war state of affairs were, of course, world and Australian market conditions which now seem no longer as limiting as they were then. The changed outlook is associated with:

a) Rising populations in Canada, the United States and Argentina have increased home consumption in those countries and so reduced the pressure on world markets that would have otherwise resulted from the admittedly large increases in production which have occurred in Canada and the United States.

b) The rising populations and living standards in Asia which are of particular importance for the marketing of grain for human consumption. It is frequently overlooked that in terms of dry matter the world's food supplies comprise about 94 per cent grains and other plant food and only 6 per cent of animal products. ${ }^{20}$ Moreover, while it is true that as incomes per head rise a smaller and smaller proportion of the additional income is spent on food as a whole, it is unwise to translate this to mean that as living standards in Asia rise the market for our grains will not expand. Quite apart from their rapidly growing numbers, peoples whose living standards are improving from low to little better than low are likely still to spend a quite large proportion of their additional income on basic foods rather than luxury foods and non-foodstuffs. This explains the considerable political importance of grain supplies in the relations of the Western world and Eastern Europe with Asia.

c) Full employment as a world policy, if successfully sustained, must make a tremendous difference to the market outlook for exporting countries as compared with the pre-war situation. Undoubtedly the greatest factor in

20 Estimate by Pearson and Harper in The World's Hunger, p. 6. 
the existence of "burdensome surpluses" in the 'thirties was large-scale unemployment in Europe and North America - much of it seemingly permanent in character. ( $c f$. the "depressed areas"). In fact, successful policies of full employment on an international scale are much more likely to promote security for primary industries and at less cost to the general taxpayer than the best devised stabilization schemes which may be planned in the expectation of severe economic depressions. In passing, however, it should be noted that few blessings are unqualified. Full employment also brings with it problems for Australian agriculture as I shall shortly explain.

d) The United Kingdom is no longer quite the limiting factor in our total market prospects that it was in the pre-war period, although it is of critical importance for certain products, especially for meat, dairy and fruit products.

e) Australia is a sterling area supplier and while the dollar problem remains with us, and it is likely to for some time, Australian products will enjoy a competitive advantage in sterling area and non-dollar markets on this score alone.

f) The long run trends in the United States favour increasing imports of certain foodstuffs and of raw materials, notably wool and minerals.

g) Not the least favourable factor in the outlook for Australian agriculture is the growth of Australian population - a principal element, indeed, as we have seen, in present production policies.

All told, then, there are good reasons why the prospects for primary production are good. The expectations of improved terms of trade for Australian exports seem well based on the demand side and in this sense at least Colin Clark $^{21}$ deserves honour for his prophecies. The demand outlook is good - but it doesn't follow that the cost of imports to Australia will fall or lag relatively to the level of our export returns. At the present time export prices are showing a small but significant advantage in our terms of trade. There is a danger, however, in dealing in aggregates only, for if wool and wheat are excluded, the terms of trade for our exports in relation to imports are less favourable than before the war, although in the last year or two improvement is noticeable. Meanwhile we

21 See Economics of 1960, and for more moderate estimates, W. A. Lewis in Journal of the Manchester School of Economic and Social Studies, May, 1952. 
can assume that the prospects are that raw material and most food prices will remain firm (excluding annual and cyclical fluctuations) comparatively to prices of manufactured goods - particularly if trade in manufactured goods becomes a little freer than it is now.

While the pull of world demand is in the right direction for Australia, it should not be assumed that the rope will always be at full stretch. The fluctuations we have had in the wool market should be sufficient warning of that. Likewise, present difficulties in marketing some of our exports point to other problems. It is well to look at the possible sources of trouble. Our exports may suffer decreased returns or fail to be competitive for any or all of a number of reasons. For example: a) There is the possibility that full employment will not be steadily maintained in North America or the United Kingdom. Even a small recession in the United States can produce a major set-back for areas supplying raw materials such as wool, rubber and minerals;

b) Asiatic economies may not remain politically and economically open for trade of mutual advantage - particularly if the technical assistance aid programmes from the West prove inadequate in volume and tempo;

c) Substitutes may be developed for commodities now in demand. Wool interests, and therefore Australians have every reason to be watchful under this heading, having in mind the inroads, in markets previously held by wool, already made by artificial fibres;

d) Most painfully apparent at the present time in Australia is the inflation of costs which reduces the competitive advantages of Australian exports in world markets. This becomes the more difficult to handle if cost inflation proceeds at a faster rate than in economies competitive with us or buying our commodities. This is what has occurred during the last two years, and the position would become worse if inflation were to recede elsewhere while ours continued. There is no need to exaggerate this problem for, in fact, we are still comfortably competitive in the basic exports like wool, grains, meat and minerals. Dairy products and processed foods - especially canned goods - have reached a point in costs, however, at which competition in price terms has become more difficult; 
e) Some commodities now covered by long-term contracts would have difficulties in an open market quite apart from the general cost question, because of subsidized competition from major suppliers, notably the United States. This is particularly likely for dried and fresh fruits and may also affect processed milks.

\section{The problem of inflation}

Of these grounds for uncertainty, the two most important are overseas employment policies and internal inflation. About the former we can do little, but the latter is our own responsibility. Farm costs can be attacked from two sides. The first is by increasing productiveness per unit of investment - that is, by increasing output per combined unit of land, labour and capital. This must be a major field of endeavour for research and extension authorities, Commonwealth and State. The second, the present concern of my remarks, is by effective anti-inflation policies. Apart from the personal problem of fixed income receivers, the real cost of general inflation in Australia has been twofold. It has robbed export industries of some of their comparative advantage - defined as the cost at which our goods can profitably be delivered in oversea markets in competition. It has also made more difficult the very expansion of production on existing farms by which cost increases might have been off set; and has greatly inflated the cost of establishing new farms.

Full employment does not necessarily mean inflation of the order we have had. But it is worth noting the further difficulties which inflation and over-full employment have produced for agriculture. In a country as urbanized as Australia, unless agricultural employment opportunities match those of the capital cities, rural labour and farmer-operator groups will be reduced in numbers - attracted by the economic lure of the cities. In turn the effort of those who remain may be less than economic returns would justify because of the lack of labour. If full employment is also sustained, as it has been, at the expense of output of agricultural equipment and materials, the discouragement may well be complete.

The answer to the difficulties produced by rapid inflation is not to eschew full employment but rather the more difficult course of sustaining full employment on a basis which keeps costs in check and which makes it possible for agriculture 
to attract the investment and resources without which it cannot hope to raise its own efficiency of production.

\section{Incentives, taxation and prices}

If we believe we can curb our own cost inflation and have faith in the ability of other nations to purchase our commodities (there is no doubt about their need for them) there is no reason for primary producers to fear a return of the 1930's. There are other problems to be recognized - especially the threat of substitutes for wool - but grounds for optimism are more solid than they were in 1939.

Our next major question then becomes: do the tangible incentives to produce match the generally favourable outlook? This raises the twin devils of tax and price policies, than which no other devils in the agricultural policy hierarchy seem to have more terrifying horns.

I do not intend to review the taxation question except in one most important aspect There can be no doubt that the pitch fork of this devil is well blunted in favour of the primary producer willing and able to develop his farm resources. For this two Governments deserve credit.

In 1947 certain types of capital expenditure incurred on farms were included in items which are allowed as full deductions from gross income for purposes of calculation of taxable income. These included expenditure on eradication of pests and weeds, land clearing, draining of swamps, preventing or combating soil erosion and the construction of dams and water improvements.

In 1952 it was decided that the depreciation rates allowable on all items of plant used exclusively for agricultural and pastoral production were to be fixed at 20 per cent per annum. The commencing date of the 20 per cent depreciation allowance, $1^{\text {st }}$ July, 1951, coincides with the terminal date of the special initial depreciation allowance of 40 per cent. This latter initial allowance applied in the first year of purchase only, and was introduced originally in 1945. It was also allowed to taxpayers who were not primary producers. The new depreciation rates are 20 per cent each year for five years, when the asset will be written off for taxation purposes. The rates are also restricted to units of property used wholly 
and exclusively for agricultural and pastoral pursuits and to buildings on land used for such purposes. The major items excluded are the farmer's own home and motor cars. Farm buildings, fences, machinery and employee accommodation are all included. The increases are particularly important for structural improvements, such as farm buildings and fences, for which depreciation allowances were previously only 2 per cent to 3 per cent per annum. The new rate, applicable to employee accommodation, is also an important incentive for farmers to provide better accommodation facilities for employees.

It is not possible to demonstrate conclusively that the rates of tax payable by farmers are deterrents to production. The problem is of most concern in the sheep industry, in which farmers have moved into higher income ranges to which higher rates of tax apply. In some cases, decisions to grow wheat or graze sheep by large landowners would appear to be influenced not only by such factors as the need to rest the land, but also by the effects of taxation "step rates" on the additional income earned. But the everyday decisions of the majority of farmers cannot be adjusted to avoid taxation, since seasonal conditions exert such a great influence on income. Sales of stock toward the end of the income year may also be affected to some extent by consideration of the effect of such sales on taxable income in that year.

For the rest, the farmer is treated much like any other citizen and has the same right to growl as the rest of us.

\section{Farm prices}

Price questions cannot be so lightly treated, and I feel obliged to state some of the elements in current controversies even if I am not able airily to offer the solutions. Even if greater production appears to be the central objective of agricultural policy, price policy gives every appearance of the principal actor - perhaps in the role of Mephistopheles. Our interest in price policy derives from four aspects: export prices determine export incomes; export prices frequently set floors to domestic prices; export and domestic prices determine farmers' gross income; and finally, the relationships among farm prices have a bearing on the allocation of farm resources between the various end-products. In a completely free market system, export and domestic prices would be identical, and the relationship between 
prices for the various commodities would be a reflection of the relative strength of consumers' demands for them. Thus a rise in wool prices relatively to wheat would suggest diversion of resources to wool. Or again if beef prices were to rise relatively to butter, then the incentive would be for dairying to transfer to beef production where the new land use is feasible.

In fact, however, the whole apparatus of the price mechanism is complicated in its operation by the varying degrees of freedom which operate in the market. The price systems of our exportable primary products may be grouped as follows: Completely free: Wool, which is governed by an auction system open to all comers.

Subject to export controls, otherwise free (or virtually free): oats, barley, maize, and grain sorghum are subject to export permits which can have the effect of placing some ceiling on home prices. Oats are otherwise free from restriction. Barley, maize and grain sorghum are subject to varying degrees of home price control, barley being virtually free as price control has been lifted in the main producing States. Dried vine fruits are subject to a United Kingdom contract but are otherwise free, although, like barley and eggs, Board control represents in itself a form of "administered" pricing.

Subject to UK export contracts and home price control: butter, cheese are subject to contract with the United Kingdom except for an agreed proportion available for "free markets"; and are also subject to strict home and export price controls. Canned fruit is subject to annual purchase contracts with the United Kingdom and home price control.

Subject to home price control but relatively free on export market: wheat at present is subject to three types of "administered" prices:

(i) Export price: most sold under International Wheat Agreement (IWA), balance "free".

(ii) Home price, for human consumption: sold at cost of production.

(iii) Home price, for stockfeed: returns to growers equal ruling IWA parity substantially assisted to this level by Commonwealth subsidy to enable lower prices to egg, dairy and pig raising industries. 
With this array of "free", "fairly free" and "administered prices", it is almost impossible to talk of agricultural price policy as a homogeneous concept. The price system would appear even more complex if I extended the classification to cover additional export products. In practice the best thing to do is to examine the price system proposed for each commodity in the light of stated objectives, and, at the same time, try to remember that hardly any single agricultural commodity price is free from some implications for the production of other commodities. Here I will content myself by reviewing certain principles and illustrate them by reference to actual commodities. ${ }^{22}$ Remember again that the objectives are: (i) to secure to producers returns which will keep them in production - mainly because incomes are satisfactory; (ii) to maximize export earnings; and (iii) result in a pattern of production conforming to the general production programme laid down by the Australian Agricultural Council.

In determining for each commodity a price policy appropriate to these objectives, ${ }^{23}$ the following principles may be useful:

a) The first is quite pragmatic: wool marketing is free and will remain so, except in total war - a contingency outside the scope of this paper. Wool growing is quite profitable and more profitable than most lines of production, despite growing costs. It will therefore continue to attract investment. The decline in prices from the great boom of early 1951, coupled with the traditional uncertainty of wool prices, will reverse some of the swing over to it shown up to 1951 . However, the industry should develop further, particularly dual purpose sheep, in areas suitable to pasture improvement and in the wheat belt where sheep must play an increasingly important part in the farming system. Since wool is not subject to "administered" prices, price policy for other commodities must always have one eye cocked for the actual situation in wool.

b) The relationship between prices must correspond, if practicable, to the needed distribution of resources. This is really a difficult problem in a mixed price system in which wool is free to follow the market while other commodities

22 For those interested in actual price trends since 1939, see Appendix prepared by Mr. E. A. Saxon of the Bureau of Agricultural Economics, showing changes in prices received in relation to prices paid by farmers and changes in the ratio of prices under UK export contracts to import prices

23 It need not be assumed that price policy alone will secure any given objective - $c f$. remarks on dairying below. 
are subject to varying degrees of control. On the whole, however, the pricing system in Australia has conformed fairly well to the normal development of an economic market through rising living standards. Thus, if Australia is regarded as a closed economy or even taken in conjunction with Great Britain, the outlook would conform to the actual development which has occurred, viz., the relative decline in grains for human consumption and a relative increase in livestock output. In fact, however, Australia is not a closed economy in this sense, and the real need is for both. As we have already noted, grain is of great economic and political importance in our relations with the sterling area and particularly with near Asiatic countries. This is why wheat presents a special problem, since acreage is now almost four million short of the desired level. Wheat growing is profitable, but it is contended that the price incentive is inadequate. This is the one part of my paper in which I feel obliged to exercise the reticence of an official, since wheat policy is very much the subject of current inter-Governmental discussions in which I am a participant.

c) The price for any product needs to be profitable enough to induce the level of production desired. If this production is greater than that normally obtained from existing farms, regard must be paid to the cost of expansion, whether on existing farms or from new farms. If the marginal costs of expansion seem high, then price policy may not be an adequate instrument - the answer may lie in direct forms of assistance such as cheap credit, fertilizer subsidies and, not least important, taxation concessions of the kind now available to stimulate farm improvements. As already noted, mere profitability may not be enough if products competitive with that desired are more profitable. Thus in some areas barley and oats offer better returns than wheat. Yet it should be noted that this is only a small part of the explanation of declining wheat acreages. The truth seems to be that wheat has been only partly replaced by other products. Since wheat growing continues to be profitable, it seems to many that given adequate labour and machinery, a substantial recovery in wheat acreage (much of it in the new areas of New South Wales and Queensland) could be expected without loss to the production of other products.

d) Another principle which suggests itself is that returns for extra investment should be comparable with those obtainable outside agriculture. I think I should say that I do not believe that farmers make economic choices as 
rationally as economic theory might suggest. If they did it would be necessary to ensure that the returns on extra investment in farming matched those obtainable by investing their capital, for example, in secondary enterprise. I doubt if farmers think this way. Given the physical means of production, most farmers are willing, and, indeed, probably prefer, to re-invest in their own enterprises if this course of action is shown to be useful (e.g. to set sons up in farming) and profitable. A frequent reaction is merely to let idle balances accumulate.

e) Price policy needs to avoid the impression of inequitable treatment as between commodities. Wheat again presents a special problem, where apparent inequity in curbing home prices must be assessed in the light of offsetting factors, such as the nature of guarantees given to assure satisfactory long-term returns to growers. Undoubtedly, the inflationary effects of domestic price de-control present a genuine problem for Governments. If such effects are taken as decisive in policy, producers will certainly examine the nature of compensations of a non-price character such as guarantees against export losses.

f) The method of price fixing needs to be such that increased efficiency brings gain to the farmers. To the extent that export prices are given and home prices fixed independently of costs, every increase in efficiency as measured by costs per unit of output will add to farmers' profits and, at the same time, will increase their competitive ability in world markets. However, if home prices vary with average production costs, as they do at present for wheat and butter, there is prone to be some indifference on the part of farmers as a group to reduce costs by more efficient methods. Some method of sharing the results of increased efficiency with the consumer needs to be devised, although it remains true that the individual farmer who keeps his costs below the average is still a gainer.

g) An important element in production planning is knowledge of future prices. If a market is "free" this is not possible, but where prices are "administered" an effort should be made to inform farmers ahead of their production cycle of the order of magnitude of prices. This was an important element in the anxiety of the Australian Agricultural Council, at its July meeting in Perth, 
to reach an early decision on wheat policy to cover the 1953-54 crop, the present plan expiring with the crop now growing.

h) You will have noticed that I have not advocated costs of production as a principle of price fixing. Obviously, if prices are regarded by an industry as profitable they will necessarily cover costs for producers so satisfied. I believe costs can be measured accurately enough to check the equity of annual price adjustments as, for example, in oversea contracts, and to test whether returns are, on average, profitable. They also serve as a warning - as in the case of butter - that price fixing in terms of costs alone may only be a partial answer to the industry's problems. Thus, if costs exceed export returns and produce consumer resistance, the time has come to find other ways and means of sustaining and promoting satisfactory economic health in the industry. Costs also have their place in guarantee schemes where they represent a suitable floor to returns expected normally to exceed costs. Wheat fits into this category.

I feel that I must finish this set of so-called principles with a reference to export pricing policy. Wool calls for no comment, while export prices for wheat - both in the case of "free" market sales and sales under the International Wheat Agreement - have been satisfactory. Despite heavy North American crops, wheat prices are likely on the average to be profitable, though in the absence of an Agreement price fluctuations are likely to be greater. The real controversies relate to the United Kingdom contracts for meat, dairy produce, eggs, copra and dried fruit, it being contended by critics that the free world market would be better. In making judgment on this question two or three dominating facts must be kept in mind:

(i) The United Kingdom bulk-purchases most of her foodstuffs. While this continues it is impossible to avoid some form of contract negotiations with the Ministry of Food.

(ii) While it is true that higher prices for meat and dairy produce prevail in markets other than the United Kingdom, there is really no such thing as an unlimited or "free" world market in the sense that the United Kingdom could be replaced at will by other markets. Thus we are selling substantial quantities of dairy produce and meat (including 46,000 tons carcase equivalent in cans) in free markets, but the United States is not significantly 
one of them. This is because that country restricts imports of dairy produce and offers only limited facilities for other food products. I believe we can develop the meat market in the United States steadily but moderately, and there is no reason why this can't be done under the present contract. Nevertheless, the United Kingdom remains the major market for our meat, including canned meat (which is sold outside the long-term contract). Our policy objective must be to secure the best return possible on that market. One valuable feature of the 15 -year meat contract which is already paying dividends is the unique provision under which cost increases in Australia must be substantially covered in the annual price adjustments. A second provision of great importance is that when the United Kingdom gives up bulk purchase, satisfactory floor prices will be guaranteed even though transactions will then be on a trader to trader, or free market basis.

(iii) The third thing to note is that for some contracts prices are undoubtedly better than the free market. Thus copra and dried fruit prices are better than prices on open markets.

The conclusion concerning contracts is clear. There can be no sweeping praise or condemnation of them: each has to be judged on its merits. Bulk purchase by the United Kingdom and closed markets elsewhere partly dictate the answer but the wise course of policy is the greatest flexibility possible consistent with our recognition of Britain as a major and indispensable market.

Price policy is certainly a mixed bag, if I may now leave the metaphor of the devil behind. Despite the fact that farm prices as a group are likely to remain consistent with a dear rather than a cheap food era, they cannot be treated in terms of a homogeneous policy. Policy decisions are affected not only by production aims but by implications for consumers, the division of our price fixing powers, the varying character of the commodities themselves, and, not least, by the character of world markets. For these reasons, it is futile to expect to achieve our agricultural policy objectives through the operations of price policy alone. The aim must be to avoid conflict between production and farm welfare aims on the one hand and price policy on the other. Nevertheless, it is to factors in production other than price to which we must turn also for substantial assistance in promoting the expansion of production. 


\section{Wherewithal of production}

It is indeed in the ability to procure materials and equipment and labour that a, if not the, principal key to the future of Australian agriculture still lies. I have earlier suggested that the post-war tragedy for agriculture was the dearth of sup plies and have cited authorities to suggest that we are not yet at the limits of use of our land resources. Given satisfactory price incentives, investment in expanded farm enterprises becomes a question of adequate supplies of the physical factors in production. Wire, building materials, machinery and fertilizers are prime requisites. Even costly materials are now made attractive by the taxation concessions available, and Australian steel and iron materials and equipment are not costly by world standards.

As already argued, post-war agriculture in Australia has been faced with a gigantic problem of deferred maintenance and replacement without which a satisfactory forward move is difficult. Imports in great volume in 1950 and 1951 helped ease the position and the dollar loans have been particularly import ant. Nevertheless, the great lack has been in Australian produced equipment and materials. Fortunately the basic factors in the production of agricultural requirements in Australia are improving: labour supplies, coal, steel and iron output and zinc supplies for the production of agricultural machinery and equipment are greatly improved and at last offer prospects of overcoming the backlog of demand. The steel industry and zinc suppliers are co-operating in a very fine manner in an effort to meet Government policy wishes. The fertilizer position is less satisfactory although progress is evident. Superphosphate requirements for the full production programme aimed at for 1957-58 are about 2.4 million tons ${ }^{24}$ as against current production of about 1.6 million tons. Imported sulphur is less plentiful and dearer, and conversion of plant to the use of indigenous sulphurbearing pyrites will not result in cheaper fertilizer. The present superphosphate production programme promises an adequate volume but there is a grave possibility that fertilizer costs will rise to a point at which farmers' demands may be discouraged. This may well emerge as a vital matter of policy in the next two or three years, since we cannot achieve our production aims without the use of more fertilizers for pasture and crop development. ${ }^{25}$

24 Estimate by the Bureau of Agricultural Economics.

25 Fortunately a notable exception to this is wheat, in which industry the greatest expansion may well take place in areas not requiring fertilizers - e.g. in northern NSW and in Queensland. 
Part of the recent apparent easing of the situation in respect of supplies of equipment has been due to a falling off of demand. Much of this has been due to the existence of duplicated orders, but a disturbing amount is allegedly due to credit restrictions and uncertainty in farmers' minds about their future policy. Of credit restrictions I will say a word or two shortly. Meanwhile, let me stress that the gap between supply and demand has narrowed only partly because of much needed increases on the supply side. The requirements of the production programme for 1957-58 exceed the now current rate of supply. Once farmers respond to the programme - and I believe they will - the rate of supply of wire, fencing materials, machinery and fertilizers must be stepped up commensurately.

\section{Labour position}

Shortage of labour is often spoken of as a limiting factor on farms. This is true, but I believe that the magnitude of the problem is not as great as often stated. Under conditions of rising productivity per man, fewer men are needed for any given output. Our task, however, is to increase total output substantially. Our 243,000 holdings employ some 395,000 people full time, including the owner-operator or manager, giving an average of 1-6 persons per holding. If the average per farm unit were to rise to 2 , the additional labour force would be some 90,000. I believe 50,000 additional full time hands would make a tremendous difference to the capacity of existing holdings to increase the effective use of land and equipment, either through direct employment or through share-farming. It must be remembered, too, that increasing mechanization and the use of contract services for land clearing and pasture establishment call for more specialized labour in ancillary services.

Fortunately the immigration programme and the general attack on inflation are providing labour resources for farming. Nearly 4,000 additional workers have been placed in farm employment since March, 1952. Taxation concessions will encourage the use of permanent labour by cheapening the cost of providing accommodation and the resources to be used by the extra labour. 


\section{Credit}

One of the most serious problems, judging by Departmental correspondence, is credit for development. The cash position of farmers is strong, but unevenly so. Industries other than wool and mixed livestock/wheat farmers have not enjoyed the boom prosperity many believe. About 15 per cent of farmers, even in 195051 , did not earn a taxable income. Their problem is not always one of price but rather more often one of poorly developed holdings. The agricultural credit system is of great importance in this connection and it is open to question whether it is adequate for the task ahead. ${ }^{26}$

Inadequate funds rather than facilities are perhaps to blame. Banks have in fact increased advances to farmers, but not as much as to other users of credit. Total bank advances to farm enterprises have fallen from 27 per cent of total advances $^{27}$ as at December, 1948, to 18 per cent in December, 1951 - with a further slight fall evident since that date. Total business advances went from $£ 346 \mathrm{~m}$. to $£ 580 \mathrm{~m}$. in that period, while advances for agricultural, grazing and dairying purposes rose only by $£ 25 \mathrm{~m}$. - from $£ 110 \mathrm{~m}$. to $£ 135 \mathrm{~m}$. The explanation is not entirely to be found in credit restriction on policy grounds, for part of the explanation is undoubtedly that high wool incomes reduced the need for credit. Moreover, farmers with a will to borrow couldn't obtain the real resources for development. Banks naturally lent elsewhere, and it is proving difficult to redirect funds to primary production.

Credit must frankly be put down as one policy problem not yet satisfactorily solved. The recent abolition of Central Bank restrictions must finally demonstrate whether or not the difficulties have arisen, not from Central Bank policy, but rather from a tightness of funds and general preference by banks for non-farm investments. It will be another kind of tragedy if, as equipment and labour supplies improve, credit and cash re serves cannot be combined to enable development to take place. In this connection, it should be noted that funds for farm purchase are less important than credit for clearing and water conservation, pasture improvement, fencing and-mechanization.

$26 C f$. the Fifth Report of the Rural Reconstruction Committee.

27 Total banks: Commonwealth Bank and Trading Banks and excludes State Banks. Source: Commonwealth Banks and Commonwealth Statistician's returns as published. 


\section{"Know-how"}

What, in using the vernacular, I have called "know-how" is something which Australian farmers possess in fair abundance, but not as much as the increasing store of knowledge available to our scientists would warrant. In my view we have hardly begun to show farmers what can really be done with their land. For too long Australia has boasted of its high output per man and has appeared to discount the scope for more per farm and per unit of total resources invested. The goal should be to bring knowledge of proven practices to all farms, not just a few. Quoting Sherman Johnson ${ }^{28}$ we can assume certain changes within agriculture. "We can safely predict a continuation of the shift to mechanical power. ... Further progress is to be expected in crop and livestock improvements, use of lime and fertilizer, conservation, pest and disease control, and other improved practices." The object of policy will be to bring the benefits of these practices to all farmers not yet enjoying them. This is primarily a field for State endeavour. States between them now spend well over $£ 3 \mathrm{~m}$. on technical services of the kind contemplated. The Commonwealth, apart from the efforts of the CSIRO, ${ }^{29}$ has been supplementing State efforts, particularly through the dairy grant of $£ 250,000$ per annum. This year it has offered an additional $£ 200,000$ for increased extension activity. Further, the Commonwealth Government has invited the States to work out with it, a longer-term plan giving continuity to its assistance. It is also inviting industry groups to assist from their own financial resources, as indeed the wool, meat and dairy industries have been doing.

The main principle which calls for recognition in this work is that ideas conveyed to farmers must be those which it will pay them to adopt. Further, the educational effort will be use less if not backed by supplies of material or the financial credit which may be necessary.

\section{The role of public investment}

From the expenditure of public funds on farm advisory service it is a natural step to the wider question of the role of public investment in agricultural policy. This

28 See Journal of Farm Economics, May, 1950, p. 233.

29 Although not discussed in this paper, I regard the scientific research of Commonwealth and State bodies as being of first class importance in a successful agricultural policy. 
role is of high importance in the creation of new farms and in the development of ancillary needs for farm production, such as the improvement of stock routes and of transport facilities. In all the fields of public investment it is safe to say, unfortunately, that the rate of developmental activity is lagging behind need. It is fair to admit, too, that the problems both for Commonwealth and State are very great. It is here that the status of the Commonwealth's declared policy is most open to doubt. If it is to rank in importance with defence, then public investment in agricultural development is due for a fresh approach, in which both Commonwealth and State Governments are involved. Two difficult priority decisions have to be made. The first is the share of total investment to be allotted to the needs of agricultural policy, and the second is the order of preference within that share. Since we operate on a federal system the desirable course of action would be for all Governments to get together on a total plan of development. The States have primary rights and responsibilities in these questions: yet Commonwealth assistance is so much sought that I believe the Commonwealth must share with the States its views on the relative importance of various projects submitted to it. Likewise, the Commonwealth's own public investment programme in agricultural fields - not inconsiderable in closer settlement - needs to be fitted into the total scheme.

It is quite possible that the problem will not in fact be tackled this way but that the final shape of the public investment programme will develop as the result of independent decisions by the several Governments. This need not spell disaster for agricultural policy if in fact the emphasis on agricultural works is nevertheless increased. In this respect there is certainly scope for closer Commonwealth relations with the States severally. For example, the needs of the beef industry call for close co-operation in Northern Australia between the Commonwealth and Western Australia and Queensland. Again, expanding closer settlement activities call for similar co-operation. It is especially a serious matter that closer settlement activities should in fact be declining in some States and barely holding recent levels in the others. War Service Land Settlement has made an important contribution in developing new areas in most States and in intensifying production in Victoria and New South Wales. Even so, the total number of farms (not all additional) being provided now amounts only to 7,000. The terms of settlement are very generous and the scheme has succeeded for those settled, where that of the 1920's failed. However, there is a danger that the scheme will establish a comparatively 
few settlers very well, but not as many as it could, or as the situation demands. The time has come to review the agreements with a view to modifications which might stimulate a greater rate of settlement.

An important element in current difficulties in opening up new farms is the great increase in costs. To establish efficient farm units on a fully operating basis now requires three times the capital necessary in 1939, and twice that needed in $1945 .{ }^{30}$ It should be possible to proceed at a faster rate of settlement if private capital contributions were given greater scope. A certain proportion of closer settlement activity could be reserved still for participation by those with no capital, but a parallel settlement scheme should be possible in which a requisite for participation is a higher capital contribution by the settler. In this way a given amount of public expenditure will produce more result; especially in those States where suitable Crown lands are still available for use. The tedium of this paper will be too greatly increased if I dilate further on public investment. Accordingly I will be content with reasserting that public investment is most necessary, whether it be in more railways in the North or more irrigation farms in Queensland or land clearing in Western Australia. I would like to state, also, that there is room for the combined efforts of public and private capital investment - not only in the way just mentioned but also in the way being pioneered by the AMP Society in South Australia. It is true that from existing farms we are likely, in the short run, to gain most of the increase in production. It is equally true that in the long run we must have more farms and much more transport development. But we cannot afford in this connection to think of the "long run" as being a much more distant period. Public policy statements recognize this, but have yet to come to firm grips with the problems implicit in the need for public in vestment in agricultural expansion.

\section{Machinery of policy making}

It is not unreasonable to comment that if public actions in support of stated policy objectives seem less than completely integrated, the position would be even less satisfactory were it not for the work of the Australian Agricultural Council.

30 Estimates from the Bureau of Agricultural Economics. 
In the international field Australia has participated fully in the work of $\mathrm{FAO}$, and through this and other international activities has much improved its knowledge of the needs of others for its food and raw material production. It has developed quite close liaison in food policy planning with the United Kingdom. This is of particular importance to defence preparations but of wider significance also. It is in process of developing relations with the United States which promise a more in formed mutual understanding of the role of Australian agriculture in the affairs of the world. Yet, if planning be a fair description of agricultural policy making in this country, the planning machinery is the Australian Agricultural Council - a body which, in my view, has received rather less than justice at the hands of its critics.

\section{The Australian Agricultural Council}

The Council was established in 1934 with several functions, all related to the "promotion of the welfare and development of agricultural industries." The Council has two parts. The Council proper is a body of Ministers comprising the Minister for Commerce and Agriculture as Chairman and the State Ministers for Agriculture. There is provision for the Council to co-opt such other Ministers as are concerned with special matters on the agenda. The Standing Committee comprises the permanent heads of the Department of Commerce and Agriculture, the Commonwealth Scientific and Industrial Research Organization and the State Departments of Agriculture, together with representatives of the Commonwealth Departments of Health, Treasury, and, latest addition, Department of Territories. The Committee meets before the Council, prepares an agenda and recommendations for Ministers or material for Ministers to debate. The Commonwealth provides the Secretariat.

The work of the Council has been criticised $^{31}$ on the score that it did not meet often enough; that the Commonwealth prepared too many schemes from inexperience of the real problems of agriculture, and then forced them on reluctant States; that the Commonwealth gave the States less than adequate information; and that the Council lacked authority in its decisions. Some of the

31 Those interested may refer to the Rural Reconstruction Commission's Report, No. 6, for a statement of functions as well as a critical review of the Council in action. See also address by writer in Public Administration, September, 1952. 
criticisms of the Council's work in the war years had force, but I believe those directed principally at the Commonwealth now lack validity. Moreover, I doubt whether the fact that Commonwealth and State Ministers confer without final authority from their Governments is necessarily a fatal criticism. There is very little in the content of agricultural policy - particularly in its economic aspects - which does not have important implications beyond the scope of agriculture itself. It is accordingly right and proper that the final decisions remain with the Cabinets of the Commonwealth and State Governments concerned.

The important fact is that in a federal system there is instrument for Commonwealth-State co-operation in agricultural policy. What is more, the machinery is growing in effectiveness. The atmosphere of the Council's meetings is good and marked by an effort to reach rational understandings on matters at issue. My major criticism would be that too little use is made of the constitutional provision which authorizes the Council to have present at its discussions Ministers concerned with irrigation and closer settlement. At present the Council is diffident about discussing these matters which are most vital to its production programme. I believe, however, that this further development of the scope of the Council's work is not an improbable one.

The Council has certainly made an effort to review the implications of its agricultural objectives and has welcomed a lead from the Commonwealth where this is appropriate, as, for example, on the need for a vigorous programme of expansion in agricultural production. Likewise, it is through the Council that there are evolved effective working relations between Commonwealth and States in the detailed activities of research, extension and marketing. The forum is frequently marked by strong exchanges of divergent opinions but this is hardly a matter for surprise or worry in so complex a field as agricultural policy. The final test is understanding and agreement: on this test the positive score of the Council is mounting.

\section{The role of industry groups}

The Australian Agricultural Council, then, is the instrument of policy making where joint action between Commonwealth and States is required. The several Governments have their own administrative apparatus with which I need not 
weary you. However, in concluding this reference to policy making it is necessary to refer to relations between Governments and industry. ${ }^{32}$ Both Commonwealth and States necessarily have dealings with organized industry groups. Until recently, however, there has been no single group endeavouring to understand and argue the broad issues of national agricultural policy without reference to the particular brand of politics or the platform of specific industry groups. Thus, relations with industry have been very much in terms of wheat, wool, meat, apples, dairy products, and so on. Some of the States are well served with non-political, nonindustry groups such as the Agricultural Bureau in South Australia. In the federal sphere there has recently developed the National Farmers' Union. This body comprises representatives of various industry organizations, but endeavours to speak on matters which are of common concern to them all. It has a long way to go before it can compare in power with the policy making farmer organizations in the United States. Yet, it has recently shown a capacity and willingness to make informed comment and constructive criticism on national agricultural policy.

It remains true, nevertheless, that policy making is pretty much a matter for Governments, consulting the views and wishes of the specialist industry organisations on particular rather than general issues of policy. I suspect this position will last until the National Farmers' Union, or an equivalent organization, attracts more attention from the policy makers. Meanwhile, there are very few other than the most general decisions by Governments which are made in ignorance of the views of organised industry groups. Thus, the decision to seek an expansion of wheat acreage was not dependent upon industry consultation; but the views of industry as to what is necessary to induce this result are very well known indeed!

\section{Conclusion}

In short summary I might conclude with five propositions:

a) There is an Australian agricultural policy - limited in concept but clearly expressed in a production programme. The fact that the policy objective relates to production, rather than to the usual concepts of agricultural welfare, is a reflection of the need - national and international - which has given rise to

32 A subject treated in rather controversial form in the 10th Report of the Rural Reconstruction Commission. 
b) The policy objective - increased production - is reasonably sound in terms of the world market outlook with cost inflation a major danger already assuming serious proportions.

c) Although the picture is confused, incentives for production are, on the whole, better than before the war and supplies of physical resources are now improving after an almost disastrous early post-war experience of shortages.

d) The new policy is still very young, yet the main unresolved issues are fairly readily recognizable. These include wheat stabilization policy, credit for private developmental activity and the rate and direction of public investment in agricultural development.

e) The machinery of policy making comprises the Government organs in the States and the Commonwealth, acting severally and also collectively through the Australian Agricultural Council. Industry opinion is a vital factor in policy making, but for the most part, it is expressed through the specialist bodies representing separately wheat, wool, dairy and other commodity producers.

I would wish to conclude this address by emphasizing that it has not been my intention to argue that there exists a complete and perfectly consistent body of policy. Nor have I conceived it necessary to offer an apologia for the operations of Government.

I live too close to the problem and to Government to be completely free from the danger of rationalizing actions in many of which my own advice has played some part. Nevertheless, my very experience has taught me the futility of expecting to solve agricultural problems through any simple formula. as Dr. Parks ${ }^{33}$ of Iowa State College has expressed it: "The very difficulty and complexity of agricultural problems and the complex role which government is expected to play in agriculture put a limit upon the value of sheer rationality in the development of programmes . . . Therefore, in developing agricultural policies, it may often be soundest for policy makers to proceed in a sort of piecemeal fashion, prepared to let individual circumstances influence the nature of the ... action to be planned in specific cases."

33 The conclusions here expressed are in agreement with judgments made, perhaps a priori, by W. R. Parks in "Guidelines for Agricultural Policy", Journal of Farm Economics, May, 1951. 
I am rather comforted by Dr. Parks' words for they go some way to explain, and perhaps to justify, the obvious ad hoc character of our agricultural policy. If there is anything surprising about that policy as I understand it, it is not the bitsand pieces character of it nor the obvious incompleteness of it, but rather that an attempt is being made to weld the several parts behind a clearly stated objective. If we achieve our production aims in or about 1957 we will then be able to argue whether or not success was due to the various policy decisions made five years earlier, or despite them. 


\section{Appendix}

by E. A. Saxon (Bureau of Agricultural Economics)

\section{Comparison of movements in contract prices with movements in import prices, retail and wholesale prices and prices paid by farmers in New South Wales.}

Shortly after the outbreak of the 1939-45 war, the United Kingdom negotiated contracts for the supply of certain basic foodstuffs with a number of countries, including Australia. These contracts were on a Government to Government basis, the initial contract prices being determined on the basis of what was considered a fair and reasonable level, having regard to prices which had prevailed in the free market immediately be fore the war. The actual terms of the contracts varied as between the different commodities, and provision was made for renewal of the contracts and revision of prices at stated intervals.

As the war progressed, the general level of prices increased steadily in both Australia and the United Kingdom, although an effective brake was applied to the rate of increase by the operation of price control. Increases in contract prices negotiated at intervals compensated farmers in varying degrees for increases in their costs.

When the war ended, the United Kingdom found itself still faced with serious food problems, and in its endeavours to maximize food imports from countries willing to accept sterling in payment, the United Kingdom Government decided to continue the wartime contract buying, and negotiated a new set of contracts for the more important foodstuffs which it needed to import. As a result, Australia is still supplying the United Kingdom with a number of foodstuffs on a contract basis, prices being re-negotiated at agreed intervals - mostly annually.

This Appendix aims to show the relative movements in the contract prices for these foodstuffs and to compare these movements with movements in prices for imports and in prices paid by farmers for goods and services they buy for 
use on the farm and in the home. No attempt has been made to give details of contracts or to indicate money prices. Instead, all prices have been converted to index numbers, the prices in the first year of contract buying (i.e. 1939-40) being equated to $100 .^{34}$ These index numbers are set out in Table $1 \mathrm{~A}$ Table $1 \mathrm{~B}$ reproduces portion of the same series, using the average of the 5 years ended 1949-50 as base. This later base helps to high light post-war developments and permits the inclusion of the Index of Prices Paid by Farmers in NSW, this latter index not having been calculated for years prior to 1945-46.

In Table 2 indexes have been prepared showing variations in the ratios Contract prices Import prices

and

$$
\frac{\text { Contract prices }}{\text { Prices paid by farmers }}
$$

The first set of ratios shows that import prices have in creased to a greater extent since 1939-40 than contract prices for most products. However, if the comparison is based on post-war rather than early war-time experience, the rise in con tract prices much more closely approximates the rise in import prices ( $c f$. Table 1B).

The second set of ratios compares movements in contract prices with movements in prices paid by farmers and shows that contract prices rose relatively more than prices paid in the earlier post-war years, but that from 1950-51 onwards, farmers' costs rose more rapidly. However, it should be emphasized that prices for the two principal non-contract commodities (wool and wheat) rose to a greater extent during this post war period than either prices paid or contract prices.

The tables reveal appreciable differences in rates of increase for different commodities; Table 1 further shows that while import prices rose much more steeply than domestic prices during the war, the rates of increase of both import and domestic prices have differed far less during the post-war years.

34 The last year shown in the tables is 1951-52; thus the prices fixed during the recent contract negotiations with the United Kingdom are not included. 


\begin{tabular}{|c|c|c|c|c|c|c|c|c|c|c|c|c|c|c|c|c|}
\hline$\hat{\mathscr{u}}$ & & 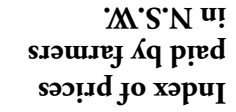 & & 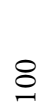 & & 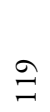 & $\vec{n}$ & $\stackrel{\varpi n}{n}$ & $\stackrel{+}{n}$ & $\tilde{n}$ & $\hat{n}$ & $\stackrel{N}{n}$ & 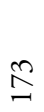 & $\precsim$ & $\tilde{n}$ & 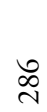 \\
\hline$\frac{0}{\frac{0}{3}}$ & & 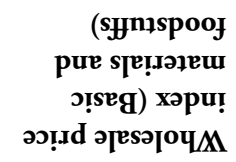 & & & & & & & & & & & & & & \\
\hline דृ & & 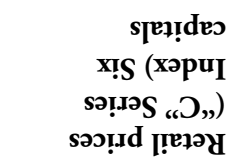 & & 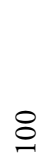 & & $\stackrel{\beth}{\beth}$ & $\stackrel{\text { I }}{\text { I }}$ & $\vec{\beth}$ & $\vec{\beth}$ & $\vec{\beth}$ & $\stackrel{\sharp}{\beth}$ & $\tilde{2}$ & $\stackrel{n}{ \pm}$ & $\approx$ & $\stackrel{\infty}{\infty}$ & $\overrightarrow{\mathrm{N}}$ \\
\hline 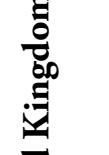 & & 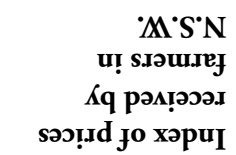 & & & & & & & & & & & & & & \\
\hline 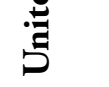 & & 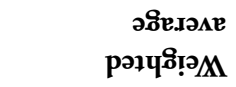 & & 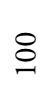 & తి & $\stackrel{n}{\varrho}$ & $\stackrel{0}{\beth}$ & $\stackrel{\beth}{\Xi}$ & $\vec{n}$ & $\stackrel{m}{n}$ & $\underset{\sim}{-}$ & $\stackrel{\infty}{\infty}$ & $\stackrel{\infty}{\stackrel{\sim}{~}}$ & $\stackrel{\sim}{\sim}$ & $\approx$ & $\hat{\wedge}$ \\
\hline 8 & 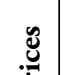 & Je8̂n & 8 & 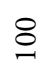 & 巳 & $\stackrel{\circ}{=}$ & ป & 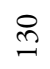 & $\stackrel{n}{n}$ & 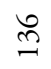 & $\stackrel{\infty}{\circ}$ & $\tilde{n}$ & $\widehat{\widehat{N}}$ & $\stackrel{\star}{N}$ & ते & ñ \\
\hline 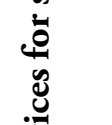 & 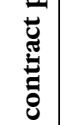 & 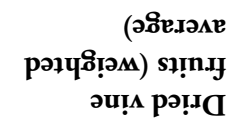 & $\begin{array}{l}\text { के } \\
\text { ồ }\end{array}$ & $\stackrel{8}{ }$ & $\stackrel{n}{=}$ & $\stackrel{\text { I }}{二}$ & 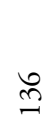 & $\stackrel{\overbrace{}}{ \pm}$ & กี & $\stackrel{n}{\simeq}$ & $\stackrel{゚}{\beth}$ & $\stackrel{\infty}{\Perp}$ & 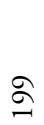 & ڤ્స & m & 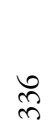 \\
\hline ț & 苞 & Y.10 & 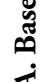 & $\stackrel{8}{0}$ & $\stackrel{8}{0}$ & $\oslash$ & ঃ & $\Xi$ & $\Xi$ & $\Xi$ & ક્木 & $\stackrel{\curvearrowright}{ \pm}$ & $\stackrel{\circ}{\sim}$ & $\stackrel{\sim}{\sim}$ & $\hat{\wedge}$ & $\stackrel{\infty}{\curvearrowright}$ \\
\hline & & uonnW & & $\stackrel{8}{\circ}$ & $\stackrel{8}{\circ}$ & ᄋ & $\stackrel{\circ}{\circ}$ & $\stackrel{\Perp}{\beth}$ & తิ & సે & 음 & $\stackrel{\circ}{\circ}$ & $\infty$ & $\hat{\text { N }}$ & $\hat{\text { N }}$ & $\stackrel{\infty}{n}$ \\
\hline & & qure $T$ & & 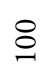 & 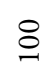 & 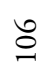 & $\stackrel{\circ}{\circ}$ & ๖ & $\stackrel{ }{=}$ & $\stackrel{ }{=}$ & $\stackrel{?}{ \pm}$ & $\stackrel{\Re}{ \pm}$ & 气ิ & 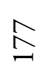 & 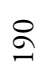 & $\underset{\sim}{\sim}$ \\
\hline : & & fəəg & & $\stackrel{8}{\circ}$ & $\stackrel{8}{\circ}$ & $\stackrel{\circ}{\circ}$ & $\stackrel{\circ}{\circ}$ & $\stackrel{\Xi}{\beth}$ & $\stackrel{\varpi}{\beth}$ & $\Xi$ & 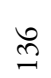 & 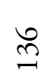 & $\stackrel{ }{I}$ & $\stackrel{ \pm}{2}$ & $\overrightarrow{\widetilde{N}}$ & $\stackrel{\overbrace{}}{\curvearrowright}$ \\
\hline 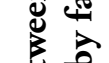 & & sึి. & & $\stackrel{8}{\circ}$ & $\stackrel{ }{=}$ & , & 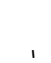 & 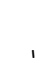 & $\stackrel{2}{2}$ & $\stackrel{\sim}{n}$ & 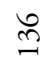 & $\stackrel{n}{n}$ & $\Omega$ & $\stackrel{\infty}{\beth}$ & 穴 & $\stackrel{\sim}{\sim}$ \\
\hline 을 & & әรәәчว & & 8 & 8 & oิ & $\Xi$ & $\Xi$ & 움 & 움 & $\sqrt{6}$ & § & $\stackrel{n}{\sim}$ & సิ & $\underset{\sim}{\stackrel{d}{~}}$ & ث্ণ \\
\hline . & & .jonng & & $\stackrel{8}{\circ}$ & $\stackrel{8}{\circ}$ & $\stackrel{8}{\circ}$ & $\stackrel{\Xi}{O}$ & $\stackrel{\Xi}{\circ}$ & $\tilde{n}$ & $\tilde{n}$ & $\stackrel{\infty}{n}$ & 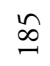 & $\stackrel{n}{\sim}$ & సે & $\underset{\sim}{\stackrel{f}{d}}$ & 규 \\
\hline & & (Yuxg & & $\stackrel{8}{\circ}$ & $\stackrel{\infty}{=}$ & $\hat{n}$ & $\stackrel{\infty}{n}$ & ఠ్ర & $\stackrel{n}{N}$ & 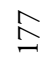 & ชิ & $\stackrel{\sim}{\sim}$ & $\stackrel{\infty}{\sim}$ & 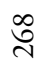 & $\stackrel{n}{n}$ & สู \\
\hline$\dot{2}$ & & $\begin{array}{r}\text { xəpu! əọ!d } \\
\text { p.odu! } \\
\text { ux!̣e.nsn }\end{array}$ & & $\begin{array}{l}\stackrel{+}{1} \\
\text { } \\
\text { }\end{array}$ & 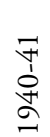 & $\underset{\stackrel{7}{+}}{\stackrel{7}{\leftrightarrows}}$ & 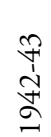 & 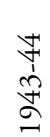 & 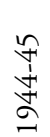 & \begin{tabular}{l}
$\stackrel{0}{+}$ \\
\multirow{2}{*}{} \\
$\stackrel{2}{2}$
\end{tabular} & $\begin{array}{l}\text { fr } \\
\text { bे } \\
\stackrel{+}{=}\end{array}$ & 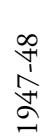 & 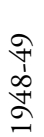 & ڤ̊ & $\begin{array}{l}\tilde{n} \\
\hat{\delta} \\
\end{array}$ & $\frac{\tilde{n}}{\hbar}$ \\
\hline
\end{tabular}




\begin{tabular}{|c|c|c|c|c|c|c|c|c|c|c|}
\hline 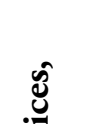 & & 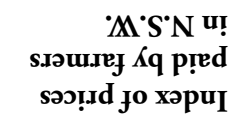 & & $\infty$ & $\infty$ & $\hat{\sigma}$ & ळे & $\vec{\beth}$ & $\vec{n}$ & ڤ \\
\hline$\frac{0}{\frac{0}{3}}$ & & 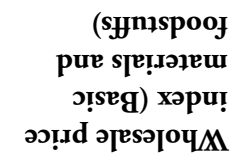 & & $\curvearrowleft$ & 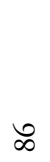 & ๙ & $\stackrel{\circ}{\circ}$ & $\stackrel{\overbrace{}}{\sim}$ & $\stackrel{\infty}{ \pm}$ & $\stackrel{\infty}{\infty}$ \\
\hline 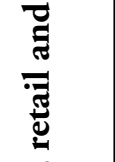 & & 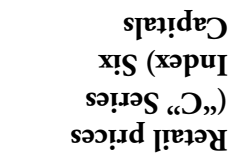 & & ळे & $\bar{\sigma}$ & $\hat{a}$ & $\hat{O}$ & 三 & $\stackrel{n}{n}$ & $\underset{\sigma}{\sigma}$ \\
\hline 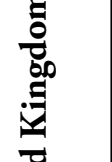 & & 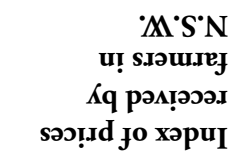 & & 6 & $\infty$ & $\hat{\sigma}$ & 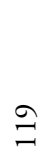 & $\stackrel{\infty}{\sim}$ & $\vec{\sim}$ & $\cong$ \\
\hline 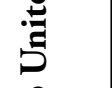 & & 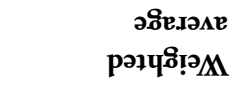 & $\dot{8}$ & $\stackrel{m}{\wedge}$ & $\infty$ & $\stackrel{0}{\circ}$ & $\stackrel{ \pm}{\beth}$ & 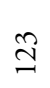 & $\stackrel{\sim}{\leftrightarrows}$ & $\stackrel{\sim}{\sim}$ \\
\hline 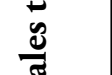 & 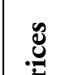 & se8̊ns & ถุ & $\approx$ & $\bar{\sigma}$ & $\Xi$ & $\stackrel{\infty}{=}$ & 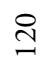 & $\stackrel{\Re}{ \pm}$ & $\stackrel{\Perp}{n}$ \\
\hline$\stackrel{\ddot{\theta}}{\ddot{d}}$ & 节 & 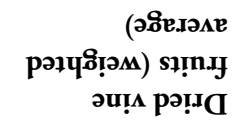 & 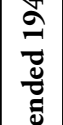 & た & 茫 & $n$ & $\succsim$ & $\Xi$ & $\stackrel{\varrho}{\bumpeq}$ & $\stackrel{\infty}{\infty}$ \\
\hline$\overline{\tilde{g}}$ & 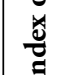 & $\mathbf{Y}^{10} \mathbf{d}$ & 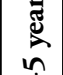 & ৫ & $\infty$ & $\infty$ & 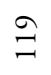 & $\stackrel{ }{Ð}$ & $\mathfrak{n}$ & $\triangleq$ \\
\hline 8 & & uomn & فू & n & ळ & ळ & $\stackrel{0}{\circ}$ & $\cong$ & $\cong$ & $\stackrel{n}{n}$ \\
\hline 苛 & & que'T & & $\curvearrowleft$ & $\stackrel{\infty}{\curvearrowleft}$ & $\stackrel{\infty}{\sigma}$ & $\stackrel{\infty}{\circ}$ & $\vec{\beth}$ & $\stackrel{\overbrace{}}{n}$ & $\stackrel{n}{n}$ \\
\hline : & & fəag & & $\curvearrowright$ & ฉ & ฉ & $\stackrel{\sim}{\Xi}$ & $\stackrel{\infty}{\sim}$ & 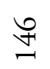 & 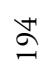 \\
\hline 总 & & s.8̊日 & & ț & $\stackrel{\infty}{\infty}$ & $\stackrel{\infty}{\Omega}$ & $\Xi$ & 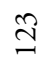 & $\stackrel{\text { I }}{=}$ & 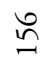 \\
\hline$\stackrel{0}{=} \stackrel{a}{a}$ & & әรәәчว & & $\curvearrowleft$ & $\infty$ & ప્ & $\stackrel{\Xi}{\Xi}$ & $\underset{\nearrow}{\beth}$ & $\cong$ & $\Xi$ \\
\hline. & & .Jonng & & $\stackrel{m}{n}$ & $\infty$ & ప્ర & $\stackrel{0}{=}$ & $\stackrel{\Perp}{\sim}$ & $\stackrel{\leftrightarrow}{n}$ & $\stackrel{ \pm}{ \pm}$ \\
\hline & & (Yurg & & $\stackrel{\infty}{\wedge}$ & ळे & $\stackrel{+2}{\stackrel{2}{0}}$ & $\stackrel{\circ}{=}$ & $\stackrel{\infty}{=}$ & $\stackrel{ \pm}{ \pm}$ & $\stackrel{8}{0}$ \\
\hline$\dot{2}$ & & $\begin{array}{r}\text { xəpu! әэ!nd } \\
\text { p.odu! } \\
\text { ue!̣ןensn }\end{array}$ & & 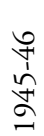 & $\begin{array}{l}\text { fr } \\
\text { bे } \\
\text { ఫે }\end{array}$ & 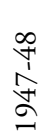 & 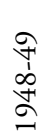 & 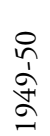 & 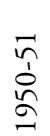 & $\frac{\tilde{n}}{\tilde{n}}$ \\
\hline
\end{tabular}




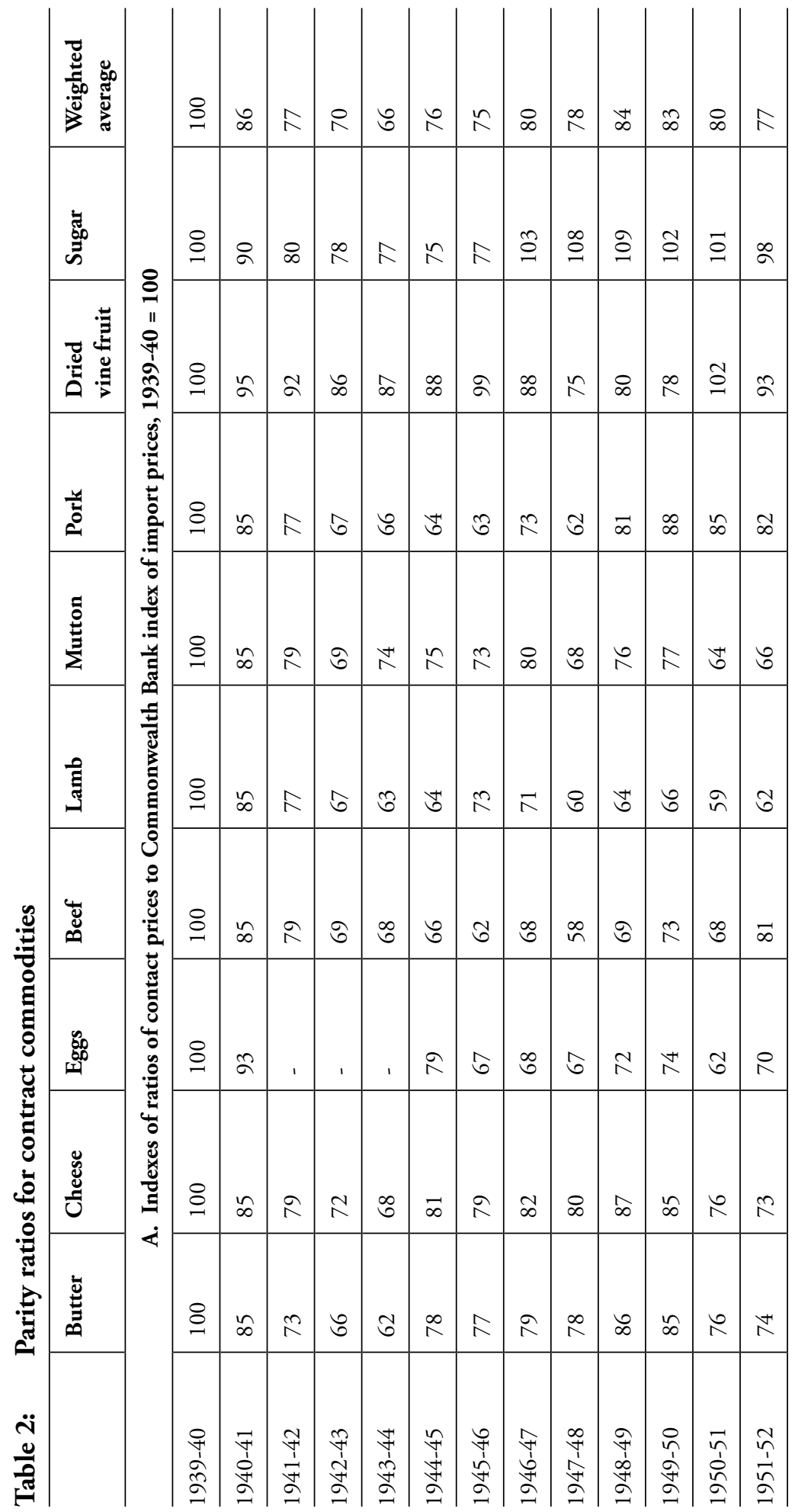




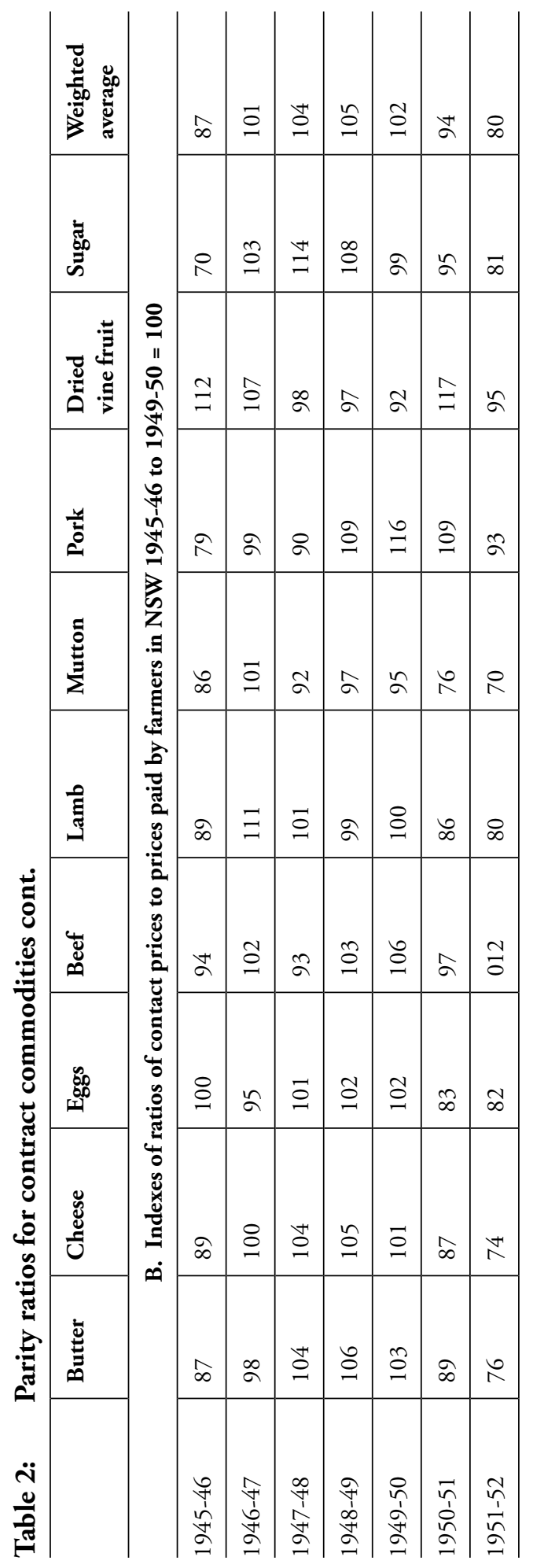





\section{6}

\section{The economics of Federal-State finance}

\section{Wilfred Prest $t^{t}$}

The problems of federal-state financial relations have always been of considerable importance to the economy of South Australia. Some discussion of the issues involved will, therefore, I hope, provide a suitable subject for the Joseph Fisher Lecture, particularly as the issues are not merely local in character. Indeed they are of importance to every federal country, and with the creation since the War of new federations in countries such as Nigeria, Rhodesia and Nyasaland and the British West Indies, they have become the subject of much discussion throughout the British Commonwealth.

It would not be possible in the time available to survey systematically the whole range of federal-state financial problems, and I therefore propose to concentrate on the following three major issues, and to confine my attention to their economic, as distinct from their constitutional and political aspects:

1) co-ordination of the public borrowing of federal and state governments, exemplified in Australia by the Loan Council system.

2) the allocation of Special Grants from the federal government to those member states which experience difficulty in raising revenue and providing services on the same level as other states. In Australia such grants are made on the recommendation of the Commonwealth Grants Commission under section 96 of the Constitution. ${ }^{2}$

1 Twenty-sixth Joseph Fisher Lecture, 2 September 1954.

2 The name "Special Grant" has become traditional usage in Australia for this type of grant. In Canada the Rowell-Sirois Commission suggested name "National Adjustment Grant." In England somewhat similar grants are paid to local authorities under the name of "Exchequer Equalisation Grants." Instead of being made separately, Special Grants can be incorporated in General Grants, provided the latter are allocated on a "needs" basis. See below. 
3) the allocation of general grants from the federal government to all states, such grants being necessary because the federal government has revenues in excess of its needs, whereas the states are in the opposite situation. The chief examples of these grants in Australia are the tax reimbursement grants payable under the uniform tax system.

One reason for concentrating on these problems is their intrinsic importance. Another is that the branches of economic theory most relevant to them happen to have been themselves the occasion for much controversy and for revolutionary changes of thought during the past twenty years or so. Thus, the first problem has to be considered in the light of what has come to be known as the Keynesian Revolution; the second problem raises fundamental issues of Welfare Economics; and both Keynesian Economics and Welfare Economics are relevant to the third problem. It will therefore be pertinent to compare modern theory with traditional thought and practice in each of these three fields.

\section{Economics of public borrowing in a Federation}

Until about twenty years ago prevailing economic doctrine provided little or no theoretical justification for public borrowing except for financially reproductive works. It was widely supposed that borrowing for other purposes could lead only to inflation, a conclusion supported rather than contradicted by the experience of the First World War and its aftermath. It is true that Australian public authorities, in common with those in other "new" countries, had for many years engaged in large-scale borrow to finance development, even when no direct financial return could be attributed to the investment within the foreseeable future. But even Australian faith in the merits of loan finance was shaken by the depression of the 1930's. The supply of loan funds was restricted, the States cut their loan programmes and in 1938-39 net loan expenditure on public works by all government authorities was probably little more than $£ 20 \mathrm{~m}$. - and this at a time when the Civilian Register recorded 300,000 unemployed.

The renewal in the post-war years of large-scale loan expenditure for development purposes has coincided with the change in the climate of economic thought for which the late Lord Keynes was principally responsible. This is not the place to attempt summarise Keynes' work. It will suffice to note that Keynes 
demonstrated that public borrowing would not necessarily lead to inflation so long as reserves of idle men and machines were available. Indeed, deficit financing might be essential in order to maintain full employment. By raising incomes, full employment would itself provide the funds to support public borrowing; while the interest rate could be controlled by credit creation through the banking system. Although originally formulated to provide the basis for a full employment policy, Keynes' theory is also relevant to the control of inflation and to problems associated with long-term economic development. It is not too much to say that over the past two decades it has brought about a complete change in the public attitude towards government borrowing and works expenditure.

The economic effects of a public borrowing programme depend not only on its size but also on how it is controlled and organised. A federal state differs in this respect from a unitary state. In the latter the approval of the central government is required for local authority borrowing in excess of certain limits, which limits are themselves determined by legislative act of the central government. In a federation on the other hand, the states enjoy independent borrowing powers equally with the central government. It may be that, by virtue of the constitutional division of powers, borrowing for war and defence is a prerogative of the central government, but the states have a status equal to that of the central government in borrowing for normal civilian purposes.

In Australia, however, this mutual independence has to be interpreted in the light of the Financial Agreement of 1927. Under that agreement the total loan moneys to be raised each year for purposes other than defence, the nature and terms of the securities to be offered, and the allocation of the proceeds among the several governments - all became matters for joint and collective decision by the Prime Minister of the Commonwealth and the State Premiers assembled in the newly constituted Loan Council. Public loans, except those for local and semi-governmental authorities, were to be arranged by the Commonwealth and the proceeds subsequently allocated among the States, which were thus able to borrow on the credit of the Commonwealth. Although in this respect the Commonwealth was in a special position, acting as an agent on behalf of the States, it had like them agreed to refrain from exercising its borrowing powers in independently. In this way formal equality of status between the various governments was preserved. 
Since the end of the War, however, the Commonwealth's position has changed from that of one borrower amongst several to that of, if not the chief creditor, at least the major supplier of the available loan funds. This development has come about in three ways. First of all, the Commonwealth, after its heavy wartime borrowing, refrained from borrowing to finance its own capital works in peace-time, preferring to meet their cost from current revenue. ${ }^{3}$ This policy has continued despite criticism from the States, which would also like to participate in this source of interest-free finance, and from the political advocates of lower taxation or higher social services. Since the War the only funds which the Commonwealth has regularly sought through the Loan Council have been for advances to the States under the Commonwealth-State Housing Agreement. This policy does not imply any fall in the volume of public works undertaken by the Commonwealth. On the contrary the Commonwealth share of public authority expenditure on "new works and maintenance" (excluding defence) has risen from 10 per cent before the War to nearly 20 per cent in recent years. ${ }^{4}$ The Commonwealth's ability to finance this increased proportion of works expenditure without borrowing arises from the strength of its budgetary position under the uniform tax system. In this connection it is perhaps significant that the Commonwealth similarly met its public works expenditure out of revenue during the first ten years of its existence, when customs and excise revenue, like income tax receipts today, provided a surplus over its own needs.

The second important factor affecting the relative position of the Commonwealth and the States has been the virtual cessation of overseas borrowing by Australian governments in the post war period. At the time of the Financial Agreement in 1927 Australian governments still relied heavily on overseas borrowing, and Principal Mackintosh has suggested that the reason why such an agreement was acceptable in Australia, but not in Canada, is to be found in our relatively greater "dependence on a distant external market." ${ }^{5}$ Certainly, the

3 In the early post-war years this policy seems to have been adopted the then Treasurer, Mr. Chifley, as a means of achieving a cash surplus and checking inflation. It has been continued under changed circumstances by the present Treasurer, ostensibly because sufficient loan funds are not available to finance Commonwealth as well as State public works (Budget Speech, October 18, 1954, p. 5.)

4 White Paper on National Income and Expenditure 1953-4. (Govt Printer, Canberra.) Appendix, Tables VIII-X.

5 W. A. Mackintosh, Chapter on "Federal Finance (Canada)" in Federalism (Ed. Sawer), Melbourne, 1952 , p. 85. 
control and coordination of overseas borrowing was one of the major objectives of the Financial Agreement. During the depression of the 1930's, however, the supply of overseas funds declined and since the War Commonwealth borrowings overseas have been confined almost wholly to comparatively small hard-currency loans from international institutions.

So long as Australian governments relied principally on overseas loans, the supply of funds was something over which the Commonwealth had no control. The local supply of funds is, however, another matter. Some sources, such as its own trust funds, are under direct Commonwealth control. Others, such as the banking system, can obviously be influenced directly by Commonwealth policy. Others again are subject to indirect control, particularly through alterations in income tax rates. Thus with the change from overseas to local borrowing, the Commonwealth, instead of being an agent seeking overseas loans for itself and the States, has found itself in the position of influencing, if not actually determining, what can be lent. The realities of the new situation were clearly recognised by the Fiscal Commission for Rhodesia and Nyasaland in 1952. In their report they wrote:

"We have studied the model of the Australian Loan Council we are convinced that arrangements on similar lines would be suitable for the Central African Federation. We envisage that the Loan Council will be the sole authority for external loans except defence. The Loan Council, however, should have no jurisdiction over internal loans . . . Not because we feel that consultation and co-ordination in matters of internal borrowing is less necessary, but because these are so intimately connected with general control over monetary policy which can only be effectively exercised by the Federal Government . . . It appears natural to assume that no public issue of an internal loan would be made by a Territorial Government or even by a Municipality without the cognisance of the Federal Treasury."

Thirdly, the very magnitude of post-war investment and borrowing has compelled the Commonwealth to have regard to its general economic

6 Report of Fiscal Commission on Draft Federal Scheme for S. Rhodesia, N. Rhodesia and Nyasaland (Cmd. 8672), Paragraphs 35-37 have been run together in the above quotation. 
consequences. In a federation responsibility for full employment, economic development and the avoidance of inflation must necessarily rest with the central government, one of whose primary functions is the operation of a common monetary and credit system. In Australia this has entailed the two-fold task of, first, restraining the States from undertaking borrowing and investment programmes too large for the economy to support without inflation; and then ensuring that essential investment programmes are not jeopardised by inadequate subscriptions to Commonwealth loans. In recent years Loan Council borrowings have amounted to about $£ 200 \mathrm{~m}$., and local and semi-governmental borrowings to a further $£ 70 \mathrm{~m}$. or $£ 80 \mathrm{~m}$. per annum. The States have regularly submitted much larger borrowing programmes to the Loan Council but the Commonwealth has opposed them. On several occasions the States have been able to outvote the Commonwealth, but they have had no power to compel it to make available the credit that alone could render their decisions effective. The Commonwealth's view has therefore prevailed in spite of the decision of the Loan Council. On the other hand, the Commonwealth; has maintained the supply of loan funds for the States at that level which it considers adequate by itself taking up special bond issues, financed by funds that would otherwise have been: used to redeem Treasury Bills. Real authority has thus been shown to lie elsewhere than in the Loan Council, and the cleavage of interest between the Commonwealth and the States has become acute.

In the post-war period Commonwealth policy, and the Commonwealth's view of what the economy can stand, has thus imposed an effective limit on public investment expenditure, hence on public borrowing programmes. This is very different from the situation that existed before the War when public borrowing was restrained by an equally effective limiting factor but one that admitted of less argument. This was the fear of both lenders and borrowers that increased public debt charges would have disastrous consequences on state budgets. Nor was the fear unfounded. In 1938-39 public debt charges amounted to 46 per cent of state expenditure, other than current expenditure on business undertakings, and it is clear from the early reports of the Commonwealth Grants Commission that they had a crippling effect on state budgets. ${ }^{7}$ Since the War, however, the

7 e.g. Commonwealth Grants Commission, Third Report (Canberra 1936); pp. 25, 41 and 177. 
relative importance of debt charges has been greatly reduced They now account for only 21 per cent of state expenditure, other than current expenditure on business undertakings. The reason for this change is not far to seek. The postwar inflation has reduced the burden of debt charges relatively to other items in the state budgets whereas the deflation of the 1930's had worked in the opposite direction and made the burden heavier.

The submergence of debt charges by the inflation may, how ever, have been a temporary phenomenon. With the attainment of economic stability and the continuance of heavy state loan programmes, debt charges are likely to acquire an increasing importance in the next few years. In this connection it is disquieting to observe that they are rising at the rate of about $£ 5$ m. per annum. In 1947-48 they still stood at their pre-war figure of about $£ 40 \mathrm{~m}$. but in $1953-54$ they had risen to about $£ 60 \mathrm{~m} .{ }^{8}$ The day, therefore, may not be far distant when they will re emerge as an important factor in public finance.

To the extent that this happens the consequences of the Keynesian Revolution may prove somewhat less far-reaching than appeared likely in the immediate post-war years. This is not to say that any government could ever again tolerate the proportion of unemployment that prevailed in the 1930's. Governments may, however, be compelled to weigh more carefully the cost of borrowing against the advantages that accrue in the maintenance of full employment, the absorption of migrants and the development of the economy. What this comes down to is simply the need for more careful calculation of priorities between different projects and different avenues of expenditure. This in its turn, however, seems likely to increase rather than reduce the financial predominance of the Commonwealth Government.

\section{The economics of special grants}

In every federation substantial differences exist between the various member states in respect of area, population and come; and sometimes of language, religion and culture as well. On the financial side these differences are likely to result in some

8 This figure is an estimate. Actual figures for previous years can be found in the Commonwealth Year Books, Finance Bulletins and Reports of the Commonwealth Grants Commission. 
states being able to raise less revenue per head than others, even with the same tax rates; or incurring heavier administrative costs in providing the same services. They will therefore experience greater difficulty in balancing their budgets and may be forced to raise tax rates above, or to reduce services below, the general level. It is the purpose of Special Grants from the central government to enable such states "to function at a standard not appreciably below that of other states," - to quote the well known phrase from the Third Report of the Commonwealth Grants Commission. ${ }^{9}$

The arguments advanced by economists in justification of Special Grants have generally been based on the propositions of Welfare Economics. They take the form of regarding federal grants to a poor state as analagous to the provision of social: services to the poorer citizens of a unitary country, and as justifiable in similar terms, i.e. by reference to the supposed increase in "welfare" obtainable by transferring income from the rich to the poor.

Welfare Economics and its child, the Welfare State, are today often branded as peculiarly insidious forms of socialism In fact, however, their ancestry derives not from the Marxists, or even the Fabians, but from the utilitarian philosophy of $19^{\text {th }}$ century English Liberals. The formal application of utilitarian principles to public finance was effected by Edgeworth and Pigou early in the present century. The particular problem d federal-state financial relations was analysed in welfare terms by Professor Adarkar some twenty years ago. ${ }^{10}$. A systemic treatment by another Indian economist, R. N. Bhargava, appeared the Economic Journal last year. ${ }^{11}$

Bhargava advances three reasons for the payment of Special Grants to lowincome states:

1) Such grants permit the realisation, over the country as a whole, of Pigou's famous principle that the benefit (or utility) derived from an extra $£ 1$ of government expenditure should be equal to the sacrifice (or disutility) incurred in respect of an extra $£ 1$ of taxation. Without Special Grants, this

9 Op. cit. p. 75.

10 Adarkar, B. P., Principles and Problems of Federal Finance (P.S King, London, 1933).

11 Bhargava, R. N. "Theory of Federal Finance" in Economic Journal March 1953, pp.83-9. 
equality would be attained at a level of utility and disutility which was higher in a low-income state than in a high-income state.

2) Special Grants should be made to low-income states (or rather special taxes should be levied on the residents of high-income states) so as to impose equalmarginal sacrifice on all taxpayers wherever they reside, thereby realising the still more famous Edgeworth-Pigou principle of Least Aggregate Sacrifice. Without Special Grants (or special taxes), marginal sacrifice might be equal as between taxpayers within each state, but unequal as between taxpayers residing in different states.

3) Special Grants to low-income states would permit the realisation of the principle that the benefit (or utility) derived from government expenditure is maximised when the marginal utility of every type of public expenditure, whether federal or state, is equalised over the country as a whole. Without Special Grants, this equality would be effected at a higher level of utility in low-income states than in high-income states.

The first and third of these principles are fundamentally similar, being concerned with equilibrium between public and private expenditure, and between different forms of public expenditure respectively ${ }^{12}$. Their strict application, however, would seem to leave no room for the possibility that the ideas of state governments might properly differ, not only from one another but also from those of the federal government, concerning the utility to be derived from different types of expenditure, or from public expenditure generally as against private expenditure. Surely the whole purpose of a federation is to permit variety of local opinion and practice within a certain range of functions. Decisions regarding this range of functions are made by governments elected regionally, whereas decisions regarding other functions are made by a government elected nationally. If this means that there is no machinery for equating the marginal utility of state and federal expenditure, that has to be accepted as part of the price of federalism. It may be observed that in Australia the Commonwealth Grants Commission

12 It is interesting to note that these theoretical principals are endorsed by two authorities with experience of the practical problems of budgeting. One is Professor Arthur Smithies, formerly of the US Bureau of the Budget ("Federal Budgeting and Fiscal Policy" in Survey of Contemporary Economics, 1949, pp. 192-3). The other is no loss a person than Dr. Hugh Dalton, former British Chancellor of the Exchequer (Dalton, Public Finance, 1954 Edition, chap. III). 
has always endeavoured to leave the claimant states free to deter mine their own pattern of taxation and expenditure.

The second principle if pursued to its logical conclusion would, in a federal as in a unitary country, lead to equality of incomes, after the deduction of taxes and the addition of social service benefits, between all citizens wherever they resided. It assumes, however, that inter-personal comparisons of utility are possible; that a community of rich persons has no greater inherent capacity for enjoyment than a community of poor persons; and that the marginal utility of a high per capita income is less than that of a low per capita income. But this is precisely the point at which traditional welfare theory is most vulnerable. These assumptions have in fact been a matter for dispute at least since the publication of Professor Robbins', Nature and Significance of Economic Science in 1932. In view of the controversy that they have aroused it is remarkable that Mr. Bhargava should take them so much for granted.

The challenge to these basic assumptions of welfare theory has been countered by efforts to restate some at least of its main conclusions on more objective and defensible premises. An attempt to do this for the theory of Special Grants has been made by J. M. Buchanan. ${ }^{13}$ In place of inter-personal comparisons of income and the Least Aggregate Sacrifice Principle, Buchanan has fallen back on the older Equity Principle, by which "similar and similarly situated persons ought to be treated similarly." 14 Buchanan's argument is that Special Grants to a low income state are justified in order to ensure that the net result of fiscal operations, including not only taxation but also the benefits derived from government expenditure, should be equal for all taxpayers at each level of income, in whatever state they reside. "The principle establishes a firm basis for the claim that the citizens of the low-income states within a national economy possess the right that their citizens to be placed in a position of fiscal equality with their equals in other states. A transfer viewed in this light is in no sense a gift or subsidy from the citizens in more favoured regions." 15

13 J. M Buchanan: "Federalism and Fiscal Equity" in American Economic Review, Sept., 1950, pp. 583-99.

14 Compare Professor Maxwell s pertinent question "Are needy individuals in a Federal country to be deprived of desirable governmental services because of niceties of constitutional law?" Maxwell, J. A., Fiscal Impact of Federalism the United States, p. 30 (Harvard. 1946).

15 Buchanan, op. cit., p. 596. 
In its general application to public finance the Equity Principle has been criticised on the ground that it provides no clue as to how dissimilar individuals should be treated. This criticism, however, does not seem relevant to its application to the problem of special Grants since the pattern of fiscal benefits and sacrifices is set by that which prevails in the higher-income states. The Equity Principle, unlike the Least Aggregate Sacrifice Principle, has to take that pattern as a datum, but this may be all that is necessary for practical purposes. The difficulty from the practical point of view is the statistical one of calculating the net effect of all fiscal operations on taxpayers in each income bracket and in each state. In Australia the Commonwealth Grants Commission regularly compares the per capita cost of social services in the various states and estimates the relative severity of state taxation, but these are only two elements in the problem. Nevertheless, although statistical difficulties may limit the practical usefulness of Buchananan's formulation, it does serve a valuable purpose in systemising previously vague notions of a fairness or "equity", and expressing them in economic terms.

The arguments so far considered have been concerned with the effects on "welfare" or " equity" of a redistribution of income from richer to poorer states by way of Special Grants. These somewhat subjective benefits might, however, be offset if the Special Grants, by removing income inequalities, also removed incentives to the migration of labour, and thereby adversely affected the level of production. This argument, which transfers the discussion from the plane of the redistributive aspect of welfare theory to its production aspect, has been developed in some detail by Mr. A. D. Scott. ${ }^{16} \mathrm{Mr}$. Scott argues that sub standard services and high taxation in a state where incomes (and labour productivity) are low, provides an incentive for labour to move to a state where incomes (and labour productivity) are higher; and that such a movement will bring about a better distribution of resources and a higher national product. He therefore concludes that if Special Grants permit a low income state to maintain the same level of taxation and services as a high-income state such grants will "counteract this incentive to labour mobility and thus prevent the maximisation of national production." 17

16 A.D Scott, "Note on Grants in Federal Countries," Economics, November, 1950, pp. 416-22.

17 ibid, p. 419. 
Insofar as a state is over-populated and income, or employment, is therefore relatively depressed in all occupations Mr. Scott's argument might be valid. Suppose, however, that relatively large proportion of the population of a state is engaged in an occupation which is depressed in all states. The appropriate remedy then would be a transfer of workers into other occupations and not necessarily to other states. This was in fact the situation in Australia in the 1930's. At that time the Commonwealth Grants Commission recognised that if a state was over-populated, "the excess population should move", but the Commission did not consider over-population to be the primary cause of the difficulties of the claimant states. ${ }^{18}$ Incomes were low in those states because a relatively large proportion of their population was engaged in primary production, which was depressed throughout the Commonwealth. The chance of finding employment as primary producers in the other states was virtually nil. The problem was to raise the general level of employment in all states, and to open up other avenues of employment outside primary production.

It is also necessary to remember that variation in per capita income, apart from this inherent ambiguity, is only one of 1 factors responsible for the differences between states that rise to the need for Special Grants. Mr. Scott admits that his argument would not apply insofar as Special Grants are made to enable a state to meet the burden of debt charges arising from public investment policy. ${ }^{19}$ As noticed in the preceding section this factor certainly loomed large in Australia during; the 1930's. Another equally important factor is the smallness and dispersion of a state's population. If the population of a state is relatively small, and still more if it is scattered over a large area, that state is likely to incur heavier administrative overheads than a more populated, and/or more compact, state and will therefore have to increase its tax rates or reduce the standard of its services below the level of its larger neighbours. Moreover a decline in its population would only increase such a state's difficulties, still further forcing tax rates up and services down. ${ }^{20}$ Under these circumstances, budgetary equilibrium

18 Third Report, p. 139.

19 Scott, op. cit. p. 421.

20 This will be particularly so if migration is most common among young adults. Their departure will reduce the proportion of wages in the population, and so depress the over-all per capita income. Correspondingly, the proportion of school-children, pensioners and other dependents for whom social services are necessary will be increased as compared with other states. 
becomes impossible without a Special Grant. Solid reasons for Special Grants thus exist which are quite independent of interstate differences in per capita income.

Special Grants can thus be defended against those who criticise their production effects, as well as against those who criticise their re-distributive effects. For neither purpose is it necessary to accept the more dubious premises of Welfare Economics. It is however necessary to bring back into the picture some features which are commonly forgotten. In this aspect the modern discussion compares unfavourably with the approach developed by the original members of the Commonwealth Grants Commission twenty years ago. Somewhat paradoxically perhaps, they were able to take a broad view in spite of concentrating their attention upon the budgetary difficulties and Fiscal needs of governments. At first sight this seems a narrower and more technical issue than the broad questions of welfare and equity in relation to the individual citizen, and has indeed been criticised as lacking in ethical force. ${ }^{21}$ In fact, however, by admitting "financial stress from any cause" as a prima facie reason for a Special Grant, the Commission of 1933-38 was able to develop a broadly based approach which took account of all the relevant factors and avoided the pitfalls of too exclusive a preoccupation with per capita income or any other single factor contributing to the inability of a state government to discharge its functions. On the other hand they did little to integrate the theory of Special Grants with economic theory in general, and whatever the shortcomings of the modern discussion, it has been valuable in that respect.

\section{The economics of general grants}

Even if we confine our attention to current expenditure and revenue, and exclude the special difficulties which may afflict some member states, we find in most federations a chronic maladjustment between the allocation of functions on the one hand and that of financial resources on the other. Moreover the maladjustment is practically always such as to leave the central government with financial resources in excess of, and the state governments with financial resources in defect of what their respective functions normally require. Under these circumstances it is inevitable that there should be a system of federal giants to all states generally and not merely to states in special difficulties.

21 Buchanan, op. cit, p. 586. 
Two basic reasons for the maladjustment of functions and financial resources, and thereby for general grants, are to be found in the very nature and purpose of federalism itself. One of the objectives of every federation is the establishment of "free trade" among the member states. This requires the transfer to the federal government of an exclusive power to levy customs and excise duties. Historically, this has involved the sacrifice by the federating states of their major source of revenue. The Australian constitution tried to meet this situation by that famous "Braddon clause", which required the Commonwealth to transfer to the States three-quarters of its net revenue from customs and excise duties during the first ten years of federation, and thereafter until Parliament otherwise provided. ${ }^{22}$ In the event Parliament did otherwise provide and subsequent grants to the States have been made out of general revenue, except for road grants which, since 1931, have been mainly provided out of revenue from duties on petroleum products.

Constitutional provisions for the transfer of part of customs and excise revenue to the states are common to many federations and are now proposed for Nigeria and the British West Indies. ${ }^{23}$ The Australian Constitution, however, seems to have been unique in giving the federal parliament power to vary such an arrangement after a limited term of years. Nevertheless, from the States' point of view this may have been less serious than the judicial decisions which have deemed sales taxes to be excise duties and precluded the States from this field of taxation also. ${ }^{24}$ In this respect the situation in Australia is very different from that in the United States and Canada, where not only the states or provinces, but also the local authorities, derive a substantial part of their revenue from sales taxes or purchase taxes. ${ }^{25}$

Another necessary function of the central government in any federation is Defence. The financial power to cope with an emergency must therefore be vested in, or acquired by, that government. In this connection what appears to be

22 Commonwealth Constitution, Sec. 87.

23 See Report of Fiscal Commissioner, Nigeria, Cmd. 9026, H.M.S.O., London, 1953, para. 43-44; and Financial Aspects of Federation of B.W.I. Territories. Dispatch from Comptroller of Development and Welfare, Barbados, 1953, p. 5.

24 Arndt, H. W.; Judicial Review under Section 90 of the Constitution, in Australian Law Journal, Vol. 25, 1952, pp. 676-7.

25 Binns, K. J., Federal Financial Relations in Canada and Australia, Hobart. 1948, p. 5. 
an excessive revenue in normal peace-time conditions may well turn out to be a deficiency in the abnormal conditions of war. It was largely because of the increase in defence expenditure prior to the First World War that the Commonwealth Government discontinued the payment of customs and excise revenue to the States, after the statutory ten-year period expired. Also it was during the First World War that the Commonwealth first imposed an income tax. More significant still, it was during the Second World War that the Commonwealth excluded the States entirely from the income tax field. It is worth recalling that the Commonwealth was impelled to take this step in order to tap unused taxable capacity in States where income tax rates were relatively low. In normal times the existence of unused taxable capacity in some States might not have mattered, but it became important in war-time when every pound that could be raised by the income tax system was necessary for defence purposes.

These two inherent constitutional reasons for the financial preponderance of the central government in a federation have been powerfully supplemented in recent years by two economic arguments, derived from the developments of economic thought discussed in the two preceding sections of this paper. From the side of Keynesian Economics comes the argument that the levying of income tax should be a prerogative of the central government since it has the responsibility for maintaining full employment. While Keynes himself stated the positive side of his theory mainly in terms of direct control over the level of public investment, and indirect control over the level of private investment through the manipulation of interest rates, his successors and expositers have shown that the same objectives can be achieved by adjustments in current government expenditure in tax rates. The most effective taxes for these purposes are undoubtedly income tax and sales tax. Keynesian Economics, therefore, leads to the conclusion that these taxes should be a federal monopoly.

Finally, from the side of Welfare Economics comes another argument to support the financial predominance of the central government. If welfare can be increased by taxing the rich progressively, and subsidising the poor in cash or in kind, heavy reliance must be placed on income tax, supplemented perhaps by estate and probate duties. There will then be an obvious practical reason for the federalisation of income tax, be with high levels of taxation and social services, any differences among the states might lead the rich to congregate in states which 
the income tax was low, and the poor in states in which the benefits were high. The budgetary equilibrium of all the states would then be disturbed, the former showing progressively larger surpluses and the latter progressively larger deficits.

Economic considerations thus supplement the inherent constitutional factors making for the financial predominance of the central government in every federation. They provide additional reasons for a federal monopoly of income tax and they can also be used to support federal monopolies of sales tax, death duties and pay-roll tax. The logical conclusion is that the states are left with only a narrow range of taxes, mostly of the licence variety, which are neither very remunerative nor very flexible; and that they must, therefore, rely on federal grants for the greater part of their revenue. This is virtually what has happened in Australia, except that the States still levy their own death duties. Even so, federal grants stand to state taxation revenue in the ratio of 2:8:1. ${ }^{26}$ The same tendencies are present in other federations, but nowhere else have they gone so far. In the United States federal grants stand to state taxation revenue in the ratio of only 0:25:1. ${ }^{27}$ Even in Canada the ratio between federal grants and provincial taxation revenue was, in 1951, no more than 1:1 for the provinces which had voluntarily agreed to forego their rights to levy income tax and succession duties. For the two remaining provinces of Ontario and Quebec the ratio was much less. ${ }^{28} \mathrm{In}$ both Canada and the United States, however, a substantial part of state taxation revenue is derived from fields to which the Australian States have no access, such as tobacco and petrol taxation; or only limited access, such as liquor taxation.

General grants from the central government to the member states of a federation may be most usefully discussed, in their Australian context, under the following four headings: (a) the principle of financial responsibility; (b) unconditional versus conditional grants; (c) allocation among the states; and (d) the effects of inflation.

26 In $1952-53$ state taxation and net lottery revenue amounted to $£ 75.8 \mathrm{~m}$. (including payments to special funds), and financial assistance from the Commonwealth amounted to $£ 214-7 \mathrm{~m}$. See 21st Report Commonwealth Grants Commission, app. 3 and 6. Both figures are higher than those shown in the Quarterly Summary of Australian Statistics.

27 Chamber of Commerce of the United States: Federal Grant-In-Aid Program, Washington, 1954, p. 3.

28 Moore and Perry, Financing Canadian Federation, Canadian Tax Foundation, Toronto, 1953, Table 11. Ontario did not enter Into a tax agreement with the Dominion Government until 1952. 


\section{The principle of financial responsibility}

A system of inter-governmental grants which enables one government to spend funds raised by another government is often criticised on the ground that it undermines the sense of financial responsibility on the part of the recipient government. In its absolute form this doctrine was shown to be untenable by the late Professors Giblin and Mills, over a quarter of a century ago. ${ }^{29}$ In 1936 the Commonwealth Grants Commission in its Third Report observed that grants are inevitable in all federations, and provided that they give "the recipient states considerably less than they require to raise, the principle of responsibility is not seriously affected." ${ }^{30}$ More recently Professor J. R Hicks has gone so far as to suggest that federal grants can amount to as much as 75 per cent of a state's revenue without seriously impairing its sense of responsibility. ${ }^{31}$ This limit may well be set too high, but it is being approached in Australia, where Commonwealth payments amounted to 63 per cent of state revenue in $1952-53 .^{32}$

In Australia federal financial assistance to the States b mostly unconditional in character. It is true that some grants are earmarked for special purposes, such as state debt charge under the Financial Agreement, road works, and university pur poses. Nevertheless over 70 per cent of federal assistance to the States comprises general purpose grants, which are earmarked for specific purposes and to which no strings are attached. ${ }^{33}$ In this respect Australia again differs from other federations. In the United States practically all federal grants are for specific purposes and typically require some "matching" expenditure by the states. Even in Canada something like half of the federal grants to the provinces are of this character.

29 L. F. Giblin, "Federation and Finance," Economic Record, 1926, pp. 145-160; and R. C. Mills, "Financial Relations of Commonwealth and States," Economic Record, 1928, pp. 1-14. A few years later Sir Keith Hancock dismissed the same doctrine as "naïve" (Australia, 1945 Edition, p. 96). But the weight of even these authorities was insufficient to prevent its recent revival.

30 op. cit., p. 19.

31 Nigeria: Report of the Commission on Revenue Allocation, Lagos 1951, p. 77.

32 State Revenue is here taken to include Commonwealth assistance $(£ 214.7 \mathrm{~m})$, tax revenue $(£ 75.8 \mathrm{~m})$ and "other revenue" ( $£ 50.6 \mathrm{~m})$. Revenue from Business Undertakings is excluded since it is substantially offset by expenditure on Business Undertakings.

33 It is an illusion to suppose that, because a number of new conditional grants have been introduced in recent years, such grants are growing in relative importance. On the contrary, the proportion of Commonwealth financial assistance given in the form of special purpose or conditional grants fell from 49 per cent in 1945-46 to 29 per cent in 1952-53. See 21 $1^{\text {st }}$ Report of Commonwealth Grants Commission, Appendix 3. 


\section{Unconditional versus conditional grants}

American writers justify the conditional grants system on the ground that it promotes a sense of financial responsibility on the part of the recipient governments. In Professor Maxwell's words, the attachment of conditions to a grant is a substitute for the exercise of control by the taxpayer. ${ }^{34}$ It should be noted, however, that conditional grants in the United States and Canada are almost all designed to induce the states, or provinces, to initiate particular social services and to maintain them at a certain minimum level. This is necessary because in both countries the federal governments have only limited constitutional powers in respect of social services. In the United States the only federally administered welfare scheme is the Old Age and Survivors' Insurance System. ${ }^{35}$ In Canada only three of the major welfare services are federally administered, namely old age contributory pensions, unemployment insurance and family endowment. In Australia, on the other hand, the provision of (non-contributory) old age and invalid pensions was one of the original powers vested in the Commonwealth Government and it has been exercised since $1908 .{ }^{36}$ As a matter of interest it may be observed that this section was inserted in the Constitution at the suggestion of the Hon. J. H. Howe, a South Australian dele gate to the Constitutional Convention of $1897 .{ }^{37}$ It was probably accepted by the other delegates as a means of winning popular support for federation. But its implications could hardly have been appreciated at the time. In the event, the Commonwealth has not confined its cash social benefits to old age and invalid pensions but has extended them to include maternity allowances, child endowment, widows' pensions, unemployment benefits, student allowances, and sickness and health benefits. The validity of these extensions was confirmed in 1946 by the only successful constitutional amendment of recent years. ${ }^{38}$ It follows that in Australia it is

34 Maxwell, op. cit., p. 37. Professor Maxwell also favours state and local administration on the ground that "there are many social services affecting the diverse daily life of the people about which uniform regulation and administration from a central source would be mischievous as well as impractical" (p. 31). In Great Britain, however, where constitutional obstacles do not arise, the advantages of centralised administration have been found to outweigh its disadvantages over an increasingly wide field of services. Cf. Hicks, U K, Public Finance, p. 264.

35 This is a contributory pensions scheme. Non-contributory pensions, where they exist, are provided by the states.

36 Commonwealth Constitution, Section 51 (23).

37 My attention was called to this point by my colleague, Professor J. A. La Nauze.

38 Commonwealth Constitution, Section 51 (23A). 
unnecessary for the federal government to administer cash social benefits through a system of conditional grants to the States. ${ }^{39}$

\section{Allocation among the states}

Another distinctive feature of federal financial assistance in Australia is the basis on which the income tax reimbursement grant is allocated among the States. The formula takes $\mathrm{w}$ account of what Professor Hicks has called the principle of derivation, by which states receive grants in proportion to federal tax collections from their citizens. ${ }^{40}$ Neither does it provide for allocation in fixed proportions subject to periodical review, as has been proposed for Rhodesia and Nyasaland. ${ }^{41}$ Instead, the allocation of the reimbursement grant is based partly on what may be called the compensation principle and partly on needs. Originally the allocation was made exclusively on the compensation principle, the grants being based on the States' own income tax collections prior to the introduction of uniform taxation. By 1957-58, however, the allocation will be made exclusively on the needs principle, the needs of the States being measured by their "adjusted population", which is defined as total population, weighted by the number of children aged 5-15 and the proportion of persons living in sparsely settled areas. ${ }^{42}$ Account is thus taken of some of the factors which are also considered in the determination of Special Grants, but the weight given to them is not sufficient to enable Australia to dispense altogether with Special Grants, as Canada has done. On the contrary

39 The extent to which the Commonwealth Government has entered Into the direct administration of social services is seen by the fact that its expenditure for this purpose rose from 1.8 per cent of Gross National Product in 1938-39 to 4.0 per cent in 1952-53, whereas over the same period state expenditure on social services remained a practically constant proportion of Gross National Product, increasing only from 28 per cool to 2.9 per cent. See 21st Report of Commonwealth Grants Commission, App. 19 and 21.

40 Nigeria, op. cit., pp. 53 and 77. See also Cmd. 9206, par. 28-34.

41 Cmd. 8672, par. 23.

42 The formula for adjusted population is:

$(\mathrm{P}+4 \mathrm{a})(\mathrm{P}+3 / 4 \mathrm{k}+1 / 2 \mathrm{~m}+1 / 4 \mathrm{n})$

$\mathrm{P}$

where

$\mathrm{P}=$ estimated population of a state at beginning of year;

$\mathrm{a}=$ children aged $5-15$ inclusive;

$\mathrm{k}=$ persons living in areas with density of $<1$ person per sq. mile;

$\mathrm{m}=$ persons living in areas with density of $1<2$ persons per sq. mile;

$\mathrm{n}=$ persons living in areas with density of $2<3$ per sq. mile.

This formula is reminiscent of that for Block Grants to British local authorities under the 1929 Act. 
the Special Grants now constitute a substantially larger proportion of the revenue of the claimant States than they did before the introduction of uniform taxation, having increased from little more than one-fifth to about two-fifths of the revenue from state taxation and reimbursement grants combined. ${ }^{43}$

The accompanying table illustrates for the year 1952-53 the differences between these various principles. Column 1 shows the actual allocation of tax reimbursement grants in 1952-53, in which year the allocation was based half on state tax proceeds prior to the introduction of uniform taxation and half on "adjusted population". Column 2 shows the allocation which would have resulted from applying the former basis exclusively, and Column 3 shows the allocation which would have resulted from applying the "adjusted population" basis exclusively. It is apparent that the change from the former basis to the latter is gradually benefiting Victoria and Tasmania at the expense of the other States.

The last two columns of the table show the allocation which would have resulted from applying the principle of derivation, returning to each State a certain proportion of the proceeds of Commonwealth income tax levied on individuals resident within its borders (Col. 4), or on individuals and companies whose income originated within its borders (Col. 5). These two columns also indicate the revenue which each State could have raised itself, if the Commonwealth had reduced its own income tax collections by $£ 135 \mathrm{~m}$., and if the subsequent combined Commonwealth-State tax rates had remained equal to the rates actually in force. On either basis Victoria would have gained but Queensland would have lost so considerably as to make the return of taxing powers to the States almost a political impossibility. Such a course would be much easier if the reimbursement grants had been based even partially on the derivation principle.

43 See 21st Report of Commonwealth Grants Commission, app. 8 and 10. The collection of tax revenue according to capacity and its allocation among the States according to need, was also a feature of the Per Capita Grants of 1910-27, and one which the late Professor Giblin described as "an adjusting factor in the greatest nicety". Giblin, op. cit., p. 156. 
Table 26.1: Commonwealth tax reimbursement and special financial assistance grants

\begin{tabular}{|c|c|c|c|c|c|}
\hline \multicolumn{6}{|c|}{ Allocation among the States, 1952-53 (Em) } \\
\hline \multirow[b]{2}{*}{ State } & \multirow[b]{2}{*}{$\begin{array}{l}\begin{array}{l}\text { Actual } \\
\text { allocation }\end{array} \\
1952-53^{\mathrm{a}} \\
\text { Col. } 1\end{array}$} & \multirow[b]{2}{*}{$\begin{array}{l}\text { Compensation } \\
\text { Principle } \\
\text { (1946-47 basis) } \\
\text { Col. } 2\end{array}$} & \multirow[b]{2}{*}{$\begin{array}{l}\text { Needs } \\
\text { Principle } \\
\text { (1957-58 } \\
\text { basis) } \\
\text { Col. } 3\end{array}$} & \multicolumn{2}{|c|}{ Derivation Principle } \\
\hline & & & & $\begin{array}{l}\text { Residence } \\
\text { (individuals } \\
\text { only) } \\
\text { Col. } 4\end{array}$ & $\begin{array}{l}\text { Origin } \\
\text { (individuals } \\
\text { and } \\
\text { companies) } \\
\text { Col. } 5\end{array}$ \\
\hline NSW & 54.0 & 55.6 & 52.4 & 51.1 & 53.0 \\
\hline Vic. & 32.4 & 29.9 & 34.8 & 41.6 & 41.3 \\
\hline Qld. & 21.7 & 22.3 & 21.1 & 14.3 & 14.7 \\
\hline SA & 11.6 & 11.7 & 11.5 & 13.1 & 12.2 \\
\hline WA & 10.8 & 11.4 & 10.3 & 12.0 & 10.3 \\
\hline Tas. & 4.5 & 4.1 & 4.8 & 3.0 & 3.5 \\
\hline Total & 135.0 & 135.0 & 135.0 & 135.0 & 135.0 \\
\hline
\end{tabular}

Notes: a. excludes deductions for state tax arrears, and $£ 900,000$ extra assistance to Victoria and Tasmania. b. Report by Treasury Officers: Resumption of Income Tax by the States, Canberra, 1953, p. 32. c. Ibid., p.33.

\section{The effects of inflation}

The real weakness of the Australian system of reimbursement grants, however, is not their relative magnitude, nor the absence of conditions governing their payment, nor again the basis on which they are allocated. It is that the States have found it easier to obtain extra funds by pressing the Commonwealth for larger grants rather than by increasing their own taxes, or public utility charges. A formula does indeed exist for the determination of the total reimbursement grant, but each year since 1948-49 this determination has been supplemented by a Special Financial Assistance Grant, the size of which is largely arbitrary and the outcome of acrimonious political bargaining. ${ }^{44}$ This situation might have been

44 Under the formula the total reimbursement grant for each year is determined by adjusting the basic grant of $£ 4 \mathrm{~m}$. paid in $1847-48$, by the increase in the population of the Commonwealth since July, 1947 , and also by the increase in the average annual wage since 1945-46. This formula takes no account of the yield which the Commonwealth actually obtains from income tax. Nor does it, on the other hand, adequately measure the needs of the States, since there is (a) a one-year lag in the wages adjustment, and (b) there is no allowance for increases in incomes other than wages, e.g. farm incomes. It should also be noted that the total reimbursement grant is not, as in Canada, merely the sum of previously determined allocations to the States. On the contrary, the total grant is determined first and the allocation among the States is then made according to a separate formula (for which see note 41 above). 
less serious had it not been for the inflation of 1949-50-51, but basically it arises because of certain fundamental features of our financial arrangements.

In the first place, the taxes that remain to the States are, as noticed above, largely of the licence variety and do not therefore automatically yield an increased revenue during inflation. The taxes that do show an automatic increase in yield are in come tax and sales tax, and both are monopolised by the Commonwealth. Secondly, the functions that remain to the States require the employment of large labour forces, and their costs therefore rise as wages increase. In the social services field, for example, this is so with respect to schools and hospitals, both of which are the responsibility of the States. On the other hand, the need for unemployment and other cash benefits, which are the responsibility of the Commonwealth, may very well decline during an inflation. Again, the Australian States, unlike those in many other federations, are responsible for the operation of numerous public utility undertakings, and in particular for railways. ${ }^{45}$ Here also a heavy burden has fallen on the state budgets, since public utility charges tend to lag behind costs during a period of inflation.

In these circumstances increased Commonwealth assistance has been politically the easiest, and in practice the only available remedy for the budgetary difficulties of the States. The danger, of course, is that additional federal grants may be used, not only to cover the unavoidable additional costs arising from inflation, but also to finance extra expenditure of a type which would not be undertaken if the States had to raise their own taxation to pay for it. It is in this sense that the present system threatens to undermine the financial responsibility of the State governments. ${ }^{46}$

The problem then is to ensure federal control over certain major sources of revenue in the interest of internal free trade, defence, and now full employment and social security; and at the same time to leave the States with a margin of

45 In the United States, the railways are privately owned. In Canada they are partly privately and partly federally owned. In other federations, e.g. South Africa and Rhodesia-Nyasaland, they are the solo respondbility of the federal government.

46 cf. Moore and Perry, op. cit. p. 66. "As long as provincial government have to turn to their own tax fields whenever they wish to add additional sums of money, there seems little danger that they will lose contact with their electors. Decisions are made at the margin; it is the balancing of the advantages of raising the additional revenue, that keeps government budgets sound." 
independent revenue sufficient to ensure flexibility, in the dual sense of (a) responsiveness to changes in economic conditions, and (b) capacity to finance for themselves any additional services they may wish to provide for their citizens. These objectives may well be irreconcilable in any ultimate sense, but that does not preclude the possibility of a working compromise that would bring us within reasonable striking distance of each. The Commonwealth for its part might have to be satisfied under normal peace-time conditions with something less than absolute control over all the major avenues of taxation. On the other hand, there would appear to be no particular virtue in returning to the States taxing powers sufficient to yield precisely the amount of the current reimbursement grants. Something less might well suffice to give them the necessary freedom of action. Similarly income tax is not the only tax the yield of which is responsive to economic changes. Some commodity taxes may be even more responsive. Certainly American and Canadian experience suggests that, if the constitutional obstacles can be circumvented, state tobacco, liquor and petrol taxes can go a long way to towards giving the necessary flexibility to state revenues.

\section{Conclusion}

We have now seen how in each of three fields of federal-state financial relations, the central government has come to play an increasingly predominant role vis-avis the states. This phenomenon is not confined to Australia, but is common in greater or lesser degree to all federations. Fundamentally it can be ascribed to new conceptions of the functions of government, the emergence of which is closely associated with the reorientation of economic thought manifested in Keynesian Economics and Welfare Economics.

It has become fashionable to conclude that in Australia the States are destined to become merely the administrative agencies of the federal government, like the local authorities in a unitary system. One may well doubt whether this is really likely to happen to any significant extent. Certainly the Commonwealth Government does not seem at all eager to assume responsibility for state railways or schools, to quote only two examples. Nor is there any sign of the States being voluntarily prepared to surrender their sovereignty in respect of these or any other matters. However, even if all policy-making were to pass to the Commonwealth, 
the administrative duties left to the States would still require for their proper discharge soundly based financial relations as well as a healthy political life. That this is so can be readily seen from the example of British Local Authorities, some of which are larger than Australian States, not only in population, but also in the size of their annual budgets.

The above problems will thus remain, whatever the future of the States may be, and whatever degree of sovereignty they retain. My purpose here has been to analyse the problems rather than to offer solutions. That is a matter for politicians, administrators and constitutional lawyers as much as, if not more than, for economists. Upon the efforts which they make, and the success that attends them, depends not merely the financial standing of the State Treasuries, but the political health and well-being of the whole federation.

\section{(Footnotes)}

1 Prices commenced to fall about August, 1920. Thus the wholesale index number dropped from 2,692 in August, 1920, to 2,245 in December. 